\title{
Management of High-Need, High-Cost Patients: A "Best Fit" Framework Synthesis, Realist Review, and Systematic Review
}




\section{Management of High-Need, High-Cost Patients: A "Best Fit" Framework Synthesis, Realist Review, and Systematic Review}

\section{Prepared for:}

Agency for Healthcare Research and Quality

U.S. Department of Health and Human Services

5600 Fishers Lane

Rockville, MD 20857

www.ahrq.gov

Contract No. 290-2015-00011-I

Prepared by:

RTI International-University of North Carolina at Chapel Hill Evidence-based Practice Center Research Triangle Park, NC

Investigators:

Nancy D. Berkman, Ph.D.

Eva Chang, Ph.D.

Julie Seibert, Ph.D.

Rania Ali, M.P.H.

Deborah Porterfield, M.D.

Linda Jiang, B.A.

Roberta Wines, M.P.H.

Caroline Rains, M.P.H.

Meera Viswanathan, Ph.D.

AHRQ Publication No. 21(22)-EHC028

October 2021

Errata and Addendum October 2022

Addendum revised November 2022 


\section{Errata}

We made changes to the final report regarding two studies included to answer Key Question 3 (Assessing the Effectiveness of Interventions for HNHC Patients) based on further review of the evidence. First, the primary setting (and resulting grouping) of one study (Vickery et al. Med Care Res Rev 2020; Sandberg et al. Health Aff 2014;33(11):1975-1984) was changed from primary care models to ambulatory intensive caring unit (aICU) models. Second, the risk of bias of another study (Horn et al. Popul Health Manag 2016;19(6):398-404) was increased from some concerns for risk of bias to high risk of bias because the study did not control for important baseline characteristics that differed in the treatment and control groups.

We updated the descriptions and findings for the Key Question 3 sections on aICU models and primary care models.

- aICU models: Based on the abovementioned changes, the strength of evidence was newly graded for the outcomes of all-cause emergency department visits, all-cause inpatient visits, and primary care visits for aICU models. All of these outcomes were graded as insufficient.

- Primary care models: The strength-of-evidence grade for the outcome inpatient days was removed because it was reported by only one study.

Our main conclusions for aICU models and primary care models remain unchanged. aICU models were associated with a greater reduction in total costs (low strength of evidence for favorable findings). Primary care models were associated with greater reductions in inpatient admissions and total cost (both low strength of evidence for favorable findings) and reductions in influenza vaccine uptake (low strength of evidence for unfavorable findings). The evidence was insufficient to judge other utilization, cost, and clinical and functional outcomes.

We have revised the relevant parts of this report to account for these changes. 
This report is based on research conducted by the RTI International-University of North Carolina at Chapel Hill Evidence-based Practice Center (EPC) under contract to the Agency for Healthcare Research and Quality (AHRQ), Rockville, MD (Contract No. 290-2015-00011-I). The findings and conclusions in this document are those of the authors, who are responsible for its contents; the findings and conclusions do not necessarily represent the views of AHRQ. Therefore, no statement in this report should be construed as an official position of AHRQ or of the U.S. Department of Health and Human Services.

\section{None of the investigators have any affiliations or financial involvement that conflicts with the material presented in this report.}

The information in this report is intended to help healthcare decision makers - patients and clinicians, health system leaders, and policymakers, among others-make well-informed decisions and thereby improve the quality of healthcare services. This report is not intended to be a substitute for the application of clinical judgment. Anyone who makes decisions concerning the provision of clinical care should consider this report in the same way as any medical reference and in conjunction with all other pertinent information, i.e., in the context of available resources and circumstances presented by individual patients.

This report is made available to the public under the terms of a licensing agreement between the author and the Agency for Healthcare Research and Quality. This report may be used and reprinted without permission except those copyrighted materials that are clearly noted in the report. Further reproduction of those copyrighted materials is prohibited without the express permission of copyright holders.

AHRQ or U.S. Department of Health and Human Services endorsement of any derivative products that may be developed from this report, such as clinical practice guidelines, other quality enhancement tools, or reimbursement or coverage policies, may not be stated or implied.

AHRQ appreciates appropriate acknowledgment and citation of its work. Suggested language for acknowledgment: This work was based on an evidence report, Management of High-Need, HighCost Patients: A "Best Fit" Framework Synthesis, Realist Review, and Systematic Review, by the Evidence-based Practice Center Program at the Agency for Healthcare Research and Quality (AHRQ).

Suggested citation: Berkman ND, Chang E, Seibert J, Ali R, Porterfield D, Jiang L, Wines R, Rains C, Viswanathan M. Management of High-Need, High-Cost Patients: A "Best Fit" Framework Synthesis, Realist Review, and Systematic Review. Comparative Effectiveness Review No. 246. (Prepared by the RTI International-University of North Carolina at Chapel Hill Evidence-based Practice Center under Contract No. 290-2015-00011-I.) AHRQ Publication No. 21(22)-EHC028. Rockville, MD: Agency for Healthcare Research and Quality; October 2021. Errata and Addendum October 2022. Addendum revised November 2022.

DOI: https://doi.org/10.23970/AHRQEPCCER246. Posted final reports are located on the Effective Health Care Program search page. 


\section{Preface}

The Agency for Healthcare Research and Quality (AHRQ), through its Evidence-based Practice Centers (EPCs), sponsors the development of systematic reviews to assist public- and private-sector organizations in their efforts to improve the quality of healthcare in the United States. These reviews provide comprehensive, science-based information on common, costly medical conditions, and new healthcare technologies and strategies.

Systematic reviews are the building blocks underlying evidence-based practice; they focus attention on the strength and limits of evidence from research studies about the effectiveness and safety of a clinical intervention. In the context of developing recommendations for practice, systematic reviews can help clarify whether assertions about the value of the intervention are based on strong evidence from clinical studies. For more information about AHRQ EPC systematic reviews, see https://effectivehealthcare.ahrq.gov/about/epc/evidence-synthesis.

AHRQ expects that these systematic reviews will be helpful to health plans, providers, purchasers, government programs, and the healthcare system as a whole. Transparency and stakeholder input are essential to the Effective Health Care Program. Please visit the website (www.effectivehealthcare.ahrq.gov) to see draft research questions and reports or to join an email list to learn about new program products and opportunities for input.

If you have comments on this systematic review, they may be sent by mail to the Task Order Officer named below at: Agency for Healthcare Research and Quality, 5600 Fishers Lane, Rockville, MD 20857, or by email to epc@ahrq.hhs.gov.

David Meyers, M.D. Acting Director Agency for Healthcare Research and Quality

Craig Umscheid, M.D., M.P.H.

Director

Evidence-based Practice Center Program

Center for Evidence and Practice Improvement Agency for Healthcare Research and Quality
Arlene S. Bierman, M.D., M.S.

Director

Center for Evidence and Practice Improvement

Agency for Healthcare Research and Quality

Elise Berliner, Ph.D.

Task Order Officer

Center for Evidence and Practice Improvement

Agency for Healthcare Research and Quality 


\section{Acknowledgments}

The authors gratefully acknowledge the following individuals for their contributions to this project and deeply appreciate their considerable support, commitment, and contributions: Elise Berliner, Ph.D., our AHRQ Task Order Officer (TOO); Eric Bass, M.D., our EPC Associate Editor; RTI International-University of North Carolina at Chapel Hill EPC staff: Lynn Whitener, Dr.P.H.; Christopher Beadles, Ph.D.; Sharon Barrell, M.A.; Loraine Monroe; and Carol Woodell, B.S.P.H.

\section{Key Informants}

In designing the study questions, the EPC consulted several Key Informants who represent the end-users of research. The EPC sought the Key Informant input on the priority areas for research and synthesis. Key Informants are not involved in the analysis of the evidence or the writing of the report. Therefore, in the end, study questions, design, methodological approaches, and/or conclusions do not necessarily represent the views of individual Key Informants.

Key Informants must disclose any financial conflicts of interest greater than $\$ 5,000$ and any other relevant business or professional conflicts of interest. Because of their role as end-users, individuals with potential conflicts may be retained. The TOO and the EPC work to balance, manage, or mitigate any conflicts of interest.

The list of Key Informants who provided input to this report follows:

Melinda K. Abrams, M.S.

Executive Vice President

The Commonwealth Fund

Washington, DC

Steven B. Cohen, Ph.D., M.S.*

Vice President, Division for Statistical and

Data Sciences

RTI International

Washington, DC

Annette Dubard, M.D., M.P.H.

Market President and Vice President of

Clinical Strategy

Aledade, Inc.

Chapel Hill, NC

*Provided input on Draft Report.
Mark P. Jarrett, M.D., M.B.A.

Senior Vice President and Chief Quality

Officer

Northwell Health

New Hyde Park, NY

Maria C. Raven, M.D., M.P.H., M.Sc.

Associate Professor of Emergency Medicine University of California, San Francisco

School of Medicine

San Francisco, CA

Lucy Savitz, Ph.D., M.B.A.*

Director, Center for Health Research

Kaiser Permanente Northwest

Portland, OR 


\section{Technical Expert Panel}

In designing the study questions and methodology at the outset of this report, the EPC consulted several technical and content experts. Broad expertise and perspectives were sought. Divergent and conflicted opinions are common and perceived as healthy scientific discourse that results in a thoughtful, relevant systematic review. Therefore, in the end, study questions, design, methodologic approaches, and/or conclusions do not necessarily represent the views of individual technical and content experts.

Technical Experts must disclose any financial conflicts of interest greater than $\$ 5,000$ and any other relevant business or professional conflicts of interest. Because of their unique clinical or content expertise, individuals with potential conflicts may be retained. The TOO and the EPC work to balance, manage, or mitigate any potential conflicts of interest identified.

The list of Technical Experts who provided input to this report follows:

Elizabeth Bayliss, M.D., M.S.P.H.*

Senior Investigator

Institute for Health Research

Kaiser Permanente Colorado

Aurora, CO

Professor of Family Medicine

University of Colorado School of Medicine

Aurora, CO

Steven B. Cohen, Ph.D., M.S.*

Vice President, Division for Statistical and

Data Sciences

RTI International

Washington, DC

Allison Hamblin, M.S.P.H.*

President and CEO

Center for Health Care Strategies

Hamilton, NJ

Kat Livingston, M.D., M.P.H.

Associate Professor of Family Medicine

Oregon Health \& Science University

Portland, OR
Ellen Meara, Ph.D.*

Professor of Health Economics and Policy

Department of Health Policy and

Management

Harvard T.H. Chan School of Public Health

Boston, MA

Adjunct Professor

The Dartmouth Institute for Health Policy \&

Clinical Practice

Lebanon, $\mathrm{NH}$

Renee Mentnech, M.S.

Director of the Research and Rapid Cycle

Evaluations Group

Center for Medicare and Medicaid

Innovation

Baltimore, MD

Jane Noyes, Ph.D.*

Professor in Health and Social Services

Bangor University

Bangor, Wales, UK

Lucy Savitz, Ph.D., M.B.A.*

Director, Center for Health Research

Kaiser Permanente Northwest

Portland, OR 
Geoff Wong, M.D., M.A., M.B.B.S.*

Clinical Research Fellow

Department of Primary Care Health Services

University of Oxford

Oxford, England, UK

*Provided input on Draft Report.

\section{Peer Reviewers}

Prior to publication of the final evidence report, EPCs sought input from independent Peer Reviewers without financial conflicts of interest. However, the conclusions and synthesis of the scientific literature presented in this report do not necessarily represent the views of individual reviewers.

Peer Reviewers must disclose any financial conflicts of interest greater than $\$ 5,000$ and any other relevant business or professional conflicts of interest. Because of their unique clinical or content expertise, individuals with potential nonfinancial conflicts may be retained. The TOO and the EPC work to balance, manage, or mitigate any potential nonfinancial conflicts of interest identified.

The list of Peer Reviewers follows:

Tim Engelhardt, M.H.S.

Director, Medicare-Medicaid Coordination Office

Centers for Medicare \& Medicaid Services

Baltimore, MD

Samantha Iovan, M.P.H.

Lead Analyst

Center for Health and Research Transformation, Michigan Medicine

University of Michigan

Ann Arbor, MI 


\section{Management of High-Need, High-Cost Patients: A "Best Fit" Framework Synthesis, Realist Review, and Systematic Review}

\section{Structured Abstract}

Background. In the United States, patients referred to as high-need, high-cost (HNHC) constitute a very small percentage of the patient population but account for a disproportionally high level of healthcare use and cost. Payers, health systems, and providers would like to improve the quality of care and health outcomes for HNHC patients and reduce their costly use of potentially preventable or modifiable healthcare services, including emergency department (ED) and hospital visits.

Methods. We assessed evidence of criteria that identify HNHC patients (best fit framework synthesis); developed program theories on the relationship among contexts, mechanisms, and outcomes of interventions intended to change HNHC patient behaviors (realist review); and assessed the effectiveness of interventions (systematic review). We searched databases, gray literature, and other sources for evidence available from January 1, 2000, to March 4, 2021. We included quantitative and qualitative studies of HNHC patients (high healthcare use or cost) age 18 and over who received intervention services in a variety of settings.

Results. We included 110 studies (117 articles). Consistent with our best fit framework, characteristics associated with HNHC include patient chronic clinical conditions, behavioral health factors including depression and substance use disorder, and social risk factors including homelessness and poverty. We also identified prior healthcare use and race as important predictors. We found limited evidence of approaches for distinguishing potentially preventable or modifiable high use from all high use. To understand how and why interventions work, we developed three program theories in our realist review that explain (1) targeting HNHC patients, (2) engaging HNHC patients, and (3) engaging care providers in these interventions. Theories identify the need for individualizing and tailoring services for HNHC patients and the importance of building trusting relationships. For our systematic review, we categorized evidence based on primary setting. We found that ED-, primary care-, and home-based care models result in reduced use of healthcare services (moderate to low strength of evidence [SOE]); ED, ambulatory intensive caring unit, and primary care-based models result in reduced costs (low SOE); and system-level transformation and telephonic/mail models do not result in changes in use or costs (low SOE).

Conclusions. Patient characteristics can be used to identify patients who are potentially HNHC. Evidence focusing specifically on potentially preventable or modifiable high use was limited. Based on our program theories, we conclude that individualized and tailored patient engagement and resources to support care providers are critical to the success of interventions. Although we found evidence of intervention effectiveness in relation to cost and use, the studies identified in this review reported little information for determining why individual programs work, for whom, and when. 


\section{Contents}

Evidence Summary ...................................................................................................................................1

Chapter 1. Introduction..................................................................................................................1

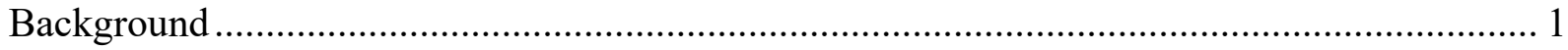

The Decisional Dilemma: Identifying and Addressing High Utilization and Cost

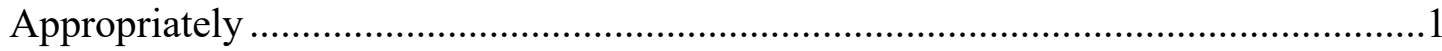

Description of the HNHC Patient Population ..................................................................2

What Is Known From Other Systematic Reviews .............................................................

Intervention Strategies …………………................................................................... 3

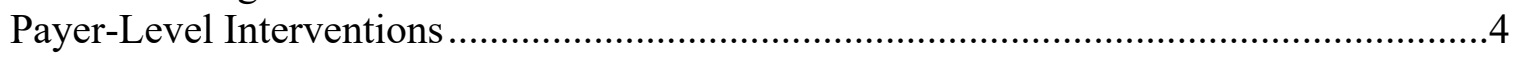

Health System- and Provider-Level Interventions ..........................................................

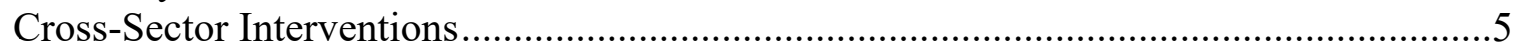

Complex Interventions for HNHC Patients .................................................................

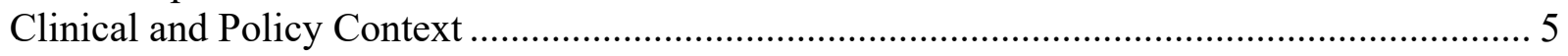

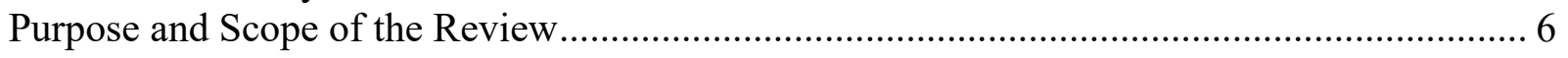

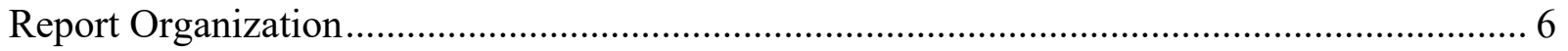

Chapter 2. Methods ...........................................................................................................................................

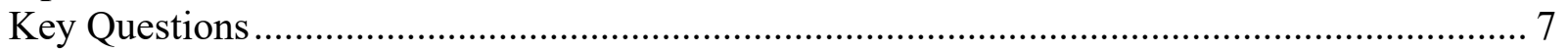

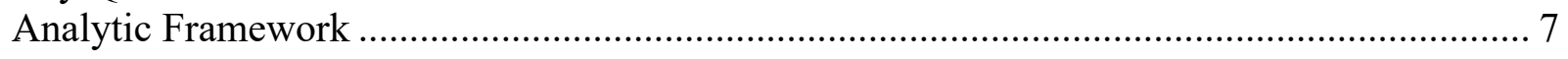

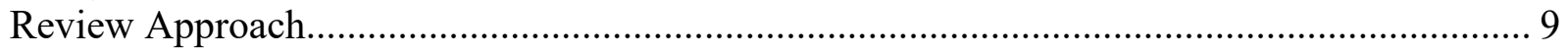

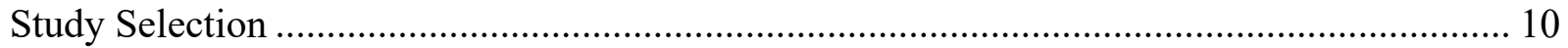

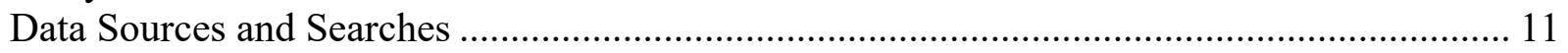

Data Extraction and Risk-of-Bias/Risk-of-Rigor Assessments ............................................... 11

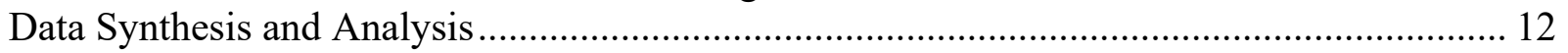

Grading the Strength of the Body of Evidence ....................................................................... 13

Chapter 3. Results .............................................................................................................................15

Literature Searches and Study Characteristics.................................................................. 15

Description of Included Evidence ………………………................................................ 15

KQ 1. What criteria identify or predict that patients will be HNHC? ..................................... 17

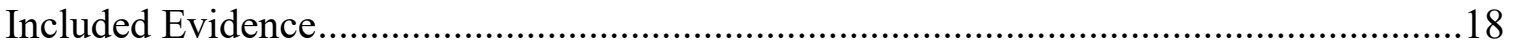

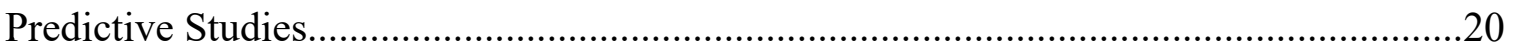

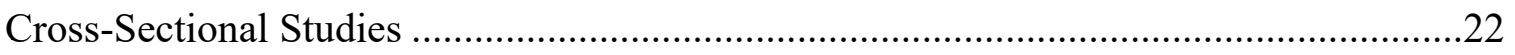

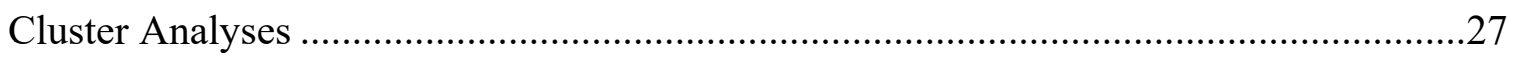

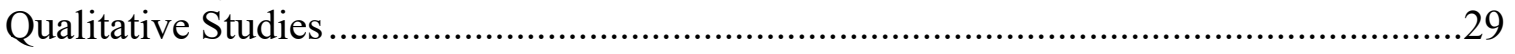

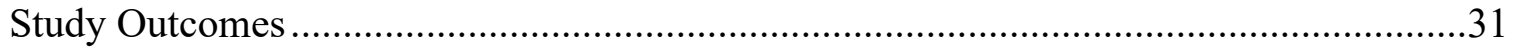

KQ 1a. How do criteria incorporate patient clinical characteristics? ........................................ 33

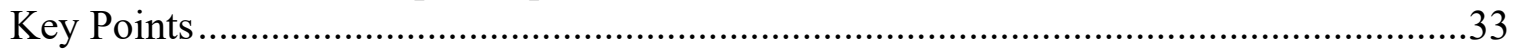

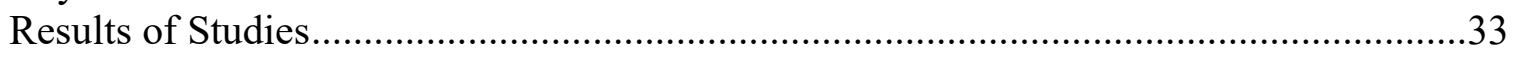

KQ 1b. How do criteria incorporate patient demographic, behavioral health, and social risk

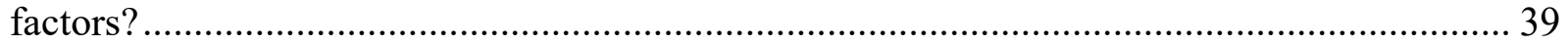

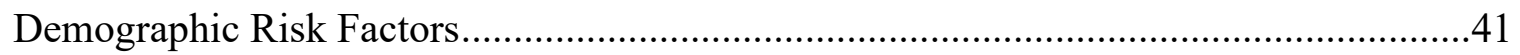

Behavioral Health Risk Factors .......................................................................................

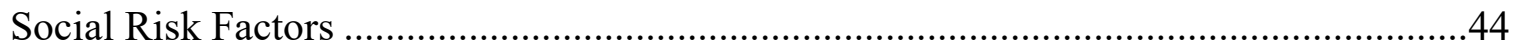

KQ 1c. How do criteria incorporate types, amount, duration, and patterns of healthcare use? 45

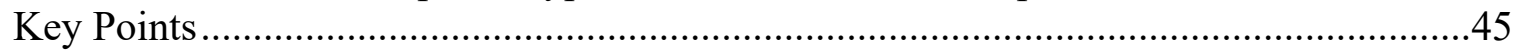

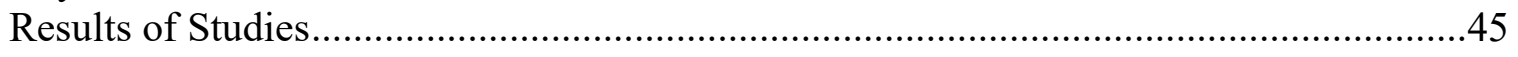


KQ 1d. Do criteria differ when HNHC is identified at the population, payer, healthcare

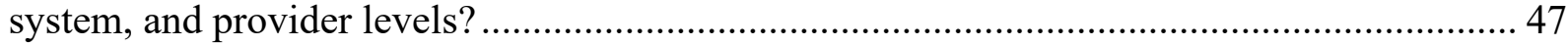

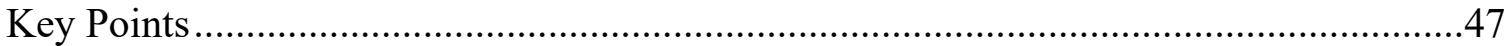

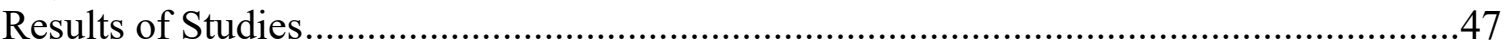

KQ 1e. How can potentially preventable or modifiable high use of healthcare be differentiated

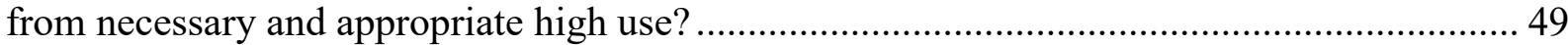

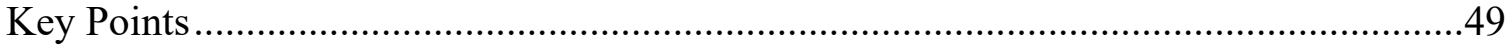

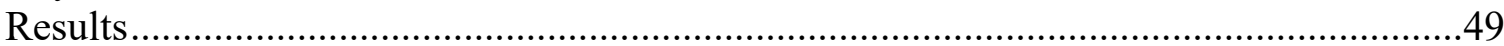

KQ 2. What are the mechanisms that lead to reductions in potentially preventable or modifiable healthcare use and result in improved health outcomes and cost savings in

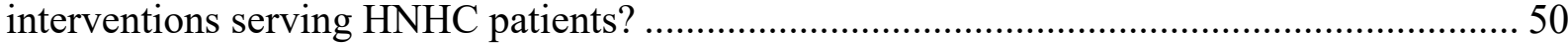

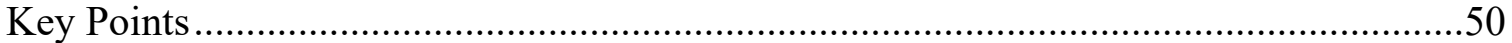

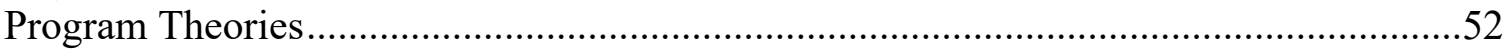

KQ 3. Overall, what is the effectiveness and what are the harms of interventions for HNHC patients in reducing potentially preventable or modifiable healthcare use and costs and in

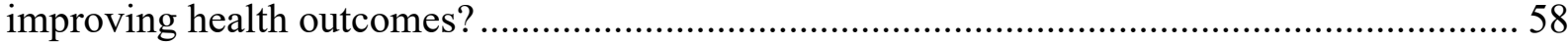

Literature Searches, Study Characteristics, and Overview of Findings..........................59

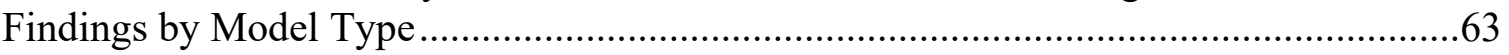

Chapter 4. Discussion .......................................................................................................94

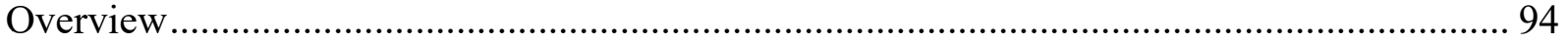

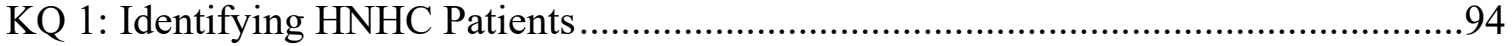

KQ 2: Understanding How and Why HNHC Patient Interventions Work .......................96

KQ 3: Assessing the Effectiveness of Interventions for HNHC Patients ........................97

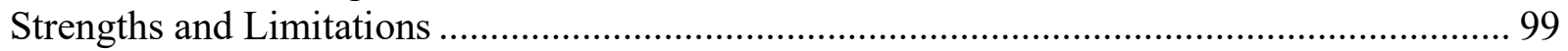

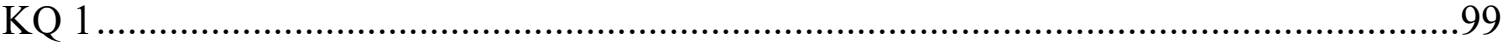

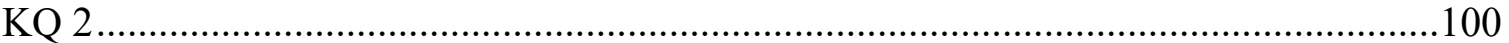

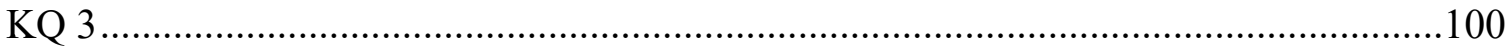

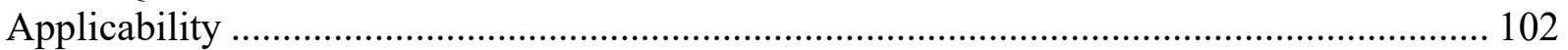

Implications for Clinical Practice, Education, Research, or Health Policy ......................... 102

Implications for Clinical Practice and Education .......................................................102

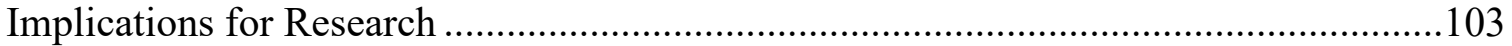

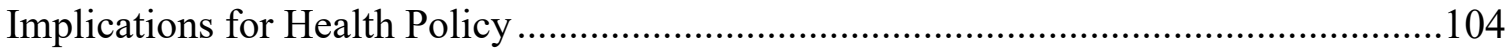

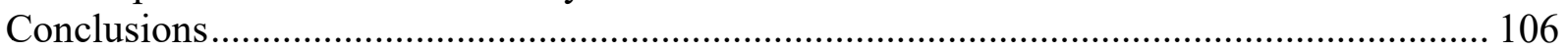

References.......................................................................................................................107

Management of High-Need, High-Cost Patients: Addendum.................................................122

\section{Tables}

Table 1. Key characteristics of included studies................................................................ 15

Table 2. Number of studies by population level and criteria used to define HNHC patients....... 19

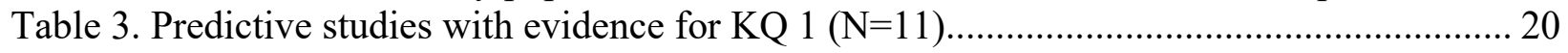

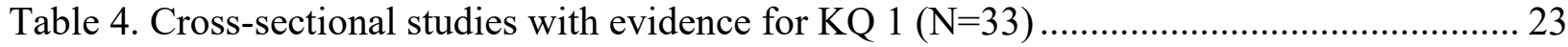

Table 5. Cluster analysis studies with evidence for KQ $1(\mathrm{~N}=12)$.................................... 27

Table 6. Qualitative studies with evidence for KQ $1(\mathrm{~N}=6)$.............................................. 30

Table 7. Definitions of HNHC patient healthcare use or cost across studies ............................ 32

Table 8. Number and results of studies examining the association between chronic clinical conditions and high ED use 
Table 9. Number and results of studies examining the association between chronic clinical conditions and high number of inpatient visits

Table 10. Number and results of studies examining the association between chronic clinical conditions and high healthcare use, based on all visits.

Table 11. Number and results of studies examining the association between chronic clinical conditions and high cost of care. 36

Table 12. Number of studies that identify chronic clinical conditions as characteristics defining high-utilization/high-cost clusters.

Table 13. Number of multivariate studies examining demographic characteristics associated with high healthcare use or cost among HNHC patients, by direction and significance of effect ....... 40 Table 14. Number of multivariate studies examining behavioral health and social risk factors associated with high healthcare use or cost among HNHC patients by direction and significance

of effect

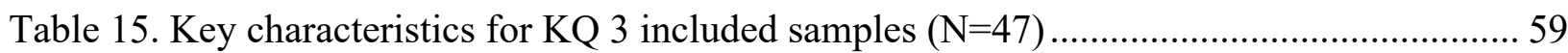

Table 16. Summary of strength of evidence for HNHC patients by intervention model type for outcomes reported in more than one sample

Table 17. Summary of findings for system-level transformation models versus usual-care outcomes 66

Table 18. Summary of findings for telephonic/mail models versus usual-care outcomes ${ }^{\mathrm{a}}$.......... 69

Table 19. Summary of findings for community-based models versus usual-care outcomes........ 74

Table 20. Summary of findings for ED-based models versus usual-care outcomes .................. 79

Table 21. Summary of findings for aICU-based models versus usual-care outcomes ................ 82

Table 22. Summary of findings for primary care-based models versus usual-care outcomes..... 86

Table 23. Summary of findings for home-based care-based models versus usual-care outcomes

\section{Figures}

Figure A. Framework of optimizing interventions for HNHC patients.................................... 3

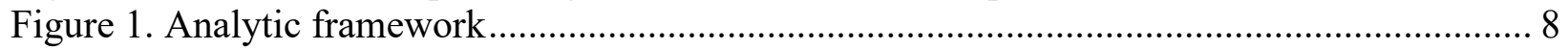

Figure 2. Article flow diagram................................................................................ 17

Figure 3. Best fit framework synthesis: National Academy of Medicine High-Need, HighCost patient characteristic taxonomy ........................................................ 18

Figure 4. Framework of optimizing interventions for HNHC patients.................................. 51

\section{Appendixes}

Appendix A. Detailed Methods

Appendix B. Results

Appendix C. Appendix References 


\section{Evidence Summary}

\section{Main Points}

- Data from claims and health records can identify characteristics associated with being high-need, high-cost (HNHC) patients but are limited in selecting specific patients who are most appropriate for care management interventions.

- Much work remains in distinguishing preventable and modifiable high healthcare use from high use more generally.

- Identifying and targeting HNHC patients for interventions to change their healthcare use requires capturing their medical and social complexities. Building and maintaining trusting, caring relationships between $\mathrm{HNHC}$ patients and care providers underpins successful patient interventions. Both patients and care providers require support and practical resources to foster an effective relationship.

- We found moderate to low strength of evidence (SOE) that emergency department (ED)-based, primary care-based, and home-based care models are associated with reduced use of healthcare services; low SOE that ED, ambulatory intensive caring unit (aICU), and primary care models are associated with reduced costs; and low SOE that system-level transformation and telephonic/mail models are not associated with use or cost differences.

\section{Background and Purpose}

In the United States, payers, health systems, and providers focus on the HNHC patient population because they account for a disproportionally high level of healthcare utilization and cost, even though they constitute a small percentage of the patient population. Payers, particularly Medicare and Medicaid, are moving from fee-for-service payment arrangements to alternative payment models. Financial success of these models can depend, in large part, on their effectiveness in addressing care for HNHC patients.

Poor control of chronic clinical conditions, particularly when coupled with functional limitations, mental health conditions, and social risk factors, can result in potentially preventable or modifiable overreliance on the ED and hospital. Interventions for HNHC patients aim to improve their quality of care and health outcomes while reducing their healthcare use and cost. The goal of this review is to provide actionable evidence to help identify HNHC patients and determine the causal mechanisms and effectiveness of complex interventions that intend to improve HNHC patient and healthcare system outcomes.

\section{Methods}

We used review approaches best suited to assess the evidence for our Key Questions (KQs). To determine how to identify HNHC patients (KQ 1), we used the best-fit framework synthesis approach to consider our findings in relation to a National Academy of Medicine (NAM) taxonomy. To examine the causal mechanisms and contexts of interventions leading to reductions in healthcare use and cost (KQ 2), we used realist review methodology. Finally, to synthesize the evidence of the effectiveness of interventions targeting HNHC patients (KQ 3), 
we used systematic review methodology. We searched multiple databases and the gray literature using publication dates from January 1,2000, to March 4, 2021. We included quantitative and qualitative studies of adult $\mathrm{HNHC}$ patients (high healthcare use or cost) in the United States. We describe our methods in the full report.

\section{Results}

We included 110 studies (117 articles) in our review. KQ 1 includes 60 studies (61 articles). KQ 2 includes 48 studies (51 articles; 14 articles were also evidence for KQ 1 and 27 articles for KQ 3). KQ 3 includes 40 studies (46 articles).

KQ 1: Criteria that can be used to identify or predict HNHC patients. Consistent with the NAM taxonomy, we found that chronic conditions, whether measured individually or through an algorithm, rating scale, or counts, were associated with being an HNHC patient, as were behavioral health risk factors, including depression and substance use disorder, and social risk factors, including homelessness and poverty. We also identified prior high use and race as consistent predictors of being an $\mathrm{HNHC}$ patient. Few studies sought to differentiate high use of care that is potentially preventable from all high use.

KQ 2: Contexts, mechanisms, and outcomes of interventions that reduce preventable or modifiable healthcare use among HNHC patients. We developed three realist program theories. Figure A presents a framework showing their relationship. Program Theory 1 explains that the pathway for identifying $\mathrm{HNHC}$ patients for inclusion in interventions requires capturing a combination of their prior use of and experience accessing healthcare services, chronic disease(s), nonmedical barriers to care, clinician judgment, and willingness to participate. Program Theory 2 explains that once HNHC patients are enrolled, engaging them in interventions requires building a trusting relationship between the patient and care providers. Tailored, individualized assistance for medical and nonmedical needs, emotional support, and self-management education empower patients to participate in their own care. Program Theory 3 explains that care provider engagement is facilitated by targeted outreach, adequate staffing support with shared values, and regular and open communication. 
Figure A. Framework of optimizing interventions for HNHC patients

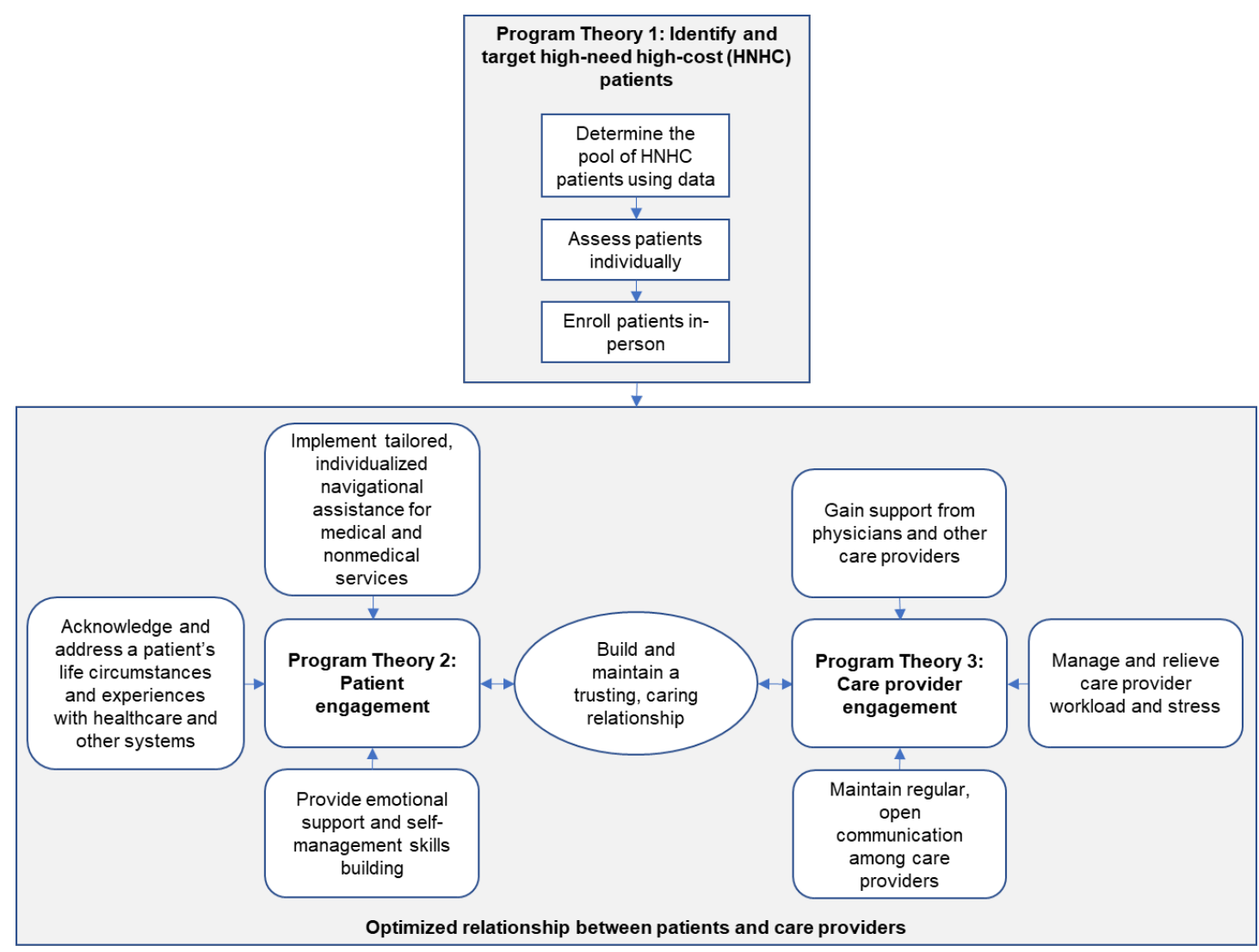

KQ 3: Effectiveness and harms of interventions for $\mathrm{HNHC}$ patients in reducing potentially preventable or modifiable healthcare use and costs and improving health outcomes. All but one study compared interventions with usual care. We categorized the evidence based on the primary setting of the intervention (system level, telephonic/mail, community, ED, aICU, primary care, and home based). Findings were limited.

In relation to changes in utilization, ED-based models resulted in a reduction in all-cause ED visits (moderate SOE), while telephonic/mail models achieved no difference in all-cause ED visits (low SOE) or ambulatory care sensitive condition ED visits (low SOE). ED- and primary care-based models resulted in a reduction in all-cause inpatient admissions (low SOE), while telephonic/mail models resulted in no difference (low SOE). Home-based care models resulted in lower ambulatory care sensitive condition inpatient admissions (low SOE). Primary care visits increased among ED model participants, a favorable outcome because it supports the goal of shifting care from the ED to a more appropriate source of care (low SOE).

In relation to total costs, aICU and primary care-based models were associated with reductions (both low SOE), while system-level transformation models and telephone/mail models resulted in no difference (low SOE). ED models were also associated with lower ED costs (low SOE) but no change in inpatient costs (low SOE).

Telephonic/mail models, home-based care models, and community-based models found no difference in mortality (low SOE for all 3 models). 
Studies identified virtually no harms and reported few health and patient-reported outcomes and no social risk outcomes. The evidence was insufficient to draw conclusions for these outcomes.

\section{Limitations}

Each of the three methodological approaches brings unique strengths and weaknesses to our findings. A constraint to identifying patient characteristics associated with being $\mathrm{HNHC}$ is a limited methodology for distinguishing high use that is modifiable. As a result, the effect of patient and health system factors were generally evaluated only in relation to all high use. For the realist review, our analysis depended primarily on the studies included in the systematic review. Many of these studies contained minimal information about the implementation of the interventions at the clinic level, limiting our ability to more fully construct our program theories. For the systematic review, while effectiveness studies reported changes in cost and use, we found virtually no patient-reported or process outcomes, further limiting our ability to understand why some interventions were successful while others were less so.

\section{Implications and Conclusions}

A central dilemma facing interventions intended to reduce the healthcare use and cost of HNHC patients is how to reliably identify the patient population and to do so before a future period of preventable or modifiable high use. Using patient characteristics available in electronic patient data is a first step, but identification of good candidates for HNHC patient interventions is improved through individualized participant selection. Similarly, interventions themselves need to be individualized to address the complex needs of HNHC patients. Although we found some evidence of overall intervention effectiveness in relation to use and cost, the studies identified in this review provide little information for determining why individual programs work, for whom, within different contexts. 


\section{Chapter 1. Introduction}

\section{Background}

In the United States, the patient population referred to as high-need, high-cost (HNHC) is often the focus of healthcare payers, health systems, and providers. Although no single definition of HNHC exists, it is generally understood that these patients constitute a very small percentage of the population but account for a disproportionally high level of healthcare use and cost. ${ }^{1-5}$ Payers in the United States, particularly Medicare and Medicaid, are increasingly requiring health systems, coordinated care organizations, and healthcare providers to progress from payment through fee-for-service arrangements toward alternative payment models that include financial risk. ${ }^{6-9}$ Participants in alternative payment models, particularly those that include financial risk, acknowledge that their success in these models depends, in large part, on their effectiveness in addressing the care and costs for HNHC patients. ${ }^{10,11}$

Payers and health systems would like to accomplish two goals in relation to HNHC patients: (1) reduce their healthcare use and ensuing costs that are potentially preventable or modifiable, which is often overuse of acute care in an emergency department (ED) or multiple hospital inpatient admissions resulting from poor control of medical conditions, ${ }^{12-16}$ and (2) improve their quality of care and health outcomes. ${ }^{14-16}$ Despite strong motivation to address how to more appropriately provide healthcare for HNHC patients, challenges and controversies complicate approaches to both identifying these patients and determining the mechanisms of complex interventions that can affect their healthcare use, cost, and quality of care.

\section{The Decisional Dilemma: Identifying and Addressing High Utilization and Cost Appropriately}

A key challenge for practitioners (which we define as healthcare providers, payers, and health systems), as well as researchers, is that there is no consensus on a definition of HNHC patients, those high-need patients for whom high costs or use are potentially preventable or modifiable. The most common approach is to define the HNHC population as the patients with the highest healthcare use or costs during a historical time period, but no consensus has been reached on the appropriate duration of the time period and the number and types of services. ${ }^{12,13}$ Also, focusing on use and cost alone can obscure detecting future high-need patients. Many highcost patients use this level of care for a relatively short period of time, and it is the appropriate choice for treating their condition (e.g., certain types of cancer or orthopedic surgery patients). ${ }^{17}$ A second approach is to identify HNHC patients based on diagnoses, such as individuals with multiple co-occurring chronic conditions. ${ }^{18,19}$ Relying chiefly on a diagnostic criterion, however, ignores that not all high-need patients have high costs that are preventable or modifiable. A large percentage of high-need patients use care appropriately, even if it may be costly (i.e., needed healthcare is received through ongoing relationships with primary care and specialist providers). Often, factors co-occurring with physical diagnoses, including functional limitations, mental health conditions, substance use, and social risk factors, are important drivers of high healthcare use and cost. ${ }^{20}$ Overall, HNHC patients are those patients with chronic conditions for whom reducing use of high-cost healthcare services in favor of other types of care is theorized to result in better care and better outcomes. For the purposes of this review, we focus on studies of patients with high healthcare costs or use. Within this larger group of studies, we will highlight 
analyses that more directly identify patients whose use of healthcare services would be considered inappropriate and is potentially preventable or modifiable.

\section{Description of the HNHC Patient Population}

A common approach to describing the magnitude of the HNHC patient population nationally is in relation to the concentration of healthcare costs or use disproportionately attributed to a specific percentage of the population. National data from the Agency for Healthcare Research and Quality (AHRQ)-sponsored Medical Expenditure Panel Survey reports that, in 2016, patients ranked in the top 5 percent by their healthcare expenditures accounted for 50 percent of total healthcare expenditures. ${ }^{21}$ Among these top 5 percent of spenders, 42 percent were 65 years of age or older. Persons in the top 5 percent of spending were more likely to have at least one inpatient stay during the year with inpatient stays accounting for 40 percent of their healthcare expenditures. ${ }^{21}$ The Pew Charitable Trust found that the top 5 percent of Medicaid patients nationally use 60 percent of Medicaid funding. ${ }^{22}$ In relation to ED use, AHRQ's Healthcare Cost and Utilization Project data reported that among Medicare beneficiaries 65 years of age or older, approximately 5 percent of the population accounted for 16 percent of ED visits and 14 percent of ED charges. ${ }^{23}$ Among Medicare beneficiaries younger than 65 years, 6 percent accounted for 26 percent of ED visits and 24 percent of ED charges. Further, a systematic review on frequent ED use across payers found that, across studies, approximately 5 to 8 percent of patients visiting the ED were frequent users, with this small group accounting for 21 to 28 percent of all ED visits. $^{24}$

The HNHC patient population can be further characterized in relation to the prevalence of multiple chronic conditions. According to the Center for Health Care Strategies (CHCS), 80 percent of high-cost Medicaid beneficiaries have three or more chronic conditions. ${ }^{25} \mathrm{CHCS}$ further found that among Medicaid-only beneficiaries with a disability, each additional chronic condition was associated with an average increase in costs of \$8,400/year. Among Medicaidonly beneficiaries, the most common diagnostic pairs of diseases among the highest cost patients are cardiovascular-pulmonary (30\%), cardiovascular-gastrointestinal $(25 \%)$, cardiovascularcentral nervous system (25\%), central nervous system-pulmonary (24\%), and pulmonarygastrointestinal $(24 \%){ }^{25}$ Based on Centers for Medicare \& Medicaid Services administrative data from 2011, the burden of multiple $(\geq 2)$ chronic conditions among Medicare beneficiaries is high, accounting for over two-thirds of the fee-for-service population, while those with six or more conditions account for 14 percent of the population. ${ }^{26}$

\section{What Is Known From Other Systematic Reviews}

The present work builds on and extends earlier systematic reviews. We identified three reviews focusing on characteristics associated with being HNHC patient and eight reviews of interventions for these patients.

The three reviews of studies of HNHC patient characteristics identified their populations differently. One focused on high-cost patients, ${ }^{27}$ the second on frequent ED users, ${ }^{28}$ and a third on ED users whose visits were identified as primary care sensitive, preventable, inappropriate, or unnecessary. ${ }^{29} \mathrm{All}$ three reviews elucidated factors associated with being HNHC, organized according to Andersen's model of predisposing, enabling, and need characteristics. ${ }^{30}$ The study of high-cost patients found that having multiple chronic conditions, mental illness, and advancing age were all associated with higher healthcare costs. ${ }^{27}$ Patient income had a variable effect. Frequent ED users were more likely to have a fair or poor self-perception of their health 
coupled with mental health and substance abuse concerns ${ }^{31}$ Characteristics associated with high primary care-sensitive ED use included being female, being black, and having Medicaid coverage. ${ }^{29}$

The present review modified the approach used in these reviews in several ways. The Wammes et al. review of high-cost patients included studies from multiple countries, while we limit our work to the United States, so that our findings are generalizable to the United States' healthcare coverage and delivery systems. ${ }^{27} \mathrm{We}$ add to the literature on characteristics associated with high healthcare use by separately examining high inpatient or outpatient use, as well as high ED use. We also include studies of chronic disease subgroups. Finally, while the earlier reviews organized their findings using the Anderson chronic disease framework, we group characteristics associated with being HNHC patients using the typology developed by the National Academy of Medicine. ${ }^{20}$

Multiple reviews have synthesized the literature on interventions that are hoping to change the utilization patterns, decrease costs, and improve clinical outcomes among HNHC patients. One review by Raven and colleagues (2016) examined studies of interventions, implemented in the United States, intended to reduce ED visits. ${ }^{32}$ They found that case management reduced ED use and increasing ED copayments had mixed results. We identified six other reviews focusing on ED use. ${ }^{12,13,33-37}$ Of these, five were not limited to studies conducted in the United States so the findings would not necessarily be applicable to the U.S. healthcare system. ${ }^{12,13,33,34,36} \mathrm{~A}$ sixth review of ED interventions was limited to studies conducted in the United Sates but allowed the weaker pre-post designs that did not control for confounding. ${ }^{37}$ Similarly, a review of interventions to address frequent hospitalization ${ }^{38}$ and one of intensive outpatient care programs $^{39}$ also included pre-post designs.

Some of the limitations of earlier reviews of intervention studies are addressed in the present review. In prior work, the institutional settings in which studies were conducted were often not adequately described. ${ }^{12}$ Also, information about social determinants of health, including socioeconomic status, behavioral health status, housing stability, and racial/ethnic demographics, was often missing. When systematic reviews included important social variables, analysis was limited to one or two factors. For example, several key systematic reviews (e.g., Soril et al., ${ }^{13}$ Edwards et al., ${ }^{15}$ and Baker et al. ${ }^{14}$ ) contain scant detail regarding social risk factors of health and the settings within which interventions occurred.

Attempts to synthesize the literature on interventions for HNHC patients are challenged by the absence of a consensus in the field of a unifying classification schema or taxonomy organizing key dimensions of these complex interventions into meaningful distinctions for grouping and separately considering their components. ${ }^{40}$ Intervention classification in recent systematic reviews regarding high utilizers differed significantly. One systematic review stratified interventions by home based, clinic based, and primary care augmentation. ${ }^{15}$ Another categorized interventions into case management, individual care plans, and information sharing. ${ }^{13}$ Baker et al. ${ }^{14}$ stratified interventions by population type: adults (1) with two or more chronic diseases, (2) with one chronic disease and depression, and (3) identified at risk for high healthcare utilization.

\section{Intervention Strategies}

Complex interventions designed to target HNHC patients have been developed at multiple organizational/system levels. The following strategies are ways of organizing the delivery of healthcare that are theorized as the context for influencing and improving both care delivery and 
costs for HNHC patients. We stratified the universe of interventions in terms of "levels" of intervention. Recognizing that these strata are interconnected, they are intended to specifically name the organizational actor that is the potential intervention implementer.

\section{Payer-Level Interventions}

Payers are invested in reducing healthcare costs and inappropriate use by HNHC patients. Various alternative models of health services delivery can support HNHC patient interventions. For example, accountable care organizations (ACOs) align financial incentives and health outcome accountability to promote care coordination among a large group of healthcare providers across the care continuum (ambulatory outpatient, acute care, post-acute care, and home health settings). ACOs use a variety of strategies to accomplish these goals. They support care coordination by increasing physicians' access to a uniform source of complete information about patients' health service use and health status. Techniques such as population segmentation and risk stratification can be used to focus resources on HNHC patient populations. Together, these enhancements can increase coordination among healthcare settings, particularly during transitions between settings in episodes of care.

One example of a payer-driven model is home-based primary care. This model moves the delivery of the majority of primary care from an ambulatory office-based setting to a patient's residence. ${ }^{41}$ Intended to be a comprehensive care delivery model, this model typically involves a team-based approach and combines home-based care for medical needs with intensive management and care coordination. Home-based care programs serve a patient population that has a high probability of being HNHC because participants commonly have complex chronic conditions, functional limitations, and physical restrictions in accessing traditional office-based care. Home-based primary care may benefit HNHC patients if such approaches can better address patients' specific needs, values, and preferences.

\section{Health System- and Provider-Level Interventions}

Many complex healthcare interventions are organized at the health system and provider levels. Health system-level interventions are often designed to support changes at the patient population level by promoting a culture that furthers program goals and organizes intervention activities across participants. ${ }^{42}$ Rather than focusing on individual patients, system-level participants are generally clinics or practices, which in turn are often expected to implement provider- and patient-level interventions. Provider-level interventions target care providers to change how they treat patients. Examples of provider-level interventions include the distribution of evidence-based guidelines and protocols, provider education and training, and provider feedback reports.

At the health system and provider levels, data are often used to report healthcare service use that may indicate that a patient is HNHC and needs additional services. One example is ED alerts. ED alerts inform clinicians that a patient has received care in the ED, which can help them identify patients whose patterns of care might be considered HNHC and in need of additional support services. Another strategic use of data to identify HNHC patients is "hotspotting." This strategy uses data to identify individuals whose high costs are outliers, understand the problem, dedicate resources, and design effective interventions. ${ }^{43}$ Hotspotting interventions typically include multidisciplinary, coordinated care that treats the whole patient, including the nonmedical and social determinants that affect health, such as housing, mental health, substance abuse, and emotional support. The underlying idea is that intensive and highly individualized 
care addressing the unique needs of an HNHC patient, including social determinants of health, will improve clinical outcomes and reduce health expenditures beyond the cost of the highintensity, highly individualized hotspotting intervention. ${ }^{44}$

\section{Cross-Sector Interventions}

Although not traditionally considered in the domain of healthcare, supportive services addressing social risk factors can affect the success or failure of complex interventions for HNHC patients. Interventions that focus on cross-sector issues intend to bridge the gap between engaging healthcare professionals who deliver direct care and addressing individual patients' nonmedical needs. A variety of roles, such as care managers, social workers, community health workers, patient navigators, and peer-to-peer networks, can directly provide or connect patients with needed support services.

Support services are intended to address patient barriers related to resource limitations, health literacy, and treatment adherence, thereby improving patient outcomes. Relatedly, staff providing supportive services can assist with social risk factors that have been identified as predisposing factors limiting access to care. Predisposing factors may include low income, poor education, poor nutrition, homelessness, and lack of transportation. For example, stable housing could improve patients' ability to interact consistently with their healthcare providers and social support systems, which, in turn, could increase adherence to their treatment plan. ${ }^{40}$

\section{Complex Interventions for HNHC Patients}

Intervention strategies that target $\mathrm{HNHC}$ patients encompass the approaches discussed above. We grouped interventions for HNHC patients, using the scheme proposed by Bodenheimer to group care management programs, into seven categories based on the primary setting in which the intervention is delivered (with several modifications). ${ }^{45} \mathrm{We}$ included system-level transformation models that affect a larger population of patients, but we only report findings for those patients who are HNHC. We did not include hospital discharge models because they are outside the scope of this review. Most of the interventions designed to target the complex needs of HNHC patients are themselves complex and are often a hybrid of various models, so some may not neatly fit into one of these seven categories.

- System-level transformation model: Clinics, practices, and other organizations modify how care is delivered to all patients.

- Telephonic/mail model: Care is delivered remotely by telephone or mail.

- Community-based model: Care provider meets with the patient wherever the patient is located.

- ED-based model: Patients are recruited and receive care in the ED.

- aICU (ambulatory intensive caring unit) model: Care is received in a separate highrisk clinic or through a high-risk team within a primary care clinic.

- Primary care model: Care is embedded in one or more primary care practices.

- Home-based care model: Care is delivered in the patient's home.

\section{Clinical and Policy Context}

As discussed above, an important health policy context for this review is payers in the U.S. healthcare system incentivizing complex healthcare systems and their providers to move toward new structures of care, such as ACOs. At the same time, they are increasingly requiring or 
creating incentives for these healthcare systems to accept payment models that include financial risk. ${ }^{6-9}$ Healthcare systems participating in these payment models acknowledge that addressing the utilization and costs of HNHC patients is critical to their success in meeting their performance and financial goals. ${ }^{10,11}$

Key to meeting policy goals is equipping health systems, individual providers, and patients with clinical supports. Issues in changing health systems' and providers' delivery of care include leadership support, changes in workflow, provider and staff skills development, adequate infrastructure, and staffing. Barriers for patients may include insufficient understanding, affordability, acceptability, and accessibility.

\section{Purpose and Scope of the Review}

This review has three main objectives, all with the shared purpose of identifying actionable evidence to support informed decisions concerning care for $\mathrm{HNHC}$ patients. The intended audience of the review reflects the broad range of stakeholders who are concerned about care in this population, including clinicians, healthcare systems, payers, and policymakers at the local, State, and national levels. Our first objective is to summarize the evidence related to identifying HNHC patient populations. The second is to develop and refine causal theories explaining why particular interventions, in various circumstances, are more likely to be successful in changing potentially preventable or modifiable healthcare use among HNHC patients. Our third objective is to review the evidence supporting the overall effectiveness of interventions for HNHC patients.

Interventions to address the needs of HNHC patients are frequently complex. Often, we have a limited understanding of the role that individual components of these interventions (such as care management) independently or synergistically contribute to the intervention's outcomes. Sources of complexity can include characteristics of the intervention itself (e.g., multiple components) or of its causal pathway (e.g., multiple mediators or moderators, feedback loops, synergies between components, multiple outcomes, or interaction between the intervention and context). ${ }^{46}$ For the purpose of this review, we explored the nature of interactions between the interventions and the setting and investigated the underlying causal mechanisms that may explain the outcomes of the intervention, considering differences in the patient population, intervention setting, and provider context.

\section{Report Organization}

Chapter 2 of the report presents the three Key Questions (KQs) that guide the review, the approaches used to address the KQs, and an overview of the methods used to conduct the review. Chapter 3 presents the findings for the KQs; this chapter presents an overview of the literature yield across the KQs and then presents detailed findings by KQ. Finally, Chapter 4 summarizes our findings and discusses the implications of the findings for clinical practice, education, research, and policy.

We provide additional details of our approach to conducting the review in Appendix A and additional supporting details on our results in Appendix B. Appendix references are shown in Appendix C. 


\section{Chapter 2. Methods}

Below we list the Key Questions (KQs), illustrate the analytic framework, and describe the approaches used in this review. We also briefly outline the study selection criteria, data sources and searches, data extraction and risk of rigor/bias, data synthesis and analysis, and grading of the strength of the body of evidence. Additional details can be found in the methods appendix (Appendix A).

\section{Key Questions}

The review addresses the following three KQs.

KQ 1.What criteria identify or predict that patients will be high-need, high-cost $(\mathrm{HNHC})$ ?

a. How do criteria incorporate patient clinical characteristics?

b. How do criteria incorporate patient demographic, behavioral health, and social risk factors?

c. How do criteria incorporate types, amount, duration, and patterns of healthcare use?

d. Do criteria differ when HNHC is identified at the population, payer, healthcare system, and provider levels?

e. How can potentially preventable or modifiable high use of healthcare be differentiated from necessary and appropriate high use?

KQ 2.What are the mechanisms that lead to reductions in potentially preventable or modifiable healthcare use, and result in improved health outcomes and cost savings in interventions serving HNHC patients?

a. What are the important contexts, such as the characteristics of HNHC patients, the broader healthcare delivery system, and the community, that affect whether mechanisms facilitate the desired outcomes?

KQ 3. Overall, what is the effectiveness and what are the harms of interventions for $\mathrm{HNHC}$ patients in reducing potentially preventable or modifiable healthcare use and costs and in improving health outcomes?

\section{Analytic Framework}

The framework in Figure 1 illustrates the relationships across the KQs, including the target population, interventions, contexts, mechanisms, and outcomes. 


\section{Figure 1. Analytic framework}

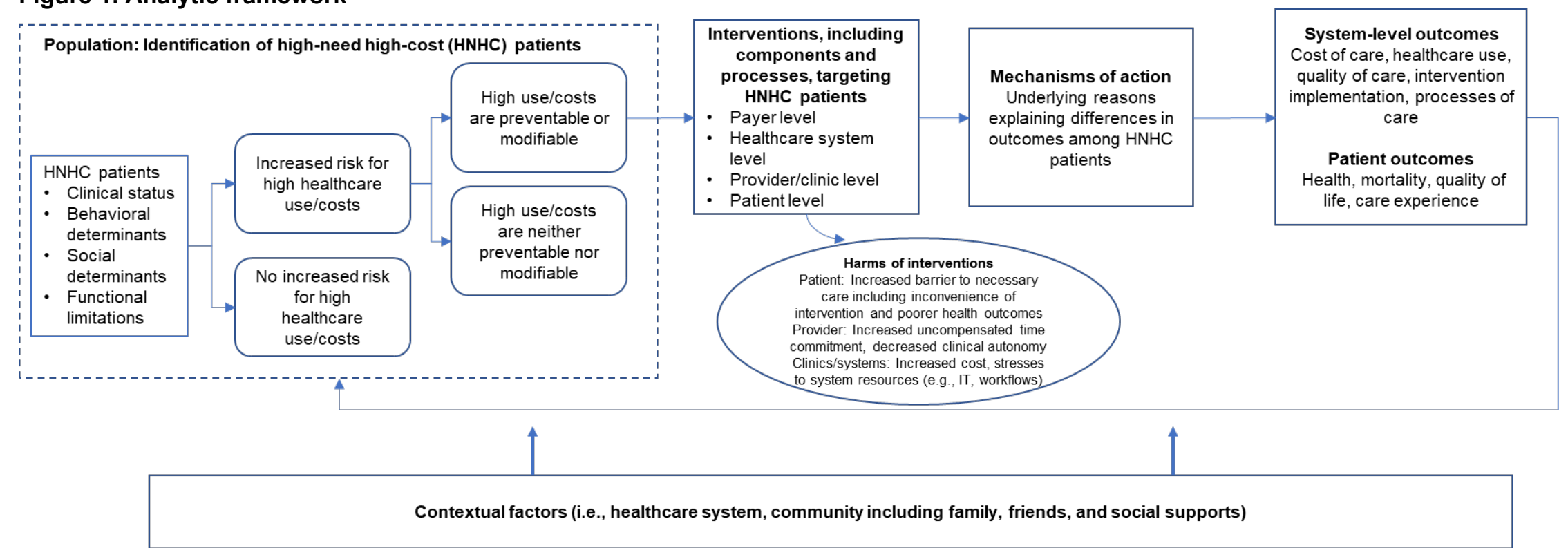

$\mathrm{HNHC}=$ high-need, high-cost; IT = information technology; KQ = Key Question. 


\section{Review Approach}

We used three methodologies to conduct our review, tailoring our approach for each KQ. We used a "best fit" framework synthesis approach for KQ 1, ${ }^{47,48}$ a realist review approach for KQ $2,{ }^{49}$ and a systematic review methodology for KQ $3 .^{50}$

The topic of this report was developed by the Agency for Healthcare Research and Quality (AHRQ) in consultation with the Oregon Health Evidence Review Commission. We conferred with a six-member Key Informant (KI) stakeholder panel to help ensure that the review team understood the most up-to-date policy perspectives and activities in the field and could focus the review so that it would be relevant across potential end users. The KIs provided insights that were useful in designing the project's taxonomy for grouping characteristics of HNHC patients and appreciating important intervention features to inform the review. The review team also was advised by a Technical Expert Panel (TEP) who further commented on the approach being used in the review. The TEP included individuals with expertise in the different review methodologies being used.

To answer KQ 1, we used a "best fit" framework synthesis as an a priori framework to sort evidence into themes across included studies to achieve our aim of describing the HNHC patient population. ${ }^{47,48}$ Consistent with this approach, we began from an identified framework that we used to sort evidence into themes across included studies (i.e., the distinguishing characteristics and reasons why some patients are HNHC). During our review of the evidence, we used an iterative process to consider new themes that were not captured in the initial framework. In the end, we present a summary of the data and syntheses of the evidence and our conclusions within a framework corresponding to our final conceptual model.

The realist review approach we used to answer KQ 2 is intended to facilitate developing program theories explaining and describing how complex HNHC patient interventions work, for whom, and in what particular contexts and settings, as supported by evidence from qualitative and quantitative studies. ${ }^{51} \mathrm{We}$ used this approach to unpack and understand the causal processes for achieving outcomes within complex interventions. To explain these causal processes, we developed, refined, and tested context-mechanism-outcome (CMO) configurations. CMOs are the building blocks for developing program theories that explain the underlying (often unseen and intangible) causal mechanisms that underpin interventions. ${ }^{52}$ Realist review findings can provide support for theories for why outcomes may differ because of interpersonal relationships and subtle contextual conditions.

To answer KQ 3, we used a systematic review approach to synthesize and assess the evidence on the impact of interventions for HNHC patients on specific outcomes of interest. The systematic review followed AHRQ's Methods Guide for Effectiveness and Comparative Effectiveness Reviews (available at https://effectivehealthcare.ahrq.gov/topics/cer-methodsguide/overview). Our reporting is in accordance with the Preferred Items for Reporting in Systematic Reviews and Meta-Analyses. ${ }^{50}$

Discussions with our KI and TEP panels contributed to the development of potential mechanisms for our KQ 2 realist review. In keeping with realist review methods, for KQ 2 we refined the scope of the realist review as we uncovered evidence and focused the depth and breadth of the review. ${ }^{53}$

The final protocol is posted on the Effective Health Care website at https://effectivehealthcare.ahrq.gov/products/high-utilizers-health-care/protocol. The PROSPERO registration is CRD42020161179. 


\section{Study Selection}

Eligible studies met the following inclusion criteria: (1) included noninstitutionalized adults, 18 years of age or older, (2) analyzed an eligible outcome (e.g., healthcare use, cost, patient health management behaviors, clinical outcomes, and satisfaction with care; physicians' and health professionals' satisfaction with clinical practice; patient and health professional harms), (3) measured outcomes after at least 6 months, (4) were conducted in the United States, and (5) published in English.

Studies included for each KQ met additional criteria specific to the KQ.

For KQ 1, eligible studies included quantitative and qualitative designs. We required that all quantitative cohort and cross-sectional studies of exposures control for potential confounding (i.e., univariate results were not included). We also included latent class and cluster analysis designs.

Eligible KQ 2 studies were any design, quantitative or qualitative, considered to be of sufficient rigor (i.e., the method used to generate the particular piece of data was considered by the review team to be credible [plausible] and trustworthy) ${ }^{54}$ Furthermore, studies needed to provide information on $\mathrm{HNHC}$ interventions that was relevant for adding to theory and explanation of CMO configurations. ${ }^{55}$

Eligible KQ 3 studies were randomized controlled trials (RCTs), cluster randomized trials, cohort studies, case-control studies, and quasi-experimental designs. Included studies needed to compare results for intervention participants with a comparison group in any other intervention or treatment as usual.

Intervention studies included as evidence for KQ 2 and KQ 3 were conducted in any outpatient healthcare delivery settings, including ambulatory care, emergency department, the community, and the home. KQ 2 and KQ3 interventions included, but were not limited to, alternative delivery models, system- or practice-level interventions, patient supportive services (e.g., community health workers, patient navigators), and social determinants of health-related interventions (e.g., transportation, health literacy, housing, and caregiver support). We excluded studies conducted solely in an inpatient setting that supported discharge planning because previous reviews are available about these interventions. However, we included studies that identified patients in the inpatient setting when intervention services were mostly provided after discharge.

For all KQs, we included studies that involved HNHC patients with 6 or more months of high healthcare cost or use. Among studies included for KQ 2 and KQ 3, we sought to also identify the subgroup of studies that met a more stringent criterion-HNHC patients with 6 or more months of high healthcare cost or use AND either two or more chronic physical health conditions or a combination of one or more chronic physical health conditions and one or more behavioral health conditions. For KQs 2 and 3, we sought to understand what, if any, differences were observed in intervention components, context, and effectiveness. Across all studies, we accepted the authors' definitions of HNHC that otherwise met our other inclusion criteria (e.g., length of time, conducted in the United States). In most studies, high use or cost was measured without directly evaluating whether individual episodes of care were potentially preventable or modifiable.

Appendix A lists detailed inclusion and exclusion criteria, organized by a PICOTS (population, intervention, comparator, outcome, timing, setting, and study design) framework. 


\section{Data Sources and Searches}

We conducted focused searches of MEDLINE ${ }^{\circledR}$ via PubMed ${ }^{\circledR}$, the Cochrane Clinical Trials Central Register, CINAHL ${ }^{\circledR}$, Embase $^{\circledR}$, PsycINFO $^{\circledR}$, Web of Science, Academic Search Premier, and Scopus from January 1, 2000, to March 4, 2021. We also conducted targeted searches for grey literature on the Centers for Medicare \& Medicaid Services website, the Commonwealth Fund website, and SIREN Evidence Library, among others. We posted a Federal Register notice on December 16, 2019 and requested supplemental evidence and data on January 16, 2020. Additional information on the data sources and searches is provided in Appendix A. We updated the literature search on March 4, 2021, during the public posting period of the draft report.

\section{Data Extraction and Risk-of-Bias/Risk-of-Rigor Assessments}

For each included study for KQ 1 and KQ 3, one investigator extracted information specifically selected to address each KQ into an evidence table. This included information about design, population, intervention, and outcomes. A second investigator reviewed the information for completeness and accuracy.

KQ 2 data extraction was guided by uncovering information that explained the cause for a particular outcome under the influence of one or more contexts. Data were abstracted into NVivo software using a coding framework grounded in our initial program theory of CMOs. One investigator extracted relevant excerpts from the studies, and a second investigator audited the extractions. Coding of all included studies using the coding framework proceeded as both an inductive and deductive process; that is, we continued to identify and add to the coding framework as we proceeded with data extraction.

For KQ 1, we did not assess the risk of bias of included studies. The studies we included to answer KQ 1 were mostly quantitative observational studies of exposures (multivariate predictive or cross-sectional designs), and fewer were cluster analyses or qualitative studies. No validated tool is available for evaluating the risk of bias of cross-sectional or cluster analysis studies (the majority of our included studies). ${ }^{56}$

In relation to the rigor of quantitative studies included to answer KQ 1, we limited our review to multivariate designs that controlled for potential confounding. Predictive studies are multivariate analyses where the outcome (use or cost) is measured in a later period than the independent variables included to "predict" the outcome. In cross-sectional studies, all data are obtained during the same period. Cluster analysis, and the associated technique latent class analysis, are statistical methods for identifying "hidden" or unobservable class membership (groupings) among subjects using observed variables. ${ }^{57}$

We appraised the rigor of qualitative studies included to answer KQ 1 (methodological strength and limitations) as recommended in the Cochrane Handbook. ${ }^{58}$ We conducted the assessment using the Critical Appraisal Skills Programme tool. ${ }^{59}$ Included quantitative and qualitative studies were determined to have clear aims and research questions.

For KQ 2, we used RAMESES (Realist And Meta-narrative Evidence Syntheses: Evolving Standards) project standards to guide our judgments in quality appraisal tasks. ${ }^{53,54,60,61}$ Data were appraised based on relevance, trustworthiness, plausibility of the argument underlying the theory, and rigor. We did not formally assess methodological rigor (risk of bias) because all relevant information in a document may be used to build and refine the program theories, including the discussion. ${ }^{60}$ However, we globally assessed the quality of the included documents to determine whether the data were trustworthy and credible. Studies were considered 
sufficiently rigorous (trustworthy and credible) based on two senior team members' assessment that the study followed its specified methodology and was credible.

For KQ 3 studies, the criteria set forth by AHRQ's Methods Guide for Comparative Effectiveness Reviews guided our assessment of methodological risk of bias. ${ }^{50}$ Two independent investigators assessed the risk of bias of each study, using predefined criteria established in the Cochrane Risk Of Bias In Non-randomized Studies - of Interventions (ROBINS-I) ${ }^{62}$ tool for observational studies and the Cochrane $\mathrm{RCT}^{63}$ tool for RCTs. We rated outcomes as low, some concerns, high, or unclear risk of bias for each study in KQ 3.

\section{Data Synthesis and Analysis}

Describing the HNHC patient population (KQ 1). The a priori framework we used to initially structure the best-fit framework synthesis is the taxonomy developed by the National Academy of Medicine (NAM) in their report Effective Care for High-Need Patients: Opportunities for Improving Outcomes, Value, and Health as our a priori framework. ${ }^{20}$ This $^{2}$ taxonomy groups HNHC patients first based on their clinical and functional characteristics. Among the six patient groups presented in the taxonomy, four met the inclusion criteria for this review: nonelderly disabled, multiple chronic conditions, major complex chronic conditions, and frail elderly. NAM's other two categories - children with complex needs and individuals with advancing illness/end-of-life care-are outside the scope of the review because interventions for these two groups have significantly different intervention goals and pathways for delivering care. Within these clinical and functional groups, the taxonomy proposed additional, cross-patient group assessments based on behavioral health factors and social risk factors that are believed to influence how individuals use healthcare and increase the risk of receiving fragmented care. Behavioral health factors included serious mental illness, substance use disorder, cognitive decline, and chronic toxic stress. Social risk factors included low socioeconomic status, low health literacy, social isolation, community deprivation, and housing insecurity. Based on the evidence from our included studies, we considered whether the NAM taxonomy was the best fit for the evidence or if modifications would be useful.

Understanding interventions for HNHC patients (KQ 2). We used a realist review approach to gain a greater understanding of the complex payment and delivery models, social interventions, and health programs used to address healthcare utilization among HNHC patients. Consistent with this approach, our goal was to explain what works (or fails), for whom, under what circumstances, and why. ${ }^{52}$ We sought to identify, elucidate, and refine the various underlying theories that could explain the approach of different complex interventions, explore implementation chains, assess intermediate outcomes, and examine modifications or adaptations applied in various circumstances. ${ }^{52}$

Once all papers were coded at the conceptual level, one investigator sorted excerpts across studies by concepts and developed initial, partial CMO configurations. A second investigator reviewed the CMOs for agreement with their own interpretation. The team then examined the CMOs alongside the developing program theories and iteratively reworked the CMOs as more data were added and the program theories were refined.

Review of the evidence supporting the effectiveness of interventions for HNHC patients (KQ 3). To further support the goal of producing actionable information, we used traditional Evidence-based Practice Center (EPC) Program systematic review methods to synthesize the evidence of the overall effectiveness of the interventions on cost, utilization, clinical and functional, and social risk outcomes. We categorized the evidence based on the primary setting 
of the intervention (system-level transformation, telephonic, community, emergency department, ambulatory intensive caring unit, primary care, and home based), generally following the framework proposed by Bodenheimer to group care management interventions. ${ }^{45}$

Several studies included as evidence for KQ 3 assessed multiple cohorts or conducted multiple analyses. Some interventions were assessed in relation to two separate and distinct HNHC patient cohorts who received the same treatment. ${ }^{64-68}$ Other interventions looked at outcomes for HNHC patients, distinct from a more general patient population; some patients might have been included in multiple cohorts constructed for separate studies. ${ }^{69,70,71}$ Still other interventions conducted multiple analyses on different subsets of their HNHC patient population to answer different research questions. ${ }^{72}$ We refer to each of these cohorts, populations, and analyses as "samples," and each sample is considered as evidence from a separate study.

Because of the diversity of intervention designs and outcomes, we generally used a narrative synthesis approach to report most of our findings. We conducted a quantitative synthesis of results by calculating a pooled estimate when three or more samples with the same study design had similar treatment and comparison groups and reported an estimate of the same outcome measure within a setting. Pooled estimates were not calculated if samples were potentially overlapping. We used Stata ${ }^{\circledR} 16$ (StataCorp, College Station, TX) to calculate effect sizes and associated 95 percent confidence intervals.

\section{Grading the Strength of the Body of Evidence}

We graded the strength of evidence for KQ 3 outcomes based on guidance established for the EPC Program. ${ }^{73}$ Developed to grade the overall strength of a body of evidence, this approach incorporates five key domains: risk of bias (includes study design and aggregate quality), consistency, directness, precision of the evidence, and reporting bias. This approach requires looking beyond statistical significance alone. It requires considering whether studies are consistent and of high quality and outcomes are direct and clinically relevant. It emphasizes the adequacy of the sample size to rule out spurious associations and results.

The domains listed above are reflected in an overall rating regarding the strength of the evidence of high, moderate, low, or insufficient. Two reviewers assessed each domain for each key outcome with differences resolved by consensus.

- A high rating indicates high confidence that the evidence reflects the true effect. Further research is very unlikely to change our confidence in the estimate of effect.

- A moderate rating indicates moderate confidence that the evidence reflects the true effect. Further research may change our confidence in the estimate of the effect and may change the estimate.

- A low rating indicates low confidence that the evidence reflects the true effect. Further research is likely to change our confidence in the estimate of the effect and is likely to change the estimate.

- An insufficient rating indicates that the evidence does not permit estimation of an effect because the evidence is limited to a single study, or multiple domain ratings indicate weakness in the evidence base (i.e., the evidence base may comprise studies with limitations; be inconsistent, indirect, or imprecise; or be biased in reporting). When high risk-of-bias studies are likely to alter the judgment, we offer a strength-of-evidence grade that relies on the better quality evidence. When the signals from the evidence base are conflicting and we cannot attribute the differences to risk of bias alone, we assign the grade as insufficient. 
Evidence bases consisting of RCTs begin with an overall rating of high; downgrading any domain (study limitations, precision, consistency, directness, and reporting bias) results in lower ratings. Evidence bases consisting of observational studies begin with a rating of low. They may be downgraded for the domains listed above. They may also be upgraded on three domains: dose-response association, plausible confounding that would decrease the observed effect, and strength of association (magnitude of effect). Often our strength-of-evidence grades that were higher than insufficient included a combination of RCT and observational evidence. For some outcomes, we have graded the evidence as a finding of no difference between the intervention and comparison groups. In these cases, we concluded that the effect estimate and corresponding confidence interval are within the boundaries of a minimally important difference. ${ }^{74}$

Based on EPC Program guidance, the evaluation of reporting bias is limited to RCTs. Because many of the RCTs we included in the review reported null findings, we concluded that reporting bias is not a particular concern in this body of evidence. 


\section{Chapter 3. Results}

In this chapter, we present the yield from literature searches first, followed by a brief description of the characteristics of included studies. The remainder of the chapter presents results organized by Key Question (KQ). Within each KQ section, we first present key points followed by detailed results. The detailed results for KQ 1 use a best fit synthesis approach to organize and synthesize evidence from studies that examine patient healthcare use, chronic conditions, and other risk factors that were used to identify or predict who will be a high-need, high-cost (HNHC) patient. The detailed results for KQ 2 present results from a realist review from which we developed three program theories related to interventions for HNHC patients: recruiting patients, engaging patients, and engaging clinicians. The detailed results for KQ 3 present evidence on the effectiveness of outcomes from interventions for $\mathrm{HNHC}$ patients.

In this chapter, we separately present our evidence and findings for each of the KQs.

Details on results of literature searches, included studies, excluded studies, and results for all outcomes can be found in the Appendix B, Results.

\section{Literature Searches and Study Characteristics}

The electronic search, grey literature, and reference mining identified 2,923 citations. After title and abstract screening, 873 studies were retrieved for full-text review. A total of 110 studies (117 articles) met our eligibility criteria and were included in the analyses.

\section{Description of Included Evidence}

The evidence includes a mix of study designs to answer the different KQs (Table 1).

Table 1. Key characteristics of included studies

\begin{tabular}{|c|c|c|c|c|c|}
\hline $\begin{array}{l}\text { Study } \\
\text { Characteristics }\end{array}$ & Categories & $\begin{array}{l}\text { Total \# of Unique } \\
\text { Studies (Articles) }\end{array}$ & $\begin{array}{l}\text { \# KQ } 1 \text { Studies } \\
\text { (Articles) }\end{array}$ & $\begin{array}{l}\text { \# KQ } 2 \text { Studies } \\
\text { (Articles) }\end{array}$ & $\begin{array}{l}\text { \# KQ } 3 \text { Studies } \\
\text { (Articles) }\end{array}$ \\
\hline Total & & $110(117)$ & $60(61)$ & $48(51)$ & $40(46)$ \\
\hline \multirow[t]{6}{*}{ Study design } & RCT & $19(20)$ & $0(0)$ & $15(16)$ & $19(20)$ \\
\hline & $\begin{array}{l}\text { Intervention study: } \\
\text { observational with } \\
\text { comparison }\end{array}$ & $23(28)$ & $0(0)$ & $13(15)$ & $21(26)$ \\
\hline & $\begin{array}{l}\text { Exposure study: } \\
\text { cluster analysis }\end{array}$ & $10(10)$ & $11(11)^{\mathrm{a}}$ & $1(1)$ & $0(0)$ \\
\hline & $\begin{array}{l}\text { Exposure study: } \\
\text { multivariate cross- } \\
\text { sectional }\end{array}$ & $33(33)$ & $33(33)$ & $0(0)$ & $0(0)$ \\
\hline & $\begin{array}{l}\text { Exposure study: } \\
\text { multivariate } \\
\text { predictive }\end{array}$ & $11(12)$ & $11(12)^{a}$ & $5(5)$ & $0(0)$ \\
\hline & $\begin{array}{l}\text { Qualitative study: } \\
\text { various designs }\end{array}$ & $14(14)$ & $6(6)$ & $14(14)$ & $0(0)$ \\
\hline \multirow{3}{*}{$\begin{array}{l}\text { Healthcare } \\
\text { coverage of study } \\
\text { participants }\end{array}$} & Medicaid only & $14(17)$ & $8(9)$ & $6(8)$ & $5(7)^{b}$ \\
\hline & $\begin{array}{l}\text { Medicare only or } \\
\text { dual Medicare/ } \\
\text { Medicaid }\end{array}$ & $35(37)$ & $17(17)$ & $16(16)$ & $17(19)$ \\
\hline & Commercial only & $9(9)$ & $9(9)$ & $1(1)$ & $0(0)$ \\
\hline
\end{tabular}




\begin{tabular}{|c|c|c|c|c|c|}
\hline $\begin{array}{l}\text { Study } \\
\text { Characteristics }\end{array}$ & Categories & $\begin{array}{l}\text { Total \# of Unique } \\
\text { Studies (Articles) }\end{array}$ & $\begin{array}{l}\text { \# KQ } 1 \text { Studies } \\
\text { (Articles) }\end{array}$ & $\begin{array}{l}\text { \# KQ } 2 \text { Studies } \\
\text { (Articles) }\end{array}$ & $\begin{array}{l}\text { \# KQ } 3 \text { Studies } \\
\text { (Articles) }\end{array}$ \\
\hline $\begin{array}{l}\text { Healthcare } \\
\text { coverage of study } \\
\text { participants }\end{array}$ & $\begin{array}{l}\text { Mixed coverage } \\
\text { across } \\
\text { participants }\end{array}$ & $39(40)$ & $26(26)$ & $18(19)$ & $5(6)$ \\
\hline \multirow[t]{2}{*}{ (continued) } & Uninsured & $3(4)$ & $0(0)$ & $2(2)$ & $3(4)$ \\
\hline & Unknown & $10(10)$ & $0(0)$ & $5(5)$ & $10(10)$ \\
\hline
\end{tabular}

${ }^{a}$ One study included two types of analyses and is, therefore, counted twice; predictive and cluster. ${ }^{75}$

${ }^{\mathrm{b}}$ One companion article was the evaluation report for multiple studies; this article was a companion article for two studies. $\mathrm{KQ}=$ Key Question; RCT $=$ randomized controlled trial.

For KQ 1, we identified 60 studies reported in 61 articles, including 11 multivariate predictive studies, ${ }^{75-86} 33$ multivariate cross-sectional studies, ${ }^{87-119} 10$ cluster analysis studies, ${ }^{120-}$ 129 and six qualitative studies. ${ }^{130-134}$

For KQ 2, we identified 48 studies (51 articles). ${ }^{20,44,64-69,72,76,79,80,82,85,124,130-164}$ Of these, 12 studies were also used to answer KQ 1 (13 articles), 25 studies were also used to answer KQ 3 (27 articles), and 11 studies were unique to KQ 2 (11 articles). ${ }^{20,136,142,144,146,147,154-156,163,164}$

For KQ 3, we identified 40 studies, including 19 randomized controlled trials (RCTs) and 21 observational studies (46 articles). Five RCTs were assessed as having low risk of bias, and 14 RCTs (15 articles) were assessed as having some concerns for bias, ${ }^{44,64-68,137,140,143,149,151,158-162,}$ 165-168 No observational studies were assessed as having low risk of bias, 13 observational studies (17 articles) were assessed as having some concerns for bias, and 8 observational studies ( 9 articles) were assessed as having high risk of bias. ${ }^{69-72,138,139,141,145,148,150,152,153,157,169-181}$

Figure 2 (also shown as Figure B-1) presents the flow of articles considered for inclusion at the title/abstract and full-text stages of review and those ultimately included in our syntheses. 
Figure 2. Article flow diagram

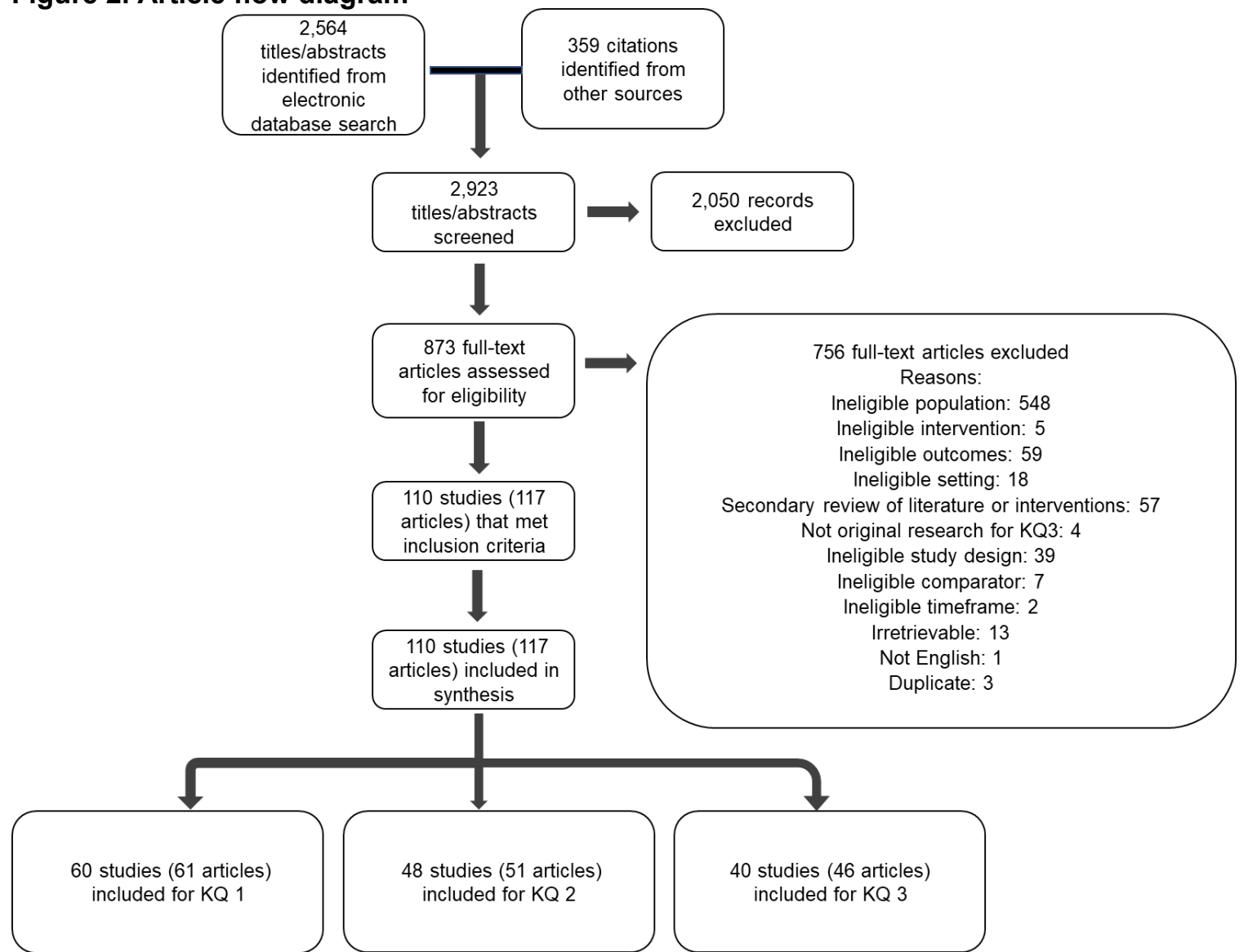

Note: The sum of the number of studies per KQ exceeds the total number of studies because some studies were applicable to multiple KQs.

$\mathrm{KQ}=$ Key Question.

\section{$\mathrm{KQ}$ 1. What criteria identify or predict that patients will be HNHC?}

We used a "best fit" framework synthesis approach to consider our findings in relation to an existing framework. ${ }^{47,48}$ (Chapter 2 includes a description of the best fit framework methodological approach to study synthesis.) In keeping with this approach, we reviewed included studies to determine if the key HNHC patient characteristics identified in studies echoed themes in the taxonomy developed by the National Academy of Medicine (NAM) in their report Effective Care for High-Need Patients: Opportunities for Improving Outcomes, Value, and Health. ${ }^{20}$ Figure 3 depicts the NAM taxonomy, which groups HNHC patients first based on their clinical and functional characteristics. The taxonomy further conceptualizes behavioral health and social risk factors as affecting healthcare utilization across clinical and functional groups. A goal of the taxonomy was to identify smaller homogeneous subgroups for targeting interventions. ${ }^{20}$ Based on the evidence from our included studies, we used an iterative process to consider whether the NAM taxonomy is the best fit for the evidence or if modifications would be useful. 
Figure 3. Best fit framework synthesis: National Academy of Medicine High-Need, High-Cost patient characteristic taxonomy

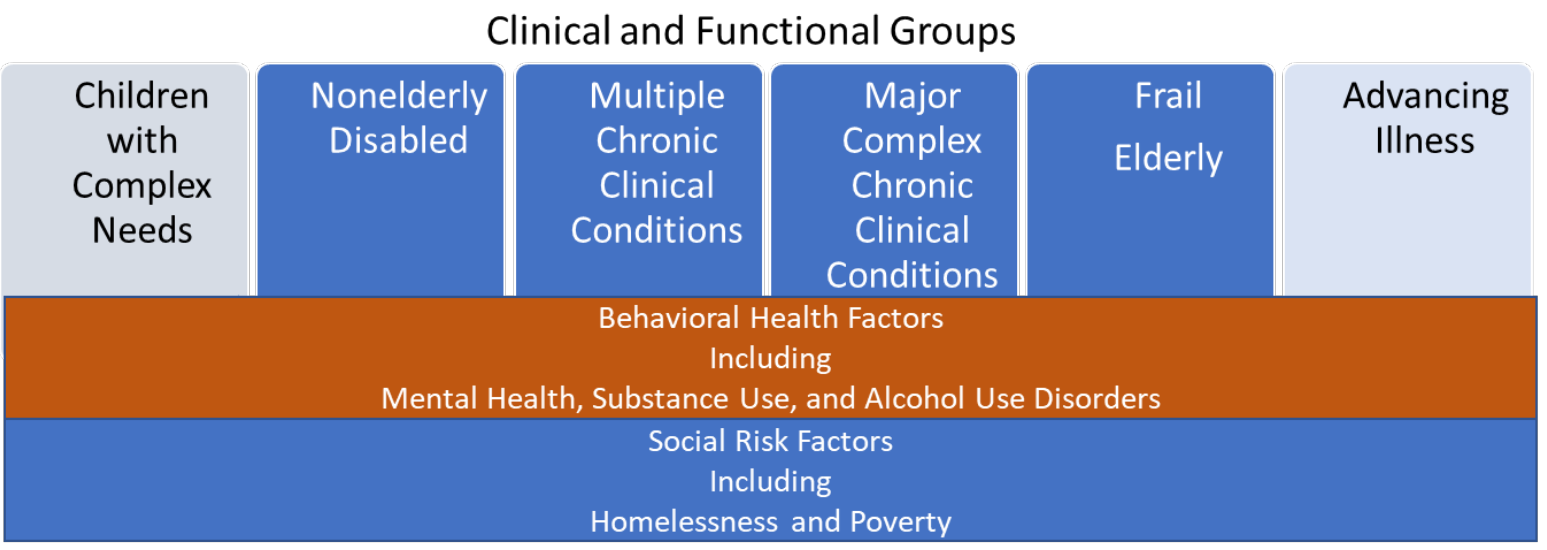

Source: Adapted and reproduced with permission from the National Academy of Sciences (Effective Care for High-Need Patients: Opportunities for Improving Outcomes, Value, and Health) ${ }^{20}$ and from Abrams (Matching Patients to Tailored Care Models: A Strategy to Enhance Care, Improve Outcomes, and Curb Costs). ${ }^{182}$

Our review encompassed four of the six NAM taxonomy clinical and functional groups: nonelderly disabled, multiple chronic clinical conditions, major complex chronic clinical condition, and frail elderly. We did not consider children with complex needs because our review was limited to adults. Our scope also did not include the advancing illness group because the characteristics and goals of care management, the focus of this review, differ from those of interventions that focus on end-of-life care.

In the NAM taxonomy, the multiple chronic and major complex chronic clinical condition groups differ by the type, number, and combination of conditions. The multiple chronic clinical condition group is defined as having only one complex chronic condition and/or between one and five noncomplex chronic conditions. ${ }^{20}$ The major complex chronic clinical condition group is defined as having two or more complex chronic conditions or at least six noncomplex chronic conditions. Examples of complex chronic clinical conditions include acute myocardial infarction, ischemic heart disease, chronic kidney disease, congestive heart failure, dementia, diabetes, chronic lung disease, and stroke. Examples of chronic clinical conditions considered noncomplex include arthritis, immune disorders, cancer, inflammatory bowel disease, osteoporosis, hypertension, and thyroid disease.

\section{Included Evidence}

We identified 60 studies (reported in 61 articles) that examined characteristics of noninstitutionalized HNHC patients, 18 years of age and older (Table 2). We considered HNHC as having 6 months or more of potentially preventable or modifiable high healthcare use or cost. Studies differed in their definition of HNHC patients. Almost always, HNHC was defined solely as a measure of high use, whether in relation to emergency department (ED) visits $(\mathrm{N}=31)$, inpatient visits $(\mathrm{N}=12)$, or a mix of types of visits $(\mathrm{N}=7)$. Less often, HNHC was measured in relation to high cost $(\mathrm{N}=14)$. In each study, authors uniquely established criteria that they determined represented inappropriately high use or cost and examined the patient (and 
sometimes the healthcare system) characteristics significantly related to meeting these criteria. Only a few studies sought to more directly define and measure high-use episodes or costs that were potentially preventable or modifiable.

Table 2. Number of studies by population level and criteria used to define HNHC patients

\begin{tabular}{|c|c|c|c|c|}
\hline Level & ED Visits & IP Visits & All Utilization & Cost \\
\hline Population based & $\begin{array}{l}\text { Cross-sectional: } 8^{92,} \\
93,95,100-104\end{array}$ & - & $\begin{array}{l}\text { Cross-sectional: } 1^{114} \\
\text { Qualitative: } 1^{183}\end{array}$ & Cross-sectional: $1^{118}$ \\
\hline Payer: Medicaida & $\begin{array}{l}\text { Predictive: } 2^{79,81} \\
\text { Cross-sectional: } 2^{105} \text {, } \\
107\end{array}$ & Predictive: $2^{84,85}$ & - & Predictive: $2^{76,78,82}$ \\
\hline Payer: Medicare & $\begin{array}{l}\text { Predictive: } 1^{80} \\
\text { Cross-sectional: } 1^{108}\end{array}$ & $\begin{array}{l}\text { Predictive: } 1^{88} \\
\text { Cross-sectional: } 1^{108}\end{array}$ & Cluster: $1^{126}$ & $\begin{array}{l}\text { Predictive: } 1^{86} \\
\text { Cross-sectional: } 1^{119} \\
\text { Cluster: } 2^{127,128}\end{array}$ \\
\hline $\begin{array}{l}\text { Health plans, including } \\
\text { managed care and } \\
\text { accountable care } \\
\text { organizations }^{b, c, d}\end{array}$ & Cross-sectional: $1^{113}$ & $\begin{array}{l}\text { Cross-sectional: } 2^{111,} \\
{ }_{113}\end{array}$ & - & $\begin{array}{l}\text { Predictive: } 1^{75} \\
\text { Cross-sectional: } 3^{115-} \\
117 \\
\text { Cluster: } 2^{75,122}\end{array}$ \\
\hline $\begin{array}{l}\text { Veterans Health } \\
\text { Administration }\end{array}$ & Cross-sectional: $1^{88}$ & $\begin{array}{l}\text { Predictive: } 1^{83} \\
\text { Cluster: } 2^{124,125}\end{array}$ & $\begin{array}{l}\text { Cross-sectional: } 1^{77} \\
\text { Cluster: } 1^{123}\end{array}$ & - \\
\hline $\begin{array}{l}\text { Health system or multiple } \\
\text { facilities }^{b}\end{array}$ & $\begin{array}{l}\text { Cross-sectional: } 3^{87}, \\
91,113\end{array}$ & - & $\begin{array}{l}\text { Cluster: } 1^{129} \\
\text { Qualitative: } 1^{134}\end{array}$ & - \\
\hline Single facility ${ }^{b}$ & $\begin{array}{l}\text { Cross-sectional: } 9^{89-} \\
91,94,96-99,106 \\
\text { Cluster: } 1^{121} \\
\text { Qualitative: } 2^{131,132}\end{array}$ & $\begin{array}{l}\text { Cross-sectional: } 2^{109}, \\
\text { Qualitative: } 1^{133}\end{array}$ & Cross-sectional: $1^{112}$ & Qualitative: $1^{130}$ \\
\hline
\end{tabular}

${ }^{a}$ Medicaid or Medicare populations are counted with the payer, even if the analysis was limited to single or multiple facilities.

${ }^{\mathrm{b}}$ Study population included multiple payers.

${ }^{\mathrm{c}}$ One study separately analyzed HNHC in relation to ED and IP visit patient outcomes. ${ }^{113}$

${ }^{\mathrm{d}}$ One study included both a cross-sectional and cluster analysis. ${ }^{75}$

- Denotes no studies.

$\mathrm{ED}=$ emergency department; HNHC = high-need, high-cost; IP = inpatient.

The evidence included to answer KQ 1 fell into four broad groups of methodological approaches. We present characteristics for each included study in separate tables by analysis type: predictive (Table 3), cross-sectional (Table 4), cluster (Table 5), and qualitative (Table 6). For cross-sectional (Table 4) and predictive studies (Table 3), we also present outcomes and categories of predictors included in multivariate models. For cluster analyses (Table 5), we also present clusters identified in the analysis. For qualitative studies (Table 6), we also present the main findings.

We structured the presentation of our results to separately answer each of our KQ 1 subquestions and correspond to the NAM taxonomy:

- KQ 1a: Patient clinical conditions (corresponding to the NAM clinical and functional groups)

- KQ 1b: Patient demographic, behavioral health, and social risk factors (encompassing the NAM behavioral health and social risk factors)

- KQ 1c: Types, amount, duration, and patterns of use

- KQ 1d: Differences by payer, healthcare system, and provider level

- KQ 1e: Identifying potentially preventable and modifiable use

Although most studies included patients across clinical and behavioral health conditions, nine studies focused on subgroups of HNHC patients. Subgroups included those with specific chronic 
clinical conditions associated with high healthcare use (i.e., asthma, ${ }^{95}$ chronic obstructive pulmonary disease [COPD], ${ }^{93}$ acute heart failure syndrome, ${ }^{92}$ migraine headache,${ }^{102}$ or mental health conditions). ${ }^{85,87,90}$ Another subgroup study was limited to disabled Medicaid beneficiaries. ${ }^{85}$ The ninth subgroup study separately analyzed Medicare beneficiaries younger than 65 years of age and those 65 years of age and older. ${ }^{108}$

\section{Predictive Studies}

Predictive analysis is deemed to be the most rigorous design, among available analytic approaches, because it is better able to establish causation (i.e., the use or cost outcome occurred after the diagnosis and other characteristics of interest). All predictive studies used regression analysis suited to the functional form of the outcome (e.g., logistic, Poisson) and the intent of the analysis (e.g., stepwise, lasso linear) to identify predictors of HNHC patient healthcare use or cost in a subsequent period, while controlling for potential confounding variables. Predictive analyses examined the association between HNHC patients' characteristics and/or behavior during an index time period, typically a year, and their healthcare use or cost in a future time period, ranging from 6 months or longer, most often 1 year. We identified 11 predictive studies, reported in 12 articles (Table 3 ).

Table 3. Predictive studies with evidence for KQ 1 ( $N=11)$

\begin{tabular}{|c|c|c|c|c|c|c|c|}
\hline Author, N & $\begin{array}{l}\text { HNHC } \\
\text { Outcome } \\
\text { Measured } \\
\text { During the } \\
\text { Followup } \\
\text { Period }^{\mathrm{a}} \\
\end{array}$ & $\begin{array}{l}\text { Study } \\
\text { Population }\end{array}$ & $\begin{array}{l}\text { Clinical } \\
\text { Health } \\
\text { Conditions }\end{array}$ & $\begin{array}{l}\text { Demographic } \\
\text { Character- } \\
\text { istics }\end{array}$ & $\begin{array}{l}\text { High-Impact } \\
\text { Behavioral } \\
\text { Character- } \\
\text { istics }\end{array}$ & $\begin{array}{l}\text { High-Impact } \\
\text { Social Risk } \\
\text { Character- } \\
\text { istics }\end{array}$ & $\begin{array}{l}\text { Provider } \\
\text { and Health } \\
\text { System } \\
\text { Character- } \\
\text { istics }\end{array}$ \\
\hline $\begin{array}{l}\text { Billings et al., } \\
2013 \\
N=212,259^{81}\end{array}$ & $\begin{array}{l}\text { ED visits } \\
(3+, 5+, 8+ \\
10+)\end{array}$ & $\begin{array}{l}\text { Medicaid: } \\
\text { Frequent ED } \\
\text { users in NYC, } \\
2007\end{array}$ & $\begin{array}{l}\text { Number of } \\
\text { chronic } \\
\text { conditions, } \\
\text { diagnosis, } \\
\text { CCl rating } \\
\text { scale }\end{array}$ & $\begin{array}{l}\text { Age, gender, } \\
\text { race }\end{array}$ & MI, SUD & $\begin{array}{l}\text { Not } \\
\text { measured }\end{array}$ & $\begin{array}{l}\text { Utilization } \\
\text { over prior } 3 \\
\text { years }\end{array}$ \\
\hline $\begin{array}{l}\text { Colligan et al., } \\
2016 \\
N=5,400,237^{80}\end{array}$ & ED visits (4+) & $\begin{array}{l}\text { Medicare: } \\
\text { national } 20 \% \\
\text { sample, 2009- } \\
2010\end{array}$ & $\begin{array}{l}\text { Diagnoses, } \\
\text { HCC score }\end{array}$ & $\begin{array}{l}\text { Age, gender, } \\
\text { race }\end{array}$ & $\mathrm{MI}$ & $\begin{array}{l}\text { Not } \\
\text { measured }\end{array}$ & $\begin{array}{l}\text { Medicaid, } \\
\text { Prior year: } \\
\text { level of ED } \\
\text { use, } \\
\text { continuity of } \\
\text { care index }\end{array}$ \\
\hline $\begin{array}{l}\text { Kanzaria, } \\
2017 \\
(\mathrm{~N}=173,273)^{79}\end{array}$ & $\begin{array}{l}\text { ED visits } \\
(4+), \\
\text { persistent } \\
\text { over } 2,3,6, \\
\text { and } 11 \text { years }\end{array}$ & $\begin{array}{l}\text { California } \\
\text { nonelderly } \\
\text { adults, 2005- } \\
2015 \text {; ED visits } \\
4+\text { in 2005, } \\
2005-2015 \\
\end{array}$ & $\begin{array}{l}\text { Not } \\
\text { measured }\end{array}$ & Age, race & $\begin{array}{l}\text { Anxiety } \\
\text { disorder, } \\
\text { Depression, } \\
\text { SMI, SUD, } \\
\text { AUD }\end{array}$ & $\begin{array}{l}\text { Urbanicity, } \\
\text { poverty }\end{array}$ & $\begin{array}{l}\text { Insurance } \\
\text { type, level } \\
\text { of ED use in } \\
\text { the base } \\
\text { year }\end{array}$ \\
\hline $\begin{array}{l}\text { Billing et al., } \\
2007 \\
(\mathrm{~N}=98,000)^{85}\end{array}$ & $\begin{array}{l}\text { Inpatient } \\
\text { readmissions } \\
(1+)\end{array}$ & $\begin{array}{l}\text { NYC, Medicaid } \\
\text { enrollees, } \\
\text { disabled and } \\
\text { SMI subgroups, } \\
2000-2004\end{array}$ & Diagnosis & $\begin{array}{l}\text { Age, race, } \\
\text { gender }\end{array}$ & SMI, MI, SUD & Zip code & $\begin{array}{l}\text { Prior } \\
\text { utilization }\end{array}$ \\
\hline
\end{tabular}




\begin{tabular}{|c|c|c|c|c|c|c|c|}
\hline Author, N & $\begin{array}{l}\text { HNHC } \\
\text { Outcome } \\
\text { Measured } \\
\text { During the } \\
\text { Followup } \\
\text { Perioda }\end{array}$ & $\begin{array}{l}\text { Study } \\
\text { Population }\end{array}$ & $\begin{array}{l}\text { Clinical } \\
\text { Health } \\
\text { Conditions }\end{array}$ & $\begin{array}{l}\text { Demographic } \\
\text { Character- } \\
\text { istics }\end{array}$ & $\begin{array}{l}\text { High-Impact } \\
\text { Behavioral } \\
\text { Character- } \\
\text { istics }\end{array}$ & $\begin{array}{l}\text { High-Impact } \\
\text { Social Risk } \\
\text { Character- } \\
\text { istics }\end{array}$ & $\begin{array}{l}\text { Provider } \\
\text { and Health } \\
\text { System } \\
\text { Character- } \\
\text { istics }\end{array}$ \\
\hline $\begin{array}{l}\text { Chang et al., } \\
2019 \\
(\mathrm{~N}=258,759)^{83}\end{array}$ & $\begin{array}{l}\text { Risk of 90-day } \\
\text { inpatient } \\
\text { readmission } \\
\text { (persistently } \\
\text { high, } \\
\text { intermittently } \\
\text { high, or initially } \\
\text { high) }\end{array}$ & $\begin{array}{l}\text { VA population } \\
\text { in top 5\% risk } \\
\text { of inpatient } \\
\text { admission, } \\
\text { based on CAN } \\
\text { score, 2012- } \\
2014\end{array}$ & Diagnoses & $\begin{array}{l}\text { Age, race, } \\
\text { gender }\end{array}$ & MI, SUD & $\begin{array}{l}\text { Zip code } \\
\text { change, urban }\end{array}$ & $\begin{array}{l}\text { Prior } \\
\text { utilization }\end{array}$ \\
\hline $\begin{array}{l}\text { Raven, } 2008 \\
(\mathrm{~N}=36,457)^{84}\end{array}$ & $\begin{array}{l}\text { Inpatient } \\
\text { admissions } \\
(1+ \\
\text { readmission) }\end{array}$ & $\begin{array}{l}\text { Medicaid } \\
\text { patients at } 1 \\
\text { NYC public } \\
\text { hospital users, } \\
2001-2006\end{array}$ & $\begin{array}{l}\text { Chronic } \\
\text { condition, } \\
\text { self-rated } \\
\text { health status }\end{array}$ & Not measured & MI, SUD & $\begin{array}{l}\text { Homeless- } \\
\text { ness, Social } \\
\text { Isolation }\end{array}$ & $\begin{array}{l}\text { Prior } \\
\text { utilization }\end{array}$ \\
\hline $\begin{array}{l}\text { Meek, } 2000 \\
(\mathrm{~N}=4,210)^{77}\end{array}$ & $\begin{array}{l}\text { All utilization } \\
(6+ \\
\text { encounters in } \\
6 \text { months })\end{array}$ & $\begin{array}{l}\text { Midwest, } \\
\text { commercial } \\
\text { managed care } \\
\text { enrollees, } 6 \\
\text { primary care } \\
\text { visits in past } \\
\text { year, } 1997\end{array}$ & $\begin{array}{l}\text { Self- } \\
\text { reported } \\
\text { health rating } \\
\text { scale }\end{array}$ & $\begin{array}{l}\text { Age, race, } \\
\text { gender }\end{array}$ & $\mathrm{Ml}$ & Not measured & $\begin{array}{l}\text { Prior } \\
\text { utilization }\end{array}$ \\
\hline $\begin{array}{l}\text { Yang et al., } \\
2017,2019 \\
\text { ( } N=\text { between } \\
464,572 \text { and } \\
535,422 \text { in } \\
\text { each of the } \\
\text { years) })^{76,82}\end{array}$ & $\begin{array}{l}\text { Cost higher } \\
\text { than expected, } \\
\text { after risk } \\
\text { adjustment }\end{array}$ & $\begin{array}{l}\text { Texas } \\
\text { Medicaid } \\
\text { beneficiaries, } \\
\text { 2011-2014 }\end{array}$ & $\begin{array}{l}\text { Disease } \\
\text { diagnoses }\end{array}$ & $\begin{array}{l}\text { Age, race, } \\
\text { gender, } \\
\text { disabled status }\end{array}$ & $\begin{array}{l}\text { Not } \\
\text { measured }\end{array}$ & $\begin{array}{l}\text { County of } \\
\text { residence }\end{array}$ & $\begin{array}{l}\text { Prior } \\
\text { utilization, } \\
\text { fee-for- } \\
\text { service or } \\
\text { MCO }\end{array}$ \\
\hline $\begin{array}{l}\text { Yang et al., } \\
2018 \\
(\mathrm{~N}=1,734,896) \\
78\end{array}$ & $\begin{array}{l}\text { Cost (top } 10 \% \\
\text { expenditures) }\end{array}$ & $\begin{array}{l}\text { Texas } \\
\text { Medicaid } \\
\text { beneficiaries, } \\
\text { 2011-2014 }\end{array}$ & $\begin{array}{l}\text { Disease } \\
\text { diagnoses }\end{array}$ & $\begin{array}{l}\text { Age, race, } \\
\text { gender, } \\
\text { disabled status }\end{array}$ & $\begin{array}{l}\text { Not } \\
\text { measured }\end{array}$ & Not measured & $\begin{array}{l}\text { Prior } \\
\text { utilization }\end{array}$ \\
\hline $\begin{array}{l}\text { Bayliss et al., } \\
2016^{b} \\
(\mathrm{~N}=6,047)^{75}\end{array}$ & $\begin{array}{l}\text { Cost (top 25\%, } \\
\text { total costs) }\end{array}$ & $\begin{array}{l}\text { Kaiser } \\
\text { Permanente } \\
\text { Colorado, } \\
\text { newly enrolled } \\
\text { ACA } \\
\text { members, } \\
2014 ; \\
\text { completed the } \\
\text { Brief Health } \\
\text { Questionnaire } \\
\end{array}$ & $\begin{array}{l}\text { Number of } \\
\text { chronic } \\
\text { conditions, } \\
\text { condition } \\
\text { that } \\
\text { interferes } \\
\text { with daily } \\
\text { activity, self- } \\
\text { reported } \\
\text { health } \\
\end{array}$ & Age, gender & Depression & $\begin{array}{l}\text { Financial } \\
\text { constraints }\end{array}$ & $\begin{array}{l}\text { Prior } \\
\text { insurance } \\
\text { coverage, } \\
\text { type of } \\
\text { coverage, } \\
\text { prior ED and } \\
\text { IP use, } \\
\text { prescription } \\
\text { medications }\end{array}$ \\
\hline $\begin{array}{l}\text { Keeney, } 2020 \\
(\mathrm{~N}=3,093,211) \\
86\end{array}$ & $\begin{array}{l}\text { Cost (top 10\% } \\
\text { of } \\
\text { expenditures) }\end{array}$ & $\begin{array}{l}\text { Fee-for- } \\
\text { service } \\
\text { Medicare } \\
\text { beneficiaries, } \\
2013-2016 \\
\end{array}$ & $\begin{array}{l}\text { Multimorbidit } \\
\text { y, medical } \\
\text { complexity }\end{array}$ & $\begin{array}{l}\text { Age, gender, } \\
\text { race }\end{array}$ & $\begin{array}{l}\text { Not } \\
\text { measured }\end{array}$ & Not measured & $\begin{array}{l}\text { Persistence } \\
\text { of high-need } \\
\text { status, } \\
\text { Medicaid } \\
\text { dual eligible }\end{array}$ \\
\hline
\end{tabular}

a The outcome is measured in the next 12-month period unless otherwise specified.

b This study also included a cluster analysis.

$\mathrm{ACA}=$ Affordable Care Act; AUD = alcohol use disorder; CAN = Care Assessment Need model; CCI = Charlson Comorbidity Index; $\mathrm{ED}=$ emergency department; $\mathrm{HCC}=$ hierarchical condition categories; $\mathrm{HNHC}=$ high-need, high-cost; IP = inpatient; KQ $=$ Key Question; $\mathrm{MCO}=$ managed care organization; $\mathrm{MI}=$ mental illness; $\mathrm{N}=$ number; $\mathrm{NYC}=$ New York City; $\mathrm{SMI}=$ serious mental illness; SUD = substance use disorder; VA = Veterans Health Administration. 


\section{Predictive Tools and Modeling}

Some of the predictive studies developed, tested, or refined tools or modeling techniques to predict future use or cost. These studies reported on the overall performance of the tool or modeling technique and did not always separately report on the individual patient characteristics that were included in the prediction.

Among these, Billings and colleagues developed and tested an algorithm to identify disabled Medicaid beneficiaries at high risk of rehospitalization and high costs within 12 months of an index hospitalization. ${ }^{85}$ Raven and colleagues assessed the accuracy of Billings and colleagues' algorithm to identify Medicaid patients at high risk of subsequent rehospitalization within 12 months, based on their diagnoses and prior service use. ${ }^{84}$ In both studies, the algorithm calculated a rehospitalization positive predictive value (PPV) of 0.67 among individuals with a risk score greater than 50 (on a scale ranging from 0-100). Billings and colleagues also developed an algorithm to predict future high ED use among Medicaid beneficiaries, based on prior use and medical and behavioral health conditions. ${ }^{81}$ The PPV for this algorithm was 0.663.

Chang and colleagues tested a previously validated algorithm, the Care Assessment Needs (CAN) score, for predicting the persistence of risk of rehospitalization in the Veterans Health Administration (VA) system for a period of 24 months. The analysis examined predictors significantly associated with being persistently high risk, as measured by the CAN score. ${ }^{83}$

Yang and colleagues assessed several methodological approaches to examining analytic model residuals to identify HNHC patients who have higher than expected healthcare expenditures from year to year with the goal of distinguishing potentially preventable from nonpreventable healthcare use. ${ }^{76,82}$ Yang and colleagues also used Medicaid claims data to examine different analytic approaches to using machine learning models to accommodate a large number of interaction terms and recurrent neural networks to process sequential events and predict future costs. ${ }^{78}$ Major findings from Yang and colleagues' analyses are reported in relation to answering KQ 1e.

Several studies examined the role of patient self-reported information in predicting future high cost and use. Meek and colleagues tested a patient self-reported health perception assessment tool for predicting future use of all services (PPV $=0.67) .{ }^{77}$ Bayliss and colleagues examined the effectiveness of the Brief Health Questionnaire, a 10-question needs assessment, coupled with demographic information, in predicting future high cost, measured as being in the top 25 percent in the subsequent 6 to 12 months. ${ }^{75}$ The authors considered the approach to be "moderately predictive" in identifying patients who would be high cost (c-statistic=0.75).

\section{Cross-Sectional Studies}

Cross-sectional studies $(\mathrm{N}=33)$ seek to identify HNHC patients by analyzing the association between patient characteristics and high utilization or cost in a single time period. All studies used a regression model suited to the functional form of the outcome (e.g., logistic, multinomial, Poisson) and attempted to control for potential confounding variables. Table 4 presents characteristics for each of the cross-sectional studies. 
Table 4. Cross-sectional studies with evidence for $K Q 1(\mathrm{~N}=33)$

\begin{tabular}{|c|c|c|c|c|c|c|c|}
\hline $\begin{array}{l}\text { Study Citation } \\
\text { Sample Size }\end{array}$ & $\begin{array}{l}\text { HNHC } \\
\text { Outcome }\end{array}$ & Population & $\begin{array}{l}\text { Clinical } \\
\text { Health } \\
\text { Conditions }\end{array}$ & Demographics & $\begin{array}{l}\text { High-Impact } \\
\text { Behavioral } \\
\text { Variables }\end{array}$ & $\begin{array}{l}\text { High-Impact } \\
\text { Social } \\
\text { Variables }\end{array}$ & $\begin{array}{l}\text { Provider and } \\
\text { Health } \\
\text { System } \\
\text { Variables }\end{array}$ \\
\hline $\begin{array}{l}\text { Doran et al., } \\
2013 \\
(\mathrm{~N}=5,531,379)^{88}\end{array}$ & $\begin{array}{l}\text { ED visits }(1,2- \\
4,5-10,11- \\
25,>25)\end{array}$ & $\begin{array}{l}\text { VA population } \\
\text { in } 2010\end{array}$ & $\begin{array}{l}\text { Diagnoses, } \\
\text { CSI }\end{array}$ & Gender, Age & $\begin{array}{l}\text { Depression, } \\
\text { SMI, MI, SUD, } \\
\text { AUD }\end{array}$ & $\begin{array}{l}\text { Homeless- } \\
\text { ness, income }\end{array}$ & $\begin{array}{l}\text { Outpatient } \\
\text { clinic visits }\end{array}$ \\
\hline $\begin{array}{l}\text { Behr et al., } \\
2016 \\
(\mathrm{~N}=1,443)^{89}\end{array}$ & $\begin{array}{l}\text { ED visits } \\
(2+, 3+, 4+ \\
5+)\end{array}$ & $\begin{array}{l}\text { Urban Level } 1 \\
\text { trauma center } \\
\text { ED patients, } \\
\text { triaged ESI 4- } \\
5 \text { (least } \\
\text { urgent), data } \\
\text { period NR }\end{array}$ & $\begin{array}{l}\text { Patient } \\
\text { perception of } \\
\text { seriousness } \\
\text { of need }\end{array}$ & Gender, race & MI, SUD & $\begin{array}{l}\text { Employment, } \\
\text { consulted with } \\
\text { family member } \\
\text { prior to visit }\end{array}$ & $\begin{array}{l}\text { Insurance } \\
\text { type, patient } \\
\text { report of prior } \\
\text { utilization, } \\
\text { service quality }\end{array}$ \\
\hline $\begin{array}{l}\text { Buhumaid et } \\
\text { al., } 2015 \\
(\mathrm{~N}=569)^{90}\end{array}$ & $\begin{array}{l}\text { ED visits } \\
(4+)\end{array}$ & $\begin{array}{l}\text { Patients with } \\
\text { MI dx and ED } \\
\text { use in DC } \\
\text { academic } \\
\text { hospital, } \\
2009 \\
\end{array}$ & $\begin{array}{l}1 \text { or more } \\
\text { chronic } \\
\text { conditions }\end{array}$ & $\begin{array}{l}\text { Age, gender, } \\
\text { race }\end{array}$ & SUD, AUD & $\begin{array}{l}\text { Homeless- } \\
\text { ness }\end{array}$ & Insurance type \\
\hline $\begin{array}{l}\text { Thakarar et al., } \\
2015(\mathrm{~N}=412)^{91}\end{array}$ & $\begin{array}{l}\text { ED visits } \\
(2+)\end{array}$ & $\begin{array}{l}\text { ED patients } \\
\text { enrolled in } \\
\text { homelessness } \\
\text { program with } \\
1+\text { OP visit to } \\
\text { Boston safety } \\
\text { net hospital, } \\
2011-2013\end{array}$ & $\begin{array}{l}\text { Diagnoses } \\
\text { rating scale }\end{array}$ & $\begin{array}{l}\text { Age, gender, } \\
\text { race }\end{array}$ & MI, SUD & $\begin{array}{l}\text { Housing } \\
\text { status }\end{array}$ & Utilization \\
\hline $\begin{array}{l}\text { Hasegawa et } \\
\text { al., } 2014 \\
(\mathrm{~N}=1,890)^{93}\end{array}$ & $\begin{array}{l}\text { ED visits (3+ } \\
\text { for acute } \\
\text { exacerbation } \\
\text { of COPD) }\end{array}$ & $\begin{array}{l}\text { CA and FL ED } \\
\text { patients with } \\
\text { acute } \\
\text { exacerbation } \\
\text { of COPD, } \\
2010-2011 \\
\end{array}$ & $\begin{array}{l}\text { Selected } \\
\text { diagnoses }\end{array}$ & $\begin{array}{l}\text { Age, gender, } \\
\text { race }\end{array}$ & $\begin{array}{l}\text { Depression, } \\
\text { SMI, SUD }\end{array}$ & Area income & Insurance type \\
\hline $\begin{array}{l}\text { Doran et al., } \\
2014(\mathrm{~N}=965)^{94}\end{array}$ & ED visits $(3+)$ & $\begin{array}{l}\text { ED patients } \\
\text { with low acuity } \\
\text { complaints, } \\
\text { NYC ED, } \\
2007-2008 \\
\end{array}$ & $\begin{array}{l}\text { Chief } \\
\text { complaint, } \\
\text { overall health }\end{array}$ & $\begin{array}{l}\text { Age, gender, } \\
\text { race }\end{array}$ & Not measured & $\begin{array}{l}\text { Education, } \\
\text { employment }\end{array}$ & $\begin{array}{l}\text { Self-reported } \\
\text { access and } \\
\text { quality of care }\end{array}$ \\
\hline $\begin{array}{l}\text { Hasegawa et } \\
\text { al., } 2014 \\
(\mathrm{~N}=965)^{95}\end{array}$ & $\begin{array}{l}\text { ED visits for } \\
\text { asthma }(3+)\end{array}$ & $\begin{array}{l}\text { Patients with } \\
\text { asthma at } 48 \\
\text { EDs across } 23 \\
\text { states, 2011- } \\
2012 \\
\end{array}$ & Not measured & $\begin{array}{l}\text { Age, gender, } \\
\text { race }\end{array}$ & Not measured & Area income & Insurance type \\
\hline $\begin{array}{l}\text { Liu, 2013 } \\
(\mathrm{N}=965)^{96}\end{array}$ & ED visits $(3+)$ & $\begin{array}{l}\text { ED patients, } \\
\text { one urban ED, } \\
2007-2008\end{array}$ & Overall health & $\begin{array}{l}\text { Age, gender, } \\
\text { race }\end{array}$ & MI, SUD, AUD & Employment, & $\begin{array}{l}\text { Prior } \\
\text { utilization, } \\
\text { access, cost, } \\
\text { quality of care } \\
\end{array}$ \\
\hline
\end{tabular}




\begin{tabular}{|c|c|c|c|c|c|c|c|}
\hline $\begin{array}{l}\text { Study Citation } \\
\text { Sample Size }\end{array}$ & $\begin{array}{l}\text { HNHC } \\
\text { Outcome }\end{array}$ & Population & $\begin{array}{l}\text { Clinical } \\
\text { Health } \\
\text { Conditions }\end{array}$ & Demographics & $\begin{array}{l}\text { High-Impact } \\
\text { Behavioral } \\
\text { Variables }\end{array}$ & $\begin{array}{l}\text { High-Impact } \\
\text { Social } \\
\text { Variables }\end{array}$ & $\begin{array}{l}\text { Provider and } \\
\text { Health } \\
\text { System } \\
\text { Variables }\end{array}$ \\
\hline $\begin{array}{l}\text { Milbrett, } 2009 \\
(\mathrm{~N}=201)^{97}\end{array}$ & $\begin{array}{l}\text { ED visits } \\
\text { (continuous } \\
\text { measure) }\end{array}$ & $\begin{array}{l}\text { Midwestern } \\
\text { hospital ED } \\
\text { patients with } \\
6+\text { visits, } \\
2005-2006 \\
\end{array}$ & Diagnoses & Gender, race & SMI & $\begin{array}{l}\text { Employment } \\
\text { status, marital } \\
\text { status }\end{array}$ & $\begin{array}{l}\text { Insurance } \\
\text { type, have } \\
\text { PCP }\end{array}$ \\
\hline $\begin{array}{l}\text { Ruger, } 2004 \\
(\mathrm{~N}=71,941 \\
\text { visits })^{98}\end{array}$ & $\begin{array}{l}\text { ED visits }(2,3- \\
5,6-20,>20)\end{array}$ & $\begin{array}{l}\text { Urban, } \\
\text { academic } \\
\text { hospital ED } \\
\text { patients, } 2001\end{array}$ & $\begin{array}{l}\text { ED Triage } \\
\text { Acuity Level, } \\
\text { DRG severity } \\
\text { level }\end{array}$ & Age, gender & $\begin{array}{l}\text { Not } \\
\text { measured }\end{array}$ & Not measured & Insurance type \\
\hline 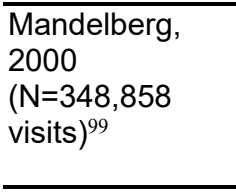 & $\begin{array}{l}\text { ED visits } \\
(5+)\end{array}$ & $\begin{array}{l}\text { Urban, } \\
\text { academic } \\
\text { hospital ED } \\
\text { patients, } \\
1993-1998 \\
\end{array}$ & Not measured & $\begin{array}{l}\text { Age, gender, } \\
\text { race }\end{array}$ & $\begin{array}{l}\text { Not } \\
\text { measured }\end{array}$ & $\begin{array}{l}\text { Homeless- } \\
\text { ness }\end{array}$ & Insurance type \\
\hline $\begin{array}{l}\text { Vinton, } 2014 \\
(N=157,818)^{100}\end{array}$ & $\begin{array}{l}\text { ED visits } \\
(4+, 10+)\end{array}$ & $\begin{array}{l}\text { National } \\
\text { Health } \\
\text { Interview } \\
\text { Survey, 2004- } \\
2009\end{array}$ & $\begin{array}{l}\text { Diagnoses, } \\
\text { rating scale }\end{array}$ & $\begin{array}{l}\text { Age, gender, } \\
\text { race }\end{array}$ & $\mathrm{Ml}, \mathrm{AUD}$ & $\begin{array}{l}\text { Employment, } \\
\text { income }\end{array}$ & $\begin{array}{l}\text { Insurance } \\
\text { type, prior ED } \\
\text { and outpatient } \\
\text { use }\end{array}$ \\
\hline $\begin{array}{l}\text { Hunt, } 2006 \\
(\mathrm{~N}=59,725)^{101}\end{array}$ & $\begin{array}{l}\text { ED visits } \\
(4+)\end{array}$ & $\begin{array}{l}\text { Community } \\
\text { Tracking } \\
\text { Study } \\
\text { Household } \\
\text { Survey, 2000- } \\
2001\end{array}$ & Rating scale & Race & $\mathrm{Ml}$ & Income & $\begin{array}{l}\text { Insurance } \\
\text { type, prior ED } \\
\text { and outpatient } \\
\text { use, } \\
\text { relationship } \\
\text { with physician }\end{array}$ \\
\hline $\begin{array}{l}\text { Friedman, } 2009 \\
(\mathrm{~N}=59,725)^{102}\end{array}$ & ED visits $(4+)$ & $\begin{array}{l}\text { Nationally } \\
\text { representative } \\
\text { survey of } \\
\text { migraine } \\
\text { sufferers, } \\
2004 \\
\end{array}$ & $\begin{array}{l}\text { Headache } \\
\text { disability score }\end{array}$ & Age & Depression & Income & $\begin{array}{l}\text { Insured status, } \\
\text { medication } \\
\text { use, provider } \\
\text { type, prior ED } \\
\text { use for other } \\
\text { conditions } \\
\end{array}$ \\
\hline $\begin{array}{l}\text { Zuckerman, } \\
2004 \\
(\mathrm{~N}=89,626)^{103}\end{array}$ & ED visits $(3+)$ & $\begin{array}{l}\text { Urban } \\
\text { Institute's } \\
\text { National } \\
\text { Survey of } \\
\text { America's } \\
\text { Families, } 1997 \\
\text { and 1999 }\end{array}$ & $\begin{array}{l}\text { Rating scale, } \\
\text { disability } \\
\text { status }\end{array}$ & Race & $\begin{array}{l}\text { Not } \\
\text { measured }\end{array}$ & Income & $\begin{array}{l}\text { Insurance } \\
\text { type, Access } \\
\text { to care, } \\
\text { outpatient use }\end{array}$ \\
\hline $\begin{array}{l}\text { Castillo, } 2018 \\
(\mathrm{~N}=71,449)^{104}\end{array}$ & ED visits $(6+)$ & $\begin{array}{l}\text { ED patients in } \\
\text { CA, age } 65+\text {, } \\
2014\end{array}$ & $\begin{array}{l}\text { Pain, Injury, } \\
\mathrm{CCl}\end{array}$ & $\begin{array}{l}\text { Age, gender, } \\
\text { race }\end{array}$ & $\begin{array}{l}\text { Psychiatric, } \\
\text { SUD }\end{array}$ & Not measured & $\begin{array}{l}\text { Admitted/ } \\
\text { transferred }\end{array}$ \\
\hline $\begin{array}{l}\text { Kanzaria, } 2019 \\
(\mathrm{~N}=20,661)^{105}\end{array}$ & ED visits (4-7) & $\begin{array}{l}\text { Medicaid ED } \\
\text { patients, } \\
\text { nonaged, San } \\
\text { Francisco } \\
\text { MCO Health } \\
\text { network, } \\
2013-2015 \\
\end{array}$ & $\begin{array}{l}\text { Selected } \\
\text { comorbidities, } \\
\text { disabled }\end{array}$ & $\begin{array}{l}\text { Age, gender, } \\
\text { race }\end{array}$ & $\begin{array}{l}\text { Alcohol use, } \\
\text { drug use } \\
\text { disorders, } \\
\text { psychoses, } \\
\text { depression }\end{array}$ & $\begin{array}{l}\text { Homeless- } \\
\text { ness, jail }\end{array}$ & Not measured \\
\hline Ali, $(\mathrm{N}=474)^{106}$ & ED visits $(3+)$ & $\begin{array}{l}\text { Medicaid ED } \\
\text { patients } \\
\text { receiving care } \\
\text { at an ED in } \\
\text { Washington, } \\
\text { DC, } 2015- \\
2016 \\
\end{array}$ & $\begin{array}{l}\text { Physical } \\
\text { illness score }\end{array}$ & Age, gender & MI, SUD & $\begin{array}{l}\text { Homeless- } \\
\text { ness }\end{array}$ & Not measured \\
\hline
\end{tabular}




\begin{tabular}{|c|c|c|c|c|c|c|c|}
\hline $\begin{array}{l}\text { Study } \\
\text { Citation } \\
\text { Sample Size }\end{array}$ & $\begin{array}{l}\text { HNHC } \\
\text { Outcome }^{a}\end{array}$ & Population & $\begin{array}{l}\text { Clinical } \\
\text { Health } \\
\text { Conditions } \\
\end{array}$ & Demographics & $\begin{array}{l}\text { High-Impact } \\
\text { Behavioral } \\
\text { Variables } \\
\end{array}$ & $\begin{array}{l}\text { High-Impact } \\
\text { Social } \\
\text { Variables }\end{array}$ & $\begin{array}{l}\text { Provider and } \\
\text { Health System } \\
\text { Variables } \\
\end{array}$ \\
\hline $\begin{array}{l}\text { Kalyani, } \\
(\mathrm{N}=54,981)^{107}\end{array}$ & ED visits $(2+)$ & $\begin{array}{l}\text { Medicaid } \\
\text { enrollees in } \\
\text { PA with MI, } \\
2007-2012\end{array}$ & $\begin{array}{l}\text { Elixhauser } \\
\text { comorbidity } \\
\text { index }\end{array}$ & $\begin{array}{l}\text { Age, gender, } \\
\text { race }\end{array}$ & $\begin{array}{l}\text { Multiple MI } \\
\text { conditions, } \\
\text { Substance } \\
\text { use }\end{array}$ & Not measured & $\begin{array}{l}\text { Medicaid } \\
\text { eligibility type, } \\
\text { prior PCP and } \\
\mathrm{BH} \text { use }\end{array}$ \\
\hline $\begin{array}{l}\text { Surbhi, } 2020 \\
(N=1,092)^{108}\end{array}$ & $\begin{array}{l}\text { ED visits, } \\
\text { inpatient } \\
\text { admissions for } \\
\text { ACSCs over } \\
\text { 6- month } \\
\text { period }\end{array}$ & $\begin{array}{l}\text { Medicare } \\
\text { beneficiaries } \\
\text { Memphis, TN, } \\
\text { one or more } \\
\text { ACSCs, } \\
\text { Inpatient } \\
\text { admissions } \\
\text { (3+) or } \\
\text { (Inpatient } \\
\text { admissions 2+ } \\
\text { and 2+ ED } \\
\text { visits in } 6 \\
\text { months), } \\
2011-2013\end{array}$ & $\begin{array}{l}\text { ACSC } \\
\text { conditions } \\
\text { (hypertension, } \\
\text { type } 2 \\
\text { diabetes, } \\
\text { congestive } \\
\text { heart failure, } \\
\text { coronary } \\
\text { artery disease, } \\
\text { COPD, } \\
\text { asthma, } \mathrm{CCl}\end{array}$ & $\begin{array}{l}\text { Age, gender, } \\
\text { race }\end{array}$ & $\mathrm{Ml}$ & Dual eligible & $\begin{array}{l}\text { Medication } \\
\text { nonadherence, } \\
\text { unique } \\
\text { medication, } \\
\text { prescribers, } \\
\text { office visits }\end{array}$ \\
\hline $\begin{array}{l}\text { Bell, } 2017 \\
(\mathrm{~N}=494)^{109}\end{array}$ & $\begin{array}{l}\text { Inpatient } \\
\text { admissions } \\
(3+)\end{array}$ & $\begin{array}{l}\text { Atlanta, GA } \\
\text { large safety- } \\
\text { net hospital } \\
\text { ED patients, } \\
2011-2013\end{array}$ & $\begin{array}{l}\text { Number of } \\
\text { chronic } \\
\text { conditions }\end{array}$ & $\begin{array}{l}\text { Age, gender, } \\
\text { race }\end{array}$ & MI, SUD, AUD & $\begin{array}{l}\text { Homeless- } \\
\text { ness, income }\end{array}$ & Insurance type \\
\hline $\begin{array}{l}\text { Porter, } 2019 \\
(\mathrm{~N}=2,621)^{110}\end{array}$ & $\begin{array}{l}\text { Inpatient } \\
\text { readmissions } \\
(3+)\end{array}$ & $\begin{array}{l}\text { Southeast } \\
\text { academic } \\
\text { medical center } \\
\text { inpatients, } \\
2014-2016\end{array}$ & $\begin{array}{l}\text { Number of } \\
\text { chronic } \\
\text { conditions, } \\
\text { rating scale }\end{array}$ & $\begin{array}{l}\text { Age, race, } \\
\text { gender }\end{array}$ & MI, SUD & Not measured & $\begin{array}{l}\text { Insurance } \\
\text { status }\end{array}$ \\
\hline $\begin{array}{l}\text { Emechebe, } \\
2019 \\
(\mathrm{~N}=19,817)^{111}\end{array}$ & $\begin{array}{l}\text { Inpatient } \\
\text { readmissions } \\
\text { by } 180 \text { days } \\
(1+)\end{array}$ & $\begin{array}{l}\text { Medicaid } \\
\text { managed care } \\
\text { and Medicare } \\
\text { Advantage } \\
\text { patients } \\
\text { insured by } \\
\text { WellCare } \\
\text { Health Plan, } \\
2013-2017\end{array}$ & $\mathrm{CCl}$ & $\begin{array}{l}\text { Age, race, } \\
\text { gender }\end{array}$ & $\begin{array}{l}\text { Alcohol abuse, } \\
\text { anxiety, } \\
\text { depression, } \\
\text { SMI }\end{array}$ & $\begin{array}{l}\text { Financial } \\
\text { assistance, } \\
\text { other social } \\
\text { needs } \\
\text { assistance, } \\
\text { food, housing, } \\
\text { transportation }\end{array}$ & $\begin{array}{l}\text { Type of } \\
\text { insurance }\end{array}$ \\
\hline $\begin{array}{l}\text { Rohrer, } 2008 \\
(\mathrm{~N}=698)^{112}\end{array}$ & $\begin{array}{l}\text { All outpatient } \\
\text { utilization }(27+ \\
\text { visits) }\end{array}$ & $\begin{array}{l}\text { Family } \\
\text { medicine } \\
\text { practice, } \\
2005-2006\end{array}$ & Rating scale & Age, gender & Not measured & Not measured & Not measured \\
\hline $\begin{array}{l}\text { Blumenthal } \\
2017 \\
(\mathrm{~N}=2,639)^{113}\end{array}$ & $\begin{array}{l}\text { Top 5\%: ED } \\
\text { visits, acute } \\
\text { hospitaliz- } \\
\text { ations }\end{array}$ & $\begin{array}{l}\text { Partners } \\
\text { Healthcare } \\
\text { ACO } \\
\text { members (12 } \\
\text { practices), } \\
2014-2015 \\
\end{array}$ & $\begin{array}{l}\text { Self-report } \\
\text { rating scale, } \\
\mathrm{CCl}\end{array}$ & $\begin{array}{l}\text { Age, race, } \\
\text { gender }\end{array}$ & $\mathrm{Ml}$ & Not measured & Not measured \\
\hline $\begin{array}{l}\text { Reichard } 2015 \\
(\mathrm{~N}=53,586)^{114}\end{array}$ & $\begin{array}{l}\text { All utilization } \\
\left(\geq 75^{\text {th }}\right. \\
\text { percentile in } 2 \\
\text { years })\end{array}$ & $\begin{array}{l}\text { Weighted } \\
\text { sample of } \\
\text { working age } \\
\text { adults, 2006- } \\
2008\end{array}$ & $\begin{array}{l}\text { Number of } \\
\text { chronic } \\
\text { conditions, } \\
\text { disability } \\
\text { status }\end{array}$ & Not measured & Not measured & Not measured & $\begin{array}{l}\text { Insurance } \\
\text { status, } \\
\text { utilization }\end{array}$ \\
\hline $\begin{array}{l}\text { Walker et al., } \\
2003 \\
(\mathrm{~N}=1,963)^{115}\end{array}$ & $\begin{array}{l}\text { Costs: total, } \\
\text { inpatient and } \\
\text { ED }\end{array}$ & $\begin{array}{l}\text { Female Puget } \\
\text { Sound HMO } \\
\text { members, } \\
1996-1997\end{array}$ & Not measured & Age, race & $\begin{array}{l}\text { PTSD, other } \\
\text { MI }\end{array}$ & Not measured & Not measured \\
\hline
\end{tabular}




\begin{tabular}{|c|c|c|c|c|c|c|c|}
\hline $\begin{array}{l}\text { Study } \\
\text { Citation } \\
\text { Sample Size }\end{array}$ & $\begin{array}{l}\text { HNHC } \\
\text { Outcome }^{a}\end{array}$ & Population & $\begin{array}{l}\text { Clinical } \\
\text { Health } \\
\text { Conditions }\end{array}$ & Demographics & $\begin{array}{l}\text { High-Impact } \\
\text { Behavioral } \\
\text { Variables }\end{array}$ & $\begin{array}{l}\text { High-Impact } \\
\text { Social } \\
\text { Variables }\end{array}$ & $\begin{array}{l}\text { Provider and } \\
\text { Health } \\
\text { System } \\
\text { Variables }\end{array}$ \\
\hline $\begin{array}{l}\text { Robinson et } \\
\text { al., } 2016 \\
(\mathrm{~N}=1,921)^{116}\end{array}$ & $\begin{array}{l}\text { Cost (top 10\% } \\
\text { total costs) }\end{array}$ & $\begin{array}{l}\text { Commercial } \\
\text { health plan } \\
\text { enrollees in } 14 \\
\text { geographically } \\
\text { diverse U.S. } \\
\text { plans with } \\
\text { depression, } \\
2011,2009- \\
2010\end{array}$ & $\begin{array}{l}\text { Diagnosis, } \\
\text { rating scale }\end{array}$ & Age, gender & MI, SUD, AUD & Employment & $\begin{array}{l}\text { All commer- } \\
\text { cially insured }\end{array}$ \\
\hline $\begin{array}{l}\text { Sterling et al., } \\
2018 \\
(\mathrm{~N}=378)^{117}\end{array}$ & $\begin{array}{l}\text { Cost (top 20\% } \\
\text { over } 2 \text { years) }\end{array}$ & $\begin{array}{l}\text { Kaiser } \\
\text { Permanente } \\
\text { Northern } \\
\text { California } \\
\text { members with } \\
\text { chronic } \\
\text { conditions or } \\
\text { stable } \\
\text { disability, } \\
\text { 2009-2011 } \\
\end{array}$ & Not measured & Age, gender & $\mathrm{MI}$ & Income & Not measured \\
\hline $\begin{array}{l}\text { Berkowitz et } \\
\text { al., } 2018 \\
(\mathrm{~N}=11,781)^{118}\end{array}$ & $\begin{array}{l}\text { Cost (top } \\
10 \% \text {, top } 5 \% \text {, } \\
\text { top } 2 \% \text { ) }\end{array}$ & $\begin{array}{l}\text { Adults, } \\
\text { National } \\
\text { Health } \\
\text { Interview } \\
\text { Survey 2011, } \\
\text { MEPS 2012- } \\
2013\end{array}$ & Not measured & $\begin{array}{l}\text { Age, gender, } \\
\text { race }\end{array}$ & Not measured & $\begin{array}{l}\text { Food } \\
\text { insecure, } \\
\text { education, } \\
\text { income, urban } \\
\text { residence, } \\
\text { region }\end{array}$ & $\begin{array}{l}\text { Health } \\
\text { insurance }\end{array}$ \\
\hline $\begin{array}{l}\text { Figueroa, } \\
2019 \\
(\mathrm{~N}=5,507,218) \\
119\end{array}$ & $\begin{array}{l}\text { Cost (top 10\% } \\
\text { of } \\
\text { expenditures) }\end{array}$ & $\begin{array}{l}\text { Medicare } \\
\text { beneficiary } \\
20 \% \text { sample, } \\
2012-2014\end{array}$ & $\begin{array}{l}\text { Chronic } \\
\text { conditions }\end{array}$ & $\begin{array}{l}\text { Age, gender, } \\
\text { race }\end{array}$ & Depression & $\begin{array}{l}\text { Income, } \\
\text { region }\end{array}$ & $\begin{array}{l}\text { Has Part D, } \\
\text { Medicaid dual } \\
\text { eligible, high } \\
\text { cost in earlier } \\
\text { year }\end{array}$ \\
\hline
\end{tabular}

a The outcome in the next 12-month period unless otherwise specified.

$\mathrm{ACO}=$ accountable care organization; $\mathrm{ACSC}=$ ambulatory care sensitive condition; AHFS = acute heart failure syndrome; AUD $=$ alcohol use disorder; $\mathrm{BH}=$ behavioral health; $\mathrm{CA}=$ California; $\mathrm{CCI}=$ Charlson Comorbidity Index; $\mathrm{COPD}=$ chronic obstructive pulmonary disease; $\mathrm{CSI}=$ Charlson severity index; $\mathrm{DC}=$ District of Columbia; $\mathrm{DRG}=$ diagnosis-related group; $\mathrm{dx}=$ diagnosis; ED = emergency department; ESI = Emergency Severity Index; FL = Florida; GA = Georgia; HMO = health maintenance organization; $\mathrm{HNHC}=$ high-need, high-cost; $\mathrm{KQ}=$ Key Question; $\mathrm{MCO}=$ managed care organization; MEPS=Medical Expenditure Panel Survey; $\mathrm{MI}=$ mental illness; $\mathrm{N}=$ number; $\mathrm{NR}=$ not reported; $\mathrm{NYC}=\mathrm{New}$ York City; OP = outpatient; PA = Pennsylvania; $\mathrm{PCP}=$ primary care physician; $\mathrm{PTSD}=$ post-traumatic stress disorder; $\mathrm{SMI}=$ serious mental illness; SUD = substance use disorder; TN = Tennessee; U.S. = United States; VA = Veterans Health Administration.

Unlike the predictive analyses, cross-sectional studies cover the same time period for the outcome and independent variables. Because of this, it is often difficult to establish if timevarying patient characteristics, such as diagnoses or insurance type, were present at the start of the study period. This prevented inferences of temporal associations (e.g., presence of diagnoses predicts future high-need or high-cost utilization). Cross-sectional studies are also generally unable to provide insights about the persistence of patients being HNHC over time. For these reasons, we present predictive and cross-sectional results separately. 


\section{Cluster Analyses}

We identified 12 cluster analyses examining combinations of characteristics of HNHC patients (Table 5). Cluster analysis and the associated technique latent class analysis are statistical methods for identifying "hidden" or unobservable class membership (groupings) among subjects using observed variables. ${ }^{57}$ These analyses separate groups of HNHC patients based on combinations of both modifiable and nonmodifiable characteristics, including healthcare utilization patterns, disease groups, demographic characteristics, and level of functioning. The analyses are considered particularly useful for identifying homogeneous subgroups of HNHC patients to include in interventions. In the text, we use the term "cluster analysis" to denote all forms of analysis designed to identify unobservable groupings (e.g., latent class, item response, structural equation modeling). See Table 5 for the specific analytic approach to clustering that was used in each study.

Table 5. Cluster analysis studies with evidence for $K Q 1(\mathrm{~N}=12)$

\begin{tabular}{|c|c|c|c|c|}
\hline $\begin{array}{l}\text { Study Citation } \\
\text { Sample Size }\end{array}$ & $\begin{array}{l}\text { Analytic } \\
\text { Approach }\end{array}$ & Population & $\begin{array}{l}\text { Clusters: } \\
\text { Number and } \\
\text { Types }\end{array}$ & Cluster Results \\
\hline $\begin{array}{l}\text { Yang, } 2018 \\
(\mathrm{~N}=1,734,896)^{120}\end{array}$ & $\begin{array}{l}\text { Latent class } \\
\text { analysis }\end{array}$ & $\begin{array}{l}\text { Texas Medicaid } \\
\text { beneficiaries with } 12 \\
\text { or more ED visits in } 4 \\
\text { years, 2011-2014 }\end{array}$ & $\begin{array}{l}3 \text { clusters } \\
\text { based on } \\
\text { timing of } \\
\text { intervals } \\
\text { between ED } \\
\text { visits }\end{array}$ & $\begin{array}{l}\text { - Cluster } 1 \text { (peak at } 64-128 \text { days between visits): } \\
\text { younger adult patients with asthma or vulnerable } \\
\text { to respiratory infections with } 2 \text { to } 3 \text { months } \\
\text { between ED visits } \\
\text { - Cluster } 2 \text { (peak at } 4-16 \text { days between visits): } \\
\text { mentally or chronically ill with } 1 \text { to } 2 \text { weeks } \\
\text { between ED visits } \\
\text { Cluster } 3 \text { (peak not specified): Pregnant women } \\
\text { with ED visit frequency between that of Clusters } \\
1 \text { and } 2\end{array}$ \\
\hline $\begin{array}{l}\text { Birmingham, } \\
2020 \\
(\mathrm{~N}=5,731)^{121}\end{array}$ & $\begin{array}{l}\text { Latent class } \\
\text { analysis }\end{array}$ & $\begin{array}{l}\text { One Midwestern } \\
\text { hospital-based ED } \\
\text { patients with 4+ visits, } \\
2015\end{array}$ & $\begin{array}{l}4 \text { groups of ED } \\
\text { frequent users }\end{array}$ & $\begin{array}{l}\text { - } \quad \text { Cluster 1: short-term: tend to stop within a year } \\
\text { - } \quad \text { Cluster 2: heart-related conditions } \\
\text { - } \quad \text { Cluster 3: long-term: highest proportion of } \\
\text { Medicaid and Medicare <65 groups } \\
\text { - Minor care: all had visits with musculoskeletal } \\
\text { discharge diagnoses }\end{array}$ \\
\hline $\begin{array}{l}\text { Bayliss et al., } \\
2016(\mathrm{~N}= \\
1,512)^{75}\end{array}$ & $\begin{array}{l}\text { Cluster } \\
\text { analysis }\end{array}$ & $\begin{array}{l}\text { Kaiser Permanente } \\
\text { Colorado, newly } \\
\text { enrolled ACA } \\
\text { members, top } 25 \% \\
\text { total costs, } 2014\end{array}$ & $\begin{array}{l}8 \text { clusters } \\
\text { based on self- } \\
\text { reported } \\
\text { functioning, } \\
\text { health status, } \\
\text { and healthcare } \\
\text { utilization }\end{array}$ & $\begin{array}{l}\text { Clusters that authors considered actionable: } \\
\text { - Fair/poor health, requiring prescription } \\
\text { medications, with financial constraints, a } \\
\text { positive depression screen, and high hospital } \\
\text { utilization in the prior year } \\
\text { - } \quad \text { Low morbidity and low prior utilization, but } \\
\text { moderate prescription medication needs } \\
\text { - Good health, but lacking health insurance in } \\
\text { the preceding year so needing preventive care } \\
\text { - } \quad \text { Low morbidity and high ED use } \\
\end{array}$ \\
\hline $\begin{array}{l}\text { Newcomer, } 2011 \\
(\mathrm{~N}=15,480)^{122}\end{array}$ & $\begin{array}{l}\text { Latent class } \\
\text { analysis }\end{array}$ & $\begin{array}{l}\text { Kaiser Permanente } \\
\text { Colorado members, } \\
\text { top } 20 \% \text { total costs in } \\
\text { both of } 2 \text { years, } 2+ \\
\text { chronic conditions, } \\
2006-2007\end{array}$ & $\begin{array}{l}10 \text { clusters } \\
\text { based on } \\
\text { chronic } \\
\text { conditions, } \\
\text { including } \mathrm{BH} \\
\mathrm{dx}\end{array}$ & $\begin{array}{l}\text { - } \text { Frail elderly } \\
\text { - } \text { Kidney disease with diabetes and obesity } \\
\text { - } \text { Diabetes with obesity and MH conditions } \\
\text { - } \text { Cardiac disease and obesity } \\
\text { - } \text { MH conditions and obesity in younger adults } \\
\text { - Cancer with obesity and MH conditions } \\
\text { - COPD with obesity and MH conditions } \\
\text { - } \text { Abdominal and orthopedic surgeries with obesity } \\
\text { - Gastrointestinal bleeding with obesity and MH } \\
\quad \text { conditions }\end{array}$ \\
\hline
\end{tabular}




\begin{tabular}{|c|c|c|c|c|}
\hline $\begin{array}{l}\text { Study Citation } \\
\text { Sample Size }\end{array}$ & $\begin{array}{l}\text { Analytic } \\
\text { Approach }\end{array}$ & Population & $\begin{array}{l}\text { Clusters: } \\
\text { Number and } \\
\text { Types }\end{array}$ & Cluster Results \\
\hline $\begin{array}{l}\text { Szymkowiak et } \\
\text { al., } 2017 \\
(\mathrm{~N}=16,912)^{123}\end{array}$ & $\begin{array}{l}\text { Latent class } \\
\text { analysis }\end{array}$ & $\begin{array}{l}\text { VA homeless veterans } \\
\text { with } \geq 1 \text { hospital } \\
\text { admission and/or } \geq 2 \\
\text { ED visits, during any } \\
\text { of } 8 \text { quarters, 2014- } \\
2015\end{array}$ & $\begin{array}{l}7 \text { clusters } \\
\text { based on } \\
\text { healthcare } \\
\text { utilization }\end{array}$ & $\begin{array}{ll}\text { - } & \text { Medical inpatients: } 24 \% \\
\text { - } & \text { ED only medical: } 24 \% \\
\text { - } & \text { ED only MH/SU: } 13 \% \\
\text { - } & \text { MH inpatient only: } 13 \% \\
\text { - } & \text { SU inpatient only: } 10 \% \\
\text { - } & \text { MH inpatient + ED: } 8 \% \\
\text { - } & \text { SU inpatient + ED: } 7 \%\end{array}$ \\
\hline $\begin{array}{l}\text { Wong et al., } \\
2018 \\
(\mathrm{~N}=7,289)^{124}\end{array}$ & $\begin{array}{l}\text { Latent class } \\
\text { analysis }\end{array}$ & $\begin{array}{l}\text { VA hospital inpatients } \\
\text { during } 1 \text {-week period, } \\
\text { top } 5 \% \text { for risk of } \\
\text { future hospitalization, } \\
\text { based on CAN score, } \\
\text { November } 2012\end{array}$ & $\begin{array}{l}2 \text { clusters } \\
\text { based on risk } \\
\text { of } \\
\text { rehospitalizatio } \\
\text { n over a two- } \\
\text { year period }\end{array}$ & $\begin{array}{l}\text { Baseline characteristics explained } 23 \% \text { of variation } \\
\text { in group assignment } \\
\text { Moderately high risk ( } 65 \% \text { of patients) } \\
\text { - Greater decline in risk of hospitalization over } \\
\text { time } \\
\text { Persistently high risk ( } 35 \% \text { of patients) } \\
\text { - Higher rates of healthcare use, particularly } \\
\text { number of hospitalizations } \\
\text { - Higher rates of nearly all comorbidities, } \\
\text { including COPD and heart failure } \\
\text { - Higher rates of alcohol abuse and SUD } \\
\end{array}$ \\
\hline $\begin{array}{l}\text { Prenovost, } 2018 \\
(\mathrm{~N}=68,400)^{125}\end{array}$ & $\begin{array}{l}\text { Item response } \\
\text { theory }\end{array}$ & $\begin{array}{l}\text { VA } \\
\text { CAN score in top } 10 \% \text {; } \\
\text { predicted risk of } \\
\text { hospitalization } \geq 25 \% \text {, } \\
2014\end{array}$ & $\begin{array}{l}6 \text { clusters } \\
\text { based on } \\
\text { chronic } \\
\text { conditions, } \\
\text { including } \mathrm{BH}\end{array}$ & $\begin{array}{l}\text { - Substance abuse and additional complexity } \\
\text { because of depression, anxiety, liver disease, } \\
\text { and chronic hepatitis } \\
\text { - Complex } \mathrm{MH} \text { : depression most frequent dx, } \\
\text { often increased complexity with diabetes and } \\
\text { hypertension } \\
\text { - Complex diabetes: comorbid dx associated with } \\
\text { complexity: hypertension, diabetes, renal failure, } \\
\text { and depression, with depression an important } \\
\text { marker of complexity } \\
\text { - Liver disease or chronic hepatitis: intermediate } \\
\text { complexity related to hypertension or diabetes } \\
\text { Cancer and cardiovascular disease: } \\
\text { hypertension most common comorbid dx, } \\
\text { followed by CAD and CHF } \\
\text { Cancer and MH dx: depression most frequent } \\
\text { BH dx }\end{array}$ \\
\hline $\begin{array}{l}\text { Hyer, } 2020 \\
(\mathrm{~N}=19,522)^{126}\end{array}$ & $\begin{array}{l}\text { Cluster } \\
\text { analysis }\end{array}$ & $\begin{array}{l}\text { Medicare } \\
\text { beneficiaries, age 65+, } \\
\text { underwent a total hip } \\
\text { or total knee } \\
\text { arthroplasty, highest } \\
\text { median pre-operative } \\
\text { expenditure, 2012- } \\
2016\end{array}$ & 5 clusters, & $\begin{array}{l}\text { - Annual preoperative expenditures lowest and } \\
\text { relatively low preoperative utilization } \\
\text { - } \quad \text { Preoperative expenditures a little higher than } \\
\text { cluster } 1 \text {. Costs largely driven by } \\
\text { medical/surgical supplies and surgical care } \\
\text { before hip or knee surgical admission } \\
\text { - } \text { Female }(63 \%) \text {, median preoperative health } \\
\text { expenditures } \$ 3,500 \text { more than cluster } 2 \text {, lowest } \\
\text { number of preoperative inpatient encounters, } \\
\text { highest pharmacy charges } \\
\text { - Median preoperative health expenditures similar } \\
\text { to cluster 3, highest medical/surgical supply } \\
\text { charges } \\
\text { Highest comorbidity burden; highest annual } \\
\text { preoperative expenditures, high pharmacy } \\
\text { charges, lab services, diagnostic radiology } \\
\text { services }\end{array}$ \\
\hline
\end{tabular}




\begin{tabular}{|c|c|c|c|c|}
\hline $\begin{array}{l}\text { Study Citation } \\
\text { Sample Size }\end{array}$ & $\begin{array}{l}\text { Analytic } \\
\text { Approach }\end{array}$ & Population & $\begin{array}{l}\text { Clusters: } \\
\text { Number and } \\
\text { Types }\end{array}$ & Cluster Results \\
\hline $\begin{array}{l}\text { Lee, } 2016 \\
(N=14,855)^{127}\end{array}$ & $\begin{array}{l}\text { Cluster } \\
\text { analysis }\end{array}$ & $\begin{array}{l}\text { Medicare fee-for- } \\
\text { service Cleveland } \\
\text { Clinic health system } \\
\text { patients, top } 10 \% \text { of } \\
\text { costs, } 2012\end{array}$ & 5 clusters & $\begin{array}{l}\text { - Ambulatory care: primarily outpatient care, } \\
\text { cancer and chemotherapy most common } \\
\text { conditions } \\
\text { - Surgical: median } 2 \text { IP surgeries vs. none } \\
\text { - Critically ill: higher odds of heart failure and } \\
\text { cardiac arrhythmia and arrest and the highest } \\
\text { median } \\
\text { - } \text { inpatient costs } \\
\text { - Frequent care: median of } 2 \text { IP, } 3 \text { ED, and } 29 \\
\text { outpatient visits. Common: MH, SUD, and } \\
\text { COPD/asthma } \\
\text { - Mixed utilization: median of } 1 \text { admission, } 1 \text { ED } \\
\text { visit, and } 23 \text { outpatient visits }\end{array}$ \\
\hline $\begin{array}{l}\text { Powers, } 2018 \\
(\mathrm{~N}=6,154)^{128}\end{array}$ & $\begin{array}{l}\text { Cluster } \\
\text { analysis }\end{array}$ & $\begin{array}{l}\text { Members of a } \\
\text { Medicare Advantage } \\
\text { plan, top } 10 \% \text { of costs, } \\
2013-2015\end{array}$ & 10 clusters & $\begin{array}{l}\text { - } \text { Acute exacerbations of chronic disease (mixed) } \\
\text { - } \text { End-stage renal disease } \\
\text { - } \text { Recurrent gastrointestinal bleed } \\
\text { - } \text { Orthopedic trauma } \\
\text { - } \text { Sascular disease } \\
\text { - } \text { Cirrhosical infections and other complications } \\
\text { - ESRD with increased medical and behavioral } \\
\text { - Comorbidity } \\
\text { - } \text { therapy } \\
\text { - Neurologic disorders }\end{array}$ \\
\hline $\begin{array}{l}\text { Grant, } 2020 \\
(\mathrm{~N}=104,869)^{129}\end{array}$ & $\begin{array}{l}\text { Latent class } \\
\text { analysis }\end{array}$ & $\begin{array}{l}\text { Kaiser Permanente of } \\
\text { Northern California } \\
\text { members with high } \\
\text { utilization (high } \\
\text { likelihood of hospitaliz- } \\
\text { ation and/or } 2 \text { ED } \\
\text { visits), 2017-2019 }\end{array}$ & $\begin{array}{l}7 \text { clusters } \\
\text { based on } \\
\text { clinical profiles }\end{array}$ & $\begin{array}{l}\text { - Highest acuity: highest utilization (both inpatient } \\
\text { and outpatient) with most comorbid conditions } \\
\text { - } \text { Older patients with CVD } \\
\text { - } \text { Frail elderly: highest 1-year mortality and most } \\
\text { frailty-related needs } \\
\text { - Chronic pain management: high outpatient use } \\
\text { and medical needs complicated by MH needs } \\
\text { - Active cancer treatment: intensive oncologic } \\
\text { therapy with } \\
\text { associated medical and pain management } \\
\text { issues } \\
\text { - Psychiatric illness: severe mental illness } \\
\text { complicated by } \\
\text { low income, social needs, and pain } \\
\text { management } \\
\text { Less clinically engaged: prevalent comorbidities } \\
\text { but fewer } \\
\text { Visits }\end{array}$ \\
\hline
\end{tabular}

$\mathrm{ACA}=$ Affordable Care Act; $\mathrm{BH}=$ behavioral health CAD = coronary artery disease CAN = Care Assessment Needs; $\mathrm{CHF}=$ congestive heart failure; $\mathrm{COPD}=$ chronic obstructive pulmonary disease; $\mathrm{CVD}=$ cardiovascular disease; $\mathrm{dx}=\mathrm{diagnosis} ; \mathrm{ED}=$ emergency department; ESRD = end-stage renal disease; IP = inpatient; KQ = Key Question; $\mathrm{MH}=$ mental health; $\mathrm{N}=$ number; $\mathrm{SU}=$ substance use; $\mathrm{SUD}=$ substance use disorder; VA = Veterans Health Administration.

\section{Qualitative Studies}

We identified six qualitative articles for answering KQ 1 (Table 6). The studies relied on chart review and interviews with patients, providers, administrators, and stakeholders. They largely discuss high-impact patient clinical and demographic characteristics, as well as behavioral health and social risk factors associated with high utilization. The studies included personal experience 
and informed opinions characterizing HNHC patient and health system mismatch that may be relevant for developing successful care management strategies. ${ }^{130,133}$

Table 6. Qualitative studies with evidence for $K Q 1(\mathrm{~N}=6)$

\begin{tabular}{|c|c|c|c|}
\hline $\begin{array}{l}\text { Study } \\
\text { Citation } \\
\text { Sample Size }\end{array}$ & $\begin{array}{l}\text { Definition of HNHC } \\
\text { Patient Population/ } \\
\text { Setting }\end{array}$ & Analytic Approach & Main Findings \\
\hline $\begin{array}{l}\text { Ganguli, } \\
2017^{130}(\mathrm{~N}=5)\end{array}$ & $\begin{array}{l}\text { Patients selected } \\
\text { from among } 50 \text { who } \\
\text { had the highest total } \\
\text { costs } \\
\text { Academic medical } \\
\text { center }\end{array}$ & $\begin{array}{l}\text { Mixed methods: } \\
\text { patient/caregiver interviews, } \\
\text { analysis of claims data, and } \\
\text { chart review }\end{array}$ & $\begin{array}{l}\text { Patients with complex medical issues, physical } \\
\text { disability, frailty, and BH use seemed to have } \\
\text { increased healthcare costs } \\
\text { Patient socioeconomic status, social network, } \\
\text { activation, and trust in clinicians and the } \\
\text { health system appeared to affect costs, with } \\
\text { patient activation and trust appearing to } \\
\text { mediate costs }\end{array}$ \\
\hline $\begin{array}{l}\text { Hardy et al., } \\
2018^{131} \\
(\mathrm{~N}=260)\end{array}$ & $\begin{array}{l}\text { 5+ ED visits among } \\
\text { patients enrolled in } \\
\text { primary care clinic } \\
\text { Large primary care } \\
\text { safety net clinic in } \\
\text { North } \\
\text { Carolina }\end{array}$ & $\begin{array}{l}\text { Mixed methods: analysis of } \\
\text { electronic health record data } \\
\text { matched with encounter data; } \\
\text { chart review of } 10 \text { highest ED } \\
\text { users for top } 3 \text { complaints }\end{array}$ & $\begin{array}{l}\text { HNHC patients' chief presenting complaints } \\
\text { were similar to other patients but most had a } \\
\text { greater number (4+ complaints) that were } \\
\text { associated with chronic conditions, often } \\
\text { confounded by BH concerns and treatment } \\
\text { nonadherence } \\
\text { HNHC patients had more ED visits for the } \\
\text { same types of complaints and visits occurred } \\
\text { more closely together in clusters }\end{array}$ \\
\hline $\begin{array}{l}\text { Birmingham et } \\
\text { al., 2017 } \\
(\mathrm{N}=100)\end{array}$ & $\begin{array}{l}\text { 4+ ED visits } \\
\text { Patients meeting high } \\
\text { ED use criteria at an } \\
\text { urban, level } 1 \\
\text { trauma center }\end{array}$ & $\begin{array}{l}\text { Structured interviews with } \\
\text { patients }\end{array}$ & $\begin{array}{l}\text { The primary reason for ED use was emergent } \\
\text { health concerns, although many would prefer } \\
\text { after-hours alternatives. A majority thought } \\
\text { that it would be helpful having a nurse } \\
\text { providing one-on-one help managing their } \\
\text { care } \\
\text { Barriers to care included forgetting to } \\
\text { schedule regular health checkups and having } \\
\text { difficulty taking time away from daily } \\
\text { responsibilities for necessary medical care }\end{array}$ \\
\hline $\begin{array}{l}\text { Hasselman et } \\
\text { al., } 2013^{183} \\
\text { (N=14 Summit } \\
\text { participants) }\end{array}$ & $\begin{array}{l}\text { Programs included a } \\
\text { variety of definitions: } \\
\text { common } \\
\text { characteristics } \\
\text { included high ED } \\
\text { use, inpatient } \\
\text { admissions, } \\
\text { readmissions, and } \\
\text { poly-pharmacy } \\
\text { Medicaid }\end{array}$ & $\begin{array}{l}\text { Expert panel testimony at } \\
\text { "Super utilizer summit"; } \\
\text { panel members included } \\
\text { representatives from HNHC } \\
\text { patient intervention programs, } \\
\text { states, CMS, health plans, } \\
\text { and other stakeholders }\end{array}$ & $\begin{array}{l}\text { The panel identified strategies for targeting } \\
\text { HNHC patient subgroups that are most likely } \\
\text { to be affected by complex care management } \\
\text { - Use multiple data sources to ID HNHC } \\
\text { patients to avoid inaccuracies, including } \\
\text { real-time notification of inpatient } \\
\text { admissions, patient assessments, EHRs, } \\
\text { conversations with caregivers } \\
\text { - Assess social determinants of health } \\
\text { - Predictive modeling can be an alternative } \\
\text { to waiting for delays in availability of } \\
\text { claims data } \\
\text { The HNHC patient population is } \\
\text { heterogeneous; cluster analysis can be } \\
\text { used to ID subgroups } \\
\text { ID exclusions, including pregnancy, } \\
\text { oncology, surgery for acute conditions, } \\
\text { age } 80 \text { and older with dementia } \\
\text { HNHC patient identification is an iterative } \\
\text { process }\end{array}$ \\
\hline
\end{tabular}




\begin{tabular}{|c|c|c|c|}
\hline $\begin{array}{l}\text { Study } \\
\text { Citation } \\
\text { Sample Size } \\
\end{array}$ & $\begin{array}{l}\text { Definition of HNHCa } \\
\text { Patient Population/ } \\
\text { Setting }\end{array}$ & Analytic Approach & Main Findings \\
\hline $\begin{array}{l}\text { Chan et al., } \\
2019^{133} \\
(\mathrm{~N}=15 \text { clinic } \\
\text { staff) }\end{array}$ & $\begin{array}{l}\text { 1+ inpatient } \\
\text { admissions in the prior } \\
6 \text { months, with multiple } \\
\text { medical or } \mathrm{MH} \\
\text { conditions or poor } \\
\text { engagement } \\
\text { in care } \\
\text { FQHC in Portland, } \\
\text { Oregon }\end{array}$ & $\begin{array}{l}\text { Semi-structured interviews } \\
\text { with staff participating in an } \\
\text { intervention for HNHC } \\
\text { homeless patients }\end{array}$ & $\begin{array}{l}\text { HNHC patient complexities are driven } \\
\text { mainly by nonmedical factors including } \\
\text { poverty, homelessness, low health literacy, } \\
\text { MH, and substance use disorders } \\
\text { Patient-health system mismatch arises from } \\
\text { patient's social circumstances limiting } \\
\text { access to services, BH issues interfering } \\
\text { with care engagement, and lack of health } \\
\text { system flexibility to address the mismatch, } \\
\text { such as availability of longer visits }\end{array}$ \\
\hline $\begin{array}{l}\text { Das et al. } \\
2019^{134} \\
\text { ( } \mathrm{N}=56 ; 11 \\
\text { health system } \\
\text { leaders; } 21 \\
\text { physicians; } \\
21 \text { patients } \\
\text { and } 3 \\
\text { caregivers) }\end{array}$ & $\begin{array}{l}1 \text { chronic condition } \\
\text { and either } 3+\text { ED visits } \\
\text { or } 2+\text { inpatient } \\
\text { admissions } \\
5 \text { health systems in } 3 \\
\text { cities: New York City; } \\
\text { Gainesville, Florida; } \\
\text { and Chicago, Illinois }\end{array}$ & $\begin{array}{l}\text { Interviews with health system } \\
\text { leaders and focus groups of } \\
\text { HNHC patients, caregivers, } \\
\text { and physicians }\end{array}$ & $\begin{array}{l}\text { Key themes identified as drivers of } \\
\text { preventable high healthcare utilization: } \\
\text { Unmet BH needs: inadequate access to MH } \\
\text { and substance use disorder treatment, poor } \\
\text { patient followup to care due to depression, } \\
\text { and state MH involuntary treatment laws not } \\
\text { able to address root causes of disorders } \\
\text { Social determinants of health: inadequate } \\
\text { health literacy, unstable housing, lack of } \\
\text { adequate social support, and financial } \\
\text { burdens of co-pays for care and } \\
\text { medications } \\
\text { Challenges accessing the healthcare } \\
\text { delivery system: lack of transportation, long } \\
\text { wait times for outpatient appointments, } \\
\text { unable to find doctors who take Medicaid, } \\
\text { and administrative pressure for physicians } \\
\text { to keep outpatient visits short }\end{array}$ \\
\hline
\end{tabular}

$\mathrm{BH}=$ behavioral health; $\mathrm{CMS}=$ Centers for Medicare \& Medicaid Services; $\mathrm{dx}=$ diagnosis; ED = emergency department; EHR $=$ electronic health record; FQHC = Federally Qualified Health Center; HNHC = high-need, high-cost; ID = identify; KQ = Key Question; $\mathrm{MH}=$ mental health; $\mathrm{N}=$ number.

\section{Study Outcomes}

We found wide variation across studies in the definition of high healthcare use or cost that was used as the outcome in regression analyses across predictive and cross-sectional exposure studies and used to define the HNHC patient population in cluster analyses. Table 7 presents the criteria used across predictive, cross-sectional and cluster analysis studies.

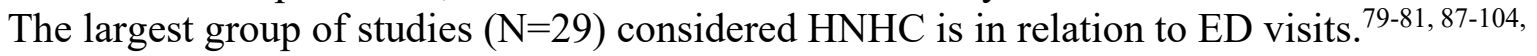
$108,120,131,132$ No standard or consensus definition for frequent or persistent ED use currently exists, as several studies noted, resulting in the number of ED visits varying across studies. Some studies included multiple analyses with different cutoffs, with the exploratory goal of identifying how differences in the definition for high ED use affected which characteristics would be significantly associated with the outcome. The number of ED visits categorized as HNHC ranged from two or more ED visits in a 12-month time period in four studies ${ }^{89,91,98,107}$ to over 25 visits in a 12-month time period in one study on the VA population. ${ }^{88}$ The median number of ED visits categorized as $\mathrm{HNHC}$ was four or more visits. 
Table 7. Definitions of HNHC patient healthcare use or cost across studies

\begin{tabular}{|c|c|c|c|c|c|c|c|c|c|c|c|c|c|c|}
\hline $\begin{array}{l}\text { Study } \\
\text { Popula- } \\
\text { tion }\end{array}$ & $\begin{array}{l}\text { Analysis } \\
\text { Type }\end{array}$ & $\begin{array}{l}2+ \\
\text { ED } \\
\text { Visits }\end{array}$ & $\begin{array}{l}3+ \\
\text { ED } \\
\text { Visits }\end{array}$ & $\begin{array}{l}\text { 4+ } \\
\text { ED } \\
\text { Visits }\end{array}$ & $\begin{array}{l}5+ \\
\text { ED } \\
\text { Visits }\end{array}$ & $\begin{array}{l}6+ \\
\text { ED } \\
\text { Visits }\end{array}$ & $\begin{array}{l}>6 \\
\text { ED } \\
\text { Visits }\end{array}$ & $\begin{array}{l}\text { Multiple } \\
\text { Measures }\end{array}$ & $\begin{array}{l}2+\text { IP } \\
\text { Admis- } \\
\text { sion }\end{array}$ & $\begin{array}{l}\text { All } \\
\text { Utiliza- } \\
\text { tion in } \\
\text { Top } \\
\text { Decile } \\
\left(\geq 75^{\text {th }}\right) \\
\end{array}$ & $\begin{array}{l}\text { Top } \\
10 \% \\
\text { in } \\
\text { Cost }\end{array}$ & $\begin{array}{l}\text { Top } \\
20 \% \\
\text { in } \\
\text { Cost }\end{array}$ & $\begin{array}{l}\text { Top } \\
25 \% \\
\text { in } \\
\text { Cost }\end{array}$ & $\begin{array}{l}\text { Cost } \\
\text { Ratios }\end{array}$ \\
\hline \multirow[t]{2}{*}{ Medicaid } & Predictive & - & $2^{81}$ & - & $1^{81}$ & - & - & $1^{81}$ & $2^{84,85}$ & - & $\begin{array}{l}2^{76,78,} \\
82\end{array}$ & - & - & - \\
\hline & $\begin{array}{l}\text { Cross- } \\
\text { sectional }\end{array}$ & $1^{107}$ & - & $1^{105}$ & - & - & - & - & - & - & - & - & - & - \\
\hline \multirow[t]{3}{*}{ Medicare } & Predictive & - & - & $1^{80}$ & - & - & - & - & - & - & $\begin{array}{l}3^{86} \\
127,128\end{array}$ & - & - & - \\
\hline & $\begin{array}{l}\text { Cross- } \\
\text { sectional } \\
\end{array}$ & $1^{108}$ & - & - & - & - & - & - & $1^{108}$ & - & $1^{119}$ & - & - & - \\
\hline & $\begin{array}{l}\text { Cluster } \\
\text { analysis }\end{array}$ & - & - & - & - & - & - & - & - & - & $1^{126}$ & - & - & - \\
\hline \multirow[t]{2}{*}{ VA } & Predictive & - & - & - & - & - & - & - & 183 & - & - & - & - & - \\
\hline & $\begin{array}{l}\text { Cross- } \\
\text { sectional }\end{array}$ & $1^{\mathrm{a} 88}$ & - & - & $1^{\mathrm{b} 88}$ & - & $1^{88}$ & $1^{88}$ & - & $1^{123}$ & - & - & - & - \\
\hline \multirow{3}{*}{$\begin{array}{l}\text { Hospital/ } \\
\text { health } \\
\text { system }\end{array}$} & Predictive & - & - & $1^{87}$ & - & - & - & - & - & - & - & - & - & - \\
\hline & $\begin{array}{l}\text { Cross- } \\
\text { sectional }\end{array}$ & $\begin{array}{l}2^{89,91} \\
95,98\end{array}$ & $\begin{array}{l}5^{89,92-} \\
95\end{array}$ & $\begin{array}{l}4^{89,90,} \\
95,96, \\
106\end{array}$ & $\begin{array}{l}3^{89,95} \\
96,99\end{array}$ & $1^{87}$ & $2^{95-98}$ & $4^{89,95,96,98}$ & $2^{109,110}$ & $2^{112,113}$ & - & - & - & - \\
\hline & $\begin{array}{l}\text { Cluster } \\
\text { analysis }\end{array}$ & - & - & $1^{121}$ & - & - & - & - & - & $1^{129}$ & - & - & - & - \\
\hline \multirow{2}{*}{$\begin{array}{l}\text { Com- } \\
\text { mercial } \\
\text { (includ- } \\
\text { ing } \\
\text { HMO) }\end{array}$} & Predictive & - & - & - & - & - & - & - & - & 177 & - & - & $1^{75}$ & - \\
\hline & $\begin{array}{l}\text { Cross- } \\
\text { sectional }\end{array}$ & - & - & - & - & - & - & - & - & - & $1^{116}$ & $1^{117}$ & - & $1^{115}$ \\
\hline \multirow{2}{*}{$\begin{array}{l}\text { Popula- } \\
\text { tion } \\
\text { based }\end{array}$} & Predictive & - & - & $1^{79}$ & - & - & - & - & - & - & - & - & - & - \\
\hline & $\begin{array}{l}\text { Cross- } \\
\text { sectional }\end{array}$ & - & - & $\begin{array}{l}3^{100-} \\
102\end{array}$ & $1^{104}$ & - & - & $1^{100,101}$ & - & $1^{114}$ & $1^{118}$ & - & - & - \\
\hline
\end{tabular}

a The outcome is $2-4$ visits.

${ }^{\mathrm{b}}$ The outcome is $5-10$ visits.

- Denotes no studies.

$\mathrm{ED}=$ emergency department; $\mathrm{HMO}=$ health maintenance organization; $\mathrm{HNHC}=$ high-need, high-cost; IP = inpatient; VA = Veterans Health Administration.

Eleven studies considered HNHC in relation to inpatient admissions. ${ }^{83-85,108-111,124,125,133,134}$ Criteria ranged from two or more admissions in nine studies $83-85,108,111,124,125,133,134$ to three or more admissions in two studies. ${ }^{109,110}$

More global measures that considered more than one type of healthcare utilization were included in six studies. ${ }^{18,113-115,172,184}$ These measures included all healthcare utilization, ${ }^{77,112,114}$ all outpatient utilization, ${ }^{18}$ or a combination of ED use and inpatient utilization. ${ }^{108,113}$

Lastly, high cost was considered in 10 studies reported in 11 articles. $^{75,76,78,82,86,115-119}$ High cost was typically defined as inclusion in the top 10 percent of total expenditures; however, two studies defined high cost as the top 20 and 25 percent of expenditures, ${ }^{75,117}$ and one study defined high cost as higher than expected expenditures after risk adjustment. ${ }^{76,82}$ 


\section{$\mathrm{KQ}$ 1a. How do criteria incorporate patient clinical characteristics?}

\section{Key Points}

- Eleven of 13 studies that assessed the role of specific complex chronic conditions (i.e., congestive heart failure, COPD, cardiovascular disease, dementia, and diabetes) found positive associations with high-use outcomes, including ED visits, inpatient admissions, total healthcare visits, and total cost.

- We found virtually no data on the association between combinations of two or more specific chronic conditions and high use or cost. However, both studies that used predictive and cross-sectional designs found a positive association between high use or cost and having a greater number of comorbid conditions. Many individually measured chronic conditions had an independent effect on high use or cost.

- Several rating scales or assessments, including the Charlson Comorbidity Index (CCI), the hierarchical condition category (HCC), and the CAN score, predicted high use. The $\mathrm{HCC}$ and CAN are population specific to Medicare beneficiaries and VA patients, respectively. The CAN score was also effective in identifying latent clusters among VA HNHC patients.

- Higher scores on patient self-assessment tools, such as the global health score, were associated with high use. The evidence was limited to cross-sectional studies.

\section{Results of Studies}

We present our findings describing chronic clinical conditions associated with high use or cost, separately by predictive, cross-sectional and cluster analysis study design, in Tables 8 through 12. The clinical conditions are presented in three ways: specific diagnoses, number of conditions, and rating scales assessing condition severity. Additional study detail is included in Appendix Tables B-1 and B-2. 
Table 8. Number and results of studies examining the association between chronic clinical conditions and high ED use

\begin{tabular}{|c|c|c|}
\hline Diagnosis, Health Condition, or Rating Scale & Predictive Studies & Cross-Sectional Studies \\
\hline Diagnosis: Arthritis & $1^{a, b, 80}$ & $2^{a, b, 99,100}$ \\
\hline Diagnosis: Asthma & - & $1^{97}$ \\
\hline Diagnosis: Cerebrovascular disease ${ }^{d}$ & - & $1^{a, b, 100}$ \\
\hline Diagnosis: Congestive heart failure ${ }^{d}$ & $1 \mathrm{a},{ }^{*} 80$ & $3^{a, b, 88,93,105}$ \\
\hline Diagnosis: COPDd & $1^{a,{ }^{*} 80}$ & $4^{a, b, 88,92,99,105}$ \\
\hline Diagnosis: Cardiovascular disease ${ }^{d}$ & - & $2^{\mathrm{a}, \mathrm{b}, 93,100}$ \\
\hline Diagnosis: Dementia $^{d}$ & $1^{a,{ }^{*} 80}$ & - \\
\hline Diagnosis: Diabetes $^{d}$ & $1^{a},{ }^{*} 80$ & $4^{a, b, 92,93,100,105}$ \\
\hline Diagnosis: Heart disease $^{\mathrm{d}}$ & - & $1^{87}$ \\
\hline Diagnosis: Hepatitis C & - & $1^{a, b, 91}$ \\
\hline Diagnosis: Hepatobiliary disease & - & $1^{a, b, 87}$ \\
\hline Diagnosis: HIV & - & $191 ; 1^{a, b, 105}$ \\
\hline Diagnosis: Hypertension & $1^{a, b, 80}$ & $1^{100}$ \\
\hline Diagnosis: Obesity & - & $1^{e, 93}$ \\
\hline Diagnosis: Pancreatic disease & - & $1^{87}$ \\
\hline Diagnosis: Renal disease & $1^{80}$ & $3^{a, b, 88,92,99}$ \\
\hline Diagnosis: Seizure & - & $1^{a, b, 99}$ \\
\hline Diagnosis: Sickle cell & - & $1^{a, b, 99}$ \\
\hline Diagnosis: Vascular disease ${ }^{d}$ & - & $1^{87}$ \\
\hline Health Condition: \# of Conditions & - & - \\
\hline Rating Scale: Charlson Comorbidity Index & $1^{a, b, 81}$ & $3^{a, b, 88,104,108:} 1^{91}$ \\
\hline Rating Scale: Poorer global health rating & & $5^{\mathrm{a}, \mathrm{b}, 100,101,103,106,113}$ \\
\hline Rating Scale: Hierarchic categorical condition score & $1^{a, b, 80}$ & - \\
\hline Rating Scale: DRG Severity Index & - & $1^{a, b, 98}$ \\
\hline Rating Scale: Elixhauser index & - & $1^{\mathrm{a}, \mathrm{b}, 107}$ \\
\hline Rating Scale: MIDAS disability score & $-c$ & $1^{a, b, 102}$ \\
\hline
\end{tabular}

Note: When the relationship in a study was not statistically significant, the direction of effect is not shown.

${ }^{\text {a }}$ Denotes positive association

${ }^{\mathrm{b}}$ Denotes if the association, positive or negative, is statistically significant.

- Denotes no studies.

${ }^{\mathrm{d}}$ Denotes complex chronic clinical conditions as defined by NAM. Psychiatric disease is presented separately under findings for

KQ $1 b$.

${ }^{\mathrm{e}}$ Denotes negative association.

$\mathrm{DRG}=$ diagnosis-related group; $\mathrm{ED}=$ emergency department; HIV = human immunodeficiency virus; KQ = Key Question; MIDAS = Migraine Disability Assessment; NAM = National Academy of Medicine . 
Table 9. Number and results of studies examining the association between chronic clinical conditions and high number of inpatient visits

\begin{tabular}{|c|c|c|}
\hline $\begin{array}{l}\text { Diagnosis, Health Condition, or } \\
\text { Rating Scale }\end{array}$ & Predictive Studies & Cross-Sectional Studies \\
\hline Diagnosis: Arthritis & $1^{a, b, 83}$ & - \\
\hline Diagnosis: Chronic kidney disease ${ }^{\mathrm{d}}$ & $1^{a, b, 83}$ & - \\
\hline Diagnosis: Congestive heart failure ${ }^{d}$ & $1^{a, b, 83}$ & - \\
\hline Diagnosis: Cardiovascular disease ${ }^{\mathrm{d}}$ & $1^{a, b, 83}$ & - \\
\hline Diagnosis: Diabetes $^{d}$ & $1^{a, b, 83}$ & - \\
\hline Diagnosis: Hypertension & $1^{a, b, 83}$ & - \\
\hline Health Condition: \# of Conditions & - & $2^{\mathrm{a}, \mathrm{b}, 109,110}$ \\
\hline $\begin{array}{l}\text { Rating Scale: Charlson Comorbidity } \\
\text { Index-based rating }\end{array}$ & - & $2^{a, b, 108,110}$ \\
\hline $\begin{array}{l}\text { Rating Scale: Global self-report health } \\
\text { rating }\end{array}$ & & $1^{\mathrm{a}, \mathrm{b}, 113}$ \\
\hline \multicolumn{3}{|c|}{$\begin{array}{l}\text { Note: When the relationship in a study was not statistically significant, the direction of effect is not shown. } \\
\text { a Denotes positive association. } \\
\text { b Denotes if the association, positive or negative, is statistically significant. } \\
\text { - Denotes no studies. } \\
\text { d Denotes complex chronic conditions as defined by NAM. Psychiatric disease is presented separately under findings for KQ } 1 \mathrm{~b} \text {. }\end{array}$} \\
\hline
\end{tabular}

$\mathrm{KQ}=$ Key Question; NAM = National Academy of Medicine.

Table 10. Number and results of studies examining the association between chronic clinical conditions and high healthcare use, based on all visits

\begin{tabular}{lll}
\hline $\begin{array}{l}\text { Diagnosis, Health Condition, or } \\
\text { Rating Scale }\end{array}$ & Predictive Studies & Cross-Sectional Studies \\
\hline Diagnosis: COPD & $1^{\mathrm{b}, \mathrm{c}, 77}$ & - \\
\hline Diagnosis: Diabetes & $1^{\mathrm{b}, \mathrm{c}, 77}$ & - \\
\hline Diagnosis: Hypertension & $1^{77}$ & - \\
\hline Health Condition: \# of Conditions & - & $1^{\mathrm{b}, 114}$ \\
\hline $\begin{array}{l}\text { Rating Scale: Charlson Cormorbidity } \\
\text { Index }\end{array}$ & - & $1^{\mathrm{b}, \mathrm{c}, 112}$ \\
\hline Rating Scale: Other rating scale & - & $1^{\mathrm{b}, \mathrm{c}, 114}$ \\
\hline
\end{tabular}

Note: when the relationship in a study was not statistically significant, the direction of effect is not shown.

${ }^{a}$ Denotes complex chronic conditions as defined by NAM. Psychiatric disease is presented separately under findings for KQ $1 \mathrm{~b}$.

${ }^{\mathrm{b}}$ Denotes positive association.

${ }^{c}$ Denotes if the association, positive or negative, is statistically significant.

- Denotes no studies.

$\mathrm{COPD}=$ chronic obstructive pulmonary disease; KQ = Key Question; NAM = National Academy of Medicine 
Table 11. Number and results of studies examining the association between chronic clinical conditions and high cost of care

\begin{tabular}{|c|c|c|}
\hline Diagnosis, Health Condition, or Rating Scale & $\begin{array}{l}\text { Predictive } \\
\text { Studies }\end{array}$ & Cross-Sectional Studies \\
\hline Diagnosis: Cerebrovascular disease ${ }^{a}$ & - & $1^{116 ;} ; 1^{\mathrm{b}, \mathrm{b}, 119}$ \\
\hline Diagnosis: Cardiovascular disease ${ }^{\mathrm{a}}$ & - & $2^{\mathrm{b}, \mathrm{b}, 116,119}$ \\
\hline Diagnosis: Diabetes ${ }^{a}$ & - & $1^{\mathrm{c}, \mathrm{c}, 116 ;} ; 1^{\mathrm{b}, \mathrm{b}, 119}$ \\
\hline Diagnosis: Hypertension & - & - \\
\hline Diagnosis: Pulmonary circulation disorder & - & $1^{\mathrm{b}, \mathrm{b}, 119}$ \\
\hline Health Condition: \# of Conditions & $1^{\mathrm{b}, 75}$ & $1^{\mathrm{b}, \mathrm{b}, 114}$ \\
\hline Rating Scale: Charlson Cormorbidity Index-based rating & - & $1^{\mathrm{b}, \mathrm{b}, 116}$ \\
\hline Rating Scale: Global health rating & $1^{\mathrm{b}, \mathrm{b}, 75}$ & $1^{116}$ \\
\hline \multicolumn{3}{|c|}{$\begin{array}{l}\text { Note: when the relationship in a study was not statistically significant, the direction of effect is not shown. } \\
\text { a Denotes complex chronic conditions as defined by NAM. Psychiatric disease is presented separately under findings for KQ } 1 \text { b. } \\
{ }^{b} \text { Denotes statistically significant positive association. } \\
\text { c Denotes statistically significant negative association. } \\
\text { - Denotes no studies. }\end{array}$} \\
\hline
\end{tabular}

Table 12. Number of studies that identify chronic clinical conditions as characteristics defining high-utilization/high-cost clusters

\begin{tabular}{ll}
\hline Diagnosis, Health Condition, or Rating Scale & Number of Studies, Citations \\
\hline Diagnosis: Cerebrovascular disease ${ }^{a}$ & $1^{122,128}$ \\
\hline Diagnosis: Chronic kidney disease & $1^{122}$ \\
\hline Diagnosis: Congestive heart failure ${ }^{a}$ & $2^{124,125,127}$ \\
\hline Diagnosis: COPD $^{a}$ & $2^{122,124,127}$ \\
\hline Diagnosis: Cardiovascular disease ${ }^{a}$ & $3^{122,125,129}$ \\
\hline Diagnosis: Dementia $^{a}$ & $1^{122}$ \\
\hline Diagnosis: Diabetes $^{a}$ & $2^{122,125}$ \\
\hline Diagnosis: Heart disease ${ }^{a}$ & $2^{121,122}$ \\
\hline Diagnosis: Hepatitis & $1^{125}$ \\
\hline Diagnosis: Hepatobiliary disease & $1^{125}$ \\
\hline Diagnosis: Hypertension & $2^{124,125}$ \\
\hline Diagnosis: Musculoskeletal & $1^{121}$ \\
\hline Diagnosis: Obesity & $1^{122}$ \\
\hline Diagnosis: Renal disease & $3^{124,125,128}$ \\
\hline Rating Scale: Global health rating & $1^{75}$ \\
\hline
\end{tabular}

${ }^{a}$ Denotes complex chronic conditions as defined by NAM. Psychiatric disease is presented separately under findings for KQ $1 \mathrm{~b}$.

$\mathrm{COPD}=$ chronic obstructive pulmonary disease; KQ = Key Question; NAM = National Academy of Medicine.

\section{Specific Diagnoses}

Diagnoses and counts of chronic clinical conditions included in studies were based on International Statistical Classification of Diseases and Related Health Problems (ICD)-9 or ICD10 codes and identified in electronic health records, claims data, or state or facility databases. Specific conditions included both complex chronic and noncomplex chronic conditions, consistent with those identified though the NAM framework. ${ }^{185}$ Studies often assessed the independent effect of more than one condition but rarely assessed combinations of specific conditions, making a direct comparison with the NAM framework difficult.

Across predictive and cross-sectional studies, five complex chronic conditions (congestive heart failure, COPD, cardiovascular disease, dementia, or diabetes) consistently had a positive significant association with high-utilization outcomes, including ED visits, ${ }^{80,}, 88,92,93,99,100,105$ inpatient admissions, ${ }^{83}$ and total healthcare visits ${ }^{77}$ as well as high cost. ${ }^{119}$ Consistent with these 
findings, heart-related conditions were identified as a defining characteristic in two cluster analyses. ${ }^{121,129}$

Four studies focused on patients with a specific chronic clinical condition: heart failure, ${ }^{92}$ COPD,${ }^{93}$ acute asthma,${ }^{95}$ and severe headache. ${ }^{102}$ The studies of heart failure and COPD patients found that having both health failure and COPD significantly increased the odds of high ED use. Diabetes also increased the odds of high ED use.

Among a Medicaid population, the correlation between being in the top 10 percent 1 of expenditures, after 6 and 12 months, was similar in specific disease cohorts (diabetes, COPD, hypertension, and asthma) as in the more general population. ${ }^{78}$

Two studies of patients with mental health diagnoses did not consistently find a significant association between specific chronic conditions and high use or cost. ${ }^{87,116}$ In one study, high ED use was associated with hepatobiliary disease but not other measured complex chronic conditions, such as heart disease or kidney disease.$^{87}$ In the other study, high healthcare costs among patients with depression were not associated with having cerebrovascular disease or diabetes but were related to having cardiovascular disease and obesity. ${ }^{116}$

Chronic pain was not a focus in the NAM framework. However, we found that it was associated with being $\mathrm{HNHC}$ in three ${ }^{88,104,116}$ of four exposure studies. ${ }^{97}$ Chronic pain was also identified as a group in two cluster analyses ${ }^{122,129}$ and as a defining characteristic in one qualitative study. ${ }^{183}$

\section{Number of Chronic Conditions}

Having a greater number of chronic conditions was found to be positively associated with being HNHC in two predictive studies ${ }^{75,114}$ and three cross-sectional studies. ${ }^{88,109,110}$ Similarly, one qualitative study of high ED use found that both HNHC patients and less frequent users generally had complaints related to chronic conditions. ${ }^{131}$ However, HNHC patients had a greater number of complaints. ${ }^{131}$

One of the cross-sectional studies, conducted by Reichard and colleagues, explored the association of the number of chronic conditions and disability with high overall utilization and cost (Table 7). ${ }^{114}$ They found that although the number of chronic conditions was positively related to high utilization and high cost, the resulting groups had diverse healthcare needs. Their model estimate was improved by also taking disability into account. The authors concluded that the best model includes functional disability and service utilization over the preceding year, in addition to the number of chronic conditions.

\section{Functional Limitations and Frailty}

Similar to the Reichard et al. study, Bayliss and colleagues tested a predictive model of characteristics associated with patients being in the top 25 percent for healthcare costs in the succeeding 6 to 12 months. They showed that Kaiser member self-report of having conditions that interfere with daily activities was a significant predictor of future high cost. ${ }^{75} \mathrm{Cluster}$ analyses, using Kaiser member data in this and a second study, similarly found that chronic conditions that interfere with activities of daily living ${ }^{75}$ and being frail elderly ${ }^{129}$ were distinct clinical profiles. A qualitative study of five high-cost patients further supported that physical disability and frailty contribute to higher costs. ${ }^{130}$ 


\section{Rating Scales}

Many analyses included rating scales or assessments, conducted by a clinician, provided through patient self-report, or developed through secondary data. Specific assessments included the CCI, the HCC, the CAN score, the diagnosis-related group (DRG) Severity Index, health needs assessment (HNA), the Migraine Disability Assessment (MIDAS) questionnaire, and global health scores. Three predictive studies ${ }^{75,80,81}$ and 11 cross-sectional studies ${ }^{88,100-104,110,112-}$ 114, 116 included an assessment tool or rating scale to characterize HNHC patients.

The CCI rating scale was used most often across studies. The CCI is a comorbidity summary measure that has been widely used in the healthcare literature. ${ }^{186,187} \mathrm{CCI}$ encompasses 19 medical conditions that are weighted to reach a total score ranging from 0 to 37 , based on the relative risk of death within 12 months associated with the condition. To account for the effects of increasing age, one point is added to the CCI score for each decade of life over the age of 50. ${ }^{188}$ The CCI, as well as its adaptations, such as the Quan-Charlson, have been validated in multiple studies. ${ }^{189,190}$

A higher CCI score was found to be associated with HNHC across studies. One predictive study, conducted in a New York City Medicaid population, reported a positive association between a higher CCI and high ED use. ${ }^{81}$ Cross-sectional studies reported positive associations between higher CCI scores and high ED use in two studies: ${ }^{88,104}$ high total healthcare visits in one study ${ }^{112}$ and cost in one study. ${ }^{116}$ These associations were found across diverse patient populations: veterans, seniors, patients served by hospitals in the state of Florida, and commercial health maintenance organization (HMO) members.

The HCC score is a risk adjustment approach created by the Centers for Medicare \& Medicaid Services (CMS) to calculate risk scores for Medicare to reimburse managed care plans. HCC scores are designed to represent the expected medical costs of a Medicare beneficiary in the coming year. HCC scores cluster ICD codes into 79 categories. ${ }^{191}$ One predictive study by Colligan and colleagues found HCC score to be positively related to future frequent ED use in a Medicare population, controlling for other patient characteristics. ${ }^{80}$

The CAN score is a tool developed by the VA to identify patients who are the highest risk of rehospitalization or mortality within a specific time period, such as 90 days or 1 year. The score estimates a patient's risk based on demographic characteristics, comorbid conditions, and healthcare use. ${ }^{192}$

The CAN score was used to identify clusters of HNHC patients in four studies of patients served by the VA (Table 4). ${ }^{83,123-125}$ One study, using the CAN score, identified seven clusters among homeless veterans. The groups differentiated patients based on whether high use was related to inpatient or ED services or both, mental health problems, and substance use disorder (SUD) diagnosis. ${ }^{123}$ In another study, the VA sought to identify unique clusters of HNHC patients that could be used to develop tailored care management strategies for clinically distinct groups and avoid applying "one-size-fits" all strategies. Using the CAN score, six distinct groups of HNHC patients were revealed, based on comorbid physical and mental health diagnoses, including substance use comorbid with liver disease and hepatitis, complex diabetes comorbid with renal failure and depression, and liver disease comorbid with hypertension or diabetes. ${ }^{125}$ The analysis showed that the groups differed by demographic characteristics and use patterns, which underscored how each group was unique. Another study used CAN scores to determine if it were possible to identify clusters of high-risk patients based on risk scores trajectories. ${ }^{124}$ Using patient scores over a 2-year period, researchers identified two subgroups of patients: one subgroup with patients exhibiting higher mean hospitalization probabilities that remained 
persistently high over time and another subgroup with patients exhibiting lower mean hospitalization probabilities and a more pronounced decline in hospitalization risk over time. The CAN score was used in another study of VA patients to examine the tool's ability to identify patterns of risk status over time. ${ }^{83}$ This study found that among the high-risk population the majority of patients did not remain persistently high-risk during 2 years of followup. Instead, they found 29 percent of VA patients were persistently high risk after 1 year, and 14 percent remained persistently high risk after 2 years. Almost half $(42 \%)$ were classified as persistently low risk by the end of the study.

The DRG Severity Index ranges from 0 to 4, least to most severe. Based on medical records, it categorizes illness severity based on principal medical diagnosis, comorbidities, and procedures. ${ }^{98}$ A cross-sectional study in one ED found that a higher DRG Severity Index was generally related to a higher number of ED visits when comparing one to two but not when comparing 20 or more visits to one. ${ }^{98}$

The self-reported global health score refers to a single-item health measure in which patients use a Likert scale to rate their current health status from excellent to poor. It is a popular mechanism for assessing health because it is easy to use. The rating scale has been extensively studied and has been shown to be a good predictor of disability and mortality from many diseases. ${ }^{193-195}$ One predictive study and five cross-sectional studies included a measure of selfreported health. ${ }^{75,100,101,103,113,116}$ Among these, three studies found a significant positive relationship between self-reported poor health and high ED utilization. ${ }^{100,101,103}$ A fourth study examined the feasibility of using a self-reported physical health measure to assess the risk for high healthcare utilization. The study determined that poorer self-reported physical health, measured during routine healthcare visits, was associated with significantly higher rates of hospitalization but not ED visits. ${ }^{113}$ Poorer self-reported health was significantly related to higher future costs, ${ }^{75}$ but was it was not significantly associated with cost in a cross-sectional study that also controlled for CCI score and specific chronic disease diagnoses. ${ }^{116}$

The MIDAS disability score is based on a brief, self-administered questionnaire designed to quantify headache-related disability over a 3-month period and measures disability in terms of days missed at work and reduced productivity in work and nonwork activities. The MIDAS score has been shown to have moderate reliability in predicting the need for medical care. ${ }^{196}$ A 2004 population-based survey from the American Migraine Prevalence and Prevention Study found a positive association between the MIDAS disability score and frequent ED use. ${ }^{102}$

\section{$\mathrm{KQ} 1 \mathrm{~b}$. How do criteria incorporate patient demographic, behavioral health, and social risk factors?}

To answer KQ 1b, we synthesized the evidence on patient demographic characteristics, behavioral health, and social risk factors associated with being HNHC. Tables 13 and 14 present an overview of our findings by outcome and study design. We discuss each of these characteristics in separate sections below. Additional detail concerning these factors can be found in Tables B-9 and B-10 in Appendix B. 
Table 13. Number of multivariate studies examining demographic characteristics associated with high healthcare use or cost among HNHC patients, by direction and significance of effect

\begin{tabular}{|c|c|c|c|c|c|c|c|}
\hline Outcome & $\begin{array}{l}\text { Study } \\
\text { Design }\end{array}$ & $\begin{array}{l}\text { Male Versus } \\
\text { Female }\end{array}$ & $\begin{array}{l}\text { Black } \\
\text { Versus } \\
\text { White }\end{array}$ & $\begin{array}{l}\text { Hispanic } \\
\text { Versus } \\
\text { White }\end{array}$ & $\begin{array}{l}\text { Native } \\
\text { American } \\
\text { Versus } \\
\text { White }\end{array}$ & $\begin{array}{l}\text { Asian } \\
\text { Versus } \\
\text { White }\end{array}$ & $\begin{array}{l}\text { Combined } \\
\text { Minority } \\
\text { Versus } \\
\text { White }\end{array}$ \\
\hline \multirow[t]{6}{*}{ ED visits } & Predictive & - & $1^{a, 80}$ & $1^{a, 80}$ & $1^{a, 80}$ & $1^{b, 80}$ & - \\
\hline & & & $1^{79}$ & $1^{b, 79}$ & & & \\
\hline & Cross- & $7^{a, 88,92,93,95,97}$ & $9^{\mathrm{a}, 89,90,92,99,}$ & $2^{a, 92,104}$ & $1^{a, 99}$ & $4^{b, 99,100,104,105}$ & $1^{b, 97}$ \\
\hline & sectional & 104,105 & $100,103-105$ & $3^{b, 93,99,100}$ & & $1^{103}$ & $1^{91}$ \\
\hline & & $4^{b, 89,100,106,107}$ & $2^{107,108}$ & $2^{103,105}$ & & & \\
\hline & & $5^{87,90,91,99,108}$ & & & & & \\
\hline \multirow{2}{*}{$\begin{array}{l}\text { IP } \\
\text { admissions }\end{array}$} & Predictive & $1^{a, 83}$ & $1^{\mathrm{b}, 108}$ & $1^{a, 83}$ & - & - & - \\
\hline & $\begin{array}{l}\text { Cross- } \\
\text { sectional }\end{array}$ & - & - & - & - & - & - \\
\hline \multirow[t]{2}{*}{ All utilization } & Predictive & $1^{b, 77}$ & - & - & - & - & - \\
\hline & $\begin{array}{l}\text { Cross- } \\
\text { sectional }\end{array}$ & $1^{112}$ & - & - & - & - & - \\
\hline \multirow[t]{2}{*}{ Cost } & Predictive & $1^{b, 75}$ & - & - & - & - & - \\
\hline & $\begin{array}{l}\text { Cross- } \\
\text { sectional }\end{array}$ & $\begin{array}{l}1^{a, 119} \\
2^{116,118}\end{array}$ & $1^{\mathrm{a}, 119}$ & $1^{\mathrm{a}, 119}$ & - & - & - \\
\hline
\end{tabular}

${ }^{a}$ Denotes positive direction, all significant meaning positively associated with higher utilization or cost.

${ }^{\mathrm{b}}$ Denotes negative direction, all significant meaning negatively associated with lower utilization or cost.

If no superscript letter, then denotes nonsignificant.

- Denotes no studies.

$\mathrm{ED}=$ emergency department; $\mathrm{HNHC}=$ high-need, high-cost; IP = inpatient; vs. = versus.

Table 14. Number of multivariate studies examining behavioral health and social risk factors associated with high healthcare use or cost among HNHC patients by direction and significance of effect

\begin{tabular}{|c|c|c|c|c|c|c|c|c|c|}
\hline Outcome & $\begin{array}{l}\text { Study } \\
\text { Design }\end{array}$ & $\begin{array}{l}\text { Depres- } \\
\text { sion }\end{array}$ & SMI & $\begin{array}{l}\text { Otherl } \\
\text { Unspecified } \\
\text { Mental } \\
\text { Health } \\
\text { Conditions }\end{array}$ & SUD & AUD & $\begin{array}{l}\text { Home- } \\
\text { less }\end{array}$ & Employed & $\begin{array}{l}\text { Low } \\
\text { Income or } \\
\text { Poverty }\end{array}$ \\
\hline \multirow[t]{2}{*}{ ED visits } & Predictive & $1^{\mathrm{a}, 79}$ & $1^{79}$ & $2^{a, 79,80}$ & $1^{\mathrm{a}, 79}$ & $1^{\mathrm{a}, 79}$ & - & - & $\begin{array}{l}1^{\mathrm{a}, 102} \\
1^{79}\end{array}$ \\
\hline & $\begin{array}{l}\text { Cross- } \\
\text { sectional }\end{array}$ & $\begin{array}{l}4^{a, 88,92,93,} \\
105 \\
1^{102}\end{array}$ & $\begin{array}{l}4^{\mathrm{a}, 88,93,105,} \\
197 \\
1^{97}\end{array}$ & $\begin{array}{l}8^{\mathrm{a}, 88,89,96,100} \\
101,104,107,108 \\
3^{91,106,113}\end{array}$ & $\begin{array}{l}9^{a, 87-89,92,93,} \\
96,104,105,107 \\
3^{90,91,106}\end{array}$ & $\begin{array}{l}5^{\mathrm{a}, 88,90,96,99} \\
105 \\
3^{87,91,100}\end{array}$ & $\begin{array}{l}4^{a, 87,88,90,99} \\
1^{91}\end{array}$ & $3^{\mathrm{b}, 89,97,100}$ & $\begin{array}{l}7^{a, 92,93,100,} \\
101,103,108,119 \\
2^{95,108}\end{array}$ \\
\hline \multirow[t]{2}{*}{$\begin{array}{l}\text { IP } \\
\text { admissions } \\
\end{array}$} & Predictive & - & $1^{\mathrm{a}, 85}$ & $1^{\mathrm{a}, 83}$ & - & - & $1^{\mathrm{b}, 83}$ & - & - \\
\hline & $\begin{array}{l}\text { Cross- } \\
\text { sectional }\end{array}$ & - & - & $2^{108,113}$ & $1^{\mathrm{a}, 109}$ & $1^{109}$ & $1^{\mathrm{a}, 109}$ & - & $\begin{array}{l}1^{108} \\
2^{108,109} \\
\end{array}$ \\
\hline \multirow[t]{2}{*}{$\begin{array}{l}\text { All } \\
\text { utilization }\end{array}$} & Predictive & - & - & 177 & - & - & - & - & - \\
\hline & $\begin{array}{l}\text { Cross- } \\
\text { sectional }\end{array}$ & - & - & - & - & - & - & - & - \\
\hline \multirow[t]{2}{*}{ Cost } & Predictive & - & - & - & - & - & - & - & - \\
\hline & $\begin{array}{l}\text { Cross- } \\
\text { sectional }\end{array}$ & $\begin{array}{l}1^{\mathrm{a}, 198} \\
1^{117} \\
\end{array}$ & - & $3^{a, 115-117}$ & $1^{a, 116}$ & - & - & $1^{\mathrm{b}, 116}$ & $1^{118}$ \\
\hline
\end{tabular}

${ }^{a}$ Denotes positive direction, all significant meaning positively associated with higher utilization or cost.

${ }^{b}$ Denotes negative direction, all significant meaning, negatively associated with lower utilization or cost.

If no superscript letter, then denotes nonsignificant.

- Denotes no studies 
Findings for Kanzaria ${ }^{79}$ are presented at the 1-year followup only for consistency with other evidence. The study also presented findings at 2-, 5-, and 10-year followups.

Findings for $\mathrm{Meek}^{77}$ are based on self-report and are mixed.

$\mathrm{AUD}=$ alcohol use disorder; $\mathrm{ED}=$ emergency department; HNHC = high-need, high-cost; IP = inpatient; $\mathrm{SMI}=$ serious mental illness; SUD = substance use disorder.

\title{
Demographic Risk Factors
}

\section{Key Points}

- Older age was generally associated with measures of HNHC. The exception is the nonaged disabled Medicare patients where measures of HNHC, particularly ED use, were higher in the younger group.

- The association between gender and measures of HNHC was mixed.

- The association between race and ethnicity with healthcare use varied by group. In comparison with white race, black race was associated with higher ED use, Asian race was associated with lower ED and inpatient use, and the results for Hispanic ethnicity were mixed.

\section{Results of Studies}

Demographic characteristics, including age, gender, and race, were included in almost all studies. In some analyses, they were used solely as control variables in multivariate models and findings were not presented.

\begin{abstract}
Age
Virtually all predictive and cross-sectional articles included age in modeling characteristics to identify HNHC patients. No cluster analysis included age as an indicator for creating clusters, and no qualitative studies discussed age as a factor contributing to HNHC. Because of differences in the age range across studies and categories used to depict age in analyses, we did not identify one metric that would be helpful in sorting our findings into a table. Therefore, we do not report findings by age in Table 12 .

Older age was commonly associated with higher healthcare use and cost, compared with younger age, across predictive and cross-sectional studies. An exception is one study of high inpatient use that found the opposite relationship. ${ }^{110}$ Patients who were 60 years of age and older, originally admitted to one family medicine inpatient service, had lower odds of a "high frequency readmission" ( 3 or more inpatient readmissions in a given year) compared with younger patients. ${ }^{110}$ The family medicine inpatient service consisted of a team of interns, residents, and pharmacy students supervised by an attending physician. The role of the team was to promote greater continuity between outpatient primary care providers and the hospital medicine team. Because the finding of this study was counterintuitive, the authors theorized that these physicians might not be as alert to the possibility of readmission among younger patients and may not probe to ensure that this high-risk portion of the nonaged population has appropriate aftercare supports.

Consistent with the NAM framework, in Medicare population studies, the effect of age also followed a different pattern. Based on a national sample, Colligan and colleagues found that, compared with beneficiaries 65 to 74 years of age, the probability of frequent future ED use was higher among nonaged disabled Medicare beneficiaries. ${ }^{80}$ Beneficiaries 18 to 34 years old had
\end{abstract}


the largest relative risk of future frequent ED use (relative risk ratio $=3.1$ [3.0 to 3.2]) - even higher than other younger than 65 age groups. The significant effect of age was observed in this study after controlling for the potential confounder of disability as the reason for Medicare entitlement (the reason those younger than 65 years would qualify for Medicare). Consistent with these findings, in one cluster analysis of frequent ED users, a defining characteristic of one identified group was having Medicare coverage because of nonaged disability. ${ }^{121}$

Being a nonelderly disabled Medicare beneficiary was also related to being persistently high cost. One study found this group to be more likely to be high cost each year in a 3-year period rather than transition in and out of cost periods, compared with older beneficiaries. ${ }^{119}$

Another study of Medicare beneficiaries examined ambulatory care sensitive conditions (ACSC)-related ED and inpatient visits, separately among the elderly and younger disabled populations, to see whether the factors driving high use were the same or differed between the groups. ${ }^{108}$ In both groups, a greater number of ED visits was related to medication nonadherence, a higher CCI score, and having a mental health condition. Only in the younger group were ED visits positively related to the number of unique prescribers, and only in the elderly group were they positively related to the number of office visits. Similarly, a greater number of inpatient admissions was related to medication nonadherence and a higher CCI score in both groups but related to only dual eligibility in the older group.

\section{Gender}

Gender was a covariate in virtually all multivariate models. In a number of analyses, gender was included in the model to control for potential confounding, and the independent effect of the variable was not reported. Overall, we found no discernible pattern of differences by gender across studies.

\section{Race/Ethnicity}

Racial groups and/or Hispanic ethnicity (compared with white race) were commonly included variables in analyses (20 predictive and cross-sectional studies) (Table 12). Race was not a characteristic of note in cluster or qualitative analyses.

The interpretation of race/ethnicity in findings is complicated by possible mediating factors. Considerations such as poverty and access to care have been known to have a complex relationship with race, particularly black race. As a result, in some cases, race may be a proxy for some other patient characteristics, rather than an additional risk factor. ${ }^{199-201}$ A recent study found that algorithms that predict future costs and use the data to qualify individuals for HNHC patient interventions may underestimate the needs of black patients. ${ }^{202}$ Black patients have been found to use fewer services than white patients, relative to their illness severity. Because of this, predictions and access to interventions based on just being in the highest cost group can be racially biased. The study also found that black patients tend to generate different types of service costs, including lower rates of surgical inpatient services and higher rates of ED services.

The effect of black relative to white race was measured in relation to high ED use and inpatient use. We generally found black race to be associated with a greater probability of high ED use, including two predictive ${ }^{79,80}$ and nine cross-sectional studies. ${ }^{89,90,92,99,100,103-105,203}$ Black race was related to lower inpatient use in two studies. ${ }^{83,204}$

Differences between Asian race or Hispanic ethnicity and white race were measured in fewer studies. Asian race was associated with a lower probability of high ED use and inpatient episodes. ${ }^{80,104,105}$ The relationship between Hispanic ethnicity and high use was mixed. 
In relation to high cost, among Medicare beneficiaries, black race or Hispanic ethnicity was positively associated with being persistently high cost over a 3-year period, controlling for chronic conditions and poverty. ${ }^{119}$

\section{Behavioral Health Risk Factors}

\section{Key Points}

- Mental health concerns, such as depression or mental health disorders that occur along with a physical health diagnosis, are indicators of high use and high cost and often defining characteristics in patient clusters. The results for serious mental illness (SMI) are mixed.

- SUD is consistently associated with high use and high cost.

- Results for the association between alcohol use disorder (AUD) and high use are mixed.

\section{Results of Studies}

Twenty-six studies examined the association between behavioral health conditions (mental health concerns, SUDs, and/or AUDs) and being a HNHC patient (Table 13). Mental health concerns were further delineated as depression, SMI, and other mental health disorders.

\section{Mental Health Conditions}

The independent effect of depression on being a HNHC patient was measured in relation to ED use and high cost. Depression was significantly associated with high ED use (1 predictive study after 2 years ${ }^{79}$ and 4 cross-sectional studies). ${ }^{88,92,93,105}$ Depression was also related to high cost (1 predictive study among a commercial HMO population ${ }^{75}$ and 1 cross-sectional study). ${ }^{119}$ A qualitative study described depression as being associated with seeking inappropriate hospital care and difficulty advocating for less aggressive medical care. ${ }^{130}$

The findings for diagnoses reflective of SMI were nuanced in one predictive analysis that examined patterns in high ED use over time. Schizophrenia was significantly negatively associated with persistent high ED use (compared with nonpersistent high use) at the 3- and 6year followups but not by 11 years. ${ }^{79}$ Instead, persistent high ED use after 11 years was associated with having an anxiety disorder or having attempted suicide or intentionally selfinflicted injury.

Similarly, four cross-sectional studies revealed a positive association between SMI and high ED use ${ }^{88,93,105,107}$ Among these, the relationship was found among patients with COPD $^{93}$ and among patients with a broader range of psychiatric conditions. ${ }^{107}$ In the psychiatric population, having multiple psychiatric conditions was also a significant predictor. ${ }^{107}$

Five cluster analysis studies included behavioral health characteristics. ${ }^{122,123,125,129,205}$ Generally, a measure of poor mental health functioning or mental health diagnoses stood out as a characteristic among clusters. In one analysis, severe mental illness, coupled with low income, social needs, and pain management, was identified as one HNHC patient clinical profile. ${ }^{129}$

Qualitative studies support the quantitative findings of association between SMI and high healthcare use. One such study clarified that unmet behavioral health needs and poorly managed SMI, not just the presence of SMI, were significant drivers of preventable high levels of healthcare use among HNHC patients. ${ }^{134}$ Several other qualitative studies concluded that patientsystem mismatch, not patient diagnosis alone, contributed to high utilization. ${ }^{130,133} \mathrm{High}$ utilization can result from patients' "behavioral issues interfering with care engagement, and lack 
of health system flexibility to address these barriers"133, p. 497 in primary care, partially due to the limited time allowed to spend with each patient. "When you're looking at your work list and there are 30 people and you know you'll only get to 20 that day and when there's someone who keeps paging you and demanding your attention and you know there won't be any impact or reward, it's really hard to put your time there."130, p. 209

Other measures of mental health disorders were global mental health assessments obtained by clinicians or through self-report. The identification of a mental health disorder through one of these assessments was associated with high ED use in two predictive studies ${ }^{79,80}$ and six crosssectional studies. ${ }^{87-89,96,101,104}$ It was also a predictor of future high inpatient utilization. ${ }^{83,85}$

Three cross-sectional studies found a positive association between other mental health conditions and high healthcare cost. ${ }^{115-117}$ In one of these studies, HMO members with high symptom severity related to post-traumatic stress disorder (PTSD) were estimated to have healthcare costs twice those of patients without PTSD in adjusted analyses. ${ }^{115}$ Another study of HMO members revealed that being in the highest cost group significantly increased with the presence of any psychiatric diagnosis or adverse childhood experience (defined as physical, sexual, or emotional abuse; physical or emotional neglect; having a substance-abusing or mentally ill parent; having an incarcerated parent; or witnessing domestic violence). ${ }^{117}$ One qualitative study supported these findings, noting the association of childhood trauma with high use of healthcare. Based on the experience of defining HNHC patient clusters, a healthcare program noted that although identified clusters were largely heterogeneous the prevalence of childhood trauma was a "common thread" across the groupings. ${ }^{183}$

In two studies of patients with psychiatric diagnoses, high ED use was positively associated with having Medicare coverage and homelessness. ${ }^{87,} 90$ The effect of other characteristics, such as SUD, AUD, and Medicaid coverage, were inconsistent across the two studies.

\section{Substance and Alcohol Use Disorders}

SUDs were associated with high use: a predictor of both future high ED utilization ${ }^{79}$ and inpatient admission. ${ }^{85}$ Similarly, in cross-sectional studies, SUD was associated with high ED

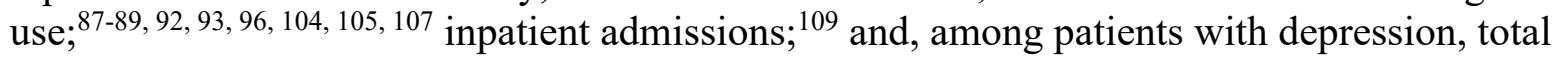
costs (odds ratio $[\mathrm{OR}]=5.4){ }^{83}$

Results from studies examining comorbid AUDs and high ED utilization were mixed. One predictive study showed a positive association between AUD and persistent high ED use. ${ }^{79}$ Five cross-sectional studies showed a positive association, ${ }^{88,90,96,99,105}$ while three did not find a relationship. ${ }^{87,91,100}$

\section{Social Risk Factors}

\section{Key Points}

- Studies conducted in hospitals and health systems, including the VA, found homelessness to be associated with high ED utilization.

- Studies conducted in hospitals and health systems and population-based survey data did not find a clear relationship between employment status and high healthcare utilization.

- The role of poverty, as defined by either an individual's low income or neighborhood poverty rate, is unclear. 


\section{Results of Studies}

Twenty-seven predictive or cross-sectional studies evaluated social risk factors (i.e., homelessness, unemployment, poverty/low income, and education) (Table 7). ${ }^{79,83,87-93,95,97,99-}$ 103, 105, 106, 109, 111, 116-119, 125, 203, 204

Predictive studies' results were mixed regarding the association between both homelessness or low income and being a HNHC patient. ${ }^{79,83,87,204}$ Five cross-sectional studies found a positive association between homelessness and high ED utilization. ${ }^{87,88,90,99,105}$ Patient self-identified need for housing support was significantly related to higher inpatient use in one study. ${ }^{11}$

Among 11 cross-sectional studies that examined the relationship between poverty and high utilization, seven studies found that low income or poverty was related to high utilization of healthcare, ${ }^{92,93,100-103,119}$ and four studies indicated no significant association. ${ }^{95,109,118}$ However, the measure of poverty in several of the studies did not capture individual patient income, but instead, the neighborhood poverty rate, while also controlling for type of insurance. ${ }^{79,92,93,95,109}$

One study attempted to tease out the independent effect of food insecurity, separate from the more commonly measured risk factors of low income and education. ${ }^{118}$ Based on data from a national sample of adults, self-reported food insecurity was significantly related to an increased odds of being in the top 10 percent of expenditures (adjusted odds ratio [AOR] $=1.73$ ), while income level and education were not. Access to care, as indicated by having health insurance coverage, was also a significant predictor in the model.

\section{$\mathrm{KQ} 1 \mathrm{c}$. How do criteria incorporate types, amount, duration, and patterns of healthcare use?}

\section{Key Points}

- We identified 12 studies that included baseline healthcare use or cost to measure high healthcare use or cost in a future period. Five of the studies included baseline healthcare use or cost as components of algorithms developed to predict the risk of future behavior. Commonly, these algorithms did not report on the independent effect of prior cost or use on outcomes, limiting our available evidence to predict or explain the role of this characteristic separate from others.

- Prior ED visits are a strong predictor of future use. A higher number of prior ED visits is associated with greater odds of ED use in a subsequent period.

- We identified more limited evidence linking a positive association between multiple years of being high cost and predicting high cost in a subsequent period.

\section{Results of Studies}

Each of the 12 predictive studies that modeled future high healthcare use or cost included cost or use measures at baseline as covariates in regression models. Although most of the studies reported the independent effect of earlier use or cost, five of the studies developed algorithms that incorporated measures of prior healthcare use but only reported on the algorithm's overall performance in effectively predicting high use and cost outcomes. ${ }^{76,78,82-85}$ Because of this, we cannot report on the unique contribution of earlier cost or use in some of the studies. (Each of the algorithms is described earlier in the chapter.)

In contrast, and more commonly, all other predictive studies separately measured and reported prior healthcare use in regression models. Across three studies predicting high ED use 
in a future period, baseline ED use was a large and consistent predictor. ${ }^{79-81}$ One study of Medicare beneficiaries found that both frequent (4+) and infrequent (1-4) prior ED visits were the largest predictors of future high ED use. ${ }^{80}$ The magnitude of effect of being a frequent user at baseline (rate ratio $[R R]=35.2$ ) dwarfed the effect of being an infrequent user $(R R=4.2)$. Similarly, one study of the CA nonaged population found the odds of high ED use in a future period (4+ visits) to be positively related to a larger number of ED visits in the base year; ranging from 5 to 7 visits $(\mathrm{AOR}=1.6)$ to $18+$ visits $(\mathrm{AOR}=6.07) .{ }^{79}$

Consistent with predictive analyses, high ED use was associated with prior use based on selfreport data from the National Health Interview Survey, the Community Tracking Study Household Survey, the American Migraine Prevalence and Prevention Study, and the National Survey of American Families. ${ }^{100-103}$ In the National Health Interview Survey, high ED use was associated with the ED being identified as the usual source of care (AOR=7.09) and in the migraine study with the ED being a frequent source of care for other ailments $(\mathrm{AOR}=42.0)$. In the three nationally representative surveys, high ED use was associated with having a larger number of outpatient visits in the past year; in one study: $A O R=5.5$ for four to nine visits, ${ }^{100}$ in a second study: $\mathrm{AOR}=3.02$ for five or more visits, ${ }^{101}$ and in a third: $\mathrm{AOR}=5.29$ for three or more visits. ${ }^{103}$

Among Medicaid frequent ED users (12 or more visits over 4 years), three clusters were identified, based on timing between visits and common diagnoses. ${ }^{120}$ The most frequent visiting pattern (peak at 4 to 166 days between visits) consisted of more individuals who were chronically physically or mentally ill.

Three studies predicted future inpatient use among patients with one or more admissions during a baseline period. All of the studies that examined inpatient use tested algorithms and did not separately report on the role of earlier use. ${ }^{83-85}$ One cluster analysis of VA patients at the highest risk for rehospitalization based on their CAN score found that the cluster of individuals at persistently high risk had a higher rate of healthcare use, particularly inpatient visits, coupled with a higher rate of comorbidities, SUD, and AUD. ${ }^{124}$

Four other studies examined characteristics associated with being high cost in a future time period. One study examined Medicare enrollees high cost in 2016 (top 10\%) in relation to their pattern of high-need status from 2013-2015. High need was defined by multimorbidity, medical complexity, frailty, functional limitations that require assistance, and receipt of acute or postacute care services ${ }^{86}$ Compared with never being high need during 2013-2015, the adjusted odds of being high cost in 2016 was positively related to being high need in the earlier period: persistently high need $(\mathrm{AOR}=11.7)$, transiently high need $(\mathrm{AOR}=5.1)$, and newly high need in 2015 (AOR=5.8). A second study of newly insured Kaiser members found that a positive predictor of high cost was prior year ED use $(\mathrm{OR}=1.8) .{ }^{75}$ The other two studies reported the predictive success of algorithms. ${ }^{76,78,82}$

Only one study predicted future use in relation to all encounters (6 or more) including inpatient, outpatient, labs, and pharmacy, for example. ${ }^{77}$ In an analysis primarily focused on the role of patient self-reported health perceptions, the researchers found that prior hospitalizations and physician visits were positively related to future encounters.

Five cluster analyses grouped patients who were identified as being in the highest percentile of total costs. ${ }^{75,122,126-128}$ Two of the studies based clusters on prior utilization: in one based on type and frequency/pattern of use ${ }^{127}$ and in another based on type of use and condition. ${ }^{75}$ 


\section{$\mathrm{KQ} 1 \mathrm{~d}$. Do criteria differ when HNHC is identified at the population, payer, healthcare system, and provider levels?}

\section{Key Points}

- Analyses across payers revealed that prior high healthcare use and behavioral health diagnoses are predictive of high ED across populations (levels) of analysis. Specifically, prior high healthcare use was predictive of high ED use among Medicaid, Medicare, VA, hospital/health systems, and population-based studies. Behavioral health diagnoses were predictive of high ED use among Medicare, VA, and hospital/health system populations.

- Among multipayer and population-based studies, having Medicare and Medicaid insurance coverage was predictive of high healthcare use.

\section{Results of Studies}

We compared the criteria used to define $\mathrm{HNHC}$ and significant population characteristics or predictors in studies by the level of analysis (i.e., population, payer, healthcare system, or provider). Table 7 provides a summary of outcomes by study population level.

The largest group of the identified studies, 22 of the 60 reviewed, were conducted by single hospitals, multiple hospitals located in specific geographic areas such as states or counties, or health systems. ${ }^{87,89-91,94,96-99,106,109,110,112,113,121,129-134}$ This was followed by 11 population-

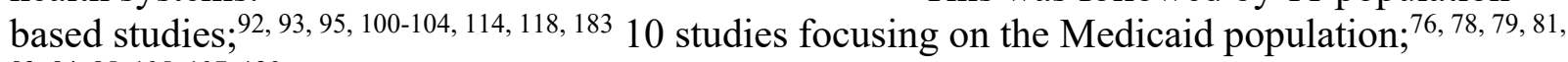
$82,84,85,105,107,120$ nine studies of health plan enrollees, including managed care and accountable care organizations (ACOs) ${ }^{75,111,113,115-117,122}$ seven studies of the Medicare population; ${ }^{80,86,108,}$ ${ }^{119,126-128}$ and six studies focusing on patients who use the VA healthcare system. ${ }^{77,83,88,123-125}$

We found that two factors, prior high healthcare utilization and behavioral health diagnoses, were predictive of high future healthcare use and cost across all payers. Specifically, prior high healthcare use was predictive of high ED and inpatient (IP) utilization among Medicaid, Medicare, VA, hospitals/health systems, and population-based studies. Studies involving Medicaid beneficiaries showed that prior high primary care use predicted high future ED visits and prior hospitalization predicted high future IP use. ${ }^{81,84}$ Two studies of state Medicaid populations, published in three articles, found prior high healthcare use of any kind predicted future high cost. ${ }^{76,78,82}$ One study focusing on the Medicare population found that frequent ED use in 1 year (4 or more visits compared with no visits) was the strongest predictor of ED use in the subsequent year $(\mathrm{RR}=35.2){ }^{80}$

Of note, one population-based predictive study found that persistent frequent ED use at 3-, 6, and 11-year intervals in a State-level population was predicted by the intensity of ED use at baseline across the time interval, controlling for other factors. ${ }^{79}$ Population-based cross-sectional studies supported the findings regarding prior utilization. One study found a positive association between heavy use of other outpatient care with frequent ED use. ${ }^{101}$ Another cross-sectional population-based study found that having had three or more outpatient visits but perceiving that one has unmet medical needs was associated with high ED use. ${ }^{103}$ A population-based study of individuals with debilitating headaches found that, after controlling for disease severity, frequent ED use was associated with lower income and prior utilization of the ED for reasons other than headache. ${ }^{102}$

A predictive population-based study supported prior utilization, defined as at least one ED visit, at least one inpatient admission, or at least 10 health professional office visits during the 
past 12 months, as a predictor of high inpatient hospital care. ${ }^{206}$ The study found that prior healthcare utilization yielded the single largest incremental gain in predictive performance of an inpatient utilization predictive model. They also found that the predictive ability of the model was improved by adding health conditions and health-related quality of life to prior use. ${ }^{206}$

Behavioral health diagnoses were predictive of high healthcare utilization and cost among Medicare, VA, and hospital/health system populations. One study of Medicare beneficiaries in Memphis, TN, found a strong association between a mental health condition and ED visits and inpatient stays for ambulatory care sensitive conditions. ${ }^{108}$ Another study of Medicare beneficiaries that analyzed a 20 percent national sample, using 2012-2014 data, found an association between a diagnosis of depression and having high healthcare expenditures. ${ }^{119}$ The impact of behavioral health diagnoses on high utilization and cost predominated in studies of the VA population. Two of the VA studies focused on behavioral health and social risk factors as drivers of HNHC patient outcomes. One cross-sectional study of ED utilization found that the factors most strongly associated with multiple distinct levels of ED use, including 1, 2 to 4, 5 to 10,11 to 25 , and greater than 25 ED visits per year, were a diagnosis of schizophrenia, homelessness, and opioid prescriptions. ${ }^{88}$ Persistent risk of inpatient utilization was predicted by number of mental health visits. The study found a negative relationship between persistent inpatient utilization and homelessness but included a caveat that the finding could have been mediated by specialized services for the homeless provided in the area. ${ }^{83}$ Additionally, three of the publications conducted in the VA medical system were cluster analyses, designed to better identify unique subpopulations that would lend themselves to more efficient and effective care management strategies to reduce high utilization and high costs. ${ }^{123-125}$ Each of these studies identified behavioral health conditions as a defining component of clusters of HNHC patients. Two cross-sectional health system studies found an association between behavioral health conditions, defined as illicit drug use or a mental health condition ${ }^{91}$ or a poor global mental health scale score. ${ }^{113}$

Among multipayer and population-based studies, having Medicare and Medicaid insurance coverage was found to be predictive of high healthcare utilization. Five multipayer crosssectional studies evaluated multiple aspects associated with high ED utilization and found an association between Medicaid and/or Medicare coverage and high ED utilization. ${ }^{89,90,93,95,99}$ An additional cross-sectional study focused on frequent ED use among a cohort of ED users with a primary psychiatric complaint. Significant predictors of ED use included Medicare coverage, along with a positive screen for cocaine use, homelessness, personality disorder, and hepatobiliary disease. ${ }^{87}$

Several population-based studies evaluated the association of public insurance with high ED utilization. One predictive study found that persistent frequent ED utilization was positively associated with having public health insurance (Medicaid or Medicare) compared with commercial insurance. ${ }^{79}$ Cross-sectional studies also supported the findings regarding insurance status. Two studies found a positive association between having public insurance, as opposed to private insurance, and frequent ED use. ${ }^{101,103}$

Despite the prevalence of chronic disease and disability among the elderly population, we found few studies focused solely on Medicare beneficiaries. ${ }^{80,86,108,119,126-128}$ Predictors of frequent ED among the Medicare population included younger age, chronic medical or mental health conditions, HCC score, dual enrollment in Medicaid, and five or more physician visits. 


\section{$\mathrm{KQ} 1 \mathrm{e}$. How can potentially preventable or modifiable high use of healthcare be differentiated from necessary and appropriate high use?}

\section{Key Points}

- One study, reported in two publications, sought to directly differentiate between potentially preventable use of healthcare and high use. The study reported an alternative mechanism for identifying individuals at risk for potentially preventable healthcare use that relied on examination of higher than expected expenditures (high residuals based on regression analysis). The study found patient high residuals to be generally consistent across at least two time periods.

- Two studies examined patients who used the ED for nonemergent care. However, neither study was able to identify differences between frequent and less frequent users.

- All other studies examined high use or cost. No quantitative studies sought to distinguish individual visits or costs that might have been preventable or modifiable from total visits or costs.

\section{Results}

Generally, studies set thresholds for identifying HNHC patients based on being high users (e.g., 4 or more outpatient visits in 12 months or top decile of all-cause total costs). ${ }^{116}$ Uniquely, a Yang et al. study, reported in two publications, sought to differentiate potentially preventable use of healthcare from other high use. The analysis was conducted using 4 years of Medicaid data from Texas. ${ }^{76,82}$ The study compared two modeling approaches: linear regression and gradient boosting machine tree-based models. High utilizers were defined as those with higher than expected costs (identified through high residuals), after adjusting for diagnoses, demographics (age, sex, race, and disability status), county of residence, and whether enrolled in a fee-for-service or managed care organization (MCO) plan. Residuals were used to define an empirical threshold for identifying higher than expected utilizers to "formally discriminate the point at which the right long tail of residuals consistently deviates from the normal distribution." ${ }^{22, \text { p. } 5}$ The study then examined correlations in excessive utilization over time to determine if the model could predict persistent patterns. It found consistent temporal patterns of high use between 2 consecutive years, HNHC patients in the top 5 percent in 1 year ranked at approximately 75 percent in residuals' percentile in the following year, compared with other patients, who on average had a rank of 50 percent. The temporal association decreased with time.

Yang et al. compared the results from their modeling with results using the $3 \mathrm{M}^{\mathrm{TM}}$ Potentially Preventable Events software. The $3 \mathrm{M}$ software is considered an approach to identifying future potentially preventable inpatient readmission and ED visits. However, the $3 \mathrm{M}$ software is proprietary, so the authors of this study were seeking an alternative using readily available data and analytic approach. They found that there were moderate positive correlations between $3 \mathrm{M}$ potentially preventable readmission events and the residuals approach to identifying high utilizers, ranging from 0.26 to 0.30 . Similarly, the correlation between $3 \mathrm{M}$ potentially preventable ED visits and the residual approach ranged from 0.25 to 0.34 . A limitation of this study, cited by Yang et al., is that some patient-level characteristics that could add to the precision of the modeling were unavailable, such as disease severity and social risk factors, because the study relied on claims data. 
Three cross-sectional studies concerned patient population whose ED use may be preventable or modifiable, at least in part. The studies focused on patients receiving care at an ED who were assigned an Emergency Severity Index score of 4 or 5 at one visit, a classification of least urgent/nonemergent. ${ }^{94,98}$ Across the studies, the authors did not evaluate the severity score of these patients' earlier ED visits. Therefore, we cannot conclude that the characteristics they found associated with high use across all ED visits can be extrapolated to apply to patients who only have ED use that would be considered preventable or modifiable. Still, two studies found that least urgent/nonemergent ED care was associated with a greater number of visits. ${ }^{98}$ The third study ${ }^{94}$ surveyed patients to understand their reasons for using the ED. They found that high- and low-use groups did not significantly differ in their reasons (i.e., need, convenience, access, costs, and quality), controlling for potential confounding. One qualitative study found that although high-ED-use patients primarily reported using the ED for emergent concerns, they would prefer after-hours alternatives and more help managing their care. ${ }^{132}$

Several cross-sectional studies examined preventable ED visits. One cross-sectional analysis in a dissertation measured variables associated with a continuous measure of preventable ED visits. An ED visit was defined as primary care treatable if the evaluation and management code on the claim was not listed under the ED Indicator Procedure List. ${ }^{106}$ Significant characteristics associated with a larger number of preventable ED visits included being homeless, poorer social support, and having both SUD and mental illness diagnoses. Having a regular source of care and the level of continuity of care were not associated with the outcome. As discussed in greater detail in the age-related results, a cross-sectional study of HNHC Medicare patients examined predictors of ACSC ED and inpatient visits and found that medication nonadherence was a predictor for greater use for both types of care. ${ }^{108}$

One cross-sectional study sought to distinguish characteristics associated with persistent high cost (every year during a 3-year period) from transient high cost ( 1 or 2 years during the same period) in the Medicare population. ${ }^{119}$ Significant predictors were specific chronic conditions, depression, higher income, being younger than 65 years of age, being black or Hispanic, and being eligible for Medicare because of end-stage renal disease (ESRD). The increased odds from ESRD dwarfed all other characteristics $(\mathrm{OR}=26.5)$.

\section{KQ 2. What are the mechanisms that lead to reductions in potentially preventable or modifiable healthcare use and result in improved health outcomes and cost savings in interventions serving $\mathrm{HNHC}$ patients?}

\section{Key Points}

- Using 48 studies (51 articles), we developed three program theories to explain the context-mechanism-outcome (CMO) relationships concerning $\mathrm{HNHC}$ patient recruitment and patient and provider engagement in $\mathrm{HNHC}$ patient interventions.

- Program Theory 1. Identifying and targeting HNHC patients for interventions intended to reduce potentially preventable or modifiable healthcare use and costs require capturing their complexity, based on consideration of a combination of factors. A patient's prior use of healthcare services, chronic diseases, nonmedical barriers to accessing care, experience with the healthcare system, clinician judgment, and willingness to participate in an intervention may all contribute. 
- Program Theory 2. Trusting relationships are the basis for engaging patients in care management, particularly patients with complex medical, social, and behavioral needs, such as HNHC patients. Establishing trust is crucial to an intervention's ability to empower patients to manage their chronic conditions and overall health and to engage with intervention staff and other care providers.

- Program Theory 3. Obtaining healthcare provider buy-in and building structures and processes to give them support for their efforts are crucial components for engaging care providers in interventions for HNHC patients. Engagement of care providers helps improve intervention performance and outcomes because providers affect the successful implementation of the intervention through their actions and inactions.

In total, 48 studies (51 articles) were included in the realist review. Of the 51 articles, 14 were also used as evidence in KQ 1, and 27 articles were used as evidence in KQ 3. These studies were used to develop CMO configurations related to the implementation of interventions for $\mathrm{HNHC}$ patients. These CMOs were then used to iteratively refine three realist program theories (our model of how and under what conditions an intervention is expected to work).

Program Theory 1 concerns the pathway for identifying and targeting individuals for HNHC patient interventions. Once patients are enrolled in interventions, building and maintaining trusting and caring relationships between patients and care providers can help interventions succeed. We set out key considerations for engaging HNHC patients (Program Theory 2) and for engaging care providers (Program Theory 3 ) so that each has the necessary emotional support and practical resources to develop and maintain an effective ongoing relationship. Figure 4 presents a framework showing the relationship between the three program theories.

Figure 4. Framework of optimizing interventions for HNHC patients

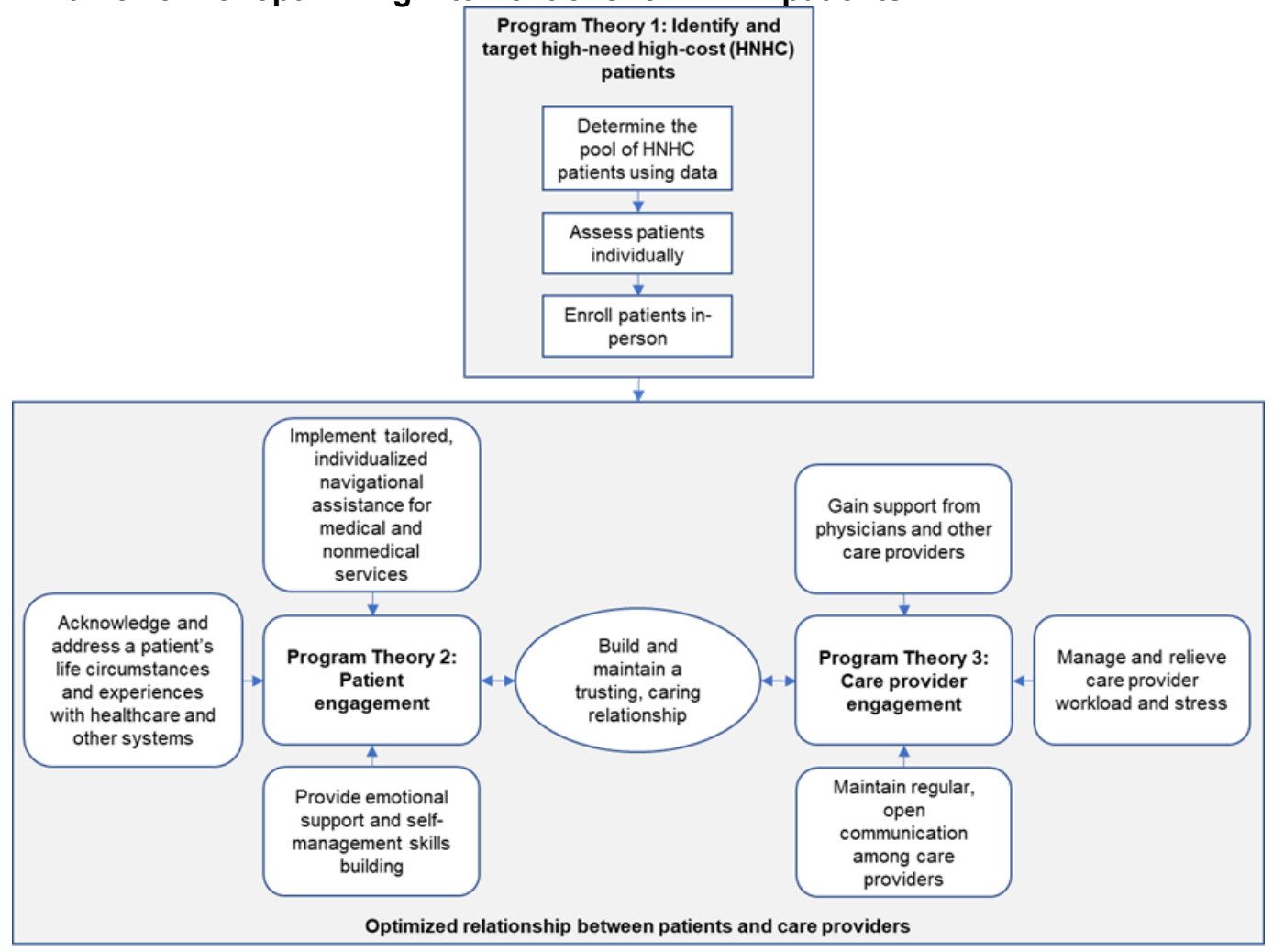




\section{Program Theories}

\section{Program Theory 1: Identifying and Targeting HNHC Patients for Inclusion in Interventions}

A necessary initial step in the pathway to effecting change in HNHC patients' use of potentially preventable or modifiable healthcare - and related costs - is for interventions to identify which patients are likely to be HNHC in a future period. Determining the optimal combination of characteristics has been described as "a delicate balance." ${ }^{20}$ Basing identification of high-need patients exclusively on cost algorithms will miss many people; alternatively, if the focus is exclusively on chronic conditions, a large number of people may be identified whose chronic conditions are under control. ${ }^{20}$ In addition, social risk factors can increase nonmedical barriers to accessing care. ${ }^{20}$ Appendix Table B-11 presents the detailed CMO configurations that underpin this program theory.

\section{Determining HNHC Patients Using Data}

As a first step to specifying the patient population from which to select intervention participants, claims and other sources of electronic health data can be used to identify individuals with current high healthcare use and costs and disease complexity. Current healthcare use and

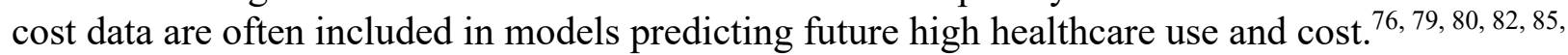
124, 135-137, 158 However, while these data are generally considered necessary, they are not sufficient for identifying the population. The data on prior cost or use have been described as being limited to providing "broad brush information" because no algorithm or predictive model specification has been found that is able to reliably predict future high use across patients with chronic disease $^{66,136,183}$ (see also KQ 1 findings). One barrier to developing accurate projections is "regression to the mean" (a patient with high cost and use in a baseline period using closer to the average level of service and costs in the followup period). ${ }^{64,65,85,137}$

The accuracy of data-based healthcare use and cost projections can be facilitated by refining current period specifications in some specific ways: (1) limiting data to healthcare use that would be the focus of an HNHC patient intervention, that is, care that is potentially preventable or modifiable (i.e., excluding services such as chemotherapy for cancer treatment, orthopedic surgery, and HIV treatment); ${ }^{138}$ (2) including data across care settings and payers to capture the continuum of care, ${ }^{134,136,138,159}$ (3) focusing on use of services in "real time," $67,138,158,160,183$ particularly, if possible, while a patient is still hospitalized, to identify the urgent need for an intervention; ${ }^{65,85}$ and, when considering ED visits, (4) focusing on visits that occur in clusters (more than one visit during a relatively short period of time), even if the presenting complaints are not categorically different from those of lower utilizers (those who would not be considered HNHC patients), because a cluster pattern has been found to be associated with HNHC patient ED service use. ${ }^{131,161}$

In addition to providing information on individuals' levels of healthcare costs and use, claims data and other electronic health data can be used to identify individuals with complex chronic disease. Indicators include whether the patient has multiple chronic conditions, ${ }^{64}$ functional limitations ${ }^{20}$ and high scores on measures of clinical risk severity, such as the Chronic Condition Indicator, ${ }^{64,66-68,139,140,158}$ concurrent $\mathrm{HCC},{ }^{67}$ and the Predictive Risk Intelligence SysteM (PRISM). ${ }^{162}$

The accuracy of identifying HNHC patients can be improved by also identifying behavioral health diagnoses. Behavioral health diagnoses include mental health diagnoses (ranging from 
depression and anxiety to serious mental illness) and substance use disorder diagnoses. Behavioral health diagnoses comorbid with chronic medical conditions are associated with higher ED use and poorer disease management. ${ }^{68,85,134,141,183}$ However, determining the correct pattern of healthcare claims to use to identify the HNHC patient population can be obfuscated by the co-occurrence of multiple complex medical conditions and social risk factors. ${ }^{131}$ For example, among HNHC patients with mental illness or substance abuse in addition to medical conditions, fewer visits may be associated with the mental illness or substance abuse condition than expected. ${ }^{131}$ Partnering and sharing data with public health agencies and community-based organizations may also help identify hard-to-reach patients with multiple challenges. ${ }^{163}$

\section{Assessing Patients Individually}

HNHC patients' self-assessments of characteristics about themselves, which are not generally available through electronic clinical data, can be obtained during an enrollment decision process. This information can be used to further refine predictions of future modifiable high-cost care and use. An example of one tool is the Medicare Health Risk Assessment, which captures a patient's self-assessment of health status, psychosocial risks, depression, behavioral risks, pain, activities of daily living, and instrumental activities of daily living. ${ }^{142,143}$ Other simple assessments that can be administered directly to patients to assess their risk include determining whether they are only somewhat or not very confident that they can manage and control most of their health problems; have had moderate or severe pain during the past 4 weeks; have been bothered extremely or quite a bit during the past 4 weeks by emotional problems, such as anxiety, irritability, depression, or sadness; believe that the medications they are receiving may be causing illness or side effects; and have been prescribed more than five medications. ${ }^{140}$ The Patient Activation Measure can identify "less activated" patients who are less able to effectively manage their conditions and therefore have a greater likelihood of needing care management services. ${ }^{154}$ Low health literacy scores are associated with poorer patient activation. $^{134}$

HNHC patients may also face healthcare system-related barriers that negatively affect their ability to self-manage their health and that may not be identifiable through claims data or selfassessment tools. HNHC patients' reliance on the ED system is related to negative prior experiences with the traditional service delivery system not being designed for patients with complex healthcare needs. ${ }^{133,134}$ Resulting specific barriers to changing their behavior include distrust for providers and the larger healthcare system; ${ }^{130,139,144}$ the time and expense of getting to a primary care provider's office, particularly if multiple visits and public transportation are required; ${ }^{134}$ providers not accepting their insurance; ${ }^{134}$ the cost of care being expensive; ${ }^{134}$ long wait times to see a primary care provider; care after hours not being available; ${ }^{134}$ and the belief that better quality of care is available in the ED than with the primary care provider/clinic. ${ }^{132}$ Among HNHC patients who are homeless or who have unstable housing, greater ED use is also associated with the ED providing shelter and respite. ${ }^{134}$

\section{Enrolling Patients in Person}

The intake assessment can be used to facilitate the decision to enroll and the strategy to engage an HNHC patient by determining the patient's willingness to participate in the program, be monitored and contacted, and comply with therapy and the intervention. ${ }^{138,139,144-147}$ The HNHC patient's current provider's judgment can add to the identification and selection of patients who are appropriate for the intervention. ${ }^{145,147}$ Notably, socioeconomically 
disadvantaged or marginalized HNHC patients may appear less willing to engage in the program because of distrust of the healthcare system and symptoms of their conditions (and/or substance use). ${ }^{147}$ To prevent further marginalization or exclusion, more subtle indicators or extended periods of outreach and trust-building may be necessary to accurately gauge a patient's willingness to participate. ${ }^{147,148}$ Indicators among marginalized populations of their willingness to participate can be as subtle as returning or answering phone calls from the care team or showing up for an initial appointment. ${ }^{147}$ Community health workers can help the care team understand the challenges and needs of these patients. ${ }^{144}$ Excluding the patients who are more difficult to engage may reinforce and exacerbate disparities. ${ }^{147}$

Successful enrollment of HNHC patients who might otherwise be excluded in an intervention is facilitated by two logistical considerations: (1) conducting the enrollment in person is more successful than by telephone ${ }^{65}$ and (2) when an intervention seeks to include participants who have been recently hospitalized, conducting the enrollment process before inpatient discharge can increase participation because many patients live in difficult social circumstances and locating them after discharge to initiate an intervention can be challenging. ${ }^{44,85,141}$

\section{Program Theory 2: Engaging HNHC Patients in Interventions To Improve Their Management of Their Chronic Conditions}

HNHC patients commonly have a long history of personal and health system barriers that have kept them from receiving appropriate care. Patients can be engaged in care management interventions that can help them change their health behaviors if care providers can gain patients' trust and if intervention programs are individualized to meet each patient's unique combination of medical and psychiatric diagnoses and social risk factors. Appendix Table B-12 presents the detailed CMO configurations and supporting data that underpin this program theory.

\section{Addressing Patients' Life Circumstances and Prior Experiences}

After successfully enrolling HNHC patients into an intervention intended to change their use of healthcare services, intervention care providers need to focus on building relationships with patients that will facilitate behavior change. HNHC patients often come to interventions that are primarily intended to help them manage their chronic diseases with a complex history of personal, social, and medical issues. Personal and current life circumstances can inhibit HNHC patients' ability to benefit from the interventions. A diverse set of life challenges may include mental illnesses, substance abuse, emotional or physical traumas that may stem from early life, extreme poverty, and low literacy. ${ }^{44,68,85,134,139,144,155}$

Many personal challenges may also be compounded by system-level barriers that cause further distrust and marginalization among HNHC patients. System-level barriers pervade all levels of healthcare with issues ranging from the lack of systemic support or safety net (e.g., lack of Medicaid insurance or housing) to cultural and communication barriers that arise from the lack of cultural competency and inadequate translation services. ${ }^{134,139,144,150,160,162}$ These barriers often prevent HNHC patients from identifying, asking for, and receiving needed social and medical services.

In addition to inhibiting their ability to enroll in interventions, HNHC patients' history of negative experiences and attitudes toward the healthcare system and providers also contribute to their not accepting and seeking all of the help and care they need. ${ }^{134,139,150,155}$ Patients may have experienced disrespect by providers as a result of sex-, race-, or socioeconomic-based discrimination or feel uncared about, disengaged from maintaining self-care, or a lack of self- 
worth or deservingness of services. ${ }^{144,155}$ These past experiences may lead to further difficult interactions with the healthcare system, distrust and avoidance of specific providers or settings, and a lower likelihood of engaging with their treatment. Patients may see themselves as outsiders, as someone who would "never want to conform to the rules."139, 144, 150,155

\section{Building Relationships With Care Providers}

Critical to engaging HNHC patients in an intervention, improving disease self-management skills, and addressing a negative history with the healthcare system, patients need to trust the individuals providing the intervention services. ${ }^{139}$ Care team members with roles such as care or case managers, community navigators, and social workers are often tasked with being the primary person to build a trusting relationship with participating HNHC patients. ${ }^{67-69,148,150}$ Initially, providing basic help can support initial steps in establishing a trusting relationship. This type of help can range from basic life needs such as arranging transportation to helping with other medical and nonmedical needs, such as modifying cooking practices to improve diet and organizing medications. ${ }^{139-141,144,148,155-157,164}$

Patients value care managers who make them feel listened to and who are easy to talk to, who can explain things in lay terms, and who can be a conduit to other members of the care team. ${ }^{69} \mathrm{HNHC}$ patients report feeling more supported, confident, and motivated in their efforts to change when they have more frequent and longer visits with a care manager and, relatedly, have a greater opportunity to discuss both their clinical and psychosocial needs and receive feedback more often, especially after taking small steps on their own. ${ }^{133,139,150,155,156}$

Patients are reassured knowing they have a care team to support them in managing their health and welfare. ${ }^{68,133,139,149,155}$ Actively involving patients in decision making can help build their self-confidence, and a caring and emotionally supportive care team and support group can provide HNHC patients with the motivation to improve their health behaviors. ${ }^{134,150,155}$ One key marker of program success occurs when a patient who is frightened or in a crisis calls a trusted member of their care team, receives and can access the reassurance they need to avoid an unnecessary hospital or ED visit, and is able to wait to receive care at an outpatient appointment. ${ }^{67}, 139,150,155$

\section{Providing Individualized Care for Medical and Nonmedical Services}

Given the HNHC patient population's heterogeneity and challenging life circumstances, patients can better respond to interventions that are individualized and tailored, offer access to nonmedical services, are flexible in how or when services are provided, and consider that psychosocial needs may initially take precedence over medical services and treatment. Allowing interventions to specifically address each patient's needs and circumstances empowers providers to work with patients and their families to develop targeted interventions that reflect the patient's diverse needs. ${ }^{133,138,139,141,144,159,161,169}$ Interventions may need to resolve nonmedical needs and facilitate access to services addressing these needs because these issues may drive patients' perceived ability to cope with and benefit from healthcare interventions. ${ }^{68,85,133,139,141,159}$ High co-occurrence of mental illnesses, substance abuse, and housing instability among HNHC patients suggests that interventions targeting HNHC patients need to address these issues concurrently or before managing health. ${ }^{85,133}$

Interventions may teach patients how to connect to medical and nonmedical services to

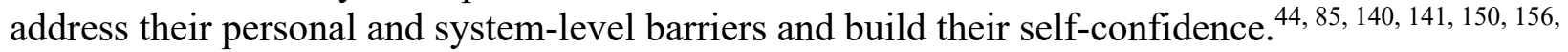
157, 160 Patients also enhance their self-efficacy by learning how to navigate these services for 
themselves. Because the burden of coexisting chronic diseases is heterogeneous and periods of time of decompensation differ, the necessary length of time in interventions differs, and interventions end when a patient "graduates" or demonstrates the interventions objective (e.g., self-management behavior. ${ }^{139,}, 144$

\section{Recognizing Barriers to Patient Change}

Even after establishing successful relationships between members of the care team and HNHC patients, an intervention may not lead to reductions in potentially preventable or modifiable hospital admissions or ED visits, at least in the short term. ${ }^{149}$ Some patients may continue to prefer to visit the ED, despite being provided with alternatives, because they believe that the ED is the best place to receive care or because the ED does not require a copay. ${ }^{72,}{ }^{150}$ For HNHC patient interventions, patient-centered success may need to be evaluated in relation to incremental goals, such as changes in self-care behaviors, interactions with the clinic, and relationships with providers, rather than achieving healthcare utilization or cost goals. ${ }^{44,133,149}$ However, gradual improvements in patients' experiences with their care providers may lead to long-term benefits in health behaviors and clinical outcomes. ${ }^{149}$

\section{Program Theory 3: Supporting Care Providers Participating in Interventions To Improve HNHC Patients' Management of Their Chronic Conditions}

Interventions for complex HNHC patients are themselves complex, changing the process of delivering care, often with multiple components that require coordination among a multidisciplinary set of care providers, to offer an individualized array of services to each HNHC patient. Intervention care providers often include physicians and nurses, with additional services provided through such roles as care or case managers, social workers, community health workers, care coordinators, administrative support, nutritionists, and mental health and addiction specialists. ${ }^{44,64,65,68,140,141,149-152}$ Obtaining care providers' buy-in and building structures and processes to support their efforts help improve intervention performance and outcomes, because care providers affect the success of the intervention through both their actions and inactions. Appendix Table B-13 presents the detailed CMO configurations and supporting data that underpin this program theory.

\section{Gaining Support From Physicians and Other Care Providers}

Initially, support from organizational leaders and physician champions of the HNHC patient intervention can help smooth the path for implementing new processes into a care setting. ${ }^{65,68}$ Buy-in for the intervention is crucial across all care providers, and leadership support should be used to help attain staff support. ${ }^{68}$ For example, organizational leadership involvement in coordinating the introduction of new care processes and new care team members, across the healthcare system, encourages existing care providers to accept new resources and approaches. ${ }^{68}$

When implementing interventions, health systems' use of targeted outreach to physicians supports securing their engagement, a necessary component for program success. ${ }^{65,68,137}$ Garnering initial physician support and participation in an intervention is facilitated by outreach to physicians directly by a medical director ${ }^{68}$ or nurse ${ }^{137}$ or indirectly through practice staff and practice administrators by a nurse. ${ }^{137}$ Outreach is more likely to be effective when it is practice specific, tailored, and face-to-face. ${ }^{68,137}$ Physicians' support for an HNHC patient intervention is increased if they believe the intervention will benefit their patients' care. ${ }^{66,68,137}$ Giving 
physicians themselves a role in targeting the patients they identify as those most likely to benefit from the intervention can add to gaining physician support. ${ }^{66}$ Recruiting physician champions can also facilitate support among fellow physicians, ${ }^{65}$ as well as others among the practice staff. ${ }^{68}$ Gaining buy-in from other practice staff, such as practice nurses, is similarly facilitated through face-to-face conversations about how the intervention goals and processes will supplement existing services. ${ }^{68}$

After initial physician support is obtained, it needs to be maintained and supported. A sufficient number of patients within a practice need to be participating in the intervention to justify the up-front work and cost to the practice. ${ }^{65,66}$ Designing an intervention that acknowledges the additional time needed to care for HNHC patients can be used to encourage physicians' continued support. ${ }^{65,68,134,145,164}$ These designs may range from healthcare systemwide modifications such as providing higher reimbursements for sicker patients or using a capitation payment model that pays providers a set monthly amount per patient to other financial incentives such as physician enrollment incentives or counting of HNHC patients as more than one non-HNHC patient on physician panels.

\section{Managing and Relieving Care Provider Workload and Stress}

Acknowledging and managing care provider workload and stress are vital for sustaining interventions for HNHC patients. Interventions that provide medical and support services to HNHC patients can lead to provider stress and feelings of being overwhelmed. Ultimately, these feelings can result in turnover among physicians, care managers, and other care providers. ${ }^{69,} 153$ The increase in stress can be explained by the increase in workload and responsibilities that many providers experience when participating in HNHC patient interventions ${ }^{153}$ and by the emotional toll of working among sicker and frailer patients. ${ }^{68}$

To address the added workload and responsibilities, successful interventions change their organization of care and make additional resources available to practices and care providers to ensure they have the confidence and skills they need. This support may include training, supporting dedicated time to implement new processes, creating new positions, and hiring new support staff for care providers. ${ }^{68,69,134,144,153} \mathrm{HNHC}$ patient interventions often organize providers into care teams to both deliver more coordinated HNHC patient care and provide mutual support for each other. ${ }^{68,69,72,133,139,153}$ As members of a care team, physicians can focus their efforts on providing high-quality patient clinical care, while additional care providers, like care or case managers and social workers, do many of the supportive tasks (e.g., building trust, managing medication, referring community resources). ${ }^{68,69,144,158,160,161,164}$ Other staff, such as community health workers, may add additional, nonclinical peer perspectives and insights into the needs and challenges faced by HNHC patients that the more traditional, health systemfocused care team members may not have considered previously. ${ }^{144,}{ }^{158}$ As the care team gains experience with the workload and responsibilities of care managers and social workers, tasks that do not require their expertise (e.g., appointment reminders) may be delegated to other staff members, like administrative assistants. ${ }^{144}$ Care provider caseloads can also be reassessed after initial implementation. The care team will be better able to judge the necessary and sustainable levels of support and services provided to patients of different levels of need and modify the protocol to support fewer services for patients with less need. ${ }^{69}$

Finally, team members may gain emotional and technical support through peer counseling across offices and healthcare systems. ${ }^{68,69,153}$ Providing regular opportunities for care team members to talk to other providers facing similar challenges helps them cope with their 
frustrations in caring for HNHC patients and receive mutual support and assistance. ${ }^{153}$ For example, a care manager network across health systems gives care managers opportunities to share best practices and provide emotional support for each other. ${ }^{68,69}$

\section{Maintaining Communication Across Care Providers}

Regular, open communication among care team members supports the complexity of treating HNHC patients by fostering the development of cohesive coordinated care teams with shared values and commitments. ${ }^{72,133}$ Tools to ensure regular communication among all care team members include regular newsletters, email feedback, intervention websites, and care team meetings. ${ }^{65,68,153}$

Regular, multidisciplinary team meetings are an important forum for care teams to provide or exchange information on performance and care delivery and may be conducted at multiple organizational levels. ${ }^{72}$ Organization-wide meetings may be used to discuss broader performance and intervention goals and implications. Practice-level meetings may be used to discuss practicespecific issues, including individual physician performance, protocol development, and trainings. ${ }^{68,72,160}$ At the care team level, meetings or huddles that include all care team members provide the opportunity to openly discuss specific patient cases and develop care plans. ${ }^{68,72,144 \text {, }}$ 153, 160, 164 These open discussions foster a supportive environment for discussing positive and negative elements of patient care approaches ${ }^{68}$ and performance on quality metrics, outcomes, and other performance goals. ${ }^{72}$ Physicians also receive practical, constructive feedback on approaches to care during care team meetings. ${ }^{72,153}$ To maximize the benefits of care team meetings, physicians and other care providers need sufficient time to attend the meetings and to act on patient care plans. ${ }^{153}$

Placing care team members in the same physical location also facilitates communication by making it easier for team members to discuss patient concerns and coordinate patient care. ${ }^{72}$ Being co-located in the same practice, having spaces designed to encourage face-to-face conversations, or, even better, sitting next to each other allow all team members to be heard, thus fostering strong working relationships, good team communication, and ultimately improvements in the coordination of patient care. ${ }^{66,72,133,164}$ When introducing new positions such as care managers or care coordinators, having these individuals embedded in practices and be physically part of the care team is particularly valuable because it encourages physicians and other existing practice staff to use their services. ${ }^{66,68,69}$ Strong team communication and coordination related to patients' needs can ultimately help teams achieve long-term intervention goals (e.g., avoiding unnecessary readmissions, inpatient admissions, and ED visits). ${ }^{72}$ Conversely, care teams find it challenging to effectively and efficiently communicate with all of an HNHC patient's providers when they receive part of their care from providers with whom communication processes have not been established, such as when providers are located in other healthcare systems. ${ }^{66,137}$

\section{KQ 3. Overall, what is the effectiveness and what are the harms of interventions for HNHC patients in reducing potentially preventable or modifiable healthcare use and costs and in improving health outcomes?}

For KQ 3, we organized our findings by seven intervention model types, based on the principal setting: system-level transformation, telephonic/mail, community, ED, ambulatory intensive caring unit (aICU), primary care, and home based. For each model type, we present an overview of our findings followed by detailed results. The detailed results describe the included 
studies and then present outcomes by the following categories: utilization outcomes, cost outcomes, clinical and functional outcomes, and social risk outcomes.

Within each outcomes section, we present strength-of-evidence findings for outcomes graded as moderate or low. (We found no high strength-of-evidence bodies of evidence.) Summary tables in Appendix B present greater detail on study characteristics, including risk-of-bias assessments, intervention components, and outcomes.

\section{Literature Searches, Study Characteristics, and Overview of Findings}

Among the 40 studies included in KQ 3 (see the beginning of the chapter for a breakdown of the studies by design and risk of bias), 47 samples were included in the analysis. As described in the Methods section, six studies included multiple cohorts, populations, or analyses. We considered each comparison between an intervention and comparison group to be a "sample." Each sample is included as evidence from a separate study.

Our inclusion criteria require patients to have had high healthcare cost or use. In almost half of the study samples, researchers also required patients to have at least one chronic condition (Table 15). More than half of the samples had more than 1,000 patients. The number of intervention sites varied across studies, ranging from one site (38\% of samples) to six or more sites ( $34 \%$ of samples).

Table 15. Key characteristics for $K Q 3$ included samples ( $N=47)$

\begin{tabular}{|c|c|c|c|}
\hline Study Characteristics & Categories & Number of Samples & Percentage of Samples \\
\hline \multirow[t]{4}{*}{$\begin{array}{l}\text { Risk-of-bias assessment } \\
\text { by study design }\end{array}$} & $\begin{array}{l}\text { RCT: Low risk-of-bias } \\
\text { studies }\end{array}$ & 6 & $13 \%$ \\
\hline & $\begin{array}{l}\text { RCT: Some concerns for } \\
\text { risk-of-bias studies }\end{array}$ & 18 & $38 \%$ \\
\hline & $\begin{array}{l}\text { Observational: Some } \\
\text { concerns for risk-of-bias } \\
\text { studies }\end{array}$ & 15 & $32 \%$ \\
\hline & $\begin{array}{l}\text { Observational: High risk-of- } \\
\text { bias studies }\end{array}$ & & $17 \%$ \\
\hline \multirow[t]{4}{*}{ Participant eligibility } & High use only & 22 & $47 \%$ \\
\hline & High cost only & 2 & $4 \%$ \\
\hline & $\begin{array}{l}\text { High use and any chronic } \\
\text { condition }\end{array}$ & 12 & $26 \%$ \\
\hline & $\begin{array}{l}\text { High cost and any chronic } \\
\text { condition }\end{array}$ & 11 & $23 \%$ \\
\hline \multirow[t]{4}{*}{ Participant age range } & $<65$ only & 3 & $6 \%$ \\
\hline & $65+$ only & 16 & $34 \%$ \\
\hline & All adults & 25 & $53 \%$ \\
\hline & Not reported & 3 & $6 \%$ \\
\hline \multirow[t]{3}{*}{ Participant race } & Majority white $(>50 \%)$ & 6 & $13 \%$ \\
\hline & Majority nonwhite (>50\%) & 17 & $36 \%$ \\
\hline & Not reported & 24 & $51 \%$ \\
\hline
\end{tabular}




\begin{tabular}{|c|c|c|c|}
\hline Study Characteristics & Categories & $\begin{array}{l}\text { Number of } \\
\text { Samples }\end{array}$ & $\begin{array}{l}\text { Percentage } \\
\text { of Samples }\end{array}$ \\
\hline \multirow[t]{5}{*}{ Participant high-risk conditions } & $\begin{array}{l}\text { Majority with mental health diagnosis } \\
(>50 \%)^{a}\end{array}$ & 4 & $9 \%$ \\
\hline & Majority with substance abuse $(>50 \%)^{\mathrm{b}}$ & 3 & $6 \%$ \\
\hline & Majority with COPD diagnosis ( $>50 \%)$ & 1 & $2 \%$ \\
\hline & $\begin{array}{l}\text { Majority with heart disease diagnosis } \\
(>50 \%)^{c}\end{array}$ & 3 & $6 \%$ \\
\hline & Majority with social risk $(>50 \%)^{\mathrm{d}}$ & 1 & $2 \%$ \\
\hline \multirow[t]{5}{*}{ Participant insurance status } & Medicare only or dual Medicare/Medicaid & 25 & $53 \%$ \\
\hline & Medicaid only & 5 & $11 \%$ \\
\hline & Mixed across participants & 4 & $9 \%$ \\
\hline & Uninsured or Medicaid & 4 & $9 \%$ \\
\hline & Unknown & 9 & $19 \%$ \\
\hline \multirow[t]{4}{*}{ Sample size } & $<100$ & 6 & $13 \%$ \\
\hline & 100 to $<1,000$ & 13 & $28 \%$ \\
\hline & 1,000 to $<9,999$ & 16 & $34 \%$ \\
\hline & $\geq 10,000$ & 12 & $26 \%$ \\
\hline \multirow[t]{2}{*}{ Comparison group } & Usual care & 46 & $98 \%$ \\
\hline & $\begin{array}{l}\text { Received education materials and an } \\
\text { incentive }\end{array}$ & 1 & $2 \%$ \\
\hline \multirow[t]{4}{*}{ Number of study sites } & 1 & 18 & $38 \%$ \\
\hline & 2 to 5 & 12 & $26 \%$ \\
\hline & $6+$ & 16 & $34 \%$ \\
\hline & Not reported & 1 & $2 \%$ \\
\hline
\end{tabular}

${ }^{a}$ Mental health diagnoses include schizophrenia and other psychotic disorders, bipolar disorder, and major depression.

${ }^{\mathrm{b}}$ Substance abuse includes alcohol and drug abuse.

${ }^{\mathrm{c}}$ Heart disease diagnoses include coronary artery/vascular disease, congestive heart failure, stroke/myocardial infarction, and cardiac arrest.

d Social risk factors include homelessness, low income, low education, and social isolation.

$\mathrm{COPD}=$ chronic obstructive pulmonary disease; KQ = Key Question; RCT = randomized controlled trial.

Table 16 provides a summary of our strength-of-evidence decisions by outcomes by intervention model type. (Appendix Table B-14 is a more detailed listing with over 100 unique outcomes, by intervention model type). Among the 30 outcomes reported by two or more samples within a model type, we found favorable findings (moderate to low strength of evidence) in relation to changes in utilization and cost from ED, aICU, primary care, and homebased care models. Outcomes were graded as low for no difference in effect if at least several large RCT samples reported no difference between the intervention and treatment groups. Much of the evidence was graded as insufficient. Generally, these results across studies were inconsistent or imprecise, and meaningful conclusions cannot be drawn with the current evidence. 
Table 16. Summary of strength of evidence for HNHC patients by intervention model type for outcomes reported in more than one sample

\begin{tabular}{|c|c|c|c|c|c|c|c|c|}
\hline Outcome Group & Outcome Measure (Subgroup) & $\begin{array}{l}\text { System } \\
\text { Level }\end{array}$ & $\begin{array}{l}\text { Tele- } \\
\text { phonic/ } \\
\text { Mail }\end{array}$ & $\begin{array}{l}\text { Com- } \\
\text { munity } \\
\text { Based }\end{array}$ & $\begin{array}{l}\text { ED } \\
\text { Based }\end{array}$ & alCU & $\begin{array}{l}\text { Primary } \\
\text { Care }\end{array}$ & $\begin{array}{l}\text { Home } \\
\text { Based }\end{array}$ \\
\hline \multirow[t]{10}{*}{ Utilization outcomes } & ED visits, all-cause & $\mathrm{I}$ & L-ND & $\mathrm{I}$ & M-F & 1 & 1 & $\mathrm{I}$ \\
\hline & ED visits, ACSC & - & L-ND & - & - & - & 1 & 1 \\
\hline & Inpatient admissions, all-cause & $\mathrm{I}$ & L-ND & $\mathrm{I}$ & L-F & I & $\mathrm{I}$ & $\mathrm{I}$ \\
\hline & Inpatient admissions, any & - & 1 & - & - & - & $\mathrm{L}-\mathrm{F}$ & 1 \\
\hline & Inpatient admissions, ACSC & - & L-ND & - & - & - & $\mathrm{I}$ & $\mathrm{L}-\mathrm{F}$ \\
\hline & Inpatient admissions, any ACSC & - & 1 & - & - & - & $\mathrm{I}$ & $L-F$ \\
\hline & Inpatient days & - & - & $\mathrm{I}$ & - & - & - & - \\
\hline & Outpatient visits & - & - & - & 1 & - & I & - \\
\hline & Primary care visits & - & - & - & $L-F^{a}$ & 1 & $\mathrm{I}$ & - \\
\hline & 180-day readmission, count & - & - & 1 & - & - & - & - \\
\hline \multirow[t]{7}{*}{ Cost outcomes } & Total costs & L-ND & L-ND & I & - & $\mathrm{L}-\mathrm{F}$ & L-F & $\mathrm{I}$ \\
\hline & Inpatient costs & - & - & $\mathrm{I}$ & ${\mathrm{L}-N D^{\mathrm{a}}}$ & - & - & - \\
\hline & ED costs & - & - & 1 & $\mathrm{~L}-\mathrm{F}$ & - & - & - \\
\hline & Hospital costs of care & - & - & - & 1 & - & - & - \\
\hline & Outpatient costs & - & - & - & $\rho^{a}$ & - & - & - \\
\hline & Total costs (high-cost, high-risk HNHC patients) & - & - & - & - & - & - & $\mathrm{I}$ \\
\hline & Total costs (high-cost HNHC patients) & - & - & - & - & - & - & 1 \\
\hline \multirow{10}{*}{$\begin{array}{l}\text { Clinical and functional } \\
\text { outcomes }\end{array}$} & Mortality rate & - & L-ND & L-ND & - & I & $\mathrm{I}$ & L-ND \\
\hline & Influenza vaccine & - & 1 & - & - & - & $\mathrm{L}-\mathrm{U}$ & $\mathrm{L}-\mathrm{F}$ \\
\hline & Progression to ESRD & - & I & - & - & - & - & - \\
\hline & Progression to ESRD (CKD patients) & - & I & - & - & - & - & - \\
\hline & $\begin{array}{l}\text { Graft or fistula prior to hemodialysis (CKD } \\
\text { patients) }\end{array}$ & - & 1 & - & - & - & - & - \\
\hline & $\begin{array}{l}\text { Graft or fistula prior to hemodialysis (ESRD } \\
\text { patients) }\end{array}$ & - & I & - & - & - & - & - \\
\hline & HbA1c test (diabetes patients) & - & 1 & - & - & - & $\mathrm{I}$ & $\mathrm{I}$ \\
\hline & LDL test (diabetes patients) & - & $\mathrm{I}$ & - & - & - & $\mathrm{I}$ & $\mathrm{I}$ \\
\hline & LDL test (IVD patients) & - & 1 & - & - & - & 1 & 1 \\
\hline & Eye exam (diabetes patients) & - & 1 & - & - & - & - & - \\
\hline
\end{tabular}




\begin{tabular}{|c|c|c|c|c|c|c|c|c|}
\hline Outcome Group & Outcome Measure (Subgroup) & $\begin{array}{l}\text { System } \\
\text { Level }\end{array}$ & $\begin{array}{c}\text { Tele- } \\
\text { phonic/ } \\
\text { Mail }\end{array}$ & $\begin{array}{l}\text { Com- } \\
\text { munity } \\
\text { Based }\end{array}$ & $\begin{array}{c}\text { ED } \\
\text { Based }\end{array}$ & alCU & $\begin{array}{l}\text { Primary } \\
\text { Care }\end{array}$ & $\begin{array}{l}\text { Home } \\
\text { Based }\end{array}$ \\
\hline \multirow{3}{*}{$\begin{array}{l}\text { Clinical and functional } \\
\text { outcomes (continued) }\end{array}$} & Nephrology/nephropathy test (diabetes patients) & - & 1 & - & - & - & - & - \\
\hline & Lipid test (IVD patients) & - & 1 & - & - & - & - & - \\
\hline & Oxygen saturation test (COPD patients) & - & - & - & - & - & - & 1 \\
\hline
\end{tabular}

I: Insufficient, two or more samples reporting on the outcome within the model type; L-F: Low strength of evidence for favorable findings for the outcome; L-ND: Low strength of evidence for no difference for the outcome; L-U: Low strength of evidence for unfavorable findings for the outcome; -: No eligible evidence; M-F: Moderate strength of evidence for favorable findings for the outcome.

${ }^{a}$ Shumway et al. ${ }^{166}$ specified the outpatient and inpatient costs as medical outpatient costs and medical hospital costs.

$\mathrm{ACSC}=$ ambulatory care sensitive conditions; aICU = ambulatory intensive caring unit; $\mathrm{CKD}=$ chronic kidney disease; $\mathrm{COPD}=$ chronic obstructive pulmonary disease; $\mathrm{ED}=$ emergency department; ESRD = end-stage renal disease; HbAlc = hemoglobin A1c; HNHC = high-need, high-cost; IVD = ischemic vascular disease; LDL = low-density lipoprotein. 
Notably, no social risk outcomes (i.e., variables in the social services domain that may affect care delivery $)^{20}$ and a limited number of clinical and functional outcomes were reported in two or more samples within a model type. Therefore, evidence for these outcomes was often either not available or rated as insufficient strength of evidence.

\section{Findings by Model Type}

\section{System-Level Transformation Models}

\section{Overview}

- Four observational studies, including five samples, each rated some concerns for risk of bias, reported on system-level transformation models.

- We found no difference in total costs among system-level transformation models $(-\$ 5.41$ [ $95 \%$ confidence interval (CI), -38.28 to 49.10 ]; 5 observational samples, $\mathrm{I}^{2}=44.6 \%$ ), based on evidence from all five observational samples (low strength of evidence for no difference between interventions and usual care).

- We found insufficient evidence to judge all utilization and clinical and functional outcomes.

\section{Detailed Results}

Four studies, including five samples, reported on system-level transformation models compared with usual care (Appendix Table B-15). ${ }^{69-72,180,181}$ This set of models consisted of interventions that were designed, funded, and overseen by CMS. They were designed to be relevant to the delivery of care to all of the practice's or clinic's patient population. The models tested whether organizations were able to implement a diverse set of changes to alter how they deliver care and whether those changes affected the cost and quality of care their patients received. All four studies were observational designs and were rated as some concerns for risk of bias.

One study, the Federally Qualified Health Center (FQHC) Advanced Primary Care Practice initiative, aimed to help FQHCs obtain patient-centered medical home (PCMH) status. ${ }^{71}$ PCMH status would signify that the $\mathrm{FQHC}$ provides continuous, comprehensive, coordinated, and patient-centered medical care. In this study, $503 \mathrm{FQHC}$ intervention sites were compared with 827 comparator $\mathrm{FQHC}$ sites at the end of 3 years. ${ }^{71}$

The second study focused on one component of CMS's Independence at Home (IAH) demonstration. IAH supported the provision of team-based primary care in the homes of chronically ill and functionally limited fee-for-service (FFS) Medicare enrollees by providing financial incentives to home-based primary care practices. ${ }^{72,180}$ The IAH evaluation conducted two analyses using different study populations. The first analysis (included in this section) assessed the 5-year average annual effect of the IAH payment incentive to home-based primary care practices on cost and utilization outcomes. IAH practices earned a payment incentive if Medicare expenditures for their IAH patients were below a spending target and the practice met quality standards. ${ }^{72}$ The IAH incentive payment analysis compared all IAH-eligible patients in IAH practices, including those who received home-based care before the demonstration began, with IAH-eligible patients from the same geographic area who did not receive care at IAH practices and did not ever receive home-based primary care. ${ }^{72}$ The second analysis assessed the 
effect of home-based primary care patient services (discussed in the Home-Based Care Models section). ${ }^{72}$

The other two system-level models, the Comprehensive Primary Care (CPC) initiative and the Comprehensive Primary Care Plus $(\mathrm{CPC}+)$ initiative, were multipayer models that aimed to reform care delivery and payment in primary care practices. CPC's goal was to improve primary care delivery by offering care management fees and shared savings to primary care practices to support improvements across five care delivery functions: access, chronic and preventive care, care management, patient and caregiver engagement, and care coordination. ${ }^{69}$ The CPC study compared 4-year outcome differences between 497 intervention practices with 908 matched comparison practices.

$\mathrm{CPC}+$ built on the $\mathrm{CPC}$ model and required primary care practices to make more advanced care delivery changes and to target more complex patients. ${ }^{70,181}$ In the first 2 (of 5) years of $\mathrm{CPC}+$, primary care practices focused on improving the quality of care they provided to patients, including setting up processes and staff for care management and for screening and addressing unmet behavioral health and social service needs; improving coordination with hospitals, EDs, and specialists; and improving timely followup with patients after an ED or hospital visit. The $\mathrm{CPC}+$ study included two samples consisting of practices located across 18 geographical regions. The first sample compared 1,373 CPC+ practices with 5,243 matched comparison practices. A second sample compared 1,515 CPC+ practices with 3,784 comparison practices. Compared with the first $\mathrm{CPC}+$ sample, the second sample of practices was required to make more advanced care delivery changes to support their complex patients. The practices in the second sample received more financial payments to support their changes.

\section{Intervention Characteristics}

Across the four interventions, CMS provided organizations with different levels of financial and learning support and data feedback (Appendix Table B-16). FQHCs transforming to PCMH status received a quarterly care management payment of $\$ 18$ for each eligible Medicare patient to support delivery of patient-centered care; technical assistance from the National Committee for Quality Assurance (NCQA); and feedback reports on their achievement toward NCQA PCMH status, utilization, and expenditure measures. ${ }^{71}$

Similar to the FQHC intervention, CPC and CPC+ provided financial support to practices, including care management fees to assist in practice reforms. ${ }^{69,}{ }^{70} \mathrm{CPC}$ also offered shared savings to practices to reward cost savings, and CPC + also offered prospective performancebased payments. Financial support was provided by Medicare and other payers including Medicaid and various commercial payers. CPC and CPC+ intervention practices received technical assistance, data feedback, and learning support (e.g., group learning activities and individualized coaching). ${ }^{69,70}$ Compared with CPC, CPC+ practices had more requirements related to care delivery, such as developing care plans, following up with patients after ED or hospital discharge, and implementing enhanced health information technology functionalities to support care delivery requirements. ${ }^{70}$

The IAH model differed from the other transformation models in that it used an incentive payment to motivate IAH practices to implement a variety of strategies to improve care and reduce unnecessary costs. ${ }^{72}$ The incentive payment was proportional to the difference between the practices' targeted and actual spending and performance on quality measures.

FQHC, CPC, and CPC + noted variation across sites in the uptake of intervention components, including learning support, ${ }^{69}$ technical assistance, and data feedback reports. ${ }^{71}$ For the FQHC intervention, the study authors noted that isolating an intervention effect was difficult 
because comparison sites had access to many of the same resources to support efforts toward achieving PCMH status. These resources included technical assistance and funding from the Health Resources and Services Administration, state Medicaid programs, and private MCOs, ${ }^{71}$ including support for tracking quality and providing feedback to physicians. In IAH, practices developed and tested their own strategies to identify effective processes to improve their quality of care; some practices provided performance feedback to their providers. ${ }^{72}$

While the interventions across the four studies included all patients, we present the findings specific to the HNHC patient subgroup. The FQHC study reported on two samples of intervention patients that met our HNHC inclusion criteria. One sample was patients whose number of ED visits was in the 90th percentile, and the second was patients whose number of FQHC visits was in the 90th percentile. Both samples were compared with patients with visits below the 90th percentile of the same metric in comparison sites. ${ }^{71}$ The two FQHC samples may include overlapping patients. Because of this concern, we report on just one of the patient populations, the ED patients with high use. We selected the ED patient analysis because a selection criterion based on ED use was more like the criteria used by other studies. All IAH participants were HNHC patients. Medicare patients were included in the IAH payment incentive analysis if they had two or more chronic conditions, two or more difficulties in performing activities of daily living that require human assistance, and a hospitalization and use of acute or subacute rehabilitation services in the previous 12 months. ${ }^{72} \mathrm{CPC}$ reported on one HNHC patient sample, defined as two or more hospitalizations in the past 2 years, with at least 2 of 13 chronic conditions. CPC+ reported on two HNHC patient samples based on the two samples of practices; both samples were defined as one or more hospitalizations in the past year, with at least 2 of 12 frequently occurring chronic conditions. ${ }^{70}$

\section{Intervention Outcomes}

\section{Utilization Outcomes}

Utilization outcomes were available for the IAH and FQHC interventions only. In relation to ED visits, the IAH incentive payment intervention group experienced a favorable, significantly greater decrease in ED visits than its comparison group while the FQHC sample did not experience an effect (Appendix Table B-17). Because of mixed findings, we rated ED visits as insufficient strength of evidence (Table 17; full strength-of-evidence domain decisions can be found in Appendix Table B-18). Neither of the interventions found a significant difference from the comparison group in the number of inpatient admissions, and this outcome was also graded as insufficient strength of evidence. ${ }^{71,72}$

\section{Cost Outcomes}

All four studies found no differences in changes in total costs among the five samples of HNHC patients (Appendix Tables B-19 and B-20). ${ }^{69-72,180,181}$ The pooled effect size showed no difference in annual total cost between the groups (mean difference, $-\$ 5.41$ [95\% CI, -38.28 to 49.10]; 5 observational samples, $\mathrm{I}^{2}=44.6 \%$ ) (Appendix Figure B-2). Because total costs were observed to not be less across all five samples, we rated this outcome as low strength of evidence for no difference (Table 17). Notably, CPC + Sample 2 intervention group found an unfavorable, significantly greater increase in total costs than its comparison group. However, study authors suggested interpreting this finding with caution because many subgroup analyses were performed and this significant difference may have occurred because of chance. ${ }^{181}$ The 
Table 17. Summary of findings for system-level transformation models versus usual-care outcomes

\begin{tabular}{|c|c|c|c|c|}
\hline Outcome & Population & $\begin{array}{l}\text { \# Samples/Design } \\
\text { (n Analyzed) }\end{array}$ & Findings $^{\text {b }}$ & Strength of Evidence \\
\hline ED visits, all cause & HNHC patients & $\begin{array}{l}2 \mathrm{OBS}^{71,72} \\
\left(\mathrm{~N}=\mathrm{NR}^{\mathrm{a}}\right)\end{array}$ & $\begin{array}{l}1 \text { OBS sample had } \\
\text { favorable findings and } \\
1 \text { OBS sample found } \\
\text { no difference }\end{array}$ & Insufficient \\
\hline $\begin{array}{l}\text { Inpatient admissions, } \\
\text { all cause }\end{array}$ & HNHC patients & $\begin{array}{l}2 \mathrm{OBS}^{71,72} \\
\left(\mathrm{~N}=\mathrm{NR}^{\mathrm{a}}\right)\end{array}$ & $\begin{array}{l}2 \text { of } 2 \text { OBS samples } \\
\text { found no difference }\end{array}$ & Insufficient \\
\hline Total cost & HNHC patients & $\begin{array}{l}5 \mathrm{OBS}^{69-72} \\
\left(\mathrm{~N}=\mathrm{NR}^{\mathrm{a}}\right)\end{array}$ & $\begin{array}{l}4 \text { of } 5 \text { OBS samples } \\
\text { found no difference; } 1 \\
\text { of } 5 \text { OBS samples had } \\
\text { unfavorable findings } \\
\text { MA pooled mean } \\
\text { difference: }-\$ 5.41 \\
(95 \% \mathrm{Cl},-38.28 \text { to } \\
49.10) ; 5 \\
\text { observational } \\
\text { samples, }\left.\right|^{2}=44.6 \%\end{array}$ & Low (No difference) \\
\hline
\end{tabular}

${ }^{\mathrm{a}}$ The $\mathrm{FQHC},{ }^{71} \mathrm{CPC},{ }^{69}$ and $\mathrm{CPC}+{ }^{70}$ studies did not report sample sizes for their HNHC patient populations; the total sample size for FQHC was 730,353, 1,730,958 for CPC, 5,163,969 for CPC+ Sample 1, and 4,804,265 for CPC+ Sample 2. The sample size was 42,132 for the IAH study. ${ }^{72}$

${ }^{\mathrm{b}}$ Findings were determined to be favorable or unfavorable based on the intent of the intervention. For example, if the intent of the intervention was to lower total cost, then a greater increase in total cost among intervention group patients compared with comparison group patients was classified as unfavorable. Similarly, changes in utilization may be identified as favorable or unfavorable depending on the intent of the intervention and the specific outcome. For studies that intended to reduce ED visits and shift service use to primary care, a greater increase in the use of ED visits among intervention group patients compared with comparison group patients would be unfavorable, while an increase in primary care visits would be favorable.

$\mathrm{CPC}=$ Comprehensive Primary Care $\mathrm{CPC}+=$ Comprehensive Primary Care Plus; $\mathrm{ED}=$ emergency department; $\mathrm{FQHC}=$ Federally Qualified Health Center; $\mathrm{HNHC}=$ high need, high cost; IAH = Independence at Home; $\mathrm{MA}=$ meta-analysis; $\mathrm{N}=$ number; $\mathrm{NR}=$ not reported; $\mathrm{OBS}=$ observational study.

authors also hypothesized that total costs may have increased for HNHC patients because increased care management led to identification of additional health problems and subsequent service use.

\section{Clinical and Functional Outcomes}

In relation to clinical and functional outcomes, differences in mortality rate were reported only in the IAH incentive payment sample and were found to be not significant. ${ }^{72}$ The FQHC sample was the only other study to report any clinical and functional outcomes, and no differences were observed for receipt of hemoglobin A1c (HbA1c) tests, low-density lipoprotein (LDL) tests, eye exams, nephropathy tests, and lipid checks, among diabetic and ischemic vascular disease (IVD) patients (Appendix Tables B-21 and B-22). ${ }^{71}$

\section{Social Risk Outcomes}

No social risk outcomes were reported among the system-level transformation studies.

\section{Telephonic/Mail Models}

\section{Overview}

- Five RCTs and one observational study reported on telephonic/mail models. Telephonic/mail models were interventions where services were primarily provided 
remotely (telephonically or by mail) by a health plan. Three of the RCTs randomized two samples, an original sample and a refresh sample, so a total of nine samples were included in the evidence.

- The evidence on telephonic/mail models comes from studies with moderate study limitations.

- Based on evidence from four RCT samples $(\mathrm{N}=20,693)$, we found no difference in the number of ED visits (RR, 1.01 [95\% CI, 0.94 to 1.08]; $\mathrm{I}^{2}=0 \%$ ); ACSC ED visits (RR, 0.99; $95 \%$ CI, 0.88 to $1.10 ; \mathrm{I}^{2}=0 \%$ ), inpatient admissions ( $\mathrm{RR}, 0.99$ [95\% CI, 0.92 to 1.06]; $\mathrm{I}^{2}=0 \%$ ), and ACSC inpatient admissions (RR, 0.95 [95\% CI, 0.85 to 1.06$] ; \mathrm{I}^{2}=0 \%$ ) (low strength of evidence for no difference).

- We found that change in total healthcare cost was not improved by the interventions, based on evidence from seven RCT samples (mean difference, $-\$ 8.52$ [95\% CI, -130.02 to 112.98 ]; 7 RCT samples; $\mathrm{N}=25,000 ; \mathrm{I}^{2}=22.4 \%$ ) (low strength of evidence for no difference).

- We found no difference in the mortality rate (mean difference, 0.34 [95\% CI, -1.06 to 1.74]; $\left.\mathrm{I}^{2}=0 \%\right)$, based on evidence from four RCT samples $(\mathrm{N}=20,693)$ (low strength of evidence for no difference).

- The evidence is insufficient to judge other utilization, cost, and clinical and functional outcomes.

\section{Detailed Results}

Six studies, analyzing nine samples, reported on telephonic/mail models (Appendix Tables B-23 and B-24). ${ }^{64-66,137,143,171}$ A telephonic/mail model is an intervention where most services are provided remotely, either telephonically or by mail. These interventions were generally operated by a health plan.

\section{Intervention Characteristics}

Five of the six studies (reporting on 8 samples) were RCTs. ${ }^{64-66,137,143}$ All five RCTs were rated as some concerns for risk of bias. The one included observational study was rated some concerns for risk of bias. ${ }^{171}$

In one RCT, Kaiser Permanente of Ohio provided the HNHC patient intervention group with Healthtrac, a health promotion program. Healthtrac mailed health education materials and questionnaires to members and returned a personalized letter and feedback with recommendations and actions to reduce the risks identified in the letter. ${ }^{143}$ The HNHC patient comparison group received baseline education materials and incentives but did not receive personalized followup materials. ${ }^{143}$ Eligible Kaiser Permanente members had 11 or more outpatient visits in the past 2 years and a diagnosis of one of three target conditions (arthritis, hypertension, diabetes). ${ }^{143}$

The other four RCTs were separate programs implemented as part of the Medicare Care Management for High Cost Beneficiaries (CMHCB) demonstration. ${ }^{64-66,137}$ The CMHCB programs were multifaceted interventions that tested a pay-for-performance contracting model and provided new care management or coordination for high-cost or complex Medicare FFS patients. Through the pay-for-performance model, CMHCB programs received a negotiated monthly management fee for each of their intervention group members and a share of any Medicare savings achieved among the intervention group. Programs administered patient assessments to help them create services tailored to an individual patient's needs. CMHCB 
compared intervention-group patients with those receiving usual care. Usual-care patients were not contacted.

One CMHCB RCT, Texas Senior Trails (TST), provided multidisciplinary care management to help multimorbid patients coordinate health and social services. ${ }^{137}$ In TST, nurse care managers provided services most often in writing or by telephone. Twenty percent of participants received in-person services. The program emphasized sharing information with patients' physicians. $^{137}$

The second CMHCB RCT, the Health Buddy Consortium program, was a care management program for heart failure, diabetes, and COPD patients. ${ }^{66}$ The intervention provided patients with a Health Buddy device, a home monitoring device set to 1 of 13 disease-specific programs, that allowed nurse care managers to monitor and communicate with patients daily. Alternatively, intervention participants who did not use the Health Buddy device could receive regular, scheduled phone calls. ${ }^{66}$

Both the TST and Health Buddy programs included a broader group of participants than the HNHC patient population. We present only the findings specific to the HNHC patient subgroup, defined as those with $\$ 6,000$ or more in Medicare costs in the previous year and an HCC risk score of 1.7 or greater. ${ }^{66,137}$ This HCC score indicates that the patient was predicted to have 70 percent or higher total Medicare spending than an average Medicare patient.

The other two CMHCB RCTs were Phase I and Phase II of the Village Health program. In Phase I, Village Health tested a disease and care management program for chronic kidney disease (CKD) patients in three counties in New York City. ${ }^{64}$ In Phase II, Village Health expanded their patient focus to target patients with ESRD and extended their geographical territory to include five New York regions. ${ }^{65}$

Village Health nurse care managers provided support only through the telephone for CKD participants and through telephone or in person for ESRD participants. This support was complemented by pharmacists, social workers, and dietitians and access to a 24 -hour hotline. ${ }^{64}$ In Phase II, Village Health retained the same intervention structure and added more frequent contact with patients; in-person education classes; an expanded clinical focus to include ESRD patients; and relationships with more nephrologists, local hospitals, skilled nursing facilities, rehabilitation facilities, and community organizations. ${ }^{65}$ Both Village Health RCTs included patients who had $\$ 5,000$ or more in Medicare costs in the previous year and a CKD diagnosis. ${ }^{64}$, 65

Three of the CMHCB programs, Health Buddy, Village Health Phase 1, and Village Health Phase 2, implemented the RCT in two separate samples, an original sample and a "refresh" sample. All samples were followed for at least 1 year. Both samples received the same intervention. ${ }^{64-66}$ The refresh sample supplemented the original sample with additional, new patients to offset the impact of attrition, primarily due to death, in the original sample. ${ }^{64-66}$

The sixth telephonic/mail model study was observational. Compared with usual care, the Health Leads program, implemented at Kaiser Permanente Southern California, provided social needs screening and navigation of community-based services by telephone through nonclinical program staff. ${ }^{171}$ Eligible patients were predicted to be in the top 1 percent of healthcare utilization in the upcoming year. ${ }^{171}$ 


\section{Intervention Outcomes}

\section{Utilization Outcomes}

Four of the six studies (6 samples) reported on the effect of the intervention on healthcare utilization (Appendix Tables B-25 and B-26).

ED visit outcomes were reported in the two Village Health studies (4 RCT samples; original and refresh samples in Phase I and Phase II) and in 1 observational study sample. In the four RCT samples, ED visits increased in both the intervention and comparison groups, but the change was not significantly different between the two groups. ${ }^{64,}{ }^{65}$ Pooled RRs for all-cause ED visits (RR, 1.01 [95\% CI, 0.94 to 1.08]; 4 RCT samples; $\mathrm{N}=20,693 ; \mathrm{I}^{2}=0 \%$ ) and ACSC ED visits (RR, 0.99 [95\% CI, 0.88 to 1.10]; 4 RCT samples; $N=20,693 ; I^{2}=0 \%$ ) also were not significantly different in these RCT samples (Appendix Figures B-3 and B-4). The evidence led to a grade of low strength of evidence for no difference for both all-cause and ACSC ED visits (Table 18; full strength of evidence can be found in Appendix Table B-27).

Inpatient-related outcomes were also limited to evidence from the Village Health samples and 1 observational study sample. Among the four Village Health RCT samples, differences between the intervention and comparison groups were not significantly different for all inpatient outcomes (both all-cause admissions and ACSC-related admissions) ${ }^{64,}{ }^{65}$ Pooled RRs for allcause inpatient admissions ( $\mathrm{RR}, 0.99$ [95\% CI, 0.92 to 1.06]; 4 RCT samples; $\mathrm{N}=20,693 ; \mathrm{I}^{2}=0 \%$ ) and ACSC inpatient admissions (RR, 0.95 [95\% CI, 0.85 to 1.06]; 4 RCT samples; N=20,693; $\mathrm{I}^{2}=0 \%$ ) showed no difference between groups and both were graded as low strength of evidence for no difference (Appendix Figures B-5 and B-6) (Table 18).

The Healthtrac RCT was the only telephonic/mail model study that measured outpatient visits. Changes in the number of visits were measured - for both the total sample and by chronic condition subgroup (arthritis, blood pressure, and diabetes). ${ }^{143}$ At 6 months, the RCT did not observe any significant differences, but by 30 months, reductions were greater in the intervention group, predominately driven by the reduction in visits among arthritis patients.

The Health Leads program, the observational study, reported no differences in total utilization or the total number of ED, outpatient, and inpatient visits between the intervention and comparison groups. ${ }^{171}$

Table 18. Summary of findings for telephonic/mail models versus usual-care outcomes ${ }^{a}$

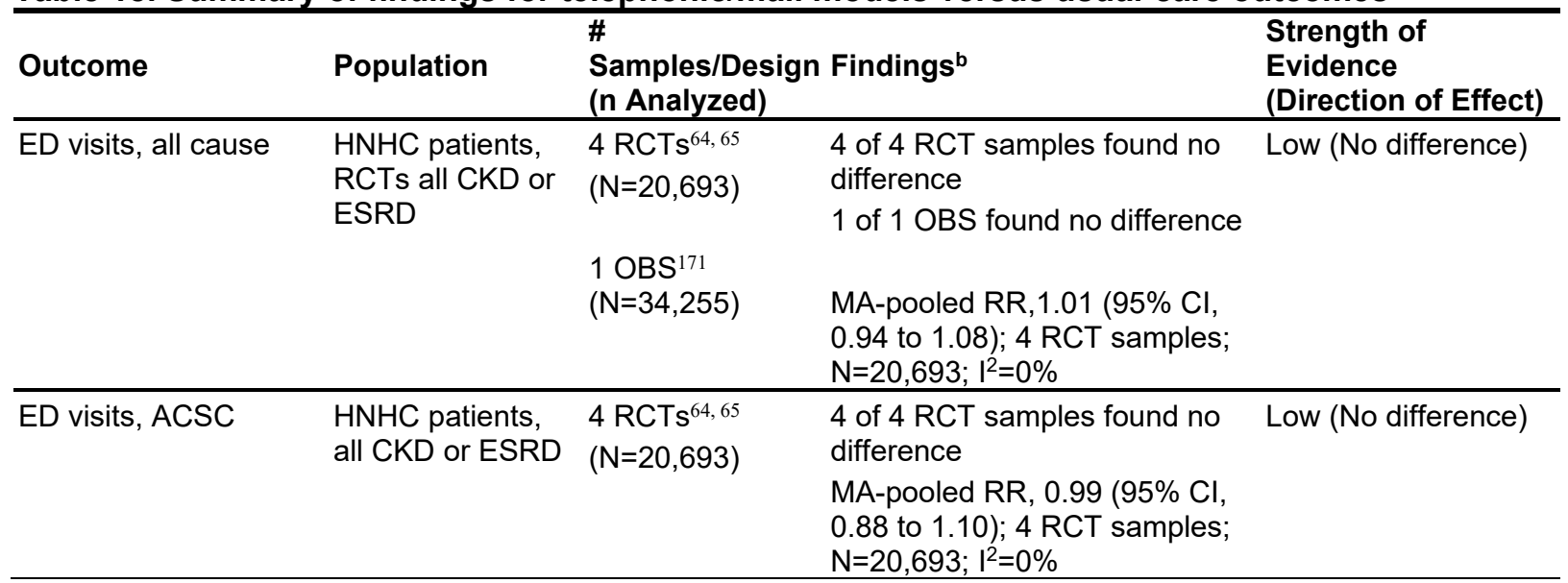




\begin{tabular}{|c|c|c|c|c|}
\hline Outcome & Population & $\begin{array}{l}\text { \# } \\
\text { Samples/Design } \\
\text { (n Analyzed) }\end{array}$ & Findings $^{b}$ & $\begin{array}{l}\text { Strength of } \\
\text { Evidence } \\
\text { (Direction of Effect) }\end{array}$ \\
\hline $\begin{array}{l}\text { Inpatient admissions, } \\
\text { all cause }\end{array}$ & $\begin{array}{l}\text { HNHC patients, } \\
\text { RCTs all CKD or } \\
\text { ESRD }\end{array}$ & $\begin{array}{l}4 \mathrm{RCTS}^{64,65} \\
(\mathrm{~N}=20,693) \\
1 \mathrm{OBS}^{171} \\
(\mathrm{~N}=34,255)\end{array}$ & $\begin{array}{l}4 \text { of } 4 \text { RCT samples found no } \\
\text { difference } \\
1 \text { of } 1 \text { OBS found no difference } \\
\text { MA-pooled RR, } 0.99 \text { ( } 95 \% \mathrm{Cl} \text {, } \\
0.92 \text { to } 1.06) ; 4 \text { RCT samples; } \\
\mathrm{N}=20,693 ;\left.\right|^{2}=0 \%\end{array}$ & Low (No difference) \\
\hline $\begin{array}{l}\text { Inpatient admissions, } \\
\text { ACSC }\end{array}$ & $\begin{array}{l}\text { HNHC patients, } \\
\text { all CKD or ESRD }\end{array}$ & $\begin{array}{l}4 \mathrm{RCTs}^{64,65} \\
(\mathrm{~N}=20,693)\end{array}$ & $\begin{array}{l}4 \text { of } 4 \text { RCT samples found no } \\
\text { difference } \\
\text { MA-pooled RR, } 0.95 \text { ( } 95 \% \mathrm{Cl} \text {, } \\
0.85 \text { to } 1.06) ; 4 \text { RCT samples; } \\
\mathrm{N}=20,693 ; I^{2}=0 \%\end{array}$ & Low (No difference) \\
\hline $\begin{array}{l}\text { Inpatient admissions, } \\
\text { any }\end{array}$ & HNHC patients & $\begin{array}{l}2 \mathrm{RCTs}^{64} \\
(\mathrm{~N}=10,337)\end{array}$ & $\begin{array}{l}2 \text { of } 2 \text { RCT samples found no } \\
\text { difference }\end{array}$ & Insufficient \\
\hline $\begin{array}{l}\text { Inpatient admissions, } \\
\text { any ACSC }\end{array}$ & HNHC patients & $\begin{array}{l}2 \mathrm{RCTs}^{64} \\
(\mathrm{~N}=10,337)\end{array}$ & $\begin{array}{l}2 \text { of } 2 \text { RCT samples found no } \\
\text { difference }\end{array}$ & Insufficient \\
\hline Total cost & HNHC patients & $\begin{array}{l}7 \text { RCTs }^{64-66,137} \\
(\mathrm{~N}=25,000)\end{array}$ & $\begin{array}{l}7 \text { of } 7 \text { RCT samples found no } \\
\text { difference } \\
\text { MA-pooled mean difference, - } \\
\$ 8.52(95 \% \mathrm{Cl},-130.02 \text { to } \\
112.98) ; 7 \mathrm{RCT} \text { samples; } \\
\mathrm{N}=25,000 ; I^{2}=22.4 \%\end{array}$ & Low (No difference) \\
\hline Mortality rate & HNHC patients & $\begin{array}{l}4 \mathrm{RCTs}^{64,65} \\
(\mathrm{~N}=20,693)\end{array}$ & $\begin{array}{l}4 \text { of } 4 \text { RCT samples found no } \\
\text { difference } \\
\text { MA-pooled mean difference, } \\
0.34(95 \% \mathrm{Cl},-1.06 \text { to } 1.74) ; 4 \\
\text { RCT samples; } N=20,693 ; \\
\left.\mathrm{I}^{2}=0 \%\right)\end{array}$ & Low (No difference) \\
\hline Influenza vaccine & HNHC patients & $\begin{array}{l}2 \mathrm{RCTs}^{64} \\
(\mathrm{~N}=10,337)\end{array}$ & $\begin{array}{l}2 \text { of } 2 \text { RCT samples found no } \\
\text { difference }\end{array}$ & Insufficient \\
\hline Progression to ESRD & HNHC patients & $\begin{array}{l}2 \mathrm{RCTS}^{64} \\
(\mathrm{~N}=10,337)\end{array}$ & $\begin{array}{l}2 \text { of } 2 \text { RCT samples found no } \\
\text { difference }\end{array}$ & Insufficient \\
\hline Progression to ESRD & $\begin{array}{l}\text { HNHC patients, } \\
\text { CKD subgroup }\end{array}$ & $\begin{array}{l}2 \mathrm{RCTs}^{65} \\
(\mathrm{~N}=4,822)\end{array}$ & $\begin{array}{l}2 \text { of } 2 \text { RCT samples found no } \\
\text { difference }\end{array}$ & Insufficient \\
\hline $\begin{array}{l}\text { Graft or fistula prior to } \\
\text { hemodialysis }\end{array}$ & $\begin{array}{l}\text { HNHC patients, } \\
\text { CKD subgroup }\end{array}$ & $\begin{array}{l}2 \mathrm{RCTs}^{65} \\
(\mathrm{~N}=4,822)\end{array}$ & $\begin{array}{l}1 \text { of } 2 \text { RCT samples had } \\
\text { favorable findings } \\
1 \text { of } 2 \text { RCT samples found no } \\
\text { difference }\end{array}$ & Insufficient \\
\hline $\begin{array}{l}\text { Graft or fistula prior to } \\
\text { hemodialysis }\end{array}$ & $\begin{array}{l}\text { HNHC patients, } \\
\text { ESRD subgroup }\end{array}$ & $\begin{array}{l}2 \mathrm{RCTs}^{64} \\
(\mathrm{~N}=428)\end{array}$ & $\begin{array}{l}2 \text { of } 2 \text { RCT samples found no } \\
\text { difference }\end{array}$ & Insufficient \\
\hline HbA1c test & $\begin{array}{l}\text { HNHC patients, } \\
\text { diabetes } \\
\text { subgroup }\end{array}$ & $\begin{array}{l}4 \mathrm{RCTs}^{64,65} \\
(\mathrm{~N}=7,931)\end{array}$ & $\begin{array}{l}4 \text { of } 4 \text { RCT samples found no } \\
\text { difference }\end{array}$ & Insufficient \\
\hline LDL test & $\begin{array}{l}\text { HNHC patients, } \\
\text { diabetes } \\
\text { subgroup }\end{array}$ & $\begin{array}{l}4 \mathrm{RCTs}^{64,65} \\
(\mathrm{~N}=7,931)\end{array}$ & $\begin{array}{l}4 \text { of } 4 \text { RCT samples found no } \\
\text { difference }\end{array}$ & Insufficient \\
\hline LDL test & $\begin{array}{l}\text { HNHC patients, } \\
\text { IVD subgroup }\end{array}$ & $\begin{array}{l}2 \mathrm{RCTs}^{64} \\
(\mathrm{~N}=3,942)\end{array}$ & $\begin{array}{l}2 \text { of } 2 \text { RCT samples found no } \\
\text { difference }\end{array}$ & Insufficient \\
\hline Eye exam & $\begin{array}{l}\text { HNHC patients, } \\
\text { diabetes } \\
\text { subgroup }\end{array}$ & $\begin{array}{l}2 \mathrm{RCTs}^{65} \\
(\mathrm{~N}=7,931)\end{array}$ & $\begin{array}{l}2 \text { of } 2 \text { RCT samples found no } \\
\text { difference }\end{array}$ & Insufficient \\
\hline
\end{tabular}




\begin{tabular}{|c|c|c|c|c|}
\hline Outcome & Population & $\begin{array}{l}\# \\
\text { Samples/[ } \\
\text { (n Analyze }\end{array}$ & Findings $^{b}$ & $\begin{array}{l}\text { Strength of } \\
\text { Evidence } \\
\text { (Direction of Effect) }\end{array}$ \\
\hline Nephrology test & $\begin{array}{l}\text { HNHC patients, } \\
\text { diabetes } \\
\text { subgroup }\end{array}$ & $\begin{array}{l}2 \mathrm{RCTS}^{65} \\
(\mathrm{~N}=7,931)\end{array}$ & $\begin{array}{l}2 \text { of } 2 \text { RCT samples found no } \\
\text { difference }\end{array}$ & Insufficient \\
\hline Lipid panel & $\begin{array}{l}\text { HNHC patients, } \\
\text { IVD subgroup }\end{array}$ & $\begin{array}{l}2 \mathrm{RCTS}^{65} \\
(\mathrm{~N}=4,092)\end{array}$ & $\begin{array}{l}1 \text { of } 1 \text { RCT sample had } \\
\text { favorable findings } \\
1 \text { of } 1 \text { RCT sample found no } \\
\text { difference }\end{array}$ & Insufficient \\
\hline
\end{tabular}

${ }^{a}$ Comparison group participants for Dally et al. received baseline education materials and incentives. ${ }^{143}$

${ }^{b}$ Findings were determined to be favorable or unfavorable based on the intent of the intervention. For example, if the intent of the intervention was to lower total cost, then a greater increase in total cost among intervention group patients compared with comparison group patients was classified as unfavorable. Similarly, changes in utilization may be identified as favorable or unfavorable depending on the intent of the intervention and the specific outcome. For studies that intended to reduce ED visits and shift service use to primary care, a greater increase in the use of ED visits among intervention group patients compared with comparison group patients would be unfavorable, while an increase in primary care visits would be favorable.

$\mathrm{ACSC}=$ ambulatory care sensitive conditions; $\mathrm{CKD}=$ chronic kidney disease; $\mathrm{ED}=$ emergency department; $\mathrm{ESRD}=\mathrm{end}$-stage renal disease; $\mathrm{HbA1} \mathrm{c}=$ hemoglobin $\mathrm{Al}$; $\mathrm{HNHC}=$ high-need, high-cost; IVD = ischemic vascular disease; $\mathrm{LDL}=$ low-density lipoprotein; $\mathrm{MA}=$ meta-analysis; $\mathrm{N}=$ number; $\mathrm{OBS}=$ observational study; $\mathrm{RCT}=$ randomized controlled trial; $\mathrm{RR}=$ rate ratio.

\section{Cost Outcomes}

Four of six studies reported on the impact of the intervention on costs (Appendix Table B-28). The seven samples from the four CMHCB programs ${ }^{64-66,137}$ all found no significant differences in changes in total cost between the study arms. The pooled mean difference showed no difference between groups (mean difference, $-\$ 8.52$ [95\% CI, -130.02 to 112.98]; 7 RCT samples; $\mathrm{N}=25,000 ; \mathrm{I}^{2}=22.4 \%$ ) (Appendix Figure B-7).

The direction of change in costs over time varied across samples. The TST program observed reductions in costs for both intervention and comparison groups, ${ }^{137}$ as did the two samples for the Health Buddy program. ${ }^{66}$ The Phase I Village Health groups for both the original and refresh samples moved in tandem, with increased costs in all groups over time. ${ }^{64}$ The original and refresh samples for Phase II Village Health moved in opposite directions: costs for both the intervention and comparison groups increased over time in the original sample and decreased over time in the refresh sample. ${ }^{64}$ This evidence led to a grade of low strength of evidence for no difference in total cost (Table 18).

\section{Clinical and Functional Outcomes}

Clinical and functional outcomes for HNHC patients were reported only in the four samples in the two Village Health RCTs (Appendix Tables B-29 and B-30) ${ }^{64,} 65$ Based on meta-analysis, we found no significant differences between groups in mortality rates (mean difference, 0.34 [95\% CI, -1.06 to 1.74 ]; 4 RCT samples; $\mathrm{N}=20,693 ; \mathrm{I}^{2}=0 \%$ ) (low strength of evidence for no difference) (Table 16 and Appendix B Figure B-8). We also found no significant differences in any clinical measures among the Phase I original or refresh patients. For Phase II patients, findings were mixed. We graded all other clinical and functional outcomes as insufficient strength of evidence (Table 18).

\section{Social Risk Outcomes}

No social risk outcomes were reported among the telephonic/mail studies. 


\section{Community-Based Models}

\section{Overview}

- Three RCT and six observational studies (9 samples) reported on community-based models, including three studies of the Camden Core Model.

- We found low strength of evidence that community-based interventions were not associated with changes in mortality, based on evidence from three RCT samples (low strength of evidence for no difference).

- The evidence is insufficient to judge all other healthcare outcomes, including inpatient admissions, inpatient days, readmissions, and healthcare cost.

\section{Detailed Results}

Nine studies in 11 publications, analyzing nine samples, reported on community-based models (Appendix Table B-31). ${ }^{44,139,141,148,157,159,162,169,172,174,176}$ The defining characteristic of this type of model is that the intervention team provides care management or care coordination assistance inside and outside of the healthcare system, wherever the patients are. ${ }^{45}$ All interventions were compared with usual care.

Three studies (1 RCT and 2 observational studies) evaluated the Camden Core Model, an intensive, relationship-based "hotspotting" program that used real-time data to identify and recruit HNHC patients. In the RCT (rated low risk of bias), four local-area hospital systems in Camden, NJ, implemented the model. ${ }^{44}$ Similarly, the Rutgers Center for State Health Policy (CSHP) evaluated the Camden Core Model in a large observational study (rated some concerns for risk of bias) of provider groups in four states. Although the model was implemented across payers, the CSHP evaluation results were limited to Medicare FFS patients. ${ }^{139,}{ }^{172}$ Another observational study, Bridges to Care (B2C) (rated some concerns for risk of bias), also evaluated adoption of the Camden Core Model. ${ }^{141} \mathrm{~B} 2 \mathrm{C}$ was one of the CSHP sites, so there is likely some overlap with the larger CSHP study. However, B2C was not limited to Medicare FFS patients and primarily served Medicaid-eligible patients.

Another RCT (rated some concerns for risk of bias) evaluated Project Welcome Home (PWH), an intervention that provided chronically homeless adult participants in Santa Clara County, CA, with housing and intensive case management services. ${ }^{159}$ A third RCT (also rated some concerns for risk of bias) evaluated the Kings County Care Partners (KCCP) program, a registered nurse-led care management intervention for Medicaid patients with disabilities or substance abuse problems. ${ }^{162}$

The other four studies were observational. One of these studies (rated some concerns for risk of bias) evaluated the Preventable Admissions Care Team program (PACT). PACT is a care coordination and transitional care program with the goal of reducing inpatient readmissions. PACT social workers, affiliated with one New York City hospital, collaborated with patients and their families to promote access to home, medical, and community care. ${ }^{169}$

The other three observational studies (all were rated high risk of bias and did not control for potential confounding) intervened by helping low-income patients with their medical and social needs. ${ }^{148,157,174,176}$ Among these, the Care Management Program (CMP) was implemented in a California safety net hospital. CMP assigned low-income uninsured patients a personal care manager to help them navigate and coordinate services in the healthcare and social services systems. Personal care managers met with patients at appointments, their homes, or resource centers. ${ }^{157}$ The Familiar Faces program used community navigators (a blend of community 
health workers [CHWs] and patient navigators) to link HNHC patients in low-income neighborhoods with healthcare and community resources to reduce hospital utilization. ${ }^{148}$ Dallas, Texas's Project Access Dallas (PAD) was a community-based care coordination program across healthcare providers, businesses, faith organizations, and public health entities. Through PAD, CHWs provided case management and access to primary and preventive services to low-income, uninsured individuals. ${ }^{174,176}$

\section{Intervention Characteristics}

Across community-based intervention studies, HNHC patient eligibility differed. The Camden RCT enrolled participants with two or more chronic conditions and two traits or conditions that indicated medical complexity, in addition to the utilization criterion of one or more inpatient admissions in the past 6 months. ${ }^{44}$ CSHP, B2C, and PACT focused on high healthcare use as the main eligibility criterion, ${ }^{139,}, 141,169,172$ while PWH focused on high use across multiple county-funded systems including ED, inpatient, and jail. ${ }^{159} \mathrm{KCCP}$ eligibility was based on an algorithm predicting future high cost, based on current costs and other criterion. ${ }^{162}$ In addition to meeting utilization criteria, PAD and CMP targeted uninsured HNHC patients, ${ }^{157}$, ${ }^{174,176}$ PWH targeted homeless individuals, ${ }^{159}$ and Familiar Faces targeted residents of the poorest zip codes in Memphis. ${ }^{148}$

All community-based interventions reported providing services tailored to individual patient needs that could include developing care plans, scheduling appointments, facilitating communication with providers, managing medication, and transportation (Appendix Table B-32). Five interventions (Camden RCT, CSHP, B2C, KCCP, PAD) provided patients with education and coaching related to their health, chronic conditions, self-care, and selfsufficiency. ${ }^{44,139,141,148,162,172,174,176}$ All interventions except PACT connected participants to community-based services through referrals or enrollment assistance. While PWH provided supportive services such as medication management and mental health services, the intervention was unique in that it focused on providing participants with permanent housing. ${ }^{159}$

Care team composition differed across programs. The Camden Core Model was an intensive, face-to-face intervention. All three Camden Core Model studies sought to maintain frequent contact with patients through large, multidisciplinary teams of registered nurses, social workers, licensed practical nurses, CHWs, and health coaches. ${ }^{44,139,141,172}$ KCCP was a nurse-led intervention with support from social workers and counselors with drug and alcohol addiction training. ${ }^{162}$ The other community-based interventions had smaller teams, but services were provided by similar types of staff. The majority of services were provided by CHWs, ${ }^{174,176}$ social workers, ${ }^{169}$ care managers, ${ }^{157}$ or community navigators. ${ }^{176} \mathrm{PWH}$ was notable in that the intervention did not include any physicians or nurses on the case management teams; instead, the teams were composed of social behavioral health providers, case managers, and staff with lived experience (peers). ${ }^{159}$

\section{Intervention Outcomes}

\section{Utilization Outcomes}

All nine interventions reported on at least one healthcare utilization outcome (Appendix Tables B-33 and B-34). The Camden RCT did not observe significant differences between groups in two inpatient measures-180-day readmissions and inpatient days. ${ }^{44} \mathrm{PACT}$, the only other study reporting 180-day readmissions, also did not observe significant differences between groups. ${ }^{169}$ The strength of evidence is insufficient for 180-day readmissions (Table 19; full 
strength of evidence can be found in Appendix Table B-35). The evidence on inpatient days is from the Camden and PWH RCTs and three high risk of bias observational studies. Of these, both RCTs and the CMP observational study reported no significant differences between groups in inpatient days. In contrast, PAD and Familiar Faces observed lower use of inpatient days in the intervention group. ${ }^{148,157,174,176}$ Because of the mixed findings, we graded the strength of evidence to be insufficient for inpatient days (Table 19).

Table 19. Summary of findings for community-based models versus usual-care outcomes

\begin{tabular}{|c|c|c|c|c|}
\hline Outcome & Population & $\begin{array}{l}\text { \# Samples/Design } \\
\text { (n Analyzed) }\end{array}$ & Findings $^{a}$ & $\begin{array}{l}\text { Strength of Evidence } \\
\text { (Direction of Effect) }\end{array}$ \\
\hline 180-day readmissions & HNHC patients & $\begin{array}{l}1 \mathrm{RCT}^{44}(\mathrm{~N}=800) \\
1 \mathrm{OBS}^{169}(\mathrm{~N}=1,158)\end{array}$ & $\begin{array}{l}1 \text { of } 1 \text { RCT sample } \\
\text { found no difference } \\
1 \text { of } 1 \text { OBS sample } \\
\text { found no difference }\end{array}$ & Insufficient \\
\hline ED visits, all cause & HNHC patients & 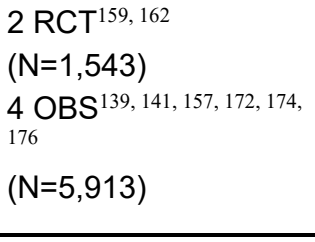 & $\begin{array}{l}2 \text { of } 2 \text { RCT samples } \\
\text { found no difference } \\
3 \text { of } 4 \text { OBS samples } \\
\text { had favorable findings } \\
1 \text { of } 4 \text { OBS samples } \\
\text { found no difference }\end{array}$ & Insufficient \\
\hline $\begin{array}{l}\text { Inpatient admissions, } \\
\text { all cause }\end{array}$ & HNHC patients & $\begin{array}{l}2 \mathrm{RCT}^{159,162} \\
(\mathrm{~N}=1,543) \\
3 \mathrm{OBS}^{139,141,157,172} \\
(\mathrm{~N}=5,339)\end{array}$ & $\begin{array}{l}2 \text { of } 2 \text { RCT samples } \\
\text { found no difference } \\
1 \text { of } 3 \text { OBS samples } \\
\text { had favorable findings } \\
2 \text { of } 3 \text { OBS samples } \\
\text { found no difference }\end{array}$ & Insufficient \\
\hline Inpatient days & HNHC patients & $\begin{array}{l}2 \mathrm{RCT}^{44,159} \\
(\mathrm{~N}=1,223) \\
3 \mathrm{OBS}^{148,157,174,176} \\
(\mathrm{~N}=1,271)\end{array}$ & $\begin{array}{l}2 \text { of } 2 \text { RCT samples } \\
\text { found no difference } \\
2 \text { of } 3 \text { OBS samples } \\
\text { had favorable findings } \\
1 \text { of } 3 \text { OBS samples } \\
\text { found no difference }\end{array}$ & Insufficient \\
\hline Total cost & HNHC patients & $\begin{array}{l}1 \mathrm{RCT}^{162} \\
(\mathrm{~N}=1,120) \\
2 \mathrm{OBS}^{139,148,172} \\
(\mathrm{~N}=1,271)\end{array}$ & $\begin{array}{l}1 \text { of } 1 \text { RCT sample } \\
\text { found no difference } \\
2 \text { of } 2 \text { OBS samples } \\
\text { found no difference }\end{array}$ & Insufficient \\
\hline Inpatient costs & HNHC patients & $\begin{array}{l}1 \mathrm{RCT}^{162} \\
(\mathrm{~N}=1,120) \\
1 \mathrm{OBS}^{139,172} \\
(\mathrm{~N}=1,279) \\
\end{array}$ & $\begin{array}{l}1 \text { of } 1 \text { RCT sample } \\
\text { found no difference } \\
1 \text { of } 1 \text { OBS sample } \\
\text { found no difference }\end{array}$ & Insufficient \\
\hline ED costs & HNHC patients & $\begin{array}{l}1 \mathrm{RCT}^{162} \\
(\mathrm{~N}=1,120) \\
1 \mathrm{OBS}^{174,176} \\
(\mathrm{~N}=574)\end{array}$ & $\begin{array}{l}1 \text { of } 1 \text { RCT sample } \\
\text { found no difference } \\
1 \text { of } 1 \text { OBS sample } \\
\text { had favorable findings }\end{array}$ & Insufficient \\
\hline Mortality & HNHC patients & $\begin{array}{l}3 \mathrm{RCT}^{44,159,162} \\
(\mathrm{~N}=2.343)\end{array}$ & $\begin{array}{l}3 \text { of } 3 \text { RCT samples } \\
\text { found no difference }\end{array}$ & Low (No difference) \\
\hline
\end{tabular}

${ }^{a}$ Findings were determined to be favorable or unfavorable based on the intent of the intervention. For example, if the intent of the intervention was to lower total cost, then a greater increase in total cost among intervention group patients compared with comparison group patients was classified as unfavorable. Similarly, changes in utilization may be identified as favorable or unfavorable depending on the intent of the intervention and the specific outcome. For studies that intended to reduce ED visits and shift service use to primary care, a greater increase in the use of ED visits among intervention group patients compared with comparison group patients would be unfavorable, while an increase in primary care visits would be favorable. 
$\mathrm{ED}=$ emergency department HNHC = high-need, high-cost; $\mathrm{N}=$ number; $\mathrm{OBS}=$ observational study $; \mathrm{RCT}=$ randomized controlled trial.

Six studies reported various ED visit outcomes. The PWH RCT and KCCP RCT reported ED visits over the length of their interventions and did not observe significant differences between the intervention and comparison groups. The PWH RCT did observe a significant reduction in psychiatric ED visits. The four observational studies reported ED visits at 1 year. CSHP did not find a significant difference, but B2C reported a significantly greater reduction. ${ }^{139,141,172}$ Both CMP and PAD observed fewer ED visits in the intervention group. ${ }^{157,174,176}$ The mixed findings across the studies led to a grade of insufficient strength of evidence for ED visits (Table 19). Sevak et al. hypothesized that the difference between two Camden Core Model findings, the CSHP and B2C models, may reflect the Camden Core Model being more likely to have an effect among certain subpopulations, like the Medicaid population that B2C targeted and CSHP did not evaluate. ${ }^{139,172}$

Five studies reported inpatient admissions. As observed for ED visits, the PWH RCT and KCCP RCT did not result in significant differences between the intervention and comparison groups. Among the three observational studies, we found a similar pattern as ED visits in the CSHP and B2C studies. CSHP again did not find a significant difference. ${ }^{139,}{ }^{172}$ In contrast, B2C reported a significantly greater reduction in inpatient admissions in the intervention group and, at 180 days, among patients with a comorbid mental health diagnosis. ${ }^{141}$ Like CSHP, CMP did not observe a significant differences between groups. ${ }^{157}$ The strength of evidence is insufficient for inpatient admissions because of inconsistent findings (Table 19).

Several of the studies examined changes in outpatient or primary care visits. For these outcomes, the study authors hypothesized that the intervention would result in reductions in inpatient admissions or ED visits and corresponding increases in outpatient or primary care visits in the intervention group (more appropriate type of care). We did not assess the strength of evidence of these outcomes because no two studies assessed the same measure. Although neither the PWH RCT nor the KCCP RCT observed significant reductions in overall ED visits or inpatient admissions, both reported favorable utilization changes related to outpatient mental health visits. ${ }^{159,162}$ The PWH RCT reported a significantly greater increase in the number of outpatient mental health visits in the intervention group, while the KCCP RCT reported a significantly greater increase in any outpatient mental health visits in the intervention group. The B2C community-based model examined changes in primary care visits. As the study authors had hypothesized, primary care visits significantly increased in the intervention group, while ED visits decreased. B2C found this result for the intervention group overall and among those with a comorbid mental health diagnosis. ${ }^{141}$

\section{Cost Outcomes}

Five of nine studies reported the effect of the intervention on costs over 6 or more months of followup (Appendix Table B-36). The KCCP RCT and two observational studies (CSHP and Familiar Faces) observed no significant difference in total costs. ${ }^{139,}$ 148, 162, 172 We graded total costs as insufficient strength of evidence (Table 19). The Camden RCT observed no significant difference in hospital costs. ${ }^{44}$ The KCCP RCT also observed no significant difference in ED costs or inpatient costs. ${ }^{162}$ PAD (rated high risk of bias) observed a significantly greater reduction in the intervention group in ED costs, while CSHP did not observe any differences in inpatient costs. ${ }^{139,174,176}$ Changes in inpatient costs and ED costs were graded as insufficient strength of evidence. 


\section{Clinical and Functional Outcomes}

Among the community-based studies, all three RCTs reported mortality (Appendix Table B-37). The three RCTs observed no significant difference in mortality rate from the comparison group. ${ }^{44,159,162}$ We graded mortality as low strength of evidence for no difference (Table 19).

\section{Social Risk Outcomes}

Even though each of the three community-based RCTs reported key social risk outcomes, no two studies reported the same outcome. Among three social risk measures reported by the Camden RCT (Appendix Table B-38), the authors reported a significant increase in participation in the Supplemental Nutrition Assistance Program 6 months after discharge, but no difference in participation in Temporary Assistance for Needy Families or General Assistance. ${ }^{44}$ The PWH RCT and KCCP reported several outcomes related to housing and criminal justice. In line with a housing intervention, the PWH RCT reported significantly more intervention group participants being ever housed and having fewer shelter days compared with comparison group participants but no difference between the groups in jail stays. The care management-focused KCCP RCT did not observe a difference between the treatment and comparison groups in homelessness, criminal convictions, or drug and alcohol treatment.

\section{Emergency Department-Based Models}

\section{Overview}

- ED-based models were reported in seven studies (7 samples). The interventions differed across studies. One RCT examined clinical case management, one RCT examined CHW care coordination, two RCTs and one observational study examined patient navigation, one observational study examined case management and housing support, and one observational study examining care coordination.

- We found a greater reduction in ED visits in the intervention group, based on consistent and precise evidence from four RCTs and two observational studies (moderate strength of evidence for favorable findings).

- We found a reduction in inpatient admissions, based on consistent and precise evidence from one RCT and one observational study (low strength of evidence for favorable findings).

- We found an increase in primary care visits, based on consistent and precise evidence from one RCT and one observational study (low strength of evidence for favorable findings).

- We found a greater reduction in ED costs, based on consistent evidence from three RCTs and one observational study (low strength of evidence for favorable findings).

- We found that ED-based models were not associated with a change in inpatient costs, based on evidence from two RCTs and one observational study (low strength of evidence for no difference).

- The evidence is insufficient to judge all other outcomes.

\section{Detailed Results}

Seven studies in seven publications, analyzing seven samples, reported on ED-based models. All were evaluated in comparison with usual care (Appendix Table B-39). ${ }^{160,161,166,168,170,175,177}$ 
This type of model is described as one in which patients are recruited in the ED, and often an ED-affiliated team provides care. ${ }^{45}$

Four of the studies were RCTs conducted at urban EDs. ${ }^{160,} 161,166,168$ One RCT, the EDinitiated Patient Navigation (ED-PN) program (rated low risk of bias), identified Medicaid patients in the ED with high ED use (4 to 18 visits in 12 months). The ED-PN intervention provided patients with a patient navigator with the goals of improving healthcare access and ultimately decreasing ED visits, inpatient admissions, and costs. ${ }^{160}$ The other three RCTs were rated some concerns for risk of bias. One of these RCTs also tested a patient navigation program (hence referred to as "ED navigation RCT"), examining whether a trained patient navigator could reduce ED use and costs and increase primary care appointments and satisfaction among ED patients with high ED use (5 or more visits in 12 months). ${ }^{168}$ Another RCT assessed the effectiveness of clinical case management for frequent users of the ED. ${ }^{166}$ The intervention focused on addressing psychosocial problems common among frequent ED users, including homelessness, alcohol problems, lack of health insurance and income, and psychiatric conditions. The fourth RCT assessed a pilot intervention that used CHWs to assist high-ED-use patients with care coordination and addressing social issues. ${ }^{161}$

One observational study, the Emergency Room Decision-Support (ERDS) program (rated some concerns for risk of bias), provided care coordination to patients with high ED use (3 or more visits in the past year), who were enrolled in the UnitedHealthCare AARP Supplement Insurance Plan. ${ }^{170}$ Through the ERDS program, nurse care managers, available via telephone, discussed treatment options and provided assistance with making appointments and navigating health resources. ${ }^{170}$

The remaining two observational studies were rated high risk of bias. One of the studies assessed an ED navigation program, conducted across nine EDs in one healthcare system. CHWs provided navigational services to promote appropriate primary care use and prevent or reduce primary care-related ED (PCR-ED) use among Medicaid and uninsured patients. ${ }^{175}$ PCR-ED visits were defined as visits for conditions that are preventable or treatable with appropriate primary care (e.g., did not require medical care within 12 hours, could be addressed by immediate care in a primary care clinic, or emergent needs that could have been prevented by routine primary care).

The other high risk-of-bias observational study evaluated an ED-based case management and homeless outreach program for high-use ED patients (5 or more visits annually for 2 consecutive years) who were chronically homeless and alcohol dependent. In addition to providing case management, this intervention aimed to help patients access housing resources. Notably, this study compared intervention patients with both a retrospective control group and a prospective control group. ${ }^{177}$

\section{Intervention Characteristics}

HNHC patient eligibility across these interventions required high service use, but it was defined differently across studies. In the ED-PN RCT, ${ }^{160}$ high use was defined as having 4 to 18 visits in the prior 12 months, while the ED case management RCT and the ED navigation RCT defined high use as five or more ED visits in the prior 12 months. ${ }^{166,168}$ The CHW RCT identified high-ED-use patients as patients with the most ED visits in both the past 12 month and in the past 30 days. ${ }^{161}$ The case management RCT further limited enrollment to patients with psychosocial problems that could be addressed with case management. ${ }^{166}$ PCR-ED included frequent users of the ED for primary care who were covered by Medicaid, a Texas program that subsidizes medical costs for eligible residents, or were uninsured/self-pay. ${ }^{175}$ The ED and 
housing observational study defined high use as five or more ED visits for 2 consecutive years and one ED visit in the last 6 months. This study also selected individuals who were undomiciled without shelter for 9 to 24 months. ${ }^{177}$

Common elements across the interventions included staff to help patients address health and social services needs and improve access to community resources. Each of the interventions included initial patient needs assessments, followed by case management or patient navigator services (Appendix Table B-40).

In the ED case management RCT, over a 24-month period, psychiatric social workers collaborated with nurse practitioners and primary care physicians to help patients obtain stable housing, income entitlements, and referrals to mental health and substance abuse treatment. Case managers also provided links to medical care, conducted assertive community outreach, and assisted in obtaining stable housing. ${ }^{166}$

Across the ED patient navigator interventions, the service intensity varied. The navigators in the ED navigation RCT interacted with patients at ED visits and subsequent to the initial visit and followed up by telephone within 2 weeks and 12 months of the initial ED visit. The navigators reviewed prescriptions and diagnoses with patients, arranged followup appointments, and identified relevant community resources. ${ }^{168}$ In the ED-PN RCT, patients received more intensive patient navigation services. Patient navigators met with patients every 2 weeks for the first month, then every 4 weeks for the rest of the year. ${ }^{160}$ The navigators helped patients access primary care, accompanied patients to primary care appointments, connected patients with community resources, and helped patients overcome personal barriers. In the CHW RCT, the ED-based CHW met with patients during their ED visits and subsequently used telephone and home visits to help patients coordinate care, including accessing primary care and identifying and addressing unmet social and behavioral needs that contributed to high ED use. ${ }^{161}$ In the PCR-ED observational study, the CHWs called patients within 3 to 10 days of the initial ED visit. They educated patients on the importance of primary care and making and keeping appointments, helped patients identify specific barriers to seeking and getting primary care, and connected patients with community resources or healthcare providers. ${ }^{175}$

In the ERDS program, a nurse helped patients make connections with health resources and care coordination programs and make appointments with providers. ${ }^{170}$

In the ED and housing observational study, social workers and an outreach team met with patients during ED visits to help them follow their care plan to obtain housing. ${ }^{177}$

\section{Intervention Outcomes}

\section{Utilization Outcomes}

All seven studies reported on healthcare utilization (Appendix Table B-41). All studies found ED visits decreased in both the intervention and comparison groups. The reduction was significantly larger in the intervention groups in three of four RCTs. ${ }^{160,166,168,170,175,177}$ The EDPN RCT, ED navigation RCT, ED case management RCT, and the ERDS observational study all found the reduction in the number of ED visits to be significantly larger among patients with high ED use in the 12 months before the intervention. The CHW RCT observed a reduction in ED visits in the intervention group compared with the comparison group but this difference was not statistically different between the groups. ${ }^{161}$ In the high risk-of-bias ED and housing observational study, the reduction in ED visits in the intervention group was statistically different than the reduction in ED visits when compared with the prospective control groups but not statistically different when compared with the retrospective control group. ${ }^{177} \mathrm{We}$ graded the 
strength of evidence of a reduction in ED visits as favorable finding because of the consistent findings among all four RCTs and precise findings among three of four RCT studies (moderate strength of evidence) (Table 20; full strength-of-evidence decisions can be found in Appendix Table B-42).

Table 20. Summary of findings for ED-based models versus usual-care outcomes

\begin{tabular}{|c|c|c|c|c|}
\hline Outcome & Population & $\begin{array}{l}\text { \# Samples/Design } \\
\text { (n Analyzed) }\end{array}$ & Findings $^{a}$ & $\begin{array}{l}\text { Strength of Evidence } \\
\text { (Direction of Effect) }\end{array}$ \\
\hline ED visits, all cause & HNHC patients & $\begin{array}{l}4 \text { RCTs }^{160,161,166,168} \\
(\mathrm{~N}=728) \\
2 \mathrm{OBS}^{170,177} \\
(\mathrm{~N}=14,200)\end{array}$ & $\begin{array}{l}3 \text { of } 4 \text { RCT samples } \\
\text { had favorable findings } \\
1 \text { of } 4 \text { RCT samples } \\
\text { found no difference } \\
1 \text { of } 2 \text { OBS samples } \\
\text { had favorable findings } \\
1 \text { of } 2 \text { OBS samples } \\
\text { had favorable findings } \\
\text { compared with one } \\
\text { control group and no } \\
\text { difference compared } \\
\text { with one control group }\end{array}$ & $\begin{array}{l}\text { Moderate (Favorable: } \\
\text { reduction) }\end{array}$ \\
\hline $\begin{array}{l}\text { Inpatient } \\
\text { admissions, all } \\
\text { cause }\end{array}$ & HNHC patients & $\begin{array}{l}1 \mathrm{RCT}^{160} \\
(\mathrm{~N}=100) \\
1 \mathrm{OBS}^{170} \\
(\mathrm{~N}=14,140)\end{array}$ & $\begin{array}{l}1 \text { of } 1 \text { RCT sample had } \\
\text { favorable findings } \\
1 \text { of } 1 \text { OBS sample had } \\
\text { favorable findings }\end{array}$ & $\begin{array}{l}\text { Low (Favorable: } \\
\text { reduction) }\end{array}$ \\
\hline Primary care visits & HNHC patients & $\begin{array}{l}1 \mathrm{RCT}^{168} \\
(\mathrm{~N}=304) \\
1 \mathrm{OBS}^{170} \\
(\mathrm{~N}=14,140) \\
\end{array}$ & $\begin{array}{l}1 \text { of } 1 \text { RCT sample had } \\
\text { favorable findings } \\
1 \text { of } 1 \text { OBS sample had } \\
\text { favorable findings }\end{array}$ & Low (Favorable: increase) \\
\hline Outpatient visits & HNHC patients & $2 \mathrm{RCTs}^{160,166}$ & $\begin{array}{l}2 \text { of } 2 \text { RCT samples } \\
\text { found no difference }\end{array}$ & Insufficient \\
\hline ED costs & HNHC patients & $\begin{array}{l}3 \text { RCTs }^{161,166,168} \\
(\mathrm{~N}=628) \\
1 \mathrm{OBS}^{170} \\
(\mathrm{~N}=14,140)\end{array}$ & $\begin{array}{l}2 \text { of } 3 \text { RCT samples } \\
\text { had favorable findings } \\
1 \text { of } 3 \text { RCT samples } \\
\text { found no difference } \\
1 \text { of } 1 \text { OBS sample } \\
\text { found no difference }\end{array}$ & $\begin{array}{l}\text { Low (Favorable: } \\
\text { reduction) }\end{array}$ \\
\hline Inpatient costs & HNHC patients & $\begin{array}{l}2 \mathrm{RCTs}^{161,166} \\
(\mathrm{~N}=324) \\
1 \mathrm{OBS}^{170} \\
(\mathrm{~N}=14,140)\end{array}$ & $\begin{array}{l}2 \text { of } 2 \text { RCT samples } \\
\text { found no difference } \\
1 \text { of } 1 \text { OBS sample } \\
\text { found no difference }\end{array}$ & Low (No difference) \\
\hline $\begin{array}{l}\text { Hospital costs of } \\
\text { care }\end{array}$ & HNHC patients & $\begin{array}{l}2 \mathrm{RCTs}^{160,166} \\
(\mathrm{~N}=352)\end{array}$ & $\begin{array}{l}2 \text { of } 2 \text { RCT samples } \\
\text { found no difference }\end{array}$ & Insufficient \\
\hline Outpatient costs & HNHC patients & $\begin{array}{l}1 \mathrm{RCT}^{166} \\
(\mathrm{~N}=252) \\
1 \mathrm{OBS}^{170} \\
(\mathrm{~N}=14,140)\end{array}$ & $\begin{array}{l}1 \text { of } 1 \text { RCT sample } \\
\text { found no difference } \\
1 \text { of } 1 \text { OBS sample } \\
\text { found no difference }\end{array}$ & Insufficient \\
\hline
\end{tabular}

${ }^{a}$ Findings were determined to be favorable or unfavorable based on the intent of the intervention. For example, if the intent of the intervention was to lower total cost, then a greater increase in total cost among intervention group patients compared with comparison group patients was classified as unfavorable. Similarly, changes in utilization may be identified as favorable or unfavorable depending on the intent of the intervention and the specific outcome. For studies that intended to reduce ED visits and shift service use to primary care, a greater increase in the use of ED visits among intervention group patients compared with comparison group patients would be unfavorable, while an increase in primary care visits would be favorable.

$\mathrm{ED}=$ emergency department; $\mathrm{HNHC}=$ high-need, high-cost; $\mathrm{N}=$ number; $\mathrm{OBS}=$ observational study; RCT = randomized controlled trial. 
Differences in inpatient admissions were reported by the ED-PN RCT and the ERDS observational study. Both studies reported significantly greater reductions in inpatient admissions among the intervention group compared with the comparison group. We graded inpatient admissions to have favorable findings (low strength of evidence) (Table 20).

Three of the RCTs and one of the observational studies examined whether the intervention affected use of healthcare services beyond reductions in ED use. The ED navigation RCT observed greater use of primary care visits in the intervention group, suggesting that the navigation program may positively influence patients to seek more appropriate care. ${ }^{168}$ Similarly, the ERDS observational study reported a smaller reduction in primary care visits in the intervention group than the comparison group. The study authors suggested that the intervention helped ED patients seek care in a more appropriate setting, away from ED and inpatient care toward physician office visits. ${ }^{170} \mathrm{We}$ graded the increase in primary care visits as a favorable low strength of evidence finding. In contrast, the case management RCT and the ED-PN RCT tested, but did not find, a difference between groups in outpatient visits (insufficient strength of evidence). ${ }^{160,166}$

\section{Cost Outcomes}

The four RCTs and the ERDS study reported changes in cost (Appendix Table B-43). The ED navigation RCT and case management RCT found that ED costs decreased in both intervention and comparison groups but were significantly lower in the intervention group. ${ }^{166,168}$ Both the CHW RCT and the ERDS study also reported a greater reduction in the intervention group than the comparison group, this difference was not statistically significant, ${ }^{161,170}$ The precise and consistent evidence in two RCTs supported by consistent evidence in one other RCT and one observational study led to a grade of favorable findings (low strength of evidence) for ED costs (Table 20). In relation to inpatient costs, the CHW RCT, case management RCT, and the ERDS observational study did not find a difference between groups; we graded this outcome as low strength of evidence for no difference. The ED-PN RCT, case management RCT, and the ERDS observational study found no differences in outpatient costs and hospital costs of care (or the actual cost to hospital), and both outcomes were graded as insufficient strength of evidence.

\section{Clinical and Functional Outcomes}

The case management RCT, ED navigation RCT, and ED and housing observational study reported clinical and functional outcomes, but no outcomes were reported across studies. The case management RCT found no differences in psychiatric symptom scores (Appendix Table B-44). ${ }^{166}$ The ED navigation RCT reported no difference in patient satisfaction. ${ }^{168}$ The ED and housing observational study reported mortality rate but did not determine whether the difference was significant. Although no deaths were reported among intervention patients during the followup period, one participant death that occurred 4 months after the study may have been study related. ${ }^{177}$

\section{Social Risk Outcomes}

Only the case management RCT and ED and housing observational study reported social risk outcomes. The case management RCT found that homelessness and social security income outcomes were significantly better in the intervention group (Appendix Table B-45). ${ }^{166}$ The ED and housing observational study reported higher accepted shelter rates in the intervention group. ${ }^{177}$ 


\section{Ambulatory Intensive Caring Unit Model}

\section{Overview}

- One RCT and three observational studies (4 samples) reported on aICU models.

- aICU models were associated with a greater reduction in total costs (low strength of evidence for favorable findings).

- Evidence was insufficient to judge all other outcomes.

\section{Detailed Results}

Four studies in six publications, analyzing four samples, reported on aICU models (Appendix Table B-46). ${ }^{138,140,145,149,152,173}$ This type of model is a separate clinic or a team within a clinic that provides care to a panel of complex HNHC patients. ${ }^{45}$ One study was an RCT (rated some concerns for risk of bias) in which five VA facilities compared an aICU intervention, the Patient Aligned Care Team-Intensive Management (PIM) intervention, with usual care, the PACT PCMH. ${ }^{140,149}$ The other three studies were observational designs. The first (rated some concerns for risk of bias) compared enrollment in Hennepin Health ( $\mathrm{HH}$ ), a Medicaid risk-sharing ACO, with enrollment in Medicaid MCOs. ${ }^{152,173}$ The Hennepin Health Accountable Care Organization (HH ACO) created a network of providers, clinics, and hospitals that coordinated care for their enrollees, including multidisciplinary care coordination teams in their clinics and referrals to intensive primary care. The HH ACO was available to all their Medicaid enrollees. We present only the findings specific to the HNHC patient population. A second observational study (also rated some concerns for risk of bias) compared an aICU model within one integrated delivery system, called the Intensive Outpatient Clinic (IOC), with care received by historic controls, HNHC patients in the regular primary care clinic during an earlier period. ${ }^{138}$ The second observational study (rated high risk of bias due to inadequate control for confounding) compared an aICU model called Care One, implemented in one medical center, with usual care. ${ }^{145}$

\section{Intervention Characteristics}

HNHC patients were eligible for these interventions based on prior service use: in $\mathrm{HH}$ ACO, four or more ED visits or two or more hospitalizations, ${ }^{152}$ in PIM, high inpatient use over a 6month period, ${ }^{140,149}$ and in IOC, high inpatient use over a 12-month period. ${ }^{138}$ Care One eligibility was based on high inpatient cost, measured over a 12 -month period. ${ }^{145}$ PIM and Care One further selected participants based on the team's judgment that an individual would be responsive and benefit from the services of an aICU.

Across programs, intervention components included an initial assessment, followed by an array of care management and healthcare services (Appendix Table B-47). In three interventions, service intensity could vary across participants. Some participants received a high level of services, including multiple face-to-face encounters, which may have been in the home. In contrast, other participants received no services. Thirty-seven percent of individuals in the PIM intervention group and 33 percent of individuals in the IOC intervention group had no intervention encounters. ${ }^{138,149}$ Both studies primarily attributed this to inefficiencies in targeting participants who would be a good match for the program. While service intensity was not specified for $\mathrm{HH}$ ACO, each multidisciplinary team included a care coordinator, provider, social worker, and psychologist and served approximately 125 high-risk patients. ${ }^{152,173}$ Care One also provided incentives to primary care physicians for accepting complex, Care One patients in their panels. ${ }^{145}$ 


\section{Intervention Outcomes}

\section{Utilization Outcomes}

Three of the four studies reported the effect of the intervention on changes in utilization (Appendix Table B-48). Two of the studies (PIM RCT ${ }^{140}$ and $\mathrm{HH} \mathrm{ACO}{ }^{152,173}$ ) reported on changes in patients' number of ED visits and found no significant differences between groups (insufficient strength of evidence) (Table 21). Two observational studies reported contradictory findings on changes in inpatient admissions. HH ACO observed a greater reduction in inpatient admissions among intervention group participants compared with the comparison group ${ }^{152,173}$ while IOC reported significantly more inpatient admissions than expected among the intervention group patients. ${ }^{138}$ We graded the strength of evidence for inpatient admissions insufficient due to these mixed findings. (All aICU strength-of-evidence grades can be found in Appendix Table B-50.)

Two interventions examined changes in the use of outpatient visits. The PIM RCT ${ }^{140}$ reported significant favorable increases in the primary care visits among the intervention group compared with the comparison group, while the observational $\mathrm{HH} \mathrm{ACO}^{152,173}$ did not report a difference between the two groups (insufficient strength of evidence because of mixed evidence).

\section{Cost Outcomes}

Three of the four studies reported the effect of the intervention on changes in total costs/charges (Appendix Table B-49). All three studies found reductions in both the intervention and comparison groups. In the PIM RCT, the difference in the reduction between the two groups was not significantly different. A significantly greater increase in outpatient costs (primary care, care management, and mental healthcare) in the PIM group was offset by a larger, but not significantly different, reduction in inpatient costs. In the two observational studies, IOC and Care One (rated high risk of bias), the reduction was significantly greater in the intervention than in the comparison group (Appendix Table B-49). The consistent evidence across the three studies and precise evidence from the two observational studies led to a grade of favorable findings (low strength of evidence) for reduction in total costs (Table 21; full strength of evidence can be found in Appendix Table B-50).

Table 21. Summary of findings for alCU-based models versus usual-care outcomes

\begin{tabular}{|c|c|c|c|c|}
\hline Outcome & Population & $\begin{array}{l}\text { \# Samples/Design } \\
\text { (n Analyzed) }\end{array}$ & Findings $^{a}$ & $\begin{array}{l}\text { Strength of } \\
\text { Evidence (Direction } \\
\text { of Effect) }\end{array}$ \\
\hline ED visits, all cause & HNHC patients & $\begin{array}{l}1 \mathrm{RCT}^{140} \\
(\mathrm{~N}=2,210) \\
1 \mathrm{OBS}^{152,173} \\
\left(\mathrm{~N}=\mathrm{NR}^{\mathrm{b}}\right)\end{array}$ & $\begin{array}{l}1 \text { of } 1 \text { RCT sample } \\
\text { found no difference } \\
1 \text { of } 1 \text { OBS sample } \\
\text { found no difference }\end{array}$ & Insufficient \\
\hline $\begin{array}{l}\text { Inpatient admissions, } \\
\text { all cause }\end{array}$ & HNHC patients & $\begin{array}{l}2 \mathrm{OBSs}^{138,152,173} \\
\left(\mathrm{~N}=\mathrm{NR}^{\mathrm{b}}\right)\end{array}$ & $\begin{array}{l}1 \text { of } 2 \text { OBS samples } \\
\text { had favorable } \\
\text { findings } \\
1 \text { of } 2 \text { OBS samples } \\
\text { had unfavorable } \\
\text { findings }\end{array}$ & Insufficient \\
\hline Primary care visits & HNHC patients & $\begin{array}{l}1 \mathrm{RCT}^{140} \\
(\mathrm{~N}=2,210) \\
1 \mathrm{OBS}^{152,173} \\
\left(\mathrm{~N}=\mathrm{NR}^{\mathrm{b}}\right)\end{array}$ & $\begin{array}{l}1 \text { of } 1 \text { RCT sample } \\
\text { had favorable } \\
\text { findings } \\
1 \text { of } 1 \text { OBS sample } \\
\text { found no difference }\end{array}$ & Insufficient \\
\hline
\end{tabular}




\begin{tabular}{|c|c|c|c|c|}
\hline Outcome & Population & $\begin{array}{l}\text { \# Samples/Design } \\
\text { (n Analyzed) }\end{array}$ & Findings $^{a}$ & $\begin{array}{l}\text { Strength of } \\
\text { Evidence (Direction } \\
\text { of Effect) }\end{array}$ \\
\hline Total costs & HNHC patients & $\begin{array}{l}1 \mathrm{RCT}^{140} \\
(\mathrm{~N}=2,210) \\
2 \mathrm{OBS}^{138,145} \\
(\mathrm{~N}=5,183)\end{array}$ & $\begin{array}{l}1 \text { of } 1 \text { RCT sample } \\
\text { found no difference } \\
2 \text { of } 2 \text { OBS samples } \\
\text { had favorable } \\
\text { findings }\end{array}$ & $\begin{array}{l}\text { Low (Favorable: } \\
\text { reduction) }\end{array}$ \\
\hline Mortality rate & HNHC patients & $\begin{array}{l}1 \mathrm{RCT}^{140} \\
(\mathrm{~N}=2,210) \\
1 \mathrm{OBS}^{138} \\
(\mathrm{~N}=3,636)\end{array}$ & $\begin{array}{l}1 \text { of } 1 \text { RCT sample } \\
\text { found no difference } \\
1 \text { of } 1 \text { OBS sample } \\
\text { had favorable } \\
\text { findings }\end{array}$ & Insufficient \\
\hline
\end{tabular}

${ }^{\text {a }}$ Findings were determined to be favorable or unfavorable based on the intent of the intervention. For example, if the intent of the intervention was to lower total cost, then a greater increase in total cost among intervention group patients compared with comparison group patients was classified as unfavorable. Similarly, changes in utilization may be identified as favorable or unfavorable depending on the intent of the intervention and the specific outcome. For studies that intended to reduce ED visits and shift service use to primary care, a greater increase in the use of ED visits among intervention group patients compared with comparison group patients would be unfavorable, while an increase in primary care visits would be favorable.

$\mathrm{b}$ The HH ACO ${ }^{152,173}$ study did not report sample sizes for their HNHC populations; the total sample size for the study was 92,891. The sample size for the IOC study was 3,636. ${ }^{138}$

aICU = Ambulatory Intensive Caring Unit Model; ED = emergency department; HNHC = high need, high cost; IOC $=$ Intensive Outpatient Clinic; $\mathrm{N}=$ number; $\mathrm{OBS}=$ observational study; $\mathrm{RCT}=$ randomized controlled trial.

\section{Clinical and Functional Outcomes}

Change in mortality was the only clinical or functional outcome reported across studies (Appendix Table B-51). Results were mixed. The PIM RCT found no difference between groups, while the IOC study found lower mortality in the IOC group than the comparison group (insufficient strength of evidence) (Table 21).

Only the PIM RCT reported on additional clinical and functional outcomes. The PIM participants had significantly better outcomes for measures of trusted relationship with providers and patient assessment of chronic illness care score. No differences were reported between the groups on measures of access to care or satisfaction with care.

\section{Social Risk Outcomes}

No social risk outcomes were reported among the aICU model studies.

\section{Primary Care-Based Interventions}

\section{Overview}

- Five RCTs and three observational studies, representing nine samples, reported on primary care-based models.

- We found a greater reduction in the number of patients with an inpatient admission among primary care-based interventions, based on evidence from two RCT samples (low strength of evidence for favorable findings).

- We found a reduction in total healthcare cost among primary care-based interventions, based on evidence from four RCT samples and one observational sample (low strength of evidence for favorable findings). We calculated a pooled mean difference from three RCT samples that measured cost similarly (mean difference, $-\$ 3,848.43[95 \%$ CI, $-5,514.24$ to $-2,182.61] ; 3$ RCT samples; $\left.\mathrm{N}=7,196 ; \mathrm{I}^{2}=0.0 \%\right)$. The fourth RCT sample reported no significant difference between the groups but did not report an effect 
estimate. The observational study reported an increase in total cost, but the effect was not significantly different from the control group.

- We found a reduction in influenza vaccine uptake among primary care-based interventions, based on evidence from two samples (low strength of evidence for unfavorable findings).

- The evidence is insufficient to judge other utilization, cost, and clinical and functional outcomes.

\section{Detailed Results}

Primary care-based interventions were reported in 9 samples in eight studies, published in

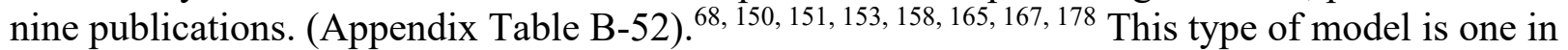
which the intervention team is embedded in one or more primary care practices. ${ }^{45}$ Usual care was the comparison in all analyses.

Five of the eight studies were RCTs. ${ }^{68,151,158,165,167}$ One RCT (rated low risk of bias), Primary Intensive Care (PIC), was a case management intervention at one site, with a strong mental health focus, implemented for a clinically heterogeneous group of patients. ${ }^{165}$ A second RCT, the Massachusetts General Hospital and Massachusetts General Physicians Organization (MGH) CMP (rated low risk of bias), a CMHCB demonstration site, aimed to provide comprehensive, practice-based outpatient case management for high-risk patients. ${ }^{68}$ This RCT included two intervention group samples, an original and a refresh sample. ${ }^{68}$ The third RCT (rated some concerns for risk of bias) tested whether primary care group visits would lower ED use among older adults with chronic conditions. ${ }^{167}$ The fourth RCT (rated some concerns for risk of bias) examined a depression management program (DMP) for high users of outpatient visits. ${ }^{151}$ The fifth RCT (rated some concerns for risk of bias) tested the impact of a complex care management (CCM) intervention at one site for HNHC Medicaid patients. ${ }^{158}$

Three of the eight studies were observational designs. ${ }^{72,150,153,178}$ One observational study (rated some concerns for risk of bias) assessed the impact of the Community-Based Care Management (CBCM) program, an MCO-led care coordination and disease management intervention, on HNHC Medicaid patients enrolled in the MCO. ${ }^{178}$ The other two observational studies were rated high risk of bias because neither analysis controlled for potential confounding. ${ }^{150,153}$ The first, Bridges to Health, was a primary care team-based intervention that included group visits and case management for patients with complex medical and behavioral problems. ${ }^{150}$ The other was a small pilot program $(\mathrm{N}=21)$ testing the effect of a clinic-based interdisciplinary care teams for patients who frequently visited a family medicine residency clinic. $^{153}$

\section{Intervention Characteristics}

The levels of high use or cost required for patient inclusion varied across studies. Three of the studies used high use criteria to identify eligible patients. Criteria included two or more hospitalizations in the past year in the PIC RCT, ${ }^{165}$ six or more ED visits in the past year for Bridges to Health, ${ }^{150}$ and eight or more clinic visits for the interdisciplinary pilot study. ${ }^{153}$ Two studies required both high use and diagnosis of a condition. The group-visit RCT included patients with 11 or more outpatient visits in the past 18 months and at least one self-reported chronic condition, ${ }^{167}$ while the DMP used a positive depression screen and a percentile threshold (i.e., number of outpatient visits above the 85 th percentile in the previous 2 years). ${ }^{151}$ The CBCM observational study included participants based on high cost, those who were in the top 10 
percent of total cost for at least 1 month of the 24-month study period. ${ }^{178}$ The MGH RCT used a combination of a cost threshold and high risk for future costs for its inclusion criteria (annual Medicare costs of $\$ 2,000$ or more and an HCC risk score $\geq 2.0$ or costs of $\$ 1,000$ or more and an HCC risk score $\geq 3.0 .{ }^{68}$ Finally, the CCM RCT used a more complex algorithm that identified patients through cost, use, and need. Patients were included if (1) they were in the top 5 percent of costs in the prior 12 months, top 5 percent of predicted costs in the subsequent 12 months, or through team nomination and (2) had two or more inpatient admissions, three or more ED visits, or two or more chronic conditions. ${ }^{158}$

The nine studies tested various approaches to delivering and paying for care for HNHC patients through primary care (Appendix Table B-53). All of the interventions integrated care management, case management, and care coordination into their primary care practices. Care managers or coordinators were central to many interventions and help communication and collaboration across multidisciplinary care teams. One $\mathrm{RCT}^{167}$ and one observational study ${ }^{150}$ tested the effectiveness of group visits, while two RCTs included home visits as needed. ${ }^{68,165}$ Interventions generally included efforts to educate patients on health topics and available resources, connect patients with community services to meet social and health needs, share information with other healthcare providers, and collaborate with specialists, such as psychiatrists. In the group-visit RCT and the clinic-based interdisciplinary care teams observational study, all interactions between the care manager and the patient were face-toface. ${ }^{153,167}$ The other studies described one-on-one interactions occurring in person or via telephone. The MGH intervention tested an alternative payment approach (i.e., care management fees and shared savings) to incentivize efficiency and higher-quality care. ${ }^{68}$

\section{Intervention Outcomes}

\section{Utilization Outcomes}

All eight studies reported one or more measures of healthcare utilization (Appendix Table B-54). ${ }^{68,150,151,153,165,167}$ Because the pilot interdisciplinary care teams observational study was very small $(\mathrm{N}=21)$, the authors reported only numeric differences between the intervention and comparison groups and not the precision of the differences. Findings for this study are not described in the text. ${ }^{153}$

Six samples from five studies reported on changes in the number of ED visits. Results were mixed. Three analyses (the MGH RCT refresh sample and the two group-visit studies [the groupvisit RCT and the Bridges to Health observational study]) reported significantly fewer ED visits in the intervention group compared with usual care. ${ }^{68,150,167}$ In contrast, the CBCM observational study reported significantly more ED visits in the intervention group compared with the comparison group. ${ }^{178}$ Unlike the MGH RCT refresh sample, the MGH RCT original sample did not report a statistically significant difference between the two groups. ${ }^{68}$ The PIC RCT and CCM RCT did not report any significant differences between the intervention and comparison groups. ${ }^{158,165}$ Because of the mixed results across the samples, we graded the strength of evidence for reduction in ED visits as insufficient (Table 22; full strength of evidence can be found in Appendix Table B-55). Both MGH RCT samples also reported change in ACSC ED visits and found no significant difference between the groups (insufficient strength of evidence). ${ }^{68}$ 
Table 22. Summary of findings for primary care-based models versus usual-care outcomes

\begin{tabular}{|c|c|c|c|c|}
\hline Outcome & Population & $\begin{array}{l}\text { \# Samples/Design } \\
\text { (n Analyzed) }\end{array}$ & Findings $^{s}$ & $\begin{array}{l}\text { Strength of Evidence } \\
\text { (Direction of Effect) }\end{array}$ \\
\hline \multirow[t]{5}{*}{ ED visits, all cause } & \multirow[t]{5}{*}{ HNHC patients } & \multirow{5}{*}{$\begin{array}{l}5 \mathrm{RCTs}^{68,158,165,167} \\
(\mathrm{~N}=7,587) \\
3 \mathrm{OBS}^{150,153,178} \\
(\mathrm{~N}=3,141)\end{array}$} & $\begin{array}{l}2 \text { of } 5 \text { RCT samples had } \\
\text { favorable findings }\end{array}$ & \multirow[t]{5}{*}{ Insufficient } \\
\hline & & & $\begin{array}{l}3 \text { of } 5 \text { RCT samples found no } \\
\text { difference }\end{array}$ & \\
\hline & & & $\begin{array}{l}1 \text { of } 3 \text { OBS samples had } \\
\text { favorable findings }\end{array}$ & \\
\hline & & & $\begin{array}{l}1 \text { of } 3 \text { OBS samples found no } \\
\text { difference }\end{array}$ & \\
\hline & & & $\begin{array}{l}1 \text { of } 3 \text { OBS samples had } \\
\text { unfavorable findings }\end{array}$ & \\
\hline ED visits, ACSC & $\mathrm{HNHC}$ patients & $\begin{array}{l}2 \mathrm{RCTs}^{68} \\
(\mathrm{~N}=6,943)\end{array}$ & $\begin{array}{l}2 \text { of } 2 \text { RCT samples found no } \\
\text { difference }\end{array}$ & Insufficient \\
\hline \multirow[t]{4}{*}{$\begin{array}{l}\text { Inpatient admissions, } \\
\text { all cause }\end{array}$} & \multirow[t]{4}{*}{ HNHC patients } & \multirow{4}{*}{ 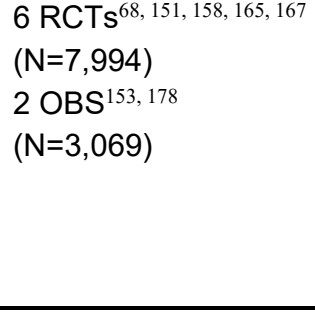 } & $\begin{array}{l}4 \text { of } 6 \text { RCT samples had } \\
\text { favorable findings }\end{array}$ & \multirow[t]{4}{*}{ Insufficient } \\
\hline & & & $\begin{array}{l}2 \text { of } 6 \text { RCT samples found no } \\
\text { difference }\end{array}$ & \\
\hline & & & $\begin{array}{l}1 \text { of } 2 \text { OBS samples found no } \\
\text { difference }\end{array}$ & \\
\hline & & & $\begin{array}{l}1 \text { of } 2 \text { OBS samples had } \\
\text { unfavorable findings }\end{array}$ & \\
\hline $\begin{array}{l}\text { Inpatient admissions, } \\
\text { any }\end{array}$ & $\mathrm{HNHC}$ patients & $\begin{array}{l}2 \mathrm{RCTs}^{68} \\
(\mathrm{~N}=6,943)\end{array}$ & $\begin{array}{l}2 \text { of } 2 \text { RCT samples had } \\
\text { favorable findings }\end{array}$ & Low (Favorable) \\
\hline $\begin{array}{l}\text { Inpatient admissions, } \\
\text { ACSC }\end{array}$ & HNHC patients & $\begin{array}{l}2 \mathrm{RCTS}^{68} \\
(\mathrm{~N}=6,943)\end{array}$ & $\begin{array}{l}2 \text { of } 2 \text { RCT samples found no } \\
\text { difference }\end{array}$ & Insufficient \\
\hline \multirow[t]{2}{*}{$\begin{array}{l}\text { Inpatient admissions, } \\
\text { any ACSC }\end{array}$} & \multirow[t]{2}{*}{ HNHC patients } & \multirow[t]{2}{*}{$\begin{array}{l}2 \mathrm{RCTs}^{68} \\
(\mathrm{~N}=6,943)\end{array}$} & $\begin{array}{l}1 \text { of } 2 \text { RCT samples had } \\
\text { favorable findings }\end{array}$ & \multirow[t]{2}{*}{ Insufficient } \\
\hline & & & $\begin{array}{l}1 \text { of } 2 \text { RCT samples found no } \\
\text { difference }\end{array}$ & \\
\hline \multirow[t]{2}{*}{ Primary care visits } & \multirow[t]{2}{*}{ HNHC patients } & $\begin{array}{l}2 \mathrm{RCTs}^{165,167} \\
(\mathrm{~N}=391)\end{array}$ & $\begin{array}{l}2 \text { of } 2 \text { RCT samples found no } \\
\text { difference }\end{array}$ & \multirow[t]{2}{*}{ Insufficient } \\
\hline & & $\begin{array}{l}1 \mathrm{OBS}^{178} \\
(\mathrm{~N}=3,048)\end{array}$ & $\begin{array}{l}1 \text { of } 1 \text { OBS sample had } \\
\text { unfavorable findings }\end{array}$ & \\
\hline \multirow[t]{2}{*}{ Outpatient visits } & \multirow[t]{2}{*}{ HNHC patients } & $\begin{array}{l}1 \mathrm{RCT}^{151} \\
(\mathrm{~N}=407)\end{array}$ & $\begin{array}{l}1 \text { of } 1 \text { RCT sample had } \\
\text { favorable findings }\end{array}$ & \multirow[t]{2}{*}{ Insufficient } \\
\hline & & $\begin{array}{l}1 \mathrm{OBS}^{153} \\
(\mathrm{~N}=21)\end{array}$ & $\begin{array}{l}1 \text { of } 1 \text { OBS sample found no } \\
\text { difference }\end{array}$ & \\
\hline \multirow[t]{4}{*}{ Total cost } & \multirow[t]{4}{*}{ HNHC patients } & $\begin{array}{l}4 \mathrm{RCTs}^{68,158,165} \\
(\mathrm{~N}=7,292)\end{array}$ & $\begin{array}{l}3 \text { of } 4 \mathrm{RCT} \text { samples had } \\
\text { favorable findings }\end{array}$ & \multirow[t]{4}{*}{ Low (Favorable) } \\
\hline & & $\begin{array}{l}1 \mathrm{OBS}^{178} \\
(\mathrm{~N}=3.048)\end{array}$ & $\begin{array}{l}1 \text { of } 4 \text { RCT samples found no } \\
\text { difference }\end{array}$ & \\
\hline & & & $\begin{array}{l}1 \text { of } 1 \text { OBS sample found no } \\
\text { difference }\end{array}$ & \\
\hline & & & $\begin{array}{l}\text { MA-pooled mean difference: - } \\
\$ 3,848.43(95 \% \mathrm{Cl},-5,514.24 \text { to } \\
-2,182.61) ; 3 \mathrm{RCT} \text { samples; } \\
\mathrm{N}=7,196 ; \mathrm{I}^{2}=0.0 \%\end{array}$ & \\
\hline \multirow[t]{2}{*}{ Mortality rate } & \multirow[t]{2}{*}{ HNHC patients } & \multirow[t]{2}{*}{$\begin{array}{l}2 \mathrm{RCTs}^{68} \\
(\mathrm{~N}=6,943)\end{array}$} & $\begin{array}{l}1 \text { of } 2 \text { RCT samples had } \\
\text { favorable findings }\end{array}$ & \multirow[t]{2}{*}{ Insufficient } \\
\hline & & & $\begin{array}{l}1 \text { of } 2 \text { RCT samples found no } \\
\text { difference }\end{array}$ & \\
\hline
\end{tabular}




\begin{tabular}{|c|c|c|c|c|}
\hline Outcome & Population & $\begin{array}{l}\text { \# Samples/Design } \\
\text { (n Analyzed) }\end{array}$ & Findings $^{s}$ & $\begin{array}{l}\text { Strength of Evidence } \\
\text { (Direction of Effect) }\end{array}$ \\
\hline Influenza vaccine & HNHC patients & $\begin{array}{l}2 \mathrm{RCTs}^{68} \\
(\mathrm{~N}=6,943)\end{array}$ & $\begin{array}{l}2 \text { of } 2 \text { RCT samples had } \\
\text { unfavorable findings }\end{array}$ & Low (Unfavorable) \\
\hline $\mathrm{HbA1c}$ test & $\begin{array}{l}\text { HNHC patients, } \\
\text { Diabetes } \\
\text { subgroup }\end{array}$ & $\begin{array}{l}2 \mathrm{RCTs}^{68} \\
(\mathrm{~N}=1,959)\end{array}$ & $\begin{array}{l}2 \text { of } 2 \text { RCT samples found no } \\
\text { difference }\end{array}$ & Insufficient \\
\hline LDL test & $\begin{array}{l}\text { HNHC patients, } \\
\text { Diabetes } \\
\text { subgroup }\end{array}$ & $\begin{array}{l}2 \mathrm{RCTs}^{68} \\
(\mathrm{~N}=1,959)\end{array}$ & $\begin{array}{l}2 \text { of } 2 \text { RCT samples found no } \\
\text { difference }\end{array}$ & Insufficient \\
\hline LDL test & $\begin{array}{l}\text { HNHC patients, } \\
\text { IVD subgroup }\end{array}$ & $\begin{array}{l}2 \mathrm{RCTs}^{68} \\
(\mathrm{~N}=1,923)\end{array}$ & $\begin{array}{l}2 \text { of } 2 \text { RCT samples found no } \\
\text { difference }\end{array}$ & Insufficient \\
\hline
\end{tabular}

a Findings were determined to be favorable or unfavorable based on the intent of the intervention. For example, if the intent of the intervention was to lower total cost, then a greater increase in total cost among intervention group patients compared with comparison group patients was classified as unfavorable. Similarly, changes in utilization may be identified as favorable or unfavorable depending on the intent of the intervention and the specific outcome. For studies that intended to reduce ED visits and shift service use to primary care, a greater increase in the use of ED visits among intervention group patients compared with comparison group patients would be unfavorable, while an increase in primary care visits would be favorable.

ACSC $=$ ambulatory care sensitive conditions; $\mathrm{ED}=$ emergency department; HbAlc $=$ hemoglobin Alc; HNHC= high-need, high-cost; IVD = ischemic vascular disease; $\mathrm{LDL}=$ low-density lipoprotein; $\mathrm{MA}=$ meta-analysis; $\mathrm{N}=$ number; $\mathrm{OBS}=$ observational study; RCT $=$ randomized controlled trial.

Significantly greater reductions in the number of inpatient admissions in the intervention group were observed in four analyses: both MGH RCT samples,${ }^{68}$ the group-visit RCT, ${ }^{167}$ and the CCM RCT. ${ }^{158}$ In contrast, the CBCM observational study reported significantly more inpatient admissions in the intervention group compared with the comparison group. ${ }^{178}$ The PIC RCT and DMP RCT did not find significant differences in inpatient admissions. ${ }^{151,}{ }^{165}$ Because of the mixed results across the samples, we graded the strength of evidence for reduction in the number of inpatient admissions as insufficient (Table 22).

Both MGH RCT samples also reported whether patients had any inpatient admissions. Both samples reported a greater reduction in the number of patients having an inpatient admission in the intervention group compared with the comparison group. ${ }^{68}$ Based on consistent and precise evidence we graded the reduction in the probability of an inpatient admission as low strength of evidence for a favorable findings (Table 22).

Evidence on ACSC inpatient admissions was also limited to the two MGH RCT samples. Both analyses found no significant difference in the number of admissions between the two groups. ${ }^{68}$ However, in relation to any ACSC inpatient admissions, the original sample reported a greater reduction in number of patients with an ACSC inpatient admission in the intervention group, while the refresh sample reported no difference. ${ }^{68} \mathrm{We}$ graded both measures of ACSC inpatient admissions as insufficient strength of evidence.

Some of the studies also sought to determine if the interventions would increase use of outpatient office visits. Increases in office visits, coupled with reductions in ED and hospital visits, could indicate that the intervention resulted in patients seeking care in more appropriate settings. However, we found no significant differences in primary care visits compared with usual care across two studies (PIC RCT and group-visit RCT) ${ }^{165,167}$ and significantly fewer primary care visits in the intervention group compared with the comparison group in the $\mathrm{CBCM}$ observational study. ${ }^{178}$ These mixed findings led to a rating of insufficient strength of evidence (Table 22). Study authors of the CBCM observational study had not expected to see reductions in 
primary care visits because intervention patients received care coordination and disease management in outpatient settings. ${ }^{178}$

Consistent with the intervention's goal of improving primary care access for mental health patients, the DMP RCT reported favorable, increased use of outpatient visits, antidepressant prescriptions, and specialty mental health visits among intervention patients. ${ }^{151}$ The interdisciplinary care team observational study also reported a positive effect on outpatient visits, but the sample was too small to report on precision. We graded the limited evidence to be insufficient.

\section{Cost Outcomes}

Cost outcomes were reported in four studies, representing five samples (Appendix Table B-56). ${ }^{68,158,165,178}$ The MGH RCT reported that increases in per-beneficiary per-month (PBPM) costs were significantly smaller in the intervention group than the comparison group in both the original sample and refresh samples. ${ }^{68}$ Similarly, the CCM RCT reported a significantly lower annual total cost for the intervention group compared with the comparison group. ${ }^{158}$ In contrast, the PIC RCT and the CBCM reported no differences in total cost between the two groups; the PIC RCT did not report a specific effect estimate. ${ }^{165,178}$ The pooled mean difference for annual total cost was $-\$ 3,848.43(95 \%$ CI, $-5,514.24$ to $-2,182.61 ; 3$ RCT samples; $\mathrm{N}=7,196$; $\mathrm{I}^{2}=0.0 \%$ ) (Appendix Figure B-9). This evidence led to a grade of low strength of evidence for favorable findings for total cost (Table 22).

\section{Clinical and Functional Outcomes}

Clinical and functional outcomes were reported in three RCTs, representing four samples (Appendix Tables B-57 and B-58). ${ }^{68,151,165}$ However, only the two samples of the MGH RCT reported the same outcomes.

In the MGH RCT, mortality rate and receipt of an influenza vaccine were measured in both the original and refresh samples. ${ }^{68}$ The MGH RCT refresh sample reported a lower mortality rate in the intervention group, while the original sample did not observe any significant differences between groups. This mixed evidence led to a grade of insufficient strength of evidence for mortality (Table 22). For influenza vaccine, the vaccination rate increased for both the intervention and comparison groups, but the rate increased less for the intervention group. The study authors explained that this finding may be due to the much higher baseline rate in the intervention group compared with the comparison group. ${ }^{68}$ The evidence led to a rating of low strength of evidence for unfavorable findings for likelihood of receiving an influenza vaccine (Table 22).

The MGH RCT also reported on nine outcomes assessed through a self-report survey from a more limited sample of 590 respondents. The survey reported significantly better outcomes for the intervention group in relation to discussion of treatment choices and communication with providers.

In the MGH RCT, subgroup analyses were conducted in the refresh and original samples. ${ }^{68}$ No differences were found between groups for the following tests: HbA1c tests among diabetics, LDL-C test among diabetics, and LDL-C test among IVD patients (insufficient strength of evidence) (Table 22). 


\section{Social Risk Outcomes}

Evidence on social risk outcomes was limited to one study (Appendix Table B-59). No differences were found between intervention and comparison groups in overall patient wellbeing in the interdisciplinary care team observational study. ${ }^{153}$

\section{Home-Based Care Models}

\section{Overview}

- One RCT with two samples and two observational studies, representing four samples, reported on home-based care models. Three samples were rated as having moderate risk of bias and one of the observational studies was rated high risk of bias.

- We found reductions in ACSC inpatient admissions among home-based care interventions. Based on evidence from two RCT samples and one observational sample, we found a reduction in the number of patients with any ACSC inpatient admissions (low strength of evidence for favorable findings). Based on evidence from two RCT samples, we also found a reduction in the number of ACSC inpatient admissions (low strength of evidence for favorable findings).

- We found no difference in the mortality rate, based on evidence from two RCT samples and one observational study (low strength of evidence for no difference).

- We found an increase in influenza vaccine uptake among home-based care intervention participants, based on evidence from two samples (low strength of evidence for favorable findings).

- The evidence is insufficient to judge all other outcomes.

\section{Detailed Results}

Home-based care models were reported in three studies with four samples in three publications. All were implemented for Medicare populations (Appendix Table B-60). ${ }^{67,72,179}$ This type of model provides care in the home for patients who have difficulty leaving or who are unable to leave their homes. ${ }^{45}$ Usual care was the comparison for all analyses.

One study was an RCT (rated some concerns for risk of bias) called Care Level Management (CLM) in which a care management organization in three states provided patients with multiple chronic conditions with physician home visits by a personal visiting physician that complemented care from their primary care practice. ${ }^{67}$ CLM was a Medicare CMHCB Demonstration intervention. Two study populations were assessed: an original sample and a refresh sample. ${ }^{67}$

The other two studies are related to the IAH observational intervention. As previously mentioned in the System-Level Transformation section, CMS's IAH demonstration (rated some concerns for risk of bias) supported primary care at home for Medicare FFS patients who were chronically ill and functionally limited by providing financial incentives to home-based primary care practices. ${ }^{72}$ The study analyzed two components of the model, the effectiveness of a demonstration payment incentive (included in the System-Level Transformation section) and the effectiveness of a home-based primary care services model (included in this section). In the home-based care services model, the IAH home-based primary care service was evaluated to determine if receipt of home-based primary care resulted in lower costs. ${ }^{72}$ The analysis compared patients who newly received home-based primary care with patients who did not receive these services. $^{72}$ 
The final observational study (rated high risk of bias) evaluated whether patients receiving home-based care with integrated long-term services and supports (LTSS) at three IAH practices had lower long-term institutionalization and mortality. The intervention group was compared to two comparison groups of patients who received care at non-intervention practices, concurrent patients who did not receive home-based care and concurrent patients who received home-based care. ${ }^{179}$

\section{Intervention Characteristics}

Across studies, HNHC patients eligibility for home-based primary care was based on hospital use over a 1-year period. ${ }^{67,72,179}$ In the CLM RCT original sample, patients were eligible if they had two or more hospitalizations in the past 12 months, Medicare costs in the top 5 percent, high risk of future costs (high HCC risk score), and a chronic condition diagnosis. ${ }^{67}$ In the CLM RCT refresh sample, the eligibility criteria were simplified; patients were eligible if they had two or more hospitalizations in the past 12 months. Patients with select psychosocial problems, such as drug/alcohol dependence or bipolar disorders, were explicitly excluded from the refresh sample. ${ }^{67}$

As a result of sample size concerns, the IAH home-based primary care analysis was expanded from Medicare patients at IAH practices to include all Medicare patients new to homebased primary care residing in the same region as IAH practices. These patients were not required to receive their home-based care from an IAH practice. For this review, we present the home-based primary care findings that include only patients who received home-based care from an IAH practice. In addition to being new to home-based primary care in an IAH region, Medicare patients were eligible for the IAH home-based primary care analysis if they had two or more chronic conditions, two or more difficulties in performing activities of daily living that require human assistance, a hospitalization and use of acute rehabilitation services in the previous 12 months, and the majority of their office visits took place at home or in an assisted living facility after the first home-based primary care visit. ${ }^{72}$

For the LTSS study, patients were eligible for inclusion if they were enrolled in one of three IAH sites, had two or more chronic conditions, had a hospitalization and used acute rehabilitation services in the previous 12 months, and had a JEN Frailty Index (JFI) score of six or higher. ${ }^{179}$ The LTSS study differed from the IAH study by using the JFI to determine eligibility instead of an assessment of activities of daily living because the activities of daily living data were not available.

Across the studies, intervention components included an initial assessment, followed by faceto-face care management and medical care (Appendix Table B-61). Participants received care coordination and referral to community-based support services, as needed. Within each of the interventions, the intensity of services received varied across individual patients. In the CLM RCT, 75 percent of participants had one or more physician home visits. Eighty-eight percent received a telephone call from a nurse or physician, with 39 percent receiving 20 or more calls. Twelve percent of those enrolled received no contact from the intervention. ${ }^{67}$ The IAH study tested a team-based primary care model for delivering home-based care. Clinician workload consisted of anywhere from 3 to 15 home visits per day, with the intensity of care per patient based on clinician judgment or patient risk stratification. A clinician was available for participants at all hours and used electronic health information systems to help provide comprehensive care. ${ }^{72}$ The intensity of the home-based intervention provided to the patients in the LTSS study was not reported. ${ }^{179}$ The three practices provided patients with integrated care 
coordination and community support using care managers or social workers who were part of a larger, interdisciplinary team.

\section{Intervention Outcomes}

\section{Utilization Outcomes}

Three of four samples reported the effect of the intervention on changes in healthcare utilization (Appendix Table B-62). Neither the two CLM RCT samples nor the IAH home-based care sample found a significant difference in change in ED visits when compared with a comparison group. ${ }^{67,72}$ Imprecise findings led to a grade of insufficient strength of evidence (Table 23; full strength of evidence can be found in Appendix Table B-63). Similarly, no significant differences in ACSC ED visits were observed in any of the three samples. The imprecise evidence led to a grade of insufficient strength of evidence (Table 23).

Table 23. Summary of findings for home-based care-based models versus usual-care outcomes

\begin{tabular}{|c|c|c|c|c|}
\hline Outcome & Population & $\begin{array}{l}\text { \# Samples/Design } \\
\text { (n Analyzed) }\end{array}$ & Findings $^{a}$ & $\begin{array}{l}\text { Strength of Evidence } \\
\text { (Direction of Effect) }\end{array}$ \\
\hline ED visits, all cause & HNHC patients & $\begin{array}{l}2 \mathrm{RCTs}^{67} \\
(\mathrm{~N}=34,421) \\
1 \mathrm{OBS}^{72} \\
(\mathrm{~N}=181,001)\end{array}$ & $\begin{array}{l}2 \text { of } 2 \text { RCT samples } \\
\text { found no difference } \\
1 \text { of } 1 \text { OBS sample } \\
\text { found no difference }\end{array}$ & Insufficient \\
\hline ED visits, ACSC & HNHC patients & $\begin{array}{l}2 \mathrm{RCTs}^{67} \\
(\mathrm{~N}=34,421) \\
1 \mathrm{OBS}^{72} \\
(\mathrm{~N}=181,001)\end{array}$ & $\begin{array}{l}2 \text { of } 2 \text { RCT samples } \\
\text { found no difference } \\
1 \text { of } 1 \text { OBS sample } \\
\text { found no difference }\end{array}$ & Insufficient \\
\hline $\begin{array}{l}\text { Inpatient admissions, } \\
\text { all cause }\end{array}$ & HNHC patients & $\begin{array}{l}2 \mathrm{RCTs}^{67} \\
(\mathrm{~N}=34,421) \\
1 \mathrm{OBS}^{72} \\
(\mathrm{~N}=181,001)\end{array}$ & $\begin{array}{l}2 \text { of } 2 \text { RCT samples } \\
\text { found no difference } \\
1 \text { of } 1 \text { OBS sample } \\
\text { had unfavorable } \\
\text { findings }\end{array}$ & Insufficient \\
\hline $\begin{array}{l}\text { Inpatient admissions, } \\
\text { ACSC }\end{array}$ & HNHC patients & $\begin{array}{l}2 \mathrm{RCTs}^{67} \\
(\mathrm{~N}=34,421) \\
1 \mathrm{OBS}^{72} \\
(\mathrm{~N}=181,001)\end{array}$ & $\begin{array}{l}2 \text { of } 2 \text { RCT samples } \\
\text { had favorable findings } \\
1 \text { of } 1 \text { OBS sample } \\
\text { found no difference }\end{array}$ & Low (Favorable) \\
\hline $\begin{array}{l}\text { Inpatient admissions, } \\
\text { any all cause }\end{array}$ & HNHC patients & $\begin{array}{l}2 \mathrm{RCTs}{ }^{67} \\
(\mathrm{~N}=34,421)\end{array}$ & $\begin{array}{l}2 \text { of } 2 \text { RCT samples } \\
\text { found no difference }\end{array}$ & Insufficient \\
\hline $\begin{array}{l}\text { Inpatient admissions, } \\
\text { any ACSC }\end{array}$ & HNHC patients & $\begin{array}{l}2 \mathrm{RCTs}^{67} \\
(\mathrm{~N}=34,421)\end{array}$ & $\begin{array}{l}2 \text { of } 2 \text { RCT samples } \\
\text { had favorable findings }\end{array}$ & Low (Favorable) \\
\hline Total cost & HNHC patients & $\begin{array}{l}2 \mathrm{RCTs}^{67} \\
(\mathrm{~N}=34,421) \\
1 \mathrm{OBS}^{72} \\
(\mathrm{~N}=181,001)\end{array}$ & $\begin{array}{l}2 \text { of } 2 \text { RCT samples } \\
\text { found no difference } \\
1 \text { of } 1 \text { OBS sample } \\
\text { had unfavorable } \\
\text { findings }\end{array}$ & Insufficient \\
\hline Total cost & $\begin{array}{l}\text { HNHC patients, high risk } \\
\text { patient subgroup }\end{array}$ & $\begin{array}{l}2 \mathrm{RCTs}^{67} \\
(\mathrm{~N}=15,400)\end{array}$ & $\begin{array}{l}2 \text { of } 2 \text { RCT samples } \\
\text { found no difference }\end{array}$ & Insufficient \\
\hline Total cost & $\begin{array}{l}\text { HNHC patients, high } \\
\text { cost only patient } \\
\text { subgroup }\end{array}$ & $\begin{array}{l}2 \mathrm{RCTs}^{67} \\
(\mathrm{~N}=5,758)\end{array}$ & $\begin{array}{l}2 \text { of } 2 \text { RCT samples } \\
\text { found no difference }\end{array}$ & Insufficient \\
\hline Mortality & HNHC patients & $\begin{array}{l}2 \mathrm{RCTS}^{67} \\
(\mathrm{~N}=34,421) \\
1 \mathrm{OBS}{ }^{179} \\
(\mathrm{~N}=1,376) \\
\end{array}$ & $\begin{array}{l}2 \text { of } 2 \text { RCT samples } \\
\text { found no difference } \\
1 \text { of } 1 \text { OBS sample } \\
\text { found no difference }\end{array}$ & Low (No difference) \\
\hline Influenza vaccine & HNHC patients & $\begin{array}{l}2 \mathrm{RCTs}^{67} \\
(\mathrm{~N}=34,421)\end{array}$ & $\begin{array}{l}2 \text { of } 2 \text { RCT samples } \\
\text { had favorable findings }\end{array}$ & Low (Favorable) \\
\hline $\begin{array}{l}\text { Oxygen saturation } \\
\text { test }\end{array}$ & $\begin{array}{l}\text { HNHC patients, COPD } \\
\text { subgroup }\end{array}$ & $\begin{array}{l}2 \mathrm{RCTs}^{67} \\
(\mathrm{~N}=8,079)\end{array}$ & $\begin{array}{l}2 \text { of } 2 \text { RCT samples } \\
\text { found no difference }\end{array}$ & Insufficient \\
\hline
\end{tabular}




\begin{tabular}{|c|c|c|c|c|}
\hline Outcome & Population & $\begin{array}{l}\text { \# Samples/Design } \\
\text { (n Analyzed) }\end{array}$ & Findings $^{a}$ & $\begin{array}{l}\text { Strength of Evidence } \\
\text { (Direction of Effect) }\end{array}$ \\
\hline HbA1c test & $\begin{array}{l}\text { HNHC patients, Diabetes } \\
\text { subgroup }\end{array}$ & $\begin{array}{l}2 \mathrm{RCTs}^{67} \\
(\mathrm{~N}=10,452)\end{array}$ & $\begin{array}{l}2 \text { of } 2 \text { RCT samples } \\
\text { found no difference }\end{array}$ & Insufficient \\
\hline LDL test & $\begin{array}{l}\text { HNHC patients, Diabetes } \\
\text { subgroup }\end{array}$ & $\begin{array}{l}2 \mathrm{RCTs}^{67} \\
(\mathrm{~N}=10,452)\end{array}$ & $\begin{array}{l}2 \text { of } 2 \text { RCT samples } \\
\text { found no difference }\end{array}$ & Insufficient \\
\hline LDL test & $\begin{array}{l}\text { HNHC patients, IVD } \\
\text { subgroup }\end{array}$ & $\begin{array}{l}2 \mathrm{RCTs}^{67} \\
(\mathrm{~N}=14,910)\end{array}$ & $\begin{array}{l}2 \text { of } 2 \text { RCT samples } \\
\text { found no difference }\end{array}$ & Insufficient \\
\hline
\end{tabular}

a Findings were determined to be favorable or unfavorable based on the intent of the intervention. For example, if the intent of the intervention was to lower total cost, then a greater increase in total cost among intervention group patients compared with comparison group patients was classified as unfavorable. Similarly, changes in utilization may be identified as favorable or unfavorable depending on the intent of the intervention and the specific outcome. For studies that intended to reduce ED visits and shift service use to primary care, a greater increase in the use of ED visits among intervention group patients compared with comparison group patients would be unfavorable, while an increase in primary care visits would be favorable.

$\mathrm{ACSC}=$ ambulatory care sensitive conditions; $\mathrm{COPD}=$ chronic obstructive pulmonary disease $; \mathrm{ED}=$ emergency department; $\mathrm{HbA1}=$ hemoglobin A1c; HNHC= high-need, high-cost; IVD = ischemic vascular disease; LDL = low-density lipoprotein; $\mathrm{N}=$ number; OBS = observational study; RCT = randomized controlled trial.

Neither of the two CLM RCT samples found differences from comparison groups for allcause inpatient admissions. ${ }^{67}$ In contrast, the IAH home-based care intervention group had an unfavorable, greater increase in all-cause inpatient admissions than the comparison group. ${ }^{72}$ The strength of evidence was graded as insufficient because of mixed findings. Neither of the CLM RCT samples found a difference from the comparison group in having any inpatient admissions (insufficient strength of evidence).

In relation to ACSC inpatient admissions, the two samples of the CLM RCT reported significantly greater reductions in ACSC admissions in the intervention than the comparison group. In contrast, the IAH home-based care sample did not find a difference between the groups. ${ }^{72}$ This consistent but imprecise evidence led to a rating of favorable findings for the number of ACSC inpatient admissions (low strength of evidence) (Table 23). Both samples of the CLM RCT also reported significantly greater reductions in the number of patients with an ACSC admissions in the intervention group than the comparison group. This consistent and precise evidence led to a rating of favorable findings for the number of patients with an ACSC inpatient admission (low strength of evidence) (Table 23).

\section{Cost Outcomes}

Three of four home-based samples reported on the effect of the intervention on cost (Appendix Tables B-64 and B-65). The two RCT samples found that the home-based care interventions did not significantly change total costs. ${ }^{67,72}$ In the IAH home-based primary care sample, total cost was higher among the IAH intervention group than the comparison group, indicating that the intervention increased Medicare costs relative to office-based care. ${ }^{72}$ IAH study authors noted that intervention patients had higher costs in inpatient, physician or supplier, and hospice services, suggesting substantial differences not only in total costs, but in the mix of services paid for in the IAH intervention group relative to the matched comparison group. ${ }^{72} \mathrm{We}$ graded the evidence as insufficient because of imprecision (Table 23).

The CLM RCT also reported cost outcomes for population subgroups. In both samples, the total cost did not differ between the intervention and comparison groups within a high-cost, highrisk subgroup and a high-cost-only subgroup. We graded the total cost outcome as insufficient strength of evidence in both subgroups because of imprecision (Table 23). 


\section{Clinical and Functional Outcomes}

In relation to clinical outcomes, change in mortality was reported in both the CLM RCT original sample and refresh sample and the LTSS study. Differences between the intervention and comparison groups were not significantly different, and we graded mortality as low strength of evidence for no difference (Appendix Tables B-66 and B-67). ${ }^{67,179}$ Several additional clinical and functional outcomes were reported for both RCT samples (Table 23). The CLM RCT original and refresh samples reported significantly greater increases in the rate of influenza vaccines in the intervention group. The consistent and precise evidence led to a rating of low strength of evidence for favorable findings (Table 23). Among surveyed original sample patients, significantly better outcomes for the intervention group were found for three additional measures: discussing treatment choices, communicating with providers, and doing 30 minutes of continuous physical activity. ${ }^{67}$ No significant differences were found in relation to other measures. ${ }^{67}$

\section{Social Risk Outcomes}

No social risk outcomes were reported among the home-based care model studies. 


\section{Chapter 4. Discussion}

\section{Overview}

In this review, we sought to inform policy and clinical practice about how to identify highneed, high-cost (HNHC) patients, who are some of the heaviest and costliest users of healthcare, and reduce their inappropriate healthcare use through answering three Key Questions (KQs). To answer KQ 1, we summarized the evidence from studies that sought to identify HNHC patient characteristics. A goal of the KQ 1 review was to inform the selection of patients for interventions that target HNHC patients. KQs 2 and 3 both examined interventions for HNHC patients but used different review approaches. KQ 2 used a realist review approach to develop theories, supported by evidence, to explain the mechanisms in complex interventions, in various contexts, that are instrumental to interventions changing HNHC patient healthcare use and quality. KQ 3 used a systematic review approach to summarize the evidence of the effectiveness of interventions that either focus solely on HNHC patients or include outcomes for HNHC patients as a subgroup of a larger initiative.

Below we present a separate discussion of our findings for each of the three KQs, followed by the strengths and limitations of the evidence, and the implications of our findings.

\section{KQ 1: Identifying HNHC Patients}

KQ 1 presents a synthesis of studies that examine characteristics of HNHC patient populations. An important assumption in identifying or predicting which patients will be HNHC (high users of preventable or modifiable healthcare) is that it is possible to distinguish between high use that is emergent and appropriate (particularly in the emergency department [ED] and inpatient) from use that is preventable or modifiable. If studies can isolate preventable or modifiable use, this information can be used to target specific groups of individuals for whom a reduction in its overuse is an appropriate goal.

We used a broad definition of HNHC to help ensure that we did not miss relevant studies. Studies that met our inclusion criteria for KQ 1 considered preventable or modifiable healthcare using different approaches. The most common approach was to simply identify the highest users, individuals with the most frequent care or highest cost of care. This approach assumes that individuals with high use or cost, above a particular threshold, are likely to be using some care inappropriately. These studies differed considerably in the thresholds they used to identify high use or cost. Studies that used a somewhat more refined approach to examining high use or cost excluded specific patient populations or diagnoses. Among these excluded patients, use of services or costs may be high but transient and unlikely to be modifiable, such as services related to pregnancy and elective surgery.

We identified a small number of studies that sought to define preventable or modifiable care more directly. Two studies examined the characteristics of patients with multiple ED visits who were triaged as being least urgent. However, the researchers found that frequent and less frequent users did not differ in their reports of why they used the ED. Another study distinguished individuals with higher-than-expected costs (rather than just those with the highest costs). These researchers found a positive correlation across consecutive years among individuals having higher than expected costs and a strong positive correlation between higher-than-expected costs and potentially preventable hospital readmission and ED visits. ${ }^{76,207}$ We found no quantitative 
studies that sought to distinguish which of a patient's individual visits might be considered preventable or modifiable and those that would be considered necessary.

The evidence for KQ 1 consists of 60 studies, including exposure, cluster, and qualitative analyses. The exposure studies used regression analyses to examine patient and health system characteristics associated with high use or cost of healthcare (being HNHC). Some exposure studies were considered predictive; that is, high cost or use outcomes were measured in a subsequent period. Others were cross-sectional designs. All exposure studies controlled for confounding variables but the selection of confounding variables differed across studies. Cluster analyses seek to identify "hidden" or unobservable groupings using observed variables and can aid in choosing HNHC patients to include together in interventions. Qualitative studies provide personal experience and informed opinion.

We used the "best fit" framework synthesis approach to organize our KQ 1 findings. ${ }^{48}$ The "best fit" framework is a method for testing and building on an existing model. We selected the framework developed by the National Academy of Medicine (NAM), included in their publication Effective Care for High-Need Patients: Opportunities for Improving Outcomes, Value and Health. ${ }^{20}$ As discussed in Chapter 1, the NAM framework provides a taxonomy for identifying $\mathrm{HNHC}$ patients. Of six clinical and functional categories, four were relevant to our review: 1) nonelderly disabled, 2) multiple chronic conditions, 3) major complex chronic conditions, and 4) frail elderly. The NAM framework further recognizes the potential impact of behavioral health factors (i.e., substance use, serious mental illness, cognitive decline, and chronic toxic stress) and social risk factors (i.e., low socioeconomic status, social isolation, community deprivation, and housing insecurity). Behavioral health and social risk factors are not stand-alone categories in the NAM framework but factors that span across, affect, and are affected by all the clinical and functional categories.

We found patterns of support for the association between some characteristics and HNHC patient outcomes. Prior high use and cost were consistent and strong predictors of the same, particularly in relation to ED visits and cost. Based on cluster analysis, frequent ED patients with chronic conditions and mental illness were found to form a distinct group, characterized by having the most frequent visiting pattern. Specific complex chronic conditions, such as congestive heart failure, chronic obstructive pulmonary disease, cardiovascular disease, dementia, and diabetes, were positively associated with high use and cost. Cluster analysis also identified frailty as a distinct clinical profile. Patients' scores on self-assessment tools were associated with high use.

We found consistent support for the importance of behavioral health risk factors across diagnostic and functional groups. Co-occurring mental health conditions (most notably, depression) and substance use disorder (SUD) were positively associated with high use across analyses. The results for serious mental illness (SMI) and alcohol use disorder (AUD) were mixed. However, one qualitative study clarified that unmet behavioral health needs and poorly managed SMI, not just the presence of SMI, were significant drivers of preventable high levels of healthcare use among HNHC patients.

We also found support for the consideration of social risk factors in identifying HNHC patients. Housing insecurity was a consistent predictor, while the role of poverty varied based on whether it was measured directly or at the neighborhood level. Among multipayer and population-based studies, Medicaid and Medicare coverage were predictive of high healthcare use compared with commercial coverage. 
Several demographic characteristics were independent risk factors. Generally, being a HNHC patient is positively associated with older age. However, in the Medicare population, being a nonaged disabled enrollee was a greater risk, particularly in relation to ED use, where the youngest adult groups were more likely to have the highest use. Black race, compared with white race, was also a risk factor for higher ED use and lower inpatient use, controlling for other characteristics including poverty.

\section{Final Framework in Relation to the NAM Taxonomy}

On the whole, our findings supported NAM's taxonomy for identifying HNHC patients. ${ }^{20}$ We found general support for the four NAM clinical and functional groups: nonelderly disabled, multiple chronic conditions, major complex chronic condition, and frail elderly. Our findings support that chronic conditions, disability, and frailty are associated with HNHC.

The effect of having multiple chronic and major complex chronic conditions proved difficult to assess. While the multiple chronic condition group is defined as having only one complex chronic condition (e.g., acute myocardial infarction, ischemic heart disease, chronic kidney disease, congestive heart failure) and/or between one and five noncomplex chronic conditions (e.g., arthritis, immune disorders, cancer, inflammatory bowel disease), the studies we reviewed included an inconsistent list of single conditions and assessed their independent and individual impacts on high use or cost outcomes. Some studies included a count of conditions and found a greater number to be positively related to higher use or cost. No study included interaction terms or other methods to assess the effect of having a combination of specific chronic conditions on outcomes.

We found evidence consistent with the NAM framework's support for the overarching role of behavioral health and social needs. The NAM framework acknowledged that "addressing clinical needs alone will not improve outcomes or reduce costs for this population" "185, p. 3 and that it is "necessary to address an individual's functional, social, and behavioral needs." 185, p. 4 Similarly, our review found that behavioral health factors, including mental health and SUD and social risk factors, particularly homelessness, have a central role in contributing to high healthcare use and cost.

In our final framework, we support the NAM taxonomy but we expand it to include several additional dimensions, prior healthcare service use and race. Although research has shown that regression to the mean (ebbs and flows of individual healthcare use) can limit the ability of prior use to predict future use, prior use was still the strongest predictor across studies. Considerations include identifying high use setting (e.g., ED, inpatient) and patterns of behavior, (i.e., chronic over multiple periods or more short-term groups or episodes of care).

We also found that race, particularly black compared with white race, was an independent predictor of high use (ED) or low use (inpatient), controlling for other characteristics, including income. Including race and ethnicity in a taxonomy could help focus attention on the role of structural racism in the healthcare system on access to care.

\section{KQ 2: Understanding How and Why HNHC Patient Interventions Work}

To answer KQ 2, we used a realist review approach to present theories, supported by evidence, to explain the mechanisms in complex interventions, in various contexts, that are intended to change HNHC patient healthcare use and improve their quality of care. To our knowledge, we have conducted the first realist review of interventions for HNHC patients. Most 
of the information we used to develop our theories was gathered from descriptive and qualitative findings concerning the interventions included in our KQ 3 effectiveness review and, to a lesser extent, KQ 1 studies that identified HNHC patient characteristics. Therefore, our findings from the realist review and systematic review are intended to be synergistic and informative to each other.

We developed three program theories, considering evidence from 49 studies. Overall, we found that individualization was a key theme, both in identifying participants for HNHC patient interventions and in developing the service mix of the interventions. Unlike disease management interventions that focus on one condition, ${ }^{208}$ including patients with a heterogeneous mix of chronic diseases in interventions for HNHC patients was not considered a barrier. A key was identifying and addressing individual participant complexity, both in terms of chronic disease profile and risk factors that affect access to care (Program Theory 1). Unsurprisingly, providers expressed challenges in motivating this population to obtain adequate medical treatment for their chronic conditions. However, central to the interventions was the importance of building trusting relationships between patients and providers (Program Theory 2). Trusting relationships are considered key to being able to support and educate patients to gradually take on greater responsibility for self-managing their chronic conditions and to navigate other systems to address their behavioral health needs and social risk factors. The findings also suggest that successfully changing patients' behavior requires significant investments in staff time. Relationships require time to develop, and care providers are unlikely to successfully modify patients' long-held approaches to care, if the time allotted for the intervention is not sufficiently long. Evaluations measuring the impact of interventions may need to assess intermediate outcomes or extend their followup time.

Care providers cautioned that they feel significant stress because of the greater time and resources needed to provide and coordinate the care of HNHC patients. Although they believed that having additional time was necessary to serve this population, they often found that patients needed psychosocial and emotional support rather than medical care. Intervention sustainability is supported by supplementary processes and structures that protect and support care providers (Program Theory 3). Strategies may include healthcare system-wide modifications such as using payment models that provide higher reimbursements for sicker patients, gaining provider buy-in, redistributing workloads across staff members, and providing emotional and technical support for providers.

\section{KQ 3: Assessing the Effectiveness of Interventions for HNHC Patients}

To answer KQ 3, we conducted a systematic review of the evidence from 40 studies of the effectiveness of interventions for HNHC patients compared with usual care. For our synthesis, we categorized the studies into seven groups based on the intervention's primary setting. The largest numbers of patient samples were primary care-based models, telephonic/mail models, and community-based models (all $\mathrm{N}=9$ ), followed by ED-based models $(\mathrm{N}=7)$, system-level transformation models $(\mathrm{N}=5)$, and finally home-based models and ambulatory intensive caring unit-based models (both $\mathrm{N}=4$ ). We found moderate to low strength evidence to support intervention effectiveness in relation to a small number of outcomes in some settings. We found the evidence for most outcomes across settings to be insufficient because of no or limited evidence or inconsistent results across studies. 
ED-based models tended to have the most straightforward and least complex design. Interventions generally were conducted in the ED (a single setting). Interventions identified participants in the ED based on high frequency of ED use, and most provided all services in the ED as well. We found moderate strength of evidence that these interventions were able to reduce ED visits and low strength of evidence that they reduced ED costs. We also found low strength of evidence that ED interventions shifted service use and resulted in reduced inpatient admissions and increased primary care visits. However, we also found low strength of evidence that the intervention and comparison groups were not significantly different in relation to inpatient costs.

Primary care-based models all included multidisciplinary care teams to coordinate care, but they were otherwise more heterogenous in intervention design than ED models (e.g., some studies incorporated groups visits, ${ }^{150,167}$ while others included home visits ${ }^{68,165}$ ). We found low strength of evidence that interventions for HNHC patients set in primary care were associated with reductions in inpatient admissions and, in turn, costs.

Ambulatory intensive caring unit models, interventions that provide care through a separate intensive clinic or intensive team within a clinic, were associated with a reduction in total costs (low strength of evidence). However, the evidence was insufficient to assess what changes in utilization explain the reductions.

Evidence about home-based care models was from two large and complex Centers for Medicare \& Medicaid Services (CMS)-funded interventions. We found low strength of evidence that home-based care was associated with a reduction in inpatient admissions for ambulatory care sensitive conditions (ACSC), an increase in the uptake of influenza vaccinations, and no difference in mortality. Because ACSC admissions are a quality indicator for preventable admissions, ${ }^{209}$ our findings suggest that home-based care models may reduce utilization of preventable and modifiable services. The evidence was insufficient to determine if the reduction in admissions also resulted in a reduction in costs.

Community-based models largely provide patients with services outside of the healthcare system. These interventions were heterogenous in design and in the patients they served. The community-based interventions took on the additional challenge of addressing participants' cross-sector nonmedical issues by helping them navigate access to community resources and social services, including one study that evaluated the impact of housing and criminal justice involvement. ${ }^{159}$ The community-based models included three samples that tested the highly regarded Camden Core Model hotspotting intervention that used data to identify HNHC patients and provided them with intensive, relationship-based assistance. ${ }^{44,139,141,172}$ We found low strength of evidence that community-based models were associated with no difference in mortality. We were unable to judge the benefit for any cost or utilization outcomes because of imprecise and mixed findings.

For both system-level transformation and telephonic/mail models, we found low strength of evidence that cost-of-care outcomes were not significantly different in the intervention and comparison groups. For telephonic/mail models, we also found low strength of evidence that ED visits, inpatient admissions, and mortality did not differ between the groups. The evidence for these system-level transformation models was insufficient to judge all other outcomes.

All of the system-level transformation studies were funded by CMS and reflect the challenges of successfully assisting HNHC patients while meeting goals related to a broader patient population. These models were large-scale interventions that targeted an entire patient population of clinics and physician practices. The studies include evaluations of the 
Comprehensive Primary Care Initiative (CPC) and $\mathrm{CPC}+$. Except for the Independence at Home (IAH) study, HNHC patients were not similarly targeted for services across system-level transformation study sites.

In telephonic/mail models, the intervention was often initiated by a health plan and usually provided patients with services that were supplemental to those received from their primary providers. Given our realist review finding that providing opportunities for care team members to have face-to-face conversations about and with HNHC patients is an important context for the success of interventions, the lack of adjunct, integrated services embedded in patients' sites of care, and limited program intensity, may have presented a challenge to these telephonic/mail models.

In our analytic framework, we hypothesized that harms from interventions may arise from patients encountering increased barriers to accessing necessary care or providers experiencing insufficient resources or time to facilitate effective interventions. In our realist review, we identified insufficient provider resources and time as an important barrier to provider engagement and a key consideration when designing interventions for HNHC patients. However, in our KQ 3 review, no studies reported on participant harms. Therefore, we could not determine whether a lack of harms was related to lack of measurement or due to the true lack of harms. The sole exception was an incidental finding in one primary care intervention with two samples; the study found intervention participants to be less likely to receive an influenza vaccine than patients in usual care. ${ }^{68}$ However, the difference was relative. The rates in both groups increased during the period of the intervention. The intervention leaders commented that they did not believe that this quality measure was a good reflection of the intervention's ability to provide care management services to HNHC patients.

\section{Strengths and Limitations}

Our review questions examined a breadth of issues concerning HNHC patients, from their identification to how interventions work to outcomes from these interventions. We used three methodological approaches to answer our three KQs. Each of these approaches, separately and considered across KQs, brings unique strengths and weaknesses to our findings.

\section{KQ 1}

For the KQ 1 analysis, we reviewed articles with four distinct methodological approaches: 1) predictive, in which data from one time period were used to predict future high healthcare use or cost; 2) cross-sectional, in which factors associated with high healthcare use and cost in one time period are examined; 3) cluster analysis, which identified latent or hidden groupings among HNHC patient populations; and 4) qualitative studies. We found that criteria associated with being a HNHC patient in cross-sectional studies generally supported the predictive findings, even though regression to the mean at the individual level is a real concern when selecting intervention participants. Regression to the mean is related to healthcare use often being cyclical, so very high use in one period is often followed by less care in a subsequent period, at a rate closer to the mean. The cluster analysis studies also generally confirmed the predictive and cross-sectional findings. Similar chronic diseases, behavioral health, and social factors appeared as characteristics of cluster groupings that were significant variables in predictive and crosssectional studies. However, cluster analyses went one step further. They uncovered combinations of characteristics in individuals. Qualitative studies added insights about the impact of these characteristics on an individual patient's interaction with the healthcare system. 
The value of each KQ 1 methodology lies in its respective usage. Predictive analyses are the strongest design for creating algorithms, screening, and other tools for identifying HNHC patients in future periods. Because significant patient characteristics were generally similar in cross-sectional studies, they may be useful for exploratory purposes. However, both predictive and cross-sectional exposure study designs that rely on regression analyses can have limited power to separately examine many unique diseases. As a result, rarer complex chronic conditions and combinations of conditions that might lend themselves to HNHC patient interventions may not be identified. Cluster analysis can be useful in identifying more homogenous HNHC patient subgroups when designing targeted interventions, after the broader HNHC population has been identified.

\section{KQ 2}

To answer KQ 2, the how and why of complex interventions for HNHC patients by attempting to describe and explain causal mechanisms, our analysis depended primarily on the KQ 3 effectiveness studies that included descriptive information and/or mixed-methods approaches. Therefore, our program theories are directly relevant to these interventions. However, many of the effectiveness studies were conducted at the system or organization level and included scant descriptive contextual information, such as patients' experience in the intervention, the availability of family and other supports, or assessments of patient-centered quality-of-care outcomes. Therefore, our realist review was unable to include evidence from all included KQ 3 interventions, and our theory development may be more reflective of the patient and provider experiences from the subset of studies that included a more descriptive component.

Our focus on many of the same studies for the realist and effectiveness reviews was due to the particulars of the topic and time and resource limitations. We are reasonably confident that we identified the available effectiveness literature on HNHC patient interventions. Additional studies that did not fit our KQ 3 inclusion criteria might have furthered or modified our program theories, but we would have been required to include other bodies of literature. For example, other literature might focus on a high need population where only some members are high cost, but interventions appear to be successful in keeping participants from becoming high cost, (e.g., Medicaid health homes for individuals with chronic conditions and behavioral health diagnoses.) Other literature to have considered might have been from the perspective of the identified needs of HNHC patients, such as support and ancillary services to support navigation, case management, and education. However, given our limited time and resources, we were not able to explore the potential value of this literature for this review.

Also, given the interpretive and inductive nature of realist methodology, other researchers might arrive at different interpretations of the data and resulting program theories to explain mechanisms and outcomes for interventions for HNHC patients. Further refinement, confirmation, and refutation of the program theories should and are expected to occur as additional evidence emerges in this literature.

\section{KQ 3}

Because we primarily identified complex interventions, meaningfully classifying and synthesizing of the literature to answer KQ 3 was particularly challenging. We followed a classification scheme developed by Bodenheimer, based on the principal site of the program. ${ }^{45}$ We believed that categorizing the studies by primary setting would be the most useful for stakeholders, particularly health systems and others who are considering implementing proposed 
interventions in particular sites of care. However, while descriptions of studies included a broad overview of their components, few detailed the scope and intensity of the intervention that patients received. Interventions were generally large and complex; incorporated components used a variety of approaches and, as a result, cut across settings. Also, while interventions may be described as care management, disease management, case management, or care coordination, these terms were used inconsistently. These care delivery models overlap considerably.

We limited our effectiveness analyses to randomized controlled trials (RCTs) and observational studies that included a comparison population. We excluded observational studies without a comparison group (e.g., pre-post studies) despite their preponderance in the implementation literature because these studies cannot control for temporality and other confounders, limiting our ability to assess their effectiveness. Our Key Informants agreed with this exclusion decision but commented that this might result in our not considering some innovative initiatives.

Often included studies did not find a significant effect. In some cases, this may be related to the approach used for identifying HNHC patient participants. For comprehensiveness, this review did not predefine $\mathrm{HNHC}$ further than how study authors defined high use or high cost. This resulted in inclusion of a diverse set of interventions that targeted heterogenous populations, both within and across studies. By targeting patients with the highest prior costs or utilization, the regression to the mean phenomenon can affect findings. However, predicting which patients will be long-term chronic HNHC patients and which will have shorter episodes of high use is difficult. The result can be intervention and comparison groups not being comparable in ways that are difficult to measure and bias findings.

We considered our KQ 3 results in light of our KQ 1 analysis. Inclusion in the KQ 1 analysis required two or more utilization events in support of identifying high use, but generally studies classified the population based on much higher use. In contrast, the inclusion criteria across KQ 3 intervention studies were generally less stringent. For example, the use criterion in three studies was only one hospitalization, which may be insufficient to establish a pattern of high use. These studies are the Camden Core Model, CPC+, and IAH. All three studies required that participants have multiple chronic conditions and risk factors, but two of the three studies did not include a significant finding. Interventions may have identified HNHC patient participants who they determined had high need but baseline use may not have been high enough to easily see a significant change, relative to the comparison group, during the followup period.

Because of differences in outcomes reported across studies, a number of our strength-ofevidence grades were based on findings from one CMS demonstration. ${ }^{64-68,137}$ The evidence for several of the telephonic/mail, primary care-, and home-based model outcomes was solely from the Medicare Care Management for High Cost Beneficiaries (CMHCB) demonstration program. Because all CMHCB interventions were evaluated by the same group and reported the same large set of outcomes, the evidence from the studies was more likely to include outcomes that can be grouped to create a body of evidence. Although some of the outcomes (e.g., number of ACSC inpatient admissions) were also reported by other interventions within a model type, many of the outcomes were uniquely reported in only the CMHCB studies.

A second nuance of the CMHCB demonstration is that each intervention was often implemented within multiple samples. Because of this, many strength-of-evidence grades were based solely on two samples of a CMHCB study. For example, among home-based care models, the outcome of any ACSC inpatient admissions received a low strength-of-evidence grade for favorable finding (reported by 2 CMHCB samples). Similarly, the CMHCB demonstration's 
Village Health Phases I and II each included two rounds of patient enrollment, so for purposes of grading strength of evidence, the model counted as four RCTs. Although each of these samples is considered independent, they may limit generalizability to other settings.

\section{Applicability}

Based on the NAM taxonomy, we sought to include four of their six identified groups of HNHC patients: the nonelderly disabled, individuals with multiple chronic conditions, individuals with major complex chronic conditions, and the frail elderly. Virtually all evidence we found was focused on chronic disease patient populations. As noted previously, even though the frail elderly is an HNHC patient population of particular interest for this review, our information focusing on this group was limited to two cluster analyses that found the frail elderly to be a distinct high-use group.

By design, we excluded children with complex needs and individuals with advancing illness (end-of-life care) from the review. We did not find that the interventions we identified for adults addressed the specific care needs of children. A review of care for children who are HNHC patients would need to account for differences in complex needs and context. That review would likely require a greater emphasis on family caregiver, as well as the child's age and developmental ability. We excluded HNHC adult patient interventions for advancing illness because the goals of end-of-life care interventions would also be different from those associated with more long-term management of chronic conditions.

We limited the included literature across KQs to studies conducted in the United States, and the review is intended to be relevant to the U.S. system. Because access to healthcare and social services in the United States differs from that in other countries, the success of intervention outcomes could vary among different national healthcare settings. For example, although the goals of improving care management and expanding navigational services may be similar across countries, the activities that are required to access healthcare services in the United States are often different from those of another country, such as a country with a national health service.

\section{Implications for Clinical Practice, Education, Research, or Health Policy}

\section{Implications for Clinical Practice and Education}

A single vein that runs through the studies included across our three KQs is patient characteristics and situations that can exacerbate inadequate management of multiple chronic conditions. These include mental health and substance abuse disorders. When coupled with homelessness and poverty, care providers face challenges that go beyond the healthcare system alone. To effectively care for these complex HNHC patients, care providers will need to identify and address their behavioral and cross-sector nonmedical needs. Delivery of these services is more likely to be assured by the healthcare provider creating ongoing direct relationships with organizations that provide these other services.

Based on our realist review, we found that building relationships with HNHC patients and gaining their trust is a key mechanism in interventions successfully changing patients' behaviors. A multipronged strategy to identify HNHC patients could account for the complexity of their prior healthcare experiences, systemic barriers to access, clinician judgment, and willingness to engage in an intervention. Finally, we found that successful interventions recognize that 
relationships require the engagement of care providers. To succeed, providers need the emotional, financial, logistical, and practical resources necessary to engage and maintain relationships with HNHC patients.

However, the findings from our systematic review were mixed concerning whether interventions could generate savings to healthcare systems and payers in the short term, such as 1 year. Expectations of changing HNHC patient behaviors and resulting outcomes may need to take a longer view than was available through our included studies. Collecting and using patientcentered quality-of-care, satisfaction, and behavioral change outcomes could help interventions better anticipate whether they are likely to be on the path to achieving more global use and cost goals.

\section{Implications for Research}

Our review identified gaps in the literature that arise from the absence of studies, failures in the analytic methodology, and insufficient information on the content of interventions and outcomes. Although the results from each of the KQs are informative for policy and clinical decision making, we were less successful in our aim of closely linking findings across KQs in support of our analytic framework, which speaks to gaps in the field. The studies included for KQ 1 identify some patient characteristics that can be obtained through electronic data sources (claims, patient health records, and patient surveys) that are associated with high use of care. However, these data can only provide broad parameters of the characteristics of the population of interest. Commonly, the data do not directly identify care that is preventable and modifiable, only individuals where at least some of their care may be inappropriate and modifiable. Based on our realist review, we learned that patients need to be further identified individually to determine who is in the most need and best suited for an intervention.

More work is needed to support an understanding of targetable patient characteristics associated with modifiable and preventable high use. The single study that we found that addressed this distinction is insufficient to support clinical or policy-relevant conclusions. Future exposure study modeling needs to address multiple (and potentially correlated) factors at once, including the dynamic nature of high-cost service use among chronic, high- need patients, and be able to distinguish at the individual level between preventable or modifiable care and unavoidable service use. Relatedly, we found scant evidence explaining the role of patient health behaviors, such as self-efficacy, health literacy and activation. Because we know that individuals with the same clinical profile may use healthcare differently, direct measures of these dimensions would be informative. Based on our KQ 2 analysis, we know that these considerations need to be a primary focus in an intervention for HNHC patients.

Although behavioral health conditions were co-occurring disorders in many of the studies we reviewed, the presence and role of additional health concerns was not always clear. Additional research is needed to better understand the impact of behavioral health conditions on use of potentially preventable or modifiable high-cost medical care. The research should focus on clearly delineating behavioral health diagnosis or diagnoses, co-occurring chronic clinical conditions, the severity of the behavioral health condition, and whether the patient is actively engaged in treatment for their behavioral health problems.

Given the importance of building trusted relationships, future research may focus on developing tools to help measure patient trust in the healthcare system and in their care providers. This measure may be used to help identify patients whose lack of trust in the system needs to be intervened upon to obtain appropriate care. Similarly, intervention designers may 
want to specifically develop intervention components that support building trust between patients and care providers.

Additionally, our limited ability to fully understand the how and why interventions help HNHC patients speaks to the need for more qualitative and implementation research describing the process of care and patients' experiences. Better understanding of the experiences of individuals providing and receiving the intervention will help elucidate the often-unobservable mechanisms or responses to the resources provided by interventions. These insights can then be used to improve the design and implementation of future interventions for HNHC patients. For example, we sought to examine whether the subset of interventions that emphasize trust were more likely to have successful outcomes, but we found that the number of positive outcomes across all studies is too limited and too distal to make meaningful comparisons.

Although many of the intervention studies included for the systematic review provided services beyond healthcare, such as access to support and community resources, the outcomes they reported were largely limited to changes in global healthcare use and cost. Few studies reported changes in patients' clinical and social risk outcomes, quality of care or experience with care. Mortality was the only health outcome reported in more than one study. Only six intervention studies reported any social risk outcomes, such as receipt of temporary assistance, despite the focus on connecting patients to nonmedical resources among many of the interventions. $^{44,153,159,162,166,177,209}$ When patient care can go beyond clinical care to include nonmedical services, a truer, fuller evaluation of the impact of a complex intervention needs to include these other immediate and mediated outcomes. For example, some interventions included helping participants find stable housing because a stable living situation supports an individual's care management. If an outcome is measured only over a relatively short duration of time, patients could have obtained stable housing and be changing their health behaviors, but this intermediate outcome might not yet be reflected in changes in healthcare utilization and cost. Furthermore, studies did not report whether patients were more satisfied or happier after participating in interventions and what difficulties interventions may have faced in maintaining participant enrollment. Future research measuring and reporting more patient-centered and social risk-related outcomes would help our understanding of what interventions are accomplishing and why many are not achieving their ultimate healthcare use and cost goals.

Lastly, perhaps reflecting the relative newness of this field, we found no comparative effectiveness studies that directly compared individual interventions or types of interventions. Usual care was the comparison in virtually all studies, but the services received by patients in usual care were often unclear.

\section{Implications for Health Policy}

Based on our "best fit" framework synthesis approach, we found support for the categories included in the NAM taxonomy (chronic disease/functional limitations and across these, behavioral health and social risk factors). As discussed above, we believe that the framework would be enhanced by consideration of patterns and type of prior use and racial differences in experiences with the healthcare system.

We found strong support for including behavioral health conditions as an overarching contributor for identifying HNHC patients. However, because of the variation in behavioral health conditions and how they interact with each other and physical health conditions, a more nuanced framework than the one developed by NAM could be useful. For one, the diagnosis of depression stood out as a distinct predictor of high use in our review, while not reaching the 
same level of importance in the NAM framework. We also conclude that additional refinement of SUDs would be informative. SUDs can encompass multiple conditions, including many different substances, polysubstance use, and AUD, with each substance potentially having a distinctly different impact on physical health over the life span. ${ }^{210}$ For one, our review identified AUD as a potentially separate and distinct condition contributing to high utilization; however, the contribution was unclear. Lastly, the studies in our review did not allow us to clarify whether the relationship between behavioral health conditions and high utilization and cost considered whether individuals were in treatment for these conditions. One qualitative study emphasized that it is specifically the unmet or poorly managed behavioral health needs that were significant drivers of preventable high levels of healthcare use among HNHC patients, not just the presence of a behavioral health diagnosis. ${ }^{134}$

The findings from the KQ 1 analysis may yield support for policies for enhanced data collection efforts to identify and target HNHC patients across payers and healthcare settings. While many of the studies reviewed provided evidence for specific characteristics of HNHC patients, few studies outside of those conducted in the Veterans Health Administration system adequately and openly integrated clinical, payment, and social risk data to identify the HNHC patient population. Successfully targeting these patients may be improved through integrated data networks with timely data and evidence-based algorithms to assist providers and enhance their clinical decision making. Public sharing of algorithm would support their comparison across studies and patient populations. Increased use of existing tools such as International Statistical Classification of Diseases and Related Health Problems-10 Z codes to capture information on social determinants of health could help identify HNHC patients. We also found evidence that patient self-report about how they are managing their healthcare can provide useful information.

The findings from the KQ 1 analysis, that behavioral health characteristics are generally independent predictors of being $\mathrm{HNHC}$ patients, support increased efforts for the integration of behavioral health and physical health services. While the integration of behavioral healthcare is an aspect of some existing interventions, placing higher priority on the identification and treatment of behavioral health conditions, along with physical health management, could be explored.

Many of the interventions that were included in our review were large programs, implemented across multiple sites. Some showed reductions in healthcare use and cost, while many did not. Studies generally reported little information that can help us understand why some worked better than others. Although they are likely to have different mechanisms of action, the relative success of ED-based models in reducing unnecessary utilization and costs for HNHC patients suggests that current intervention strategies based in the ED may be more likely to be effective. However, it was clear that given the complexity of HNHC patient needs, interventions need a multipronged approach to simultaneously address medical needs and reach out to other sectors to address social risk factors. Based on our realist review, we conclude that key mechanisms of success at the care delivery level are the approach to patient identification and recruitment, engagement of patients and providers, and patient-provider relationships. More detailed descriptions of interventions, patient-centered outcomes, and qualitative assessments of both patient and provider experiences would support further policy development of best practices.

Our system-level transformation and telephonic/mail findings, of no difference in costs and use, speak to the challenges that stakeholders can face in modifying healthcare use patterns of 
HNHC patients through larger patient population-based interventions. Given recent provider and patient experience in using telehealth care because of the COVID-19 pandemic, telephone-based care management systems might consider greater reliance on video calls. Video calls can support more intimate connections between providers and patients without the time and logistical requirements of office visits. Video calls could also be used in these and other intervention formats for integrating connections with nonmedical services.

For interventions for HNHC patients to succeed, a payment model should financially support care providers in their efforts to help HNHC patients reduce use of preventable or modifiable services. Some healthcare systems are testing a delivery model that combines intensive medical and nonmedical service delivery with full-risk capitation payments that pay care providers for each patient, regardless of the amount of care provided. ${ }^{211-213}$ This model aims to provide incentives for care providers to provide HNHC patients with services that address social risk factors in hopes of preventing the use of more costly medical services. Although early reports of these models are promising, rigorous evaluations are needed to determine their effectiveness in reducing preventable or modifiable utilization among HNHC patients, while maintaining quality of care.

\section{Conclusions}

A central decisional dilemma facing interventions intended to reduce the healthcare use and cost of HNHC patients is how to reliably identify the patient population and to do so prior to a future period of high use that is preventable or modifiable. Electronic data can identify pools of patients who have characteristics associated with being HNHC. Further identification of specific HNHC patients who would be good candidates for programs is improved through individualized participant selection. Similarly, programs themselves are more complex than disease management programs and need to be able to address the complex needs of individual HNHC patient participants - some of which are likely to not be related to their medical conditions. Effectively addressing these challenges requires additional support for providers. The time needed to effect change may be lengthy and will vary by participant. Because of this, desired reductions in costs and use may take longer to realize than has been measured in many current interventions. Intermediate process outcomes and patient-centered outcomes may provide earlier results that can help predict the likelihood of clinical and more distal policy outcomes. 


\section{References}

1. Cohen $\mathrm{S}$. The concentration of health care expenditures and related expenses for costly medical conditions, 2012 Statistical Brief \#455. Rockville, MD: Agency for Healthcare Research and Quality; 2014. http:/www.meps.ahrq.gov/mepsweb/data_fi les/publications/st455/stat455.pdf

2. Cohen SB. The concentration and persistence in the level of health expenditures over time: estimates for the U.S. population, 2011-2012 Statistical Brief \#449. Rockville, MD: Agency for Healthcare Quality and Research; 2014. http:/www.meps.ahrq.gov/mepsweb/data_fi les/publications/st449/stat449.shtml

3. Cohen SB. The concentration of health care expenditures in the U.S. and predictions of future spending. J Econ Soc Meas. 2016;41:167-89.

4. Centers for Medicare \& Medicaid Services. Medicare beneficiaries at a glance.

Baltimore, MD: Centers for Medicare \& Medicaid Services; 2019.

https://www.cms.gov/Research-StatisticsData-and-Systems/Statistics-Trends-and-

Reports/Beneficiary-

Snapshot/Bene_Snapshot.html. Accessed on February 272019.

5. Centers for Medicare \& Medicaid Services. All Medicare inpatient hospitals: utilization, program payments, and cost sharing for original medicare beneficiaries, by demographic characteristics and MedicareMedicaid enrollment status, calendar year 2017. Baltimore, MD: Centers for Medicare \& Medicaid Services; n.d.

https://www.cms.gov/Research-StatisticsData-and-Systems/Statistics-Trends-andReports/CMSProgramStatistics/2017/Downl oads/UTIL/2017 CPS_MDCR_INPT_HOS P 2.PDF. Accessed on February 272019.
6.

Centers for Medicare \& Medicaid Services. CMS proposes "pathways to success," an overhaul of Medicare's ACO program. Baltimore, MD: Centers for Medicare \& Medicaid Service; 2018.

https://www.cms.gov/newsroom/pressreleases/cms-proposes-pathways-successoverhaul-medicares-acoprogram? ga $=2.111400452 .1093732935 .15$ 51231053-96630637.1551231053. Accessed on February 272018.

7. Centers for Medicare \& Medicaid Services. Medicare-Medicaid accountable care organization (ACO) model. Baltimore, MD: Centers for Medicare \& Medicaid Services; 2016. https://www.cms.gov/newsroom/factsheets/medicare-medicaid-accountable-careorganization-aco-model. Accessed on February 272019.

8. Centers for Medicare \& Medicaid Services. Vermont all-payer ACO model. Baltimore, MD: Centers for Medicare \& Medicaid Services; 2016.

https:/www.cms.gov/newsroom/factsheets/vermont-all-payer-aco-model. Accessed on February 272019.

9. Centers for Medicare \& Medicaid Services. CMS finalizes "pathways to success," an overhaul of Medicare's national ACO program. Baltimore, MD: Centers for Medicare \& Medicaid Services; 2018. https://www.cms.gov/newsroom/pressreleases/cms-finalizes-pathways-successoverhaul-medicares-national-aco-program. Accessed on February 272019.

10. Brennan A, Gaus C. ACOs at a crossroads: costs, risk and MACRA. A NAACOS policy white paper. Washington, DC: National Association of ACOs,; 2016.

https://www.naacos.com/acos-at-acrossroads Accessed on February 27, 2019.

11. Hagland M. NAACOS and ACO leaders express distress over just-announced MSSP application deadline. Sarasota, FL: Healthcare Innovation; 2019. https:/www.hcinnovationgroup.com/populat ion-healthmanagement/article/13031036/naacos-andaco-leaders-express-distress-overjustannounced-mssp-application-deadline. Accessed on February 27, 2019. 
12. Moe J, Kirkland SW, Rawe E, et al. Effectiveness of interventions to decrease emergency department visits by adult frequent users: a systematic review. Acad Emerg Med. 2017 Jan;24(1):40-52. doi: 10.1111/acem.13060. PMID: 27473387.

13. Soril LJ, Leggett LE, Lorenzetti DL, et al. Reducing frequent visits to the emergency department: a systematic review of interventions. PLoS One. 2015;10(4):e0123660. doi: 10.1371/journal.pone.0123660. PMID: 25874866 .

14. Baker JM, Grant RW, Gopalan A. A systematic review of care management interventions targeting multimorbidity and high care utilization. BMC Health Serv Res. 2018 Jan 30;18(1):65. doi: 10.1186/s12913018-2881-8. PMID: 29382327.

15. Edwards ST, Peterson K, Chan B, et al. Effectiveness of intensive primary care interventions: a systematic review. J Gen Intern Med. 2017 Dec;32(12):1377-86. doi: 10.1007/s11606-017-4174-Z. PMID: 28924747.

16. Smith SM, Wallace E, O'Dowd T, et al. Interventions for improving outcomes in patients with multimorbidity in primary care and community settings. Cochrane Database Syst Rev. 2016 Mar 14;3:CD006560. doi: 10.1002/14651858.CD006560.pub3. PMID: 26976529.

17. Cohen $\mathrm{S}, \mathrm{Yu}$ W. The concentration and persistence in the level of health expenditures over time: estimates for the U.S. population, 2008-2009. Statistical Brief \#354. Rockville, MD: Agency for Healthcare Research and Quality; January 2012.

http://www.meps.ahrq.gov/mepsweb/data fi les/publications/st354/stat354.pdf

18. Pearson SD, Katzelnick DJ, Simon GE, et al. Depression among high utilizers of medical care. J Gen Intern Med. 1999;14(8):461-8. doi: 10.1046/j.15251497.1999.06278.x.

19. Katon W, Von Korff M, Lin E, et al. Distressed high utilizers of medical care. DSM-III-R diagnoses and treatment needs. Gen Hosp Psychiatry. 1990;12(6):355-62.
20. National Academy of Medicine. Effective care for high-need patients. Opportunities for improving outcomes, value, and health. Washington, DC: National Academy of Sciences; 2017.

21. Mitchell EM. Statistical brief \#521: concentration of health expenditures and selected characteristics of high spenders, U.S. civilian noninstitutionalized population, 2016. Rockville, MD: AHRQ; 2019. https://meps.ahrq.gov/data files/publications /st521/stat521.shtml. Accessed on September 222020.

22. Ollove M. States focus on 'super-utilizers' to reduce Medicaid costs. Washington, DC: Pew Research Center; 2014.

https://www.pewtrusts.org/en/research-andanalysis/blogs/stateline/2014/12/5/statesfocus-on-superutilizers-to-reduce-medicaidcosts. Accessed on September 222020.

23. Jiang HJ, Weiss AJ, Barrett ML. Characteristics of emergency department visits for super-utilizers by payer, 2014. Washington, DC: AHRQ; 2017.

https://www.hcupus.ahrq.gov/reports/statbriefs/sb221-SuperUtilizer-ED-Visits-Payer-2014.jsp. Accessed on September 222020.

24. LaCalle E, Rabin E. Frequent users of emergency departments: the myths, the data, and the policy implications. Ann Emerg Med. 2010 Jul;56(1):42-8. doi: 10.1016/j.annemergmed.2010.01.032. PMID: 20346540.

25. Kronick RG, Bella M, Gilmer TP, et al. Faces of Medicaid II: recognizing the care needs of people with multiple chronic conditions. Hamilton, NJ: Center for Health Care Strategies, Inc.; 2007.

https://www.chcs.org/resource/the-faces-ofmedicaid-ii-recognizing-the-care-needs-ofpeople-with-multiple-chronic-conditions/. Accessed on September 2020.

26. Lochner KA, Goodman RA, Posner S, et al. Multiple chronic conditions among Medicare beneficiaries: state-level variations in prevalence, utilization, and cost, 2011. Medicare Medicaid Res Rev. 2013;3(3). doi: 10.5600/mmrr.003.03.b02. PMID: 24753976. 
27. Wammes JJG, van der Wees PJ, Tanke MAC, et al. Systematic review of high-cost patients' characteristics and healthcare utilisation. BMJ Open. 2018 Sep 8; Mar;8(9):e023113. doi: 10.1136/bmjopen2018-023113. PMID: 30196269.

28. Lockwood MB, Saunders MR, Lee CS, et al. Kidney transplant and the digital divide: is information and communication technology a barrier or a bridge to transplant for African Americans? Prog Transplant. 2013 Dec;23(4):302-9. doi: 10.7182/pit2013869. PMID: 24311393.

29. Lines L, Ash A. Predictors of potentially avoidable emergency department visits: a systematic review. 2012.

30. Andersen RM. Revisiting the behavioral model and access to medical care: does it matter? J Health Social Behavior. 1995;36(1):1-10.

31. Giannouchos TV, Kum HC, Foster MJ, et al. Characteristics and predictors of adult frequent emergency department users in the United States: A systematic literature review. J Eval Clin Pract. 2019 Jun;25(3):420-33. doi: 10.1111/jep.13137. PMID: 31044484.

32. Raven MC, Kushel M, Ko MJ, et al. The effectiveness of emergency department visit reduction programs: a systematic review. Ann Emerg Med. 2016 Oct;68(4):467-83 e15. doi:

10.1016/j.annemergmed.2016.04.015. PMID: 27287549.

33. Althaus F, Paroz S, Hugli O, et al. Effectiveness of interventions targeting frequent users of emergency departments: a systematic review. Ann Emerg Med. 2011 Jul;58(1):41-52 e42. doi: 10.1016/j.annemergmed.2011.03.007. PMID: 21689565.

34. Iovan S, Lantz PM, Allan K, et al. Interventions to decrease use in prehospital and emergency care settings among superutilizers in the United States: a systematic review. Med Care Res Rev. 2019 Apr 26:1077558719845722. doi: $10.1177 / 1077558719845722$.
35. Kumar GS, Klein R. Effectiveness of case management strategies in reducing emergency department visits in frequent user patient populations: a systematic review. J Emerg Med. 2013 Mar;44(3):71729. doi: 10.1016/j.jemermed.2012.08.035.

36. Di Mauro R, Di Silvio V, Bosco P, et al. Case management programs in emergency department to reduce frequent user visits: a systematic review. Acta Biomed. $2019 \mathrm{Jul}$ 8;90(6-s):34-40. doi: 10.23750/abm.v90i6S.8390. PMID: 31292413.

37. Iovan S, Lantz PM, Allan K, et al. Interventions to decrease use in prehospital and emergency care settings among superutilizers in the United States: a systematic review. Med Care Res Rev. 2020;77(2):99111. doi: 10.1177/1077558719845722.

38. Goodwin A, Henschen BL, O’Dwyer LC, et al. Interventions for frequently hospitalized patients and their effect on outcomes: a systematic review. J Hosp Med. 2018;13(12):853-9. doi: 10.12788/jhm.3090.

39. Delaney RK, Sisco-Taylor B, Fagerlin A, et al. A systematic review of intensive outpatient care programs for high-need, high-cost patients. Transl Behav Med. 2020;10(5):1187-99. doi: 10.1093/tbm/ibaa017.

40. Guise JM, Chang C, Butler M, et al. AHRQ series on complex intervention systematic reviews-paper 1: an introduction to a series of articles that provide guidance and tools for reviews of complex interventions. J Clin Epidemiol. 2017 Oct;90:6-10. doi: 10.1016/j.jclinepi.2017.06.011. PMID: 28720511.

41. Association of American Medical Colleges. Hot spotting guide FAQ. Washington, DC: Association of American Medical Colleges; 2019.

https://www.aamc.org/initiatives/hotspotter/f aqs/372468/hotspottingguidefaq.html. Accessed on August 122019.

42. Agency for Healthcare Research and Quality. Section 4: selecting care management interventions. Designing and implementing Medicaid disease and care management programs. Rockville, MD: Agency for Healthcare Research and Quality; 2014. 
43. Brenner J. Healthcare hotspotting. A project of the Camden Coalition of Healthcare Providers. Princeton, NJ: Robert Wood Johnson Foundation, Nicholson Foundation, and Commonwealth Fund; n.d. https://hotspotting.camdenhealth.org/.

Accessed on October 122020.

44. Finkelstein A, Zhou A, Taubman S, et al. Health care hotspotting - a randomized, controlled trial. N Engl J Med. 2020 Jan 9;382(2):152-62. doi: 10.1056/NEJMsa1906848. PMID: 31914242 .

45. Bodenheimer T. Strategies to reduce costs and improve care for high-utilizing Medicaid patients: reflections on pioneering programs. Center for Health Care Strategies. 2013 October.

46. Petticrew M, Rehfuess E, Noyes J, et al. Synthesizing evidence on complex interventions: how meta-analytical, qualitative, and mixed-method approaches can contribute. J Clin Epidemiol. 2013;66(11):1230-43. doi: 10.1016/j.jclinepi.2013.06.005.

47. Booth A, Carroll C. How to build up the actionable knowledge base: the role of 'best fit' framework synthesis for studies of improvement in healthcare. BMJ Qual Saf. 2015 Nov;24(11):700-8. doi:

10.1136/bmjqs-2014-003642. PMID: 26306609.

48. Carroll C, Booth A, Leaviss J, et al. "Best fit" framework synthesis: refining the method. BMC Med Res Methodol. 2013 Mar 13;13:37. doi: 10.1186/1471-2288-1337. PMID: 23497061.

49. Nuffield Department of Primary Care Health Sciences. The RAMESES projects. Oxford, UK: United Kingdom's National Institute of Health Research's Health Services and Delivery Research (NIHR HS\&DR)

Programme; 2013-21. https://www.ramesesproject.org/. Accessed on May 42021.

50. Agency for Healthcare Research and Quality. Methods guide for effectiveness and comparative effectiveness reviews. AHRQ Publication No. 10(14)-EHC063-EF. Rockville, MD: Agency for Healthcare Research and Quality; January 2014. www.effectivehealthcare.ahrq.gov
51. Pawson R, Greenhalgh T, Harvey G, et al. Realist synthesis: an introduction Submitted to the ESRC Research Methods Programme. Working Paper Series. Southampton, UK: ESRC Research Methods Programme; 2004.

52. Pawson R, Greenhalgh T, Harvey G, et al. Realist review--a new method of systematic review designed for complex policy interventions. J Health Serv Res Policy. 2005 Jul;10(Suppl 1):21-34. doi: 10.1258/1355819054308530. PMID: 16053581.

53. RAMESES Project. Quality standards for realist synthesis (for researchers and peerreviewers). Oxford: Nuffield Department of Primary Care Health Sciences, University of Oxford; 2014. www.ramesesproject.org). Accessed on August 122019.

54. Wong G, Greenhalgh T, Westhorp G, et al. RAMESES publication standards: realist syntheses. BMC Med. 2013 2013/01/29;11(1):21. doi: 10.1186/17417015-11-21.

55. Pawson R, Manzano-Santaella A. A realist diagnostic workshop. Evaluation.

2012;18(2):176-91. doi: $10.1177 / 1356389012440912$.

56. Sterne J. Personal communication. 2020.

57. Andersen R, Hagenaars JA, McCutcheon AL. Applied latent class analysis. Can J Sociol. 2003;28(4). doi: 10.2307/3341848.

58. Noyes J, Booth A, Cargo M, et al. Chapter 21: Qualitative evidence. In: Higgins JPT, Thomas J, Chandler J, Cumpston M, Li T, Page MJ, et al., eds. Cochrane handbook for systematic reviews of interventions version 6.2. Cochrane; 2021.

59. Critical Appraisal Skills Programme. CASP qualitative checklist. [online]. Oxford: Critical Appraisal Skills Programme; 2018. https://casp-uk.net/wpcontent/uploads/2018/01/CASP-QualitativeChecklist-2018.pdf. Accessed on November 72019.

60. Wong G. Data gathering for realist reviews: looking for needles in haystacks. In: Emmel N, Greenhalgh J, Manzano A, Monaghan M, Dalkin S, eds. Doing realist research. London: Sage; 2018. 
61. Berg RC, Nanavati J. Realist review: current practice and future prospects. J Res Pract. 2016;12(1).

62. Sterne JA, Hernan MA, Reeves BC, et al. ROBINS-I: a tool for assessing risk of bias in non-randomised studies of interventions. BMJ. 2016 Oct 12;355:i4919. doi: 10.1136/bmj.i4919. PMID: 27733354.

63. Sterne JAC, Savović J, Page MJ, et al. RoB 2: a revised tool for assessing risk of bias in randomised trials. BMJ. 2019;366:14898.

64. McCall N, Cromwell J, Urato C, et al. Evaluation of Medicare Care Management for High Cost Beneficiaries (CMHCB) Demonstration: VillageHealth's Key to Better Health (KTBH): final report RTI International Research Triangle Park, NC: 2010. https://www.cms.gov/ResearchStatistics-Data-and-Systems/StatisticsTrends-and-

Reports/Reports/downloads/McCall KTBH Final 2010.pdf

65. Urato C, McCall N, Cromwell J, et al. Evaluation of the Extended Medicare Care Management for High Cost Beneficiaries (CMHCB) Demonstration: VillageHealth's Key to Better Health (KTBH): final report RTI International Research Triangle Park, NC: 2013.

https://innovation.cms.gov/files/reports/cmh cb-villagehealth.pdf

66. McCall N, Cromwell J, Smith K, et al. Evaluation of Medicare Care Management for High Cost Beneficiaries (CMHCB) Demonstration: the Health Buddy ${ }^{\circledR}$ Consortium (HBC): revised final report RTI International Research Triangle Park, NC: April 20112011.

https:/www.cms.gov/Research-StatisticsData-and-Systems/Statistics-Trends-andReports/Reports/downloads/mccall_eval_of _cmhcb_demo_april_2011.pdf

67. McCall N, Cromwell J, Urato C, et al. Evaluation of Medicare Care Management for High Cost Beneficiaries (CMHCB) Demonstration: Care Level Management (CLM) RTI International. Research Triangle Park, NC: 2010.

https://www.cms.gov/Research-StatisticsData-and-Systems/Statistics-Trends-andReports/Reports/downloads/CMHCB_CLM _McCall_2010.pdf
68. McCall N, Cromwell J, Urato C. Evaluation of Medicare Care Management for High Cost Beneficiaries (CMHCB) Demonstration: Massachusetts General Hospital and Massachusetts General Physician Organization (MGH): final report RTI International. Research Triangle Park, NC: 2010.

69. Peikes D, Anglin G, Dale S, et al. Evaluation of the Comprehensive Primary Care initiative: fourth annual report Mathematica Policy Research. Princeton, NJ: 2018.

https://www.mathematica.org/publications/e valuation-of-the-comprehensive-primarycare-initiative-fourth-annual-report

70. Peikes D, Anglin G, Harrington M, et al. Independent evaluation of comprehensive primary care plus $(\mathrm{CPC}+)$ first annual report Mathematica Policy Research. Princeton, NJ: 2019.

https://www.mathematica.org/publications/i ndependent-evaluation-of-comprehensiveprimary-care-plus-cpc-first-annual-report

71. Kahn KL, Timbie JW, Friedberg MW, et al. Evaluation of CMS's Federally Qualified Health Center (FQHC) Advanced Primary Care Practice (APCP) Demonstration: final report RAND Corporation. Santa Monica, CA: 2017.

https://www.rand.org/pubs/research_reports/ $\underline{\text { RR886z2.html }}$

72. Kimmey L, Anderson M, Cheh V, et al. Evaluation of the Independence at Home Demonstration: an examination of the first four years Mathematica Policy Research. Princeton, NJ: 2019.

https://www.mathematica.org/publications/e valuation-of-the-independence-at-homedemonstration-an-examination-of-the-firstfour-years

73. Berkman ND, Lohr KN, Ansari MT, et al. Grading the strength of a body of evidence when assessing health care interventions: an EPC update. J Clin Epidemiol. 2015 Nov;68(11):1312-24. doi: 10.1016/j.jclinepi.2014.11.023. PMID: 25721570 .

74. Treadwell JR, Uhl S, Tipton K, et al. Assessing equivalence and noninferiority. J Clin Epidemiol. 2012 Nov;65(11):1144-9. doi: 10.1016/j.jclinepi.2012.05.001. PMID: 22732455. 
75. Bayliss EA, Powers JD, Ellis JL, et al. Applying sequential analytic methods to self-reported information to anticipate care needs. EGEMS (Wash DC). 2016;4(1):1258. doi: 10.13063/2327-9214.1258. PMID: 27563684.

76. Yang C, Delcher C, Shenkman E, et al. Identifying high health care utilizers using post-regression residual analysis of health expenditures from a state Medicaid program. AMIA Annual Symposium; 2017. 586: AMIA Symposium proceedings; 2017. pp. 1848-57.

77. Meek JA, Lyon BL, May FE, et al. Targeting high utilisers: predictive validity of a screening questionnaire. Disease Management and Health Outcomes. 2000;8(4):223-32. doi: 10.2165/00115677200008040-00005.

78. Yang C, Delcher C, Shenkman E, et al. Machine learning approaches for predicting high cost high need patient expenditures in health care. Biomed Eng Online. 2018 Nov 20;17(Suppl 1):131. doi: 10.1186/s12938018-0568-3. PMID: 30458798.

79. Kanzaria HK, Niedzwiecki MJ, Montoy JC, et al. Persistent frequent emergency department use: core group exhibits extreme levels of use for more than a decade. Health Aff (Millwood). 2017 Oct 1;36(10):1720-8. doi: 10.1377/hlthaff.2017.0658. PMID: 28971916.

80. Colligan EM, Pines JM, Colantuoni E, et al. Risk factors for persistent frequent emergency department use in Medicare beneficiaries. Ann Emerg Med. 2016 Jun;67(6):721-9. doi: 10.1016/j.annemergmed.2016.01.033. PMID: 26947801.

81. Billings J, Raven MC. Dispelling an urban legend: frequent emergency department users have substantial burden of disease. Health Aff (Millwood). 2013 Dec;32(12):2099-108. doi: 10.1377/hlthaff.2012.1276. PMID: 24301392.

82. Yang C, Delcher C, Shenkman E, et al. Expenditure variations analysis using residuals for identifying high health care utilizers in a state Medicaid program. BMC Med Inform Decis Mak. 2019;19(1):N.PAGN.PAG. doi: 10.1186/s12911-019-0870-4.
83. Chang ET, Piegari R, Wong ES, et al. Which patients are persistently high-risk for hospitalization? Am J Manag Care. 2019 Sep 1;25(9):e274-e81. PMID: 31518099.

84. Raven MC, Billings JC, Goldfrank LR, et al. Medicaid patients at high risk for frequent hospital admission: real-time identification and remediable risks. J Urban Health. 2009 Mar;86(2):230-41. doi: 10.1007/s11524008-9336-1. PMID: 19082899.

85. Billings J, Mijanovich T. Improving the management of care for high-cost Medicaid patients. Health Aff (Millwood). 2007 NovDec;26(6):1643-54. doi: 10.1377/hlthaff.26.6.1643. PMID: 17978384.

86. Keeney T, Joyce NR, Meyers DJ, et al. Persistence of high-need status over time among fee-for-service Medicare beneficiaries. Med Care Res Rev.7. doi: 10.1177/1077558719901219.

87. Chang G, Weiss AP, Orav EJ, et al. Predictors of frequent emergency department use among patients with psychiatric illness. Gen Hosp Psychiatry. 2014 Nov-Dec;36(6):716-20. doi: 10.1016/j.genhosppsych.2014.09.010. PMID: 25312277.

88. Doran KM, Raven MC, Rosenheck RA. What drives frequent emergency department use in an integrated health system? National data from the Veterans Health Administration. Ann Emerg Med. 2013 Aug;62(2):151-9. doi: 10.1016/j.annemergmed.2013.02.016. PMID: 23582617.

89. Behr JG, Diaz R. Emergency department frequent utilization for non-emergent presentments: results from a regional urban trauma center study. PLoS One.

2016;11(1):e0147116. doi: 10.1371/journal.pone.0147116. PMID: 26784515.

90. Buhumaid R, Riley J, Sattarian M, et al. Characteristics of frequent users of the emergency department with psychiatric conditions. J Health Care Poor Underserved. 2015 Aug;26(3):941-50. doi: 10.1353/hpu.2015.0079. PMID: 26320924. 
91. Thakarar K, Morgan JR, Gaeta JM, et al. Predictors of frequent emergency room visits among a homeless population. PLoS One. 2015;10(4):e0124552. doi: 10.1371/journal.pone.0124552. PMID: 25906394.

92. Hasegawa K, Tsugawa Y, Camargo CA, Jr., et al. Frequent utilization of the emergency department for acute heart failure syndrome: a population-based study. Circ Cardiovasc Qual Outcomes. 2014 Sep;7(5):735-42. doi: 10.1161/circoutcomes.114.000949. PMID: 25139183.

93. Hasegawa K, Tsugawa Y, Tsai CL, et al. Frequent utilization of the emergency department for acute exacerbation of chronic obstructive pulmonary disease. Respir Res. 2014 Apr 10;15:40. doi: 10.1186/14659921-15-40. PMID: 24717062.

94. Doran KM, Colucci AC, Wall SP, et al. Reasons for emergency department use: do frequent users differ? Am J Manag Care. 2014 Nov 1;20(11):e506-14. PMID: 25730349 .

95. Hasegawa K, Sullivan AF, Tovar Hirashima E, et al. A multicenter observational study of US adults with acute asthma: who are the frequent users of the emergency department? J Allergy Clin Immunol Pract. 2014 Nov-Dec;2(6):733-40. doi: 10.1016/j.jaip.2014.06.012. PMID: 25439365 .

96. Liu SW, Nagurney JT, Chang Y, et al. Frequent ED users: are most visits for mental health, alcohol, and drug-related complaints? Am J Emerg Med. 2013 Oct;31(10):1512-5. doi: 10.1016/j.ajem.2013.08.006. PMID: 24035051.

97. Milbrett P, Halm M. Characteristics and predictors of frequent utilization of emergency services. J Emerg Nurs. 2009 Jun;35(3):191-8; quiz 273. doi: 10.1016/j.jen.2008.04.032. PMID: 19446122 .
98. Ruger JP, Richter CJ, Spitznagel EL, et al. Analysis of costs, length of stay, and utilization of emergency department services by frequent users: implications for health policy. Acad Emerg Med. 2004 Dec;11(12):1311-7. doi: 10.1197/j.aem.2004.07.008. PMID: 15576522 .

99. Mandelberg JH, Kuhn RE, Kohn MA. Epidemiologic analysis of an urban, public emergency department's frequent users. Acad Emerg Med. 2000 Jun;7(6):637-46. doi: 10.1111/j.1553-2712.2000.tb02037.x. PMID: 10905642.

100. Vinton DT, Capp R, Rooks SP, et al. Frequent users of US emergency departments: characteristics and opportunities for intervention. Emerg Med J. 2014 Jul;31(7):526-32. doi: 10.1136/emermed-2013-202407. PMID: 24473411.

101. Hunt KA, Weber EJ, Showstack JA, et al. Characteristics of frequent users of emergency departments. Ann Emerg Med. 2006 Jul;48(1):1-8. doi:

10.1016/j.annemergmed.2005.12.030. PMID: 16781914.

102. Friedman BW, Serrano D, Reed M, et al. Use of the emergency department for severe headache. A population-based study. Headache. 2009 Jan;49(1):21-30. doi: 10.1111/j.1526-4610.2008.01282.x. PMID: 19040677.

103. Zuckerman S, Shen YC. Characteristics of occasional and frequent emergency department users: do insurance coverage and access to care matter? Med Care. 2004 Feb;42(2):176-82. doi: 10.1097/01.mlr.0000108747.51198.41. PMID: 14734955.

104. Castillo EM, Brennan JJ, Howard J, et al. Factors associated with geriatric frequent users of emergency departments. Ann Emerg Med. 2019 Aug;74(2):270-5. doi: 10.1016/j.annemergmed.2018.12.013. PMID: 30704786. 
105. Kanzaria HK, Niedzwiecki M, Cawley CL, et al. Frequent emergency department users: focusing solely on medical utilization misses the whole person. Health Aff (Millwood). 2019 Nov;38(11):1866-75. doi: 10.1377/hlthaff.2019.00082. PMID: 31682499.

106. Mohammed Moazam Ali M. The role of social and clinical determinants in the frequent utilization of emergency departments. The George Washington University, ProQuest Dissertations Publishing; 2018.

107. Gopalan K. Service delivery and quality of care for individuals with mental illness: University of Pittsburgh; 2017.

108. Surbhi S, Graetz I, Wan JY, et al. Medication nonadherence, mental health, opioid use, and inpatient and emergency department use in super-utilizers. Am J Manag Care. 2020;26(3):E98-E103. doi: 10.37765/ajmc.2020.42642.

109. Bell J, Turbow S, George M, et al. Factors associated with high-utilization in a safety net setting. BMC Health Serv Res. 2017 Apr 14;17(1):273. doi: 10.1186/s12913-0172209-0. PMID: 28410614.

110. Porter M, Quillen D, Agana DF, et al. Are patients frequently readmitted to the hospital different from the other admitted patients? J Am Board Fam Med. 2019 Jan-

Feb;32(1):58-64. doi: 10.3122/jabfm.2019.01.180052.

111. Emechebe N, Lyons Taylor P, Amoda O, et al. Passive social health surveillance and inpatient readmissions. Am J Manag Care. 2019 Aug;25(8):388-95. PMID: 31419096.

112. Rohrer JE, Rasmussen N, Adamson SA. Illness severity and total visits in family medicine. J Eval Clin Pract. 2008;14(1):659.

113. Blumenthal KJ, Chang Y, Ferris TG, et al. Using a self-reported global health measure to identify patients at high risk for future healthcare utilization. J Gen Intern Med. 2017;32(8):877-82. doi: 10.1007/s11606$017-4041-y$.
114. Reichard A, Gulley SP, Rasch EK, et al. Diagnosis isn't enough: understanding the connections between high health care utilization, chronic conditions and disabilities among U.S. working age adults. Disabil Health J. 2015;8(4):535-46. doi: 10.1016/j.dhjo.2015.04.006.

115. Walker EA, Katon W, Russo J, et al. Health care costs associated with posttraumatic stress disorder symptoms in women. Arch Gen Psychiatry. 2003 Apr;60(4):369-74. doi: 10.1001/archpsyc.60.4.369.

116. Robinson RL, Grabner M, Palli SR, et al. Covariates of depression and high utilizers of healthcare: impact on resource use and costs. J Psychosom Res. 2016;85:35-43. doi: 10.1016/j.jpsychores.2016.04.002.

117. Sterling S, Chi F, Weisner C, et al. Association of behavioral health factors and social determinants of health with high and persistently high healthcare costs. Prev Med Rep. 2018;11:154-9. doi: 10.1016/j.pmedr.2018.06.017.

118. Berkowitz SA, Seligman HK, Meigs JB, et al. Food insecurity, healthcare utilization, and high cost: a longitudinal cohort study. Am J Manag Care. 2018 Sep;24(9):399-404. PMID: 30222918.

119. Figueroa JF, Zhou X, Jha AK. Characteristics and spending patterns of persistently high-cost Medicare patients. Health Aff (Millwood). 2019 Jan;38(1):10714. doi: 10.1377/hlthaff.2018.05160. PMID: 30615516.

120. Yang C, Delcher C, Shenkman E, et al. Clustering inter-arrival time of health care encounters for high utilizers. 2018 IEEE 20th International Conference on e-Health Networking, Applications and Services, Healthcom 2018; 2018 September 17-20; Ostrava, Czech Republic. Curran Associates.

121. Birmingham LE, Cheruvu VK, Frey JA, et al. Distinct subgroups of emergency department frequent users: a latent class analysis. Am J Emerg Med. 2020

Jan;38(1):83-8. doi: 10.1016/j.ajem.2019.04.029. PMID: 31023586. 
122. Newcomer SR, Steiner JF, Bayliss EA. Identifying subgroups of complex patients with cluster analysis. Am J Manag Care. 2011 Aug 1;17(8):e324-32. PMID: 21851140 .

123. Szymkowiak D, Montgomery AE, Johnson EE, et al. Persistent super-utilization of acute care services among subgroups of veterans experiencing homelessness. Med Care. 2017 Oct;55(10):893-900. doi: 10.1097/mlr.0000000000000796. PMID: 28863030.

124. Wong ES, Yoon J, Piegari RI, et al. Identifying latent subgroups of high-risk patients using risk score trajectories. J Gen Intern Med. 2018 Dec;33(12):2120-6. doi: 10.1007/s11606-018-4653-x. PMID: 30225769 .

125. Prenovost KM, Fihn SD, Maciejewski ML, et al. Using item response theory with health system data to identify latent groups of patients with multiple health conditions. PLoS One. 2018;13(11):e0206915. doi: 10.1371/journal.pone.0206915. PMID: 30475823 .

126. Hyer JM, Paredes AZ, White S, et al. Assessment of utilization efficiency using machine learning techniques: a study of heterogeneity in preoperative healthcare utilization among super-utilizers. Am J Surg. 2020 Sep;220(3):714-20. doi: 10.1016/j.amjsurg.2020.01.043. PMID: 32008721 .

127. Lee NS, Whitman N, Vakharia N, et al. High-cost patients: hot-spotters don't explain the half of it. J Gen Intern Med. 2017 Jan;32(1):28-34. doi: 10.1007/s11606-0163790-3. PMID: 27480529.

128. Powers BW, Yan J, Zhu J, et al. Subgroups of high-cost Medicare advantage patients: an observational study. J Gen Intern Med. 2019 Feb;34(2):218-25. doi: 10.1007/s11606-0184759-1. PMID: 30511290.

129. Grant RW, McCloskey J, Hatfield M, et al. Use of latent class analysis and k-means clustering to identify complex patient profiles. JAMA Netw Open. 2020 Dec 1;3(12):e2029068. doi: 10.1001/jamanetworkopen.2020.29068. PMID: 33306116.
130. Ganguli I, Thompson RW, Ferris TG. What can five high cost patients teach us about healthcare spending? Healthc (Amst). 2017 Dec;5(4):204-13. doi: 10.1016/j.hjdsi.2016.12.004. PMID: 28039014.

131. Hardy M, Cho A, Stavig A, et al. Understanding frequent emergency department use among primary care patients. Popul Health Manag. 2018 Feb;21(1):24-31. doi: 10.1089/pop.2017.0030. PMID: 28609191.

132. Birmingham LE, Cochran T, Frey JA, et al. Emergency department use and barriers to wellness: a survey of emergency department frequent users. BMC Emerg Med. 2017 May 10;17(1):16. doi: 10.1186/s12873-017-01265. PMID: 28486935.

133. Chan B, Hulen E, Edwards S, et al. "It's like riding out the chaos": caring for socially complex patients in an ambulatory intensive care unit (A-ICU). Ann Fam Med. 2019 Nov;17(6):495-501. doi: 10.1370/afm.2464. PMID: 31712287.

134. Das LT, Kaushal R, Garrison K, et al. Drivers of preventable high health care utilization: a qualitative study of patient, physician and health system leader perspectives. J Health Serv Res Policy. 2019 Sep 10;25(4):1355819619873685. doi: 10.1177/1355819619873685. PMID: 31505976.

135. Brannon E, Wang T, Lapedis J, et al. Towards a learning health system to reduce emergency department visits at a population level. AMIA Symposium; 2018. Annual Symposium proceedings; 2018. pp. 295-304.

136. Gross K, Brenner JC, Truchil A, et al. Building a citywide, all-payer, hospital claims database to improve health care delivery in a low-income, urban community. Popul Health Manag. 2013;16:S-20. doi: 10.1089/pop.2013.0037.

137. McCall N, Cromwell J, Urato C, et al. Evaluation of Medicare Care Management for High Cost Beneficiaries (CMHCB) Demonstration: Texas Senior Trails (TST): final report RTI International Research Triangle Park, NC: 2010. https://www.cms.gov/reports/downloads/C MHCB_TST_McCall_2010.pdf 
138. Durfee J, Johnson T, Batal H, et al. The impact of tailored intervention services on charges and mortality for adult superutilizers. Healthc (Amst). 2018

Dec;6(4):253-8. doi: 10.1016/j.hjdsi.2017.08.004. PMID: 28847571 .

139. Peterson G, Blue L, Moreno L, et al. Evaluation of Health Care Innovation Awards (HCIA): Primary Care Redesign Programs: third annual report Mathematica Policy Research. Princeton, NJ: 2017. https://downloads.cms.gov/files/cmmi/hciaprimarycareredesign-thirdannualrpt.pdf

140. Yoon J, Chang E, Rubenstein LV, et al. Impact of primary care intensive management on high-risk veterans' costs and utilization. Ann Intern Med. 2018 Oct 2;169(7):515-6. doi: 10.7326/118-0461. PMID: 30285201.

141. Capp R, Misky GJ, Lindrooth RC, et al. Coordination program reduced acute care use and increased primary care visits among frequent emergency care users. Health Aff (Millwood). 2017;36(10):1705-11. doi: 10.1377/hlthaff.2017.0612.

142. Bayliss EA, Ellis JL, Powers JD, et al. Using self-reported data to segment older adult populations with complex care needs. EGEMS (Wash DC). 2019 Apr 12;7(1):12. doi: 10.5334/egems.275. PMID: 31065556.

143. Dally DL, Dahar W, Scott A, et al. The impact of a health education program targeting patients with high visit rates in a managed care organization. Am J Health Promot. 2002;17(2):101-11. doi: 10.4278/0890-1171-17.2.101.

144. Roberts SR, Crigler J, Ramirez C, et al. Working with socially and medically complex patients: when care transitions are circular, overlapping, and continual rather than linear and finite. J Healthc Qual. 2015 Jul-Aug;37(4):245-65. doi: 10.1097/jhq.0000000000000006. PMID: 26147126.

145. Horn BP, Crandall C, Moffett M, et al. The economic impact of intensive care management for high-cost medically complex patients: an evaluation of New Mexico's care one program. Popul Health Manag. 2016 Dec;19(6):398-404. doi: 10.1089/pop.2015.0142. PMID: 27031738.
146. Wilber KH, Allen D, Shannon GR, et al. Partnering managed care and communitybased services for frail elders: the care advocate program. J Am Geriatr Soc. 2003 Jun;51(6):807-12. doi: 10.1046/j.13652389.2003.51257.x. PMID: 12757567.

147. Fleming MD, Shim JK, Yen IH, et al. Patient engagement at the margins: health care providers' assessments of engagement and the structural determinants of health in the safety-net. Soc Sci Med. 2017

Jun;183:11-8. doi: 10.1016/j.socscimed.2017.04.028. PMID: 28445806.

148. Thompson MP, Podila PSB, Clay C, et al. Community navigators reduce hospital utilization in super-utilizers. Am J Manag Care. 2018 Feb;24(2):70-6. PMID: 29461853.

149. Zulman DM, Chang ET, Wong A, et al. Effects of intensive primary care on highneed patient experiences: survey findings from a Veterans Affairs randomized quality improvement trial. J Gen Intern Med. 2019 May;34(Suppl 1):75-81. doi: 10.1007/s11606-019-04965-0. PMID: 31098977.

150. Crane S, Collins L, Hall J, et al. Reducing utilization by uninsured frequent users of the emergency department: combining case management and drop-in group medical appointments. J Am Board Fam Med. 2012 Mar-Apr;25(2):184-91. doi: 10.3122/jabfm.2012.02.110156. PMID: 22403199.

151. Katzelnick DJ, Simon GE, Pearson SD, et al. Randomized trial of a depression management program in high utilizers of medical care. Arch Fam Med. 2000 Apr;9(4):345-51. doi: 10.1001/archfami.9.4.345.

152. Vickery KD, Shippee ND, Menk J, et al. Integrated, accountable care for Medicaid expansion enrollees: a comparative evaluation of Hennepin Health. Med Care Res Rev. 2020. doi: 10.1177/1077558718769481.

153. Adam P, Brandenburg DL, Bremer KL, et al. Effects of team care of frequent attenders on patients and physicians. Fam Syst Health. 2010 Sep;28(3):247-57. doi: 10.1037/a0020944. PMID: 20939629. 
154. Hibbard JH, Greene J, Sacks R, et al. Adding a measure of patient selfmanagement capability to risk assessment can improve prediction of high costs. Health Aff (Millwood). 2016 Mar;35(3):489-94. doi: 10.1377/hlthaff.2015.1031. PMID: 26953304.

155. Mautner DB, Pang HC, Brenner JC, et al. Generating hypotheses about care needs of high utilizers: lessons from patient interviews. Popul Health Manag. 2013 Oct;16:S26-S33. doi: 10.1089/pop.2013.0033.

156. Zulman DM, Ezeji-Okoye SC, Shaw JG, et al. Partnered research in healthcare delivery redesign for high-need, high-cost patients: development and feasibility of an Intensive Management Patient-Aligned Care Team (ImPACT). J Gen Intern Med. 2014 Dec;29 Suppl 4:861-9. doi: 10.1007/s11606-0143022-7. PMID: 25355084.

157. Shah R, Chen C, O'Rourke S, et al. Evaluation of care management for the uninsured. Med Care. 2011 Feb;49(2):16671. doi: 10.1097/MLR.0b013e3182028e81. PMID: 21206292.

158. Powers BW, Modarai F, Palakodeti S, et al. Impact of complex care management on spending and utilization for high-need, highcost Medicaid patients. Am J Manag Care. 2020 Feb 1;26(2):e57-e63. doi: 10.37765/ajmc.2020.42402. PMID: 32059101 .

159. Raven MC, Niedzwiecki MJ, Kushel M. A randomized trial of permanent supportive housing for chronically homeless persons with high use of publicly funded services. Health Serv Res. 2020 Oct;55 Suppl 2(Suppl 2):797-806. doi: 10.1111/1475-6773.13553. PMID: 32976633.

160. Kelley L, Capp R, Carmona JF, et al. Patient navigation to reduce emergency department (ED) utilization among Medicaid insured, frequent $E D$ users: a randomized controlled trial. J Emerg Med. 2020;58(6):967-77. doi: 10.1016/j.jemermed.2019.12.001.

161. Lin MP, Blanchfield BB, Kakoza RM, et al. ED-based care coordination reduces costs for frequent ED users. Am J Manag Care. 2017 Dec;23(12):762-6. PMID: 29261242.
162. Bell JF, Krupski A, Joesch JM, et al. A randomized controlled trial of intensive care management for disabled Medicaid beneficiaries with high health care costs. Health Serv Res. 2015 Jun;50(3):663-89. doi: 10.1111/1475-6773.12258. PMID: 25427656.

163. Sherry M, Wolff JL, Ballreich J, et al. Bridging the Silos of Service Delivery for High-Need, High-Cost Individuals. Popul Health Manag. 2016 Dec;19(6):421-8. doi: 10.1089/pop.2015.0147. PMID: 27006987.

164. Tanio C, Chen C. Innovations at Miami practice show promise for treating high-risk Medicare patients. Health Aff (Millwood). 2013 Jun;32(6):1078-82. doi: 10.1377/hlthaff.2012.0201. PMID: 23733982.

165. Sledge WH, Brown KE, Levine JM, et al. A randomized trial of primary intensive care to reduce hospital admissions in patients with high utilization of inpatient services. Dis Manag. 2006;9(6):328-38. doi: 10.1089/dis.2006.9.328.

166. Shumway M, Boccellari A, O'Brien K, et al. Cost-effectiveness of clinical case management for ED frequent users: results of a randomized trial. Am J Emerg Med. 2008 Feb;26(2):155-64. doi: 10.1016/j.ajem.2007.04.021. PMID: 18272094.

167. Coleman EA, Eilertsen TB, Kramer AM, et al. Reducing emergency visits in older adults with chronic illness. A randomized, controlled trial of group visits. Eff Clin Pract. 2001 Mar-Apr;4(2):49-57. PMID: 11329985.

168. Seaberg D, Elseroad S, Dumas M, et al. Patient navigation for patients frequently visiting the emergency department: a randomized, controlled trial. Acad Emerg Med. 2017 Nov;24(11):1327-33. doi: 10.1111/acem.13280. PMID: 28834070.

169. Weerahandi H, Basso Lipani M, Kalman J, et al. Effects of a psychosocial transitional care model on hospitalizations and cost of care for high utilizers. Soc Work Health Care. 2015;54(6):485-98. doi: 10.1080/00981389.2015.1040141. 
170. Navratil-Strawn JL, Hawkins K, Wells TS, et al. An emergency room decision-support program that increased physician office visits, decreased emergency room visits, and saved money. Popul Health Manag. 2014 Oct;17(5):257-64. doi: 10.1089/pop.2013.0117. PMID: 24865849.

171. Schickedanz A, Sharp A, Hu YR, et al. Impact of social needs navigation on utilization among high utilizers in a large integrated health system: a quasiexperimental study. J Gen Intern Med. 2019 Nov;34(11):2382-9. doi: 10.1007/s11606019-05123-2. PMID: 31228054.

172. Sevak P, Stepanczuk CN, Bradley KWV, et al. Effects of a community-based care management model for super-utilizers. Am J Manag Care. 2018 Nov 1;24(11):e365-e70.

173. Sandberg SF, Erikson C, Owen R, et al. Hennepin Health: a safety-net accountable care organization for the expanded Medicaid population. Health Aff (Millwood). 2014 Nov;33(11):1975-84. doi: 10.1377/hlthaff.2014.0648. PMID: 25367993.

174. DeHaven M, Kitzman-Ulrich H, Gimpel N, et al. The effects of a community-based partnership, Project Access Dallas (PAD), on emergency department utilization and costs among the uninsured. J Public Health (Oxf). 2012 Dec;34(4):577-83. doi: 10.1093/pubmed/fds027. PMID: 22653885.

175. Enard KR, Ganelin DM. Reducing preventable emergency department utilization and costs by using community health workers as patient navigators. J Healthc Manag. 2013 Nov-Dec;58(6):41227; discussion 28. PMID: 24400457.

176. Gimpel N, Marcee A, Kennedy K, et al. Patient perceptions of a community-based care coordination system. Health Promot Pract. 2010 Mar;11(2):173-81. doi: 10.1177/1524839908320360. PMID: 19131540 .

177. McCormack RP, Hoffman LF, Wall SP, et al. Resource-limited, collaborative pilot intervention for chronically homeless, alcohol-dependent frequent emergency department users. Am J Public Health. 2013 Dec;103 Suppl 2(Suppl 2):S221-4. doi: 10.2105/ajph.2013.301373. PMID: 24148034.
178. Harrison JM, Oganisian A, Grande DT, et al. Economic outcomes of insurer-led care management for high-cost medicaid patients. Am J Manag Care. 2020 Jul;26(7):310-6. doi: 10.37765/ajmc.2020.43769.

179. Valluru G, Yudin J, Patterson CL, et al. Integrated home- and community-based services improve community survival among independence at home Medicare beneficiaries without increasing Medicaid costs. J Am Geriatr Soc. 2019 Jul;67(7):1495-501. doi: 10.1111/jgs.15968. PMID: 31074846.

180. Li E, Kimmey L, Cheh V. Evaluation of the independence at home demonstration: an examination of the first five years Mathematica Policy Research. Princeton, NJ: 2020. https://innovation.cms.gov/files/reports/iahyr5evalrpt.pdf

181. Anglin G, Peikes D, Petersen D, et al. Independent evaluation of comprehensive primary care plus $(\mathrm{CPC}+)$ : second annual report Mathematica Policy Research. Princeton, NJ: 2020.

https://www.mathematica.org/publications/i ndependent-evaluation-of-comprehensiveprimary-care-plus-cpc-second-annual-report

182. . Matching patients to tailored care models: a strategy to enhance care, improve outcomes, and curb costs. October 21st NAM Models of Care for High-Need Patients meeting; 2016; Washington, DC. National Academy of Medicine.

183. Hasselman D. Super utilizer summit: common themes from innovative complex care management programs. Center for Health Care Strategies 2013.

184. Tempalski B, Beane S, Cooper HLF, et al. Structural determinants of Black MSM HIV testing coverage (2011-2016). AIDS Behav. 2020 Sep;24(9):2572-87. doi: 10.1007/s10461-020-02814-4. PMID: 32124108 .

185. Long P, Abrams M, Milstein A, et al. Effective care for high-need patients: opportunities for improving outcomes, value, and health. National Academy of Medicine 2017. 
186. Charlson ME, Pompei P, Ales KL, et al. A new method of classifying prognostic comorbidity in longitudinal studies: development and validation. J Chronic Dis. 1987;40(5):373-83. doi: 10.1016/00219681(87)90171-8. PMID: 3558716.

187. Austin SR, Wong YN, Uzzo RG, et al. Why summary comorbidity measures such as the Charlson Comorbidity Index and Elixhauser Score Work. Med Care. 2015

Sep;53(9):e65-72. doi: 10.1097/MLR.0b013e318297429c. PMID: 23703645.

188. Hall WH, Ramachandran R, Narayan S, et al. An electronic application for rapidly calculating Charlson comorbidity score. BMC Cancer. 2004 Dec 20;4:94. doi: 10.1186/1471-2407-4-94. PMID: 15610554.

189. Sharabiani MT, Aylin P, Bottle A. Systematic review of comorbidity indices for administrative data. Med Care. 2012 Dec;50(12):1109-18. doi: 10.1097/MLR.0b013e31825f64d0. PMID: 22929993.

190. Quan H, Sundararajan V, Halfon P, et al. Coding algorithms for defining comorbidities in ICD-9-CM and ICD-10 administrative data. Med Care. 2005;43(11):1130-1.

191. Centers for Medicare \& Medicaid Services. Report to Congress: risk adjustment in Medicare Advantage. Baltimore, MD: Centers for Medicare \& Medicaid Services; 2018. https://www.cms.gov/Medicare/HealthPlans/MedicareAdvtgSpecRateStats/Downlo ads/RTC-Dec2018.pdf. Accessed on August 242020 .

192. U.S. Department of Veterans Affairs. Organizational excellence. Care assessment needs. Washington, DC: U.S. Department of Veterans Affairs; 2019. https://www.va.gov/HEALTHCAREEXCE LLENCE/about/organization/examples/careassessment-needs.asp. Accessed on August 242020.
193. Benjamins MR, Hummer RA, Eberstein IW, et al. Self-reported health and adult mortality risk: an analysis of cause-specific mortality. Soc Sci Med. 2004

Sep;59(6):1297-306. doi: 10.1016/j.socscimed.2003.01.001. PMID: 15210100 .

194. Idler EL, Angel RJ. Self-rated health and mortality in the NHANES-I Epidemiologic Follow-up Study. Am J Public Health. 1990 Apr;80(4):446-52. doi: 10.2105/ajph.80.4.446. PMID: 2316767.

195. Wu S, Wang R, Zhao Y, et al. The relationship between self-rated health and objective health status: a population-based study. BMC Public Health. 2013 Apr 9;13:320. doi: 10.1186/1471-2458-13-320. PMID: 23570559.

196. Stewart WF, Lipton RB, Kolodner KB, et al. Validity of the Migraine Disability Assessment (MIDAS) score in comparison to a diary-based measure in a population sample of migraine sufferers. Pain. 2000;88(1):41-52. doi: 10.1016/s03043959(00)00305-5.

197. Berrettini A, Sampogna G, Gnech M, et al. Substitution phalloplasty in patients with bladder exstrophy-epispadias complex: a systematic review of techniques, complications and outcomes. J Sex Med. 2020. doi: 10.1016/j.jsxm.2020.10.007.

198. Mitnala S, Phipps-Green A, Franklin C, et al. Clinical and genetic features of diureticassociated gout: a case-control study. Rheumatology (Oxford). 2016 Jul;55(7):1172-6. doi: 10.1093/rheumatology/kew018. PMID: 26989110.

199. Gaskin DJ, Thorpe RJ, Jr., McGinty EE, et al. Disparities in diabetes: The nexus of race, poverty, and place. Am J Public Health. 2014 Nov;104(11):2147-55. doi: 10.2105/AJPH.2013.301420. PMID: 24228660 .

200. Noonan AS, Velasco-Mondragon HE, Wagner FA. Improving the health of African Americans in the USA: an overdue opportunity for social justice. Public Health Rev. 2016;37:12. doi: 10.1186/s40985-0160025-4. PMID: 29450054. 
201. Neal K. Not by proxy: Arguments for improving the use of race in biomedical research. Am J Bioeth. 2017;17.9:52-4.

202. Obermeyer Z, Powers B, Vogeli C, et al. Dissecting racial bias in an algorithm used to manage the health of populations. Science. 2019 Oct 25;366(6464):447-53. doi: 10.1126/science.aax2342. PMID: 31649194.

203. Chukmaitov AS, Tang A, Carretta HJ, et al. Characteristics of all, occasional, and frequent emergency department visits due to ambulatory care-sensitive conditions in Florida. J Ambul Care Manage. 2012 AprJun;35(2):149-58. doi: 10.1097/JAC.0b013e318244d222. PMID: 22415289.

204. Hempstead K, Delia D, Cantor JC, et al. The fragmentation of hospital use among a cohort of high utilizers: implications for emerging care coordination strategies for patients with multiple chronic conditions. Med Care. 2014 Mar;52 Suppl 3:S67-74. doi: 10.1097/mlr.0000000000000049. PMID: 24561761.

205. Takeshita T, Yamamoto-Ibusuki M, Yamamoto Y, et al. PTIP associated protein $1, \mathrm{PA} 1$, is an independent prognostic factor for lymphnode negative breast cancer. PLoS One. 2013;8(11):e80552. doi:

10.1371/journal.pone.0080552. PMID: 24260416.

206. Wherry LR, Burns ME, Leininger LJ. Using self-reported health measures to predict high-need cases among Medicaid-eligible adults. Health Serv Res. 2014 Dec;49 Suppl 2:2147-72. doi: 10.1111/1475-6773.12222. PMID: 25130916.

207. Rideout J. "Hot spots" face scrutiny in next cost and quality atlas. CHCF Blog. Oakland, CA: California Health Care Foundation; 2017.

208. Kastner M. Underlying mechanisms of complex interventions addressing the care of older adults with multimorbidity: a realist review. BMJ open. 2019 2019;9(4). doi: 10.1136/bmjopen-2018-025009.
209. NCQA. Hospitalization for potentially preventable complications (HPC). Washington, DC: NCQA; 2020.

https://www.ncqa.org/hedis/measures/hospit alization-for-potentially-preventablecomplications/. Accessed on August 26 2020.

210. Schulte MT, Hser YI. Substance use and associated health conditions throughout the lifespan. Public Health Rev. 2014;35.

211. Myers G, Price G, Pykosz M. Caring for older adults in a value-based model. NEJM Catalyst. 2016.

212. Myers G, Lee TH. Rebuilding health care as it should be: personal, equitable, and accountable. NEJM Catalyst. 2018.

213. Ghany R, Tamariz L, Chen G, et al. Hightouch care leads to better outcomes and lower costs in a senior population. Am J Manag Care. 2018 Sep 1;24(9):e300-e4. PMID: 30222926.

214. Andriotti T, Dalton MK, Jarman MP, et al. Super-Utilization of the Emergency Department in a Universally Insured Population. Mil Med. 2021 Jul 1;186(78):e819-e25. doi: 10.1093/milmed/usaa399. PMID: 33247301.

215. Giannouchos TV, Kum H-C, Gary J, et al. The Effect of the Medicaid Expansion on Frequent Emergency Department Use in New York. Journal of Emergency Medicine (0736-4679). 2021;61(6):749-62. doi: 10.1016/j.jemermed.2021.07.003.

216. Chang HY, Hatef E, Ma X, et al. Impact of Area Deprivation Index on the Performance of Claims-Based Risk-Adjustment Models in Predicting Health Care Costs and Utilization. Popul Health Manag. 2021;24(3):403-11. doi: 10.1089/pop.2020.0135.

217. Amodeo SJ, Kowalkowski HF, Brantley HL, et al. Temporal Patterns of High-Spend Subgroups Can Inform Service Strategy for Medicare Advantage Enrollees. JGIM: Journal of General Internal Medicine. 2021:1-9. doi: 10.1007/s11606-021-069124. 
218. Banerjee S, Alabaster A, Kipnis P, et al. Factors Associated With Persistent High Health Care Utilization in Managed Medicaid. Am J Manag Care. 2021;27(8):340-4. doi:

10.37765/ajmc.2021.88725.

219. Rivera-Hernandez M, Kumar A, Chou L-N, et al. Healthcare utilization and costs among high-need and frail Mexican American Medicare beneficiaries. PLoS One. 2022;17(1):1-15. doi:

10.1371/journal.pone.0262079.
220. Quinton JK, Duru OK, Jackson N, et al. High-cost high-need patients in Medicaid segmenting the population eligible for a national complex case management program. BMC Health Serv Res. 2021;21(1). doi: 10.1186/s12913-02107116-6.

221. Stata Meta-Analysis Reference Manual. Stata Press; 2021. p. 344.

222. O'Campo P, Hwang SW, Gozdzik A, et al. Food security among individuals experiencing homelessness and mental illness in the At Home/Chez Soi Trial.

Public Health Nutr. 2017 Aug;20(11):202333. doi: $10.1017 / \mathrm{s} 1368980017000489$.

PMID: 28560947. 


\section{Management of High-Need, High-Cost Patients: Addendum}

This addendum details updated results for Key Question 1 (describing characteristics associated with being a high-need, high cost [HNHC] patient) and Key Question 3 (assessing the effectiveness of interventions for HNHC patients) from accompanying manuscripts based on this report.

Key Question 1. What criteria identify or predict that patients will be HNHC?

We updated the search on January 22, 2022, using the same search strategy as we used in this report. This search yielded 291 new citations, of which 63 were retrieved for full-text screening. Ultimately, we identified seven additional studies meeting our inclusion criteria to add as evidence. Six of the studies were exposure analyses examining characteristics associated with HNHC outcomes: high emergency department (ED) use in two studies, ${ }^{214,}{ }^{215}$ high healthcare use across delivery settings in one study ${ }^{216}$ and high cost in three studies. ${ }^{217-219}$ The seventh new study used a cluster analysis design to segment high-cost patients into groups. ${ }^{220}$ Also, upon review of our earlier included evidence, we excluded three studies from our updated results that did not meet our inclusion criteria. Two of the studies were not limited to adults but included children in the sample. ${ }^{75,99}$ A third study did not examine characteristics of the highest cost group compared with other patients. Instead, the study examined whether posttraumatic stress disorder was associated with increased cost. ${ }^{115}$ As a result, the updated review included 64 studies (rather than 60) in 65 articles: 47 multivariate analyses of exposures, 11 cluster analyses, and 6 qualitative analyses. We conducted a quality assessment for each included study.

We also more fully developed a final framework. We broadly found support for the original National Academy of Medicine (NAM) taxonomy, but based on our evidence, we proposed some revisions. We simplified the NAM approach of categorizing chronic conditions as major complex chronic conditions and multiple chronic conditions, followed by considering various combinations of specific conditions of the two types. Instead, we highlight the increased risk from having specific conditions and having multiple chronic conditions. We also expanded consideration of mental health conditions beyond serious mental illness to include all mental illness diagnoses. We added prior patterns of healthcare use to the framework to highlight its importance in HNHC patient identification.

Updated results:

\begin{tabular}{|l|l|l|}
\hline $\begin{array}{l}\text { Patient } \\
\text { Characteristic }\end{array}$ & AHRQ Report & $\begin{array}{l}\text { Updated Findings for } \\
\text { Manuscript }\end{array}$ \\
\hline $\begin{array}{l}\text { Multiple chronic } \\
\text { conditions }\end{array}$ & $\begin{array}{l}\text { Having multiple chronic conditions, } \\
\text { as captured through various counts, } \\
\text { rating scales, or indices was a risk } \\
\text { factor for being HNHC. }\end{array}$ & No change \\
\hline
\end{tabular}




\begin{tabular}{|c|c|c|}
\hline $\begin{array}{l}\text { Patient } \\
\text { Characteristic }\end{array}$ & AHRQ Report & $\begin{array}{l}\text { Updated Findings for } \\
\text { Manuscript }\end{array}$ \\
\hline $\begin{array}{l}\text { Specific chronic } \\
\text { clinical conditions }\end{array}$ & $\begin{array}{l}\text { Conditions associated with an } \\
\text { increased risk of being HNHC } \\
\text { included heart failure, chronic } \\
\text { obstructive pulmonary disease, } \\
\text { cardiovascular disease, dementia, and } \\
\text { diabetes. }\end{array}$ & $\begin{array}{l}\text { We combined heart disease- } \\
\text { related conditions and chronic } \\
\text { lung disease conditions and } \\
\text { expanded our focus beyond the } \\
\text { specific conditions identified in } \\
\text { the NAM taxonomy. } \\
\text { Conditions associated with an } \\
\text { increased risk of being HNHC } \\
\text { included heart disease, chronic } \\
\text { kidney disease, chronic lung } \\
\text { disease, diabetes, cancer, } \\
\text { hypertension, and chronic pain. }\end{array}$ \\
\hline Nonelderly disabled & $\begin{array}{l}\text { Being a nonelderly disabled person } \\
\text { was a risk factor, predominately } \\
\text { identified as persons younger than } 65 \\
\text { years of age and enrolled in } \\
\text { Medicare. }\end{array}$ & No change \\
\hline Mental illness & $\begin{array}{l}\text { Depression was identified as a risk } \\
\text { factor, but results were mixed and } \\
\text { inconclusive in relation to serious } \\
\text { mental illness. }\end{array}$ & $\begin{array}{l}\text { We considered an expanded list } \\
\text { of mental health conditions and } \\
\text { found a current or prior } \\
\text { nonspecified mental health } \\
\text { diagnosis, depression, and a } \\
\text { measure of serious mental } \\
\text { illness that combined having } \\
\text { either psychosis, schizophrenia, } \\
\text { or manic disorders to all be } \\
\text { related to increased risk. }\end{array}$ \\
\hline $\begin{array}{l}\text { Drug and alcohol } \\
\text { misuse }\end{array}$ & $\begin{array}{l}\text { Substance use disorder was identified } \\
\text { as a risk factor, but results were } \\
\text { mixed and inconclusive in relation to } \\
\text { alcohol use disorder. }\end{array}$ & $\begin{array}{l}\text { Both substance and alcohol use } \\
\text { disorders were found to be risk } \\
\text { factors for being HNHC. }\end{array}$ \\
\hline $\begin{array}{l}\text { Low socioeconomic } \\
\text { status }\end{array}$ & $\begin{array}{l}\text { Poverty, based on individual or } \\
\text { neighborhood- level assessments, was } \\
\text { not a predictor across studies. }\end{array}$ & $\begin{array}{l}\text { We separately considered } \\
\text { poverty measured at the } \\
\text { individual and neighborhood } \\
\text { levels. Individual poverty was } \\
\text { defined as having low income } \\
\text { or being enrolled in Medicaid. } \\
\text { Individual poverty, but not } \\
\text { neighborhood poverty, was a } \\
\text { risk factor for being HNHC. }\end{array}$ \\
\hline $\begin{array}{l}\text { Low socioeconomic } \\
\text { status }\end{array}$ & $\begin{array}{l}\text { Food insecurity was a risk factor for } \\
\text { being HNHC. }\end{array}$ & No change \\
\hline Homelessness & $\begin{array}{l}\text { Homelessness was identified as a risk } \\
\text { factor for being HNHC. }\end{array}$ & No change \\
\hline
\end{tabular}




\begin{tabular}{|c|c|c|}
\hline $\begin{array}{l}\text { Patient } \\
\text { Characteristic }\end{array}$ & AHRQ Report & $\begin{array}{l}\text { Updated Findings for } \\
\text { Manuscript }\end{array}$ \\
\hline Social isolation & $\begin{array}{l}\text { Marital status, as a measure of social } \\
\text { isolation, was not a focus in the } \\
\text { report. }\end{array}$ & $\begin{array}{l}\text { The evidence that being } \\
\text { unmarried was a risk factor was } \\
\text { mixed and inconclusive. }\end{array}$ \\
\hline $\begin{array}{l}\text { Community } \\
\text { deprivation }\end{array}$ & $\begin{array}{l}\text { Community deprivation was not a } \\
\text { focus in the report. }\end{array}$ & $\begin{array}{l}\text { Neighborhood poverty and } \\
\text { rural residence were considered } \\
\text { as measures of community } \\
\text { deprivation. The evidence for } \\
\text { both measures as risk factors } \\
\text { was mixed and inconclusive. }\end{array}$ \\
\hline $\begin{array}{l}\text { Prior high use and/or } \\
\text { cost }\end{array}$ & $\begin{array}{l}\text { Prior high use and/or cost were } \\
\text { identified as risk factors. }\end{array}$ & No change \\
\hline Age & $\begin{array}{l}\text { Older age was identified as a risk } \\
\text { factor. }\end{array}$ & $\begin{array}{l}\text { We considered } 3 \text { distinct age } \\
\text { groupings, based on a study's } \\
\text { included age range: nonelderly } \\
\text { adults, elderly adults, and } \\
\text { adults of all ages. Results were } \\
\text { mixed and inconclusive in each } \\
\text { of the groups. }\end{array}$ \\
\hline Race/ethnicity & $\begin{array}{l}\text { Compared with White race, Black } \\
\text { race was a risk factor, and results } \\
\text { concerning Hispanic ethnicity were } \\
\text { mixed. }\end{array}$ & $\begin{array}{l}\text { Results for both groups were } \\
\text { mixed and inconclusive. }\end{array}$ \\
\hline Gender & $\begin{array}{l}\text { The effect of being female on the risk } \\
\text { of HNHC outcomes was mixed and } \\
\text { inconclusive. }\end{array}$ & No change \\
\hline
\end{tabular}

Specific details about the findings and conclusions can be found in the published journal article:

Berkman ND, Chang E, Seibert J, et al. Characteristics of high-need, high-cost patients: a "best-fit" framework synthesis. Ann Intern Med. 8 November 2022. [Epub ahead of print]. doi:10.7326/M21-4562.

Key Question 3. Overall, what is the effectiveness and what are the harms of interventions for HNHC patients in reducing potentially preventable or modifiable healthcare use and costs and in improving health outcomes?

We modified our methodological approach for an accompanying manuscript based on this report.

1. Meta-analysis. The original random-effects meta-analyses were conducted using the DerSimonian and Laird method. However, the DerSimonian and Laird method is associated with inappropriate type 1 error control due to insufficient coverage of the confidence intervals. The updated meta-analyses were conducted using the more conservative Sidik-Jonkman model with Knapp-Hartung standard errors in Stata $16 .{ }^{221}$ 
2. Because of their serious methodological flaws, we followed the ROBINS-I guidance to use high risk-of-bias observational studies solely to qualitatively consider their impact on strength-of-evidence grades. ${ }^{62}$ Nine observational studies ${ }^{145,148,150,153,157,174-177,179}$ were rated as high risk of bias because of critical flaws in one or more categories. Seven high risk-of-bias studies ${ }^{145,148,150,153,174-176,179}$ inadequately controlled for confounding, two ${ }^{175,222}$ for potential selection bias, and one ${ }^{157}$ for potential bias due to missing data.

3. Two randomized controlled trial studies (4 samples) included among the telephonic/mail intervention models ${ }^{64,65}$ tested a disease and care management intervention for chronic kidney disease patients. Because these studies tested an intervention targeted to patients with one specific condition (chronic kidney disease) rather than a more general HNHC patient population, the evidence was graded separately.

The additional analyses resulted in some changes to strength-of-evidence grades.

- Telephonic/mail models: Because most of the strength-of-evidence findings were specific to chronic kidney disease patient studies, when they were removed from the body of evidence, the strength of evidence for the outcome of total costs among the general population changed from low strength of evidence for no difference to insufficient.

- Ambulatory intensive caring unit models: The strength of evidence for total costs changed from low strength of evidence of favorable findings to insufficient. Additionally, some outcomes that were originally graded as insufficient were no longer graded for strength of evidence because of limited or no evidence.

Specific details about the findings and conclusions associated with these changes can be found in the published journal article:

Chang E, Ali R, Seibert J, et al. Interventions to improve outcomes for high-need, highcost patients: a systematic review and meta-analysis. J Gen Intern Med. 11 Oct 2022. [Epub ahead of print.] https://doi.org/10.1007/s11606-022-07809-6. 


\section{Appendix A. Detailed Methods}

\section{Details of Data Sources and Searches}

We conducted focused searches of MEDLINE via PubMed, the Cochrane Clinical Trials Central Register, CINAHL, Embase, PsycINFO, Web of Science, Academic Search Premier, and Scopus from January 1, 2000, to March 4, 2021. Medical subject headings were used as search terms when available and keywords when appropriate, focusing on terms to describe relevant populations. Our search strategy identified high-need, high-cost (HNHC) patient populations with a combined approach of text terms of "high utilizer/medically complex/high needs" and similar terms; terms of "high health care cost/high cost;" and terms for identifying multiple chronic conditions or similar terms limited to individuals with functional limitations, behavioral factors, or social risk factors.

Targeted searches for unpublished literature were conducted by searching ClinicalTrials.gov, SIREN Evidence Library, HSRProj, National Academy of Medicine, Center for Health Care Strategies, Centers for Medicare \& Medicaid Services, Camden Coalition, Commonwealth Fund, Robert Wood Johnson Foundation, California HealthCare Foundation, Institute for Healthcare Improvement, Centers for Disease Control and Prevention, Health Resources and Services Administration, Social Work Abstracts, Kaiser Family Foundation, Milbank Memorial Fund, and Patient-Centered Outcomes Research Institute. A targeted search for dissertations was also conducted by searching ProQuest. The search strategy was developed by an experienced librarian with inputs from the study investigators. To supplement electronic searches, we conducted snowball searches by reviewing the reference lists of included studies, identified if included studies are cited in newer articles, and searched for related studies such as those suggested by PubMed. We also consulted content experts to help identify relevant literature. A Federal Register notice was posted on December 16, 2019, as well as a request for supplemental evidence and data on January 16, 2020. We updated the literature search during the public posting period of the draft report on March 4, 2021.

\section{Study Selection}

Table A-1 lists inclusion and exclusion criteria.

\section{Table A-1. Inclusion/exclusion criteria}

\begin{tabular}{|c|c|c|}
\hline PICOTS & Inclusion & Exclusion \\
\hline Population & $\begin{array}{l}\text { KQs } 1,2 \text {, and } 3 \text { : Noninstitutionalized adults, } 18 \text { years of age or older } \\
\text { KQ 1: Six or more months of potentially preventable or modifiable high } \\
\text { healthcare cost and/or use } \\
\text { KQs } 2 \text { and 3, two groups: } \\
\text { a) HNHC patients with } 6 \text { or more months of potentially preventable or } \\
\text { modifiable high healthcare cost and/or use } \\
\text { b) HNHC patients with } 6 \text { or more months of potentially preventable or } \\
\text { modifiable high healthcare cost and use AND either } 2 \text { or more chronic } \\
\text { physical health conditions or a combination of } 1 \text { or more chronic } \\
\text { physical health conditions and } 1 \text { or more behavioral health conditions }\end{array}$ & $\begin{array}{l}\text { Patients receiving a high level } \\
\text { of healthcare services that are } \\
\text { considered appropriate for } \\
\text { their condition OR high level of } \\
\text { healthcare services are } \\
\text { measured for less than } 6 \\
\text { months OR end-of-life care }\end{array}$ \\
\hline
\end{tabular}




\begin{tabular}{|c|c|c|}
\hline PICOTS & Inclusion & Exclusion \\
\hline Intervention & $\begin{array}{l}\text { KQ 1: Not relevant, interventions not necessary for inclusion } \\
\text { KQs } 2 \text { and 3: } \\
\text { Alternative delivery models (e.g., ACOs, coordinated care } \\
\text { organizations, health homes, home-based primary care, behavioral } \\
\text { health integration) } \\
\text { System- or practice-level interventions (e.g., ED alerts, hotspotting) } \\
\text { Patient supportive services (e.g., community health workers, social } \\
\text { workers, patient navigators, care coordinators, case and care managers, } \\
\text { intensive primary care support, medication management, health } \\
\text { reliance specialists, self-management instruction, and peer-to-peer } \\
\text { support) } \\
\text { Social determinants of health-related interventions (e.g., transportation, } \\
\text { health literacy, housing support, caregiver support) }\end{array}$ & $\begin{array}{l}\text { KQs } 2 \text { and 3: } \\
\text { Interventions for which the } \\
\text { relevance for and impact on } \\
\text { HNHC patients cannot be } \\
\text { determined }\end{array}$ \\
\hline Comparator & $\begin{array}{l}\text { KQ 1: Comparison population or no comparator } \\
\text { KQ 2: Any intervention, treatment as usual, or no comparator } \\
\text { intervention } \\
\text { KQ 3: Any intervention or treatment as usual }\end{array}$ & KQ 3: No comparator \\
\hline Outcomes & $\begin{array}{l}\text { KQ 1: Population characteristics described or predicted } \\
\text { KQs 1, 2, and 3: } \\
\text { Healthcare use: decreases in ED visits, EMS use, and hospitalizations; } \\
\text { changes in primary care or specialist visits or other necessary and } \\
\text { appropriate types of care (e.g., care manager visits, telephone } \\
\text { followup) and use of support services } \\
\text { Patient health behavior (e.g., treatment adherence, activation, } \\
\text { empowerment, knowledge, self-care) } \\
\text { Patient health outcomes: all-cause mortality, disease and condition- } \\
\text { specific outcomes, health indicators, quality of life } \\
\text { Patient satisfaction with care } \\
\text { Physicians' and health professionals' satisfaction with clinical practice } \\
\text { Costs } \\
\text { Patient and health professional harms such as increased barriers to } \\
\text { necessary care, clinician time, or resource trade-offs of other duties }\end{array}$ & All other outcomes \\
\hline Time frame & $\begin{array}{l}\text { Potentially preventable or modifiable high cost healthcare use } \\
\text { measured for } 6 \text { months or more } \\
\text { KQ 3: Measurement of outcomes at } 6 \text { months or more after } \\
\text { implementation of the intervention. }\end{array}$ & Shorter time periods \\
\hline Settings & $\begin{array}{l}\text { Healthcare and support services delivery settings, including outpatient, } \\
\text { ED, the broader healthcare delivery environment, the home, or the } \\
\text { community } \\
\text { United States }\end{array}$ & $\begin{array}{l}\text { Institutional care settings, such } \\
\text { as hospitals, skilled nursing, } \\
\text { long-term care facilities, and } \\
\text { prisons or jails }\end{array}$ \\
\hline
\end{tabular}




\begin{tabular}{lll}
\hline PICOTS & Inclusion & Exclusion \\
\hline Study design & KQs 1 and 2: All study designs except reviews summarizing across & KQs 1 and 2: \\
& original studies or interventions & Descriptive quantitative \\
& KQ 3: Randomized controlled trials, cluster randomized trials, cohort & studies that do not control for \\
& studies, case-control studies, quasi-experimental designs with a & Kotential confounding \\
& comparison group & All other designs \\
\hline Language & Studies published in English & Studies published in \\
& & languages other than English \\
\hline $\begin{array}{l}\text { Publication } \\
\text { type }\end{array}$ & All publications that allow abstraction and interpretation of findings & Abstract-only publications \\
\hline $\begin{array}{l}\text { ACO = Accountable Care Organization; ED = emergency department; EMS = emergency management services; HNHC = high- } \\
\text { need, high-cost; KQ = Key Question; PICOTS = population, intervention, comparator, outcomes, time frame, settings }\end{array}$
\end{tabular}

We imported all citations identified through searches and other sources into EndNote v.X9. Independent reviewers screened the titles and abstracts of all citations using the inclusion and exclusion criteria using Abstrackr software. Studies included by either reviewer were retrieved for full-text screening. Independent reviewers then screened the full-text version of eligible references. Discrepancies between the reviewers were resolved through discussions and consensus or consultation with a third senior reviewer. In relation to studies included for the realist review, in keeping with realist review principles, we evaluated articles for their relevance and robustness in answering Key Question (KQ) 2 and their contribution to theory building and testing. ${ }^{1}$ Excluded studies are listed in the Results Appendix.

For each KQ, we used a different methodological approach to evidence synthesis. We used "best fit" framework synthesis approach for KQ 1, realist review methodology for KQ 2, and a systematic review approach for KQ 3.

\section{Data Abstraction}

We developed and pilot tested standardized data extraction forms for each KQ. For KQ 1, we extracted study characteristics, including study goal, design, methodological approach, data source setting, sample size, inclusion and exclusion criteria; population characteristics, including characteristics on service use, healthcare costs, clinical health conditions, behavioral conditions, social risk factors, demographic conditions, and health system; and key outcomes of interest. For KQ 3, we abstracted study characteristics, population characteristics, intervention characteristics, intervention effectiveness, subgroup intervention effectiveness, and study risk-of-bias assessment. Trained reviewers abstracted the relevant data from each included article into the evidence tables; a second member of the team reviewed all data abstractions for completeness and accuracy for KQ 1 and KQ 3.

To answer the realist review question, KQ 2, data items were driven by our purpose to refine our program theories through context-mechanism-outcome (CMO) configurations. Data were abstracted in NVivo software using a coding framework grounded in our initial program theory of CMO. Coding of all included studies using the coding framework proceeded as both an inductive and deductive process; that is, we continued to identify and add to the coding framework as we proceeded. The team developed the initial program theory by identifying categories of interventions for HNHC patients from an initial scan of the literature and articulating the underlying theory that supports those interventions. Subsequently, we refined the initial program theory into a realist program theory by creating a map of a patient journey, with corresponding lists of mechanisms operating at the patient and provider levels. We then identified additional theoretical frameworks that could inform our program theory by explaining 
mechanisms of both patients and providers and that drew from a variety of health behavior theories, most notably the Theory of Planned Behavior.

\title{
Assessment of Methodological Risk of Bias and Risk of Rigor of Individual Studies
}

\author{
KQ 1 \\ We did not assess the risk of bias or strength of evidence for studies relevant to KQ 1 . The \\ studies we included for KQ 1 were mostly quantitative observational studies of exposures \\ (multivariate predictive or cross-sectional designs) and fewer were cluster analyses or qualitative \\ studies. Because no validated tool is available for evaluating the risk of bias of cross-sectional \\ observational designs or cluster analyses (the majority of our included studies), we did not \\ evaluate the risk of bias of any studies included for KQ $1 .^{2}$ However, we limited observational \\ studies of exposures to those using a multivariate design that controlled for confounding. We \\ appraised the rigor of qualitative studies included to answer KQ 1 (methodological strength and \\ limitations) as recommended in the Cochrane handbook. ${ }^{3}$ We conducted the assessment using \\ the Critical Appraisal Skills Programme tool. ${ }^{4}$
}

\section{$K Q 2$}

For KQ 2, the studies also included for KQ 3 received a risk-of-bias assessment. Specific to KQ 2, to keep with realist review principles, we used RAMESES project standards to guide our judgments in quality appraisal tasks. ${ }^{1,5-7}$ More specifically, data were appraised based on relevance (whether included articles can contribute to theory building and testing), trustworthiness (whether the data in a study have been obtained empirically, using methods that are clearly stated, and whether the information could be found in more than one source), plausibility of the argument underlying the theory (the coherence of the argument, including its breadth in explaining the data, its simplicity and fit with existing theory), and rigor (whether included articles are methodologically credible with regard to outcomes reported and methods used for testing propositions).

\section{KQ 3}

The criteria set forth by the Agency for Healthcare Research and Quality's (AHRQ's) Methods Guide for Comparative Effectiveness Reviews guided our assessment of methodological risk of bias for KQ 3. To assess the risk of bias (i.e., internal validity), we used the ROBINS-I ${ }^{8}$ tool for observational studies and the Cochrane $\mathrm{RCT}^{9}$ tool for randomized controlled trials (RCTs). For both observational studies and RCTs, risk-of-bias assessment included questions to assess selection bias, confounding, performance bias, detection bias, and attrition bias; concepts covered include those about adequacy of randomization (for RCTs only), similarity of groups at baseline, masking, attrition, whether intention-to-treat analysis was used, method of handling dropouts and missing data, validity and reliability of outcome measures, and treatment fidelity. ${ }^{10}$

For each study included for KQ 3, two independent reviewers assigned risk-of-bias ratings for each study with disagreements resolved by discussion and consensus. Reviewers assigned a rating of low risk of bias (study met all criteria), some concerns (study met some criteria), high risk of bias (methodological shortcomings leading to high risk of bias in one or more categories), or unclear risk of bias (methods not reported clearly). 


\section{Data Synthesis}

We summarized all included studies for KQs 1 and 3 in narrative form and in summary tables that tabulate the important features of the study populations, design, intervention, comparison, outcomes, setting (including geographic location), and results.

Describing the HNHC patient population (KQ 1): To achieve our aim of describing the approach to identifying the HNHC patient population, we conducted a "best fit" framework synthesis. ${ }^{11}$ Consistent with this approach, we began from an a priori identified framework that we used to sort evidence into themes across included studies (i.e., the distinguishing characteristics and reasons why some patients are HNHC). During our review of the evidence, we used an iterative process to consider new themes that were not captured in the initial framework. In the end, we present a summary of the data and syntheses of the evidence and our conclusions within a framework corresponding to our final conceptual model.

We began the synthesis using the taxonomy developed by the National Academy of Medicine in their report Effective Care for High-Need Patients: Opportunities for Improving Outcomes, Value, and Health as our a priori framework. ${ }^{12}$ This taxonomy groups HNHC patients first based on their clinical and functional characteristics. Among the six patient groups presented in the taxonomy, four met the inclusion criteria for this review: nonelderly disabled, multiple chronic conditions, major complex chronic condition, and frail elderly. (The additional two categories, children with complex needs and individuals with advancing illness/end-of-life care, are outside the scope of the review.) Within these assigned groups, the taxonomy proposed additional, cross-patient group assessment based on behavioral health factors and social risk factors that are believed to influence how individuals use healthcare and increase the risk of receiving fragmented care. Behavioral health factors included serious mental illness, substance use disorder, cognitive decline, and chronic toxic stress. Social risk factors included low socioeconomic status, low health literacy, social isolation, community deprivation, and housing insecurity.

Understanding interventions for HNHC patients (KQ 2): To gain a greater understanding of the complex alternative payment and delivery models, social interventions, and health programs that are used to address healthcare utilization among HNHC patients, we used a realist review approach. Consistent with this approach, our goal is to explain what works (or fails), for whom, under what circumstances, and why. ${ }^{13}$ We sought to identify, elucidate, and refine several underlying theories that could explain the approach of different complex interventions, explore implementation chains, assess intermediate outcomes, and examine modifications or adaptations applied in various circumstances. ${ }^{13}$

Review of the evidence supporting the effectiveness of interventions for HNHC patients (KQ 3): To further support the goal of producing actionable information, we also used traditional Evidence-based Practice Center (EPC) systematic review methods to synthesize the evidence of the overall effectiveness of the included interventions. We conducted a quantitative synthesis of results by calculating a pooled treatment effect when three or more samples with the same study design had similar treatment and comparison groups and reported the same outcome measure within a setting. We used Stata ${ }^{\circledR} 16$ (StataCorp, College Station, TX) to calculate effect sizes and associated 95 percent confidence intervals. Because of the diversity of intervention designs and outcomes, most results were synthesized qualitatively. 


\section{Grading the Strength of Evidence}

For KQ 3, we graded the strength of evidence based on the guidance established for the EPC Program. ${ }^{14}$ Developed to grade the overall strength of a body of evidence, this approach incorporates five key domains: study limitations (includes study design and risk of bias), consistency, directness, precision of the evidence, and reporting bias. This approach requires looking beyond statistical significance alone, even when studies are consistent and of high quality and outcomes are direct and clinically relevant. It emphasizes the adequacy of the sample size to rule out spurious associations and results that are not clinically relevant. It also considers other optional domains that may be relevant to increasing the strength of evidence for some scenarios, such as a dose-response association, plausible confounding that would decrease the observed effect, and strength of association (magnitude of effect).

Table A-2 describes the grades of evidence that can be assigned. Grades reflect the strength of the body of evidence to answer KQs on the benefits and harms of the interventions included in this review. Two reviewers assessed each domain for each key outcome with differences resolved by consensus.

Table A-2. Definitions of the grades of overall strength of evidence ${ }^{14}$

\begin{tabular}{ll}
\hline Grade & Definition \\
\hline High & $\begin{array}{l}\text { High confidence that the evidence reflects the true effect. Further research is very unlikely to } \\
\text { change our confidence in the estimate of effect. }\end{array}$ \\
\hline Moderate & $\begin{array}{l}\text { Moderate confidence that the evidence reflects the true effect. Further research may change } \\
\text { our confidence in the estimate of the effect and may change the estimate. }\end{array}$ \\
\hline Low & $\begin{array}{l}\text { Low confidence that the evidence reflects the true effect. Further research is likely to change } \\
\text { our confidence in the estimate of the effect and is likely to change the estimate. }\end{array}$ \\
\hline Insufficient & Evidence either is unavailable or does not permit estimation of an effect. \\
\hline
\end{tabular}

\section{Assessing Applicability}

We assessed the applicability of individual studies as well as the applicability of a body of evidence following guidance from the Methods Guide for Effectiveness and Comparative Effectiveness Reviews. ${ }^{15}$ For individual studies, we examined conditions that may limit applicability based on the PICOTS (population, intervention, comparisons, outcomes, timing, and setting) structure. The assessment of applicability is integral to a realist review through its consideration of context within $\mathrm{CMO}$ configurations. We indicated patterns across studies and when the context does not appear to operate similarly in particular settings.

\section{Peer Review and Public Commentary}

Experts in research on care for individuals with complex chronic conditions, in health systems, and qualitative and realist review methods were invited to provide external peer review of the draft systematic review that was entitled "Management of High-Need, High-Cost Patients: A "Best Fit" Synthesis, Realist Review, and Systematic Review." AHRQ staff and an Associate Editor reviewed the draft systematic review before it went out for peer review. The EPC Associate Editors are leaders in their respective fields and are actively involved as directors or leaders at their EPCs. Their role is to assess adherence to established methodology and guidelines for EPC-based research. We revised the report in response to AHRQ staff, the Associate Editor, peer reviewer, and public comments. 


\section{Search Strategy}

\section{Published Literature Searches}

\section{PubMed}

09-07-2019

\begin{tabular}{|c|c|c|}
\hline \multicolumn{2}{|c|}{ Search Query } & \multirow{2}{*}{$\begin{array}{l}\begin{array}{l}\text { Items } \\
\text { Found }\end{array} \\
3545 \\
\end{array}$} \\
\hline \#1 & $\begin{array}{l}\text { Search ((("high utilizer" OR "high utilizers of health care" OR "high utilizing" OR "super utilizers" OR } \\
\text { "super utilizing" OR "frequent utilization" OR "frequent utilisation" OR "frequent utilizers" OR "heavy } \\
\text { utilization" OR "heavy utilizers" OR "high attenders" OR "repeat users" OR "hyperusers" OR } \\
\text { "revolving door patients" OR "hyperutilization" OR "overutilization" OR "recividism")) OR "frequent } \\
\text { users") OR "frequent user" OR "medically complex" OR "high need" Sort by: Best Match }\end{array}$ & \\
\hline$\# 2$ & Search ((“Africa”[Mesh]) OR “India"[Mesh] OR “Developing Countries"[Mesh])) Sort by: Best Match & 398504 \\
\hline \#3 & Search (\#1 NOT \#2) Sort by: Best Match & 3506 \\
\hline \#4 & $\begin{array}{l}\text { Search (\#1 NOT \#2) Sort by: Best Match Filters: Publication date from 2000/01/01; Humans; } \\
\text { English; Adult: 19+ years }\end{array}$ & 1332 \\
\hline
\end{tabular}

\section{PubMed}

03-04-2021

\begin{tabular}{|c|c|c|}
\hline \multicolumn{2}{|c|}{ Search Query } & \multirow{2}{*}{$\begin{array}{l}\begin{array}{l}\text { Items } \\
\text { Found }\end{array} \\
4341 \\
\end{array}$} \\
\hline \#1 & $\begin{array}{l}\text { Search ((("high utilizer" OR "high utilizers of health care" OR "high utilizing" OR "super utilizers" } \\
\text { OR "super utilizing" OR "frequent utilization" OR "frequent utilisation" OR "frequent utilizers" OR } \\
\text { "heavy utilization" OR "heavy utilizers" OR "high attenders" OR "repeat users" OR "hyperusers" OR } \\
\text { "revolving door patients" OR "hyperutilization" OR "overutilization" OR "recividism")) OR "frequent } \\
\text { users") OR "frequent user" OR "medically complex" OR "high need" Sort by: Best Match }\end{array}$ & \\
\hline \#2 & $\begin{array}{l}\text { Search (("Africa"[Mesh]) OR "India"[Mesh] OR "Developing Countries"[Mesh] )) Sort by: Best } \\
\text { Match }\end{array}$ & 431583 \\
\hline$\# 3$ & Search (\#1 NOT \#2) Sort by: Best Match & 4279 \\
\hline$\overline{\overline{\# 4}}$ & $\begin{array}{l}\text { Search (\#1 NOT \#2) Sort by: Best Match Filters: Publication date from 2019/03/01; Humans; } \\
\text { English; Adult: 19+ years }\end{array}$ & 266 \\
\hline
\end{tabular}

\section{PubMed}

03-04-2021

\begin{tabular}{|c|c|c|}
\hline \multicolumn{2}{|c|}{ Search Query } & \multirow{2}{*}{$\begin{array}{l}\text { Items } \\
\text { Found } \\
211\end{array}$} \\
\hline \#1 & $\begin{array}{l}\text { Search: ("high health care cost"[Title]) OR ("high cost"[Title]) Filters: Humans, English, Adult: 19+ } \\
\text { years, from 2000/1/1 - 3000/12/12 }\end{array}$ & \\
\hline \#2 & $\begin{array}{l}\text { Search: (("high utilizer" OR "high utilizers of health care" OR "high utilizing" OR "super utilizers" } \\
\text { OR "super utilizing" OR "frequent utilization" OR "frequent utilisation" OR "frequent utilizers" OR } \\
\text { "heavy utilization" OR "heavy utilizers" OR "high attenders" OR "repeat users" OR "hyperusers" } \\
\text { OR "revolving door patients" OR "hyperutilization" OR "overutilization" OR "recividism")) OR } \\
\text { "frequent users") OR "frequent user" OR "medically complex" OR "high need" Filters: Humans, } \\
\text { English, Adult: } 19+\text { years, from 2000/1/1 - 3000/12/12 }\end{array}$ & 1704 \\
\hline$\# 3$ & Search: \#1 NOT \#2 Filters: Humans, English, Adult: 19+ years, from 2000/1/1 - 3000/12/12 & 186 \\
\hline$\overline{\# \# 4}$ & $\begin{array}{l}\text { Search: (("Africa"[Mesh]) OR "India"[Mesh] OR "Developing Countries"[Mesh] )) Filters: Humans, } \\
\text { English, Adult: } 19+\text { years, from 2000/1/1 - 3000/12/12 }\end{array}$ & 105772 \\
\hline$\# \underline{5}$ & Search: \#3 NOT \#4 Filters: Humans, English, Adult: 19+ years, from 2000/1/1 - 3000/12/12 & 182 \\
\hline
\end{tabular}




\section{Cochrane Clinical Trials Central Register}

09-07-2019

\begin{tabular}{lll}
\hline Search & Query & Items Found \\
\hline$\# 1$ & Search ("high utilizers" OR "high need" OR "complex patients") & 40 \\
\hline
\end{tabular}

\section{Cochrane Clinical Trials Central Register}

03-04-2021

\begin{tabular}{lll}
\hline Search & Query & Items Found \\
\hline$\# 1$ & Search ("high utilizers" OR “high need" OR "complex patients") & 93 \\
\hline
\end{tabular}

\section{CINAHL}

09-07-2019

\begin{tabular}{lll}
\hline Search & Query & Items Found \\
\hline$\# 1$ & Search (“high utilizers” OR “high need” OR “complex patients”) & 27 \\
\hline
\end{tabular}

\section{CINAHL}

03-04-2021

\begin{tabular}{lll}
\hline Search & Query & Items Found \\
\hline$\# 1$ & Search ("high utilizers" OR “high need" OR "complex patients") & 62 \\
\hline
\end{tabular}

\section{Embase}

09-07-2019

\begin{tabular}{lll}
\hline Search & Query & Items Found \\
\hline$\# 1$ & Search (“high utilizers" OR “high need” OR “complex patients”) & 28 \\
\hline \hline
\end{tabular}

\section{Embase}

03-04-2021

\begin{tabular}{lll}
\hline Search & Query & Items Found \\
\hline$\# 1$ & Search ("high utilizers" OR “high need” OR "complex patients") & 62 \\
\hline
\end{tabular}

\section{PsycINFO}

09-07-2019

\begin{tabular}{lll}
\hline Search & Query & Items Found \\
\hline$\# 1$ & Search ("high utilizers" OR “high need" OR “complex patients") & 27 \\
\hline
\end{tabular}

\section{PsycINFO}

\section{3-04-2021}

\begin{tabular}{lll}
\hline Search & Query & Items Found \\
\hline \#1 & Search ("high utilizers" OR “high need” OR “complex patients”) & 49 \\
\hline
\end{tabular}




\section{Web of Science}

09-07-2019

Search Query

\#1 Search ("high utilizers" OR "high need" OR "complex patients")

Items Found

194

\section{Web of Science}

03-04-2021

\begin{tabular}{lll}
\hline Search & Query & Items Found \\
\hline$\# 1$ & Search (“high utilizers" OR “high need” OR “complex patients") & 96 \\
\hline
\end{tabular}

\section{Academic Search Premier}

09-07-2019

\begin{tabular}{lll}
\hline Search & Query & Items Found \\
\hline$\# 1$ & Search (“high utilizers” OR “high need” OR “complex patients”) & 25 \\
\hline
\end{tabular}

\section{Academic Search Premier}

03-04-2021

\begin{tabular}{lll}
\hline Search & Query & Items Found \\
\hline \hline 1 & Search (“high utilizers" OR “high need" OR “complex patients") & 10 \\
\hline \hline
\end{tabular}

\section{Scopus}

09-07-2019

\begin{tabular}{lll}
\hline Search & Query & Items Found \\
\hline$\# 1$ & Search (“high utilizers” OR “high need” OR “complex patients”) & 61 \\
\hline \hline
\end{tabular}

\section{Scopus}

03-04-2021

\begin{tabular}{lll}
\hline Search & Query & Items Found \\
\hline \#1 & Search ("high utilizers" OR "high need" OR "complex patients") & 60 \\
\hline
\end{tabular}

\section{Gray Literature Searches}

ClinicalTrials.gov results $=\mathbf{1 1}$

SIREN Evidence Library $=\mathbf{1 0}$

HSRProj $=18$

National Academy of Medicine $=\mathbf{3}$

Center for Health Care Strategies $=12$

Centers for Medicare and Medicaid Services $=\mathbf{4}$

Camden Coalition $=\mathbf{2}$

Commonwealth Fund $=\mathbf{6 2}$

Robert Wood Johnson Foundation $=\mathbf{9}$

California HealthCare Foundation $=\mathbf{8}$

Grey Literature Report $=94$

Institute for Healthcare Improvement $=\mathbf{3}$

Centers for Disease Control and Prevention $=\mathbf{3}$ 
Human Resources Services Administration $=\mathbf{0}$

Social Work Abstracts $=\mathbf{2}$

Kaiser Family Foundation $=\mathbf{3}$

Milbank Memorial Fund $=\mathbf{0}$

Patient-Centered Outcomes Research Institute $=\mathbf{2}$

Search-based Investigative Intelligence Platform $=\mathbf{4 1}$

\section{Search Strategy for All Gray Literature}

03-2021

"high utilizers" OR "high need" OR "complex patients"

\section{Search Strategy for All Gray Literature}

03-2021

"high utilizers" OR ("high need" AND "high cost") OR "complex patients" 


\section{Appendix B. Results}

\section{Results of Literature Searches}

The electronic search, grey literature, and reference mining identified 2,923 citations. After title and abstract screening, 873 citations were retrieved for full-text review. A total of 110 studies (117 articles) met eligibility criteria. A total of 110 studies (117 articles) were included in the analyses.

\section{Description of Included Studies}

For KQ 1, we identified 60 studies (61 articles), of which 33 were cross sectional, 10 latent class, 11 predictive, and 6 qualitative. ${ }^{16-76}$

For KQ 2, we identified we identified 48 studies (51 articles). ${ }^{12,17,22,27-29,31,49,53,55,58,61,62,77-}$

${ }^{114}$ As for unique KQ 2 includes, we identified 10 studies (10 articles). ${ }^{12,78,91,93,94,104-106,113,114}$

For KQ 3, we identified 19 trials and 21 observational studies (46 articles). Five RCTs were assessed as having low risk of bias, and 14 RCTs (15 articles) were assessed as having some concerns for bias, $79-82,84,86,87,90,96,97,99,108-112,115-118$ No observational studies were assessed as having low risk of bias, 13 observational studies (17 articles) were assessed as having some concerns for bias, and eight observational studies ( 9 articles) were assessed as having high risk of bias. . $^{2}, 85,88,92,95,98,100-103,107,119-133$ 
Figure B-1. Article flow diagram

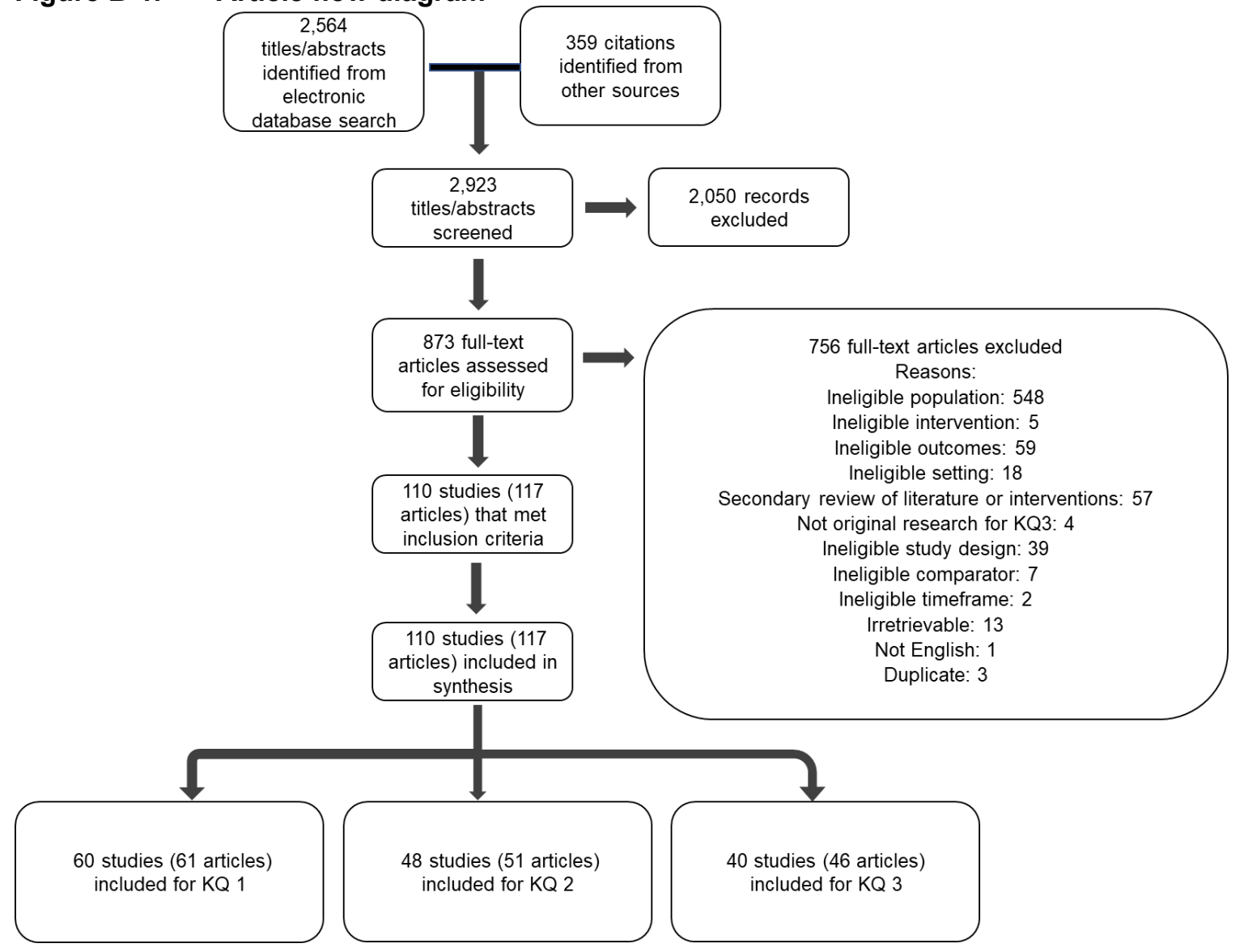

Note: The sum of the number of studies per KQ exceeds the total number of studies because some studies were applicable to multiple KQs.

$\mathrm{KQ}=$ Key Question . 


\section{List of Excluded Studies}

X1: Ineligible Population

$\mathrm{X} 2$ : Ineligible Intervention

X3: Ineligible Comparator

X4: Ineligible Outcome

X5: Ineligible Time Frame

X6: Setting/Country

X7: Secondary Review of Literature or Interventions

X8: Not Original Research for KQ 3

X9: Study Design

X10: Not English

X11: Irretrievable

X12: Duplicate

1. Magellan initiative targets high utilizers in private plans. Mental Health Weekly. 2000;10(32):1. Exclusion Code: X1.

2. Hand-held devices ease burden of behavioral health assessment. Dis Manag Advis. 2002;8(10):152-6, 45. Exclusion Code: X1.

3. Medicaid best buys: improving care management for high-need, high-cost beneficiaries. Hamilton, N.J.: Center for Health Care Strategies, Inc.; 2008. Exclusion Code: X4.

4. Medicaid best buys: critical strategies to focus on high-need, high-cost beneficiaries. Hamilton, N.J.: Center for Health Care Strategies, Inc.; 2010. Exclusion Code: X1.

5. Building the national care service. Norwich: Great Britain Stationary Office; 2010. Exclusion Code: X1.

6. ED diversion: multidisciplinary approach engages high utilizers, helps them better navigate the health care system. ED management: the monthly update on emergency department management. 2011;23(11):127-30. Exclusion Code: X1.

7. CM program keeps high utilizers out of hospital. Hosp Case Manag. 2012;20(7):108-9. Exclusion Code: X1.

8. Hospitals collaborate to reduce ED overuse. Hosp Case Manag. 2012 Oct;20(10):151-3. PMID: 23091842. Exclusion Code: X1.

9. Patient navigation for Medicaid frequent ED users. Yale University. 2013.

https://www.cochranelibrary.com/central/doi/10. 1002/central/CN-01579091/full. Exclusion Code: $\mathrm{X} 4$.
10. Identifying high utilizers of surgical care after colectomy. J Surg Res. 2014;186(2):495-. doi: 10.1016/j.jss.2013.11.036. Exclusion Code: X1.

11. Programs focusing on high-need, high-cost populations. [Trenton, N.J.]: Center for Health Care Strategies, Inc.; 2016. Exclusion Code: X1.

12. Understanding the needs of different types of high-need patients and their caregivers. Commonwealth Fund; 2019. Exclusion Code: $\mathrm{X} 1$.

13. Community Care For High-Need Patients. Health Aff (Millwood). 2019 Jun;38(6):892-3. doi: 10.1377/hlthaff.2019.00473. PMID: 31158014. Exclusion Code: X8.

14. Evaluation of a Multidisciplinary Care Coordination Program for Frequent Users of the Emergency Department. Prof Case Manag. 2019 Sep/Oct;24(5):E1-e2. doi: 10.1097/ncm.0000000000000388. PMID: 31369485. Exclusion Code: X1.

15. Extreme consumers of health care: patterns of care utilization in patients with multiple chronic conditions admitted to a novel integrated clinic. Journal of multidisciplinary healthcare. 2019;12:1075-83. doi: 10.2147/JMDH.S214770. Exclusion Code: X6.

16. Assertive Community Treatment for Alcohol Misuse Disorder Patients Who Are High Utilizers of Emergency Department Services (ARFA). Khoo Teck Puat Hospital. Jun 25,2020. Exclusion Code: X11. 
17. Ackroyd-Stolarz S, Read Guernsey J, Mackinnon NJ, et al. The association between a prolonged stay in the emergency department and adverse events in older patients admitted to hospital: a retrospective cohort study. BMJ Qual Saf. 2011 Jul;20(7):564-9. doi:

10.1136/bmjqs.2009.034926. PMID: 21209130. Exclusion Code: X1.

18. Acosta AM, Lima MA. Frequent users of emergency services: associated factors and reasons for seeking care. Rev Lat Am Enfermagem. 2015 Feb-Apr;23(2):337-44. doi: 10.1590/0104-1169.0072.2560. PMID: 26039306. Exclusion Code: X1.

19. Adler-Milstein J. Assessing the impact of Medicare advantage on high-cost, high-need beneficiaries and exploring an intervention to improve outcomes. Michigan: Commonwealth Fund; 2017. Exclusion Code: X1.

20. Agarwal G, Lee J, McLeod B, et al. Social factors in frequent callers: a description of isolation, poverty and quality of life in those calling emergency medical services frequently. BMC Public Health. 2019 Jun 3;19(1):684. doi: 10.1186/s12889-019-6964-1. PMID: 31159766. Exclusion Code: X1.

21. Agarwal G, McDonough B, Angeles R, et al. Rationale and methods of a multicentre randomised controlled trial of the effectiveness of a Community Health Assessment Programme with Emergency Medical Services (CHAP-EMS) implemented on residents aged 55 years and older in subsidised seniors' housing buildings in Ontario, Canada. BMJ Open. 2015 Jun 11;5(6):e008110. doi: 10.1136/bmjopen-2015008110. PMID: 26068514. Exclusion Code: X1.

22. Agterberg J, Zhong F, Crabb R, et al. Cluster analysis application to identify groups of individuals with high health expenditures. Health Services \& Outcomes Research Methodology. 2020;20(2/3):140-82. doi: 10.1007/s10742-02000214-8. Exclusion Code: X4.

23. Aird P, Hansford P, O'Brien R, et al. The impact of frequent users of $\mathrm{OOH}$ services. Br J Gen Pract. 2001 Jun;51(467):494-5. PMID: 11407062. Exclusion Code: X1.

24. al Yousif N, Hussain HY, El Din Mhakluf MM. Health care services utilization and satisfaction among elderly in Dubai, UAE and some associated determinants. Middle East Journal of Age \& Ageing. 2014;11(3):25-33. Exclusion Code: X1.
25. Alderwick H, Hood-Ronick CM, Gottlieb LM. Medicaid Investments To Address Social Needs In Oregon And California. Health Aff (Millwood). 2019 May;38(5):774-81. doi: 10.1377/hlthaff.2018.05171. PMID: 31059356. Exclusion Code: X1.

26. Alexander Billioux KV, Susan Anthony, Dawn Alley. Standardized Screening for Health-Related Social Needs in Clinical Settings The Accountable Health Communities Screening Tool. 2017. Exclusion Code: X2.

27. Alghanim SA, Alomar BA. Frequent use of emergency departments in Saudi public hospitals: implications for primary health care services. Asia Pac J Public Health. 2015 Mar;27(2):Np2521-30. doi: 10.1177/1010539511431603. PMID: 22186384. Exclusion Code: X1.

28. Allen CG, Escoffery C, Satsangi A, et al. Strategies to improve the integration of community health workers into health care teams: "a little fish in a big pond". Prev Chronic Dis. 2015 Sep 17;12:E154. doi: 10.5888/pcd12.150199. PMID: 26378900. Exclusion Code: X1.

29. Althaus F, Paroz S, Hugli O, et al. Effectiveness of interventions targeting frequent users of emergency departments: a systematic review. Ann Emerg Med. 2011 Jul;58(1):41-52 e42. doi: 10.1016/j.annemergmed.2011.03.007. PMID: 21689565. Exclusion Code: X1.

30. Althaus F, Stucki S, Guyot S, et al. Characteristics of highly frequent users of a Swiss academic emergency department: a retrospective consecutive case series. Eur J Emerg Med. 2013 Dec;20(6):413-9. doi: 10.1097/MEJ.0b013e32835e078e. PMID: 23337095. Exclusion Code: X1.

31. Altman D. A small group of patients account for a whole lot of spending. Axios. 2019. https://www.axios.com/drug-prices-health-carecosts-spending-employers-63a65abc-0148-4f98bd39-b30e4d3c9caf.html. Exclusion Code: X7.

32. Alvarado LP. Mobile psychiatric services decrease readmission rates among high utilizers of emergency treatment services: ProQuest Information \& Learning; 2021. Exclusion Code: $\mathrm{X} 3$.

33. Amarasingham R, Xie B, Karam A, et al. Using community partnerships to integrate health and social services for high-need, high-cost patients. Commonwealth Fund. 2018.

https://www.commonwealthfund.org/publications /issue-briefs/2018/jan/using-communitypartnerships-integrate-health-and-social. Exclusion Code: X1. 
34. Anderson DR, Mangen DJ, Grossmeier JJ, et al. Comparing alternative methods of targeting potential high-cost individuals for chronic condition management. J Occup Environ Med. 2010 Jun;52(6):635-46. doi: 10.1097/JOM.0b013e3181e31792. PMID: 20523235. Exclusion Code: X9.

35. Anderson GM. Program delivery for high-needs, high-cost populations: international perspectives on the way forward, phase I. University of Toronto, Faculty of Medicine, Institute of Health Policy, Management and Evaluation 2017. https://hsrproject.nlm.nih.gov/view_hsrproj_recor d/20191229. Exclusion Code: X7.

36. Andrews G, Sunderland M. Telephone case management reduces both distress and psychiatric hospitalization. Aust N Z J Psychiatry. 2009 Sep;43(9):809-11. doi: 10.1080/00048670903107617. PMID: 19670053. Exclusion Code: X1.

37. Angelelli J, Gifford D, Intrator O, et al. Access to postacute nursing home care before and after the BBA (Balanced Budget Act). Health Aff (Millwood). 2002 Sep-Oct;21(5):254-64. doi: 10.1377/hlthaff.21.5.254. PMID: 12224890. Exclusion Code: X1.

38. Armstrong G, De Marchis E, Mix R, et al. Using Social Needs Screening and Patient Feedback for Complex Care. National Center for Complex Health and Social Needs; 2020. alcomplex.care/researchpolicy/resources/webinars/using-social-needsscreening-and-patient-feedback-for-complexcare/2020. Exclusion Code: X1.

39. Avila J, Jupiter D, Chavez-MacGregor M, et al. High-Cost Hospitalizations Among Elderly Patients With Cancer. J Oncol Pract. 2019 May;15(5):e447-e57. doi: 10.1200/jop.18.00706. PMID: 30946640. Exclusion Code: X1.

40. Azogil-López LM, Pérez-Lázaro JJ, Ávila-Pecci $\mathrm{P}$, et al. Effectiveness of a new model of telephone derivation shared between primary care and hospital care. Atencion primaria / Sociedad Espanola de Medicina de Familia y Comunitaria. 2019;51(5):278-84. doi:

10.1016/j.aprim.2018.02.006. Exclusion Code: X10.

41. Bagnall AM, South J, Forshaw MJ, et al. Selfcare in primary care: findings from a longitudinal comparison study. Prim Health Care Res Dev. 2013 Jan;14(1):29-39. doi: 10.1017/s1463423612000199. PMID: 22717510. Exclusion Code: X1.
42. Bailey JE, Surbhi S, Wan JY, et al. Effect of Intensive Interdisciplinary Transitional Care for High-Need, High-Cost Patients on Quality, Outcomes, and Costs: a Quasi-Experimental Study. J Gen Intern Med. 2019 Sep;34(9):181524. doi: 10.1007/s11606-019-05082-8. PMID: 31270786. Exclusion Code: X1.

43. Baker JM, Grant RW, Gopalan A. A systematic review of care management interventions targeting multimorbidity and high care utilization. BMC Health Serv Res. 2018 Jan 30;18(1):65. doi: 10.1186/s12913-018-2881-8. PMID: 29382327. Exclusion Code: X1.

44. Balaban RB, Zhang F, Vialle-Valentin CE, et al. Impact of a Patient Navigator Program on Hospital-Based and Outpatient Utilization Over 180 Days in a Safety-Net Health System. J Gen Intern Med. 2017 Sep;32(9):981-9. doi: 10.1007/s11606-017-4074-2. PMID: 28523476. Exclusion Code: X1.

45. Balfour ME, Zinn TE, Cason K, et al. Providerpayer partnerships as an engine for continuous quality improvement. Psychiatr Serv. 2018;69(6):623-5. doi: 10.1176/appi.ps.201700533. Exclusion Code: X1.

46. Barker SL, Maguire NJ, Das S, et al. ValuesBased Interventions in Patient Engagement for Those with Complex Needs. Popul Health Manag. 2020;23(2):140-5. doi: 10.1089/pop.2019.0084. Exclusion Code: X1.

47. Barsky AJ, Ahern DK, Bauer MR, et al. A randomized trial of treatments for high-utilizing somatizing patients. J Gen Intern Med. 2013;28(11):1396-404. doi: 10.1007/s11606-0132392-6. Exclusion Code: X1.

48. Bauman CA, Fillingham J, Keely-Dyck E, et al. An approach to interprofessional management of complex patients: a case report. Journal of the Canadian Chiropractic Association. 2019;63(2):119-25. Exclusion Code: X6.

49. Bayliss EA, Ellis JL, Powers JD, et al. Using self-reported data to segment older adult populations with complex care needs. EGEMS (Wash DC). 2019 Apr 12;7(1):12. doi: 10.5334/egems.275. PMID: 31065556. Exclusion Code: X1.

50. Beach SR, Schulz R, Friedman EM, et al. Adverse Consequences of Unmet Needs for Care in High-Need/High-Cost Older Adults. J Gerontol B Psychol Sci Soc Sci. 2020 Jan 14;75(2):459-70. doi: 10.1093/geronb/gby021. PMID: 29471360. Exclusion Code: X3.

51. Becker T, Steffen S, Puschner B. Discharge planning, an intervention study - and where to go next? Eur Psychiatry. 2011;26. doi: 10.1016/S0924-9338(11)73744-0. Exclusion Code: X1. 
52. Bedoya P, Neuhausen K, Dow AW, et al. Student Hotspotting: Teaching the Interprofessional Care of Complex Patients. Acad Med. 2018 Jan;93(1):56-9. doi:

10.1097/acm.0000000000001822. PMID: 28700461. Exclusion Code: X1.

53. Beesley VL, Smithers BM, O'Rourke P, et al. Variations in supportive care needs of patients after diagnosis of localised cutaneous melanoma: a 2-year follow-up study. Support Care Cancer. 2017 Jan;25(1):93-102. doi: 10.1007/s00520016-3378-9. PMID: 27562298. Exclusion Code: $\mathrm{X} 1$.

54. Beima-Sofie K, Begnel ER, Golden MR, et al. "It's Me as a Person, Not Me the Disease": Patient Perceptions of an HIV Care Model Designed to Engage Persons with Complex Needs. AIDS Patient Care STDS. 2020 Jun;34(6):267-74. doi: 10.1089/apc.2019.0310. PMID: 32484744. Exclusion Code: X1.

55. Bélanger E, McHugh J, Meyers DJ, et al. Characteristics of Top-Performing Hospitals Caring for High-Need Medicare Beneficiaries. Popul Health Manag. 2020;23(4):313-8. doi: 10.1089/pop.2019.0145. Exclusion Code: X1.

56. Bellon JA, Rodriguez-Bayon A, Luna JD, et al. Successful GP intervention with frequent attenders in primary care: randomised controlled trial. Br J Gen Pract. 2008 May;58(550):324-30. doi: 10.3399/bjgp08X280182. Exclusion Code: $\mathrm{X} 1$.

57. Bergenstal TD, Reitsema J, Heppner P, et al. Personalized Care Plans: Are They Effective in Decreasing ED Visits and Health Care Expenditure Among Adult Super-Utilizers? J Emerg Nurs. 2020 Jan;46(1):83-90. doi: 10.1016/j.jen.2019.09.001. PMID: 31685338. Exclusion Code: X1.

58. Bergeron P, Courteau J, Vanasse A. Proximity and emergency department use: multilevel analysis using administrative data from patients with cardiovascular risk factors. Can Fam Physician. 2015 Aug;61(8):e391-7. PMID: 26505061. Exclusion Code: X1.

59. Bergh H, Marklund B. Characteristics of frequent attenders in different age and sex groups in primary health care. Scand J Prim Health Care. 2003 Sep;21(3):171-7. doi: 10.1080/02813430310001149. Exclusion Code: $\mathrm{X} 1$.

60. Berghofer A, Hartwich A, Bauer M, et al. Efficacy of a systematic depression management program in high utilizers of primary care: a randomized trial. BMC Health Serv Res. 2012 Sep 3;12:298. doi: 10.1186/1472-6963-12-298. PMID: 22943609. Exclusion Code: X1.
61. Berghöfer A, Roll S, Bauer M, et al. Screening for depression and high utilization of health care resources among patients in primary care. Community Ment Health J. 2014;50(7):753-8. doi: 10.1007/s10597-014-9700-4. Exclusion Code: X1.

62. Berkowitz SA. Capsule Commentary on Schickedanz et al., Impact of Social Needs Navigation on Utilization Among High-Utilizers in a Large Integrated Health System: a QuasiExperimental Study. JGIM: Journal of General Internal Medicine. 2019;34(11):2582-. doi: 10.1007/s11606-019-05296-w. Exclusion Code: $\mathrm{X} 8$.

63. Bertoli-Avella AM, Haagsma JA, Van Tiel S, et al. Frequent users of the emergency department services in the largest academic hospital in the Netherlands: a 5-year report. Eur J Emerg Med. 2017 Apr;24(2):130-5. doi: 10.1097/mej.0000000000000314. PMID: 26287805. Exclusion Code: X1.

64. Bieler G, Paroz S, Faouzi M, et al. Social and medical vulnerability factors of emergency department frequent users in a universal health insurance system. Acad Emerg Med. 2012 Jan;19(1):63-8. doi: 10.1111/j.15532712.2011.01246.x. PMID: 22221292. Exclusion Code: X1.

65. Bilazarian A. High-need high-cost patients: A Concept Analysis. Nurs Forum. 2020. doi: 10.1111/nuf.12500. Exclusion Code: X1.

66. Billett J, Cowie MR, Gatzoulis MA, et al. Comorbidity, healthcare utilisation and process of care measures in patients with congenital heart disease in the UK: cross-sectional, populationbased study with case-control analysis. Heart. 2008 Sep;94(9):1194-9. doi: 10.1136/hrt.2007.122671. PMID: 17646191. Exclusion Code: X1.

67. Bischoff RJ, Hollist CS, Patterson J, et al. Providers' perspectives on troublesome overusers of medical services. Families, Systems, \& Health. 2007;25(4):392-403. doi: 10.1037/10917527.25.4.392. Exclusion Code: X1.

68. Blair M. Organizations provide $\$ 8.7$ million to launch a national center to improve care for complex patients. Robert Wood Johnson Foundation. 2016. https:/www.rwjf.org/en/library/articles-andnews/2016/03/organizations-provide-8-7-millionto-launch-national-center.html. Exclusion Code: X7.

69. Blakey R, Court G, Peaker A, et al. High service users: does the clinical psychologist have a role? Health Bull (Edinb). 2000 May;58(3):203-9. PMID: 12813826. Exclusion Code: X1. 
70. Blank FS, Li H, Henneman PL, et al. A descriptive study of heavy emergency department users at an academic emergency department reveals heavy ED users have better access to care than average users. J Emerg Nurs. 2005 Apr;31(2):139-44. doi: 10.1016/j.jen.2005.02.008. PMID: 15834378. Exclusion Code: X4.

71. Bledsoe SE. Adult health care services and psychiatric disorders: the use and costs of health care services in a low income, minority population coming to an urban primary care clinic: ProQuest Information \& Learning; 2007. Exclusion Code: X1.

72. Bleich SN, Sherrod C, Chiang A, et al. Systematic review of programs treating highneed and high-cost people with multiple chronic diseases or disabilities in the United States, 20082014. Prev Chronic Dis. 2015 Nov 12;12:E197. doi: $10.5888 /$ pcd12.150275. Exclusion Code: X7.

73. Blumenthal D, Abrams MK. Tailoring complex care management for high-need, high-cost patients. JAMA. 2016 Oct 25;316(16):1657-8. doi: 10.1001/jama.2016.12388. Exclusion Code: $\mathrm{X} 1$.

74. Blumenthal D, Chernof B, Fulmer T, et al. Caring for high-need, high-cost patients - an urgent priority. N Engl J Med. 2016 Sep 8;375(10):90911. doi: 10.1056/NEJMp1608511. Exclusion Code: X1.

75. Bobo WV, Hoge CW, Messina MA, et al. Characteristics of repeat users of an inpatient psychiatry service at a large military tertiary care hospital. Mil Med. 2004 Aug;169(8):648-53. doi: 10.7205/milmed.169.8.648. PMID: 15379078. Exclusion Code: X1.

76. Bodenmann P, Baggio S, Iglesias K, et al. Characterizing the vulnerability of frequent emergency department users by applying a conceptual framework: a controlled, crosssectional study. Int J Equity Health. 2015 Dec 9;14:146. doi: 10.1186/s12939-015-0277-5. PMID: 26645272. Exclusion Code: X1.

77. Bodenmann P, Velonaki VS, Griffin JL, et al. Case management may reduce emergency department frequent use in a universal health coverage system: a randomized controlled trial. J Gen Intern Med. 2017 May;32(5):508-15. doi: 10.1007/s11606-016-3789-9. PMID: 27400922. Exclusion Code: X1.
78. Boehmer KR, Abu Dabrh AM, Gionfriddo MR, et al. Does the chronic care model meet the emerging needs of people living with multimorbidity? A systematic review and thematic synthesis. PLoS One. 2018;13(2):e0190852. doi: 10.1371/journal.pone.0190852. PMID: 29420543. Exclusion Code: X7.

79. Boling PA, Leff B. Comprehensive longitudinal health care in the home for high-cost beneficiaries: a critical strategy for population health management. J Am Geriatr Soc. 2014 Oct;62(10):1974-6. doi: 10.1111/jgs. 13049. PMID: 25294407. Exclusion Code: X9.

80. Bornstein D. The 5 percent: solutions reporting on care for the nation's sickest. Solutions Journalism Network, Inc.: Commonwealth Fund; 2016. Exclusion Code: X7.

81. Bradley EH. Identifying effective strategies for coordinating health care and social services for high-need, high-cost patients. Yale University, Yale School of Public Health 2015.

https://www.commonwealthfund.org/grants/ident ifying-effective-strategies-coordinating-healthcare-and-social-services-high-need-high. Exclusion Code: X7.

82. Brannon E, Wang T, Lapedis J, et al. Towards a learning health system to reduce emergency department visits at a population level. AMIA Symposium; 2018. Annual Symposium proceedings; 2018. pp. 295-304. Exclusion Code: $\mathrm{X} 1$.

83. Braveman P, Dekker M, Egerter S, et al. How does housing affect health? An examination of the many ways in which housing can influence health and strategies to improve health through emphasis on healthier homes. 2011. Exclusion Code: X1.

84. Breland JY, Chee CP, Zulman DM. Racial differences in chronic conditions and sociodemographic characteristics among highutilizing veterans. J Racial Ethn Health Disparities. 2015 Jun;2(2):167-75. doi: 10.1007/s40615-014-0060-0. PMID: 26863335. Exclusion Code: X4.

85. Brenner JC. Jeffrey C Brenner: on driving down the cost of care. Healthc Financ Manage. 2013 Jan;67(1):72-5. PMID: 23360057. Exclusion Code: X1.

86. Brewster AL, Brault MA, Tan AX, et al. Patterns of collaboration among health care and social services providers in communities with lower health care utilization and costs. Health Serv Res. 2018 Aug;53 Suppl 1:2892-909. doi: 10.1111/1475-6773.12775. Exclusion Code: X1. 
87. Brian W. Powers SP, Nupur Mehta. Impact of Complex Care Management on Spending and Utilization for High-Need, High-Cost Medicaid Patients. The American Journal of Managed Care. 2020. Exclusion Code: X12.

88. Bronsky ES, McGraw C, Johnson R, et al. CARES: a community-wide collaboration identifies super-utilizers and reduces their 9-1-1 call, emergency department, and hospital visit rates. Prehosp Emerg Care. 2017 Nov-

Dec;21(6):693-9. doi: 10.1080/10903127.2017.1335820. PMID: 28657819. Exclusion Code: X1.

89. Brooks EM, Winship JM, Kuzel AJ. A "Behindthe-Scenes" Look at Interprofessional Care Coordination: How Person-Centered Care in Safety-Net Health System Complex Care Clinics Produce Better Outcomes. International Journal of Integrated Care. 2020 Apr-Jun;20(2):10. doi: 10.5334/ijic.4734. Exclusion Code: X1.

90. Brown AF, Behforouz H, Shah A, et al. The care connections program: A randomized trial of community health workers to improve care for medically and socially complex patients. J Gen Intern Med. 2020;35(SUPPL 1):S288. doi: 10.1007/s11606-020-05890-3. Exclusion Code: $\mathrm{X} 1$.

91. Brown KE, Fiellin DA, Chawarski MC, et al. A randomized trial of primary intensive care to reduce hospital admissions in high utilizers. J Gen Intern Med. 2002 Apr;17:121-. Exclusion Code: X1.

92. Brown KE, Levine JM, Fiellin DA, et al. Primary intensive care: pilot study of a primary carebased intervention for high-utilizing patients. Dis Manag. 2005 Jun;8(3):169-77. doi: 10.1089/dis.2005.8.169. PMID: 15966782. Exclusion Code: X1.

93. Broyles J. Strategies to promulgate advanced illness care models that work. Coalition to Transform Advanced Care. Washington, DC: 2013. Exclusion Code: X1.

94. Bryk J, Fischer GS, Lyons A, et al. Improvement in quality metrics by the UPMC enhanced care program: a novel super-utilizer program. Popul Health Manag. 2018 Jun;21(3):217-21. doi: 10.1089/pop.2017.0064. PMID: 28945512. Exclusion Code: X1.

95. Buchanan D, Doblin B, Sai T, et al. The effects of respite care for homeless patients: a cohort study. Am J Public Health. 2006 Jul;96(7):127881. doi: 10.2105/ajph.2005.067850. PMID: 16735635. Exclusion Code: X1.
96. Buck JA, Teich JL, Miller K. Use of mental health and substance abuse services among highcost Medicaid enrollees. Adm Policy Ment Health. 2003 Sep;31(1):3-14. doi: 10.1023/a:1026089422101. PMID: 14650645. Exclusion Code: X9.

97. Buja A, Claus M, Perin L, et al. Multimorbidity patterns in high-need, high-cost elderly patients. PLoS One. 2018;13(12):e0208875. doi: 10.1371/journal.pone.0208875. PMID: 30557384. Exclusion Code: X1.

98. Buja A, Rivera M, De Battisti E, et al. Multimorbidity and Hospital Admissions in High-Need, High-Cost Elderly Patients. J Aging Health. 2020 Jun/Jul;32(5-6):259-68. doi: 10.1177/0898264318817091. PMID: 30522388. Exclusion Code: X6.

99. Burns C, Wang NE, Goldstein BA, et al. Characterization of young adult emergency department users: evidence to guide policy. J Adolesc Health. 2016 Dec;59(6):654-61. doi: 10.1016/j.jadohealth.2016.07.011. PMID: 27613220. Exclusion Code: X4.

100. Burns J. Treating Super Utilizers in Rural Pennsylvania. Robert Wood Johnson Foundation. Princeton, NJ: 2013. https://www.rwjf.org/en/library/articles-andnews/2013/09/treating-superusers-in-ruralpennsylvania.html. Exclusion Code: X1.

101. Burns J. Cleveland Medical Center aims to improve care for super utilizers. Robert Wood Johnson Foundation. Princeton, NJ: 2013. https://www.rwjf.org/en/library/articles-andnews/2013/09/cleveland-improves-care-forsuper-utilizers.html. Exclusion Code: X1.

102. Bush H. Caring for the costliest. (Cover story). H\&HN: Hospitals \& Health Networks. 2012;86(11):24-9. Exclusion Code: X1.

103. Bush H. Tackling the high cost of chronic disease. Hosp Health Netw. 2012 Oct;86(10):346, 8, 40. PMID: 23163172. Exclusion Code: X1.

104. Bynum JPW. Measuring what matters most to people with complex needs. Health Aff (Millwood). Bethesda, MD: Health Affairs; 2018. Exclusion Code: X1.

105. Bynum JPW, Austin A, Carmichael D, et al. High-Cost Dual Eligibles' Service Use Demonstrates The Need For Supportive And Palliative Models Of Care. Health Aff (Millwood). 2017 Jul 1;36(7):1309-17. doi: 10.1377/hlthaff.2017.0157. PMID: 28679819. Exclusion Code: X1. 
106. California Health Care Foundation. Data symposium and webinar on high utilizers of Medi-Cal Services. Oakland, CA: California Health Care Foundation; 2015.

https://www.chcf.org/event/data-symposium-andwebinar-on-high-utilizers-of-medi-calservices/2019. Exclusion Code: X1.

107. California Health Care Foundation. Integrated clinics for high utilizers conference. Oakland, CA: California Health Care Foundation; 2015. https://www.chcf.org/event/integrated-clinics-forhigh-utilizers-conference/2019. Exclusion Code: $\mathrm{X} 1$.

108. California Health Care Foundation. Care integration for patients with complex needs. California Health Care Foundation. Oakland, CA: 2017. https://www.chcf.org/project/careintegration-for-patients-with-complex-needs/. Exclusion Code: X1.

109. California Health Care Foundation. CIN Webinar Series - The ROI for addressing social needs in health care (\#2). Oakland, CA: California Health Care Foundation; 2018.

https:/www.chcf.org/event/cin-webinar-seriesroi-addressing-social-needs-health-care-2/2019. Exclusion Code: X1.

110. Capp R, Rosenthal MS, Desai MM, et al. Characteristics of Medicaid enrollees with frequent ED use. Am J Emerg Med. 2013 Sep;31(9):1333-7. doi:

10.1016/j.ajem.2013.05.050. PMID: 23850143. Exclusion Code: X4.

111. Capp R, Zane R. Using emergency department community health workers as a bridge to ongoing care for frequent ED users. Value and Quality Innovations in Acute and Emergency Care. 2017:209-14. Exclusion Code: X1.

112. Carney KJL. PRACTITIONER APPLICATION: An Evaluation of Interprofessional Patient Navigation Services in High Utilizers at a County Tertiary Teaching Health System. J Healthc Manag. 2020 Jan-Feb;65(1):71-2. doi: 10.1097/jhm-d-19-00237. Exclusion Code: X8.

113. Carpiac-Claver M, Guzman JS, Castle SC. The Comprehensive Care Clinic. Health Soc Work. 2007 Aug;32(3):219-23. doi: 10.1093/hsw/32.3.219. PMID: 17896679. Exclusion Code: X1.

114. Carroll CP, Carlton Jr H, Fagan P, et al. The course and correlates of high hospital utilization in sickle cell disease: evidence from a large, urban Medicaid managed care organization. Am J Hematol. 2009;84(10):666-70. doi: 10.1002/ajh.21515. Exclusion Code: X1.
115. Castillo EM, Brennan JJ, Killeen JP, et al. Identifying frequent users of emergency department resources. J Emerg Med. 2014 Sep;47(3):343-7. doi: 10.1016/j.jemermed.2014.03.014. PMID: 24813059. Exclusion Code: X4.

116. Center for Health Care Strategies. Medicaidfinanced services in supportive housing for highneed homeless beneficiaries. 2012. Exclusion Code: X1.

117. The Super-Utilizer Summit: resources to support emerging programs. Super-Utilizer Summit; 2013; Alexandra, Virginia. 2442: Center for Health Care Strategies. Exclusion Code: X1.

118. Center for Integrative Medicine. Webinar - new online resources for complex care. Oakland, CA: California Health Care Foundation; 2015. https://www.chcf.org/event/webinar-new-onlineresources-for-complex-care/2019. Exclusion Code: X1.

119. Chambers C, Chiu S, Katic M, et al. High utilizers of emergency health services in a population-based cohort of homeless adults. Am J Public Health. 2013;103(S2):S302-10. doi: 10.2105/AJPH.2013.301397. Exclusion Code: $\mathrm{X} 1$.

120. Chan B, Edwards ST, Devoe M, et al. The SUMMIT ambulatory-ICU primary care model for medically and socially complex patients in an urban federally qualified health center: study design and rationale. Addict Sci Clin Pract. 2018;13(1):27. doi: 10.1186/s13722-018-0128-y. Exclusion Code: X1.

121. Chan B, Edwards ST, Mitchell M, et al. Can an intensive ambulatory care intervention improve the experience of high-utilizing patients?: 6 month outcomes of the summit randomized controlled trial. J Gen Intern Med. 2019;34(2):S151-. doi: 10.1007/11606.15251497. Exclusion Code: X1.

122. Chan B, Mitchell M, Edwards ST, et al. Implementation and evaluation of summit, an ambulatory intensive care (A-ICU) model of primary care for high-utilizersata healthcare for the homeless site. J Gen Intern Med. 2018;33(2):791-2. Exclusion Code: X1.

123. Chan BT, Ovens HJ. Frequent users of emergency departments. Do they also use family physicians' services? Can Fam Physician. 2002 Oct;48:1654-60. PMID: 12449550 Exclusion Code: X1.

124. Chandler D, Spicer G. Capitated assertive community treatment program savings: system implications. Adm Policy Ment Health. 2002;30(1):3-19. Exclusion Code: X1. 
125. Chang E. Intensive Primary Care via Patient Aligned Care Teams (PACT) Intensive Management@VA. 2019. Exclusion Code: X1.

126. Chang ET, Raja PV, Stockdale SE, et al. What are the key elements for implementing intensive primary care? A multisite Veterans Health Administration case study. Healthc (Amst). 2018 Dec;6(4):231-7. doi: 10.1016/j.hjdsi.2017.10.001. PMID: 29102480. Exclusion Code: X1.

127. Chang ET, Zulman DM, Asch SM, et al. An operations-partnered evaluation of care redesign for high-risk patients in the Veterans Health Administration (VHA): study protocol for the PACT Intensive Management (PIM) randomized quality improvement evaluation. Contemp Clin Trials. 2018 Jun;69:65-75. doi:

10.1016/j.cct.2018.04.008. PMID: 29698772. Exclusion Code: X1.

128. Chang HY, Boyd CM, Leff B, et al. Identifying Consistent High-cost Users in a Health Plan: Comparison of Alternative Prediction Models. Med Care. 2016 Sep;54(9):852-9. doi: 10.1097/mlr.0000000000000566. PMID: 27326548. Exclusion Code: X9.

129. Chapman H, Farndon L, Matthews R, et al. Okay to Stay? A new plan to help people with longterm conditions remain in their own homes. Primary Health Care Research \& Development (Cambridge University Press / UK).

2019;20:N.PAG-N.PAG. doi: 10.1017/S1463423618000786. Exclusion Code: X6.

130. Chaput YJ, Lebel MJ. An examination of the temporal and geographical patterns of psychiatric emergency service use by multiple visit patients as a means for their early detection. BMC Psychiatry. 2007 Oct 29;7:60. doi: 10.1186/1471244x-7-60. PMID: 17963530. Exclusion Code: $\mathrm{X} 1$.

131. Chaput YJ, Lebel MJ. Demographic and clinical profiles of patients who make multiple visits to psychiatric emergency services. Psychiatr Serv. 2007 Mar;58(3):335-41. doi: 10.1176/ps.2007.58.3.335. PMID: 17325106. Exclusion Code: X1.

132. Chen BK, Cheng X, Bennett K, et al. Travel distances, socioeconomic characteristics, and health disparities in nonurgent and frequent use of hospital emergency departments in South Carolina: a population-based observational study. BMC Health Serv Res. 2015 May 16;15:203. doi: 10.1186/s12913-015-0864-6. PMID: 25982735. Exclusion Code: X4.
133. Cherner R, Ecker J, Louw A, et al. Lessons learned from piloting a pain assessment program for high frequency emergency department users. Scand J Pain. 2019 Jul 26;19(3):545-52. doi: 10.1515/sjpain-2018-0128. PMID: 31031261. Exclusion Code: X6.

134. Chernof B, McClellan M. Form follows funding: opportunities for advancing outcomes for complex care patients using alternative payment methods. Health Affairs Blog. Bethesda, MD: Health Affairs; 2018. Exclusion Code: X1.

135. Chhabra M, Spector E, Demuynck S, et al. Assessing the relationship between housing and health among medically complex, chronically homeless individuals experiencing frequent hospital use in the United States. Health Soc Care Community. 2020 Jan;28(1):91-9. doi: 10.1111/hsc.12843. PMID: 31476092. Exclusion Code: X1.

136. Chiu Y, Racine-Hemmings F, Dufour I, et al. Statistical tools used for analyses of frequent users of emergency department: a scoping review. Bmj Open. 2019 May;9(5). doi: 10.1136/bmjopen-2018-027750. Exclusion Code: $\mathrm{X} 1$.

137. Chiu YM, Vanasse A, Courteau J, et al. Persistent frequent emergency department users with chronic conditions: A population-based cohort study. PLoS One. 2020;15(2):e0229022. doi: 10.1371/journal.pone.0229022. PMID: 32050010. Exclusion Code: X6.

138. Chuang E, Pourat N, Haley LA, et al. Integrating Health And Human Services In California's Whole Person Care Medicaid 1115 Waiver Demonstration. Health Aff (Millwood). 2020 Apr;39(4):639-48. doi: 10.1377/hlthaff.2019.01617. Exclusion Code: $\mathrm{X} 1$.

139. Chukmaitov AS, Tang A, Carretta HJ, et al. Characteristics of all, occasional, and frequent emergency department visits due to ambulatory care-sensitive conditions in Florida. J Ambul Care Manage. 2012 Apr-Jun;35(2):149-58. doi: 10.1097/JAC.0b013e318244d222. PMID: 22415289. Exclusion Code: X3.

140. Claxton G, Rae M, Levitt L. A look at people who have persistently high spending on health care. Kaiser Family Foundation. 2019. https://www.kff.org/health-costs/issue-brief/alook-at-people-who-have-persistently-highspending-on-health-care/. Exclusion Code: X7.

141. ClinicalTrials.gov. Contra Costa Health Services Whole Person Care (CommunityConnect) Program Evaluation. https://clinicaltrials.gov/show/NCT04000074. 2019. Exclusion Code: X9. 
142. ClinicalTrials.gov. High Risk Outpatient Internled Care (HeROIC) Clinic Initiative. https://clinicaltrials.gov/show/NCT04375189. 2020. Exclusion Code: X11.

143. CMS. Integrated care resource center available to all states. Resources available to all states to coordinate care for high-cost, high-need beneficiaries. Baltimore, MD: U.S. Centers for Medicare \& Medicaid Services; 2017. Exclusion Code: X1.

144. Cohen D, Wodchis WP, Calzavara A. Can highcost spending in the community signal admission to hospital? A dynamic modeling study for urgent and elective cardiovascular patients. BMC Health Serv Res. 2018 Nov 15;18(1):861. doi: 10.1186/s12913-018-3639-z. PMID: 30442140. Exclusion Code: X1.

145. Coles S. Strategies to Improve Corporate Financial Investment in Care Coordination Programs. Walden University, ProQuest Dissertations Publishing; 2018. Exclusion Code: $\mathrm{X} 1$.

146. Colla C. Evaluating the formation and performance of accountable care organizations: focus on high-need, high-cost populations. Dartmouth College, Dartmouth Institute for Health Policy and Clinical Practice. 2014. Exclusion Code: X7.

147. Colla C, Yang WD, Mainor AJ, et al. Organizational integration, practice capabilities, and outcomes in clinically complex medicare beneficiaries. Health Serv Res. 2020

Dec;55:1085-97. doi: 10.1111/1475-6773.13580. Exclusion Code: X1.

148. Collins L, Sicks S, Hass RW, et al. Self-efficacy and empathy development through interprofessional student hotspotting. Journal of Interprofessional Care.4. doi: 10.1080/13561820.2020.1712337. Exclusion Code: X1.

149. Connors JDN, Binkley BL, Graff JC, et al. How patient experience informed the SafeMed Program: Lessons learned during a Health Care Innovation Award to improve care for superutilizers. Healthcare-the Journal of Delivery Science and Innovation. 2019 Mar;7(1):13-21. doi: 10.1016/j.hjdsi.2018.02.002. Exclusion Code: X1.

150. Considine JT. A Feasibility Study for an Advanced Practice Registered Nurse Led Community Engagement Program. Shepherd University, ProQuest Dissertations Publishing; 2018. Exclusion Code: X4.
151. Cook LJ, Knight S, Junkins EP, Jr., et al. Repeat patients to the emergency department in a statewide database. Acad Emerg Med. 2004 Mar;11(3):256-63. doi: 10.1111/j.15532712.2004.tb02206.x. PMID: 15001405. Exclusion Code: X4.

152. Cornell PY, Halladay CW, Ader J, et al. Embedding Social Workers In Veterans Health Administration Primary Care Teams Reduces Emergency Department Visits. Health Aff (Millwood). 2020 Apr;39(4):603-12. doi: 10.1377/hlthaff.2019.01589. Exclusion Code: $\mathrm{X} 1$.

153. Costi S, Pellegrini M, Cavuto S, et al. Occupational therapy in rehabilitation of complex patients: protocol for a superiority randomized controlled trial. Journal of interprofessional care. 2020:1-8. doi: 10.1080/13561820.2020.1711720. Exclusion Code: X11.

154. Coughlin TA, Long SK. Health care spending and service use among high-cost Medicaid beneficiaries, 2002-2004. Inquiry. 2009 Winter;46(4):405-17. doi: 10.5034/inquiryjrnl_46.4.405. PMID: 20184167. Exclusion Code: X9̄.

155. Couture EM, Chouinard MC, Fortin M, et al. The relationship between health literacy and quality of life among frequent users of health care services: a cross-sectional study. Health Qual Life Outcomes. 2017 Jul 6;15(1):137. doi: 10.1186/s12955-017-0716-7. PMID: 28683743. Exclusion Code: X1.

156. Couture EM, Chouinard MC, Fortin M, et al. The relationship between health literacy and patient activation among frequent users of healthcare services: a cross-sectional study. BMC Fam Pract. 2018 Mar 9;19(1):38. doi: 10.1186/s12875018-0724-7. PMID: 29523095. Exclusion Code: $\mathrm{X} 1$.

157. Cox WK, Penny LC, Statham RP, et al. Admission intervention team: medical center based intensive case management of the seriously mentally ill. Care Manag J. 2003 Winter;4(4):178-84. doi: 10.1891/cmaj.4.4.178.63694. PMID: 15628650. Exclusion Code: X1.

158. Craig C, Stiefel M, Carr E, et al. WIHI: when everyone knows your name: identifying patients with complex needs. Institute for Healthcare Improvement; 2015. Exclusion Code: X7.

159. Craig C ED, Whittington J. Care Coordination Model: Better Care at Lower Cost for People with Multiple Health and Social Needs. IHI. 2011. Exclusion Code: X11. 
160. Crane D, Christenson J. The medical offset effect: patterns in outpatient services reduction for high utilizers of health care. Contemporary Family Therapy: An International Journal. 2008;30(2):127-38. doi: 10.1007/s10591-0089058-2. Exclusion Code: X1.

161. Crane M, Warnes AM. Primary health care services for single homeless people: defects and opportunities. Fam Pract. 2001 Jun;18(3):272-6. doi: 10.1093/fampra/18.3.272. PMID: 11356733. Exclusion Code: X1.

162. Cruwys T, Wakefield JRH, Sani F, et al. Social isolation predicts frequent attendance in primary care. Ann Behav Med. 2018 Oct;52(10):817-29. doi: 10.1093/abm/kax054. Exclusion Code: X1.

163. Cullen W, O'Brien S, O'Carroll A, et al. Chronic illness and multimorbidity among problem drug users: a comparative cross sectional pilot study in primary care. BMC Fam Pract. 2009 Apr 21;10:25. doi: 10.1186/1471-2296-10-25. PMID: 19383141. Exclusion Code: X1.

164. Cunningham PJ. Predicting high-cost privately insured patients based on self-reported health and utilization data. Am J Manag Care. 2017 Jul 1;23(7):e215-e22. PMID: 28850789. Exclusion Code: X9.

165. Curtin CM, Suarez PA, Di Ponio LA, et al. Who are the women and men in Veterans Health Administration's current spinal cord injury population? J Rehabil Res Dev. 2012;49(3):35160. doi: 10.1682/jrrd.2010.11.0220. PMID: 22773195. Exclusion Code: X1.

166. Dang S, Ruiz DI, Klepac L, et al. Key Characteristics for Successful Adoption and Implementation of Home Telehealth Technology in Veterans Affairs Home-Based Primary Care: An Exploratory Study. Telemed J E Health. 2019 Apr;25(4):309-18. doi: 10.1089/tmj.2018.0009. PMID: 29969381. Exclusion Code: X11.

167. Darke S, Havard A, Ross J, et al. Changes in the use of medical services and prescription drugs among heroin users over two years. Drug Alcohol Rev. 2007 Mar;26(2):153-9. doi:

10.1080/09595230601146660. PMID: 17364850. Exclusion Code: X1.

168. Das LT, Abramson EL, Kaushal R. High-need, high-cost patients offer solutions for improving their care and reducing costs. NEJM Catal. 2019;2019. Exclusion Code: X7.

169. Das LT, Kaushal R, Garrison K, et al. Drivers of preventable high health care utilization: a qualitative study of patient, physician and health system leader perspectives. J Health Serv Res Policy. 2020;25(4):220-8. doi: 10.1177/1355819619873685. Exclusion Code: $\mathrm{X} 12$.
170. Davis A, Osuji T, Chen A, et al. Data-driven decision making for interventions with complex needs' patients: Identifying the right target population. Health Serv Res. 2020;55(SUPPL 1):75. doi: 10.1111/1475-6773.13433. Exclusion Code: X7.

171. Davis AC, Osuji TA, Chen J, et al. Identifying Populations with Complex Needs: Variation in Approaches Used to Select Complex Patient Populations. Popul Health Manag. 2020. doi: 10.1089/pop.2020.0153. Exclusion Code: X7.

172. Davis JW, Chung R, Juarez DT. Prevalence of comorbid conditions with aging among patients with diabetes and cardiovascular disease. Hawaii Med J. 2011 Oct;70(10):209-13. PMID: 22162595. Exclusion Code: X1.

173. Davis R, Nuamah A. Identifying "Rising Risk" Populations: Early Lessons from the Complex Care Innovation Lab. Center for Health Care Strategies; 2020. Exclusion Code: X2.

174. Davis R, Somers SA. A collective national approach to fostering innovation in complex care. Healthc (Amst). 2018 Mar;6(1):1-3. doi: 10.1016/j.hjdsi.2017.05.003. PMID: 28673816. Exclusion Code: X7.

175. de Miguel-Diez J, Lopez-de-Andres A, Herandez-Barrera V, et al. Effect of the economic crisis on the use of health and home care services among Spanish COPD patients. Int J Chron Obstruct Pulmon Dis. 2018;13:725-39. doi: 10.2147/copd.S150308. PMID: 29535513. Exclusion Code: X1.

176. Deacon B, Lickel J, Abramowitz JS. Medical utilization across the anxiety disorders. J Anxiety Disord. 2008;22(2):344-50. doi: 10.1016/j.janxdis.2007.03.004. PMID: 17420113. Exclusion Code: X1.

177. Delaney RK, Sisco-Taylor B, Fagerlin A, et al. A systematic review of intensive outpatient care programs for high-need, high-cost patients. Transl Behav Med. 2020;10(5):1187-99. doi: 10.1093/tbm/ibaa017. Exclusion Code: X7.

178. Delcher C, Yang C, Ranka S, et al. Variation in outpatient emergency department utilization in Texas Medicaid: a state-level framework for finding "superutilizers". Int J Emerg Med. 2017 Dec 4;10(1):31. doi: 10.1186/s12245-017-01574. PMID: 29204728. Exclusion Code: X9.

179. Dent A, Hunter G, Webster AP. The impact of frequent attenders on a UK emergency department. Eur J Emerg Med. 2010 Dec;17(6):332-6. doi: 10.1097/MEJ.0b013e328335623d. PMID: 20038842. Exclusion Code: X1. 
180. Dent AW, Phillips GA, Chenhall AJ, et al. The heaviest repeat users of an inner city emergency department are not general practice patients. Emerg Med (Fremantle). 2003 Aug;15(4):322-9. PMID: 14631698. Exclusion Code: X1.

181. Dew MA, Goycoolea JM, Harris RC, et al. An internet-based intervention to improve psychosocial outcomes in heart transplant recipients and family caregivers: development and evaluation. J Heart Lung Transplant. 2004 Jun;23(6):745-58. doi: 10.1016/j.healun.2003.07.002. PMID: 15366436. Exclusion Code: X1.

182. Di Lorenzo R, Sagona M, Landi G, et al. The revolving door phenomenon in an Italian acute psychiatric ward: a 5-year retrospective analysis of the potential risk factors. J Nerv Ment Dis. 2016;204(9):686-92. doi:

10.1097/NMD.0000000000000540. Exclusion Code: X1.

183. Di Mauro R, Di Silvio V, Bosco P, et al. Case management programs in emergency department to reduce frequent user visits: a systematic review. Acta Biomed. 2019 Jul 8;90(6-s):34-40. doi: 10.23750/abm.v90i6-S.8390. PMID: 31292413. Exclusion Code: X7.

184. Diaz T. In Memoriam. Patient Educ Couns. 2020 Jun;103(6):1258-9. doi:

10.1016/j.pec.2019.11.027. Exclusion Code: X8.

185. DiPietro BY. Medicaid accountable care organizations: a case study with Hennepin Health. 2018 May 2018. Exclusion Code: X1.

186. DiPietro BY, Kindermann D, Schenkel SM. Ill, itinerant, and insured: the top 20 users of emergency departments in Baltimore city. ScientificWorldJournal. 2012;2012:726568. doi: 10.1100/2012/726568. PMID: 22606057. Exclusion Code: X4.

187. Doheny M, Agerholm J, Orsini N, et al. Sociodemographic differences in the frequent use of emergency department care by older persons: a population-based study in Stockholm County. BMC Health Serv Res. 2019 Mar 29;19(1):202. doi: 10.1186/s12913-019-4029-x. PMID: 30922354. Exclusion Code: X1.

188. Dollard J, Harvey G, Dent E, et al. Older people who are frequent users of acute care: a symptom of fragmented care? A case series report on patients' pathways of care. J Frailty Aging. 2018;7(3):193-5. doi:

10.14283/10.14283/jfa.2018.12. PMID: 30095151. Exclusion Code: X1.
189. Dombrowski JC, Ramchandani M, Dhanireddy S, et al. The Max Clinic: medical care designed to engage the hardest-to-reach persons living with HIV in Seattle and King County, Washington. AIDS Patient Care STDS. 2018 Apr;32(4):14956. doi: 10.1089/apc.2017.0313. PMID: 29630852. Exclusion Code: X1.

190. Domenech-Briz V, Romero RG, de MiguelMontoya I, et al. Results of Nurse Case Management in Primary Heath Care: Bibliographic Review. Int J Environ Res Public Health. 2020 Dec;17(24):17. doi: 10.3390/ijerph17249541. Exclusion Code: X7.

191. Donate-Martinez A, Rodenas F, Garces J. Impact of a primary-based telemonitoring programme in HRQOL, satisfaction and usefulness in a sample of older adults with chronic diseases in Valencia (Spain). Arch Gerontol Geriatr. 2016 JanFeb;62:169-75. doi: 10.1016/j.archger.2015.09.008. PMID: 26446784. Exclusion Code: X1.

192. Doran KM, Vashi AA, Platis S, et al. Navigating the boundaries of emergency department care: addressing the medical and social needs of patients who are homeless. Am J Public Health. 2013 Dec;103 Suppl 2:S355-60. doi: 10.2105/ajph.2013.301540. PMID: 24148054. Exclusion Code: X1.

193. Doupe MB, Palatnick W, Day S, et al. Frequent users of emergency departments: developing standard definitions and defining prominent risk factors. Ann Emerg Med. 2012 Jul;60(1):24-32. doi: 10.1016/j.annemergmed.2011.11.036. PMID: 22305330. Exclusion Code: X1.

194. Dowd BE, Swenson T, Parashuram S, et al. PQRS participation, inappropriate utilization of health care services, and Medicare expenditures. Med Care Res Rev. 2016 Feb;73(1):106-23. doi: 10.1177/1077558715597846. PMID: 26324510. Exclusion Code: X1.

195. Downey LV, Zun LS. Reasons for readmissions: what are the reasons for 90-day readmissions of psychiatric patients from the ED? Am J Emerg Med. 2015 Oct;33(10):1489-91. doi: 10.1016/j.ajem.2015.06.056. PMID: 26164411. Exclusion Code: X1.

196. Dreyfus KS. Adult attachment theory and diabetes mellitus: an examination of healthcare utilization and biopsychosocial health: ProQuest Information \& Learning; 2015. Exclusion Code: $\mathrm{X} 1$.

197. Dryden EM, King K, Touw S. Facilitators and Barriers to Successful Engagement in a Complex Care Management Program: Patient and Care Manager Perspectives. J Health Care Poor Underserved. 2019 May;30(2):789-805. doi: 10.1353/hpu.2019.0056. Exclusion Code: X1. 
198. Duenas M, Sow S, Poveda C, et al. Engaging the disengaged: outcomes of recruitment and enrollment of high-risk, high-utilizers into an intensive outpatient primary care program for complex care management. J Gen Intern Med. 2018;33(2):783-4. Exclusion Code: X1.

199. DuGoff EH, Boyd C, Anderson G. Complex Patients and Quality of Care in Medicare Advantage. J Am Geriatr Soc. 2020 Feb;68(2):395-402. doi: 10.1111/jgs. 16236. PMID: 31675101. Exclusion Code: X1.

200. DuGoff EH, Buckingham W, Kind AJ, et al. Targeting high-need beneficiaries in Medicare Advantage: opportunities to address medical and social needs. Issue Brief (Commonw Fund). 2019 Feb 1;2019:1-14. PMID: 30938944. Exclusion Code: X1.

201. Durand-Zaleski I. U.S.-France International Meeting on care for high-need, high-cost patients. Assistance Publique-Hôpitaux de Paris: Commonwealth Fund; 2015. Exclusion Code: $\mathrm{X} 7$.

202. Duru OK, Harwood J, Moin T, et al. Evaluation of a National Care Coordination Program to Reduce Utilization Among High-cost, High-need Medicaid Beneficiaries With Diabetes. Med Care. 2020 Jun;58 Suppl 6 Suppl 1:S14-s21. doi: 10.1097/mlr.0000000000001315. PMID: 32412949. Exclusion Code: X1.

203. Eden E, DeKosky A, Chen LW, et al. High utilizers of condition help: demographic and medical characteristics of patients who repeatedly activate rapid response teams. J Gen Intern Med. 2017;32(2):S205-S6. Exclusion Code: X1.

204. Edwards ST, Saha S, Prentice JC, et al. Preventing hospitalization with Veterans Affairs home-based primary care: which individuals benefit most? J Am Geriatr Soc. 2017 Aug;65(8):1676-83. doi: 10.1111/jgs.14843. PMID: 28323324. Exclusion Code: X1.

205. Englander H, Michaels L, Chan B, et al. The care transitions innovation (C-train) for socioeconomically disadvantaged adults, results of a clustered randomized controlled trial. J Gen Intern Med. 2014;29:S221-. Exclusion Code: X1.

206. Epstein DH, Preston KL. Does cannabis use predict poor outcome for heroin-dependent patients on maintenance treatment? Past findings and more evidence against. Addiction. 2003 Mar;98(3):269-79. PMID: 12603227. Exclusion Code: X1.

207. Etemad LR, McCollam PL. Predictors of highcost managed care patients with acute coronary syndrome. Curr Med Res Opin. 2005 Dec;21(12):1977-84. doi: 10.1185/030079905x74970. PMID: 16368049. Exclusion Code: X4.
208. Eton DT, Lee MK, St Sauver JL, et al. Knowngroups validity and responsiveness to change of the Patient Experience with Treatment and Selfmanagement (PETS vs. 2.0): a patient-reported measure of treatment burden. Qual Life Res. 2020 Nov;29(11):3143-54. doi: 10.1007/s11136020-02546-x. Exclusion Code: X1.

209. Ettner SL, Frank RG, McGuire TG, et al. Risk adjustment alternatives in paying for behavioral health care under Medicaid. Health Serv Res. 2001 Aug;36(4):793-811. PMID: 11508640. Exclusion Code: X1.

210. Faresjo A, Grodzinsky E, Foldevi M, et al. Patients with irritable bowel syndrome in primary care appear not to be heavy healthcare utilizers. Aliment Pharmacol Ther. 2006 Mar 15;23(6):807-14. doi: 10.1111/j.13652036.2006.02815.x. PMID: 16556183. Exclusion Code: X1.

211. Feinglass J, Norman G, Golden RL, et al. Integrating Social Services and Home-Based Primary Care for High-Risk Patients. Popul Health Manag. 2018 Apr;21(2):96-101. doi: 10.1089/pop.2017.0026. PMID: 28609187. Exclusion Code: X9.

212. Ferrari S, Galeazzi GM, Mackinnon A, et al. Frequent attenders in primary care: impact of medical, psychiatric and psychosomatic diagnoses. Psychother Psychosom. 2008;77(5):306-14. doi: 10.1159/000142523. PMID: 18600036. Exclusion Code: X1.

213. Fertel BS, Hart KW, Lindsell CJ, et al. Patients who use multiple EDs: quantifying the degree of overlap between ED populations. West J Emerg Med. 2015 Mar;16(2):229-33. doi: 10.5811/westjem.2015.1.22838. PMID: 25834661. Exclusion Code: X4.

214. Fertel BS, Podolsky SR, Mark J, et al. Impact of an individual plan of care for frequent and high utilizers in a large healthcare system. Am J Emerg Med. 2019. doi: 10.1016/j.ajem.2019.02.032. Exclusion Code: $\mathrm{X} 1$.

215. Figueroa JF, Joynt Maddox KE, Beaulieu N, et al. Concentration of potentially preventable spending among high-cost Medicare subpopulations: an observational study. Ann Intern Med. 2017 Nov 21;167(10):706-13. doi: 10.7326/m17-0767. Exclusion Code: X4.

216. Figueroa JF, Lyon Z, Zhou X, et al. Persistence and Drivers of High-Cost Status Among DualEligible Medicare and Medicaid Beneficiaries: An Observational Study. Ann Intern Med. 2018 Oct 16;169(8):528-34. doi: 10.7326/m18-0085. PMID: 30285049. Exclusion Code: X9. 
217. Filippi A, Sessa E, Pecchioli S, et al. Homecare for patients with heart failure in Italy. Ital Heart J. 2005 Jul;6(7):573-7. PMID: 16274019. Exclusion Code: X1.

218. Finkelstein AN. Health care hotspotting: a randomized controlled trial. Abdul Latif Jameel

Poverty Action Lab. Cooper University Hospital, Camden, New Jersey: 2014. Exclusion Code: X1.

219. Fiorentino M, Mulles S, Cue L, et al. High Acuity of Postoperative Consults to Emergency General Surgery at an Urban Safety Net Hospital. J Surg Res. 2021 Jan;257:50-5. doi: 10.1016/j.jss.2020.07.038. PMID: 32818784. Exclusion Code: X1.

220. Fisher HM, McCabe S. Managing chronic conditions for elderly adults: the VNS CHOICE model. Health Care Financ Rev. 2005 Fall;27(1):33-45. PMID: 17288076. Exclusion Code: $\mathrm{X} 1$.

221. Fitzpatrick T, Rosella LC, Calzavara A, et al. Looking Beyond Income and Education: Socioeconomic Status Gradients Among Future High-Cost Users of Health Care. Am J Prev Med. 2015 Aug;49(2):161-71. doi:

10.1016/j.amepre.2015.02.018. PMID:

25960393. Exclusion Code: X9.

222. Flarup L, Moth G, Christensen MB, et al. Chronic-disease patients and their use of out-ofhours primary health care: a cross-sectional study. BMC Fam Pract. 2014 Jun 9;15:114. doi: 10.1186/1471-2296-15-114. PMID: 24912378. Exclusion Code: X1.

223. Fleishman JA, Cohen JW. Using information on clinical conditions to predict high-cost patients. Health Serv Res. 2010 Apr;45(2):532-52. doi: 10.1111/j.1475-6773.2009.01080.x. PMID: 20132341. Exclusion Code: X1.

224. Fleming MD, Shim JK, Yen I, et al. Caring for "Super-utilizers": Neoliberal Social Assistance in the Safety-net. Med Anthropol Q. 2019 Jun;33(2):173-90. doi: 10.1111/maq. 12481. PMID: 30291726. Exclusion Code: X9.

225. Fleury MJ, Grenier G, Bamvita JM, et al. Professional service utilisation among patients with severe mental disorders. BMC Health Serv Res. 2010 May 27;10:141. doi: 10.1186/14726963-10-141. PMID: 20507597. Exclusion Code: $\mathrm{X} 1$.

226. Flottemesch TJ, Anderson LH, Solberg LI, et al. Patient-centered medical home cost reductions limited to complex patients. Am J Manag Care. 2012 Nov;18(11):677-86. PMID: 23198711. Exclusion Code: X1.
227. Flowers A, Shade K. Evaluation of a Multidisciplinary Care Coordination Program for Frequent Users of the Emergency Department. Prof Case Manag. 2019 Sep/Oct;24(5):230-9. doi: 10.1097/ncm.0000000000000368. PMID: 31373952. Exclusion Code: X1.

228. Flynn P, Ridgeway J, Wieland M, et al. Primary care utilization and mental health diagnoses among adult patients requiring interpreters: a retrospective cohort study. J Gen Intern Med. 2013;28(3):386-91. doi: 10.1007/s11606-0122159-5. Exclusion Code: X4.

229. Foebel AD, Hirdes JP, Heckman GA, et al. A profile of older community-dwelling home care clients with heart failure in Ontario. Chronic Dis Can. 2011 Mar;31(2):49-57. PMID: 21466754. Exclusion Code: X1.

230. Fondow M, Schreiter EZ, Thomas C, et al. Initial examination of characteristics of patients who are high utilizers of an established primary care behavioral health consultation service. Families Systems \& Health. 2017 Jun;35(2):184-92. doi: 10.1037/fsh0000266. Exclusion Code: X4.

231. Foo KM, Sundram M, Legido-Quigley H. Facilitators and barriers of managing patients with multiple chronic conditions in the community: a qualitative study. BMC Public Health. 2020 Feb;20(1):15. doi: 10.1186/s12889020-8375-8. Exclusion Code: X6.

232. Ford JD, Trestman RL, Steinberg K, et al. Prospective association of anxiety, depressive, and addictive disorders with high utilization of primary, specialty and emergency medical care. Soc Sci Med. 2004 Jun;58(11):2145-8. doi: 10.1016/j.socscimed.2003.08.017. PMID: 15047073. Exclusion Code: X4.

233. Ford JD, Trestman RL, Tennen H, et al. Relationship of anxiety, depression and alcohol use disorders to persistent high utilization and potentially problematic under-utilization of primary medical care. Soc Sci Med. 2005 Oct;61(7):1618-25. doi: 10.1016/j.socscimed.2005.03.017. Exclusion Code: X1.

234. Fordyce MA, Doescher MP, Skillman SM. The aging of the rural primary care physician workforce: will some locations be more affected than others? [Seattle, WA]: WWAMI Rural Health Research Center; 2013. Exclusion Code: $\mathrm{X} 1$.

235. Fortin M, Cao Z, Fleury MJ. A typology of satisfaction with mental health services based on Andersen's behavioral model. Soc Psychiatry Psychiatr Epidemiol. 2018 Jun;53(6):587-95. doi: 10.1007/s00127-018-1498-x. PMID: 29450599. Exclusion Code: X1. 
236. Franco RA, Ashwathnarayan R, Deshpandee A, et al. The high prevalence of restless legs syndrome symptoms in liver disease in an academic-based hepatology practice. J Clin Sleep Med. 2008 Feb 15;4(1):45-9. PMID: 18350962. Exclusion Code: X1.

237. Fraze TK, Beidler LB, Briggs ADM, et al. Translating Evidence into Practice: ACOs' Use of Care Plans for Patients with Complex Health Needs. JGIM: Journal of General Internal Medicine. 2021;36(1):147-53. doi: 10.1007/s11606-020-06122-4. Exclusion Code: $\mathrm{X} 1$.

238. Fraze TK, Briggs ADM, Whitcomb EK, et al. Role of Nurse Practitioners in Caring for Patients With Complex Health Needs. Med Care. 2020 Oct;58(10):853-60. doi: 10.1097/mlr.0000000000001364. Exclusion Code: X1.

239. Fruhauf J, Schwantzer G, Ambros-Rudolph CM, et al. Pilot study using teledermatology to manage high-need patients with psoriasis. Arch Dermatol. 2010 Feb;146(2):200-1. doi: 10.1001/archdermatol.2009.375. PMID: 20157037. Exclusion Code: X1.

240. Fuda KK, Immekus R. Frequent users of Massachusetts emergency departments: a statewide analysis. Ann Emerg Med. 2006 Jul;48(1):9-16. doi:

10.1016/j.annemergmed.2006.03.001. PMID: 16781915. Exclusion Code: X4.

241. Galbraith AA, Meyers DJ, Ross-Degnan D, et al. Long-Term Impact of a Postdischarge Community Health Worker Intervention on Health Care Costs in a Safety-Net System. Health Serv Res. 2017 Dec;52(6):2061-78. doi: 10.1111/1475-6773.12790. PMID: 29130267. Exclusion Code: X1.

242. Gallagher NA, Fox D, Dawson C, et al. Improving care transitions: complex highutilizing patient experiences guide reform. Am J Manag Care. 2017 Oct 1;23(10):e347-e52. PMID: 29087639. Exclusion Code: X1.

243. Gallagher S. Exploring supportive housing's impact on health and health care quality among high-cost, high-need populations. Corporation for Supportive Housing 2017.

https://www.commonwealthfund.org/grants/explo ring-supportive-housings-impact-health-andhealth-care-quality-among-high-cost-high. Exclusion Code: X7.

244. Garg T, Young AJ, Kost KA, et al. Burden of multiple chronic conditions among patients with urological cancer. J Urol. 2018 Feb;199(2):54350. doi: 10.1016/j.juro.2017.08.005. PMID: 28789948. Exclusion Code: X1.
245. Gastal FL, Andreoli SB, Quintana MI, et al. Predicting the revolving door phenomenon among patients with schizophrenic, affective disorders and non-organic psychoses. Rev Saude Publica. 2000 Jun;34(3):280-5. doi: 10.1590/s0034-89102000000300011. PMID: 10920451. Exclusion Code: X1.

246. Geisz M. A coalition creates a citywide care management system. Robert Wood Johnson Foundation. Princeton, NJ: 2014.

https://www.rwjf.org/en/library/research/2011/01 /a-coalition-creates-a-citywide-care-managementsystem-.html. Exclusion Code: X1.

247. Gelberg L, Andersen RM, Leake BD. The Behavioral Model for Vulnerable Populations: application to medical care use and outcomes for homeless people. Health Serv Res. 2000 Feb;34(6):1273-302. PMID: 10654830. Exclusion Code: X1.

248. Geurts J, Palatnick W, Strome T, et al. Frequent users of an inner-city emergency department. Cjem. 2012 Sep;14(5):306-13. doi:

10.2310/8000.2012.120670. PMID: 22967698. Exclusion Code: X1.

249. Giannouchos TV, Kum HC, Foster MJ, et al. Characteristics and predictors of adult frequent emergency department users in the United States: A systematic literature review. J Eval Clin Pract. 2019 Jun;25(3):420-33. doi: 10.1111/jep.13137. PMID: 31044484 . Exclusion Code: X7.

250. Giannouchos TV, Washburn DJ, Kum HC, et al. Predictors of Multiple Emergency Department Utilization Among Frequent Emergency Department Users in 3 States. Med Care. 2020 Feb;58(2):137-45. doi: 10.1097/mlr.0000000000001228. PMID: 31651740. Exclusion Code: X4.

251. Gingold DB, Pierre-Mathieu R, Cole B, et al. Impact of the Affordable Care Act Medicaid expansion on emergency department high utilizers with ambulatory care sensitive conditions: A cross-sectional study. Am J Emerg Med. 2017 May;35(5):737-42. doi: 10.1016/j.ajem.2017.01.014. PMID: 28110978. Exclusion Code: X1.

252. Glick M. Systematic approach for treating the medically complex dental patient. Alpha Omegan. 2001 Jul-Aug;94(2):40-3. PMID: 11480187. Exclusion Code: X1.

253. Goldstein KM, Zullig LL, Dedert EA, et al. Telehealth interventions designed for women: an evidence map. J Gen Intern Med. 2018;33(12):2191-200. doi: 10.1007/s11606-0184655-8. Exclusion Code: X1. 
254. Goodell S, Bodenheimer T, Berry-Millett R. Care management of patients with complex health care needs. Robert Wood Johnson Foundation. Princeton, NJ: 2009.

https://www.rwjf.org/en/library/research/2009/12 /care-management-of-patients-with-complexhealth-care-needs.html. Exclusion Code: X1.

255. Goodwin A, Henschen B, Nichols N, et al. Systematic review of interventions targeting high-utilizers of inpatient resources. J Gen Intern Med. 2018;33(2):352. Exclusion Code: X1.

256. Goodwin A, Henschen BL, O'Dwyer LC, et al. Interventions for frequently hospitalized patients and their effect on outcomes: a systematic review. J Hosp Med. 2018;13(12):853-9. doi: 10.12788/jhm.3090. Exclusion Code: X1.

257. Gore S, Lind A, Somers SA. Profiles of state innovation: roadmap for improving systems of care for dual eligibles. Hamilton, N.J.: Center for Health Care Strategies, Inc.; 2010. Exclusion Code: X1.

258. Gottlieb LM, Garcia K, Wing H, et al. Clinical interventions addressing nonmedical health determinants in Medicaid managed care. Am J Manag Care. 2016 May;22(5):370-6. PMID: 27266438. Exclusion Code: X7.

259. Grazioli VS, Moullin JC, Kasztura M, et al. Implementing a case management intervention for frequent users of the emergency department (I-CaM): an effectiveness-implementation hybrid trial study protocol. BMC Health Serv Res. 2019 Jan 11;19(1):28. doi: 10.1186/s12913-018-38529. PMID: 30634955. Exclusion Code: X1.

260. Greenberg P, Corey-Lisle PK, Birnbaum H, et al. Economic implications of treatment-resistant depression among employees.

Pharmacoeconomics. 2004;22(6):363-73. doi: 10.2165/00019053-200422060-00003. PMID: 15099122. Exclusion Code: X1.

261. Gregori D, Petrinco M, Barbati G, et al. Extreme regression models for characterizing high-cost patients. J Eval Clin Pract. 2009 Feb;15(1):16471. doi: 10.1111/j.1365-2753.2008.00976.x. PMID: 19239597. Exclusion Code: X9.

262. Grembowski D, Schaefer J, Johnson KE, et al. A conceptual model of the role of complexity in the care of patients with multiple chronic conditions. Med Care. 2014 Mar;52 Suppl 3:S7-s14. doi: 10.1097/mlr.0000000000000045. PMID: 24561762. Exclusion Code: X4.

263. Griffin JL, Yersin M, Baggio S, et al. Characteristics and predictors of mortality among frequent users of an emergency department in Switzerland. Eur J Emerg Med. 2018 Apr;25(2):140-6. doi: 10.1097/mej.0000000000000425. PMID: 27749377. Exclusion Code: X1.
264. Grinspan ZM, Shapiro JS, Abramson EL, et al. Predicting frequent ED use by people with epilepsy with health information exchange data. Neurology. 2015 Sep 22;85(12):1031-8. doi: 10.1212/wnl.0000000000001944. PMID: 26311752. Exclusion Code: X4.

265. Grover CA, Crawford E, Close RJ. The efficacy of case management on emergency department frequent users: an eight-year observational study. J Emerg Med. 2016 Nov;51(5):595-604. doi: 10.1016/j.jemermed.2016.06.002. PMID: 27595372. Exclusion Code: X1.

266. Grover CA, Sughair J, Stoopes S, et al. Case management reduces length of stay, charges, and testing in emergency department frequent users. West J Emerg Med. 2018 Mar;19(2):238-44. doi: 10.5811/westjem.2017.9.34710. PMID: 29560049. Exclusion Code: X1.

267. Gruneir A, Cigsar C, Wang X, et al. Repeat emergency department visits by nursing home residents: a cohort study using health administrative data. BMC Geriatr. $2018 \mathrm{Jul}$ 5;18(1):157. doi: 10.1186/s12877-018-0854-8. PMID: 29976135. Exclusion Code: X1.

268. Gudleski GD, Satchidanand N, Dunlap LJ, et al. Predictors of medical and mental health care use in patients with irritable bowel syndrome in the United States. Behav Res Ther. 2017 Jan;88:6575. doi: 10.1016/j.brat.2016.07.006. PMID: 28110677. Exclusion Code: X1.

269. Gundlapalli A, Hanks M, Stevens SM, et al. It takes a village: a multidisciplinary model for the acute illness aftercare of individuals experiencing homelessness. J Health Care Poor Underserved. 2005 May; 16(2):257-72. doi: 10.1353/hpu.2005.0033. PMID: 15937390. Exclusion Code: X3.

270. Gundlapalli AV, Jones AL, Redd A, et al. Characteristics of the highest users of emergency services in Veterans Affairs hospitals: homeless and non-homeless. Stud Health Technol Inform. 2017;238:24-7. Exclusion Code: X4.

271. Gunnarsdottir OS, Rafnsson V. Mortality of the users of a hospital emergency department. Emerg Med J. 2006 Apr;23(4):269-73. doi: 10.1136/emj.2005.026690. PMID: 16549571. Exclusion Code: X1.

272. Gupta ND, Greve J. Overweight and obesity and the utilization of primary care physicians. Health Econ. 2011 Sep;20 Suppl 1:53-67. doi: 10.1002/hec.1711. PMID: 21351183. Exclusion Code: X1. 
273. Gusmano MK, Rodwin VG, Weisz D. Medicare Beneficiaries Living In Housing With Supportive Services Experienced Lower Hospital Use Than Others. Health Aff (Millwood). 2018

Oct;37(10):1562-9. doi:

10.1377/hlthaff.2018.0070. PMID: 30273020.

Exclusion Code: X1.

274. Gyurmey T, Kwiatkowski J. Program of AllInclusive Care for the Elderly (PACE): Integrating Health and Social Care Since 1973. R I Med J (2013). 2019 Jun 4;102(5):30-2. PMID: 31167525. Exclusion Code: X1.

275. Haas LJ, Spendlove DC, Silver MP. Expanding mental health services to older high-utilizing HMO patients: a pilot study. J Clin Psychol Med Settings. 2001;8(3):189-97. doi: 10.1023/A:1011321704324. Exclusion Code: X1.

276. Hamblin A. Opportunity knocks to improve care for "super utilizers". CHCS Blog. Hamilton, New Jersey: Center for Health Care Strategies, Inc.; 2015. Exclusion Code: X1.

277. Hamblin A. Expanding an inventory of programs serving high-need, high-cost populations. Center for Health Care Strategies 2017.

https://hsrproject.nlm.nih.gov/view_hsrproj_recor d/20191185. Exclusion Code: X7.

278. Hamblin A, Davis R, Hunt K. Outreach to highneed, high-cost individuals: best practices for New York health homes. New York: New York State Health Foundation; 2014. Exclusion Code: $\mathrm{X} 1$.

279. Hammond S. Staying home after discharge: nurse-led versus physician-led transitional care models. Nurse Leader. 2015 Jun;13(3):66-+. doi: 10.1016/j.mnl.2014.09.012. Exclusion Code: X1.

280. Hand C, McColl MA, Birtwhistle R, et al. Social isolation in older adults who are frequent users of primary care services. Can Fam Physician. 2014 Jun;60(6):e322, e4-9. PMID: 24925967.

Exclusion Code: X1.

281. Hansagi H, Olsson M, Hussain A, et al. Is information sharing between the emergency department and primary care useful to the care of frequent emergency department users? Eur J Emerg Med. 2008 Feb;15(1):34-9. doi: 10.1097/MEJ.0b013e3282aa4115. PMID: 18180664. Exclusion Code: X1.

282. Hansagi H, Olsson M, Sjoberg S, et al. Frequent use of the hospital emergency department is indicative of high use of other health care services. Ann Emerg Med. 2001 Jun;37(6):561-7. doi: 10.1067/mem.2001.111762. PMID:

11385324. Exclusion Code: X1.
283. Hardie TL, Polek C, Wheeler E, et al. Characterising emergency department highfrequency users in a rural hospital. Emerg Med J. 2015 Jan;32(1):21-5. doi: 10.1136/emermed2013-202369. PMID: 24351523. Exclusion Code: $\mathrm{X} 4$.

284. Hardin L, Trumbo S, Murray V. What matters most in driving cross-sector partnerships for complex populations.[webinar]. The National Center for Complex Health and Social Needs; 2019. https://www.nationalcomplex.care/researchpolicy/resources/webinars/what-matters-most-indriving-cross-sector-partnerships-for-complexpopulations/. Exclusion Code: X1.

285. Haroun D, Smits F, van Etten-Jamaludin F, et al. The effects of interventions on quality of life, morbidity and consultation frequency in frequent attenders in primary care: a systematic review. European Journal of General Practice. 2016;22(2):71-82. doi: 10.3109/13814788.2016.1161751. Exclusion Code: X1.

286. Harrison C, Britt H, Miller G, et al. Examining different measures of multimorbidity, using a large prospective cross-sectional study in Australian general practice. BMJ Open. $2014 \mathrm{Jul}$ 11;4(7):e004694. doi: 10.1136/bmjopen-2013004694. PMID: 25015470. Exclusion Code: X1.

287. Hart KM. Coordinated care of medically complex individuals in an individual-centered medical home: the surprising case of Mr. and Mrs. W. J Am Geriatr Soc. 2015 Jan;63(1):173-4. doi: 10.1111/jgs.13186. PMID: 25597566. Exclusion Code: X1.

288. Hawes EM, Smith JN, Pinelli NR, et al. Accountable Care in Transitions (ACTion): a team-based approach to reducing hospital utilization in a patient-centered medical home. $\mathrm{J}$ Pharm Pract. 2018 Apr;31(2):175-82. doi: 10.1177/0897190017707118. PMID: 28468524. Exclusion Code: X1.

289. Hawkins EJ, Lott AMK, Malte CA, et al. Patients' perspectives on care management services for complex substance use disorders. J Addict Dis. 2017 Jul-Sep;36(3):193-206. doi: 10.1080/10550887.2017.1326654. PMID: 28481144. Exclusion Code: X11.

290. Hayes SL, McCarthy D. Care management plus: strengthening primary care for patients with multiple chronic conditions. Commonwealth Fund. 2016.

https://www.commonwealthfund.org/publications /case-study/2016/dec/care-management-plusstrengthening-primary-care-patients-multiple. Exclusion Code: X1. 
291. Hayes SL, Salzberg CA, McCarthy D, et al. High-need, high-cost patients: who are they and how do they use health care? A population-based comparison of demographics, health care use, and expenditures. Issue Brief (Commonw Fund). 2016 Aug;26:1-14. PMID: 27571599. Exclusion Code: X4

292. Heincelman M, Schumann SO, Riley J, et al. Identification of high utilization inpatients on internal medicine services. Am J Med Sci. 2016 Jul;352(1):63-70. doi:

10.1016/j.amjms.2016.04.020. PMID: 27432036. Exclusion Code: X1.

293. Hempstead K, Delia D, Cantor JC, et al. The fragmentation of hospital use among a cohort of high utilizers: implications for emerging care coordination strategies for patients with multiple chronic conditions. Med Care. 2014;52:S67-74. doi: 10.1097/MLR.0000000000000049.

Exclusion Code: X1.

294. Hempstead K, Delia D, Cantor JC, et al. Important study on high utilization released. Hotspot Blog. Camden, NJ: Camden Coalition; 2014. Exclusion Code: X4.

295. Hempstead K, Delia D, Cantor JC, et al. The fragmentation of hospital use among a cohort of high utilizers: implications for emerging care coordination strategies for patients with multiple chronic conditions. Med Care. 2014 Mar;52 Suppl 3:S67-74. doi:

10.1097/mlr.0000000000000049. PMID: 24561761. Exclusion Code: X4.

296. Henninger DE, Whitson HE, Cohen HJ, et al. Higher medical morbidity burden is associated with external locus of control. J Am Geriatr Soc. 2012 Apr;60(4):751-5. doi: 10.1111/j.15325415.2012.03904.x. PMID: 22458257. Exclusion Code: X1.

297. Henschen BL. Understanding perspectives of frequently-admitted hospital patients (CHAMP). Northwestern Memorial Hospital. Chicago: 2017. Exclusion Code: X1.

298. Henschen BL, Chapman M, Toms A, et al. The complex high admission management program (CHAMP): development and preliminary impact on hospital utilization. J Gen Intern Med. 2017;32(2):S799-S800. Exclusion Code: X1.

299. Henschen BL, Liss DT, Golden B, et al. The education centered medical home improves primary care training and may mitigate burnout: a randomized medical education trial. J Gen Intern Med. 2019;34(2):S370-. doi:

10.1007/11606.1525-1497. Exclusion Code: X1.
300. Hensel JM, Taylor VH, Fung K, et al. Unique characteristics of high-cost users of medical care with comorbid mental illness or addiction in a population-based cohort. Psychosomatics. 2018 Mar - Apr;59(2):135-43. doi: 10.1016/j.psym.2017.10.005. PMID: 29157683. Exclusion Code: X1.

301. Hewner S, Chen CH, Anderson L, et al. Transitional Care Models for High-Need, HighCost Adults in the United States A Scoping Review and Gap Analysis. Professional Case Management. 2021 Mar-Apr;26(2):82-98. doi: $10.1097 / \mathrm{ncm} .0000000000000442$. Exclusion Code: X9.

302. Hibbard JH, Greene J, Sacks R, et al. Adding a measure of patient self-management capability to risk assessment can improve prediction of high costs. Health Aff (Millwood). 2016

Mar;35(3):489-94. doi:

10.1377/hlthaff.2015.1031. PMID: 26953304. Exclusion Code: X1.

303. Hildebrandt DE, Westfall JM, Nicholas RA, et al. Are frequent callers to family physicians high utilizers? Ann Fam Med. 2004;2(6):546-8. doi: 10.1370/afm.127. Exclusion Code: X1.

304. Hochman M, Asch SM. Disruptive Models in Primary Care: Caring for High-Needs, High-Cost Populations. J Gen Intern Med. 2017 Apr;32(4):392-7. doi: 10.1007/s11606-016-39452. PMID: 28243870. Exclusion Code: X1.

305. Horrocks D, Kinzer D, Afzal S, et al. The adequacy of individual hospital data to identify high utilizers and assess community health. JAMA Intern Med. 2016;176(6):856-8. doi: 10.1001/jamainternmed.2016.1248. Exclusion Code: X1.

306. Horvath B, Silberberg M, Landerman LR, et al. Dynamics of patient targeting for care management in medicaid: a case study of the Durham Community Health Network. Care Management Journals. 2006 Fall2006;7(3):10714. Exclusion Code: X1.

307. Horwood H, Williams MJ, Mandic S. Examining motivations and barriers for attending maintenance community-based cardiac rehabilitation using the health-belief model. Heart Lung Circ. 2015 Oct;24(10):980-7. doi: 10.1016/j.hlc.2015.03.023. PMID: 25939724. Exclusion Code: X1.

308. Hostetter M, Klein S, McCarthy D. Aging gracefully: the PACE approach to caring for frail elders in the community. [New York, NY]: Commonwealth Fund; 2016. Exclusion Code: $\mathrm{X} 1$. 
309. Hostetter M, Klein S, McCarthy D. Project ECHO's Complex Care Initiative: building capacity to help "superutilizers" in underserved communities. Commonwealth Fund. 2016. https://www.commonwealthfund.org/publications /case-study/2016/aug/project-echos-complexcare-initiative-building-capacity-help. Exclusion Code: X1.

310. Hostetter M, Klein S, McCarthy D. CareMore: improving outcomes and controlling health care spending for high-needs patients. Commonwealth Fund. 2017.

https://www.commonwealthfund.org/publications /case-study/2017/mar/caremore-improvingoutcomes-and-controlling-health-care-spending. Exclusion Code: X1

311. Hostetter M, Klein S, McCarthy D, et al. Guided care: a structured approach to providing comprehensive primary care for complex patients. Commonwealth Fund. 2016. https://www.commonwealthfund.org/publications /case-study/2016/oct/guided-care-structuredapproach-providing-comprehensive-primary. Exclusion Code: X1.

312. Hsu KY, Slightam C, Shaw JG, et al. High-Need Patients' Goals and Goal Progress in a Veterans Affairs Intensive Outpatient Care Program. J Gen Intern Med. 2019 Aug;34(8):1564-70. doi: 10.1007/s11606-019-05010-w. PMID: 31140094. Exclusion Code: X1.

313. Hu J, Wang F, Sun J, et al. A healthcare utilization analysis framework for hot spotting and contextual anomaly detection. AMIA. Annual Symposium proceedings / AMIA Symposium. 2012;2012:360-9. Exclusion Code: $\mathrm{X} 1$.

314. $\mathrm{Hu} \mathrm{Z}$, Hao S, Jin B, et al. Online Prediction of Health Care Utilization in the Next Six Months Based on Electronic Health Record Information: A Cohort and Validation Study. J Med Internet Res. 2015 Sep 22;17(9):e219. doi: 10.2196/jmir.4976. PMID: 26395541. Exclusion Code: X1.

315. Huang JA, Lai CS, Tsai WC, et al. Determining factors of patient satisfaction for frequent users of emergency services in a medical center. J Chin Med Assoc. 2004 Aug;67(8):403-10. PMID: 15553800. Exclusion Code: X1.

316. Huang JA, Tsai WC, Chen YC, et al. Factors associated with frequent use of emergency services in a medical center. J Formos Med Assoc. 2003 Apr;102(4):222-8. PMID: 12833184. Exclusion Code: X1.
317. Huang JA, Weng RH, Tsai WC, et al. Analysis of emergency department utilization by elderly patients under National Health Insurance. Kaohsiung J Med Sci. 2003 Mar;19(3):113-20. doi: 10.1016/s1607-551x(09)70458-9. PMID: 12751871. Exclusion Code: X1.

318. Huang YY, Cheng SH. A community pharmacist home visit project for high utilizers under a universal health system: a preliminary assessment. Health Policy. 2019;123(4):373-8. doi: 10.1016/j.healthpol.2019.01.011. Exclusion Code: X1.

319. Hudon C, Chouinard MC, Diadiou F, et al. The Chronic Disease Self-Management Program: the experience of frequent users of health care services and peer leaders. Fam Pract. 2016 Apr;33(2):167-71. doi: 10.1093/fampra/cmw007. PMID: 26984994. Exclusion Code: X1.

320. Hudon C, Chouinard MC, Diadiou F, et al. Case management in primary care for frequent users of health care services with chronic diseases: a qualitative study of patient and family experience. Ann Fam Med. 2015 Nov;13(6):5238. doi: 10.1370/afm.1867. PMID: 26553891. Exclusion Code: X6.

321. Hudon C, Chouinard MC, Dubois MF, et al. Case management in primary care for frequent users of health care services: a mixed methods study. Ann Fam Med. 2018 May;16(3):232-9. doi: 10.1370/afm.2233. PMID: 29760027. Exclusion Code: X1.

322. Huffstetler AN, Phillips RL. Payment Structures That Support Social Care Integration With Clinical Care: Social Deprivation Indices and Novel Payment Models. Am J Prev Med. 2019 Dec;57(6):S82-S8. doi: 10.1016/j.amepre.2019.07.011. Exclusion Code: $\mathrm{X} 1$.

323. Hulen E, Laliberte A, Ono S, et al. "Eyes in the Home": Addressing Social Complexity in Veterans Affairs Home-Based Primary Care. J Gen Intern Med. 2021 Jan 11. doi: 10.1007/s11606-020-06356-2. Exclusion Code: $\mathrm{X} 1$.

324. Humowiecki M, Kuruna T, Sax R, et al. Blueprint for complex care: advancing the field of care for individuals with complex health and social needs. National Center for Complex Health and Social Needs: Center for Health Care Strategies, and Institute for Healthcare Improvement; 2018. Exclusion Code: X7.

325. Hwang AS, Liu SW, Yelibi C, et al. Characteristics of persistent emergency department high utilizers in a large primary care practice-based research network. J Gen Intern Med. 2014 Apr;29:S47-S. Exclusion Code: X4. 
326. Hyer JM, Ejaz A, Diaz A, et al. Characterizing and Assessing the Impact of Surgery on Healthcare Spending Among Medicare Enrolled Preoperative Super-utilizers. Ann Surg. 2019 Sep;270(3):554-63. doi: 10.1097/sla.0000000000003426. PMID: 31305286. Exclusion Code: X1.

327. Hyer JM, Tsilimigras DI, Gani F, et al. Factors associated with switching between low and super utilization in the surgical population: A study in medicare expenditure. Am J Surg. 2020 Jan;219(1):1-7. doi: 10.1016/j.amjsurg.2019.07.042. PMID: 31405521. Exclusion Code: X9.

328. International R. Evaluation of Medicare care management for high cost beneficiaries (CMHCB) demonstration second annual report.Centers for Medicare \& Medicaid Services; 2008. Exclusion Code: X1.

329. Iovan S, Lantz PM, Allan K, et al. Interventions to decrease use in prehospital and emergency care settings among super-utilizers in the United States: a systematic review. Med Care Res Rev. 2019 Apr 26:1077558719845722. doi: 10.1177/1077558719845722. Exclusion Code: $\mathrm{X} 1$.

330. Iovan S, Lantz PM, Allan K, et al. Interventions to decrease use in prehospital and emergency care settings among super-utilizers in the United States: a systematic review. Med Care Res Rev. 2020;77(2):99-111. doi: 10.1177/1077558719845722. Exclusion Code: $\mathrm{X} 7$.

331. Isasi F. Helping states achieve sustainable transformation of their health systems. National Governors Association Center for Best Practices: Commonwealth Fund; 2015. Exclusion Code: $\mathrm{X} 7$.

332. Ismail MS, Dagerman K, Tariot PN, et al. National Institute of Mental Health Clinical Antipsychotic Trials of Intervention Effectiveness- Alzheimer's Disease (CATIEAD): baseline characteristics. Curr Alzheimer Res. 2007 Jul;4(3):325-35. doi: 10.2174/156720507781077214. PMID: 17627490. Exclusion Code: X1.

333. Jackson TS, Moran TP, Lin J, et al. Homelessness Among Patients in a Southeastern Safety Net Emergency Department. South Med J. 2019 Sep;112(9):476-82. doi: 10.14423/smj.0000000000001016. PMID: 31485585. Exclusion Code: X1.
334. Jean Scholz Mellum DM, Greer Glazer, Grant Martsolf, Barbara Tobias. A mixed methods study of the experience of older adults with multimorbidity in a Care Coordination Program. International Journal of Care Coordination. 2018. Exclusion Code: X11.

335. Jiang HJ, Russo A, Barrett M. Nationwide frequency and costs of potentially preventable hospitalizations, 2006. [Rockville, Md.: Agency for Healthcare Research and Quality; 2009. Exclusion Code: X1.

336. Jimenez XF. Attachment in medical care: a review of the interpersonal model in chronic disease management. Chronic Illn. 2017 Mar;13(1):14-27. doi: 10.1177/1742395316653454. PMID: 27269506. Exclusion Code: X1.

337. Johnson D, Saavedra P, Sun E, et al. Community health workers and medicaid managed care in New Mexico. J Community Health. 2012 Jun;37(3):563-71. doi: 10.1007/s10900-0119484-1. PMID: 21953498. Exclusion Code: X1.

338. Johnson I. Alcohol problems in old age: a review of recent epidemiological research. Int J Geriatr Psychiatry. 2000 Jul;15(7):575-81. doi: 10.1002/1099-1166(200007)15:7<575::aidgps151>3.0.co;2-0. PMID: 10918336. Exclusion Code: X1.

339. Johnson TL, Rinehart DJ, Durfee J, et al. For many patients who use large amounts of health care services, the need is intense yet temporary. Health Aff (Millwood). 2015 Aug;34(8):1312-9. doi: 10.1377/hlthaff.2014.1186. PMID: 26240244. Exclusion Code: X4.

340. Johnston KJ, Hockenberry JM, Wadhera RK, et al. Clinicians With High Socially At-Risk Caseloads Received Reduced Merit-Based Incentive Payment System Scores. Health Aff (Millwood). 2020 Sep;39(9):1504-12. doi: 10.1377/hlthaff.2020.00350. Exclusion Code: $\mathrm{X} 1$.

341. Johnston KJ, Wen H, Joynt Maddox KE. Inadequate Risk Adjustment Impacts Geriatricians' Performance on Medicare Cost and Quality Measures. J Am Geriatr Soc. 2020 Feb;68(2):297-304. doi: 10.1111/jgs.16297. PMID: 31880310 . Exclusion Code: X1.

342. Johnston SS, Ammann EM, Kashyap SR, et al. Body mass index and insulin use as identifiers of high-cost patients with type 2 diabetes: A retrospective analysis of electronic health records linked to insurance claims data. Diabetes Obes Metab. 2019 Jun;21(6):1419-28. doi: 10.1111/dom.13671. PMID: 30768824. Exclusion Code: X1. 
343. Jones AL, Thomas R, Hedayati DO, et al. Patient predictors and utilization of health services within a medical home for homeless persons. Subst Abus. 2018;39(3):354-60. doi: 10.1080/08897077.2018.1437500. PMID: 29412071. Exclusion Code: X11.

344. Jones IR, Ahmed N, Kelly M, et al. With an attack I associate it more with going into hospital: understandings of asthma and psychosocial stressors; are they related to use of services? Soc Sci Med. 2008 Feb;66(3):765-75. doi: 10.1016/j.socscimed.2007.09.012. PMID: 18006131. Exclusion Code: X1.

345. Jorgenson DJ, Landry EJ, Lysak KJ. A mixed methods evaluation of a patient care clinic located within a pharmacy school. Int J Clin Pharm. 2016 Aug;38(4):924-30. doi: 10.1007/s11096-016-0313-6. PMID: 27166829. Exclusion Code: X1.

346. Joynt KE, Gawande AA, Orav EJ, et al. Contribution of preventable acute care spending to total spending for high-cost Medicare patients. JAMA. 2013 Jun 26;309(24):2572-8. doi: 10.1001/jama.2013.7103. PMID: 23797716. Exclusion Code: X9.

347. Jung D, Kind A, Robert S, et al. Linking neighborhood context and health in communitydwelling older adults in the Medicare Advantage program. J Am Geriatr Soc. 2018 Jul;66(6):115864. doi: 10.1111/jgs.15366. Exclusion Code: X1.

348. Kadakia K, McClellan M, Udadyakumar K, et al. Adapting promising innovations to meet the needs of high-need, high-cost populations. 2019. https://www.commonwealthfund.org/blog/2019/a dapting-promising-innovations-meet-needs-highneed-high-cost-populations. Exclusion Code: X1.

349. Kang-Lim TJY. Emergency Department: Effectiveness of a Referral Intervention for High Utilizers: George Fox University; 2014. Exclusion Code: X3.

350. Kaplowitz RA, Scranton RE, Gagnon DR, et al. Health care utilization and receipt of cholesterol testing by veterans with and those without mental illness. Gen Hosp Psychiatry. 2006 MarApr;28(2):137-44. doi: 10.1016/j.genhosppsych.2005.10.002. PMID: 16516064. Exclusion Code: X1.

351. Kapur N. Frequent attenders in primary care; 2007. Exclusion Code: X1.

352. Kapur N, Hunt I, MacFarlane G, et al. Childhood experience and health care use in adulthood nested case-control study. Br J Psychiatry. 2004 Aug;185:134-9. doi: 10.1192/bjp.185.2.134. Exclusion Code: X1.
353. Kaskie B, Wallace N, Kang S, et al. The implementation of managed behavioral healthcare in Colorado and the effects on older Medicaid beneficiaries. J Ment Health Policy Econ. 2006 Mar;9(1):15-24. PMID: 16733268. Exclusion Code: X1.

354. Katon W, Ciechanowski P. Impact of major depression on chronic medical illness. J Psychosom Res. 2002 Oct;53(4):859-63. doi: 10.1016/s0022-3999(02)00313-6. Exclusion Code: X1.

355. Katz A, Martens P, Chateau D, et al. Do primary care physicians coordinate ambulatory care for chronic disease patients in Canada? BMC Fam Pract. 2014 Aug 30;15:148. doi: 10.1186/14712296-15-148. PMID: 25175589. Exclusion Code: $\mathrm{X} 1$.

356. Kaushal R. Identifying and predicting patients with preventable high utilization. Joan \& Sanford I. Weill Medical College of Cornell University. New York: 2017. https://www.pcori.org/researchresults/2016/identifying-and-predicting-patientspreventable-high-utilization. Exclusion Code: X7.

357. Keeney T, Belanger E, Jones RN, et al. HighNeed Phenotypes in Medicare Beneficiaries: Drivers of Variation in Utilization and Outcomes. J Am Geriatr Soc. 2020 Jan;68(1):70-7. doi: 10.1111/jgs.16146. PMID: 31454082. Exclusion Code: X1.

358. Kehusmaa S, Autti-Ramo I, Helenius H, et al. Factors associated with the utilization and costs of health and social services in frail elderly patients. BMC Health Serv Res. 2012 Jul 19;12:204. doi: 10.1186/1472-6963-12-204. PMID: 22812588. Exclusion Code: X1.

359. Ken Coburn CG, Sophia Demuynck, Margaret Hawthorne. Replicating Effective Models Of Complex Care Management For Older Adults. Health Affairs Blog; 2017. Exclusion Code: X1.

360. Kern L. Developing indicators of care fragmentation that predict service utilization by high-need, high-cost patients. Cornell University, Weill Cornell Medical College, Department of Healthcare Policy and Research 2015. https:/www.ajmc.com/journals/issue/2018/2018vol24-n9/fragmented-ambulatory-care-andsubsequent-healthcare-utilization-amongmedicare-beneficiaries?p=4. Exclusion Code: X7.

361. Kim JJ, Kwok ESH, Cook OG, et al. Characterizing highly frequent users of a large Canadian urban emergency department. West J Emerg Med. 2018 Nov;19(6):926-33. doi: 10.5811/westjem.2018.9.39369. PMID: 30429923. Exclusion Code: X1. 
362. Kim TY, Mortensen K, Eldridge B. Linking uninsured patients treated in the emergency department to primary care shows some promise in Maryland. Health Aff (Millwood). 2015 May;34(5):796-804. doi: 10.1377/hlthaff.2014.1102. PMID: 25941281. Exclusion Code: X1.

363. Kimmel HJ, Brice YN, Trikalinos TA, et al. Real-time emergency department electronic notifications regarding high-risk patients: a systematic review. Telemedicine and e-Health. 2019;25(7):604-18. doi: 10.1089/tmj.2018.0117. Exclusion Code: X1.

364. Kirk C. Telephone follow-up of older people after hospital admissions. Curr Aging Sci. 2014;7(2):144-53. doi: 10.2174/1874609807666140804120331. PMID: 25101710. Exclusion Code: X1.

365. Kirkpatrick S, Agana DFG, Lynch K, et al. Emergency department high utilizers among family medicine patients. J Am Board Fam Med. 2019;32(2):264-8. doi: 10.3122/jabfm.2019.02.180184. Exclusion Code: X4.

366. Klein S, Hostetter M, McCarthy D. Bringing primary care home: the medical house call program at MedStar Washington Hospital Center. Commonwealth Fund. 2016.

https://www.commonwealthfund.org/publications /case-study/2016/jul/bringing-primary-carehome-medical-house-call-program-medstar. Exclusion Code: X1.

367. Klein S, Hostetter M, McCarthy D. The "one care" program at Commonwealth Care Alliance. Commonwealth Fund. 2016. https://www.commonwealthfund.org/publications /case-study/2016/dec/one-care-programcommonwealth-care-alliance. Exclusion Code: $\mathrm{X} 1$.

368. Klein S, Hostetter M, McCarthy D. Caring for high-need, high-cost patients: exemplars from the field. 2016.

https://www.commonwealthfund.org/blog/2016/c aring-high-need-high-cost-patients-exemplarsfield. Exclusion Code: X1.

369. Klompstra L, Ekdahl AW, Krevers B, et al. Factors related to health-related quality of life in older people with multimorbidity and high health care consumption over a two-year period. BMC Geriatr. 2019 Jul 5;19(1):187. doi: 10.1186/s12877-019-1194-Z. PMID: 31277674. Exclusion Code: X6.
370. Knowlton A, Weir BW, Hughes BS, et al. Patient demographic and health factors associated with frequent use of emergency medical services in a midsized city. Acad Emerg Med. 2013 Nov;20(11):1101-11. doi: 10.1111/acem. 12253. PMID: 24238312. Exclusion Code: X4.

371. Knox K, Schneider J, Gatmaitan V, et al. Breaking the cycle: a successful intervention for high utilizers on a general medicine service. J Gen Intern Med. 2017 Apr;32:S738-S9. Exclusion Code: X1.

372. Ko FW, Dai DL, Ngai J, et al. Effect of early pulmonary rehabilitation on health care utilization and health status in patients hospitalized with acute exacerbations of COPD. Respirology. 2011 May;16(4):617-24. doi: 10.1111/j.1440-1843.2010.01921.x. PMID: 21199163. Exclusion Code: X1.

373. Ko M, Lee Y, Chen C, et al. Prevalence of and predictors for frequent utilization of emergency department: a population-based study. Medicine (Baltimore). 2015 Jul;94(29):e1205. doi: 10.1097/md.0000000000001205. PMID: 26200638. Exclusion Code: X1.

374. Koball AM, Rasmussen C, Olson-Dorff D, et al. The relationship between adverse childhood experiences, healthcare utilization, cost of care and medical comorbidities. Child Abuse Negl. 2019;90:120-6. doi: 10.1016/j.chiabu.2019.01.021. Exclusion Code: $\mathrm{X} 1$.

375. Koch KL, Karafin MS, Simpson P, et al. Intensive management of high-utilizing adults with sickle cell disease lowers admissions. Am J Hematol. 2015 Mar;90(3):215-9. doi: 10.1002/ajh.23912. PMID: 25469750. Exclusion Code: X4.

376. KPMG Government Institute. Investing in social services as a core strategy for healthcare organizations: developing the business case. Commonwealth Fund. 2018. https://www.commonwealthfund.org/publications /other-publication/2018/mar/investing-socialservices-core-strategy-healthcare. Exclusion Code: X1.

377. Kramer W. How employers are improving care and lowering costs for complex patients. Commonwealth Fund; 2016. Exclusion Code: $\mathrm{X} 1$.

378. Kreuter MW, Garg R, Li L, et al. How Do Social Needs Cluster Among Low-Income Individuals? Popul Health Manag. 2020 Sep 1;24(3):322-32. doi: 10.1089/pop.2020.0107. PMID: 32877298. Exclusion Code: X11. 
379. Krieg C, Hudon C, Chouinard MC, et al. Individual predictors of frequent emergency department use: a scoping review. BMC Health Serv Res. 2016 Oct 20;16(1):594. doi: 10.1186/s12913-016-1852-1. PMID: 27765045. Exclusion Code: X1.

380. Kromka W, Simpson S. A Narrative Review of Predictors of Adult Mental Health Emergency Department Return Visits and Interventions to Reduce Repeated Use. J Emerg Med. 2019 Nov;57(5):671-82. doi: 10.1016/j.jemermed.2019.08.005. PMID: 31610908. Exclusion Code: X7.

381. Krupski BJCDMCZA. Predictive Risk Intelligence System (Prism): A Decision-Support Tool for Coordinating Care for Complex Medicaid Client. Comprehensive Care Coordination for Chronically Ill Adults. 2011. Exclusion Code: X11.

382. Ku BS, Fields JM, Santana A, et al. The urban homeless: super-users of the emergency department. Popul Health Manag. 2014 Dec;17(6):366-71. doi: 10.1089/pop.2013.0118. PMID: 24865472. Exclusion Code: X4.

383. Kuek BJW, Li H, Yap S, et al. Characteristics of frequent users of emergency medical services in Singapore. Prehosp Emerg Care. 2019 MarApr;23(2):215-24. doi: 10.1080/10903127.2018.1484969. PMID: 30118627. Exclusion Code: X1.

384. Kujanp T, Ylisaukko-Oja T, Jokelainen J, et al. Prevalence of anxiety disorders among Finnish primary care high utilizers and validation of Finnish translation of GAD-7 and GAD-2 screening tools. Scand J Prim Health Care. 2014;32(2):78-83. doi:

10.3109/02813432.2014.920597. Exclusion Code: X1.

385. Kuluski K, Gandhi S, Diong C, et al. Patterns of community follow-up, subsequent health service use and survival among young and mid-life adults discharged from chronic care hospitals: a retrospective cohort study. BMC Health Serv Res. 2016 Aug 13;16(1):382. doi: 10.1186/s12913-016-1631-z. PMID: 27522347. Exclusion Code: X1.

386. Kumar GS, Klein R. Effectiveness of case management strategies in reducing emergency department visits in frequent user patient populations: a systematic review. J Emerg Med. 2013 Mar;44(3):717-29. doi: 10.1016/j.jemermed.2012.08.035. Exclusion Code: X1.
387. Kurdyak P, Newman A, Segal Z. Impact of mindfulness-based cognitive therapy on health care utilization: a population-based controlled comparison. J Psychosom Res. 2014;77(2):85-9. doi: 10.1016/j.jpsychores.2014.06.009. Exclusion Code: X1.

388. Kurpas D, Szwamel K, Mroczek B. Frequent attenders with chronic respiratory diseases in primary care settings. 2016. p. 17-29. Exclusion Code: X1.

389. Kwakkenbos L, Bluyssen SJ, Vonk MC, et al. Addressing patient health care demands in systemic sclerosis: pre-post assessment of a psycho-educational group programme. Clin Exp Rheumatol. 2011 Mar-Apr;29(2 Suppl 65):S60-5. PMID: 21586220. Exclusion Code: X1.

390. Labby D, Wright B, Broffman L, et al. Drivers of High-cost Medical Complexity in a Medicaid Population. Med Care. 2020 Mar;58(3):208-15. doi: 10.1097/mlr.0000000000001261. PMID: 31876646. Exclusion Code: X9.

391. LaCalle E, Rabin E. Frequent users of emergency departments: the myths, the data, and the policy implications. Ann Emerg Med. 2010

Jul;56(1):42-8. doi: 10.1016/j.annemergmed.2010.01.032. PMID: 20346540. Exclusion Code: X1.

392. LaFleur J, Fowler MA, McBeth C, et al. Incidence of drug-related problems among Medicaid high utilizers as identified by clinicallytrained pharmacist reviewers. Pharmacotherapy. 2005 Mar;25(3):472-. Exclusion Code: X1.

393. LaFleur J, McBeth C, Gunning K, et al. Prevalence of drug-related problems and costsavings opportunities in Medicaid high utilizers identified by a pharmacist-run drug regimen review center. J Manag Care Pharm. 2006;12(8):677-85. doi: 10.18553/jmcp.2006.12.8.677. Exclusion Code: $\mathrm{X} 1$.

394. Lally K, Tuya Fulton A, Ducharme C, et al. Using Nurse Care Managers Trained in the Serious Illness Conversation Guide to Increase Goals-of-Care Conversations in an Accountable Care Organization. J Palliat Med. 2020;23(1):112-5. doi: 10.1089/jpm.2019.0110. Exclusion Code: X1.

395. Lantz PM. "Super-utilizer" interventions: what they reveal about evaluation research, wishful thinking, and health equity. Milbank Q. $2020 \mathrm{Feb}$ 7;98(1):31-4. doi: 10.1111/1468-0009.12449. PMID: 32030820. Exclusion Code: X1. 
396. Lauffenburger JC, Mahesri M, Choudhry NK. Not there yet: using data-driven methods to predict who becomes costly among low-cost patients with type 2 diabetes. BMC Endocr Disord. 2020;20(1):N.PAG-N.PAG. doi: 10.1186/s12902-020-00609-1. Exclusion Code: X9.

397. Law DD, Crane DR, Berge JM. The influence of individual, marital, and family therapy on high utilizers of health care. J Marital Fam Ther. 2003 Jul;29(3):353-63. doi: 10.1111/j.17520606.2003.tb01212.x. PMID: 12870409. Exclusion Code: X1.

398. LaWall E, Wu YY, Fan VY, et al. Living Alone and Homelessness as Predictors of 30-Day Potentially Preventable Hospital Readmission. Prev Chronic Dis. 2019 Feb 7;16:E16. doi: 10.5888/pcd16.180189. PMID: 30730829. Exclusion Code: X1.

399. LeClair AM, Sweeney M, Yoon GH, et al. Patients' Perspectives on Reasons for Unplanned Readmissions. J Healthc Qual. 2019

Jul/Aug;41(4):237-42. doi: 10.1097/jhq.0000000000000160. PMID: 30180043. Exclusion Code: X1.

400. Ledoux Y, Minner P. Occasional and frequent repeaters in a psychiatric emergency room. Soc Psychiatry Psychiatr Epidemiol. 2006 Feb;41(2):115-21. doi: 10.1007/s00127-0050010-6. PMID: 16508721. Exclusion Code: X1.

401. Lee JY, Muratov S, Tarride JE, et al. Managing High-Cost Healthcare Users: The International Search for Effective Evidence-Supported Strategies. J Am Geriatr Soc. 2018 May;66(5):1002-8. doi: 10.1111/jgs.15257. PMID: 29427509. Exclusion Code: X6.

402. Lee KH, Davenport L. Can case management interventions reduce the number of emergency department visits by frequent users? Health Care Manag (Frederick). 2006 Apr-Jun;25(2):155-9. PMID: 16699330. Exclusion Code: X1.

403. Legault F, Humbert J, Amos S, et al. Difficulties encountered in collaborative care: logistics trumps desire. J Am Board Fam Med. 2012 MarApr;25(2):168-76. doi: 10.3122/jabfm.2012.02.110153. PMID: 22403197. Exclusion Code: X1.

404. Legramante JM, Morciano L, Lucaroni F, et al. Frequent use of emergency departments by the elderly population when continuing care is not well established. PLoS One.

2016;11(12):e0165939. doi:

10.1371/journal.pone.0165939. PMID:

27973563. Exclusion Code: X1.
405. Leininger L, Avery K. The capacity of selfreported health measures to predict high-need Medicaid enrollees. Princeton, NJ: Robert Wood Johnson Foundation; 2015. Exclusion Code: X4.

406. Leininger LJ, Friedsam D, Voskuil K, et al. Predicting high-need cases among new Medicaid enrollees. Am J Manag Care. 2014 Sep 1;20(9):e399-407. PMID: 25364876. Exclusion Code: X1.

407. Lenz O, Sadhu S, Fornoni A, et al. Overutilization of central venous catheters in incident hemodialysis patients: reasons and potential resolution strategies. Semin Dial. 2006 Nov-Dec;19(6):543-50. doi: 10.1111/j.1525139X.2006.00220.x. PMID: 17150058. Exclusion Code: X1.

408. Leporatti L, Ameri M, Trinchero C, et al. Targeting frequent users of emergency departments: prominent risk factors and policy implications. Health Policy. 2016 May;120(5):462-70. doi: 10.1016/j.healthpol.2016.03.005. PMID: 27033015. Exclusion Code: X1.

409. Levin S, Brown D, Hernandez E. Contra Costa Health Services whole person care (CommunityConnect) program evaluation (CCHS-WPC). Contra Costa Health Services. 2019. https://clinicaltrials.gov/ct2/show/record/NCT040 00074?term $=$ NCT04000074\&draw $=2 \&$ rank $=1$. Exclusion Code: X7.

410. Levinson CM, Druss BG. Health beliefs and depression in a group of elderly high utilizers of medical services. Gen Hosp Psychiatry. 2005;27(2):97-9. doi: 10.1016/j.genhosppsych.2004.09.010. Exclusion Code: X4.

411. Levy C, Balogh S, Perkins E. Realizing the potential of rehabilitative care for people with complex health conditions: the time is now. Healthc Q. 2016;19(2):49-54. PMID: 27700974. Exclusion Code: X1.

412. Lewis C, Shah A, Abrams MK, et al. Sick and struggling: high-need adults with financial difficulties have worse access to the quality care they need. 2018.

https://www.commonwealthfund.org/blog/2018/s ick-and-struggling-high-need-adults-financialdifficulties-have-worse-access-quality. Exclusion Code: X4. 
413. Lewis C, Shah T, Abrams MK. Sick and alone: high-need, socially isolated adults have more problems, but less support. Commonwealth Fund. 2018.

https://www.commonwealthfund.org/blog/2018/s ick-and-alone-high-need-socially-isolated-adultshave-more-problems-less-support. Exclusion Code: X1.

414. Lewis VA, Larson BK, McClurg AB, et al. The promise and peril of accountable care for vulnerable populations: a framework for overcoming obstacles. Health Aff (Millwood). 2012 Aug;31(8):1777-85. doi:

10.1377/hlthaff.2012.0490. PMID: 22869656.

Exclusion Code: X1.

415. Li DR, Brennan JJ, Kreshak AA, et al. Patients Who Leave the Emergency Department Without Being Seen and Their Follow-Up Behavior: A Retrospective Descriptive Analysis. J Emerg Med. 2019;57(1):106-13. doi: 10.1016/j.jemermed.2019.03.051. Exclusion Code: X9.

416. Li Z, Newton-Dame R, Tatem K, et al. Homegrown safety net system predictive model for risk stratification: Assessing potential racial bias. Health Serv Res. 2020;55(SUPPL 1):76. doi: 10.1111/1475-6773.13435. Exclusion Code: $\mathrm{X} 1$.

417. Lichtenberg P, Levinson D, Sharshevsky Y, et al. Clinical case management of revolving door patients - a semi-randomized study. Acta Psychiatr Scand. 2008 Jun;117(6):449-54. doi: 10.1111/j.1600-0447.2008.01170.x. PMID: 18331577. Exclusion Code: X4.

418. Lim A, Warning W. The role of a pharmacist in a super-utilizer care coordination team. Journal of Interprofessional Education and Practice. 2016;3:23-7. doi: 10.1016/j.xjep.2016.03.007. Exclusion Code: X1.

419. Lin S, Zhang Q, Chen F, et al. Smooth Bayesian network model for the prediction of future highcost patients with COPD. Int J Med Inform. 2019 Jun;126:147-55. doi: 10.1016/j.ijmedinf.2019.03.017. PMID: 31029256. Exclusion Code: X6.

420. Lin WC, Bharel M, Zhang J, et al. Frequent emergency department visits and hospitalizations among homeless people with Medicaid: implications for Medicaid expansion. Am J Public Health. 2015 Nov;105(Suppl 5):S716-22. doi: 10.2105/ajph.2015.302693. PMID:

26447915. Exclusion Code: X1.
421. Lindsay A, Hibbard JH, Boothroyd DB, et al. Patient activation changes as a potential signal for changes in health care costs: cohort study of US high-cost patients. J Gen Intern Med. 2018;33(12):2106-12. doi: 10.1007/s11606-0184657-6. Exclusion Code: X9.

422. Lines L, Ash A. Predictors of potentially avoidable emergency department visits: a systematic review. 2012. Exclusion Code: X7.

423. Lipsitt DR. Characteristics of patient-doctor relationships with somatizing patients. International Congress Series. 2006;1287:374-7. doi: 10.1016/j.ics.2005.12.036. Exclusion Code: $\mathrm{X} 1$.

424. Liss DT, Schaeffer-Pettigrew C, Finch E, et al. A randomized comparative effectiveness trial of a transitional care clinic: 180-day effects. J Gen Intern Med. 2017;32(2):S100. Exclusion Code: $\mathrm{X} 1$.

425. Little P, Somerville J, Williamson I, et al. Psychosocial, lifestyle, and health status variables in predicting high attendance among adults. $\mathrm{Br} \mathrm{J}$ Gen Pract. 2001 Dec;51(473):987-94. PMID: 11766871. Exclusion Code: X1.

426. Lloyd J. Opportunities to Advance Complex Care in Rural and Frontier Areas. . Center for Health Care Strategies. 2019.

https://www.chcs.org/resource/opportunities-toadvance-complex-care-in-rural-and-frontierareas/?utm_source $=$ CHCS + Email+Updates\&utm campaign $=9 \mathrm{c} 4 \mathrm{f} 67 \mathrm{c} 292$ -

TCC+Rural+brief $+05 \% 2 \mathrm{~F} 09 \% 2 \mathrm{~F} 19 \&$ utm_mediu $\mathrm{m}=$ email\&utm term $=0$ bbced $451 \mathrm{bf}-9 \mathrm{c} 4 \mathrm{f} \overline{6} 7 \mathrm{c} 292$ 157172209. Exclusion Code: X7.

427. Locke SE, Ford P, McLaughlin T. A comparative cost analysis of participating versus nonparticipating somatizing patients referred to a behavioral medicine group in a health maintenance organization. Disease Management \& Health Outcomes. 2003;11(5):327-35. Exclusion Code: X1.

428. Locker TE, Baston S, Mason SM, et al. Defining frequent use of an urban emergency department. Emerg Med J. 2007 Jun;24(6):398-401. doi: 10.1136/emj.2006.043844. PMID: 17513534. Exclusion Code: X1.

429. Loeb DF, Monson SP, Lockhart S, et al. Mixed method evaluation of Relational Team Development (RELATED) to improve teambased care for complex patients with mental illness in primary care. BMC Psychiatry. 2019;19. doi: 10.1186/s12888-019-2294-1. Exclusion Code: X1.

430. Long P. An untapped opportunity for health care progress: redesigning care for high-need patients. Health Affairs BLOG. Bethesda, MD: Health Affairs; 2018. Exclusion Code: X1. 
431. Low LL, Vasanwala FF, Ng LB, et al.

Effectiveness of a transitional home care program in reducing acute hospital utilization: a quasiexperimental study. BMC Health Serv Res. 2015 Mar 14;15:100. doi: 10.1186/s12913-015-0750-2. PMID: 25888830. Exclusion Code: X1.

432. Luciano JV, Fernandez A, Pinto-Meza A, et al. Frequent attendance in primary care: comparison and implications of different definitions. $\mathrm{Br} \mathrm{J}$ Gen Pract. 2010 Feb;60(571). doi: 10.3399/bjgp10X483139. Exclusion Code: X1.

433. Lyles JS, Hodges A, Collins C, et al. Using nurse practitioners to implement an intervention in primary care for high-utilizing patients with medically unexplained symptoms. Gen Hosp Psychiatry. 2003 Mar-Apr;25(2):63-73. PMID: 12676418. Exclusion Code: X4.

434. Machlin SR, Cohen SB, Yu W. Health care access and expenditures among non-elderly adults with multiple chronic conditions: variations by insurance coverage status, 2007-08 (average annual). [Rockville, Md.: Agency for Healthcare Research and Quality; 2011. Exclusion Code: X4.

435. Mackelprang JL, Collins SE, Clifasefi SL. Housing first is associated with reduced use of emergency medical services. Prehosp Emerg Care. 2014;18(4):476-82. doi: 10.3109/10903127.2014.916020. Exclusion Code: X1.

436. Maeng DD, Hao J, Bulger JB. Patterns of multiple emergency department visits: do primary care physicians matter? Perm J. 2017;21:16-063. doi: 10.7812/tpp/16-063. PMID: 28333606. Exclusion Code: X4.

437. Maier T. Psychosocial and psychodynamic factors influencing health care utilisation. Health Care Anal. 2006 Jun;14(2):69-78. doi: 10.1007/s10728-006-0013-9. Exclusion Code: $\mathrm{X} 1$.

438. Malmstrom T, Peltokorpi A, Lappalainen M, et al. Constructing a framework to manage high utilizers in health and social care; 2015.

Exclusion Code: X1.

439. Malone DK, Collins SE, Clifasefi SL. Single-site housing first for chronically homeless people. Housing, Care and Support. 2015;18(2):62-6. doi: 10.1108/HCS-05-2015-0007. Exclusion Code: $\mathrm{X} 1$.

440. . Identifying Super Utilizers CHCS SuperUtilizer Summit; 2013. 11585. Exclusion Code: $\mathrm{X} 1$.
441. Mancuso D. Supporting Delivery System Transformation Through Data Integration and Analytics. 2016. https://www.milbank.org/resources/supportingdelivery-system-transformation-data-integrationanalytics-2/. Exclusion Code: X4.

442. Mandelberg JH, Kuhn RE, Kohn MA. Epidemiologic analysis of an urban, public emergency department's frequent users. Acad Emerg Med. 2000 Jun;7(6):637-46. doi: 10.1111/j.1553-2712.2000.tb02037.x. PMID: 10905642. Exclusion Code: X1.

443. Mantwill S, Schulz PJ. Low health literacy and healthcare utilization among immigrants and nonimmigrants in Switzerland. Patient Educ Couns. 2017 Nov;100(11):2020-7. doi: 10.1016/j.pec.2017.05.023. PMID: 28559092. Exclusion Code: X1.

444. Margaret Trinity MBD, and Michael Bailit, Bailit Health. Integrating Health Care and Social Services: Moving from Concept to Practice. State Health \& Value Strategies 2016. Exclusion Code: X7.

445. Martin BC, Ganguly R, Pannicker S, et al. Utilization patterns and net direct medical cost to Medicaid of irritable bowel syndrome. Curr Med Res Opin. 2003;19(8):771-80. doi: 10.1185/030079903125002540. PMID: 14687449. Exclusion Code: X1.

446. Martin J, Martin A, Schultz C, et al. Innovations in care delivery: embedding civil legal aid services in care for high-utilizing patients using medical-legal partnership. Health Affairs BLOG. Bethesda, Maryland: Health Affairs; 2015. Exclusion Code: X1.

447. Master RJ, Eng C. Integrating acute and longterm care for high-cost populations. Health Aff (Millwood). 2001 Nov-Dec;20(6):161-72. doi: 10.1377/hlthaff.20.6.161. PMID: 11816654. Exclusion Code: X9.

448. Mate K. High-need, high-cost playbook version 3.0. Institute for Healthcare Improvement 2018. https://hsrproject.nlm.nih.gov/view_hsrproj_recor d/20191318. Exclusion Code: X7.

449. Mateo-Abad M, Fullaondo A, Merino M, et al. Impact Assessment of an Innovative Integrated Care Model for Older Complex Patients with Multimorbidity: The CareWell Project. International Journal of Integrated Care. 2020 Apr-Jun;20(2):11. doi: 10.5334/ijic.4711. Exclusion Code: X6.

450. Mathews SN, Lamm R, Yang J, et al. Factors associated with repeated health resource utilization in patients with diverticulitis. $\mathrm{J}$ Gastrointest Surg. 2017 Jan;21(1):112-20. doi: 10.1007/s11605-016-3245-5. PMID: 27613732. Exclusion Code: X4. 
451. Mautner D, Peterson B, Cunningham A, et al. How Multidimensional Health Locus of Control predicts utilization of emergency and inpatient hospital services. J Health Psychol. 2017

Mar;22(3):314-23. doi:

10.1177/1359105315603468. PMID: 26430065. Exclusion Code: X1.

452. McCabe BK, Potash D, Omohundro E, et al. Seven-month pilot of an integrated, continuous evaluation, and quality improvement system for a state-based home-visiting program. Matern Child Health J. 2012 Oct;16(7):1401-12. doi: 10.1007/s10995-011-0905-7. PMID: 22246712. Exclusion Code: X1.

453. McCarthy D, Ryan J, Klein S. Models of care for high-need, high-cost patients: an evidence synthesis. Commonwealth Fund. 2015. https://www.commonwealthfund.org/publications /issue-briefs/2015/oct/models-care-high-needhigh-cost-patients-evidence-synthesis. Exclusion Code: X1.

454. McConville S, Raven MC, Sabbagh SH, et al. Frequent emergency department users: a statewide comparison before and after Affordable Care Act implementation. Health Aff (Millwood). 2018 Jun;37(6):881-9. doi: 10.1377/hlthaff.2017.0784. PMID: 29863931. Exclusion Code: X4.

455. McGarrahan AG. A comparison of psychosocial and health characteristics of medical high utilizers and medical low utilizers in primary health care: ProQuest Information \& Learning; 2001. Exclusion Code: X1.

456. McHugh J, Belanger E, Manning D, et al. The care of high-need patient populations: Findings from a 2 year study of high-performing hospitals. Implement Sci. 2020 May; 15:2. Exclusion Code: X9.

457. McKenzie R, Williamson M, Roberts R. Who uses the 'after hours GP helpline'? A profile of users of an after-hours primary care helpline. Aust Fam Physician. 2016 May;45(5):313-8. PMID: 27166469. Exclusion Code: X1.

458. McLeod CC. Initial Assessment of High Utilizers of Emergency Department Services. Shepherd University, ProQuest Dissertations Publishing,; 2018. Exclusion Code: X3.

459. McMahon CG, Power Foley M, Robinson D, et al. High prevalence of frequent attendance in the over 65s. Eur J Emerg Med. 2018 Feb;25(1):537. doi: 10.1097/mej.0000000000000406. PMID: 27139928. Exclusion Code: X1.
460. Mechanic R. Testing strategies to improve healthcare for high-need, high-cost (HNHC) individuals: planning phase. Institute for Accountable Care 2018.

https://hsrproject.nlm.nih.gov/view_hsrproj_recor d/20191416. Exclusion Code: X7.

461. Meenan RT, Goodman MJ, Fishman PA, et al. Using risk-adjustment models to identify highcost risks. Med Care. 2003 Nov;41(11):1301-12. doi: 10.1097/01.Mlr.0000094480.13057.75. PMID: 14583693. Exclusion Code: X1.

462. Mehl-Madrona LE. Prevalence of psychiatric diagnoses among frequent users of rural emergency medical services. Can J Rural Med. 2008 Winter;13(1):22-30. PMID: 18208649. Exclusion Code: X1.

463. Melanie Bella CS, Karen LLanos, Stephen A. Somers. Purchasing Strategies to Improve Care Management for Complex Populations: A National Scan of State Purchasers. Center for Health Care Strategies: Strategies CfHC; 2008. https://www.chcs.org/resource/purchasingstrategies-to-improve-care-management-forcomplex-populations-a-national-scan-of-statepurchasers/. Exclusion Code: X7.

464. Meng X, Muggli T, Baetz M, et al. Disordered lives: life circumstances and clinical characteristics of very frequent users of emergency departments for primary mental health complaints. Psychiatry Res. 2017 Jun;252:9-15. doi: 10.1016/j.psychres.2017.02.044. PMID: 28237761. Exclusion Code: X1.

465. Mercer T, Bae J, Kipnes J, et al. The highest utilizers of care: individualized care plans to coordinate care, improve healthcare service utilization, and reduce costs at an academic tertiary care center. J Hosp Med. 2015;10(7):41924. doi: 10.1002/jhm.2351. Exclusion Code: X1.

466. Meyers DJ, Belanger E, Joyce N, et al. Analysis of Drivers of Disenrollment and Plan Switching Among Medicare Advantage Beneficiaries. JAMA Intern Med. 2019 Apr 1;179(4):524-32. doi: 10.1001/jamainternmed.2018.7639. PMID: 30801625. Exclusion Code: X1.

467. Middleton A, Woodward A, Gunn J, et al. How do frequent users of crisis helplines differ from other users regarding their reasons for calling? Results from a survey with callers to Lifeline, Australia's national crisis helpline service. Health Soc Care Community. 2017 May;25(3):1041-9. doi: 10.1111/hsc.12404. PMID: 27862572.

Exclusion Code: X1. 
468. Miller JB, Brauer E, Rao H, et al. The most frequent ED patients carry insurance and a significant burden of disease. Am J Emerg Med. 2013 Jan;31(1):16-9. doi:

10.1016/j.ajem.2012.05.001. PMID: 22795986. Exclusion Code: X4.

469. Minassian A, Vilke GM, Wilson MP. Frequent emergency department visits are more prevalent in psychiatric, alcohol abuse, and dual diagnosis conditions than in chronic viral illnesses such as hepatitis and human immunodeficiency virus. $\mathrm{J}$ Emerg Med. 2013 Oct;45(4):520-5. doi: 10.1016/j.jemermed.2013.05.007. PMID: 23845528. Exclusion Code: X4.

470. Mishra S, Gregson M, Lalumiere ML. Framing effects and risk-sensitive decision making. Br J Psychol. 2012 Feb;103(1):83-97. doi: 10.1111/j.2044-8295.2011.02047.x. PMID: 22229776. Exclusion Code: X1.

471. Mitton CR, Adair CE, McDougall GM, et al. Continuity of care and health care costs among persons with severe mental illness. Psychiatr Serv. 2005 Sep;56(9):1070-6. doi: 10.1176/appi.ps.56.9.1070. PMID: 16148319. Exclusion Code: X1.

472. Moe J, Bailey AL, Oland R, et al. Defining, quantifying, and characterizing adult frequent users of a suburban Canadian emergency department. Cjem. 2013 Jul;15(4):214-26. doi: 10.2310/8000.2013.130936. PMID: 23777993. Exclusion Code: X1.

473. Moe J, Kirkland SW, Rawe E, et al. Effectiveness of interventions to decrease emergency department visits by adult frequent users: a systematic review. Acad Emerg Med. 2017 Jan;24(1):40-52. doi: 10.1111/acem.13060. PMID: 27473387. Exclusion Code: X1.

474. Moon S, Shin J. Health care utilization among Medicare-Medicaid dual eligibles: a count data analysis. BMC Public Health. 2006 Apr 5;6:88. doi: 10.1186/1471-2458-6-88. PMID: 16595021. Exclusion Code: X1.

475. Moore DT, Rosenheck RA. Factors Affecting Emergency Department Use by a Chronically Homeless Population. Psychiatr Serv. 2016 Dec 1;67(12):1340-7. doi:

10.1176/appi.ps.201500526. PMID: 27417899. Exclusion Code: X1.

476. Moore G, Gerdtz M, Manias E, et al. Sociodemographic and clinical characteristics of representation to an Australian inner-city emergency department: implications for service delivery. BMC Public Health. 2007 Nov 10;7:320. doi: 10.1186/1471-2458-7-320. PMID: 17996112. Exclusion Code: X1.
477. Moore M, Conrick KM, Reddy A, et al. From Their Perspective: The Connection between Life Stressors and Health Care Service Use Patterns of Homeless Frequent Users of the Emergency Department. Health Soc Work. 2019 May 1;44(2):113-22. doi: 10.1093/hsw/hlz010. PMID: 30855682. Exclusion Code: X11.

478. Moore TA, Miller AL, Lopez L, et al. High utilizers of inpatient state hospital services. Schizophr Bull. 2009 Mar;35:133-. Exclusion Code: X1.

479. Morgan PA, Smith VA, Berkowitz TSZ, et al. Impact Of Physicians, Nurse Practitioners, And Physician Assistants On Utilization And Costs For Complex Patients. Health Aff (Millwood). 2019 Jun;38(6):1028-36. doi: 10.1377/hlthaff.2019.00014. PMID: 31158006. Exclusion Code: X1.

480. Morgello S, Gensler G, Sherman S, et al. Frailty in medically complex individuals with chronic HIV. AIDS. 2019 Aug 1;33(10):1603-11. doi: 10.1097/qad.0000000000002250. PMID: 31305330. Exclusion Code: X1.

481. Mortensen K. Access to primary and specialty care and emergency department utilization of medicaid enrollees needing specialty care. J Health Care Poor Underserved. 2014 May;25(2):801-13. doi: 10.1353/hpu.2014.0097. PMID: 24858887. Exclusion Code: X4.

482. Moschetti K, Iglesias K, Baggio S, et al. Health care costs of case management for frequent users of the emergency department: Hospital and insurance perspectives. PLoS One. 2018;13(9):e0199691. doi: 10.1371/journal.pone.0199691. PMID: 30248102. Exclusion Code: X1.

483. Moses K, Hamblin A, Somers S. Supportive housing for chronically homeless Medicaid enrollees: state strategies. [Hamilton, N.J.]: Center for Health Care Strategies; 2016. Exclusion Code: X1.

484. Mullangi S, Press MJ, Ryan AM. A delicate balance: Accountability for very high-cost patients in new payment models. Healthcare-the Journal of Delivery Science and Innovation. 2019 Dec;7(4):3. doi: 10.1016/j.hjdsi.2019.100366. Exclusion Code: X1.

485. Murphy SM, Neven D. Cost-effective: emergency department care coordination with a regional hospital information system. J Emerg Med. 2014 Aug;47(2):223-31. doi: 10.1016/j.jemermed.2013.11.073. PMID: 24508115. Exclusion Code: X1. 
486. Murtagh Kurowski E, Byczkowski T, GruppPhelan JM. Comparison of emergency care delivered to children and young adults with complex chronic conditions between pediatric and general emergency departments. Acad Emerg Med. 2014 Jul;21(7):778-84. doi:

10.1111/acem.12412. PMID: 25039935. Exclusion Code: X1.

487. Myers LA, Carlson PN, Krantz PW, et al. Development and Implementation of a Community Paramedicine Program in Rural United States. Western Journal of Emergency Medicine: Integrating Emergency Care with Population Health. 2020;21(5):1227-33. doi: 10.5811/westjem.2020.7.44571. Exclusion Code: $\mathrm{X} 1$.

488. Naessens JA, Baird MA, Van Houten HK, et al. Predicting persistently high primary care use. Ann Fam Med. 2005 Jul-Aug;3(4):324-30. doi: 10.1370/afm.352. Exclusion Code: X1.

489. National Academy for State Health Policy, Urban Institute, RTI International. Financial alignment initiative annual report: Washington health homes MFFS Demonstration Bethesda, MD: Centers for Medicare \& Medicaid Services; 2017. https://www.cms.gov/Medicare-MedicaidCoordination/Medicare-and-MedicaidCoordination/Medicare-Medicaid-CoordinationOffice/FinancialAlignmentInitiative/Downloads/ WAFirstAnnualEvalReport.pdf. Exclusion Code: $\mathrm{X} 1$.

490. Nault Connors JD, Binkley BL, Graff JC, et al. How patient experience informed the SafeMed Program: Lessons learned during a Health Care Innovation Award to improve care for superutilizers. Healthc (Amst). 2019 Mar;7(1):13-21. doi: 10.1016/j.hjdsi.2018.02.002. Exclusion Code: X1.

491. Navathe A. Spending and outcomes for complex Medicare Advantage patients. University of Pennsylvania. 2016.

https://clinicaltrials.gov/ct2/show/NCT02922361. Exclusion Code: X7.

492. Navathe AS. Segmenting high-need, high-cost veterans into potentially actionable subgroups. Corporal Michael J. Crescenz VA Medical Center, Center for Health Equity Research and Promotion 2018.

https://www.hsrd.research.va.gov/research/abstra cts.cfm?Project_ID=2141706856. Exclusion Code: X7.

493. Neighbors CJ, Yerneni R, O'Grady MA, et al. Recurrent use of inpatient withdrawal management services: characteristics, service use, and cost among Medicaid clients. J Subst Abuse Treat. 2018;92:77-84. doi: 10.1016/j.jsat.2018.06.013. Exclusion Code: X1.
494. Nejtek VA, Aryal S, Talari D, et al. A pilot mobile integrated healthcare program for frequent utilizers of emergency department services. Am J Emerg Med. 2017

Nov;35(11):1702-5. doi: 10.1016/j.ajem.2017.04.061. PMID: 28495031. Exclusion Code: X1.

495. Nelson RE, Suo Y, Pettey W, et al. Costs Associated with Health Care Services Accessed through VA and in the Community through Medicare for Veterans Experiencing Homelessness. Health Serv Res. 2018 Dec;53 Suppl 3(Suppl Suppl 3):5352-74. doi: 10.1111/1475-6773.13054. PMID: 30246368. Exclusion Code: X1.

496. Nevola A, Morris ME, Felix HC, et al. Improving quality of life assessments for high-need adult Medicaid service users with mental health conditions. Qual Life Res. 2020. doi: 10.1007/s11136-020-02694-0. Exclusion Code: X9.

497. Ng SHX, Rahman N, Ang IYH, et al. Characterization of high healthcare utilizer groups using administrative data from an electronic medical record database. BMC Health Serv Res. 2019;19(1):452. doi: 10.1186/s12913019-4239-2. Exclusion Code: X1.

498. Noble N, Paul C, Carey M, et al. A randomised trial assessing the acceptability and effectiveness of providing generic versus tailored feedback about health risks for a high need primary care sample. BMC Fam Pract. 2015 Aug 5;16:95. doi: 10.1186/s12875-015-0309-7. PMID: 26243144. Exclusion Code: X1.

499. Noel K, Messina C, Hou W, et al. Teletransitions of care (TTOC): a 12-month, randomized controlled trial evaluating the use of Telehealth to achieve triple aim objectives. BMC Fam Pract. 2020 Feb 7;21(1):27. doi: 10.1186/s12875-020-1094-5. PMID: 32033535. Exclusion Code: X5.

500. Nolan RD, Kirkland C, Johnson A, et al. International systematic review on high utilizers diagnosed with severe mental illness. Health Behavior and Policy Review. 2019 Jan;6(1):3-17. doi: 10.14485/hbpr.6.1.1. Exclusion Code: X1.

501. Norelli LJ, Coates AD, Kovasznay BM. Cancer risk from diagnostic radiology in a deliberate self-harm patient. Acta Psychiatr Scand. 2010 Nov;122(5):427-30. doi: 10.1111/j.16000447.2010.01538.x. PMID: 20136800. Exclusion Code: X1. 
502. Norman GJ, Orton K, Wade A, et al. Operation and challenges of home-based medical practices in the US: findings from six aggregated case studies. BMC Health Serv Res. 2018 Jan 27;18(1):45. doi: 10.1186/s12913-018-2855-x. PMID: 29374478. Exclusion Code: X1.

503. Norman GJ, Wade AJ, Morris AM, et al. Home and community-based services coordination for homebound older adults in home-based primary care. BMC Geriatr. 2018 Oct 11;18(1):241. doi: 10.1186/s12877-018-0931-z. PMID: 30305053. Exclusion Code: X1.

504. Nothelle S. Characterization and effect of coexistence of care management programs for highneed, high-cost older adults. Johns Hopkins Medicine, Department of Medicine. 2018. https://hsrproject.nlm.nih.gov/view_hsrproj_recor d/20191491. Exclusion Code: X7.

505. Novak M, Mucsi I, Shapiro CM, et al. Increased utilization of health services by insomniacs--an epidemiological perspective. J Psychosom Res. 2004 May;56(5):527-36. doi:

10.1016/j.jpsychores.2004.02.007. PMID:

15172209. Exclusion Code: X1.

506. Nuti SV, Doupe P, Villanueva B, et al. Characterizing subgroups of high-need, high-cost patients based on their clinical conditions: a machine learning-based analysis of Medicaid claims data. J Gen Intern Med. 2019 Aug;34(8):1406-8. doi: 10.1007/s11606-01904941-8. PMID: 30887432. Exclusion Code: X4.

507. Oderda GM, Gunning K, LaFleur J, et al. Reviews of Utah Medicaid high utilizers to control drug costs. Value Health. 2003 MayJun;6(3):206-. doi: 10.1016/s1098-

3015(10)63869-7. Exclusion Code: X1.

508. O'Donohue W, Cucciare M. Pathways to Medical utilization. J Clin Psychol Med Settings. 2005;12(2):185-97. doi: 10.1007/s10880-0053278-5. Exclusion Code: X1.

509. O'Donohue W, Cucciare MA. The role of psychological factors in medical presentations. J Clin Psychol Med Settings. 2005 Mar;12(1):1324. doi: 10.1007/s10880-005-0908-x. Exclusion Code: X1.

510. Okin RL, Boccellari A, Azocar F, et al. The effects of clinical case management on hospital service use among ED frequent users. Am J Emerg Med. 2000 Sep;18(5):603-8. doi: 10.1053/ajem.2000.9292. PMID: 10999578. Exclusion Code: X1.

511. Okunogbe A, Meredith LS, Chang ET, et al. Care coordination and provider stress in primary care management of high-risk patients. J Gen Intern Med. 2018 Jan;33(1):65-71. doi: 10.1007/s11606-017-4186-8. PMID: 28971306. Exclusion Code: X1.
512. Okuyemi KS, Frey B. Describing and predicting frequent users of an emergency department. J Assoc Acad Minor Phys. 2001 Mar;12(1-2):11923. PMID: 11851196 . Exclusion Code: X4.

513. O'Leary KJ, Chapman MM, Foster S, et al. Frequently hospitalized patients' perceptions of factors contributing to high hospital use. J Hosp Med. 2019 Mar 20;14:E1-e6. doi: 10.12788/jhm.3175. PMID: 30897060. Exclusion Code: X1.

514. Olofsson P, Carlstrom ED, Back-Pettersson S. During and beyond the triage encounter: chronically ill elderly patients' experiences throughout their emergency department attendances. Int Emerg Nurs. 2012 Oct;20(4):207-13. doi: 10.1016/j.ienj.2012.03.006. PMID: 23084509. Exclusion Code: X1.

515. Olsson M, Hansagi H. Repeated use of the emergency department: qualitative study of the patient's perspective. Emerg Med J. 2001 Nov;18(6):430-4. doi: 10.1136/emj.18.6.430. PMID: 11696488. Exclusion Code: X1.

516. O'Malley AS, Rich EC, Sarwar R, et al. How accountable care organizations use population segmentation to care for high-need, high-cost patients. Commonwealth. 2019.

https://www.commonwealthfund.org/publications /issue-briefs/2019/jan/how-acos-usesegmentation-high-need-high-cost. Exclusion Code: X1.

517. Ondler C, Hegde GG, Carlson JN. Resource utilization and health care charges associated with the most frequent ED users. Am J Emerg Med. 2014 Oct;32(10):1215-9. doi: 10.1016/j.ajem.2014.07.013. PMID: 25154348. Exclusion Code: X4.

518. Oreskovic NM, Maniates J, Weilburg J, et al. Optimizing the use of electronic health records to identify high-risk psychosocial determinants of health. JMIR Med Inform. 2017 Aug 14;5(3):e25. doi: 10.2196/medinform.8240. PMID: 28807893. Exclusion Code: X1.

519. O'Rielly C, Sutherland L, Wong C. The characteristics and effectiveness of interventions targeting chronic pain patients in the emergency department: A systematic review and metaanalysis. Canadian Journal of Emergency Medicine. 2019;21:S98-S9. doi: 10.1017/cem.2019.288. Exclusion Code: X7.

520. Orza M. High hopes: public health approaches to reducing the need for health care. Washington, D.C.: National Health Policy Forum; 2010. Exclusion Code: X1. 
521. Osborn R. Israel-United States meeting on caring for high need/high cost patients 2017. Haifa: Commonwealth Fund; 2016. Exclusion Code: $\mathrm{X} 1$.

522. Ostermeyer B, Baweja NU, Schanzer B, et al. Frequent utilizers of emergency departments: characteristics and intervention opportunities. Psychiat Ann. 2018 Jan;48(1):42-50. doi: 10.3928/00485713-20171206-02. Exclusion Code: X1.

523. Oxman TE, Dietrich AJ, Williams JW, et al. A three-component model for reengineering systems for the treatment of depression in primary care. Psychosomatics. 2002 NovDec;43(6):441-50. doi: 10.1176/appi.psy.43.6.441. Exclusion Code: X1.

524. Oyffe I, Kurs R, Gelkopf M, et al. Revolvingdoor patients in a public psychiatric hospital in Israel: cross sectional study. Croat Med J. 2009 Dec;50(6):575-82. doi: 10.3325/cmj.2009.50.575. PMID: 20017226. Exclusion Code: X1.

525. Panopalis P, Gillis JZ, Yazdany J, et al. Frequent use of the emergency department among persons with systemic lupus erythematosus. Arthritis Care Res (Hoboken). 2010 Mar;62(3):401-8. doi: 10.1002/acr.20107. PMID: 20391487. Exclusion Code: X4.

526. Parikh R, Linn K, Yan J, et al. Identifying distinct subgroups of high-need, high-cost veterans using machine learning clustering methods. J Gen Intern Med. 2020;35(SUPPL 1):S155. doi: 10.1007/s11606-020-05890-3. Exclusion Code: X1.

527. Park S, Langellier BA, Burke RE, et al. Association of Medicare Advantage Penetration With Per Capita Spending, Emergency Department Visits, and Readmission Rates Among Fee-for-Service Medicare Beneficiaries With High Comorbidity Burden. Med Care Res Rev.10. doi: 10.1177/1077558720952582. Exclusion Code: X9.

528. Parson P. PBS Newshour partnership on highneed high-cost populations. Greater Washington Educational Telecommunications Association: Commonwealth Fund; 2016. Exclusion Code: X7.

529. Patten SB, Williams JV, Esposito E, et al. Selfreported thyroid disease and mental disorder prevalence in the general population. Gen Hosp Psychiatry. 2006 Nov-Dec;28(6):503-8. doi: 10.1016/j.genhosppsych.2006.09.001. PMID: 17088166. Exclusion Code: X1.

530. Peck KA. To what extent are chronic care management processes and programs in place to manage patients with high-need, high-cost chronic illnesses? : Commonwealth Fund; 2018. Exclusion Code: X7.
531. Peddie S, Richardson S, Salt L, et al. Frequent attenders at emergency departments: research regarding the utility of management plans fails to take into account the natural attrition of attendance. N Z Med J. 2011 Mar 25;124(1331):61-6. PMID: 21725414. Exclusion Code: X1.

532. Peng CJ-D. Health services utilization of older adults with depression and comorbid chronic health conditions: evidence from China: ProQuest Information \& Learning; 2018. Exclusion Code: X1.

533. Perez Jolles M, Lengnick-Hall R, Mittman BS. Core functions and forms of complex health interventions: a patient-centered medical home illustration. J Gen Intern Med. 2019;34(6):10328. doi: 10.1007/s11606-018-4818-7. Exclusion Code: X1.

534. Petersen LA, Woodard LD, Henderson LM, et al. Will hypertension performance measures used for pay-for-performance programs penalize those who care for medically complex patients? Circulation. 2009 Jun 16;119(23):2978-85. doi: 10.1161/circulationaha.108.836544. PMID: 19487595. Exclusion Code: X1.

535. Peytremann-Bridevaux I, Voellinger R, SantosEggimann B. Healthcare and preventive services utilization of elderly Europeans with depressive symptoms. J Affect Disord. 2008 Jan;105(13):247-52. doi: 10.1016/j.jad.2007.04.011. PMID: 17509695. Exclusion Code: X1.

536. Phipps EJ, Singletary SB, Cooblall CA, et al. Food insecurity in patients with high hospital utilization. Popul Health Manag. 2016 Dec;19(6):414-20. doi: 10.1089/pop.2015.0127. PMID: 27008540. Exclusion Code: X1.

537. Pietz K, Byrne MM, Petersen LA. A decisiontheoretic approach to identifying future high-cost patients. Med Care. 2006 Sep;44(9):842-9. doi: 10.1097/01.mlr.0000220680.19667.da. PMID: 16932136. Exclusion Code: X4.

538. Placona AM, King R, Wang F. Longitudinal Clustering of High-cost Patients' Spend Trajectories:Delineating Individual Behaviors from Aggregate Trends. AMIA Annu Symp Proc. 2018;2018:907-15. PMID: 30815133. Exclusion Code: X9.

539. Pleticha J, Prakken S, Buchheit T, et al. Financial impact of intensive outpatient pain management of duke health system high utilizers. Anesth Analg. 2017 May;124:786-8. Exclusion Code: $\mathrm{X} 1$. 
540. Polluste K, Kalda R, Lember M. Satisfaction with the access to the health services of the people with chronic conditions in Estonia. Health Policy. 2007 Jun;82(1):51-61. doi:

10.1016/j.healthpol.2006.08.004. PMID: 17011063. Exclusion Code: X1.

541. Ponka D. The effectiveness of case management interventions for the homeless, vulnerably housed and persons with lived experience: A systematic review. PLoS One. 2020. Exclusion Code: X7.

542. Ponka D, Agbata E, Kendall C, et al. The effectiveness of case management interventions for the homeless, vulnerably housed and persons with lived experience: A systematic review. PLoS One. 2020;15(4):e0230896. doi: 10.1371/journal.pone.0230896. PMID: 32271769. Exclusion Code: X7.

543. Poole S, Grannis S, Shah NH. Predicting Emergency Department Visits. AMIA Jt Summits Transl Sci Proc. 2016;2016:438-45. PMID: 27570684. Exclusion Code: X1.

544. Pope D, Fernandes CM, Bouthillette F, et al. Frequent users of the emergency department: a program to improve care and reduce visits. CMAJ. 2000 Apr 4;162(7):1017-20. PMID: 10763402. Exclusion Code: X1.

545. Poremski D, Harris DW, Kahan D, et al. Improving continuity of care for frequent users of emergency departments: service user and provider perspectives. Gen Hosp Psychiatry. 2016 May-Jun;40:55-9. doi: 10.1016/j.genhosppsych.2016.01.004. PMID: 26906469. Exclusion Code: X1.

546. Powers A, Strube MJ, Oltmanns TF. Personality pathology and increased use of medical resources in later adulthood. Am J Geriatr Psychiatry. 2014 Dec;22(12):1478-86. doi:

10.1016/j.jagp.2013.10.009. PMID: 24315559. Exclusion Code: X1.

547. Powers M. Sustainable payment models to support effective care management programs for high-need, high-cost patients. Pacific Business Group on Health 2017.

https://hsrproject.nlm.nih.gov/view_hsrproj_recor d/20191027. Exclusion Code: X7.

548. Prados-Torres A, Cura-Gonzalez ID, PradosTorres JD, et al. MULTIPAP Study: improving healthcare for patients with multimorbidity. Br J Gen Pract. 2020;70. doi:

10.3399/bjgp20X711257. Exclusion Code: X6.

549. Prater L, Sanchez A, Modan G, et al. Electronic Health Record Documentation Patterns of Recorded Primary Care Visits Focused on Complex Communication: A Qualitative Study. Appl Clin Inform. 2019 Mar;10(2):247-53. doi: 10.1055/s-0039-1683986. PMID: 30970382. Exclusion Code: X1.
550. Pruitt Z, Emechebe N, Quast T, et al. Expenditure Reductions Associated with a Social Service Referral Program. Popul Health Manag. 2018 Dec;21(6):469-76. doi: 10.1089/pop.2017.0199. PMID: 29664702. Exclusion Code: X1.

551. Pyne JM, Rost KM, Farahati F, et al. One size fits some: the impact of patient treatment attitudes on the cost-effectiveness of a depression primarycare intervention. Psychol Med. 2005

Jun;35(6):839-54. doi: 10.1017/s0033291704003332. Exclusion Code: $\mathrm{X} 1$.

552. Radcliff TA, Côté MJ, Duncan RP. The identification of high-cost patients. Hosp Top. 2005 Summer;83(3):17-24. doi: 10.3200/htps.83.3.17-24. PMID: 16294676. Exclusion Code: X9.

553. Radley DC, Hayes SL, McCarthy D. Assessing state variation in high-need adult populations and their care experiences. Commonwealth Fund. 2017.

https://www.commonwealthfund.org/publications /issue-briefs/2017/aug/assessing-state-variationhigh-need-adult-populations-and-their. Exclusion Code: X1.

554. Radley DC, Hayes SL, McCarthy D. Percent of high-need adults who went without physician care and prescriptions because of costs varied widely. Commonwealth Fund; 2017. Exclusion Code: X7.

555. Radley DC, Hayes SL, McCarthy D. High-need adults more likely than adults overall to not see a doctor because of costs, but rates vary. Commonwealth Fund; 2017. Exclusion Code: X7.

556. Ramage-Morin PL, Gilmour H. Chronic pain at ages 12 to 44. Health Rep. 2010 Dec;21(4):53-61. PMID: 21269012. Exclusion Code: X1.

557. Ramey L, Goldstein R, Zafonte R, et al. Variation in 30-day readmission rates among medically complex patients at inpatient rehabilitation facilities and contributing factors. J Am Med Dir Assoc. 2016 Aug 1;17(8):730-6. doi: 10.1016/j.jamda.2016.03.019. PMID: 27161849. Exclusion Code: X1.

558. Rapoport R. Surveying high-need, high-cost patients about how they experience health system reform. SSRS. 2016.

https://www.commonwealthfund.org/grants/surve ying-high-need-high-cost-patients-about-howthey-experience-health-system-reform. Exclusion Code: X7. 
559. Raven MC. Homelessness and the Practice of Emergency Medicine: Challenges, Gaps in Care, and Moral Obligations. Ann Emerg Med. 2019 Nov;74(5s):S33-s7. doi:

10.1016/j.annemergmed.2019.08.440. PMID: 31655672. Exclusion Code: X9.

560. Raven MC, Doran KM, Kostrowski S, et al. An intervention to improve care and reduce costs for high-risk patients with frequent hospital admissions: a pilot study. BMC Health Serv Res. 2011 Oct 13;11:270. doi: 10.1186/1472-6963-11270. PMID: 21995329. Exclusion Code: X1.

561. Raven MC, Kotchko SM, Gould DA. Can targeted messaging encourage PCP contact before ED visits? Am J Manag Care. 2013 Jan;19(1):41-5. PMID: 23379743. Exclusion Code: X1.

562. Realmuto L, Walker EA, Weiss L. Struggling to stay on track: participants share benefits and barriers to completing the National Diabetes Prevention Program. New York, NY: New York Academy of Medicine; 2017. Exclusion Code: $\mathrm{X} 1$.

563. Detecting earlier indicators of homelessness in the free text of medical records. 2014. 2665: 202. Exclusion Code: X1.

564. Reddy A. Understanding the impact of health information exchange-enabled care plans to coordinate care among high-need, high-cost patients. University of Washington, School of Medicine, Department of Medicine, Division of General Internal Medicine. Seattle, Washington: 2018.

https://app.dimensions.ai/details/grant/grant.7825 128. Exclusion Code: X1.

565. Regenstein M, Andres E. Reducing hospital readmissions among Medicaid patients: a review of the literature. Qual Manag Health Care. 2014;23(1):20-42. doi: 10.1097/QMH.0000000000000016. Exclusion Code: X1.

566. Rennemark M, Holst G, Fagerstrom C, et al. Factors related to frequent usage of the primary healthcare services in old age: findings from The Swedish National Study on Aging and Care. Health Soc Care Community. 2009 May;17(3):301-11. doi: 10.1111/j.13652524.2008.00829.x. PMID: 19207603. Exclusion Code: X1.

567. Reschovsky JD, Hadley J, Saiontz-Martinez CB, et al. Following the money: factors associated with the cost of treating high-cost Medicare beneficiaries. Health Serv Res. 2011 Aug;46(4):997-1021. doi: 10.1111/j.14756773.2011.01242.x. PMID: 21306368. Exclusion Code: X9.
568. Rivlin AM, Burke SP. Preserving the bipartisan commitment to health care delivery system reform. Commonwealth Fund; 2017. Exclusion Code: X7.

569. Robst J. Developing Models to Predict Persistent High-Cost Cases in Florida Medicaid. Popul Health Manag. 2015 Dec;18(6):467-76. doi: 10.1089/pop.2014.0174. PMID: 26102363. Exclusion Code: X1.

570. Rochlin DH, Lee CM, Scheuter C, et al. Health Care Is Failing the Most Vulnerable Patients: Three Underused Solutions. Public Health Rep. 2020 Nov;135(6):711-6. doi: 10.1177/0033354920954496. Exclusion Code: $\mathrm{X} 1$.

571. Rodríguez-Queraltó O, Formiga F, López-Palop R, et al. FRAIL Scale also Predicts Long-Term Outcomes in Older Patients With Acute Coronary Syndromes. J Am Med Dir Assoc. 2020;21(5):683-7.e1. doi: 10.1016/j.jamda.2019.10.007. Exclusion Code: X6.

572. Rohrer JE, Takahashi PY, Adamson SC. Age, obesity, and medical visits in family medicine. Popul Health Manag. 2008 Oct;11(5):255-9. doi: 10.1089/pop.2008.0005. PMID: 18942917. Exclusion Code: X1.

573. Rollman BL, Belnap BH, Reynolds CF, et al. A contemporary protocol to assist primary care physicians in the treatment of panic and generalized anxiety disorders. Gen Hosp Psychiatry. 2003 Mar-Apr;25(2):74-82. doi: 10.1016/s0163-8343(03)00004-5. Exclusion Code: X1.

574. Romaire M, Alterbaum R, Collins A. Medicaid behavioral health homes: Lessons learned and early findings from Maine. Psychiatr Serv. 2020;71(11):1179-87. doi: 10.1176/appi.ps.201900490. Exclusion Code: X1.

575. Rosen CS. Telephone case monitoring for veterans with PTSD (post-traumatic stress disorder) VA Palo Alto Health Care System, Palo Alto Division. Palo Alto, California: 2006. https://www.hsrd.research.va.gov/research/abstra cts.cfm?Project_ID=2141695811. Exclusion Code: X1.

576. Rosenberg HJ, Rosenberg SD, Wolford Ii GL, et al. The relationship between trauma, PTSD, and medical utilization in three high risk medical populations. Int J Psychiatry Med. 2000;30(3):247-59. doi: 10.2190/J8M8-YDTE46CB-GYDK. Exclusion Code: X1. 
577. Rosenberg MA, Farrell PM. Predictive modeling of costs for a chronic disease with acute high-cost episodes. North American Actuarial Journal. 2008;12(1):1-19. doi:

10.1080/10920277.2008.10597497. Exclusion

Code: X1.

578. Rost K, Pyne JM, Dickinson LM, et al. Costeffectiveness of enhancing primary care depression management on an ongoing basis. Ann Fam Med. 2005 Jan-Feb;3(1):7-14. doi: 10.1370/afm.256. Exclusion Code: X1.

579. Rotenberg J, Kinosian B, Boling P, et al. Homebased primary care: beyond extension of the independence at home demonstration. J Am Geriatr Soc. 2018 Apr;66(4):812-7. doi: 10.1111/jgs.15314. PMID: 29473945. Exclusion Code: X4

580. Roudsari B, Caetano R, Field C. Alcohol intoxication/dependence, ethnicity and utilisation of health care resources in a level I trauma center. Injury. 2011 Jan;42(1):66-71. doi:

10.1016/j.injury.2010.01.097. PMID: 20106475. Exclusion Code: X1.

581. Rowe JM, Rizzo VM, Kang SY, et al. Time Contribution of Social Workers in Care Management: Value for Older Adults. Prof Case Manag. 2019 Nov/Dec;24(6):306-16. doi: 10.1097/ncm.0000000000000305. PMID: 31580298. Exclusion Code: X1.

582. Roy-Byrne PP, Wagner AW, Schraufnagel TJ. Understanding and treating panic disorder in the primary care setting. J Clin Psychiatry. 2005;66:16-22. Exclusion Code: X1.

583. Rudin RS, Schneider EC, Predmore Z, et al. Knowledge gaps inhibit health IT development for coordinating complex patients' care. Am J Manag Care. 2016 Sep 1;22(9):e317-22.

Exclusion Code: X1.

584. Ruiz S, Snyder LP, Rotondo C, et al. Innovative Home Visit Models Associated With Reductions In Costs, Hospitalizations, And Emergency Department Use. Health Aff (Millwood). 2017 Mar 1;36(3):425-32. doi:

10.1377/hlthaff.2016.1305. PMID: 28264943. Exclusion Code: X1.

585. Rutgers Biomedical and Health Sciences (RBHS) Working Group on Medicaid High Utilizers. Analysis and recommendations for Medicaid high utilizers in New Jersey. Hotspot Blog. Camden, NJ: Camden Coalition; 2016. Exclusion Code: X1.

586. Ryan J, Abrams MK, Doty MM, et al. How highneed patients experience health care in the United States. Findings from the 2016 Commonwealth Fund Survey of High-Need Patients. Issue Brief (Commonw Fund). 2016 Dec;43:1-20. PMID: 27959480. Exclusion Code: X1.
587. Ryan J, Brown M. Listening to those living with chronic conditions. Commonwealth Fund; 2016. Exclusion Code: X7.

588. Sadarangani T, Missaelides L, Eilertsen E, et al. A Mixed-Methods Evaluation of a Nurse-Led Community-Based Health Home for Ethnically Diverse Older Adults With Multimorbidity in the Adult Day Health Setting. Policy Polit Nurs Pract. 2019 Aug;20(3):131-44. doi: 10.1177/1527154419864301. PMID: 31373878. Exclusion Code: X1.

589. Sadowski LS, Kee RA, VanderWeele TJ, et al. Effect of a housing and case management program on emergency department visits and hospitalizations among chronically ill homeless adults: a randomized trial. JAMA. 2009 May 6;301(17):1771-8. doi: 10.1001/jama.2009.561. PMID: 19417194. Exclusion Code: X1.

590. Salhi BA, White MH, Pitts SR, et al. Homelessness and Emergency Medicine: A Review of the Literature. Acad Emerg Med. 2018 May;25(5):577-93. doi: 10.1111/acem.13358. PMID: 29223132. Exclusion Code: X7.

591. Salzberg CA, Hayes SL, McCarthy D, et al. Health system performance for the high-need patient: a look at access to care and patient care experiences. Issue Brief (Commonw Fund). 2016 Aug;27:1-12. PMID: 27571600. Exclusion Code: $\mathrm{X} 1$.

592. Sambamoorthi U, Walkup J, Olfson M, et al. Antidepressant treatment and health services utilization among HIV-infected Medicaid patients diagnosed with depression. J Gen Intern Med. 2000 May;15(5):311-20. doi: 10.1046/j.15251497.2000.06219.x. Exclusion Code: X1.

593. Sander LD, Albert M, Okeke N, et al. Building a Medicaid ambulatory complex care program within an urban medical home. Popul Health Manag. 2018 Dec;21(6):446-53. doi: 10.1089/pop.2017.0200. PMID: 29620961. Exclusion Code: X1.

594. Sanders J, Guse C, Onuoha BC. Pilot study of a new model for managing hypertension in an uninsured population. J Prim Care Community Health. 2013 Jan;4(1):44-9. doi: 10.1177/2150131912451742. PMID: 23799689. Exclusion Code: X1.

595. Sarabia-Cobo C, Fernandez-Pena R, Taltavull $\mathrm{JM}$, et al. Comparison between attention and experiences of chronic complex patients: A multicentric study. Health Soc Care Community.12. doi: 10.1111/hsc.13269. Exclusion Code: X6. 
596. Sarabia-Cobo C, Taltavull-Aparicio JM, Miguélez-Chamorro A, et al. Experiences of caregiving and quality of healthcare among caregivers of patients with complex chronic processes: A qualitative study. Appl Nurs Res. 2020;56:N.PAG-N.PAG. doi: 10.1016/j.apnr.2020.151344. Exclusion Code: X9.

597. Sarah B. Hunter MH, Brian Briscombe, Matthew Cefalu. Evaluation of Housing for Health Permanent Supportive Housing Program. RAND Corporation 2017. Exclusion Code: X1.

598. Sarnak DO, Ryan J. How high-need patients experiences the health care system in nine countries. Issue Brief (Commonw Fund). 2016 Jan;1:1-14. PMID: 26809154. Exclusion Code: $\mathrm{X} 1$.

599. Sarvepalli S, Parikh MP, Sarvepalli S, et al. High utilizers of inpatient services in patients with esophageal stenosis. Am J Gastroenterol. 2018 Oct;113:S198-S9. Exclusion Code: X1.

600. Saxon L ER, Sobhani M. Health impacts of unlimited access to networked transportation in older adults. The Journal of mHealth. 2019. Exclusion Code: X11.

601. Schaeffer C, Teter C, Finch EA, et al. A pragmatic randomized comparative effectiveness trial of transitional care for a socioeconomically diverse population: design, rationale and baseline characteristics. Contemp Clin Trials. 2018 Feb;65:53-60. doi: 10.1016/j.cct.2017.12.003. PMID: 29233720. Exclusion Code: X1.

602. Schaink AK, Kuluski K, Lyons RF, et al. A scoping review and thematic classification of patient complexity: offering a unifying framework. J Comorb. 2012;2:1-9. doi: 10.15256/joc.2012.2.15. PMID: 29090137. Exclusion Code: X1.

603. Schoen C, Solís-Román C, Huober N, et al. On Medicare but at risk: a state-level analysis of beneficiaries who are underinsured or facing high total cost burden. New York: Commonwealth Fund; 2016. Exclusion Code: X1.

604. Schulman M, Thomas-Henkel. Opportunities for complex care programs to address the social determinants of health. Center for Health Care Strategies. 2019.

https://www.chcs.org/media/TCC-SDOH022119.pdf. Exclusion Code: X1.

605. Seferian EG, Afessa B. Demographic and clinical variation of adult intensive care unit utilization from a geographically defined population. Crit Care Med. 2006 Aug;34(8):2113-9. doi: 10.1097/01.Ccm.0000227652.08185.A4. PMID: 16763514. Exclusion Code: X1.
606. Sewitch MJ, Blais R, Rahme E, et al. Receiving guideline-concordant pharmacotherapy for major depression: Impact on ambulatory and inpatient health service use. Canadian Journal of Psychiatry-Revue Canadienne De Psychiatrie. 2007 Mar;52(3):191-200. doi: 10.1177/070674370705200311. Exclusion Code: $\mathrm{X} 1$.

607. Shah T, Brown M, Reed B, et al. High-need patients in their own words. Commonwealth Fund. 2017.

https://www.commonwealthfund.org/blog/2017/h igh-need-patients-their-own-words. Exclusion Code: X1.

608. Shah T, Brown M, Reed B, et al. Personas for people with three or more chronic conditions. 2019.

https://www.commonwealthfund.org/publications /2019/jan/personas-people-three-or-morechronic-conditions. Exclusion Code: X1.

609. Shah T, Lewis C, Tsega M, et al. Quick reference guide to promising care models for patients with complex needs. Commonwealth Fund. 2019. https://www.commonwealthfund.org/publications /2019/feb/care-models-patients-complex-needs. Exclusion Code: X1.

610. Shah V, Stokes J, Sutton M. Effects of nonmedical health coaching on multimorbid patients in primary care: a difference-in-differences analysis. BMC Health Serv Res. 2019;19(1):N.PAG-N.PAG. doi: 10.1186/s12913-019-4367-8. Exclusion Code: $\mathrm{X} 1$.

611. Shannon GR, Wilber KH, Allen D. Reductions in costly healthcare service utilization: findings from the Care Advocate Program. J Am Geriatr Soc. 2006 Jul;54(7):1102-7. doi: 10.1111/j.15325415.2006.00799.x. PMID: 16866682. Exclusion Code: X1.

612. Sharpe M, Burton C, Sawhney A, et al. Is comorbid depression adequately treated in patients repeatedly referred to specialist medical services with symptoms of a medical condition? J Psychosom Res. 2012 Jun;72(6):419-21. doi: 10.1016/j.jpsychores.2012.03.005. Exclusion Code: X1.

613. Sheehan B, Bass C, Briggs R, et al. Somatization among older primary care attenders. Psychol Med. 2003 Jul;33(5):867-77. doi: 10.1017/s003329170300789x. Exclusion Code: $\mathrm{X} 1$.

614. Sheff A, Park ER, Neagle M, et al. The patient perspective: utilizing focus groups to inform care coordination for high-risk medicaid populations. BMC Res Notes. 2017 Jul 25;10(1):315. doi: 10.1186/s13104-017-2638-1. PMID: 28743288. Exclusion Code: X1. 
615. Shih SL, Gerrard P, Goldstein R, et al. Functional status outperforms comorbidities in predicting acute care readmissions in medically complex patients. J Gen Intern Med. 2015

Nov;30(11):1688-95. doi: 10.1007/s11606-0153350-2. PMID: 25956826. Exclusion Code: X1.

616. Shim J, Perry B. A social network analysis of poverty and health care utilization. University of California, San Francisco, School of Nursing San Franciso, California: 2018.

https://www.nsf.gov/awardsearch/showAward?A WD_ID $=1756099 \&$ HistoricalAwards $=$ false.

Exclusion Code: X1.

617. Shippee ND, Shah ND, May CR, et al. Cumulative complexity: a functional, patientcentered model of patient complexity can improve research and practice. J Clin Epidemiol. 2012 Oct;65(10):1041-51. doi:

10.1016/j.jclinepi.2012.05.005. PMID: 22910536. Exclusion Code: X1.

618. Shortell S. How physician organizations manage care for high-need, high-cost patients.

Commonwealth Fund; 2015. Exclusion Code: $\mathrm{X} 1$.

619. Shubeck SP, Thumma JR, Dimick JB, et al. Hot Spotting as a Strategy to Identify High-Cost Surgical Populations. Ann Surg. 2019 Mar;269(3):453-8. doi: 10.1097/sla.0000000000002663. PMID: 29342019. Exclusion Code: X1.

620. Simmons MM, Gabrielian S, Byrne T, et al. A Hybrid III stepped wedge cluster randomized trial testing an implementation strategy to facilitate the use of an evidence-based practice in VA Homeless Primary Care Treatment Programs. Implement Sci. 2017 Apr 4;12(1):46. doi: 10.1186/s13012-017-0563-2. PMID: 28376839. Exclusion Code: X9.

621. Simon GE, Khandker RK, Ichikawa L, et al. Recovery from depression predicts lower health services costs. J Clin Psychiatry. 2006 Aug;67(8):1226-31. doi: 10.4088/JCP.v67n0808. Exclusion Code: X1.

622. Simon GE, Manning WG, Katzelnick DJ, et al. Cost-effectiveness of systematic depression treatment for high utilizers of general medical care. Arch Gen Psychiatry. 2001;58(2):181-7. doi: 10.1001/archpsyc.58.2.181. Exclusion Code: $\mathrm{X} 1$.

623. Simpson GG, Hahn HR, Powel AA, et al. A patient-centered emergency department management strategy for sickle-cell disease super-utilizers. West J Emerg Med. 2017 Apr;18(3):335-9. doi: 10.5811/westjem.2016.11.32273. PMID: 28435481. Exclusion Code: X4.
624. Sinaiko A, Meyers D, Rosenthal MB. Review of medical homes shows reduction in spending for high-risk patients, but design and implementation matter. Commonwealth Fund; 2017. Exclusion Code: X7.

625. Sisco-Taylor B, Fagerlin A, Weir P, et al. THE IMPACT OF AN INTENSIVE OUTPATIENT CLINIC ON MEDICALLY-COMPLEX PATIENTS' DECISION MAKING OUTCOMES. Med Decis Making. 2020 Jan;40(1):E153-E. Exclusion Code: X9.

626. Siu HY, Steward N, Peter J, et al. A novel primary-specialist care collaborative demonstration project to improve the access and health care of medically complex patients. Chronic Illn. 2017 Sep;13(3):151-70. doi: 10.1177/1742395316674541. PMID: 28783974. Exclusion Code: X1.

627. Smeets RGM, Elissen AMJ, Kroese M, et al. Identifying subgroups of high-need, high-cost, chronically ill patients in primary care: A latent class analysis. PLoS One. 2020;15(1):e0228103. doi: 10.1371/journal.pone.0228103. PMID: 31995630. Exclusion Code: X6.

628. Smith BJ, McCall TC, Slaven EM, et al. PAs are a solution to the growing need for clinicians to treat an aging population. Jaapa. 2019

Dec;32(12):46-9. doi: 10.1097/01.Jaa.0000604864.79443.79. PMID: 31770305. Exclusion Code: X1.

629. Smith GM, Cenzer IS, Covinsky K, et al. Who Becomes a High Utilizer? A Case-Control Study of Older Adults in the USA. JGIM: Journal of General Internal Medicine. 2020;35(2):596-8. doi: 10.1007/s1 1606-019-05331-w. Exclusion Code: X9.

630. Smith KJ, Handler SM, Kapoor WN, et al. Automated communication tools and computerbased medication reconciliation to decrease hospital discharge medication errors. Am J Med Qual. 2016 Jul;31(4):315-22. doi: 10.1177/1062860615574327. PMID: 25753453. Exclusion Code: X1.

631. Smith KW, Bir A, Freeman NL, et al. Impact Of Health Care Delivery System Innovations On Total Cost Of Care. Health Aff (Millwood). 2017 Mar 1;36(3):509-15. doi: 10.1377/hlthaff.2016.1308. PMID: 28264953. Exclusion Code: X11. 
632. Smith MA, Vaughan-Sarrazin MS, Yu M, et al. The importance of health insurance claims data in creating learning health systems: evaluating care for high-need high-cost patients using the National Patient-Centered Clinical Research Network (PCORNet). J Am Med Inform Assoc. 2019 Nov 1;26(11):1305-13. doi:

10.1093/jamia/ocz097. PMID: 31233126. Exclusion Code: X1.

633. Smith RC, Gardiner JC, Armatti S, et al. Screening for high utilizing somatizing patients using a prediction rule derived from the management information system of an HMO: a preliminary study. Med Care. 2001 Sep;39(9):968-78. doi: 10.1097/00005650200109000-00007. PMID: 11502954. Exclusion Code: X4.

634. Smith RC, Lein C, Collins C, et al. Treating patients with medically unexplained symptoms in primary care. J Gen Intern Med. 2003 Jun;18(6):478-89. doi: 10.1046/j.15251497.2003.20815.x. Exclusion Code: X1.

635. Smith TE, Appel A, Donahue SA, et al. Determining engagement in services for highneed individuals with serious mental illness. Adm Policy Ment Health. 2014 Sep;41(5):588-97. doi: 10.1007/s10488-013-0497-1. PMID: 23636712. Exclusion Code: X1.

636. Smith TP, Kennedy SL, Smith M, et al. Physiological improvements and health benefits during an exercise-based comprehensive rehabilitation program in medically complex patients. Exerc Immunol Rev. 2006;12:86-96. PMID: 17201074. Exclusion Code: X1.

637. Smith WR, Poses RM, McClish DK, et al. Prognostic judgments and triage decisions for patients with acute congestive heart failure. Chest. 2002 May;121(5):1610-7. doi: 10.1378/chest.121.5.1610. PMID: 12006451. Exclusion Code: X1.

638. Smith WR, Sop D, Johnson S, et al. Responsivity of utilization rates to the intensity of case management over time among high-utilizing adults with sickle cell disease. Blood. 2019;134. doi: 10.1182/blood-2019-128259. Exclusion Code: X1.

639. Smits F, Brouwer HJ, van Weert HCP, et al. Predictability of persistent frequent attendance: a historic 3-year cohort study. Br J Gen Pract. 2009 Feb;59(559):114-9. doi: 10.3399/bjgp09X395120. Exclusion Code: X4.
640. Smits FT, Brouwer HJ, Zwinderman AH, et al. Morbidity and doctor characteristics only partly explain the substantial healthcare expenditures of frequent attenders: a record linkage study between patient data and reimbursements data. BMC Fam Pract. 2013;14. doi: 10.1186/14712296-14-138. Exclusion Code: X1.

641. Smits FT, Brouwer HJ, Zwinderman AH, et al. Predictability of persistent frequent attendance in primary care: a temporal and geographical validation study. PLoS One. 2013 Sep;8(9). doi: 10.1371/journal.pone.0073125. Exclusion Code: $\mathrm{X} 1$.

642. Smits FTM, Brouwer HJ, ter Riet G, et al. Epidemiology of frequent attenders: a 3-year historic cohort study comparing attendance, morbidity and prescriptions of one-year and persistent frequent attenders. BMC Public Health. 2009 Jan;9. doi: 10.1186/1471-2458-9-36. Exclusion Code: X1.

643. Smits FTM, Mohrs JJ, Beem EE, et al. Defining frequent attendance in general practice. BMC Fam Pract. 2008 Apr;9. doi: 10.1186/1471-22969-21. Exclusion Code: X1.

644. Smits FTM, Wittkampf KA, Schene AH, et al. Interventions on frequent attenders in primary care. Scand J Prim Health Care. 2008;26(2):1116. doi: 10.1080/02813430802112997. Exclusion Code: X1.

645. So C, Lage DE, Slocum CS, et al. Utility of functional metrics assessed during acute care on hospital outcomes: a systematic review. PM \& R : the journal of injury, function, and rehabilitation. 2019;11(5):522-32. doi: 10.1002/pmrj.12013. Exclusion Code: X1.

646. Somers SA, Hamblin A, Verdier JM, et al. Covering low-income childless adults in Medicaid: experiences from selected states. Hamilton, N.J.: Center for Health Care Strategies, Inc.; 2010. Exclusion Code: X1.

647. Soril LJ, Leggett LE, Lorenzetti DL, et al. Reducing frequent visits to the emergency department: a systematic review of interventions. PLoS One. 2015;10(4):e0123660. doi: 10.1371/journal.pone.0123660. PMID: 25874866. Exclusion Code: X1.

648. Sovso MB, Klojgaard TA, Hansen PA, et al. Repeated ambulance use is associated with chronic diseases - a population-based historic cohort study of patients' symptoms and diagnoses. Scand J Trauma Resusc Emerg Med. 2019 Apr 16;27(1):46. doi: 10.1186/s13049-0190624-4. PMID: 30992042. Exclusion Code: X1.

649. Sparling A. Evaluation of a Personalized Care Management Program for High Hospital Utilizers. Atrium Health. Charlotte, NC: January 27, 2021 2021. Exclusion Code: X9. 
650. Springer AM, Condon JR, Li SQ, et al. Frequent use of hospital inpatient services during a nine year period: a retrospective cohort study. BMC Health Serv Res. 2017 May 12;17(1):348. doi: 10.1186/s12913-017-2285-1. PMID: 28499388. Exclusion Code: X1.

651. Sriram V, Wiklund LO, Klein A, et al. Understanding variation in hospitalization trajectory among high cost, high need patients enrolled in the comprehensive care physician (CCP) program. J Gen Intern Med. 2019;34(2):S393-S4. doi: 10.1007/11606.1525-1497. Exclusion Code: $\mathrm{X} 1$.

652. Stahl JE, Dossett ML, LaJoie AS, et al. Relaxation response and resiliency training and its effect on healthcare resource utilization. PLoS One. 2015;10(10):e0140212. doi: 10.1371/journal.pone.0140212. PMID: 26461184. Exclusion Code: X1.

653. Stark P. Advancing Complex Case Management Competencies in a Health Care System. Prof Case Manag. 2020 Jan/Feb;25(1):19-25. doi: 10.1097/ncm.0000000000000361. PMID: 31764712. Exclusion Code: X2.

654. Stefanescu Schmidt AC, DeFaria Yeh D, Tabtabai S, et al. National trends in hospitalizations of adults with tetralogy of fallot. Am J Cardiol. 2016 Sep 15;118(6):906-11. doi: 10.1016/j.amjcard.2016.06.034. PMID: 27530825. Exclusion Code: X1.

655. Stergiopoulos V, Gozdzik A, Cohen A, et al. The effect of brief case management on emergency department use of frequent users in mental health: findings of a randomized controlled trial. PLoS One. 2017;12(8):e0182157. doi: 10.1371/journal.pone.0182157. PMID: 28771524. Exclusion Code: X1.

656. Stergiopoulos V, Gozdzik A, Tan de Bibiana J, et al. Brief case management versus usual care for frequent users of emergency departments: the Coordinated Access to Care from Hospital Emergency Departments (CATCH-ED) randomized controlled trial. BMC Health Serv Res. 2016 Aug 24;16(1):432. doi: 10.1186/s12913-016-1666-1. PMID: 27557705. Exclusion Code: X1.

657. Sterk CE, Theall KP, Elifson KW. Health care utilization among drug-using and non-drug-using women. J Urban Health. 2002 Dec;79(4):586-99. doi: 10.1093/jurban/79.4.586. PMID: 12468678. Exclusion Code: X1.
658. Stey AM, Russell MM, Zingmond DS, et al. Using merged clinical and claims registry data to identify high utilizers of surgical inpatient care 1 year after colectomy. J Am Coll Surg. 2015 Aug;221(2):441-51.e1. doi: 10.1016/j.jamcollsurg.2015.03.024. PMID: 26141469. Exclusion Code: X1.

659. Stirbu I, Kunst AE, Mielck A, et al. Inequalities in utilisation of general practitioner and specialist services in 9 European countries. BMC Health Serv Res. 2011 Oct 31;11:288. doi: 10.1186/1472-6963-11-288. PMID: 22040155. Exclusion Code: X1.

660. Straker JK, Boehle SG, Nelson IM, et al. Common sense for caring organizations: results from a study of high-performing home care agencies and nursing homes. Oxford, Ohio, Columbus, Ohio: Scripps Gerontology Center, Ohio Direct Service Workforce Initiative; 2013. Exclusion Code: X1.

661. Strategies CfHC. Complex Care Innovation Lab. 2013. https://www.chcs.org/project/complexcare-innovation-lab/. Exclusion Code: X2.

662. Stremikis K, Connors C, Hoo E. Intensive outpatient care program: a care model for the medically complex piloted by employers. Commonwealth Fund. New York, NY: Commonwealth Fund; 2017. Exclusion Code: $\mathrm{X} 1$.

663. Surbhi S, Munshi KD, Bell PC, et al. Drug therapy problems and medication discrepancies during care transitions in super-utilizers. J Am Pharm Assoc (2003). 2016 Nov - Dec;56(6):63342.e1. doi: 10.1016/j.japh.2016.07.004. PMID: 27720595. Exclusion Code: X1.

664. Szalda D, Steinway C, Greenberg A, et al. Developing a hospital-wide transition program for young adults with medical complexity. J Adolesc Health. 2019;65(4):476-82. doi: 10.1016/j.jadohealth.2019.04.008. Exclusion Code: X1.

665. Tadros AS, Castillo EM, Chan TC, et al. Effects of an emergency medical services-based resource access program on frequent users of health services. Prehosp Emerg Care. 2012 OctDec;16(4):541-7. doi: 10.3109/10903127.2012.689927. PMID: 22712694. Exclusion Code: X1.

666. Taylor L. Housing and health: an overview of the literature. Health Affairs/RWJF Health Policy Brief Princeton, NJ: 2018. https://www.healthaffairs.org/do/10.1377/hpb201 80313.396577/full/. doi: 10.1377/hpb20180313.396577. Exclusion Code: $\mathrm{X} 1$. 
667. Taylor LA, Byhoff E. Money Moves the Mare: The Response of Community-Based Organizations to Health Care's Embrace of Social Determinants. Milbank Q.38. doi: 10.1111/14680009.12491. Exclusion Code: X1.

668. Taylor WJ, Reitz AC, Coplin M, et al. Patterns of emergency department high utilizers at grady memorial hospital. Ann Emerg Med. 2017;70(4):S32. Exclusion Code: X4.

669. Teigland C, Pulungan Z. LEVERAGING DATADRIVEN INSIGHTS TO SUPPORT

DEVELOPMENT OF TARGETED

SUPPLEMENTAL BENEFITS UNDER NEWLY EXPANDED FLEXIBILITIES IN MEDICARE ADVANTAGE TO IMPROVE OUTCOMES IN HIGH-COST, HIGH-NEED BENEFICIARIES. Value Health. 2019 May;22:S302-S. doi: 10.1016/j.jval.2019.04.1456. Exclusion Code: X7.

670. ten Have M, Vollebergh W, Bijl RV, et al. Predictors of incident care service utilisation for mental health problems in the Dutch general population. Soc Psychiatry Psychiatr Epidemiol. 2001 Mar;36(3):141-9. doi: 10.1007/s001270050303. PMID: 11465786. Exclusion Code: X1.

671. Terra SM. What can claims data tell the case manager? Prof Case Manag. 2008 JulAug;13(4):195-208; quiz 9-10. doi: 10.1097/01.Pcama.0000327408.71354.52. PMID: 18636003. Exclusion Code: X1.

672. Tewarson H. Improving lives and reducing cost of care for high-need, high-cost Medicaid enrollees with mental illness and substance abuse disorders. National Governors Association, Center for Best Practices 2017. https://hsrproject.nlm.nih.gov/view_hsrproj_recor d/20191099. Exclusion Code: X7.

673. Thompson T, McQueen A, Croston M, et al. Social Needs and Health-Related Outcomes Among Medicaid Beneficiaries. Health Educ Behav. 2019 Jun;46(3):436-44. doi: 10.1177/1090198118822724. PMID: 30654655. Exclusion Code: X1.

674. Thornquist L, Biros M, Olander R, et al. Health care utilization of chronic inebriates. Acad Emerg Med. 2002 Apr;9(4):300-8. doi: 10.1111/j.15532712.2002.tb01323.x. PMID: 11927454.

Exclusion Code: X1.

675. Tompkins R, Khan A. ACHD Care in the United States: Complex Patients, Even More Complex Health Care System. Journal of the American College of Cardiology (JACC). 2020;76(2):1835. doi: 10.1016/j.jacc.2020.05.030. Exclusion Code: X1.
676. Trevena LJ, Simpson JM, Nutbeam D. Soup kitchen consumer perspectives on the quality and frequency of health service interactions. Int J Qual Health Care. 2003 Dec;15(6):495-500. doi: 10.1093/intqhe/mzg065. PMID: 14660532. Exclusion Code: X1.

677. Trivedi SP, Trawick E, Diuguid-Gerber J, et al. Resource intensive care transitions program impact on 90-day hospital readmissions. J Gen Intern Med. 2019;34(2):S763-. doi: 10.1007/11606.1525-1497. Exclusion Code: X5.

678. Tsega M, Shah T, Lewis C. The importance of sustainable partnerships for meeting the needs of complex patients: introducing the return-oninvestment calculator. Commonwealth Fund. 2019.

https://www.commonwealthfund.org/blog/2019/i mportance-sustainable-partnerships-meetingneeds-complex-patients-introducing-return. Exclusion Code: X1.

679. Turbow S, Fakunle O, Okosun IS. Multi- and single-year high-utilizers of inpatient services share many clinical and behavioral characteristics. , <Blank>: Springer Nature; 2018. p. 1614-5. Exclusion Code: X1.

680. University of New Mexico Health Sciences Center. Leverage innovative care delivery and coordination model: Project ECHO. New Mexico: CMS; 2019. Exclusion Code: X7.

681. Ustulin M, Woo J, Woo JT, et al. Characteristics of frequent emergency department users with type 2 diabetes mellitus in Korea. J Diabetes Investig. 2018 Mar;9(2):430-7. doi: 10.1111/jdi.12712. PMID: 28686322. Exclusion Code: X1.

682. Valaitis R, Cleghorn L, Ploeg J, et al. Disconnected relationships between primary care and community-based health and social services and system navigation for older adults: a qualitative descriptive study. BMC Fam Pract. 2020 Apr 23;21(1):69. doi: 10.1186/s12875-02001143-8. PMID: 32326880. Exclusion Code: X6.

683. van den Bussche H, Kaduszkiewicz H, Schafer I, et al. Overutilization of ambulatory medical care in the elderly German population?--An empirical study based on national insurance claims data and a review of foreign studies. BMC Health Serv Res. 2016 Apr 14;16:129. doi: 10.1186/s12913016-1357-y. PMID: 27074709. Exclusion Code: $\mathrm{X} 1$.

684. van der Feltz-Cornelis CM, van Oppen P, Ader $\mathrm{HJ}$, et al. Randomised controlled trial of a collaborative care model with psychiatric consultation for persistent medically unexplained symptoms in general practice. Psychother Psychosom. 2006;75(5):282-9. doi: 10.1159/000093949. Exclusion Code: X1. 
685. Van Orden J. Service design for the complex customer: An empirical analysis of mental health integration at Intermountain Healthcare: The University of Utah; 2010. Exclusion Code: X2.

686. Vanagas G, Klimaviciute-Gudauskiene R. Factors affecting electronic health information needs in primary care patients. Telemed $\mathrm{J} \mathrm{E}$ Health. 2012 Dec;18(10):724-8. doi: 10.1089/tmj.2012.0031. PMID: 23095004. Exclusion Code: X1.

687. Vargiu E, Fernandez JM, Gonzales-Gonzales M, et al. A self-management system for complex chronic patients. International Journal of Integrated Care. 2019;19:2. doi: 10.5334/ijic.s3101. Exclusion Code: X1.

688. Vedsted P, Fink P, Olesen F, et al. Psychological distress as a predictor of frequent attendance in family practice - A cohort study. Psychosomatics. 2001 Sep-Oct;42(5):416-22. doi:

10.1176/appi.psy.42.5.416. Exclusion Code: X1.

689. Veltman-Verhulst SM, van Rijn BB, Westerveld HE, et al. Polycystic ovary syndrome and earlyonset preeclampsia: reproductive manifestations of increased cardiovascular risk. Menopause. 2010 Sep-Oct;17(5):990-6. doi: 10.1097/gme.0b013e3181ddf705. PMID: 20551845. Exclusion Code: X1.

690. Verdier JM, Byrd V, Stone C. Enhanced primary care case management programs in Medicaid: issues and options for states. Hamilton, N.J.: Center for Health Care Strategies, Inc.; 2009. Exclusion Code: X1.

691. Vest JR, Grannis SJ, Haut DP, et al. Using structured and unstructured data to identify patients' need for services that address the social determinants of health. Int J Med Inform. 2017 Nov;107:101-6. doi: 10.1016/j.ijmedinf.2017.09.008. PMID: 29029685. Exclusion Code: X1.

692. Vickers KS, Ridgeway JL, Hathaway JC, et al. Integration of mental health resources in a primary care setting leads to increased provider satisfaction and patient access. Gen Hosp Psychiatry. 2013 Sep-Oct;35(5):461-7. doi: 10.1016/j.genhosppsych.2013.06.011. Exclusion Code: X1.

693. Vickery KD, Bodurtha P, Winkelman TNA, et al. Cross-Sector Service Use Among High Health Care Utilizers In Minnesota After Medicaid Expansion. Health Aff (Millwood). 2018 Jan;37(1):62-9. doi: 10.1377/hlthaff.2017.0991. PMID: 29309230. Exclusion Code: X9.
694. Vickery KD, Shippee ND, Guzman-Corrales LM, et al. Changes in quality of life among enrollees in Hennepin Health: a Medicaid expansion ACO. Med Care Res Rev. 2020 Feb;77(1):60-73. doi: 10.1177/1077558718769457. PMID: 29749288. Exclusion Code: X1.

695. Vickery KD, Shippee ND, Menk J, et al. Integrated, Accountable Care For Medicaid Expansion Enrollees: A Comparative Evaluation of Hennepin Health. Med Care Res Rev. 2020;77(1):46-59. doi: 10.1177/1077558718769481. Exclusion Code: $\mathrm{X} 12$.

696. Viveiros J. Using health care savings to construct supportive housing in New York. In Housing health: innovations in the field Exclusion Code: $\mathrm{X} 1$.

697. Viveiros J. Addressing housing as a health care treatment. Washington, D.C.: Center for Housing Policy; 2015. Exclusion Code: X1.

698. Vladutiu CJ, Stringer EM, Kandasamy V, et al. Emergency care utilization among pregnant Medicaid recipients in North Carolina: an analysis using linked claims and birth records. Maternal \& Child Health Journal. 2019;23(2):265-76. doi: 10.1007/s10995-0182651-6. Exclusion Code: X1.

699. Von Korff M, Lin EH, Fenton JJ, et al. Frequency and priority of pain patients' health care use. Clin J Pain. 2007 Jun;23(5):400-8. doi: 10.1097/AJP.0b013e31804ac020. PMID: 17515738. Exclusion Code: X4.

700. von Wachter M, Junger S, Renz D, et al. Psychosocial assessment and health care utilization after coronary bypass surgery. Gesundheitswesen. 2000 Aug-Sep;62(8-9):451-6. doi: 10.1055/s-2000-12614. Exclusion Code: X1.

701. Votto JJ, Scalise PJ, Barton RW, et al. An analysis of clinical outcomes and costs of a long term acute care hospital. J Med Econ. 2011;14(2):141-6. doi: 10.3111/13696998.2010.551163. PMID: 21241209. Exclusion Code: X1.

702. Wajnberg A, Hwang U, Torres L, et al. Characteristics of frequent geriatric users of an urban emergency department. J Emerg Med. 2012 Aug;43(2):376-81. doi: 10.1016/j.jemermed.2011.06.056. PMID: 22040771. Exclusion Code: X4.

703. Walker BH, McCown JS, Bowser D, et al. An assessment of emergency department use among Mississippi's Medicaid population. J Miss State Med Assoc. 2015 May;56(5):120-4. PMID: 26182673. Exclusion Code: X1. 
704. Walter LJ, Ackerson L, Allen S. Medicaid chemical dependency patients in a commercial health plan: do high medical costs come down over time? J Behav Health Serv Res. 2005 JulSep;32(3):253-63. PMID: 16010182. Exclusion Code: X1.

705. Wammes JJG, van der Wees PJ, Tanke MAC, et al. Systematic review of high-cost patients' characteristics and healthcare utilisation. BMJ Open. 2018 Sep 8; Mar;8(9):e023113. doi: 10.1136/bmjopen-2018-023113. PMID: 30196269. Exclusion Code: X7.

706. Wang D, Ing C, Blinderman CD, et al. Latent class analysis of specialized palliative care needs in adult intensive care units from a single academic medical center. J Pain Symptom Manage. 2019 Jan;57(1):73-8. doi: 10.1016/j.jpainsymman.2018.10.270. Exclusion Code: X1.

707. Wang L, Porter B, Maynard C, et al. Predicting risk of hospitalization or death among patients receiving primary care in the Veterans Health Administration. Med Care. 2013 Apr;51(4):36873. doi: 10.1097/MLR.0b013e31827da95a. PMID: 23269113. Exclusion Code: X1.

708. Washington C, Turbow S. Timing of hospital follow-up does not impact time to readmission among a population of high-utilizers. J Gen Intern Med. 2017 Apr;32:S355-S. Exclusion Code: X1.

709. Wasson JH, Ahles T, Johnson D, et al. Resource planning for patient-centered, collaborative care. J Ambul Care Manage. 2006;29(3):207-14. doi: 10.1097/00004479-200607000-00005. Exclusion Code: X1.

710. Watase H, Hagiwara Y, Chiba T, et al. Multicentre observational study of adults with asthma exacerbations: who are the frequent users of the emergency department in Japan? BMJ Open. 2015 Apr 28;5(4):e007435. doi: 10.1136/bmjopen-2014-007435. PMID: 25922104. Exclusion Code: X1.

711. Waxmonsky JA, Giese AA, McGinnis GF, et al. Colorado access' enhanced care management for high-cost, high-need Medicaid members: preliminary outcomes and lessons learned. J Ambul Care Manage. 2011 Apr-Jun;34(2):18391. doi: 10.1097/JAC.0b013e31820f64be. PMID: 21415616. Exclusion Code: X1.

712. Webster F, Rice K, Bhattacharyya O, et al. The mismeasurement of complexity: provider narratives of patients with complex needs in primary care settings. International Journal for Equity in Health. $2019 \mathrm{Jul}$; 18:8. doi: 10.1186/s12939-019-1010-6. Exclusion Code: X6.
713. Weeks DL, Daratha KB, Towle LA. Diabetes prevalence and influence on resource use in Washington state inpatient rehabilitation facilities, 2001 to 2007. Arch Phys Med Rehabil. 2009 Nov;90(11):1937-43. doi: 10.1016/j.apmr.2009.06.008. PMID: 19887220. Exclusion Code: X1.

714. Weil AR. Community Care For High-Need Patients. Health Aff (Millwood). 2019 Jun;38(6):891. doi: 10.1377/hlthaff.2019.00553. PMID: 31158007 . Exclusion Code: X9.

715. Weilburg JB, Wong HJ, Sistrom CL, et al. Behavioral Health Factors as Predictors of Emergency Department Use in the High-Risk, High-Cost Medicare Population. Psychiatr Serv. 2018 Dec 1;69(12):1230-7. doi: 10.1176/appi.ps.201800083. PMID: 30256183. Exclusion Code: X9.

716. Weiner JZ, McCloskey JK, Uratsu CS, et al. Primary Care Physician Stress Driven by Social and Financial Needs of Complex Patients. J Gen Intern Med. 2019 Jun;34(6):818-9. doi: 10.1007/s11606-018-4815-x. Exclusion Code: $\mathrm{X} 1$.

717. Weiner S, Schwartz A, Altman L, et al. Evaluation of a Patient-Collected Audio Audit and Feedback Quality Improvement Program on Clinician Attention to Patient Life Context and Health Care Costs in the Veterans Affairs Health Care System. JAMA Netw Open. 2020 Jul 1;3(7):e209644. doi: 10.1001/jamanetworkopen.2020.9644. PMID: 32735338. Exclusion Code: X1.

718. Weir RC, Proser M, Jester M, et al. Collecting Social Determinants of Health Data in the Clinical Setting: Findings from National PRAPARE Implementation. J Health Care Poor Underserved. 2020 May;31(2):1018-35. doi: 10.1353/hpu.2020.0075. Exclusion Code: X9.

719. Weiss Larry P. The identification of emotional disorders among high utilizers of medical care services: Adelphi; 1984. Exclusion Code: X7.

720. Weiss SJ, Ernst AA, Ong M, et al. Effect of a social services intervention among 911 repeat users. Am J Emerg Med. 2005 Jul;23(4):492-6. doi: 10.1016/j.ajem.2004.11.003. PMID: 16032618. Exclusion Code: X1.

721. Weissman GE, Kerlin MP, Yuan Y, et al. Potentially Preventable Intensive Care Unit Admissions in the United States, 2006-2015. Ann Am Thorac Soc. 2020 Jan;17(1):81-8. doi: 10.1513/AnnalsATS.201905-366OC. PMID: 31581801. Exclusion Code: X1. 
722. Wharam JF, Landon BE, Galbraith AA, et al. Emergency department use and subsequent hospitalizations among members of a highdeductible health plan. JAMA. 2007 Mar 14;297(10):1093-102. doi: 10.1001/jama.297.10.1093. PMID: 17356030. Exclusion Code: X1.

723. Wherry LR, Burns ME, Leininger LJ. Using selfreported health measures to predict high-need cases among Medicaid-eligible adults. Health Serv Res. 2014 Dec;49 Suppl 2:2147-72. doi: 10.1111/1475-6773.12222. PMID: 25130916. Exclusion Code: X1.

724. Whitson HE, Sanders LL, Pieper CF, et al. Correlation between symptoms and function in older adults with comorbidity. J Am Geriatr Soc. 2009 Apr;57(4):676-82. doi: 10.1111/j.15325415.2009.02178.x. PMID: 19392960. Exclusion Code: X1.

725. Whittington JW, Kontz C, Craig C, et al. Bright spots for patients with complex needs. Institute for Healthcare Improvement; 2014. Exclusion Code: X7.

726. Wier Guilhardi LM. An initial case study of a readmission and emergency department revisit reduction program for high utilizer patients at a large community hospital system in Massachusetts: ProQuest Information \& Learning; 2018. Exclusion Code: X1.

727. Wier Guilhardi LM. An Initial Case Study of a Readmission and Emergency Department Revisit Reduction Program for High Utilizer Patients at a Large Community Hospital System in Massachusetts. Boston University, ProQuest Dissertations Publishin; 2018. Exclusion Code: $\mathrm{X} 1$.

728. Wiler J, Pines JM, Ward MJ. Value and quality innovations in acute and emergency care. Cambridge, United Kingdom: Cambridge University Press; 2017. Exclusion Code: X1.

729. Williams BC. Limited effects of care management for high utilizers on total healthcare costs. Am J Manag Care. 2015 Apr;21(4):E244E6. Exclusion Code: X1.

730. Williams BC, Paik JL, Haley LL, et al. Centralized care management support for 'high utilizers' in primary care practices at an academic medical center. Care Management Journals. 2014;15(1):26-33. doi: 10.1891/15210987.15.1.26. Exclusion Code: X1.

731. Williamson AE, Johnson PC, Mullen K, et al. The disappearance of the "revolving door" patient in Scottish general practice: successful policies. BMC Fam Pract. 2012 Oct 4;13:95. doi: 10.1186/1471-2296-13-95. PMID: 23035887. Exclusion Code: X1.
732. Wilson K, Mottram P, Hussain M. Survival in the community of the very old depressed, discharged from medical inpatient care. Int J Geriatr Psychiatry. 2007 Oct;22(10):974-9. doi: 10.1002/gps.1773. Exclusion Code: X1.

733. Wilson M, Guta A, Waddell K, et al. The impacts of accountable care organizations on patient experience, health outcomes and costs: a rapid review. J Health Serv Res Policy. 2020;25(2):130-8. doi: 10.1177/1355819620913141. Exclusion Code: $\mathrm{X} 1$.

734. Wolff JL, Spillman B. Older adults receiving assistance with physician visits and prescribed medications and their family caregivers: prevalence, characteristics, and hours of care. J Gerontol B Psychol Sci Soc Sci. 2014 Nov;69 Suppl 1:S65-72. doi: 10.1093/geronb/gbu119. PMID: 25342825. Exclusion Code: X1.

735. Wong E, Guo R, Yoon J, et al. Impact of vha's primary intensive care management program on dual system use. Health Serv Res. 2020;55(SUPPL 1):77-8. doi: 10.1111/14756773.13437. Exclusion Code: X1.

736. Wong ES, Rosland AM, Fihn SD, et al. PatientCentered Medical Home Implementation in the Veterans Health Administration and Primary Care Use: Differences by Patient Comorbidity Burden. J Gen Intern Med. 2016 Dec;31(12):1467-74. doi: 10.1007/s11606-0163833-9. PMID: 27503440. Exclusion Code: X1.

737. Woo JH, Grinspan Z, Shapiro J, et al. Frequent users of hospital emergency departments in Korea characterized by claims data from the national health insurance: a cross sectional study. PLoS One. 2016;11(1):e0147450. doi: 10.1371/journal.pone.0147450. PMID: 26809051. Exclusion Code: X1.

738. Woodhouse J, Peterson M, Campbell C, et al. The efficacy of a brief behavioral health intervention for managing high utilization of ED services by chronic pain patients. J Emerg Nurs. 2010 Sep;36(5):399-403. doi: 10.1016/j.jen.2009.02.008. PMID: 20837207. Exclusion Code: X3.

739. Worthington DC. The role of psychology in integrated primary care for complex patients: Effects on mental health, utilization of medical services, and physiological markers of health: Virginia Commonwealth University; 2015. Exclusion Code: X1.

740. Wu FM, Slightam CA, Wong AC, et al. Intensive outpatient program effects on high-need patients' access, continuity, coordination, and engagement. Med Care. 2018 Jan;56(1):19-24. doi: 10.1097/mlr.0000000000000833. PMID: 29087980. Exclusion Code: X1. 
741. Wu J, Grannis SJ, Xu H, et al. A practical method for predicting frequent use of emergency department care using routinely available electronic registration data. BMC Emerg Med. 2016 Feb 9;16:12. doi: 10.1186/s12873-0160076-3. PMID: 26860825. Exclusion Code: X1.

742. Wyman MF, Liebzeit D, Voils CI, et al.?Hopes and wishes?: Goals of high -need, high -cost older patients and their caregivers. Patient Educ Couns. $2020 \mathrm{Jul} ; 103(7): 1428-34$. doi: 10.1016/j.pec.2020.02.022. Exclusion Code: X1.

743. Wyte-Lake T, Claver M, Johnson-Koenke R, et al. Hurricanes Harvey, Irma, and Maria: Exploring the Role of Home-Based Care Programs. Disaster Med Public Health Prep. 2020 Feb;14(1):119-24. doi: 10.1017/dmp.2019.158. Exclusion Code: X1.

744. Xiang X, Zuverink A, Rosenberg W, et al. Social work-based transitional care intervention for super utilizers of medical care: A retrospective analysis of the bridge model for super utilizers. Soc Work Health Care. 2019;58(1):126-41. doi: 10.1080/00981389.2018.1547345. Exclusion Code: X1.

745. Xin H. How do high cost-sharing policies for physician care affect inpatient care use and costs among people with chronic disease? J Ambul Care Manage. 2015 Apr-Jun;38(2):100-8. doi: 10.1097/jac.0000000000000050. PMID: 25748258. Exclusion Code: X1.

746. Xin H. High-cost sharing policies and non-urgent emergency department visits. Int J Health Care Qual Assur. 2018 Aug 13;31(7):735-45. doi: 10.1108/ijhcqa-05-2017-0089. PMID: 30354887. Exclusion Code: X1.

747. Xin H, Harman JS, Yang Z. How do high costsharing policies for physician care affect total care costs among people with chronic disease? J Insur Med. 2014;44(1):38-48. PMID: 25004597. Exclusion Code: X1.

748. Xing J, Goehring C, Mancuso D. Care coordination program for Washington State Medicaid enrollees reduced inpatient hospital costs. Health Aff (Millwood). 2015

Apr;34(4):653-61. doi:

10.1377/hlthaff.2014.0655. PMID: 25847649.

Exclusion Code: X1.
749. Yan J, Linn KA, Powers BW, et al. Applying Machine Learning Algorithms to Segment HighCost Patient Populations. J Gen Intern Med. 2019 Feb;34(2):211-7. doi: 10.1007/s11606-018-47608. PMID: 30543022. Exclusion Code: X4.

750. Yedidia MJ. Competencies for engaging highneeds patients in primary care. Healthc (Amst). 2018 Jun;6(2):122-7. doi: 10.1016/j.hjdsi.2017.06.005. PMID: 29217389. Exclusion Code: X1.

751. Yip J, Nishita CM, Crimmins EM, et al. Highcost users among dual eligibles in three care settings. J Health Care Poor Underserved. 2007 Nov;18(4):950-65. doi: 10.1353/hpu.2007.0109. PMID: 17982217. Exclusion Code: X1.

752. Yotani N, Ishiguro A, Sakai H, et al. Factorassociated caregiver burden in medically complex patients with special health-care needs. Pediatr Int. 2014 Oct;56(5):742-7. doi: 10.1111/ped.12339. PMID: 24628805. Exclusion Code: X1.

753. Zhang YK, Grinspan Z, Khullar D, et al. Developing an actionable patient taxonomy to understand and characterize high-cost Medicare patients. Healthcare-the Journal of Delivery Science and Innovation. 2020 Mar;8(1):6. doi: 10.1016/j.hjdsi.2019.100406. Exclusion Code: X9.

754. Zulman D. Evaluating innovative care models for high-utilizing patients. VA Palo Alto Health Care System, Center for Innovation to Implementation. 2013.

https://www.hsrd.research.va.gov/research/abstra cts.cfm?Project_ID=2141703149. Exclusion Code: X1.

755. Zulman DM, Chang ET, Wong A, et al. Effects of intensive primary care on high-need patient experiences: survey findings from a Veterans Affairs randomized quality improvement trial. J Gen Intern Med. 2019 May;34(Suppl 1):75-81. doi: 10.1007/s11606-019-04965-0. PMID: 31098977. Exclusion Code: X9.

756. Zulman DM, Pal Chee C, Ezeji-Okoye SC, et al. Effect of an intensive outpatient program to augment primary care for high-need Veterans Affairs patients: a randomized clinical trial. JAMA Intern Med. 2017 Feb 1;177(2):166-75. doi: 10.1001/jamainternmed.2016.8021. PMID: 28027338. Exclusion Code: X1. 


\section{Detailed Results Tables}

Key Question 1: What criteria identify or predict that patients will be highneed, high-cost ( $\mathrm{HNHC})$ ? 
KQ 1a: How do criteria incorporate patient clinical characteristics?

Table B-1. Descriptive multivariate, ED visits outcome $(n=13)$

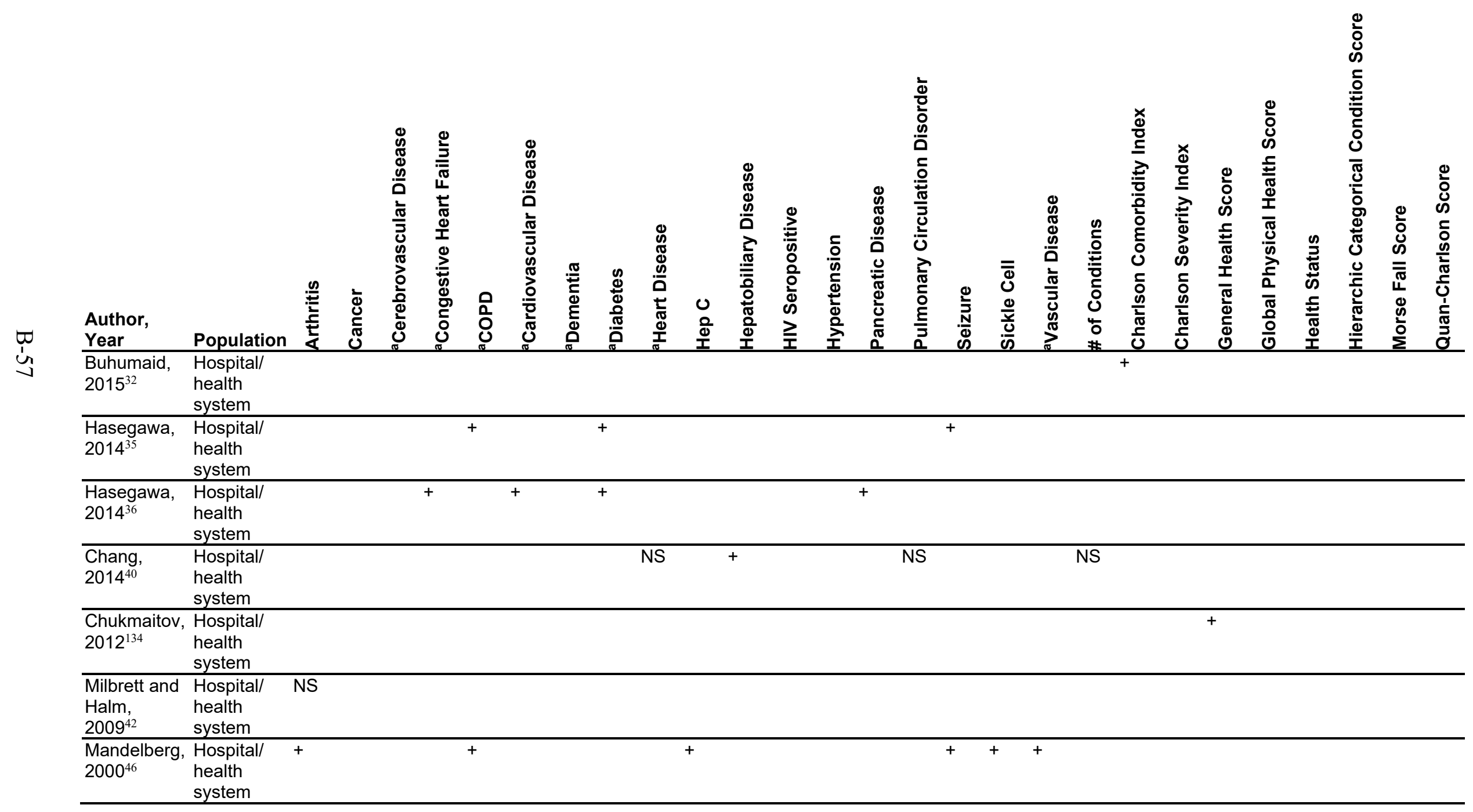




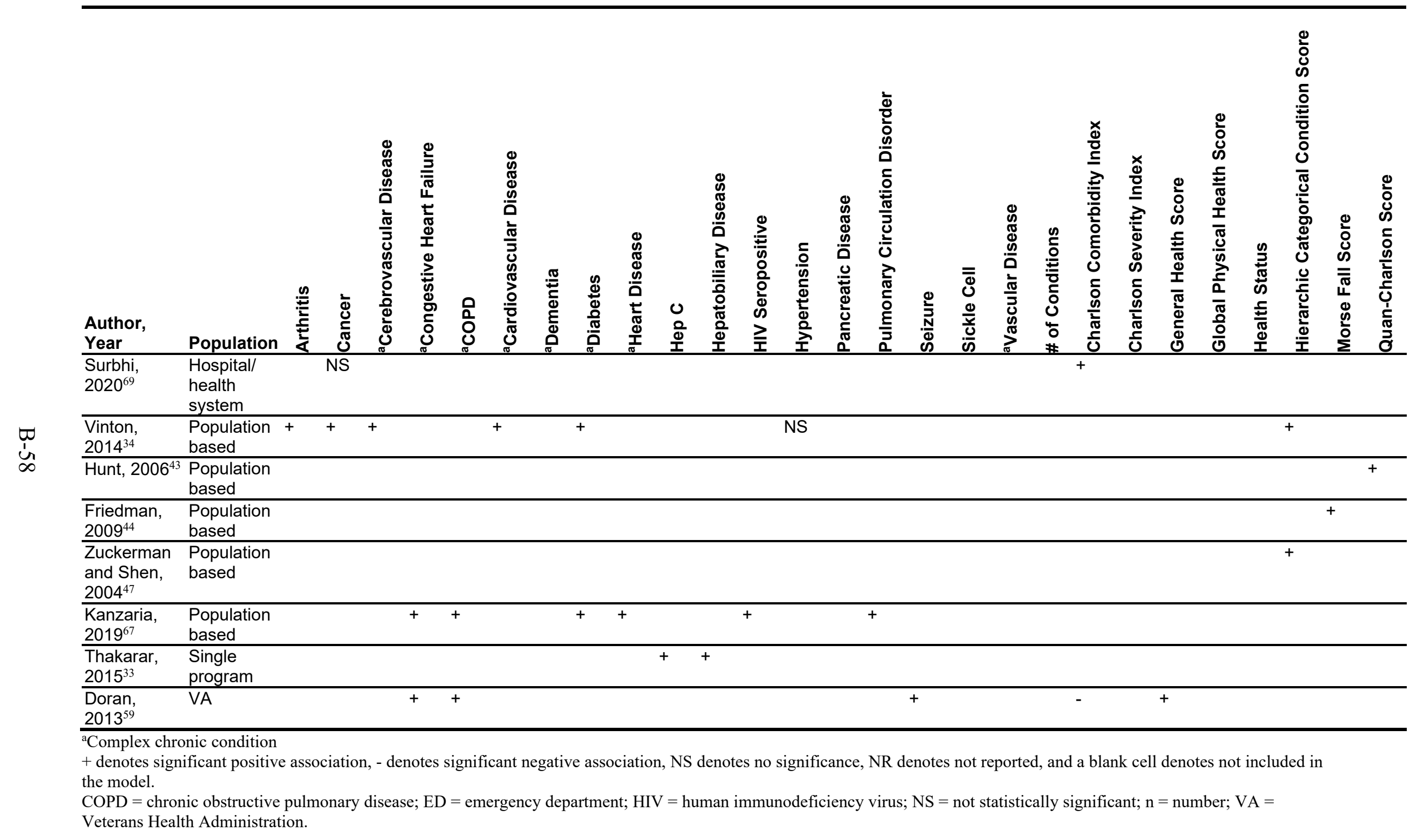




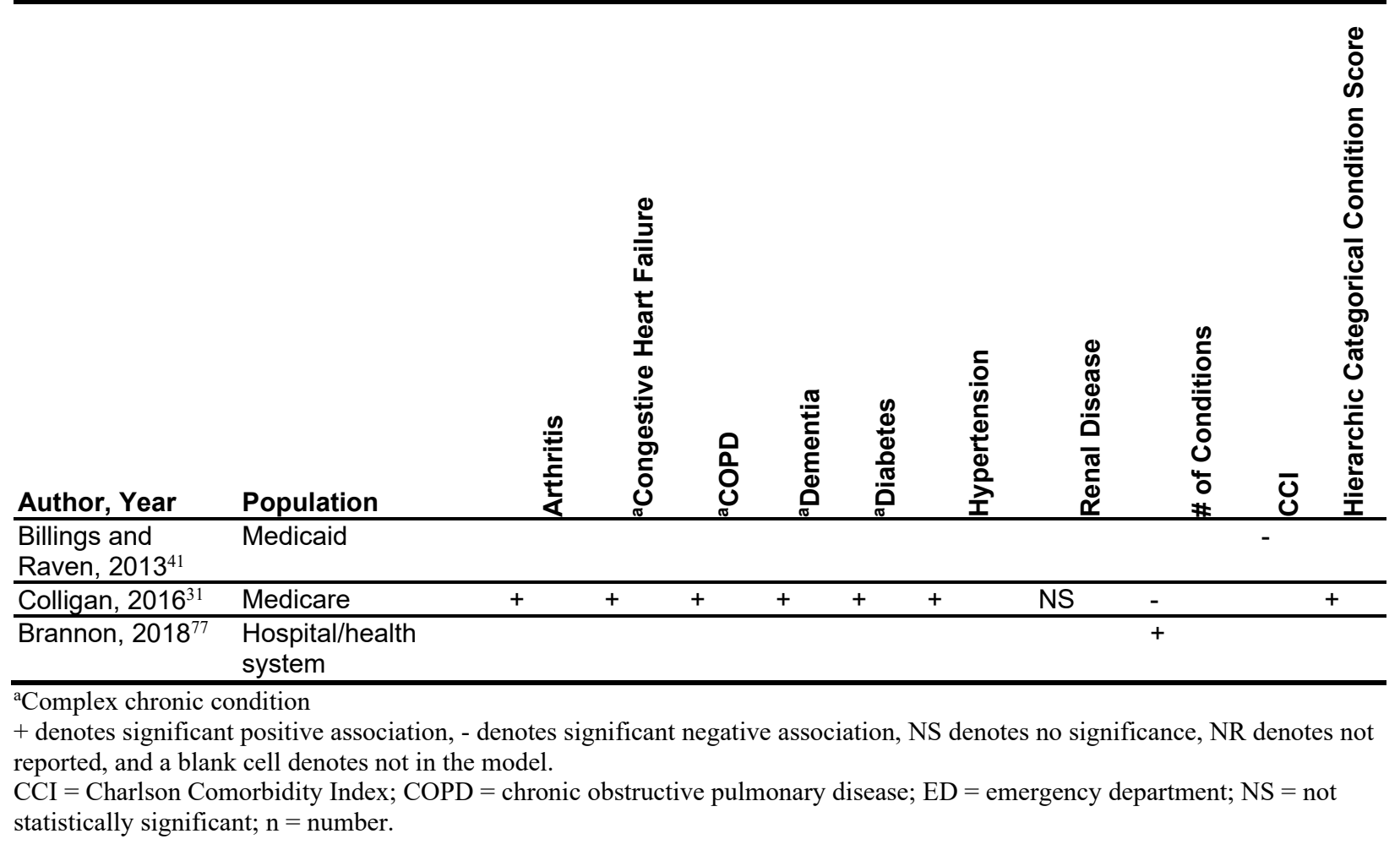

Table B-3. Descriptive multivariate, IP visits outcome $(n=2)$

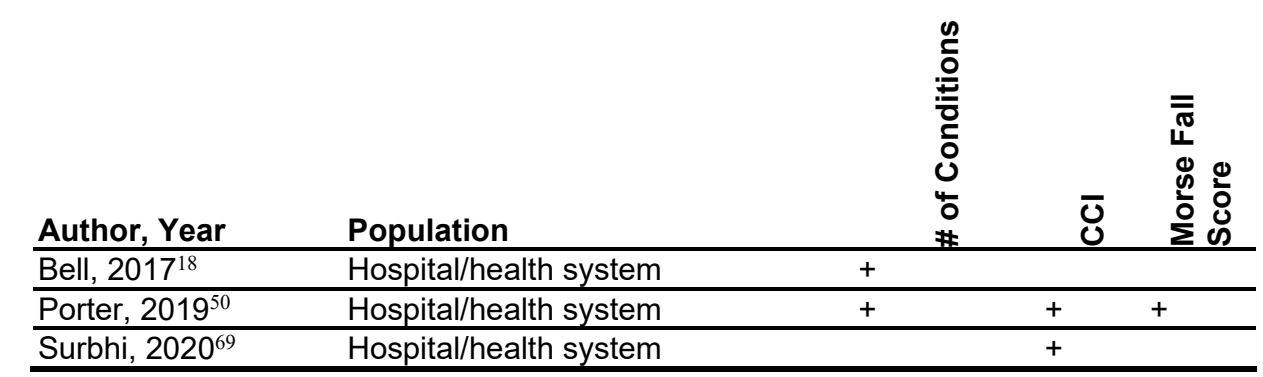

+ denotes significant positive association, - denotes significant negative association, NS denotes no significance, NR denotes not reported, and a blank cell denotes not included in the model.

$\mathrm{CCI}=$ Charlson Comorbidity Index ; IP = inpatient; $\mathrm{n}=$ number. 


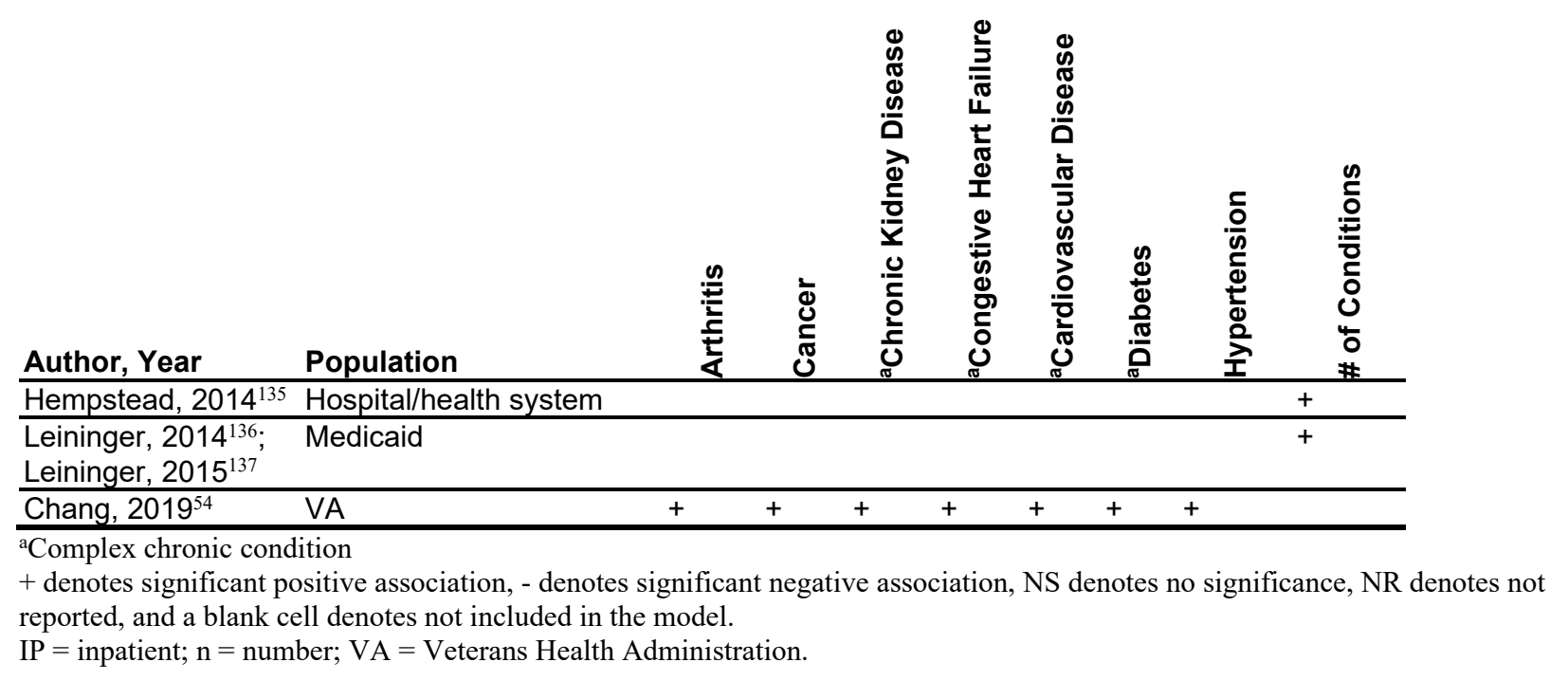

Table B-5. Descriptive multivariate, all visits outcome $(n=2)$

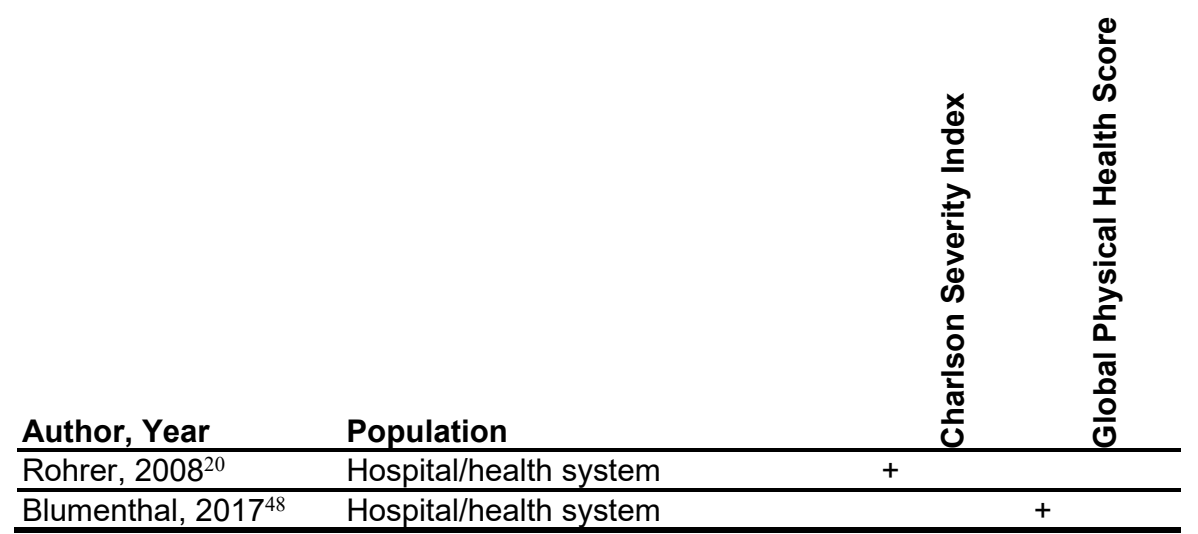

+ denotes significant positive association, - denotes significant negative association, NS denotes no significance, NR denotes not reported, and a blank cell denotes not included in the model.

$\mathrm{n}=$ number. 


\begin{tabular}{|c|c|c|c|c|c|c|c|}
\hline Author, Year & Population & 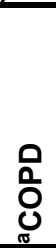 & 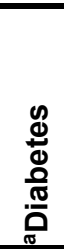 & 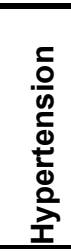 & 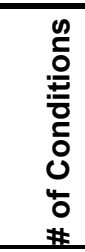 & $\bar{U}$ & 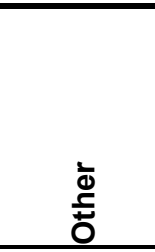 \\
\hline Meek, $2000^{24}$ & $\begin{array}{l}\text { Commercial (including } \\
\mathrm{HMO} \text { ) }\end{array}$ & & & JS & & & \\
\hline \multicolumn{4}{|c|}{$\begin{array}{l}\text { Wherry, 2014 }{ }^{138} ; \text { Leininger Population based } \\
\text { and Avery, } 2015^{137}\end{array}$} & \multicolumn{4}{|c|}{+} \\
\hline Reichard, 2015 & Population based & & & & $+/ \mathrm{NS}$ & & Disability + \\
\hline
\end{tabular}

${ }^{\mathrm{a} C o m p l e x}$ chronic condition

+ denotes significant positive association, - denotes significant negative association, NS denotes no significance, NR denotes not reported, and a blank cell denotes not included in the model. +/NS denotes performance across multiple models within the study, ranging from a positive significant association to no significance.

$\mathrm{CCI}=$ Charlson Comorbidity Index; COPD = chronic obstructive pulmonary disease; $\mathrm{HMO}=$ health maintenance organization; $\mathrm{NS}=$ not statistically significant; $\mathrm{n}=$ number.

Table B-7. Descriptive multivariate, cost outcome $(n=3)$

\begin{tabular}{|c|c|c|c|c|c|c|c|c|c|}
\hline Author, Year & Population & 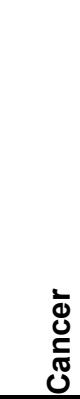 & 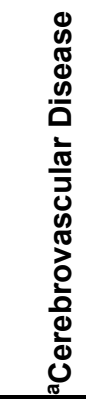 & 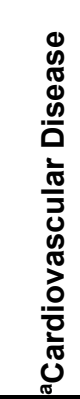 & $\begin{array}{l}\text { d } \\
\stackrel{+}{ \pm} \\
\stackrel{0}{0} \\
\stackrel{\sigma}{0} \\
\stackrel{0}{0}\end{array}$ & 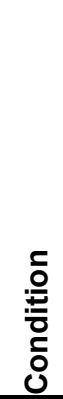 & 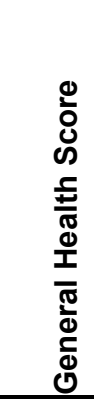 & 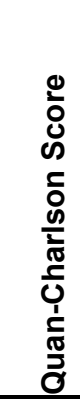 & 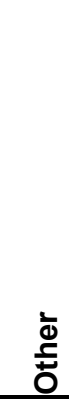 \\
\hline Bayliss, $2016^{56}$ & Commercial (including HMO) & & & & & & & & + \\
\hline Robinson, $2016^{19}$ & Commercial (including $\mathrm{HMO}$ ) & NS & NS & + & - & & NS & + & \\
\hline Figueroa, $2019^{71}$ & Medicare & & + & + & + & & & & \\
\hline
\end{tabular}


Table B-8. Predictive, cost outcome $(n=1)$

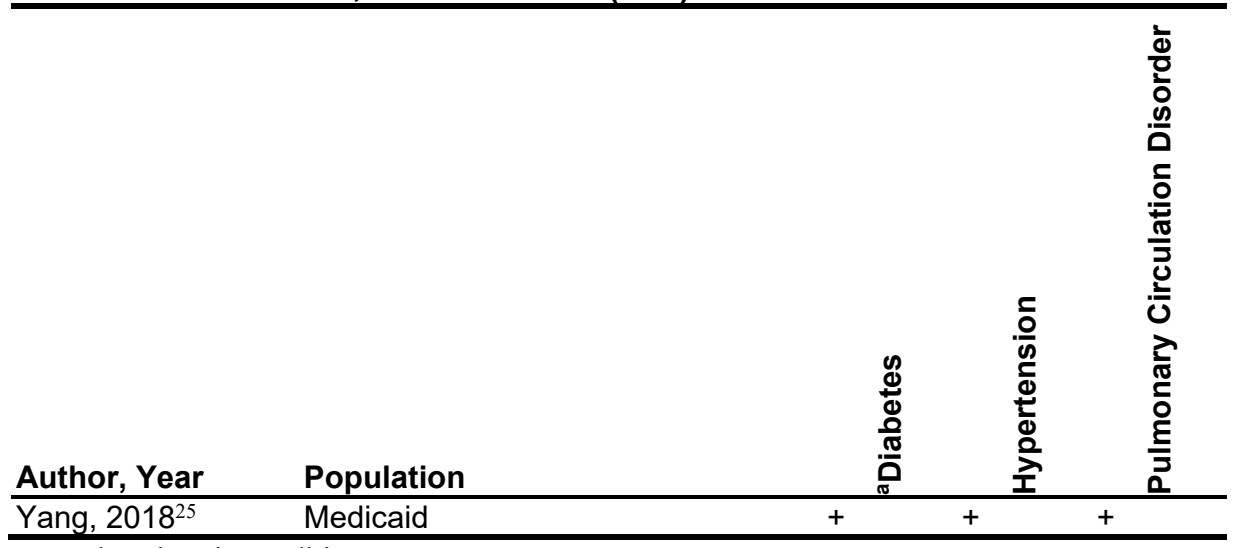

${ }^{\mathrm{a} C o m p l e x}$ chronic condition

+ denotes significant positive association, - denotes significant negative association, NS denotes no significance, NR denotes not reported, and a blank cell denotes not included in the model.

$\mathrm{n}=$ number. 
$\mathrm{KQ} 1 \mathrm{~b}$ : How do criteria incorporate patient demographic, behavioral health, and social risk factors?

Table B-9. Multivariate descriptive results

\begin{tabular}{|c|c|c|c|c|c|c|c|c|c|c|c|c|c|}
\hline Author, Year & Outcome & Population & Female & Age & Race/Ethnicity & $\begin{array}{l}\text { Depres- } \\
\text { sion }\end{array}$ & $\begin{array}{l}\text { Severe } \\
\text { Mental } \\
\text { Illness }\end{array}$ & $\begin{array}{l}\text { Other } \\
\text { Mental } \\
\text { Illness }\end{array}$ & $\begin{array}{l}\text { Sub- } \\
\text { stance } \\
\text { Use }\end{array}$ & $\begin{array}{l}\text { Alcohol } \\
\text { Use }\end{array}$ & $\begin{array}{l}\text { Home- } \\
\text { less- } \\
\text { ness }\end{array}$ & $\begin{array}{l}\text { Employ- } \\
\text { ment }\end{array}$ & $\begin{array}{l}\text { Other Social } \\
\text { Risk Factors }\end{array}$ \\
\hline $\begin{array}{l}\text { Bayliss, } \\
2016^{56}\end{array}$ & Cost (top 25\%) & $\begin{array}{l}\text { Commercial } \\
\text { (including HMO) }\end{array}$ & + & Over 55+ & & + & & & & & & & \\
\hline $\begin{array}{l}\text { Robinson, } \\
2016^{19}\end{array}$ & $\begin{array}{l}\text { Cost (top } 10 \% \text { of } \\
\text { all-cause total } \\
\text { costs) }\end{array}$ & $\begin{array}{l}\text { Commercial } \\
\text { (including } \mathrm{HMO} \text { ) }\end{array}$ & NS & NS & & NS & & $\mathrm{NS} /+$ & + & NS & & NS & \\
\hline $\begin{array}{l}\text { Sterling, } \\
2018^{21}\end{array}$ & Cost (top 20\%) & $\begin{array}{l}\text { Commercial } \\
\text { (including HMO) }\end{array}$ & & & & & & + & & & & & $\begin{array}{l}\text { Any financial } \\
\text { burden }+\end{array}$ \\
\hline $\begin{array}{l}\text { Walker, } \\
2003^{51}\end{array}$ & $\begin{array}{l}\text { Cost (adjusted } \\
\text { annual cost } \\
\text { ratios of median } \\
\text { healthcare costs) }\end{array}$ & $\begin{array}{l}\text { Commercial } \\
\text { (including } \mathrm{HMO} \text { ) }\end{array}$ & NR & NR & NR & & & PTSD+ & & & & & \\
\hline $\begin{array}{l}\text { Berkowitz, } \\
2018^{70}\end{array}$ & $\begin{array}{l}\text { Cost (top 10\%, } \\
5 \% \& 2 \% \text { ) }\end{array}$ & $\begin{array}{l}\text { Population } \\
\text { based }\end{array}$ & NS & + & $\begin{array}{l}\text { Black: + } \\
\text { White: + } \\
\text { Hispanic: }\end{array}$ & & & & & & & & $\begin{array}{l}\text { Food } \\
\text { insecurity: + } \\
\text { Ed: NS } \\
\text { Income: NS }\end{array}$ \\
\hline $\begin{array}{l}\text { Figueroa, } \\
2019^{71}\end{array}$ & Cost (top 10\%) & Medicare & - & - & $\begin{array}{l}\text { Black: + } \\
\text { Hispanic: }+\end{array}$ & + & & & & & & & $\begin{array}{l}\text { Income: + } \\
\text { Dual elig: + }\end{array}$ \\
\hline Behr, 2016 & $\begin{array}{l}\text { ED visits }(2+, 3+ \\
4+, 5+)\end{array}$ & $\begin{array}{l}\text { Hospital/health } \\
\text { system }\end{array}$ & + & & Black +/NS & & & + & + & & & $\begin{array}{l}\text { Employed } \\
+\end{array}$ & \\
\hline Bell, $2017^{18}$ & $\begin{array}{l}\text { Inpatient visits } \\
(3+)\end{array}$ & $\begin{array}{l}\text { Hospital/health } \\
\text { system }\end{array}$ & NR & NR & NS & & & & + & + & + & & $\begin{array}{l}\text { Community- } \\
\text { level income } \\
<48 \text { kS }\end{array}$ \\
\hline $\begin{array}{l}\text { Blumenthal, } \\
2017^{48}\end{array}$ & $\begin{array}{l}\text { All utilization (ED } \\
\text { visits, acute } \\
\text { hospitalizations) }\end{array}$ & $\begin{array}{l}\text { Hospital/health } \\
\text { system }\end{array}$ & NR & NR & NR & & & $\begin{array}{l}\text { Lowest } \\
\text { quartile in } \\
\text { Global } \\
\text { Mental } \\
\text { Health } \\
\text { score NS }\end{array}$ & & & & & \\
\hline $\begin{array}{l}\text { Buhumaid, } \\
2014^{32}\end{array}$ & ED visits $(4+)$ & $\begin{array}{l}\text { Hospital/health } \\
\text { system }\end{array}$ & NS & $\begin{array}{l}\text { Age }(40+) \\
\text { NS }\end{array}$ & Black + & & & & - & + & + & & \\
\hline
\end{tabular}




\begin{tabular}{|c|c|c|c|c|c|c|c|c|c|c|c|c|c|}
\hline Author, Year & Outcome & Population & Female & Age & Race/Ethnicity & $\begin{array}{l}\text { Depres- } \\
\text { sion }\end{array}$ & $\begin{array}{l}\text { Severe } \\
\text { Mental } \\
\text { Illness }\end{array}$ & $\begin{array}{l}\text { Other } \\
\text { Mental } \\
\text { Illness }\end{array}$ & $\begin{array}{l}\text { Sub- } \\
\text { stance } \\
\text { Use } \\
\end{array}$ & $\begin{array}{l}\text { Alcohol } \\
\text { Use }\end{array}$ & $\begin{array}{l}\text { Home- } \\
\text { less- } \\
\text { ness }\end{array}$ & $\begin{array}{l}\text { Employ- } \\
\text { ment }\end{array}$ & $\begin{array}{l}\text { Other } \\
\text { Social Risk } \\
\text { Factors } \\
\end{array}$ \\
\hline $\begin{array}{l}\text { Chang, } \\
2014^{40}\end{array}$ & $\begin{array}{l}\text { ED visits (4+ in } \\
12 \text { months) }\end{array}$ & $\begin{array}{l}\text { Hospital/health } \\
\text { system }\end{array}$ & NS & NS & Not in model & & & $\begin{array}{l}\text { Personality } \\
\mathrm{dx}+\end{array}$ & $\begin{array}{l}\text { SUD dx } \\
\text { NS } \\
\text { Positive } \\
\text { cocaine } \\
\text { screen+ }\end{array}$ & NS & + & & \\
\hline $\begin{array}{l}\text { Chukmaitov, } \\
2012^{134}\end{array}$ & $\begin{array}{l}\text { ED visits }(1+, \\
1-3,4+)\end{array}$ & $\begin{array}{l}\text { Hospital/health } \\
\text { system }\end{array}$ & + & $\begin{array}{l}\text { Age (30-39) } \\
- \\
(40-49) \text { NS } \\
(50-64)+ \\
(65-74)+ \\
(75-84)+ \\
(>85)-\end{array}$ & $\begin{array}{l}\text { Black + } \\
\text { Hispanic + } \\
\text { Other - }\end{array}$ & & & & & & & & \\
\hline $\begin{array}{l}\text { Doran, } \\
2014^{38}\end{array}$ & ED visits $(3+)$ & $\begin{array}{l}\text { Hospital/health } \\
\text { system }\end{array}$ & NR & NR & NR & & & & & & & & \\
\hline $\begin{array}{l}\text { Hasegawa, } \\
2014^{35}\end{array}$ & $\begin{array}{l}\text { ED visits (3+ } \\
\text { ED, 30-day ED } \\
\text { revisit, IP visit) }\end{array}$ & $\begin{array}{l}\text { Hospital/health } \\
\text { system }\end{array}$ & - & Age $(<74)+$ & $\begin{array}{l}\text { Black + } \\
\text { Hispanic + } \\
\text { Other NS }\end{array}$ & + & & & + & & & & $\begin{array}{l}\text { Quartiles } \\
\text { for median } \\
\text { household } \\
\text { income of } \\
\text { patient's } \\
\text { zip code } \\
1 \text { (lowest) } \\
\text { and } 2+ \\
3 \text { NS }\end{array}$ \\
\hline $\begin{array}{l}\text { Hasegawa, } \\
2014^{36}\end{array}$ & ED visits $(3+)$ & $\begin{array}{l}\text { Hospital/health } \\
\text { system }\end{array}$ & - & Over 54+ & $+/ \mathrm{NS}$ & + & + & & + & & & & $\begin{array}{l}\text { Lowest } \\
\text { quartile } \\
\text { median } \\
\text { income + }\end{array}$ \\
\hline $\begin{array}{l}\text { Hasegawa, } \\
2014^{37}\end{array}$ & $\begin{array}{l}\text { ED visits }(0,1- \\
2,3-5,6+)\end{array}$ & $\begin{array}{l}\text { Hospital/health } \\
\text { system }\end{array}$ & $\mathrm{NS} /-$ & $40-54 \mathrm{NS} /+$ & NS & & & & & & & & $\begin{array}{l}\text { Lowest } \\
\text { quartile } \\
\text { median } \\
\text { income NS }\end{array}$ \\
\hline Liu, $2013^{39}$ & $\begin{array}{l}\text { ED visits }(4+, \\
4-7,8-18,19+)\end{array}$ & $\begin{array}{l}\text { Hospital/health } \\
\text { system }\end{array}$ & NR & NR & NR & & & + & + & + & & & \\
\hline $\begin{array}{l}\text { Mandelburg, } \\
2000^{46}\end{array}$ & ED visits $(5+)$ & $\begin{array}{l}\text { Hospital/health } \\
\text { system }\end{array}$ & NS & $\begin{array}{l}\text { Age (30-59) } \\
+\end{array}$ & $\begin{array}{l}\text { Black + } \\
\text { Hispanic - } \\
\text { Native } \\
\text { American + } \\
\text { Asian - } \\
\text { Other - }\end{array}$ & & & & & + & + & & \\
\hline $\begin{array}{l}\text { Surbhi, } \\
2020^{69}\end{array}$ & ED visits & $\begin{array}{l}\text { Hospital/health } \\
\text { system }\end{array}$ & NS & & Black + & & & + & & & & & \\
\hline
\end{tabular}




\begin{tabular}{|c|c|c|c|c|c|c|c|c|c|c|c|c|c|}
\hline Author, Year & Outcome & Population & Female & Age & Race/Ethnicity & $\begin{array}{l}\text { Depres- } \\
\text { sion }\end{array}$ & $\begin{array}{l}\text { Severe } \\
\text { Mental } \\
\text { Illness }\end{array}$ & $\begin{array}{l}\text { Other } \\
\text { Mental } \\
\text { Illness }\end{array}$ & $\begin{array}{l}\text { Sub- } \\
\text { stance } \\
\text { Use }\end{array}$ & $\begin{array}{l}\text { Alcohol } \\
\text { Use }\end{array}$ & $\begin{array}{l}\text { Home- } \\
\text { less- } \\
\text { ness }\end{array}$ & $\begin{array}{l}\text { Employ- } \\
\text { ment }\end{array}$ & $\begin{array}{l}\text { Other Social Risk } \\
\text { Factors }\end{array}$ \\
\hline $\begin{array}{l}\text { Castillo, } \\
2018^{65}\end{array}$ & $\begin{array}{l}\text { ED visits }(>5) \\
\text { vs } 1-5\end{array}$ & $\begin{array}{l}326 \text { hospitals in } \\
\text { CA }\end{array}$ & - & $\begin{array}{l}75-84 \& \\
85+\text { vs } \\
65-73-\end{array}$ & $\begin{array}{l}\text { Black: + } \\
\text { Hispanic + } \\
\text { Asian/Pacific } \\
\text { Islander - } \\
\end{array}$ & & & + & + & & & & \\
\hline $\begin{array}{l}\text { Millbrett, } \\
2009^{42}\end{array}$ & ED visits $(>6)$ & $\begin{array}{l}\text { Hospital/health } \\
\text { system }\end{array}$ & - & & Nonblack + & & NS & & & & & $\begin{array}{l}\text { Part-time } \\
\text { employmen } \\
\mathrm{t} \\
\text { retired/une } \\
\text { mployed,++ }\end{array}$ & \\
\hline $\begin{array}{l}\text { Porter, } \\
2019^{50}\end{array}$ & $\begin{array}{l}\text { Inpatient visits } \\
(3+)\end{array}$ & $\begin{array}{l}\text { Hospital/health } \\
\text { system }\end{array}$ & NR & $\begin{array}{l}\text { Under } \\
40+\end{array}$ & NR & & & + & + & & & & \\
\hline $\begin{array}{l}\text { Emechebe, } \\
2019\end{array}$ & $\begin{array}{l}\text { Inpatient visits } \\
(2+)\end{array}$ & $\begin{array}{l}\text { Medicaid } \\
\text { managed care } \\
\text { and Medicare } \\
\text { Advantage } \\
\text { health plan }\end{array}$ & NR & NR & NR & NR & NR & NR & NR & $\mathrm{NR}$ & $\begin{array}{l}\text { Housin } \\
\text { g } \\
\text { support } \\
\text { need }+\end{array}$ & & $\begin{array}{l}\text { Needs: Financial } \\
\text { assistance +; food } \\
+; \text { transport-ation } \\
+ \text {, medication } \\
\text { assistance + }\end{array}$ \\
\hline $\begin{array}{l}\text { Rohrer, } \\
2008^{20}\end{array}$ & $\begin{array}{l}\text { All utilization } \\
\text { ( } 27+\text { outpatient } \\
\text { visits) }\end{array}$ & $\begin{array}{l}\text { Hospital/health } \\
\text { system }\end{array}$ & NS & NS & Not in model & & & & & & & & \\
\hline $\begin{array}{l}\text { Ruger, } \\
2004^{45}\end{array}$ & $\begin{array}{l}\text { ED visits }(1,2, \\
20+)\end{array}$ & $\begin{array}{l}\text { Hospital/health } \\
\text { system }\end{array}$ & NR & NR & Not in model & & & & & & & & \\
\hline $\begin{array}{l}\text { Kanzaria, } \\
2019^{67}\end{array}$ & ED visits (4-7) & $\begin{array}{l}\text { Medicaid MCO } \\
\text { in one city }\end{array}$ & - & Older: - & $\begin{array}{l}\text { Black: + } \\
\text { Hispanic: NS } \\
\text { Asian: - }\end{array}$ & + & + & + & + & + & + & & $\begin{array}{l}\text { Interaction with } \\
\text { county jail system: } \\
+\end{array}$ \\
\hline $\begin{array}{l}\text { Thakarar, } \\
2015^{33}\end{array}$ & ED visits $(2+)$ & $\begin{array}{l}\text { Hospital/health } \\
\text { system (single } \\
\text { program) }\end{array}$ & NS & $55+N S$ & Minority NS & & & NS & NS & NS & & & $\begin{array}{l}\text { More than } 1 \\
\text { housing change } \\
\text { NS }\end{array}$ \\
\hline $\begin{array}{l}\text { Freidman, } \\
2009^{44}\end{array}$ & ED visits $(4+)$ & $\begin{array}{l}\text { Population } \\
\text { based }\end{array}$ & & NS & & NS & & & & & & & $\begin{array}{l}\text { Income } \\
<\$ 40 \mathrm{k}+ \\
<\$ 90 \mathrm{k} \text { NS } \\
\end{array}$ \\
\hline Hunt, $2006^{43}$ & $\begin{array}{l}\text { ED visits (1-3, } \\
4+)\end{array}$ & $\begin{array}{l}\text { Population } \\
\text { based }\end{array}$ & & & NS & & & + & & & & & $\begin{array}{l}\text { Income by poverty } \\
\text { threshold } \\
200-399 \%+ \\
100-199 \%+ \\
\text { Below threshold + }\end{array}$ \\
\hline
\end{tabular}




\begin{tabular}{|c|c|c|c|c|c|c|c|c|c|c|c|c|c|}
\hline Author, Year & Outcome & Population & Female & Age & Race/Ethnicity & $\begin{array}{l}\text { Depres- } \\
\text { sion }\end{array}$ & $\begin{array}{l}\text { Severe } \\
\text { Mental } \\
\text { Illness }\end{array}$ & $\begin{array}{l}\text { Other } \\
\text { Mental } \\
\text { Illness }\end{array}$ & $\begin{array}{l}\text { Sub- } \\
\text { stance } \\
\text { Use }\end{array}$ & $\begin{array}{l}\text { Alcohol } \\
\text { Use }\end{array}$ & $\begin{array}{l}\text { Home- } \\
\text { less- } \\
\text { ness }\end{array}$ & $\begin{array}{l}\text { Employ- } \\
\text { ment }\end{array}$ & $\begin{array}{l}\text { Other Social Risk } \\
\text { Factors }\end{array}$ \\
\hline $\begin{array}{l}\text { Vinton, } \\
2014^{34}\end{array}$ & $\begin{array}{l}\text { ED visits }(0,1- \\
3,4-9,10+)\end{array}$ & $\begin{array}{l}\text { Population } \\
\text { based }\end{array}$ & + & $>44-$ & $\begin{array}{l}\text { Black + } \\
\text { Hispanic - } \\
\text { Asian - } \\
\text { Other NS }\end{array}$ & & & + & & NS & & $\begin{array}{l}\text { Currently } \\
\text { employed - }\end{array}$ & $\begin{array}{l}\text { Poverty-income } \\
\text { ratio (Ref is } \geq 4)+\end{array}$ \\
\hline $\begin{array}{l}\text { Zuckerman, } \\
2004^{47}\end{array}$ & ED visits $(3+)$ & $\begin{array}{l}\text { Population } \\
\text { based }\end{array}$ & & & $\begin{array}{l}\text { Black + } \\
\text { Hispanic NS } \\
\text { Asian NS }\end{array}$ & & & & & & & & $\begin{array}{l}\text { Near poor and } \\
\text { poor }+ \text { Single } \\
\text { parent }+\end{array}$ \\
\hline $\begin{array}{l}\text { Doran, } \\
2013^{59}\end{array}$ & $\begin{array}{l}\text { ED visits }(0,1, \\
2-4,5-10,11- \\
25,>25))\end{array}$ & VA & - & & & + & + & + & + & + & + & & \\
\hline $\begin{array}{l}\text { Levinson, } \\
2005^{139}\end{array}$ & $\begin{array}{l}\text { All utilization } \\
\text { ( } 3+\text { ED; } 2+ \\
\text { specialty clinic } \\
\text { visits) }\end{array}$ & VA & NR & NR & NR & & & & & & & & \\
\hline
\end{tabular}

+ denotes significant positive association, - denotes significant negative association, NS denotes no significance, NR denotes not reported, and a blank cell denotes not included in the model.

$\mathrm{CA}=$ California $\mathrm{dx}=$ diagnosis $; \mathrm{Ed}=$ education; $\mathrm{ED}=$ emergency department $\mathrm{HMO}=$ health maintenance organization; $\mathrm{IP}=$ inpatient $\mathrm{k}=$ thousand; $\mathrm{NR}=$ not reported; $\mathrm{NS}=$ 
Table B-10. Predictive results

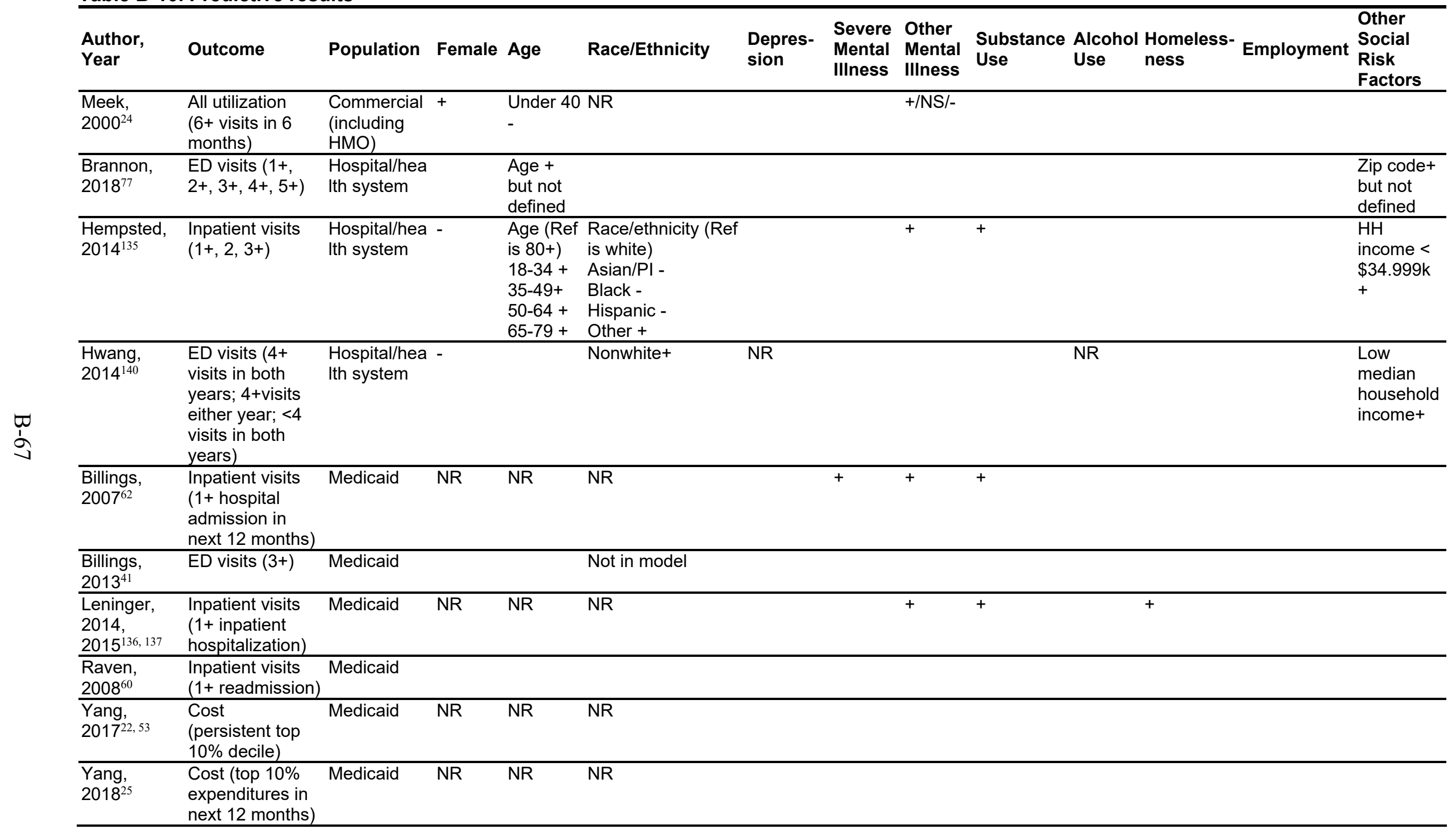




\begin{tabular}{|c|c|c|c|c|c|c|c|c|c|c|c|c|}
\hline $\begin{array}{l}\text { Author, } \\
\text { Year }\end{array}$ & Outcome & Population & Female & Age & Race/Ethnicity & $\begin{array}{l}\text { Depres- } \\
\text { sion }\end{array}$ & $\begin{array}{l}\text { Severe } \\
\text { Mental } \\
\text { Illness }\end{array}$ & $\begin{array}{l}\text { Other } \\
\text { Mental } \\
\text { Illness }\end{array}$ & $\begin{array}{l}\text { Substance } \\
\text { Use }\end{array}$ & $\begin{array}{l}\text { Alcohol } \\
\text { Use }\end{array}$ & $\begin{array}{l}\text { I Homeless- Employment } \\
\text { ness }\end{array}$ & $\begin{array}{l}\text { Other } \\
\text { Social } \\
\text { Risk } \\
\text { Factors }\end{array}$ \\
\hline $\begin{array}{l}\text { Colligan, } \\
2016^{31}\end{array}$ & $\begin{array}{l}\text { ED visits }(0,1-3, \\
4+)\end{array}$ & Medicare & & $\begin{array}{l}\leq 64+ \\
\geq 75+\end{array}$ & $\begin{array}{l}\text { Race (Ref is white) } \\
\text { Black + } \\
\text { Asian - } \\
\text { Hispanic - } \\
\text { Native American + } \\
\text { Unknown/other - }\end{array}$ & & & + & & & & \\
\hline $\begin{array}{l}\text { Kanzaria, } \\
2017^{28}\end{array}$ & $\begin{array}{l}\text { ED visits (4+ } \\
\text { visits in } 12 \\
\text { months) }\end{array}$ & $\begin{array}{l}\text { Population } \\
\text { based }\end{array}$ & & & $\begin{array}{l}\text { Black +/NS } \\
\text { Hispanic + } \\
\text { Other -/NS } \\
\end{array}$ & $+/ \mathrm{NS}$ & $-/ N S$ & + /NS & $+/ \mathrm{NS}$ & $+/ \mathrm{NS}$ & & $\begin{array}{l}\text { Poverty } \\
\text { indicator } \\
\text { NS } \\
\end{array}$ \\
\hline $\begin{array}{l}\text { Reichard, } \\
2015^{23} \\
\end{array}$ & $\begin{array}{l}\text { All utilization } \\
\left(\geq 75^{\text {th }} \text { percentile }\right)\end{array}$ & $\begin{array}{l}\text { Population } \\
\text { based }\end{array}$ & NR & NR & NR & & & & & & & \\
\hline $\begin{array}{l}\text { Wherry, } \\
2014^{137,138}\end{array}$ & $\begin{array}{l}\text { All utilization (top } \\
\text { decile) }\end{array}$ & $\begin{array}{l}\text { Population } \\
\text { based }\end{array}$ & & & & & & NS & & & & \\
\hline $\begin{array}{l}\text { Chang, } \\
2019^{54}\end{array}$ & $\begin{array}{l}\text { Inpatient visits } \\
\text { (persistently high } \\
\text { risk, intermittent, } \\
\text { or low risk in } 2 \\
\text { years) }\end{array}$ & VA & - & Over 45 & $\begin{array}{l}\text { Race (ref Hispanic) } \\
\text { White - } \\
\text { Black - } \\
\text { Other - }(p<0.05)\end{array}$ & & & + & $+($ tobacco $)$ & & - & $\begin{array}{l}\text { Number of } \\
\text { zip code } \\
\text { changes }+ \\
\text { Urban+ }\end{array}$ \\
\hline
\end{tabular}

+ denotes significant positive association, - denotes significant negative association, NS denotes no significance, NR denotes not reported, and a blank cell denotes not included in the model.

$\mathrm{ED}=$ emergency department; $\mathrm{HH}=$ household; $\mathrm{HMO}=$ health maintenance organization; $\mathrm{NR}=$ not reported; $\mathrm{NS}=$ not statistically significant; PI = Pacific Islander; Ref $=$ reference group; $\mathrm{VA}=$ Veterans Health Administration. 


\title{
Key Question 2: What are the mechanisms that lead to reductions in potentially preventable or modifiable healthcare use and result in improved health outcomes and cost savings in interventions serving $\mathrm{HNHC}$ patients?
}

\author{
Table B-11. Full list of CMO configurations and supporting data for Program Theory 1: Identifying \\ and targeting $\mathrm{HNHC}$ patients for inclusion in interventions
}

Summary: Identifying and targeting HNHC patients for interventions intended to reduce potentially preventable or modifiable healthcare use and costs requires capturing their complexity based on a combination of prior use of healthcare services, chronic disease, nonmedical barriers to accessing care, experience with the healthcare system, clinician judgment, and patient willingness to participate. ${ }^{\mathrm{a}}$

\begin{tabular}{|c|c|}
\hline CMOs & Relevant Data Extracts/Summary Information From Included Literature \\
\hline \multirow{3}{*}{$\begin{array}{l}\text { CMO 1.1. Including } \\
\text { historic information } \\
\text { obtained from claims } \\
\text { and other electronic } \\
\text { health records, that can } \\
\text { identify prior high cost } \\
\text { and/or use of healthcare } \\
\text { services [C], adds to } \\
\text { intervention designers' } \\
\text { confidence in creating } \\
\text { an algorithm [M] that will } \\
\text { result in targeting } \\
\text { patients who are at the } \\
\text { greatest risk of being } \\
\text { HNHC in the future [O]. }\end{array}$} & $\begin{array}{l}\text { Participants were drawn from adult Medicaid patients attributed to CareMore primary care } \\
\text { physicians (PCPs). Program eligibility criteria were aimed at identifying patients at risk for } \\
\text { poor outcomes and unnecessary spending, as well as those most likely to benefit from } \\
\text { complex care management. The criteria drew from analyses suggesting that combining } \\
\text { predictive models, historical claims, and clinician judgment is the most effective approach } \\
\text { to identifying patients for complex care management. Eligible patients were first required to } \\
\text { meet at least } 1 \text { of the following criteria: top } 5 \% \text { of total medical expenditures (TME) in the } \\
\text { prior } 12 \text { months, top } 5 \% \text { of Chronic Illness Intensity Index (Cl3) score, or care team } \\
\text { member nomination. }{ }^{108}\end{array}$ \\
\hline & $\begin{array}{l}\text { Predicted future health care costs are based on the Predictive Risk Intelligence SysteM } \\
\text { (PRISM) medical cost risk score developed and implemented by Washington State } \\
\text { Medicaid programs (Court et al. 2011). PRISM combines diagnostic and pharmacy data to } \\
\text { predict future expenditures based on grouping algorithms from two risk adjustment models } \\
\text { widely used by State Medicaid programs, the Chronic Illness and Disability Payment } \\
\text { System (Kronick et al. 2000) and Rx-Medicaid (Gilmer et al. 2001), both of which have } \\
\text { predictive accuracy comparable to commercial alternatives. The PRISM risk score is a } \\
\text { ratio calculated by dividing the individual's expected monthly future expenditures by the } \\
\text { average monthly future expenditures of all Medicaid SSI recipients. The risk score equals } \\
1.0 \text { if the individual's expected expenditures equal the average expenditures of the } \\
\text { group. }{ }^{112}\end{array}$ \\
\hline & $\begin{array}{l}\text { Rely on more than } 1 \text { type of data-because it may be vulnerable to inaccuracies: One } \\
\text { program said they use predictive modeling so that they are not "held hostage waiting for } \\
\text { claims to come down the road." Washington State uses predictive modeling to begin to } \\
\text { identify the target population. Using its Health Service Encounter algorithm, the state } \\
\text { examines } 15 \text { months of integrated health care claims to determine future medical costs } \\
\text { and inpatient risk scores. The state has found that conditions such as diabetes, } \\
\text { cardiovascular disease, MH and substance abuse are common among the superutilizing } \\
\text { subset of patients. It uses different approaches to further stratify subgroups for complex } \\
\text { care management including identifying individuals with extreme emergency department } \\
\text { utilization (e.g., approximately } 80 \text { to } 130 \text { ED visits in } 15 \text { months), high expected future }\end{array}$ \\
\hline
\end{tabular}

\footnotetext{
a Theory and guidance from National Academy of Medicine report: "Determining an ideal definition for a high-need patient requires a delicate balance. A highly constrained definition will risk missing people, potentially depriving them of needed resources. On the other hand, casting an overly broad definition might include people who are not high-need and do not need additional resources. Abrams noted that basing identification of high-need patients exclusively on cost will miss many people, and if the focus is exclusively on chronic conditions, a large number of people may be identified whose chronic conditions are under control." 12
} 


\begin{tabular}{l}
\hline CMOs \\
\hline CMO 1.1. Including \\
historic information \\
obtained from claims \\
and other electronic \\
health records, that can \\
identify prior high cost \\
and/or use of healthcare \\
services [C], adds to \\
intervention designers' \\
confidence in creating \\
an algorithm [M] that will \\
result in targeting \\
patients who are at the \\
greatest risk of being \\
HNHC in the future [O]. \\
(continued)
\end{tabular}

Relevant Data Extracts/Summary Information From Included Literature medical costs (predicted by high utilization and costs in the past), high prospective inpatient risk scores, and sign gaps in care and quality indicators. ${ }^{49}$

The programs represented at the Summit generally use historical claims data as a foundation to understand the size and scope of super-utilization. Claims analysis is an iterative process and includes identifying areas of high cost and high utilization, and/or identifying groups of recipients with a high number of diagnoses. With this initial broad brush information, programs are able to further shape and define the target population. For example, Community Care of North Carolina (CCNC), which includes 14 regional networks that manage the care of Medicaid beneficiaries, will analyze at least 12 months of data in order to understand which chronic illness and mental health indicators are contributing to a high number of ED visits. ${ }^{49}$

"After an individual's records were linked across data sets, the process of flagging individuals as "high utilizers" began. Instead of using charges or receipts to define high utilizers, the decision was made to rely on the number of emergency department (ED) and inpatient visits made by an individual over the prior 12-month period." 78

"From the best-fit synthesis we conducted to answer KQ 1, we identified some characteristics that are often available through electronic databases that can be used to help identify patients." (Discussion section of this report. Also see full results for KQ 1)

During the first site visit, physicians at both sites reported that they were initially very enthusiastic about the Health Buddy $®$ program, because it offered a promising way to effectively support patients with chronic disease..... Once the physicians received the list of patients who were eligible for the Health Buddy ${ }^{\circledR}$ program, they reported that they became frustrated with the project because they felt that many of the patients selected would not benefit from participating. Further, physicians reported disappointment that many of the patients they believed could be helped by the program were not eligible to participate in the program because they had not been identified through the claims based algorithm developed by $\mathrm{HHN} .^{80}$

Risk assessments of the TST participant population were conducted to inform the development of individualized care plans and assign participants to one of three risk categories to determine the level of service to be provided to each participant....TST reported that the high-risk intervention was provided to approximately $5 \%$ to $7 \%$ of the TST participant population that had depression and/or potentially critical health problems that required immediate attention....What might explain the lack of success in TST's demonstration? Ineffective Targeting. One explanation may be the inability to accurately target beneficiaries at greatest risk of intensive, costly, service use (as distinct from the need for general care management). ...When TST learned that one of its participants was admitted to the hospital, it reassigned this individual to its high-risk intervention, and when appropriate, a care manager visited the beneficiary in the hospital to determine the cause of the hospitalization and identify any new health or social issues to be addressed. Not surprisingly, TST adopted a strategy of targeting beneficiaries at greatest risk of a hospitalization and higher costs. Their targeting strategy was unsuccessful-and costly. The program was unable to predict future complications with any precision for those with initially stable, less costly, conditions. Lacking direct access to patients' medical records, the health coaches often began working with beneficiaries with incomplete information. ${ }^{79}$ There are two key elements to the success of these new efforts to target and improve care for high-cost Medicaid cases. First, it is essential to be able to identify in advance patients who are likely to have high costs in the future. Many high-cost occurrences (such as injury, acute illness, or cancer) might be episodic, and high spending in one year might not mean high spending in subsequent years. ${ }^{62}$ 


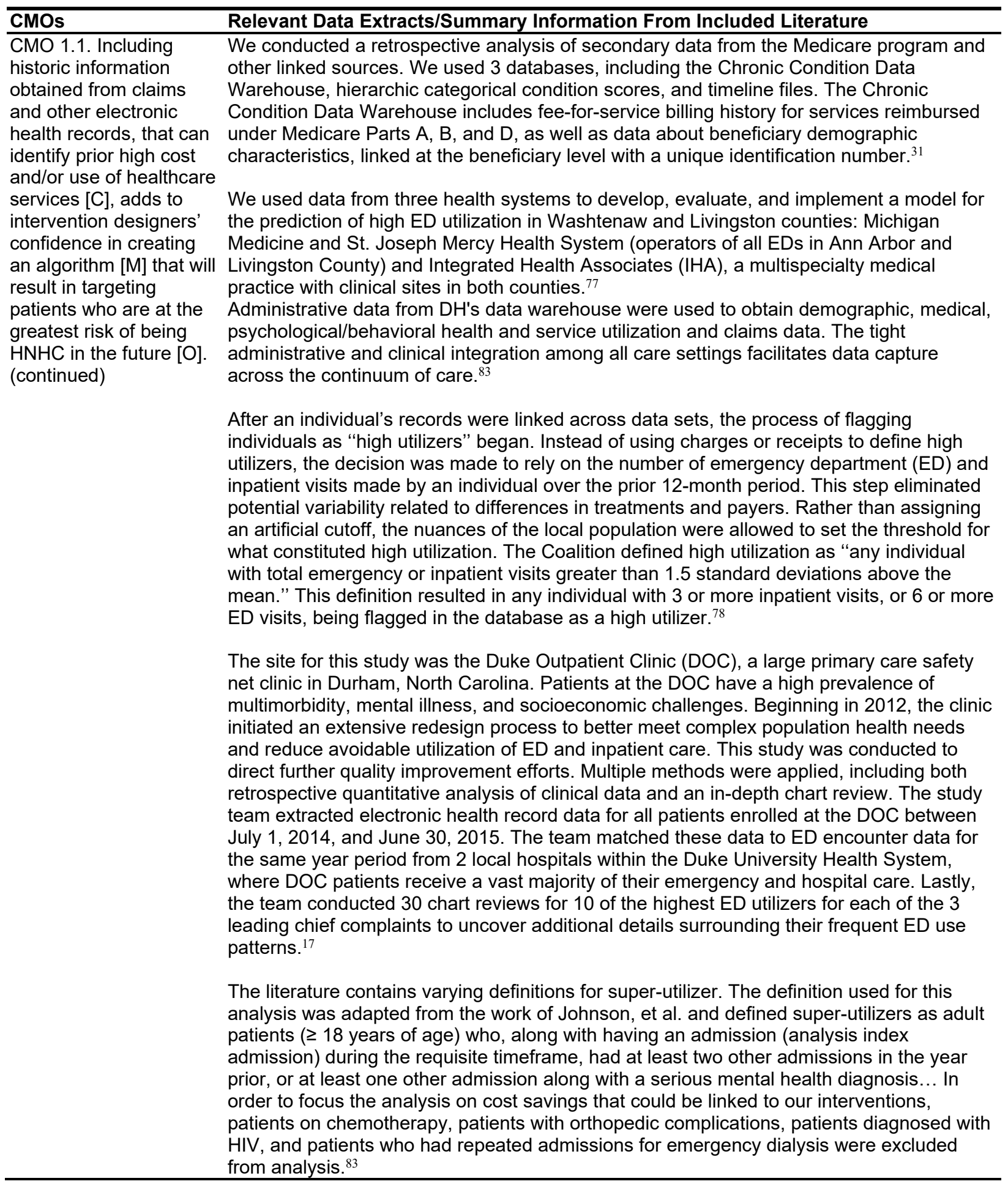




\begin{tabular}{ll}
\hline CMOs & Relevant Data Extracts/Summary Information From Included Literature \\
\hline CMO 1.2 Capturing a & More than half of patients approached in the ED refused to participate, possibly due to \\
patient's use of services & competing concerns about their illness or participating in research. Those who enrolled \\
in "real time," if possible, & may have been more engaged, and thus, more likely to respond to the intervention, than \\
while the patient is still & those who declined. Identifying and approaching patients in real time may be time \\
hospitalized [C], adds to consuming and resource intensive, but this approach has been found to be more effective \\
the intervention service & in addressing the needs of some populations of high utilizers than using historical claims \\
provider's confidence & data to identify and "segment" high utilizers with aligned interventions. \\
that a patient is identified & \\
during a period of urgent & To be most effective, complex care management programs should target patients at risk of \\
need for the services & persistently high spending and those whose spending and health outcomes are amenable \\
[M], resulting in & to complex care planning and engagement. Many complex care management programs \\
intervention services & use claims data and historical utilization patterns to identify eligible patients. Recent \\
being initiated prior to or & research has highlighted the limitations of this approach-historically high-cost patients \\
during a period of high & often return to normal patterns or spending, or they have drivers of high spending not \\
use and not during a & amenable to complex care management.
\end{tabular}

service use may have already declined In order to identify chronic frequent users, rather than those with an isolated health event requiring multiple visits, we identified patients with the most ED visits during both the 30(regression to the mean) day period and the 12-month period preceding the introduction of the program. ${ }^{111}$ [O].

The Summit participants unanimously agreed that access to real-time information-such as notifications of ED visits or inpatient admissions-and a strong analytics team provide a critical foundation for super-utilizer programs. One leader referred to data as "oxygen for our program." Programs place a high priority on developing a robust data repository that can be mined to identify groups of patients that might respond well to complex care management. 49

Eligible patients were identified through real-time automated methods and recruitment occurred while patients were still hospitalized. Patient intake included an in-depth patient assessment to determine nonmedical barriers to improved health. ${ }^{83}$

This "real time" approach of using a hospital admission as a triggering event was perceived as useful for two reasons. First, patients with a hospital admission are much more likely to have a subsequent admission in the next twelve months than patients without an admission, which improves the potential case-finding capacity of the algorithm. But, equally important, effective discharge planning is likely to be a critical component of any intervention strategy for high-cost, high risk patients. However, because of limited resources and lag time in acquiring data, our experience in other environments has suggested that some providers and payers are interested in non-"real time," retrospective analyses. Accordingly, we also examined patients with any claims in 2000-2003, to predict subsequent admissions in 2004 (regardless of whether they had a hospital admission in 2003 or any prior year). This "archival" approach to case finding is somewhat less robust (it finds fewer patients) than the "real time" method and only brief findings for this approach are presented for comparative purposes. ${ }^{62}$

Risk assessments of the TST participant population were conducted to inform the development of individualized care plans and assign participants to one of three risk categories to determine the level of service to be provided to each participant....TST reported that the high-risk intervention was provided to approximately $5 \%$ to $7 \%$ of the TST participant population that had depression and/or potentially critical health problems that required immediate attention.... What might explain the lack of success in TST's demonstration? Ineffective Targeting. One explanation may be the inability to accurately target beneficiaries at greatest risk of intensive, costly, service use (as distinct from the need for general care management)....When TST learned that one of its participants was 


\begin{tabular}{|c|c|}
\hline CMOs & I From Included Lite \\
\hline $\begin{array}{l}\text { CMO } 1.2 \text { Capturing a } \\
\text { patient's use of services } \\
\text { in "real time," if possible, } \\
\text { while the patient is still } \\
\text { hospitalized [C], adds to } \\
\text { the intervention service } \\
\text { provider's confidence } \\
\text { that a patient is identified } \\
\text { during a period of urgent }\end{array}$ & $\begin{array}{l}\text { admitted to the hospital, it reassigned this individual to its high-risk intervention, and when } \\
\text { appropriate, a care manager visited the beneficiary in the hospital to determine the cause } \\
\text { of the hospitalization and identify any new health or social issues to be addressed. Not } \\
\text { surprisingly, TST adopted a strategy of targeting beneficiaries at greatest risk of a } \\
\text { hospitalization and higher costs. Their targeting strategy was unsuccessful-and costly. } \\
\text { The program was unable to predict future complications with any precision for those with } \\
\text { initially stable, less costly, conditions. Lacking direct access to patients' medical records, } \\
\text { the health coaches often began working with beneficiaries with incomplete information. }\end{array}$ \\
\hline $\begin{array}{l}\text { need for the services } \\
\text { [M], resulting in } \\
\text { intervention services } \\
\text { being initiated prior to or } \\
\text { during a period of high } \\
\text { use and not during a } \\
\text { later period, when } \\
\text { service use may have } \\
\text { already declined } \\
\text { (regression to the mean) } \\
\text { [O]. (continued) }\end{array}$ & $\begin{array}{l}\text { What might explain the lack of success in } \\
\text { explanation may be the targeting of benef } \\
\text { service use (as distinct from the need for } \\
\text { KTBH's request, CMS staff selected a ver } \\
\text { for their intervention and comparison grou } \\
\text { substantial regression-to-the-mean (RtoM } \\
\text { design should cancel out RtoM effects an } \\
\text { churning of beneficiaries from lower (high } \\
\text { considerable statistical noise to the test of } \\
\text { the Phase II original intervention to be a s } \\
\text { increases in demonstration period costs ir }\end{array}$ \\
\hline $\begin{array}{l}\text { CMC } \\
\text { patie } \\
\text { cono } \\
\text { limit } \\
\text { seve } \\
\text { to in } \\
\text { desi } \\
\text { iden } \\
\text { patie } \\
\text { bene } \\
\text { serv }\end{array}$ & $\begin{array}{l}\text { eficiaries who had multiple chronic conditions, } \\
\text {-were identified by CBO for study of persistence } \\
\text { eficiaries that were selected based upon } \\
\text { ost groups had baseline expenditures that were } \\
\text { eference group. Beneficiaries selected based } \\
\text { ditions had baseline expenditures that were } \\
\text { a reference group. Subsequent years of costs } \\
\text { the reference group; however, total expenditures } \\
\text { who were identified as high cost due to a } \\
\text { who had had high total costs in the base year. } \\
\text { ed for beneficiaries with multiple chronic }\end{array}$ \\
\hline
\end{tabular}

future high healthcare use and cost [O2].

Denver Health reported challenges in using utilization data alone to find patients at chronic high risk of acute care use-but identifying these patients was important for the success of 21st Century Care. That is, Denver Health assumed that 21st Century Care could reduce service use (such as hospitalizations and ED visits) by identifying patients with chronic care needs and then delivering preventive care to preempt higher-cost acute care later on.... Over the course of the award, however, Denver Health learned that many of its highest-cost patients were only temporarily high cost, suggesting that many of them would have returned to moderate- or low-cost status even without intervention. For example, under its risk stratification algorithm, Denver Health identified so-called super utilizers-all of whom were Tier 4-as people with three or more hospital admissions in a 12-month period, or two or more admissions and a mental health diagnosis. These people accounted for about 30 percent of adult facility costs. By analyzing pre-intervention data, however, research staff at Denver Health showed that, even without special intervention, fewer than half of these super utilizers at a single point in time were still in the category seven months later, and only 28 percent were in the category at the end of 12 months (Johnson et al. $2015 b$ ). Because of this challenge using utilization data alone to find chronic high-risk patients, Denver Health, as noted previously, added clinical information (in the form of both CRGs and clinical data such as lab results) to its second and third iterations of the riskstratification algorithm (although lab results were later removed in subsequent algorithm iterations). Denver Health reported that each revision to the algorithm helped to identify patients who would benefit most from 21st Century Care's intensive services. ${ }^{85}$ 


\begin{tabular}{|c|c|}
\hline CMOs & Relevant Data Extracts/Summary Information From Included Literature \\
\hline $\begin{array}{l}\text { CMO 1.3. Considering } \\
\text { patients' chronic } \\
\text { conditions, functional } \\
\text { limitations, and clinical } \\
\text { severity scores [C] adds } \\
\text { to intervention } \\
\text { designers' confidence in } \\
\text { identifying HNHC } \\
\text { patients [M] who will } \\
\text { benefit from intervention } \\
\text { services [O1] and who } \\
\text { are at risk of having } \\
\text { future high healthcare } \\
\text { use and cost [O2]. } \\
\text { (continued) }\end{array}$ & $\begin{array}{l}\text { Denver Health recognized that people with exceptionally high service use at one time did } \\
\text { not necessarily continue to have exceptional service use in the future. Over the course of } \\
\text { the award, Denver Health integrated clinical information into its risk-stratification algorithm } \\
\text { to try to better identify patients who would benefit from intervention. }{ }^{85} \\
\text { Key Finding \#1: Several vulnerable subpopulations of Medicare FFS beneficiaries were } \\
\text { less likely to agree to participate in the CLM demonstration program. Of all CLM } \\
\text { intervention beneficiaries, } 65 \% \text { verbally consented to participate in the CMHCB } \\
\text { demonstration at some point during the intervention period. We found that Medicaid } \\
\text { enrollees and institutionalized beneficiaries were less likely to be participants; both groups } \\
\text { are costly and high users of acute care services. In general, participants tended to be } \\
\text { healthier than nonparticipants using baseline characteristics including the prospective HCC } \\
\text { score. However, beneficiaries with higher concurrent HCC scores based on the first } 6 \\
\text { months of the demonstration were more likely to participate than healthier beneficiaries. } \\
\text { This suggests that CLM made some inroads into engaging those with acute clinical } \\
\text { deterioration. Further, as CLM's program matured, they appeared to be more successful } \\
\text { engaging sicker and more costly beneficiaries based on baseline health status; however, } \\
\text { those with Medicare/Medicaid dual enrollment and the institutionalized were still less likely } \\
\text { to become participants. These findings suggest alternative recruiting and outreach } \\
\text { strategies are needed to reach dual Medicare/Medicaid enrollees and beneficiaries who } \\
\text { are institutionalized. }{ }^{84}\end{array}$ \\
\hline
\end{tabular}

Key Finding \#1: The HBC program was able to engage beneficiaries who were at higher risk of acute clinical deterioration as measured by the concurrent $\mathrm{HCC}$ score. Of the HBC original intervention beneficiaries, $45 \%$ verbally consented to participate in the CMHCB demonstration at some point during the intervention period; $40 \%$ of the refresh population agreed to participate. For the HBC program, we find that beneficiaries with medium and high concurrent HCC scores were more likely to be participants. Beneficiaries with higher prospective HCC scores and baseline Charlson comorbidity scores were less likely to be participants. This suggests that the HBC program was less able to engage the historically sicker Medicare beneficiaries but more able to engage those at higher risk of acute clinical deterioration as measured by the concurrent HCC score. ${ }^{80}$

While the high-need patient population is diverse, a synthesis of analyses reported in the literature identified three criteria that could form a basis for defining and identifying this population: total accrued health care costs, intensity of care utilized for a given period of time, and functional limitations. ${ }^{12}$

Medicare FFS beneficiaries with a primary residence in one of five designated counties including Boston, Massachusetts, and surrounding areas, and a high level of disease severity as indicated by Hierarchical Condition Categories (HCC) scores and high health care costs based on Medicare claims filed during calendar year 2005. Beneficiaries with $\mathrm{HCC}$ risk scores $>=2.0$ and annual costs of at least $\$ 2,000$ or $\mathrm{HCC}$ risk scores $>=3.0$ and a minimum of $\$ 1,000$ annual medical costs are eligible for the MGH's CMP. ${ }^{86}$

Eligible patients were identified by using standard criteria: a risk score in the 90th percentile for 90-day hospitalization from a validated risk-prediction algorithm (13) and a recent hospitalization or emergency department visit. ${ }^{87}$ Although high utilizers differed significantly from other patients in their medical and behavioral health needs, their presenting complaints were not categorically different from those of low utilizers-they simply had more visits for the same types of complaints utilizers were more likely to present to the ED multiple times for the same complaint. However, most high utilizers had 4 unique chief complaints, suggesting that these patients generally have several, rather than a few, reasons for seeking emergency care. No clearly defined pattern of complaints 


\begin{tabular}{|c|c|}
\hline \multirow{3}{*}{$\begin{array}{l}\text { CMOs } \\
\text { CMO 1.3. Considering } \\
\text { patients' chronic } \\
\text { conditions, functional } \\
\text { limitations, and clinical } \\
\text { severity scores [C] adds } \\
\text { to intervention } \\
\text { designers' confidence in } \\
\text { identifying HNHC } \\
\text { patients [M] who will } \\
\text { benefit from intervention } \\
\text { services [O1] and who } \\
\text { are at risk of having } \\
\text { future high healthcare } \\
\text { use and cost [O2]. } \\
\text { (continued) }\end{array}$} & t Data Extracts/Summary Information From Included Literature \\
\hline & $\begin{array}{l}\text { existed for high utilizers. High utilization in such patients is less likely to be caused by } \\
\text { clearly defined disease processes and more by a complex mix of multiple chronic medical } \\
\text { conditions and psychosocial factors, making it difficult to predict future utilization or identify } \\
\text { specific patient needs based on their chief complaint. }{ }^{17}\end{array}$ \\
\hline & $\begin{array}{l}\text { o might } \\
\text { eling } \\
\text { ngton } \\
\text { tealth } \\
\text { e } \\
\text { ind that } \\
\text { abuse } \\
\text { es to } \\
\text { uals } \\
\text { igh } \\
\text { gh } \\
49\end{array}$ \\
\hline $\begin{array}{l}\text { dds to intervention } \\
\text { esigners' confidence in } \\
\text { entifying } \mathrm{HNHC} \\
\text { atients [M] who will } \\
\text { enefit from intervention } \\
\text { ervices [O1] and who } \\
\text { e at risk of having } \\
\text { ture high healthcare }\end{array}$ & $\begin{array}{l}\text { The screening process includes administrative data screening to determine eligibility by } \\
\text { usage criteria, followed by an in-person screening to determine other eligibility criteria and } \\
\text { ability to consent. Randomization occurred after consent. A proprietary platform integrates } \\
\text { study data with real-time data feeds from multiple sources. Staff screened potential } \\
\text { participants based on their use of county-funded services over the prior } 1-2 \text { years. Our } \\
\text { research team developed an electronic triage tool that uses administrative data to predict } \\
\text { the likelihood of future high use of county-funded services. To meet criteria, potential } \\
\text { participants must have used various combinations of the ED and psychiatric ED, medical } \\
\text { and psychiatric inpatient stays in the County-funded public hospital, and/or jail over the } \\
\text { past } 1-2 \text { years, at high enough levels to meet a threshold score. We embedded the triage } \\
\text { tool into the study database and generated a list of potentially eligible participants with the } \\
\text { highest scores, redoing the calculation throughout the enrollment period. All county } \\
\text { agencies or service providers could refer individuals they suspected met eligibility criteria, } \\
\text { but study staff always used the list generated by the triage tool to confirm initial eligibility. } \\
\text { County staff used this list to outreach to the highest using individuals. }{ }^{109}\end{array}$ \\
\hline
\end{tabular}

Individuals with disability, transportation challenges, homelessness, mental health conditions, and with substance abuse or chemical addiction may be hard to find and engage when they are not actively in treatment. Partnering with public health agencies and community-based organizations was identified as an approach that allows health care organizations to more successfully identify and engage these hard-to-reach populations, some of whom harbor mistrust of health care professionals. Although such partnerships would ideally build on shared data for surveillance, programs had developed approaches in the absence of a formal data sharing system. For example, the Gatekeeper program in Ohio developed a community referral model to identify high risk individuals in partnership with a network of trained community volunteers such as bank tellers, police officers, paramedics, and pharmacists. Volunteers initiated referrals directly to the Gatekeeper program for older adults who identified as being potentially at risk or who might benefit from community services. ${ }^{113}$

The data on diagnostic history and characteristics of subsequent admissions may also provide some help in conceptualizing intervention design. The relatively high rates of chronic disease suggest the importance of a comprehensive, multidisciplinary approach to any intervention, using what we already know about improving chronic disease management (such as the chronic care model). But the extraordinarily high levels of substance abuse among high-risk patients and the history of mental illness even among the population without serious and persistent mental illness make clear that any intervention will have to take these factors into account. Whatever is on the shelf from chronic disease management vendors for commercial plans and Medicare will require a serious overhaul for adaptation to these populations. ${ }^{62}$ 


\section{CMOs \\ CMO 1.4 Considering patients' behavioral health and social risk factors (e.g., mental health and substance use disorder diagnoses and social needs) [C] adds to intervention designers' confidence in identifying $\mathrm{HNHC}$} patients [M] who will benefit from intervention services [01] and who are at risk of having future high healthcare use and cost [O2]. (continued)
Relevant Data Extracts/Summary Information From Included Literature

There are also other important questions that remain unanswered. From claims records we can say little about the social and personal characteristics of these patients. This is a population living in extreme poverty, and a broad range of factors (educational, behavioral, and coping capacity) likely complicate their lives. We have documented their mental illness and substance abuse problems, and there are also potentially high levels of homelessness and housing instability. Getting more and better information about these issues will require further work, but it is clearly critical to any intervention design. However, the potential impact of solving these problems may also be large, even for the most apparently daunting problems such as the high number of mental illness admissions. For some high-risk patients, an effective, supportive housing environment might be enough to tip the balance, allowing sufficient life stabilization to address previously intractable health and mental health problems. An emerging body of research indicates that these "social service" interventions can have a major impact on the use of health services. ${ }^{62}$

Our findings also show the importance of including patients with mental health disorders in an intervention program. John Billings and Maria Raven noted that more than a third of high utilizers have at least one claim with a mental health disorder diagnosis. Other studies have However, more than half noted that people with mental health disorders have higher rates of receiving ED and inpatient care.20 Most of the patients enrolled in our study had either depression or anxiety. While B2C did not target people with severe mental health needs (such as those recently hospitalized at a psychiatric facility), to our knowledge, the program is unique in having a behavioral health provider screen every enrollee for mental health disorders-and then address those conditions as appropriate. ${ }^{88}$

Participating super-utilizer programs reported a high prevalence of behavioral health diagnoses in high-utilizers through claims data. Indeed per capita Medicaid costs increase significantly with the addition of a mental health diagnosis, substance abuse diagnosis, or mental health plus substance abuse diagnosis ${ }^{49}$

All stakeholders identified poorly managed serious mental illness among HNHC patients as a significant driver of preventable high health care utilization. Patients often had inadequate access to mental-health and substance-abuse resources. This was because outpatient programmes did not exist, were inconveniently located or were not financially feasible to attend. This left patients without any options other than the ED for care. Additionally, several patients acknowledged that feeling depressed negatively impacted their care routines and contributed to missing provider appointments which, over time, compounded the severity of their diseases. Importantly, patients also pointed out that the stigma surrounding mental illness was detrimental to their desire to seek out treatment even if it were available. Some patients also felt that policies such as the Florida Mental Health Act (known as the Baker Act) and its equivalent in New York State (known as Kendra's Law),20,21 which allow for involuntary institutionalization and examination of an individual with possible mental illness for up to 72 hours, did not adequately address or help mitigate the root causes of substance abuse and mental-health disorders. This increased preventable ED and/or hospital utilization for psychiatric needs. ${ }^{61}$

"Most high utilizers had $\geq 4$ unique chief complaints, suggesting that these patients generally have several, rather than a few, reasons for seeking emergency care. No clearly defined pattern of complaints existed for high utilizers. High utilization in such patients is less likely to be caused by clearly defined disease processes and more by a complex mix of multiple chronic medical conditions and psychosocial factors, making it difficult to predict future utilization or identify specific patient needs based on their chief complaint." Most high utilizer ED visits appeared to occur close together in clusters presenting complaints not categorically diff from low utilizers: more visits for same type of complaints. Most common complaint across utilizer groups: abdominal pain, chest pain, 


\begin{tabular}{ll}
\hline CMOs & Relevant Data Extracts/Summary Information From Included Literature \\
\hline CMO 1.4 Considering & and shortness of breath. " The chart review in this study highlighted the inherent difficulty in \\
patients' behavioral & determining whether patterns of high utilization for these 3 complaints are related more to \\
health and social risk & medical conditions or social/behavioral factors. Although nearly all of the patients in the \\
factors (e.g., mental & chart review had mental illness and/or substance abuse, far fewer visits than expected \\
health and substance & were clearly linked to these conditions. ${ }^{17}$
\end{tabular}
use disorder diagnoses and social needs) [C] The Camden Coalition conducts a cluster analysis to ID the various subpopulations. This adds to intervention involves sorting cases (usually by patient utilization history) into groups, or clusters, so that designers' confidence in the degree of association is strong between people in the same cluster, and weak between identifying HNHC members in diff ones. Some programs stratify the typologies by the different social needs patients [M] who will faced by the patients such as homelessness, joblessness, and language preferencebenefit from intervention further indicating what interventions would be the most effective. ${ }^{49}$ services [01] and who are at risk of having future high healthcare use and cost [O2]. (continued)

Both the taxonomy developed by the Harvard T.H. Chan School of Public Health and the one developed by The Commonwealth Fund segment high-need individuals based on medical characteristics because this is a feasible starting point for most health care systems. Recognizing that a taxonomy focused on medical characteristics may neglect other factors that are key drivers of need, the taxonomy working group built on these efforts to offer a conceptual starter taxonomy that incorporates functional, social, and behavioral factors into a medically oriented taxonomy, not as independent segments but as factors that influence the care model or care team composition most likely to benefit particular patient segments (Figures S-2 and Table S-1). This starter taxonomy can provide guidance for health system leaders and payers on how to embed social risk factors, behavioral health factors, and functional limitations in a taxonomy for high-need patients. Patients would first be assigned to a clinical segment, with follow-on assessment of behavioral health issues and social services needs to determine the specific type of services that are required. Key behavioral health factors most likely to affect care delivery decisions include substance abuse, serious mental illness, cognitive decline, and chronic toxic stress and key social risk factors include low socioeconomic status, social isolation, community deprivation, and house insecurity. ${ }^{12}$

In the early stages of the CMHCB demonstration, CMP leadership learned that many high-cost, complex patients have mental health issues that were not effectively addressed by the current model of health care delivery or its pilot program. As a result, the program allocated greater resources to support mental health, hiring a social worker to assess the mental health needs of CMP participants and support them in accessing psychiatric care as needed or provide treatment if appropriate. ${ }^{86}$

\begin{tabular}{ll}
\hline CMO 1.5 Considering & Using the Medicare Health Risk Assessment, we explored two data-driven methods to \\
patients' self- & segment a heterogeneous population of older adults with potentially complex care needs \\
assessments of & into clinically meaningful subgroups using self-reported information.
\end{tabular}
"subjective" characteristics about themselves $[\mathrm{C}]$ adds to intervention designers' confidence in identifying HNHC patients [M] who will benefit from intervention services

[O1] and who are at risk The Medicare HRA is designed to help clinicians address patient-reported risks for
of having future high of having future high healthcare use and cost [O2].

Input variables for the segmentation analyses were patient-reported variables drawn from the Medicare HRA, a component of the Medicare Annual Wellness Visit designed to identify patient-reported modifiable risk factors and health needs [8]. Required elements include self-assessment of health status, psychosocial risks, depression, behavioral risks, and Activities of Daily Living and Instrumental Activities of Daily Living. Care delivery systems can add additional questions. preventable adverse outcomes. Although the HRA is most commonly applied at the point of care, if data are systematically collected, representative, and stored in extractable
formats, they can be used to inform program development, population health, and outcomes research. Although content collected through patient-reported outcomes may duplicate content obtainable through more traditional clinical data such as ICD codes, ICD codes alone are unlikely to capture subjective responses to questions about pain, loneliness, and independent activities of daily living (for example). In this project, HRA data 


\begin{tabular}{l}
\hline CMOs \\
\hline CMO 1.5 Considering \\
patients' self- \\
assessments of \\
"subjective" \\
characteristics about \\
themselves [C] adds to \\
intervention designers' \\
confidence in identifying \\
HNHC patients [M] who \\
will benefit from
\end{tabular}

intervention services

[O1] and who are at risk

of having future high

healthcare use and cost

[O2]. (continued)
Relevant Data Extracts/Summary Information From Included Literature

revealed meaningful subgroups that might not have been obvious from other electronic clinical data and could inform specific clinical interventions. Important differentiators included function, falls, perceived health status, emotional well-being, pain, and presence or absence of an advance directive. Two large subgroups comprised relatively healthy individuals who could benefit from watchful waiting and routine preventive care plus (for one group) life care planning. Much smaller subgroups could be targeted for more intensive and tailored care management. The size of these subgroups can inform resource allocation within delivery systems. ${ }^{89}$

As we enrolled patients into the group we found that, despite a broad range of medical and behavioral health problems, the common feature they shared and what ultimately served to bring them together as a group was their status of being "on the fringe," as they described themselves. Nearly every patient had experienced a number of barriers and frustrations in accessing medical care that the DIGMA team seems to have successfully addressed. ${ }^{98}$

Traditional electronic data such as diagnostic codes and laboratory values may not capture essential information on factors that drive care needs, including function, personal preferences, and social resources, that can only be reported by individuals themselves. Identifying and characterizing complex needs subpopulations requires patient-reported information to help match care delivery to personal needs. Although newer data from electronic health records (EHRs) such as symptom assessments and ICD-10 codes that capture functional status can improve our ability to identify complex needs subpopulations, subjective information can add a level of specificity unlikely to be captured with objective coding. ${ }^{89}$

Moreover, recognition that computer-based designations of being at risk for costly care (also decorously called predictive analytics) vary considerably, furnish no specific guidance, and are inaccurate is increasing. Most patients in the small, at-risk subgroup will not use such care, whereas care becomes relatively rationed for most patients not designated as such-including those who may require it.... Nevertheless, health care executives embrace the paradigm of high-risk intensive management despite its flaws....Meanwhile, many of its shortcomings can be remedied by a few standardized, patient-reported measures that forecast a patient's risk for costly care in a similar manner to predictive analytics, specifically the risk for direct services. For example, patients may simply indicate that they are only somewhat or not very confident that they can manage and control most of their health problems; have had moderate or severe pain during the past 4 weeks; have been bothered extremely or quite a bit during the past 4 weeks by emotional problems, such as anxiety, irritability, depression, or sadness; believe that the medications they are receiving may be causing illness; and have been prescribed more than 5 medications. Although some payers and providers may disagree with the specific metrics, none should assert that a patient's standardized self-report is an improper tool for guiding care. They may consider this method too old-fashioned or novel for implementation, but its modesty and low cost are remarkable. ${ }^{87}$

Dr. Wasson notes the limitations of relying on risk scores derived from electronic data. We agree that patient-reported indices have many advantages. Electronic indices, such as the Veterans Health Administration's Care Assessment Needs Score (1), also have potential advantages as a screening method in health care systems in which such data can be calculated on a population level. Some high-risk patients identified by the Care Assessment Needs Score did not need or were unlikely to benefit from intensive management, and intensive management teams in our study spent substantial time triaging the heterogeneous populations by reviewing health records, contacting primary care providers, and having telephone or in-person visits. Our results suggest that selecting patients for intervention would ideally combine the use of algorithm-based risk scores with measures focused on such issues as those raised by Dr. Wasson, including whether patients believe that they are activated in managing their health or have difficulty managing their prescriptions. ${ }^{87}$ 


\begin{tabular}{|c|c|}
\hline CMOs & Relevant Data Extracts/Summary Information From Included Literature \\
\hline ering & ata were collected through computerized administrative databases and HRA \\
\hline patients' self- & questionnaires to measure outcomes for utilization, health risk scores, and self-efficacy. ${ }^{90}$ \\
\hline assessments of & Social determinants of health. All stakeholders emphasized the importance of inadeq \\
\hline "subjective" & te \\
\hline & \\
\hline & \\
\hline confidence in & $\mathrm{H}$ \\
\hline HNHC patients [M] who & a \\
\hline nefit from & \\
\hline ntion services & disea \\
\hline it risK & \\
\hline $\begin{array}{l}\text { healthcare use and cost } \\
\text { [O2]. (continued) }\end{array}$ & education level is probably the biggest impact on the \\
\hline
\end{tabular}

Unstable housing: Physician: 'Eventually, [many] of them become homeless or [have] poor living conditions and those patients.. .arrive because of weather conditions or for other reasons to the ED to seek shelter and respite'.

Limited social support Health system leader: '[Workable solutions] probably have to do with...social support and reduction of isolation and helping them negotiate the complexities'.

Insurance challenges Patient: 'I have Medicaid and some of the doctors don't take [it], and so you say to yourself, well, even if I get an appointment, are they going to take me? So just go to the emergency room and let them handle it from there'.

Financial burden Patient: 'A lot of times [we're] on a fixed income and you need to see a specialist.. .You may have a co-pay with your specialist. It could add up if you go excessively. It's easier to go to the [ED] and get what you need'. ${ }^{61}$

Patient activation refers to an individual's knowledge, skills, and confidence related to selfmanagement. The construct is commonly measured using the Patient Activation Measure, which is a thirteen-item interval-level scale with strong psychometric properties that generates a score between 0 and 100. A Patient Activation Measure level may be assigned based on the score, from level 1 (least activated) to level 4 (most activated). Studies show that Patient Activation Measure results are predictive of most health behaviors, clinical indicators, and hospital and emergency department (ED) use. Research also shows that less activated patients with chronic illness are more likely to experience care coordination problems, compared to more activated patients. Numerous studies also indicate that compared to more activated patients, less activated ones with chronic disease are less likely to effectively manage their conditions (for example, they are less likely to adhere to medication regimens), have healthy diets and get regular exercise, regularly monitor symptoms and clinical measurements, ask questions in the medical encounter, and report satisfactory care experiences. These findings suggest that less activated patients may benefit more from care coordination and care management services than patients who have equal disease burden but are more proactive about managing their health. ${ }^{104}$

In this study we used the four Patient Activation Measure levels. Level 1 indicates that a person does not yet understand the important role that patients play in determining their health, and level 4 indicates that a person is proactive about his or her health and engages in many positive health-related behaviors. Compared with lower-risk patients, high-risk patients were twice as likely to be sixty years or older and were somewhat more likely to be lower income (Exhibit 1). High-risk patients were also almost twice as likely to be depressed and more than twice as likely to be at the lowest Patient Activation Measure level. Furthermore, in 2011 high-risk patients were three times more likely to have had an ED visit and fourteen times more likely to have had a hospitalization. Fairview Health Services, a Pioneer ACO, uses the Patient Activation Measure to allocate its resources 


\begin{tabular}{|c|c|}
\hline CMOs & Relevant Data Extracts/Summary Information From Included Literature \\
\hline $\begin{array}{l}\text { CMO } 1.5 \text { Considering } \\
\text { patients' self- } \\
\text { assessments of } \\
\text { "subjective" } \\
\text { characteristics about } \\
\text { themselves [C] adds to } \\
\text { intervention designers' } \\
\text { confidence in identifying } \\
\text { HNHC patients [M] who } \\
\text { will benefit from } \\
\text { intervention services } \\
\text { [O1] and who are at risk } \\
\text { of having future high } \\
\text { healthcare use and cost } \\
\text { [O2]. (continued) }\end{array}$ & 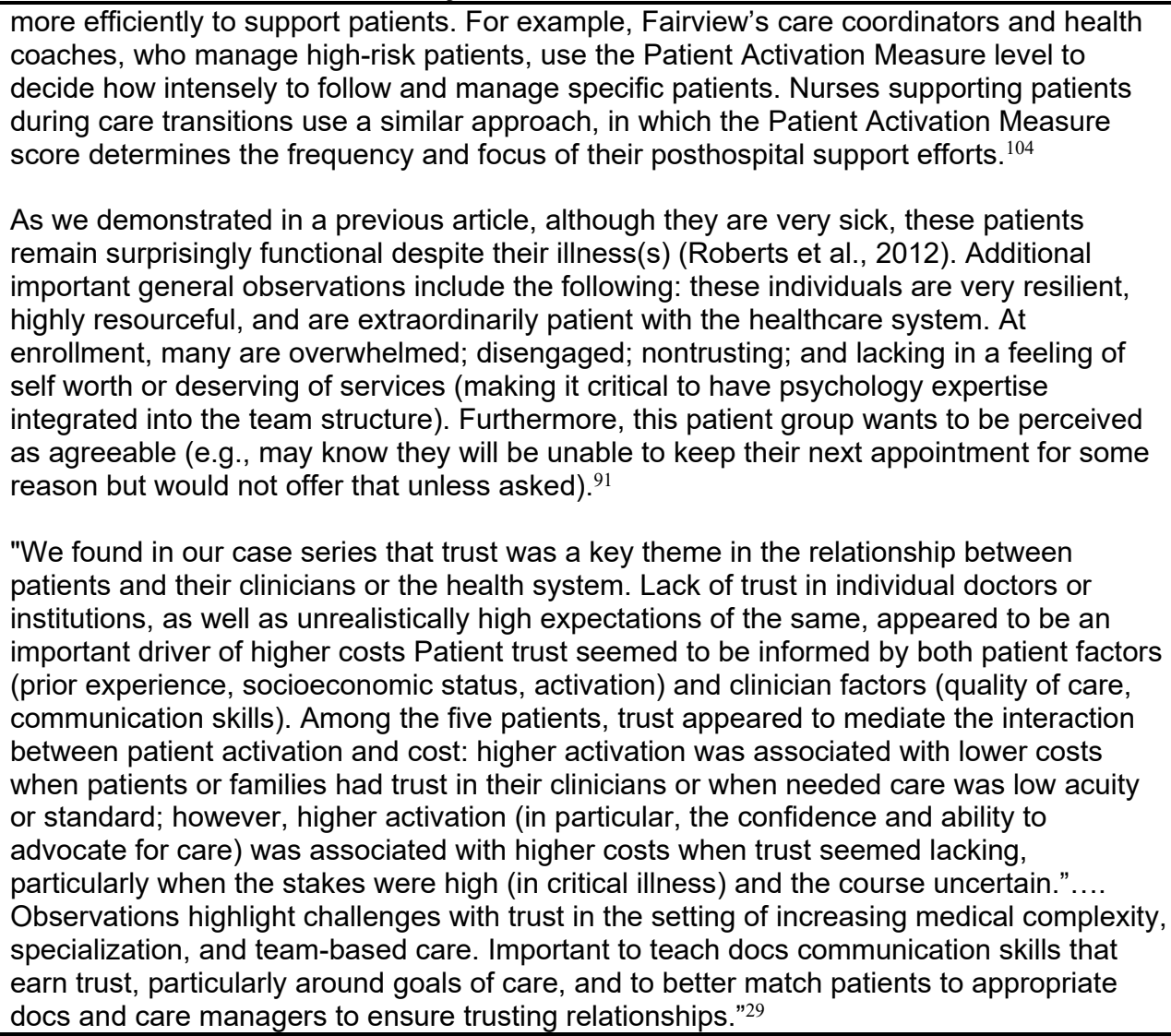 \\
\hline
\end{tabular}




\begin{tabular}{|c|c|}
\hline CMOs & Relevant Data Extracts/Summary Information From Included Literature \\
\hline $\begin{array}{l}\text { CMO } 1.6 \text { Considering } \\
\text { patients' self- } \\
\text { assessments of health } \\
\text { system-related risk } \\
\text { factors and experience } \\
\text { [C] adds to intervention } \\
\text { designers' confidence in } \\
\text { identifying HNHC } \\
\text { patients [M] who will } \\
\text { benefit from intervention } \\
\text { services [O1] and who } \\
\text { are at risk of having } \\
\text { future high healthcare } \\
\text { use and cost [O2]. }\end{array}$ & $\begin{array}{l}\text { At enrollment, the concept of self-management is not familiar to most of them. Systems, } \\
\text { like the Housing Authority, Medicaid, and health systems, often add to their burden. } \\
\text { Examples include applications for benefits are frequently difficult to figure out and time } \\
\text { consuming to file, applicants often feel disrespected or treated as if they were helpless, } \\
\text { and agency staff are often not adequately sensitive to client issues regarding low/no } \\
\text { literacy. In addition, for non-English speaking, translation services can be inadequate, } \\
\text { cultural competency is a problem, and mailed annual reapplication notices (such as for } \\
\text { Medicaid) are difficult to recognize as something official and may be disregarded. }{ }^{11} \\
\text { Example from CSHP illustrating the program's theory of action "Patient A in Kansas City } \\
\text { has multiple chronic conditions and poly-substance abuse, a history of homelessness, } \\
\text { frequent ED visits, and no PCP [primary care provider]. At the initial contact with the care } \\
\text { team, the patient stated that he would "never want to conform to the rules." The care } \\
\text { team's strategy is to first establish firm trust. They accomplished this by identifying } \\
\text { opportunities to provide basic help, such as involving family members in explaining the } \\
\text { impact on diet of modifying cooking practices, supplying a scale and log to support the } \\
\text { modification, organizing and explaining the purpose of medications, arranging for } \\
\text { transportation and enabling the patient to do so, scheduling and accompanying patients to } \\
\text { medical and social service appointments. }{ }^{85}\end{array}$ \\
\hline
\end{tabular}

Long wait times Patient: 'When I go to the emergency room, they [say], "When you get out of here go see your GI doctor". But, that's not the way it works. Last time I called to get in the next day, they told me he had 17 patients, and couldn't see me. In three months, you don't know what could happen. So, the next thing is [back to] the ED'. ${ }^{61}$

Mismatch arises from patients' social circumstances limiting access to services, behavioral issues interfering with care engagement, and lack of health system flexibility to address these barriers. A staff member reflected on the inability for a patient to receive services due to homelessness: "He was homeless when we made the referral and doesn't...fit into [the] standard hospice system.... Health care systems are designed for these neat packages of people that are housed, have family support, have access to other resources, are not actively using substances.... The services aren't really designed for complex folks, so that can be really frustrating and exhausting." (SUMMIT LCSW) ${ }^{61}$

A few [stakeholders] even suggested that sometimes it felt easier to take an ambulance to the ED and access different services at the same place and time rather than arrange transport for multiple visits including PCP, specialists, bloodwork, etc. ${ }^{61}$

Economic determinants of health care. Patients identified insurance-related factors and financial burden of upfront costs (such as co-payments) as reasons for frequent ED visits and hospitalizations. For example, several patients on Medicaid reported knowing that many physicians in their community did not accept their insurance. To avoid losing time by contacting multiple primary care offices, they would go to the ED directly. Also, for underinsured and uninsured patients, the ED was the only health care setting where they could receive health care without having to deal with implications of their insurance status or co-pays right away. Many patients also reported the negative impact of financial burden on their medication adherence as a driver of frequently presenting to the ED. They felt that some of these visits can be prevented if medications and essential medical devices were not so expensive. ${ }^{61}$ 


\begin{tabular}{|c|c|}
\hline CMOs & Relevant Data Extracts/Summary Information From Included Literature \\
\hline $\begin{array}{l}\text { CMO } 1.6 \text { Considering } \\
\text { patients' self- } \\
\text { assessments of health } \\
\text { system-related risk } \\
\text { factors and experience } \\
\text { [C] adds to intervention } \\
\text { designers' confidence in } \\
\text { identifying HNHC } \\
\text { patients [M] who will } \\
\text { benefit from intervention } \\
\text { services [O1] and who } \\
\text { are at risk of having } \\
\text { future high healthcare } \\
\text { use and cost [O2]. } \\
\text { (continued) }\end{array}$ & $\begin{array}{l}\text { Survey of frequent ED patients while in ED } \\
\text { Barriers to care: \% agree, could have multiple barriers } \\
\text { It is easy for me to make time to get to necessary med appts: } 78 \% \\
\text { I always remember to schedule my annual check-ups, tests, and/or screenings: } 65 \% \\
\text { I feel like I receive better quality health care in the ED than I do in my usual place of care } \\
\text { (PCP, clinic): } 48 \% \\
\text { whether certain services would be helpful to the patient, in the event the ED or health } \\
\text { system decided to offer the service: } \\
\text { After-hours options for minor health issues besides the ED: } 63 \% \\
\text { A nurse to work with you one-on-one to help manage health care needs: } 53 \% \\
\text { Transportation to get to medical appointments on-time: } 46 \% \\
\text { While } 42 \% \text { did not think that a PCP would be helpful, many said that they had one. }{ }^{27}\end{array}$ \\
\hline $\begin{array}{l}\text { CMO } 1.7 \text { An enrollment } \\
\text { process that includes an } \\
\text { extensive period of } \\
\text { outreach and trust } \\
\text { building [C] adds to an } \\
\text { intervention provider's } \\
\text { confidence [M] in } \\
\text { determining a } \\
\text { participant's willingness } \\
\text { and ability to participate } \\
\text { in the intervention [O]. }\end{array}$ & $\begin{array}{l}\text { The purpose of community navigators in the Familiar Faces program is to bridge the gaps } \\
\text { between their clients and the healthcare and social systems that are often fragmented and } \\
\text { difficult to navigate. Furthermore, integration of community navigators into the healthcare } \\
\text { system, specifically the information flow offered by EHRs, ensures that community } \\
\text { navigators are able to engage with patients during acute episodes of care, when their } \\
\text { needs are greatest. In addition to the expertise that community navigators provide to } \\
\text { clients in navigating healthcare and social systems, they may build trust between clients } \\
\text { and the healthcare system, as they live in the same communities as their Familiar Faces } \\
\text { clients. Mistrust of the healthcare system is often high in minority and low socioeconomic } \\
\text { populations and may result in delayed medical treatment and use of fewer preventive } \\
\text { services.... Because the community navigator was simultaneously a member of the } \\
\text { community and the healthcare system, it is possible that they were able to reach } \\
\text { community members particularly mistrustful of the healthcare system and start to build a } \\
\text { foundation of trust. }{ }^{95}\end{array}$ \\
\hline
\end{tabular}

The outreach to ESRD beneficiaries, however, was entirely new in Phase II since ESRD was not part of the clinical focus in Phase I. KTBH program leadership found that when a nurse had an in-person contact with an ESRD beneficiary, the beneficiary was more than twice as likely to enroll in the program. As a result, KTBH program leadership decided to send a nurse to every dialysis facility with more than two eligible beneficiaries. Prior to the visit, the care manager sent a packet to the facility's administrator, placed a call to the administrator, and tried to make an appointment to conduct an informational breakfast or lunch session with the entire staff to introduce the KTBH program and assuage any concerns about the program. The goal of the informational sessions was to explain to staff that the care managers hoped to accomplish things with the beneficiary that would enable the intervention participants to better manage their condition. They tried to convey to staff that the care managers were not there to make their lives more difficult or to take the place of the existing staff that provided services to beneficiaries. KTBH staff reported receiving the biggest pushback from facility social workers. KTBH staff believed that there was a direct correlation between having the support of social workers and beneficiary participation in that when they received the support of the social workers, prospective participants were more likely to join the KTBH program. ${ }^{82}$

That's been the difficult piece, finding people who are appropriate and they want our help at the same time. That's been the trickiest piece. CCM Nurse ${ }^{94}$

CCM providers in our study actively looked for positive and negative indicators that patients were willing to engage in care. Providers often found these explicit signs to be inadequate for detecting patients' desire or readiness to engage in care and therefore looked for more subtle signs and tried to make intuitive assessments. ${ }^{94}$

The enrollment criteria for the CCM programs included a willingness to engage in care. ${ }^{94}$ 


\begin{tabular}{|c|c|}
\hline MOs & it Data Extracts/Summary Information From Included Literature \\
\hline $\begin{array}{l}\text { CMO } 1.7 \text { An enrollment } \\
\text { process that includes an } \\
\text { extensive period of } \\
\text { outreach and trust } \\
\text { building [C] adds to an } \\
\text { intervention provider's } \\
\text { confidence [M] in } \\
\text { determining a } \\
\text { participant's willingness } \\
\text { and ability to participate } \\
\text { in the intervention [O]. } \\
\text { (continued) }\end{array}$ & $\begin{array}{l}\text { CCM providers looked for indicators that patients were willing to engage during initial } \\
\text { patient encounters and enrollment, and looked for signs of successful engagement in } \\
\text { ongoing assessments of patients' communication and actions. When CCM providers first } \\
\text { met patients, positive indicators that they were willing to engage included verbally agreeing } \\
\text { to take part in the program, returning phone calls to the CCM team or answering the phone } \\
\text { when CCM team members call, being receptive to a home visit, and showing up to an } \\
\text { initial appointment. CCM providers continued to assess engagement over time by } \\
\text { considering how frequently patients missed appointments, how well they adhered to } \\
\text { medication and treatment regimes, how much progress they made towards behavioral } \\
\text { changes such as reducing substance use or increasing exercise, and how candidly and } \\
\text { regularly they communicated with the CCM team. A social worker said that she considers } \\
\text { patients likely to engage over time when "we reach out to them by phone and we make an } \\
\text { appointment and they show up."'94 }\end{array}$ \\
\hline
\end{tabular}

We learned that for B2C to reduce the use of acute care, outreach to and enrollment of high utilizers had to happen in real time in the ED. ${ }^{88}$

Judgment about whether the patient is amenable to management is based on an interview with the patient by the care team and a review of medical records. The assessment of whether the patient is entered into Care One is based on a judgment that the patient has a chronic medical condition, is at high risk for future hospitalization, and is willing to attend outpatient visits and comply with therapy. Other specific exclusions from the Care One program include a single high-cost medical event (e.g., a trauma), residence outside of the hospital's catchment area, and chronic alcohol or drug abuse. ${ }^{92}$

Most deep-dive practices indicated that risk-stratification improved the organization and delivery of care. Clinicians and staff continued to report that risk-stratification increased their awareness of high-risk patients' needs and helped them better allocate staffing resources to different patient populations. For example, in a few practices, patients with a single chronic condition (such as patients with diabetes who needed basic monitoring and health education) received care management from a medical assistant. This enabled the care manager to focus on higher-risk patients (such as patients with poorly controlled diabetes and additional chronic conditions). Risk-stratification continued to help practices identify and prioritize high-risk patients and schedule longer appointments for them as needed. In contrast, respondents in one small deep-dive practice questioned the utility of risk-stratification; they perceived that clinicians knew their patients well enough to determine whether they were high-risk and they believed that the time they spent riskstratifying patients would be better spent delivering direct patient care. ${ }^{101}$

Text box III.1. Example from CSHP illustrating the program's theory of action "Patient A in Kansas City has multiple chronic conditions and poly-substance abuse, a history of homelessness, frequent ED visits, and no PCP [primary care provider]. At the initial contact with the care team, the patient stated that he would "never want to conform to the rules." The care team's strategy is to first establish firm trust. They accomplished this by identifying opportunities to provide basic help, such as involving family members in explaining the impact on diet of modifying cooking practices, supplying a scale and log to support the modification, organizing and explaining the purpose of medications, arranging for transportation and enabling the patient to do so, scheduling and accompanying patients to medical and social service appointments. ${ }^{85}$

$\mathrm{C}=$ context $\mathrm{M}=$ mechanism $; \mathrm{O}=$ outcome 
Table B-12. Full list of Context-Mechanism-Outcome (CMO) configurations with supporting data for Program Theory 2: Engaging HNHC patients in interventions to improve their management of their chronic conditions, supporting CMO relationships

\begin{tabular}{|c|c|}
\hline Program Theory Issue & CMOs \\
\hline $\begin{array}{l}\text { Patients' challenges to } \\
\text { self-care prior to and } \\
\text { during the intervention }\end{array}$ & $\begin{array}{l}\text { CMO 2.1. Past } \\
\text { experiences with the } \\
\text { healthcare system } \\
\text { including encountering } \\
\text { barriers accessing } \\
\text { medical care and } \\
\text { disrespect from provider } \\
\text { [C] cause patients to } \\
\text { distrust the system and } \\
\text { providers [M] which } \\
\text { inhibit patients from } \\
\text { accepting and seeking } \\
\text { appropriate help and } \\
\text { medical care [O]. }\end{array}$ \\
\hline
\end{tabular}

Relevant Data Extracts From Included Literature

More than half of participants $(n=12)$ related stories of

encounters that had upset them; several explicitly mentioned

withdrawing from outpatient providers by choosing not to attend appointments with those providers as a result. Over a third of participants switched providers because of dissatisfaction with those relationships. Others who had not switched chose not to disrespect from providers follow a given provider's instructions as a result of these negative interactions. Most of the stories of negative health care encounters focused on feeling disrespect from providers, while others specifically described feeling discriminated against by providers because of race or sex. ${ }^{105}$

Several participants in this study expressed that they felt that their care sometimes was compromised by perceived disrespect from health care providers, citing race-, sex- or SES [socioeconomic status]-based discrimination. ${ }^{105}$

When answering questions about trusting their health care providers, almost half $(n=9)$ of participants stated that they distrusted a particular (usually hospital-based) provider. Respondents generally expressed trust in their primary care providers. ${ }^{105}$

Nearly every patient had experienced a number of barriers and frustrations in accessing medical care that the DIGMA team seems to have successfully addressed..$^{98}$

"Patient A in Kansas City has multiple chronic conditions and poly-substance abuse, a history of homelessness, frequent ED [emergency department] visits, and no PCP [primary care provider]. At the initial contact with the care team, the patient stated that he would "never want to conform to the rules."...His sister reflects, "He used to use the ER [emergency room] for everything...." 85

Challenges associated with accessing health care delivery systems Transportation barriers. Some patients reported that primary care offices were inconveniently located and difficult to access due to transportation barriers. A few even suggested that sometimes it felt easier to take an ambulance to the ED and access different services at the same place and time rather than arrange transportation for multiple visits including primary care, specialists, bloodwork, etc. For patients who could utilize private or public transportation to get to a primary care clinic, the distance often made the trip extremely time-consuming as well as costly. Preventability of ED use appeared contingent upon logistic ease of access to services.

Long wait times. All stakeholders identified scheduling challenges at primary care clinics as an important driver. Many patients reported that they were unable to schedule first-time or follow-up appointments quickly (same-day, next day or even in upcoming weeks) and instead had to wait several months. Furthermore, if a disease exacerbation occurred after regular clinic hours or overnight, patients felt that they had no other options but to seek care in the ED. ${ }^{61}$ 


\begin{tabular}{ll}
\hline Program Theory Issue & CMOs \\
\hline Patients' challenges to & CMO 2.2. Previous and \\
self-care prior to and & current personal life \\
during the intervention & circumstances and \\
(continued) & characteristics (e.g., \\
& mental illnesses, \\
& substance abuse, \\
& emotional or physical \\
& traumas, extreme \\
& poverty, and low literacy) \\
& [C] results in feelings of \\
& stigma in patients [M] \\
& that inhibit them from \\
& seeking help and medical \\
& care [O].
\end{tabular}

Relevant Data Extracts From Included Literature

A predominance of the participants $(n=12)$ told stories of childhood instability...Significant subthemes included early life traumas, such as death of a parent or other loved one, and abusive relationships with primary caregivers throughout childhood. Some described state agencies as their primary caregivers. Transiency was noted, often in the context of escape from abusive relationships $(n=5)$, and often resulted in living on the streets or gang and drug involvement, even as children. Only 2 individuals specifically described how events in childhood affected their health during adulthood. Nevertheless, many participants related stories of how this instability may have manifested in health issues, especially with regard to care [O].

"I had sexual and physical abuse from my parents since I was a baby, since I was 3 or 4 . Mother has been very abusive over the years. Every time we went somewhere she was hitting me, punching me, scratched me, and l'd cover it up."

This individual described ongoing difficulty obtaining effective treatment for the post-traumatic stress disorder that repeatedly sent her to the ED. She reported being frequently "suicidal" and "in crisis" as a specific result of childhood abuse, for which she was "in and out of hospitals too much." She reported a shared goal with her therapist of accessing consistent communitybased mental health care rather than relying solely on the ED. Nearly half of the respondents $(n=8)$ named their mother or a mother figure as their most important primary caregiver. The other half referred to a variety of other caregivers, such as grandparents, other relatives, or the state, or they declined to answer; these situations were described by some participants as traumatic, and by others as a normal course of events. Of participants who described instability in childhood, half noted familial estrangement in adulthood $(n=6)$. When asked if there was someone they could depend on now for help, most participants spoke of having only 1 or 2 individuals that they could rely on, if any, suggesting a lack of social support in adulthood for nearly all of these respondents. ${ }^{105}$ Patients may have a variety of barriers that prevent them from accessing traditional primary care venues, particularly those settings that do not allow patients to walk in at their convenience or patients who may need intensive services during a personal crisis. Patients with difficult life circumstances also may be more likely to not show for an appointment. ${ }^{98}$

Patients in this quality improvement program tend to be younger than those targeted by previously described care transition models and many have unstable health insurance, a history of substance use, and significant mental illness. Nearly all are from socially disadvantaged communities plagued by poor health status, and low literacy is common. Many are struggling with difficult life circumstances such as an alarming number have been emotionally or physically traumatized;... and many have inadequate, or no, family and social support systems. At enrollment, the concept of self-management is not familiar to most of them. ${ }^{91}$ 


\begin{tabular}{l} 
Program Theory Issue \\
\hline Patients' challenges to \\
self-care prior to and \\
during the intervention \\
(continued)
\end{tabular}

\section{CMOs}

CMO 2.2 Previous and

current personal life

circumstances and

characteristics (e.g., mental illnesses,

substance abuse, emotional or physical traumas, extreme poverty, and low literacy) [C] results in feelings of stigma in patients [M] that inhibit them from seeking help and medical care [O]. (continued)

\section{Relevant Data Extracts From Included Literature}

There are two key elements to the success of these new efforts to target and improve care for high-cost Medicaid cases. First, it is essential to be able to identify in advance patients who are likely to have high costs in the future. Many high-cost occurrences (such as injury, acute illness, or cancer) might be episodic, and high spending in one year might not mean high spending in subsequent years. Second, and equally critical, is the ability to actually affect the care pathways and outcomes of ) these patients. Because of the circumstances that define their Medicaid eligibility (extremely low income and medical disability) and other factors that are likely to be associated with their social and personal environment (such as homelessness, substance al use, or low educational achievement), these patients will undoubtedly present major challenges. ${ }^{62}$

All stakeholders identified poorly managed serious mental illness among $\mathrm{HNHC}$ patients as a significant driver of preventable high health care utilization. Patients often had inadequate access to mental-health and substance-abuse resources. This was because outpatient programmes did not exist, were inconveniently located or were not financially feasible to attend. This left patients without any options other than the ED for care. Additionally, several patients acknowledged that feeling depressed negatively impacted their care routines and contributed to missing provider appointments which, over time, compounded the severity of their diseases. Importantly, patients also pointed out that the stigma surrounding mental illness was detrimental to their desire to seek out treatment even if it were available. Some patients also felt that policies such as the Florida Mental Health Act (known as the Baker Act) and its equivalent in New York State (known as Kendra's Law),20,21 which allow for involuntary institutionalization and examination of an individual with possible mental illness for up to 72 hours, did not adequately address or help mitigate the root causes of substance abuse and mental-health disorders. This increased preventable ED and/or hospital utilization for psychiatric needs. ${ }^{61}$

Low health literacy made it difficult for many HNHC patients to manage complex medical conditions on their own, adversely impacting their ability to follow through with day-to-day self-care regimens. ${ }^{61}$

Economic determinants of health care. Patients identified insurance-related factors and financial burden of upfront costs (such as co-payments) as reasons for frequent ED visits and hospitalizations. For example, several patients on Medicaid reported knowing that many physicians in their community did not accept their insurance. To avoid losing time by contacting multiple primary care offices, they would go to the ED directly. Also, for underinsured and uninsured patients, the ED was the only health care setting where they could receive health care without having to deal with implications of their insurance status or co-pays right away. Many patients also reported the negative impact of financial burden on their medication adherence as a driver of frequently presenting to the ED. They felt that some of these visits can be prevented if medications and essential medical devices were not so expensive. ${ }^{61}$ 


\begin{tabular}{l} 
Program Theory Issue \\
\hline Patients' challenges to \\
self-care prior to and \\
during the intervention \\
(continued)
\end{tabular}

\section{CMOs}

CMO 2.3. System-level

barriers including

inadequate systemic

support (e.g., Medicaid, translation services, housing) and lack of cultural competency [C] engenders feelings of distrust and marginalization among patients [M] that inhibit their ability to access appropriate healthcare services [01] and to participate in interventions [O2].

\section{Relevant Data Extracts From Included Literature}

...some have no income while others have income that it is insufficient to meet basic survival needs making it challenging to pay even minimal co-pays for prescriptions; many live in unstable housing or in dangerous neighborhoods....Systems, like the Housing Authority, Medicaid, and health systems, often add to their burden. Examples include applications for benefits are frequently difficult to figure out and time consuming to file, applicants often feel disrespected or treated as if they were helpless, and agency staff are often not adequately sensitive to client issues regarding low/no literacy. In addition, for nonEnglish speaking, translation services can be inadequate, cultural competency is a problem, and mailed annual reapplication notices (such as for Medicaid) are difficult to recognize as something official and may be disregarded..$^{91}$

Many participants faced a variety of barriers to appropriate care, including lack of stable income, health insurance, legal residency, English language proficiency, knowledge of the health system and chronic disease management, stable housing, social support, and transportation. Many also had issues with cultural barriers, mental illness and substance abuse (despite informal program eligibility criteria that excluded some patients with these conditions), and traumatic experiences that made stabilizing their chronic conditions more difficult. ${ }^{85}$

Many patients are unable to afford even a minimal copayment that may be expected at time of a nonemergent outpatient visit and may choose to access the ED where a copayment may not be required. ${ }^{98}$

We found that patients with low health literacy (measured by the REALM-SF) reduced ED utilization to a greater degree than patients with higher health literacy. We hypothesize that patients with lower health literacy may have encountered more barriers to accessing primary care or had greater social needs than those with higher literacy and thus, differentially benefitted from individualized assistance from a patient navigator. These preliminary results suggest that care coordination programs that aim to reduce avoidable ED use and hospital admissions may have a greater impact among patients with lower health literacy. ${ }^{110}$

In the current study, KCCP Care Managers identified multiple barriers to active participation in the intervention including basic needs for food, shelter, and transportation that took precedence over program participation; depression; not having a phone or being unable to manage a phone due to mental illness or addiction; language or other cultural barriers; and mistrust of the system (Cristofalo et al. unpublished data). ${ }^{112}$ 


\begin{tabular}{l}
\hline Program Theory Issue \\
\hline Patients' challenges to \\
self-care prior to and \\
during the intervention \\
(continued)
\end{tabular}

translation services,
housing) and lack of
cultural competency [C]
engenders feelings of
distrust and
marginalization among
patients [M] that inhibit
their ability to access
appropriate healthcare
services [O1] and to
participate in

Relationship building with CMO 2.4. Interventions Patients generally had positive impressions of their care care providers and care team members initially address patients' basic needs and explain things in lay terms [C] to establish trust with the patient [M] resulting in building a relationship with their patients [O].

\section{Relevant Data Extracts From Included Literature}

Social determinants of health. All stakeholders emphasized the importance of inadequate health literacy, unstable housing conditions, and lack of adequate social support in driving preventable high health care utilization.... They also felt that for some HNHC patients with unstable housing conditions, being in the ED or an inpatient care setting was desirable, as it was the only avenue, as one HNHC patient put it, to 'get a meal.. .have a television... stay overnight'. Finally, health system leaders as well as most physicians felt that the interplay between lack of social support and poor disease control was often a reason for presenting to the ED. ${ }^{61}$ managers. During semi-structured interviews with a sample of high-risk patients and caregivers from deep-dive practices, patients who reported having regular contact with their care manager or who were open to working with their care manager felt that the care manager was an asset to their team. Patients particularly valued care managers who listened to them and explained things in lay terms, helped to manage medications and chronic conditions, followed up after a hospitalization, and helped to navigate the health care delivery system and community resources. ${ }^{101}$

“...The patients that have been on SUMMIT [Streamlined Unified Meaningfully Managed Interdisciplinary Team] for a while who have a really solid relationship with us, that makes a huge difference. They are able to call. They are telling us what their needs are. They can make it to appointments and...coordinate all of those needs a little bit better when they know that we're going to be reliable and [here] is where they can come for help." (SUMMIT Physician). ${ }^{58}$

They [the program staff] expected that its program would have the greatest impact by preventing acute health care events among beneficiaries who were initially not having significant health issues; however, case managers found that they spent a lot of time dealing with urgent issues for patients who "spiraled out of control." Although initially some patients were skeptical about the MGH [Massachusetts General Physicians Organization] CMP [Care Management Program], overall, patients quickly formed relationships with case managers, including several who requested daily contact with their case managers to help them with their numerous issues.

The care team's strategy is to first establish firm trust. They accomplished this by identifying opportunities to provide basic help, such as involving family members in explaining the impact on diet of modifying cooking practices, supplying a scale and 


\begin{tabular}{|c|c|}
\hline Program Theory Issue & CMOs \\
\hline $\begin{array}{l}\text { Relationship building with } \\
\text { care providers } \\
\text { (continued) }\end{array}$ & $\begin{array}{l}\text { CMO } 2.4 \text { Interventions } \\
\text { and care team members } \\
\text { initially address patients' } \\
\text { basic needs and explain } \\
\text { things in lay terms [C] to } \\
\text { establish trust with the } \\
\text { patient [M] resulting in } \\
\text { building a relationship } \\
\text { with their patients [O]. } \\
\text { (continued) }\end{array}$ \\
\hline
\end{tabular}

Relevant Data Extracts From Included Literature

log to support the modification, organizing and explaining the

purpose of medications, arranging for transportation and

enabling the patient to do so, scheduling and accompanying

patients to medical and social service appointments. Within

weeks, the patient has started scheduling transportation and keeping his appointments independent of the care team, and now states that he cares about his health. His sister reflects, "He used to use the ER [emergency room] for everything. Now he asks when his appointment is." 85

Convenience And Access Our model emphasizes convenience and access, starting with location. Our centers-in the range of $6,500-10,000$ square feet-are located in urban areas with a high density of low-to-moderate-income seniors. For our patients' convenience, we offer a broad set of additional services on site, including dental care, digital x-ray, ultrasound, and acupuncture, as well as five to fifteen high-volume specialists. Our average health maintenance organization (HMO) patient received 86 percent of his or her ambulatory encounters at our centers in 2011 , although the most expensive aspects of care occurred outside of our centers - for instance, hospitalizations, surgeries, and imaging. Patients find the onestop-shop approach to care highly appealing. ${ }^{114}$

CMO 2.5. When care Care management is a vital piece of the puzzle, pulling together managers support community resources without which recovery would be patients with medical and impossible....Successful case management also includes non-medical problems [C], patients are assisting with teaching some of these patients basic life skills, for example, not to find housing for them, but rather direct them reassured [M1] and gain where to go to get housing assistance. These small, positive confidence [M2] in their ability to manage their steps are then shared with the group, which further reinforces a own care [O]. growing sense of confidence. ${ }^{98}$

Additionally, efforts to tailor-make health education programs to improve health literacy and numeracy may be warranted for patients to effectively self-manage some of their care needs. ${ }^{61}$ 


\begin{tabular}{|c|c|c|}
\hline Program Theory Issue & CMOs & Relevant Data Extracts From Included Literature \\
\hline & $\begin{array}{l}\text { CMO 2.6. Patients are } \\
\text { more motivated [M] to } \\
\text { improve their health } \\
\text { behaviors [O] when they } \\
\text { feel cared for by their } \\
\text { providers and other } \\
\text { support groups }[\mathrm{C}] \text {. }\end{array}$ & $\begin{array}{l}\text {...participants reported that "caring" providers were particularly } \\
\text { important in the trajectories of their illnesses and lives, } \\
\text { emphasizing the compassion of the Care Management Team. } \\
\text { Providers from the intervention were described as dependable, } \\
\text { sensitive, and thoughtful, suggesting that these traits in } \\
\text { providers may resonate for individuals whose childhoods lacked } \\
\text { caregivers with these qualities. }{ }^{105}\end{array}$ \\
\hline & & $\begin{array}{l}\text { Conversely, participants emphasized the importance of caring, } \\
\text { trusting, and longitudinal relationships with providers, both on } \\
\text { the Care Management Team and with primary care providers. } \\
\text { Comorbid mental illness, especially depression, makes } \\
\text { managing chronic illnesses such as diabetes more } \\
\text { challenging.34-37 Consistent, positive relationships with } \\
\text { primary care providers have been shown to decrease rates of } \\
\text { hospitalization and ED use for complex patients who struggle } \\
\text { with a combination of multiple chronic illnesses, mental illness, } \\
\text { and psychosocial challenges. }\end{array}$ \\
\hline & & $\begin{array}{l}\text { Frequent, longer visits built relationships with the care team and } \\
\text { other patients. The emotional support provided by the group } \\
\text { seemed to be a key factor in assisting patients to find solutions } \\
\text { to their health and social problems. }{ }^{98}\end{array}$ \\
\hline & & $\begin{array}{l}\text { Half of participants indicated the importance of "feeling cared } \\
\text { for" by providers }(n=10) \text {. This theme recurred throughout the } \\
\text { interviews, especially during descriptions of the Care } \\
\text { Management Team. When asked about the best part of the } \\
\text { intervention, rather than describing specific services, most } \\
\text { participants described the importance of the emotionally } \\
\text { supportive interactions they experienced. These participants } \\
\text { reported that the experience of feeling cared for was a } \\
\text { motivation to improve their own health behaviors ( } n=10) \text { (Table } \\
\text { 2). Diabetes, depression, and hypertension were the most } \\
\text { commonly reported conditions. Despite the natural history of } \\
\text { these complex chronic diseases and their tendency to reflect a } \\
\text { pattern of deterioration over time, } 7 \text { participants reported } \\
\text { improvements in their own perceived health status after the } \\
\text { intervention. Five of those participants specifically attributed this } \\
\text { improvement to the intervention. "They make you feel like } \\
\text { you're not alone, and they understand you and the things you're } \\
\text { going through. And they actually help explain why you're going } \\
\text { through these things...you don't feel like just a patient." - 24- } \\
\text { year-old African American woman with depression and Type } 1 \\
\text { diabetes. }{ }^{105}\end{array}$ \\
\hline
\end{tabular}




\section{Program Theory Issue CMOs}

Relationship building with $\mathrm{CMO} 2.7$. When

care providers

(continued) providers build trusting

relationships with

patients [C], patients

have confidence in their providers' desire to help [M] resulting in patients seeking advice from their intervention care provider before going to the ED/hospital [O] intervention care

\section{Relevant Data Extracts From Included Literature} During the early months of CLM's [Care Level Management's] program implementation, nurse care managers focused on building relationships with the patients during telephone contact between PVP visits, so that patients would be comfortable calling the nurses if health problems arose. Patients at highest risk were to receive calls on a weekly basis, whereas those at moderate and low risk were to receive calls on a monthly or bimonthly basis.... Over the course of the first year of operations, CLM reported ...that they reorganized their patient care teams to include more nursing support. CLM believed that this arrangement would allow patients to bond with the nurse care manager over time, whereas CLM had observed that the clinical specialists were not able to forge a sufficient bond as evidenced by the fact that some of their participants were going to the hospital rather than calling the clinical specialists when problems arose. ${ }^{84}$

In addition to connecting clients to health and social resources in their community, the community navigators focus on building trust between the client and navigator and subsequently with other healthcare entities and social systems in the community. ${ }^{95}$

The care manager is an experienced, calm, trusted professional patients can call when they are frightened or in crisis between groups visits, which is often the difference between going to the ED to seek immediate care or waiting a day or 2 until the next group visit. ${ }^{98}$

These participants articulated an appreciation for continuity in relationships with providers, including members of the Care Management Team. A majority of respondents $(n=14)$ described their preference for office-based primary care with their usual providers, reserving the ED for emergent medical necessity or after-hours needs. ${ }^{105}$

Individualized care for CMO 2.8. Designing Care transitions are normally linear and finite (e.g., from HNHC patients flexible interventions that Provider A to Provider B), but in our care coordination could be tailored and individualized to specific HNHC patient's needs and circumstances [C] empowers providers [M] to be responsive to each patient's needs and circumstances. based on their medical and life situations, they are not programs, the number and nature of care transitions are circular, overlapping, and continual. They involve cross-sectoral care givers including social services, government workers, and church and community members-in addition to medical, social work, and behavioral health providers in one or more health systems-and they take place at multiple locations. Because the interventions need to be tailored to each patient individually, predictable at the outset, and "model fidelity," as required by most care transition models, is not feasible. ${ }^{91}$

Specific interventions were tailored to each patient in collaboration with the patients and their family, reflecting the patient's unique needs. ${ }^{119}$

Patient intake at IOC included an in-depth patient assessment to determine non-medical barriers to improved health. Care plans and activity to address needs were individualized. ${ }^{83,85}$ 


\begin{tabular}{|c|c|c|}
\hline Program Theory Issue & CMOs & Relevant Data Extracts From Included Literature \\
\hline $\begin{array}{l}\text { Individualized care for } \\
\text { HNHC patients } \\
\text { (continued) }\end{array}$ & $\begin{array}{l}\text { CMO } 2.8 \text { Designing } \\
\text { flexible interventions that } \\
\text { could be tailored and } \\
\text { individualized to specific } \\
\text { HNHC patient's needs } \\
\text { and circumstances [C] } \\
\text { empowers providers [M] } \\
\text { to be responsive to each } \\
\text { patient's needs and } \\
\text { circumstances. } \\
\text { (continued) }\end{array}$ & $\begin{array}{l}\text { The ability to tailor care to patients' individual needs was } \\
\text { another ingredient staff members felt they provided to complex } \\
\text { patients. A SUMMIT care coordinator described a strategy to } \\
\text { assist patients with attending specialty appointments: } \\
\text { "I'll have appointments with patients just with myself if patients } \\
\text { need help with scheduling outside the clinic and scheduling } \\
\text { transportation.... If a patient chronically no-shows to a } \\
\text { (specialty) appointment...I'll make an appointment for them to } \\
\text { come [see] me and we'll schedule together and...give them an } \\
\text { appointment planner or write up all their appointments for } \\
\text { them." } 58\end{array}$ \\
\hline
\end{tabular}

Each enrollee gets a tailored 60 day care plan and associated patient services they might need including assistance obtaining housing resources, insurance, disability benefits, refugee services, transportation, coordinating primary and specialty care; and filling prescriptions. ${ }^{88}$

The housing patterns we found, however, suggest the need for flexibility. Consistent with the experience of many Housing First programs, over two-thirds of the housed intervention participants required rehousing after their first placement did not succeed. The ability to offer a new housing placement is a key component of successful Housing First strategies when working with high complexity populations. With the widespread use of Coordinated Entry that will require that counties place individuals with similar risk profiles into $\mathrm{PSH}$, our findings provide support for the need for flexibility, including the ability to rehouse individuals, in order to serve those at highest risk. Our results offer a measured sense of expected changes in their use of other services. ${ }^{109}$

Another feature of our program was the flexibility in the range and intensity of services we offered to patients. Some patients required infrequent contact to assist with scheduling and attending primary care appointments. Other patients benefited from more intensive contact, including multiple accompanied clinic visits or home visits. ${ }^{111}$

CMO 2.9. Having Theme 3: Addressing Both Psychosocial and Clinical Needs interventions address Participants noted that it wasn't possible to separate provision underlying mental health of psychosocial support from traditional medical care. This can conditions concurrently run counter to what occurs in usual care. "I spent an hour with a or before managing other patient last week and we didn't talk about medical problems.... health conditions [C] It was a therapeutic session. I'm not a trained therapist, but helps patients' ability to [that's] what it was. We didn't talk about diabetes. We didn't talk cope with their health about her foot ulcers.... A lot of times we end up doing the work conditions [M] and allows of social workers, but when you do primary care, you have to do them to benefit from that. It's not 'oh hold on,... I'm not getting into that. I'm only here interventions addressing for the medical stuff.' It all wraps up into one." (SUMMIT their chronic conditions Physician) ${ }^{58}$ [O].

But the extraordinarily high levels of substance abuse among high-risk patients and the history of mental illness even among the population without serious and persistent mental illness make clear that any intervention will have to take these factors into account. ${ }^{6}$ 


\begin{tabular}{|c|c|c|}
\hline Program Theory Issue & CMOs & Relevant Data Extracts From Included Literature \\
\hline $\begin{array}{l}\text { Individualized care for } \\
\text { HNHC patients } \\
\text { (continued) }\end{array}$ & $\begin{array}{l}\text { CMO } 2.9 \text { Having } \\
\text { interventions address } \\
\text { underlying mental health } \\
\text { conditions concurrently } \\
\text { or before managing other } \\
\text { health conditions [C] } \\
\text { helps patients' ability to } \\
\text { cope with their health } \\
\text { conditions [M] and allows } \\
\text { them to benefit from } \\
\text { interventions addressing } \\
\text { their chronic conditions } \\
\text { [O]. (continued) }\end{array}$ & $\begin{array}{l}\text { In the early stages of the CMHCB [Care Management for High } \\
\text { Cost Beneficiaries] demonstration, CMP [Care Management } \\
\text { Program] leadership learned that many high-cost, complex } \\
\text { patients have mental health issues that were not effectively } \\
\text { addressed by the current model of health care delivery or its } \\
\text { pilot program. As a result, the program allocated greater } \\
\text { resources to support mental health, hiring a social worker to } \\
\text { assess the mental health needs of CMP participants and } \\
\text { support them in accessing psychiatric care as needed or } \\
\text { provide treatment if appropriate. }{ }^{86} \\
\text { Many participants faced a variety of barriers to appropriate care, } \\
\text { including lack of stable income, health insurance, legal } \\
\text { residency, English language proficiency, knowledge of the } \\
\text { health system and chronic disease management, stable } \\
\text { housing, social support, and transportation. Many also had } \\
\text { issues with cultural barriers, mental illness and substance } \\
\text { abuse (despite informal program eligibility criteria that excluded } \\
\text { some patients with these conditions), and traumatic } \\
\text { experiences that made stabilizing their chronic conditions more } \\
\text { difficult. }{ }^{85}\end{array}$ \\
\hline
\end{tabular}

...the program is unique in having a behavioral health provider screen every enrollee for mental health disorders-and then address those conditions as appropriate. ${ }^{88}$

We found a significant reduction in use of psychiatric emergency services and a concomitant increase in scheduled mental health visits. Project Welcome Home included Intensive Case Management with a low client-staff ratio led by licensed staff with behavioral health training. Research has shown that experiencing homelessness is one factor that leads to ED visits among psychiatric patients, suggesting an unmet need for mental health care.5,18 Our findings suggest that these visits are amenable to prevention by providing housing with associated low-barriers mental health services. ${ }^{109}$

CMO 2.10. Connecting Through the CMP, patients are assigned to a personal care patients and supporting them in navigating services that cross medical sectors (e.g., geriatrics, substance disorder treatment) and non-medical sectors (e.g., employment, manager who assists with access to social and medical resources, helps patients schedule PCP appointments, and helps bridge barriers between patients and the healthcare system. Enrolled patients are assigned to 1 of 3 outpatient primary care clinics. Components of the CMP include: goal creation/assistance in reaching goals, ranging from applying for benefits and receiving stable housing to losing weight and receiving specialty care appointments; assistance with care housing, transportation) navigation (schedule appts, follow-up on referrals, and help refill [C] help patients gain the medications); arranging for social services (make personal confidence $[\mathrm{M}]$ to learn how to navigate multiple systems for themselves [O].

connections with staff at various agencies in the community and refer patients to appropriate services, including transportation resources, Legal Aid, homeless shelters, faith-based services, and substance abuse resources); care transitions (meet with patients daily while they are admitted and work with discharge planners to assist patients in receiving recommended follow-up care and understanding discharge instructions); and communication with providers (accompanying them to appointments, creating and prioritizing problems lists, coaching patients about questions to ask, and sitting with patients after their visit to explain follow-up instructions). ${ }^{107}$ 


\begin{tabular}{l}
\hline Program Theory Issue \\
Individualized care for \\
HNHC patients \\
(continued)
\end{tabular}

CMOs

CMO 2.10 Connecting

patients and supporting

them in navigating

services that cross

medical sectors (e.g., geriatrics, substance disorder treatment) and non-medical sectors (e.g., employment, housing, transportation) [C] help patients gain the confidence [M] to learn how to navigate multiple systems for themselves [O]. (continued)
Relevant Data Extracts From Included Literature

After the visit, the patient navigator and patient created a task list based on the provider's recommendations. For example, if the PCP ordered additional tests or specialist referrals, the navigators assisted in scheduling these additional appointments, phoned patients to remind them, identified and addressed any barriers such as transportation, and encouraged patients to follow PCP recommendations. When needed, navigators helped patients to access medical transportation assistance through the state Medicaid system. If the patient identified social needs such as precarious housing, food insecurity, or insurance questions, they were provided with information to connect with local resources. ${ }^{110}$

The team (1) conducted home visits, (2) scheduled and accompanied patients to initial primary and specialty care visits to ensure that such appointments are kept and that the patient understands any instructions given during the appointment, (3) coordinated follow-up care and medication management (medication reconciliations), (4) measured blood pressure and blood sugar levels when appropriate, (5) coached patients in disease-specific self care, (6) helped patients apply for social services (e.g. housing support, Social Security (including SSI), Supplemental Nutrition Assistance Program (SNAP), Temporary Aid for Needy Families (TANF), and General Assistance (GA)) and appropriate behavioral health programs. provides disease specific education, coaches the patient in self-care, and works to empower patients to manage their health issues. During subsequent home visits, the team evaluates the patient and team's progress. The care team works to connect the patient with stable, continuing, and appropriate primary and specialty care. Coalition staff may help schedule further medical appointments as necessary, continue to help organize transportation, accompany patients to medical appointments, check-in after medical appointments to help the patient implement the instructions given by the provider, and continue to organize medications. Home visits in later stages increasingly focus on self-care management skills, health care navigation skills, enhancement of self-efficacy and independence, care plan adjustment and coaching. ${ }^{96}$

The most frequently used intensive management services were social work and mental health care, highlighting the importance intensive management teams placed on these services on the basis of their comprehensive assessments of patients' needs. The intensity of services varied greatly among patients assigned to the intervention group; patients who used more services tended to be older and to have more comorbid conditions, higher rates of baseline primary care utilization, and lower rates of substance use disorders and serious mental illnesses. These findings suggest that other models of intensive management may be more appropriate for patients whose mental health and substance use conditions are severe and are likely to prevent effective engagement with the intensive management team. 


\begin{tabular}{|c|c|c|}
\hline Program Theory Issue & CMOs & Relevant Data Extracts From Included Literature \\
\hline $\begin{array}{l}\text { Individualized care for } \\
\text { HNHC patients } \\
\text { (continued) }\end{array}$ & $\begin{array}{l}\text { CMO } 2.10 \text { Connecting } \\
\text { patients and supporting } \\
\text { them in navigating } \\
\text { services that cross } \\
\text { medical sectors (e.g., } \\
\text { geriatrics, substance } \\
\text { disorder treatment) and } \\
\text { non-medical sectors } \\
\text { (e.g., employment, } \\
\text { housing, transportation) } \\
\text { [C] help patients gain the } \\
\text { confidence [M] to learn } \\
\text { how to navigate multiple } \\
\text { systems for themselves } \\
\text { [O]. (continued) }\end{array}$ & $\begin{array}{l}\text { By design, the intensive management programs seem to have } \\
\text { facilitated referrals to home-based primary, palliative or hospice, } \\
\text { geriatrics telephone, specialty mental health, and telehealth } \\
\text { care. Because sites performed comprehensive assessment of } \\
\text { patients' social issues, treatment plans, and care goals, our } \\
\text { results suggest that the intensive management programs could } \\
\text { identify unmet needs and connect patients to important } \\
\text { resources. Home visits seemed to play a key role in patient } \\
\text { assessments, because patients with more intensive services } \\
\text { had an average of } 1.5 \text { home visits. }{ }^{.7} \\
\text { - Some patients with experience in residential or other intensive } \\
\text { management programs need support when trying to complete } \\
\text { programs, and need housing/support once programs end } \\
\text { - Patients desire support when trying to return to school, find } \\
\text { employment, or find housing: "I wish someone would help me } \\
\text { navigate the system. I don't know what resources or programs } \\
\text { are available to me." } 106\end{array}$ \\
\hline
\end{tabular}

Successful case management also includes assisting with teaching some of these patients basic life skills, for example, not to find housing for them, but rather direct them where to go to get housing assistance. ${ }^{98}$

CMO 2.11. Because patients' burden of Patients are continually enrolled at different times, resulting in different lengths in the post-enrollment time frame. Patient coexisting chronic diseases and social and behavioral issues are heterogeneous, allowing the length of the intervention to vary across participants [C] helps patients feel supported [M] by providing them with sufficient time to diagnoses that are driving admissions, and their burden of coexisting chronic diseases, are heterogeneous. The natural history of these common chronic diseases is such that the patients have ever evolving health conditions intermixed with periods of disease decompensation. Length of time in the intensive intervention period is variable and determined by demonstrated need and functionality: socially, medically, and behaviorally. Our intervention is not administered by number of days exposed but instead is administered until the patient demonstrates the behavior criteria we have defined ("graduates"), the patient expires, or transitions. Because the demonstrate intervention patients are graduated according to demonstration of objective goals (e.g., selfself-management behaviors (Figure 2), the resultant management behaviors) postgraduation time frames are also variable. ${ }^{91}$ [O].

Participants' issues often took longer to resolve than the intervention's time line typically allowed. ${ }^{85}$

Barriers to $\mathrm{HNHC}$ patient $\mathrm{CMO}$ 2.12. Despite change through interventions successful engagement with the intervention and relationships between members of the care team and $\mathrm{HNHC}$ patients [C], HNHC patients may continue to prefer seeking primary care at the hospital or ED [M]. Therefore, interventions may not be able to achieve goals such as reducing use of potentially preventable or modifiable healthcare services [O].
One challenge for the demonstration was that a sizable minority of beneficiaries and caregivers would prefer to visit the ED [emergency department]-instead of contacting the IAH [Independence at Home] practice-if they were unsure whether symptoms required emergency care (Table III.3). Beneficiaries provided a number of reasons for preferring to go to the ED, including that they or their caregivers thought it was the best place to receive care. Even though three-quarters of beneficiaries reported that the IAH practice visited about as often as the patient wanted them to visit (Appendix C, Table C.8), some beneficiaries' preference for the ED in uncertain situations might contribute to the demonstration's lack of an effect on outpatient ED visits. ${ }^{103}$ 


\begin{tabular}{|c|c|c|}
\hline Program Theory Issue & CMOs & Relevant Data Extracts From Included Literature \\
\hline \multirow[t]{2}{*}{$\begin{array}{l}\text { Barriers to HNHC patient } \\
\text { change through } \\
\text { interventions (continued) }\end{array}$} & $\begin{array}{l}\text { CMO 2.12 Despite } \\
\text { successful engagement } \\
\text { with the intervention and } \\
\text { relationships between } \\
\text { members of the care } \\
\text { team and HNHC patients } \\
\text { [C], HNHC patients may } \\
\text { continue to prefer } \\
\text { seeking primary care at } \\
\text { the hospital or ED [M]. } \\
\text { Therefore, interventions } \\
\text { may not be able to } \\
\text { achieve goals such as } \\
\text { reducing use of } \\
\text { potentially preventable or } \\
\text { modifiable healthcare } \\
\text { services [O]. (continued) }\end{array}$ & $\begin{array}{l}\text { Engagement with the program was high (95\% of patients had at } \\
\text { least three encounters with program staff), and patients } \\
\text { received an intensive intervention (averaging } 7.6 \text { home visits), } \\
\text { but two program goals related to the timing of services - a } \\
\text { home visit within } 5 \text { days after hospital discharge and a visit to a } \\
\text { provider's office within } 7 \text { days after discharge - were achieved } \\
\text { less than } 30 \% \text { of the time. Challenges in reaching these goals } \\
\text { included patients' lack of stable housing or a telephone and } \\
\text { their behavioral health complexities and providers' few available } \\
\text { appointments. The difficulties that this pioneering, data-driven } \\
\text { organization had in achieving rapid assistance for patients may } \\
\text { portend difficulties in achieving it at scale. }{ }^{96} \\
\text { Patients randomized to PIM were more likely than patients in } \\
\text { PACT to strongly agree that they have a VA healthcare provider } \\
\text { whom they trust...Survey findings suggest that the program may } \\
\text { have influenced some patients' experiences with patient- } \\
\text { centered care and chronic illness care, and increased the } \\
\text { number of patients who reported having a trusted provider, but } \\
\text { did not influence satisfaction, perceived access, or most } \\
\text { measures of care coordination. }{ }^{97} \\
\text { Though the SUMMIT intervention was developed as a way to } \\
\text { address high ED and hospital utilization, staff members did not } \\
\text { mention reduced utilization as a marker of success. "We are } \\
\text { dealing with a pretty sick population.... These are patients that } \\
\text { maybe do need to be in the hospital.... A hospitalization is not } \\
\text { necessarily a bad outcome for a lot of these patients." (SUMMIT } \\
\text { Physician) }{ }^{58}\end{array}$ \\
\hline & $\begin{array}{l}\text { CMO } 2.13 . \\
\text { Improvements in } \\
\text { patients' experiences } \\
\text { with their care providers } \\
\text { through participation in } \\
\text { HNHC patient } \\
\text { interventions [C] } \\
\text { gradually rebuilds } \\
\text { patients' trust in the } \\
\text { health care system [M] } \\
\text { that may lead to long- } \\
\text { term benefits in health } \\
\text { behaviors and clinical } \\
\text { outcomes [O] }\end{array}$ & $\begin{array}{l}\text { Furthermore, relationships are at the core of primary care, so } \\
\text { this finding suggests that augmenting a medical home with an } \\
\text { intensive management program may help fulfill the promise or } \\
\text { primary care. In fact, analyses of satisfaction suggest that the } \\
\text { program improved patients' experiences with primary care, but } \\
\text { not with other services. Improving primary care processes could } \\
\text { potentially have positive long term consequences, including } \\
\text { changes in health behaviors and clinical outcomes. }{ }^{97}\end{array}$ \\
\hline
\end{tabular}

$\mathrm{C}=$ context $\mathrm{M}=$ mechanism $; \mathrm{O}=$ outcome 
Table B-13. Full list of Context-Mechanism-Outcome (CMO) configurations with supporting data for Program Theory 3: Care provider engagement in interventions for HNHC patients

\begin{tabular}{|c|c|}
\hline Program Theory Issue & CMOs \\
\hline $\begin{array}{l}\text { Gaining and maintaining } \\
\text { support from physicians } \\
\text { and other care providers }\end{array}$ & $\begin{array}{l}\text { CMO 3.1. Strong } \\
\text { leadership support that } \\
\text { facilitates systemic } \\
\text { coordination of the } \\
\text { intervention and its } \\
\text { components smooth the } \\
\text { entry of care managers } \\
\text { into practices [C] } \\
\text { provides credibility of } \\
\text { their services to existing } \\
\text { practice staff [M], so care } \\
\text { managers are more } \\
\text { easily incorporated into } \\
\text { primary care teams [O]. }\end{array}$ \\
\hline
\end{tabular}

Relevant Data Extracts From Included Literature

Once MGH [Massachusetts General Physicians Organization]

had generated lists of CMP [Care Management Program]eligible beneficiaries receiving care from each physician, the CMP medical director met with each practice to introduce the program and discuss which patients were at highest risk for acute events and should receive priority for enrollment. The medical director also met with specialty practices such as the oncology, cardiology, emergency, and orthopedics departments to explain the resources available through the program,

because case managers would likely interact with these practice staff [M], so care providers as they facilitated patient access to these services. ${ }^{86}$ primary care teams [O].

At the time of the program launch, strong integration support from MGH leadership afforded the case managers physical entry into the primary care practice settings whereby the case managers were co-located with the primary care physicians ultimately becoming a part of the beneficiaries' primary health care teams. ${ }^{86}$

CMO 3.2. Program

leaders' use of tailored strategies and physician champions to explain intervention services [C] helps endorse the intervention [M] and results in physicians participating in the intervention [O].
A second round of focus groups was conducted with physician groups to specifically discuss how the CMP could add value to their practices.

In addition to providing input about the design of the CMP, the capstone groups provided an opportunity to obtain physician buy-in to the PBCM [practice-based care management] program. Despite the fact that some physician practices already had case managers, CMP management observed that most physician practices were apprehensive about changes such as the introduction of new staff into their practice. CMP leadership used a tailored approach to discuss the project with each practice, offering positive anecdotes from the PBCM pilot project as appropriate. In addition, CMP leadership identified a physician champion for the CMP within each physician practice that had at least 25 or more CMP patients at the start if the project to further ease the transitions involved in the introduction of a case manager into the practice. During program implementation physician champions provided insight about the best way to incorporate case managers into the practice and encourage colleagues to take advantage of services available from the case managers. ${ }^{86}$

Dr. Fishbane underscored the importance of establishing effective partnerships with the partner nephrologists during [Village Health's] Phase II and was optimistic about the efforts to secure physician champions, garner enthusiasm and support, and improve physician engagement at the first Medical Advisory Board meeting. ${ }^{82}$ 


\begin{tabular}{|c|c|c|}
\hline Program Theory Issue & CMOs & Relevant Data Extracts From Included Literature \\
\hline $\begin{array}{l}\text { Gaining and } \\
\text { maintaining support } \\
\text { from physicians and } \\
\text { other care providers }\end{array}$ & $\begin{array}{l}\text { CMO 3.3. Face-to-face } \\
\text { outreach to physicians and } \\
\text { their staff by program } \\
\text { leaders and/or nurse care } \\
\text { managers [C] effectively } \\
\text { garners support of the } \\
\text { intervention from existing } \\
\text { care providers [O] by } \\
\text { helping existing care } \\
\text { providers understand the } \\
\text { value of the intervention } \\
\text { [M]. }\end{array}$ & $\begin{array}{l}\text { Case managers assigned to each practice met with physicians } \\
\text { at the practices to describe the program, the skills that they } \\
\text { bring to the physician practice, and their interest in collaborating } \\
\text { to support patients in their efforts to manage their medical } \\
\text { conditions. Case managers collected information from providers } \\
\text { about how they could add value to the medical practice. }{ }^{86} \\
\text { Acquiring buy-in from participating physician practices was } \\
\text { viewed as very important. However, it was recognized early on } \\
\text { that buy-in was needed on all levels. There was some concern } \\
\text { among practice-based nurses, particularly at smaller practices, } \\
\text { that there would be a duplication of effort. To obtain buy-in from } \\
\text { the nurses, the CMP case managers spent time working with } \\
\text { the practice-based nurses to educate them that the goal of the } \\
\text { program was to augment and not to replicate their efforts. } \\
\end{array}$ \\
\hline & $\begin{array}{l}\text { CMO 3.4. Using a multi- } \\
\text { pronged approach to } \\
\text { provide physicians with } \\
\text { information about } \\
\text { intervention services [C] } \\
\text { made it more likely to } \\
\text { reach doctors to get their } \\
\text { support and engagement } \\
\text { [M] in the intervention } \\
\text { necessary for the program } \\
\text { to succeed [O] }\end{array}$ & $\begin{array}{l}\text { The program only works well when physicians are highly } \\
\text { engaged. }{ }^{86} \\
\text { MGH enlisted physician support to help ensure the success of } \\
\text { its CMP in providing high-quality care to patients. Physicians } \\
\text { were asked to conduct the following activities: encourage } \\
\text { beneficiaries to participate in the program and enroll them in the } \\
\text { program when possible; collaborate with case managers to } \\
\text { review initial assessment findings and develop care plans for } \\
\text { each patient; inform case managers about patient events and } \\
\text { refinements to patient care plans during the demonstration } \\
\text { period; and discuss advance directives with enrolled } \\
\text { patients...MGH physicians received information about the CMP } \\
\text { from a variety of sources, including the program's medical } \\
\text { director, the MGH electronic newsletter, and case managers } \\
\text { assigned to each practice. }{ }^{86}\end{array}$ \\
\hline
\end{tabular}




\begin{tabular}{ll}
\hline Program Theory Issue & CMOs \\
\hline Gaining and maintaining & CMO 3.5. When an \\
support from physicians & intervention includes an \\
and other care providers & insufficient number of \\
(continued) & patients the physicians \\
& [C], physicians do not \\
fully engage and & participate in the program \\
& [O] because they feel the \\
& intervention is not a good \\
& investment in time and \\
& resources [M].
\end{tabular}

Relevant Data Extracts From Included Literature The staff also suggested implementing a physician referral model to gain physician buy-in and to identify sufficient numbers of patients to make a financially viable care management program. A physician referral model could increase enrollment by more than 10 times, according to one physician's estimate, with which others agreed. Interviewed physicians and care managers felt that a physician referral model would increase the appropriateness of patients referred for care management services. It was recommended that patient-specific clinical or educational goals accompany an open physician referral model in order to ensure that participants have clearly identified goals against which to measure their progress. ${ }^{80}$

Although most physicians were supportive of the outreach efforts, they generally only had one or two patients participating in the program. The program had greatest success with offices that had approximately 30 patients participating in the program...To the extent that patients were concentrated with providers, program staff felt that the physicians were better allies and facilitated the clinical interventions.

"A couple things we've gotten a little bit smarter about-one is the alignment to the provider. . . One of the things I would definitely do differently is for ESRD [end-stage renal disease] patients, I would do DaVita only and see what kind of change we could drive there. Then if we had a great solution, we could think about how we could scale it. That was probably $70 \%$ of the operational hassle that didn't actually do anything for patients but took a lot of time and energy. The same is true on the CKD [chronic kidney disease] side with the nephrologists."

Although the nephrologists were very engaged initially, the program had less of a renal focus than anticipated given that the beneficiary population did not have the extent of CKD that was originally projected. As a result, the program did not maintain as high visibility among physicians during Phase I as the KTBH [Village Health's Key to Better Health] program leadership would have liked. ${ }^{82}$

During the first site visit, physicians at both sites reported that they were initially very enthusiastic about the Health Buddy ${ }^{\circledR}$ program, because it offered a promising way to effectively support patients with chronic disease. The Health Buddy® technology coupled with telephonic care management support was viewed as an effective way to maintain and improve patient health and identify symptoms of complications early, so that timely medical intervention could be used to prevent serious problems requiring hospitalization. Once the physicians received the list of patients who were eligible for the Health Buddy ${ }^{\circledR}$ program, they reported that they became frustrated with the project because they felt that many of the patients selected would not benefit from participating. Further, physicians reported disappointment that many of the patients they believed could be helped by the program were not eligible to participate in the program because they had not been identified through the claims based algorithm developed by $\mathrm{HHN}$ [Health Hero Network]... Using information gleaned from its early experience with the program, the HBC [Health Buddy Consortium] made a series of changes and enhancements to its operations and as reported to us at our second site visit. ${ }^{80}$ 


\begin{tabular}{l} 
Program Theory Issue \\
\hline Gaining and maintaining \\
support from physicians \\
and other care providers \\
(continued)
\end{tabular}

\section{CMOs}

CMO 3.6. Developing

and implementing a

financially supportive system or model for physicians and their practice [C] encourages and motivates physicians and other care providers [M] to spend time with their patients and to continue supporting innovative intervention activities [O].
Relevant Data Extracts From Included Literature

The Care One program provides incentives to primary care providers by valuing a Care One patient as equal to 5 normal primary care patients when adjusting panel size. ${ }^{92}$

MGH provided physicians with a $\$ 150$ financial incentive per patient in Year 1 and $\$ 50$ in Years 2 and 3 to help cover the cost of physician time for these activities. ${ }^{86}$

Thus, for such team care to be sustainable, time needs to be carved out for the work involved and systems need to support the follow through. ${ }^{102}$

The staff also suggested implementing a physician referral model to gain physician buy-in and to identify sufficient numbers of patients to make a financially viable care management program. A physician referral model could increase enrollment by more than 10 times, according to one physician's estimate, with which others agreed. ${ }^{80}$

Physician: 'When your hospital is basically saying.. . 'Here is 15 minutes for a repeat visit for another patient', I mean how are you gonna be able to actually provide the kind of care they need?'61

Recent changes in the Medicare Advantage program (nearly all of ChenMed's patients are enrolled in Medicare Advantage) have created a favorable environment for delivery system innovation. In particular, the 2004 introduction of the Hierarchal Condition Categories risk adjustment model created a mechanism that reduced the financial risk of taking care of high cost patients with multiple chronic conditions. Patients with multiple chronic conditions have higher risk scores and, accordingly, higher reimbursement. Although not perfect, risk adjustment has alleviated participating payers' and providers' concerns about attracting sicker and costly patients without receiving commensurate reimbursement. ${ }^{114}$

In addition, Medicare Advantage's capitation model is more favorable to delivery system innovation than traditional fee-forservice Medicare because it eliminates the process of negotiating reimbursement for cost-reducing delivery system innovations. Because providers are paid according to the size of their patient panel in a capitated system, they have an incentive to develop and test innovations to determine which ones lower the cost of care without compromising quality-and, ideally, increase it. For those innovations judged to be cost reducing without compromising quality, providers in a capitated system have the flexibility to deploy the innovations across their network. Providers in the fee-for-service system do not have such flexibility because they must negotiate with payers for the reimbursement of care delivery innovations-a step that can delay or even block such efforts. ${ }^{114}$

Administrative pressures in health care delivery systems. Physicians and health system leaders felt existing payment structures and administrative pressures (such as the impetus to maximize the number of patients seen while minimizing visit time) negatively impacted the way they could interact with patients. Many agreed that when such a limited time frame is 


\begin{tabular}{ll}
\hline Program Theory Issue & CMOs \\
\hline CMO 3.6 (continued)
\end{tabular}

Relevant Data Extracts From Included Literature allotted for each patient, it barely gives providers time to think, resulting in the delivery of 'bad care'. This also affected the way physicians communicate with their patients in key situations including discussions of illness, treatment options and care plans. Finally, stakeholders felt that the current care delivery model significantly dis-incentivized physicians from going into primary care, leading to a primary care physician shortage. The underlying sentiment was that if there are fewer primary care doctors overall, then HNHC patients will be at a greater disadvantage to have continuity of care at a primary care site, their diseases will not be well-controlled, leading to more ED visits and inpatient admissions. ${ }^{61}$

\begin{tabular}{ll}
\hline $\begin{array}{l}\text { Staffing arrangements in } \\
\text { care management }\end{array}$ & CMO 3.7. Reducing \\
interventions & providers' workload and \\
& responsibilities \\
& associated with the \\
implementation of & complex intervention \\
& activities [C] will reduce \\
& provider stress [M] so \\
& providers are more \\
& satisfied [O1] and more \\
& willing and able to \\
& engage with their \\
& patients and in \\
& participate intervention \\
& activities [O2] such as \\
& attending care team \\
meetings, and carrying & out care plans.
\end{tabular}

At baseline, members were divided in the anticipated effect of team care on their workload and stress levels. At 3 months, one member noted a decrease in workload, and three perceived an increase. Two indicated that the intervention "increased my stress by adding to my many responsibilities." Getting to Care Team meetings on time was difficult for about half of the team members. ${ }^{102}$

Some team members felt their work increased by participating in the team. ${ }^{102}$

Early on, we determined that certain tasks the HC RNs [Health Coach Registered Nurses] and LCSWs [Licensed Clinical Social Workers] were performing could be offloaded as these did not require their level of licensure, training, and skill. By doing so, we could free up the HC RNs and LCSWs to serve more patients and increase their job satisfaction. ${ }^{91}$

Respondents from both independent and system-owned practices described turnover that occurred because care managers felt overwhelmed with numerous responsibilities. ${ }^{101}$

Patient And Physician Time We also emphasize physician and patient time. Our primary care physicians, all internists, have a panel of 350-450 patients. By comparison, physicians at many commercial "concierge" practices, where patients pay sizable out-of-pocket retainers for the additional physician time, have larger panels. Small panel sizes allow our physicians to spend more time with their patients. Our physicians average fewer than eighteen visits a day; in contrast, primary care physicians average nearly thirty. ${ }^{114}$

Physician: 'Need more primary care physicians who can manage outpatient things... And so you end up not being able to fill the need, and then we see them in the emergency department.' 61 


\begin{tabular}{|c|c|c|}
\hline Program Theory Issue & CMOs & Relevant Data Extracts From Included Literature \\
\hline $\begin{array}{l}\text { Staffing arrangements } \\
\text { in care management } \\
\text { interventions } \\
\text { (continued) }\end{array}$ & $\begin{array}{l}\text { CMO 3.8. Case } \\
\text { managers, social } \\
\text { workers, and high } \\
\text { functioning } \\
\text { administrative } \\
\text { assistants in turn take } \\
\text { on many time- } \\
\text { consuming tasks (e.g., } \\
\text { medication } \\
\text { management, } \\
\text { identifying community } \\
\text { services, outreach, } \\
\text { engagement) to help } \\
\text { engage and manage } \\
\text { HNHC patients and } \\
\text { their paperwork [C] so } \\
\text { that providers can } \\
\text { focus their efforts [M] } \\
\text { on providing } \\
\text { continuous, } \\
\text { comprehensive care } \\
\text { to patients [O]. }\end{array}$ & $\begin{array}{l}\text { Early on, we determined that certain tasks the HC RNs and LCSWs } \\
\text { were performing could be offloaded as these did not require their } \\
\text { level of licensure, training, and skill...To address this, we worked } \\
\text { with the teams to identify tasks that could be done by high } \\
\text { functioning Administrative Assistants (AAs) and we now use AAs for } \\
\text { tasks such as maintaining telephone contact with patients to remind } \\
\text { them of appointments, check up on them when they have not been } \\
\text { heard from, and assist the team members in entering and retrieving } \\
\text { data related to the patients they serve. This is effective as long as } \\
\text { there are intermittent face to face opportunities for the patients with } \\
\text { the HC RNs, LCSWs, and CCLs [Client-Community Liaison]. }{ }^{91} \\
\text { "...Case managers take care of things like preauthorization, } \\
\text { gathering documentation, medication tracking and other time- } \\
\text { consuming issues, allowing PCPs [primary care providers] to focus } \\
\text { on the relationship with patients and provide real continuity of } \\
\text { care.;...The program does what every PCP needs to be doing but } \\
\text { cannot do anymore because of the medicine practice and } \\
\text { reimbursement realities and primary care provider } \\
\text { shortages.;...Both patients and physicians love the program as case } \\
\text { managers take a lot of burden off both sides.;...Key value of the } \\
\text { program is in the help they provide PCPs with medication review } \\
\text { and management, the most difficult to resolve issue when PCPs do } \\
\text { not have any help; } \ldots \text { ". [Summary from a focus group of multiple } \\
\text { physicians] }{ }^{86}\end{array}$ \\
\hline
\end{tabular}

The care manager served primarily as an adjunct to the patients' primary physicians. ${ }^{80}$

As in 2015, deep-dive practice respondents described approaches to improving support for care managers, to clarify their roles and enhance staffing resources to help them feel less overwhelmed...A few practices were monitoring care managers' caseloads to determine whether they needed more staff to support high-risk patients, or to reduce (or even eliminate) activities focused on lowerrisk patients. These practices brought in social workers to help meet patients' social needs and medical assistants to assume logistical or administrative tasks. ${ }^{101}$

Navigators shared information about individual patients utilizing a team-based navigation model that provided flexibility in dividing the workload and providing cross coverage. ${ }^{110}$

The program was staffed by a multidisciplinary care team consisting of a community health worker (CHW), a social worker (SW), and a PCP [primary care provider]...With guidance and support from the SW and the PCP, the CHW was responsible for patient outreach, engagement, activation, and accompaniment. The SW was responsible for counseling and brief interventions for patients with behavioral health needs and for coordinating referrals to social service agencies and other medical providers. The PCP was responsible for providing comprehensive care for acute and chronic conditions and for coordinating with specialists and inpatient providers. ${ }^{108}$ 
Program Theory Issue CMOs

Staffing arrangements CMO 3.8 (continued)

in care management

interventions

(continued)
Relevant Data Extracts From Included Literature

The CHW was able to identify unmet social needs contributing to acute care utilization that may not be apparent to busy clinicians and are not readily addressed during a single ED or clinic visit. For example, one patient with chronic restrictive lung disease who was dependent on home oxygen experienced financial insecurity and anxiety related to his inability to make on-time utility payments. The $\mathrm{CHW}$ was able to enroll him in a financial assistance program to prevent utility shutoffs, provide a list of local food pantries, and accompany him to primary care appointments where he was connected with the pulmonology clinic social worker who assisted with ongoing needs. ${ }^{111}$

CMO 3.9. Providing training for staff members [C] gives them the confidence and skills [M] to function effectively as a care team [O1] and to understand and work with $\mathrm{HNHC}$ patients [O2].

"... The program has done a remarkable job in training and cultivating case managers who are very good at breaking barriers and making it work for the most difficult patients;..." [Summary from a focus group of multiple physicians] ${ }^{86}$

...our team members received minimal training in ways to decrease frequent attendance and did not follow a systematic approach in assessing the patient...A more systematic approach, however, would have improved the function of our team. ${ }^{102}$
Both navigators completed training at the Harold Freeman Institute for Patient Navigation, a 2-day intensive training program that teaches navigators to identify and eliminate barriers to care and serve as a support hub for patients moving through the health care system (22). The PN also completed local training at Gateway Community College, which emphasized needs and resources within the local community (23). ${ }^{110}$

CMO 3.10. When care As in 2015, deep-dive practice respondents described approaches managers have regular opportunities to talk across offices and health care systems [C], they are more emotionally and technically prepared [M] to work with HNHC patients [O]. to improving support for care managers, to clarify their roles and enhance staffing resources to help them feel less overwhelmed. In some practices affiliated with health systems, respondents described providing opportunities for care managers embedded in practices across the health system to meet regularly, share best practices, and offer one another support. ${ }^{101}$

CMP leadership also emphasized team support and peer counseling by developing infrastructure that provided opportunities for mutual support among CMP case managers and peer counseling from the members of the mental health team as the emotional toll on staff of working with a highly frail and sick population are substantial. ${ }^{86}$

CMO 3.11. Having In addition, the ability for a team to be small and nimble was seen as small care teams [C] a strength as it allowed for increased cohesion. "One of the issues helps teams members with complex care is [it's] spread out amongst a bunch of different develop awareness of people.... There's a learning curve each time the patient meets with each HNHC patient's a different provider.... With SUMMIT [Streamlined Unified entire complex care Meaningfully Managed Interdisciplinary Team], it's a small team.... [M] which can improve Everybody knows what's going on with the patients in terms of their the coordination of conditions and it really cuts through the confusion." (Usual Care patient care [O]. $\quad$ LCSW $)^{58}$ 


\begin{tabular}{ll}
\hline Program Theory Issue & CMOs \\
\hline Communication across & CMO 3.12. \\
the care team & Leadership-supported, \\
& regular \\
& communication across \\
& all staff [C] builds \\
& collaborative feelings \\
& among teams [M] that \\
& results in job \\
& satisfaction for care \\
& team members [O], \\
& and facilitates \\
& implementation \\
success [O].
\end{tabular}

Relevant Data Extracts From Included Literature $\begin{array}{lll}\text { Communication across } & \text { CMO 3.12. } & \text { Team communication was important for program implementation, } \\ \text { the care team } & \text { Leadership-supported, although sites had different levels of success in this area over time. }\end{array}$ regular Care teams with a solid supervisory structure and frequent

communication across collaboration across all levels of staff experienced greater collaborative feelings

$\begin{array}{ll}\text { among teams }[\mathrm{M}] & \text { that } \\ \text { results in job } & \text { leadership felt that constant and good communication between all }\end{array}$

CMO 3.13. Having

transparent and supportive communication among care team members [C] fosters shared values and commitment [M] that results in stronger, more cohesive care team [O].
Due to the complexity of the CMP demonstration population, CMP
leadership felt that constant and good communication between all staff within the program was essential. ${ }^{86}$ implementation success and staff satisfaction. ${ }^{85}$

\begin{abstract}
sis
Team members caring for HNHC patients noted the importance of shared values and commitment, citing mutual respect for other disciplines and appreciation of the need for teamwork. "We respect one another's clinical view.... We come at this from different backgrounds and feel like we get more out of our patient care experience if we hear what everyone else has to say.... We have a very supportive and inclusive team environment" (SUMMIT Physician) The importance of the team comes through particularly when patients aren't faring as well as hoped: "They [other team members] really listen and they really care and we all really feel it when someone does fail... or something bad happens. It's a very empathetic group of people...." (SUMMIT Nurse) $)^{58}$
\end{abstract}

Our finding that staff members value a sense of unity and esprit de corps speaks to the value of cohesive multidisciplinary teams doing this work. As prior studies have shown, individual members of multidisciplinary teams may have different conceptualizations of which disciplines are part of a care team-often these are only a team in name. ${ }^{58}$

CMO 3.14. Regular, multidisciplinary care team meetings that include physicians and staff $[\mathrm{C}]$ gave care team members the openness [M] to discuss patient cases [01] and the practices' performance on quality metrics, outcomes, and other performance goals [O2].

Our CHAs [Community Health Advocates] provide perspectives in huddles that often enlighten licensed staff and offer a better understanding for the team regarding the unique needs of the patients we serve. ${ }^{91}$

VPA [Visiting Physicians Association] corporate medical directors conducted weekly company-wide, web-based meetings with all clinicians, and regional managers conducted individual meetings ' with IAH practices, to review clinicians' performance on IAH [Independence at Home] quality metrics and outcomes and consider broader implications for all of their patients. ${ }^{103}$

Common themes and issues from the Virtual Rounds were also presented at bimonthly management meetings. The bi-monthly management meetings were used to review protocols, present resources, provide training, and identify issues and brainstorm solutions. ${ }^{86}$

In addition to tracking metrics, most practices reported conducting care team meetings. Care team meetings provided a forum for clinical teams and staff to review quality metrics and progress toward performance goals, discuss an individual beneficiary's case, and receive information on clinical topics. ${ }^{103}$ 


\section{Program Theory Issue CMOs}

Communication across the care team

(continued)
CMO 3.14 Regular, multidisciplinary care team meetings that include physicians and staff [C] gave care team members the openness [M] to discuss patient cases [01] and the practices' performance on quality metrics, outcomes, and other performance goals [O2]. (continued)

\section{Relevant Data Extracts From Included Literature}

We have designed processes and structures that promote a physician culture of collaboration, transparency, and accountability for high-quality care. For example, our primary care physicians meet three times a week to review hospitalized patients and discuss complex cases practice approaches. Specialists and hospitalists join these meetings as well. We use these sessions to conduct traditional morbidity and mortality review as well as to review each hospitalization and ask, "Could this hospitalization have been prevented?" Physicians are prepared to discuss each hospitalized case and explain to their peers the circumstances involved and their clinical thinking. ${ }^{114}$

The team met weekly throughout the course of the intervention. One- or two-page patient summaries were prepared by the navigators, including a detailed, written summary of the patient's medical history, prior ED use, barriers to accessing primary care services, life stressors that could be impacting their health, and type of help the patient wished to receive from the program. Each new patient was discussed by the team after the initial enrollment and on an as-needed basis (e.g., emergence of a new or challenging need or a repeat ED visit). The team discussed ways to support the patient's clinical and social needs, brainstormed specific resources that might be helpful for the patient, and provided guidance to the patient navigators (24)..$^{110}$

We held multidisciplinary team meetings weekly to develop care plans to support patients' clinical and social needs. ${ }^{110}$

CMO 3.15. Having regular care team meetings to discuss $\mathrm{HNHC}$ patients [C] The primary barriers to conducting regular Care Team meetings were the lack of time to meet and carry out the Care Plan and the difficulty of involving the patient... The team met for 40 min on a weekly basis to discuss one or two of the cases. The physicians may increase provider were the most likely to arrive late and as noted by the chart review, workloads [M] causing were at times unable to follow through on the Care Plans. ${ }^{102}$ providers' to be arrive late for meetings [01] and to not carry out care plans [O2]. CMO 3.16. When providers are given practical, constructive feedback about patient care approaches [C], providers are provided with the clinical knowledge or resources they need [M] to improve the care they provide to their patients [O]

\begin{abstract}
"[Care team meetings] give us an opportunity to look back upon our encounter with the patient and really be able to gauge, 'Was there a reason why the hospitalization happened, could it have been prevented, is there something that I missed?' ... It can be a little bit unnerving ... but it [has] actually ... strengthened my practice quite a bit. Because you learn a lot from that feedback."103
\end{abstract}

Clinicians valued receiving performance feedback and appreciated the opportunity to discuss cases with other clinicians and share ideas to improve care. ${ }^{103}$

The CMP leadership implemented Virtual Rounds, regular e-mail reports that went to all staff, as a mechanism of providing feedback on a weekly basis. Case managers used Virtual Rounds to report on difficult patients and unnecessary admissions, and to describe both positive and negative events. Virtual Rounds were also used for case reviews with forms that staff filled out at the end of the week. These case reviews were then discussed with physicians in weekly face-to-face meetings. ${ }^{86}$

Physicians in our study acknowledged their frustration in caring for frequent attenders, but also received specific, practical suggestions for changing their approach to care. ${ }^{102}$ 


\begin{tabular}{ll}
\hline Program Theory Issue & CMOs \\
\hline $\begin{array}{l}\text { Communication across } \\
\text { the care team } \\
\text { (continued) }\end{array}$ & CMO 3.16 (continued) \\
\hline & CMO 3.17. Having \\
patients who received \\
care from providers in \\
other healthcare \\
systems or locations \\
[C] creates challenges \\
for care teams [M] to \\
be able to effectively \\
and efficiently \\
communicate with the \\
patient's providers [O].
\end{tabular}

Relevant Data Extracts From Included Literature

Peer consultation provides much needed perspective, more objective assessment and support for the difficulties of the case. ${ }^{102}$

TST staff reported that most participants had a primary provider that was associated with TTUHSC [Texas Tech University Health Sciences Center]; however, many patients, particularly in Amarillo, received care from additional providers that were not associated with the university. These providers typically operated independent practices, so TST care managers had to establish relationships with a number of different practices. ${ }^{79}$

The second proposed improvement had to do with excluding beneficiaries from practices outside the care management patient's providers [O]. organizations, if a systematic means of communicating with clinicians from these practices is not established. ${ }^{80}$

Further, not all intervention beneficiaries had primary care physicians in the two study sites, therefore the care managers had to interact with community-based providers with whom they had little or no prior relationship. During our site visits, the care managers cited several challenges working with these physicians, in particular, because of communication barriers. ${ }^{80}$

CMO 3.18. Providing Our findings speak to the importance of co-located, embedded opportunities for face- teams that "hear what everyone else has to say." ${ }^{8}$

to-face conversations among care team members (e.g., being co-located, creating spaces that allow for provider conversations) [C] helps build strong working relationships [M] that improve team communication in support of ...the Health Buddy ${ }^{\circledR}$ nurse care managers often were not in direct proximity to their beneficiaries' primary care physicians, thereby potentially affecting their interactions with the beneficiaries' primary providers, changing medical care plans, or mitigating deterioration in health status...Interviewed physicians felt that care management would be more effective and efficient if care managers were colocated with primary care physicians. ${ }^{80}$

coordination of patient care $[\mathrm{O}]$

Later, they returned patient care coordinators to local practice sites after clinicians and patients expressed dissatisfaction with the centralized system. According to one respondent, locating at the practice enables patient care coordinators to have more inperson contact with clinicians and to build relationships with patients. This change promoted strong working relationships among teams of clinicians, medical assistants, and care coordinators. Those strong working relationships help to address patients' needs and avoid unnecessary readmissions and hospital and ED [emergency department] visits. Another practice changed where the physicians and other staff on the care team sat in the office. This practice clustered the care team together so they could discuss patients' concerns and care delivery more easily. ${ }^{103}$

We have also designed our centers to promote physician collaboration and conversation. They look more like an inpatient setting or intensive care unit than a traditional physician office. There is a large nurses' station in the middle of the center where specialists do their paperwork, which is a sufficient distance from the patient exam rooms to allow for spontaneous discussions between specialists and primary care physicians after the specialist has seen the patient. In addition, there is a cluster of four to six individual primary care physician workstations away from direct patient view, where private conversations among physicians can readily happen. In the vast majority of cases, a specialist is able to have a brief faceto-face conversation with the patient's primary care physician after 


\begin{tabular}{|c|c|c|}
\hline Program Theory Issue & CMOs & Relevant Data Extracts From Included Literature \\
\hline \multirow[t]{4}{*}{$\begin{array}{l}\text { Communication across } \\
\text { the care team } \\
\text { (continued) }\end{array}$} & CMO 3.18 (continued) & $\begin{array}{l}\text { she or he sees the patient. The face-to-face conversation allows for } \\
\text { more rapid alignment between primary care physician and specialist } \\
\text { than the traditional faxed consult and voice mail. }{ }^{114}\end{array}$ \\
\hline & $\begin{array}{l}\text { CMO 3.19. } \\
\text { Embedding care/case } \\
\text { managers into primary } \\
\text { care practices [C] } \\
\text { makes it more efficient } \\
\text { [M1] and convenient } \\
\text { [M2] for physicians to } \\
\text { use case managers } \\
\text { services [O]. }\end{array}$ & $\begin{array}{l}\text { One improvement proposed was featuring a care management } \\
\text { structure that pairs care managers and participants' primary care } \\
\text { physicians in the same physical location. }{ }^{80} \\
\text { CPC [Comprehensive Primary Care] practices greatly increased } \\
\text { their use of dedicated care managers who were members of the } \\
\text { primary care practice team over time. The number of practice survey } \\
\text { respondents from CPC practices who reported that "care managers } \\
\text { who were members of the practice team systematically provided } \\
\text { care management services to high-risk patients" increased from } 20 \\
\text { percent in } 2012 \text { to } 88 \text { percent in } 2014 \text { and } 2015 \text {, and } 89 \text { percent in } \\
2016 . \text { In comparison, fewer than half of comparison practices } \\
\text { reported in } 2016 \text { that care managers who were practice care team } \\
\text { members systematically provided these services to high-risk } \\
\text { patients }\end{array}$ \\
\hline & & $\begin{array}{l}\text { Most physicians supported the general concept and potential } \\
\text { benefits of the program but also expressed frustration with several } \\
\text { aspects of the current demonstration design...care managers were } \\
\text { not embedded in their physical practice locations. }{ }^{80}\end{array}$ \\
\hline & & $\begin{array}{l}\text { At the time of the program launch, strong integration support from } \\
\text { MGH leadership afforded the case managers physical entry into the } \\
\text { primary care practice settings whereby the case managers were co- } \\
\text { located with the primary care physicians ultimately becoming a part } \\
\text { of the beneficiaries' primary health care teams. }{ }^{86}\end{array}$ \\
\hline
\end{tabular}


Key Question 3: Overall, what is the effectiveness and what are the harms of interventions for $\mathrm{HNHC}$ patients in reducing potentially preventable or modifiable healthcare use and costs and in improving health outcomes? 
Table B-14. Summary of strength of evidence by outcome and study model type (by primary setting)

\begin{tabular}{|c|c|c|c|c|c|c|c|c|c|}
\hline $\begin{array}{l}\text { Outcome } \\
\text { Group }\end{array}$ & Outcome Measure & Population & $\begin{array}{l}\text { System } \\
\text { Level }(\mathrm{N}=5)\end{array}$ & $\begin{array}{l}\text { Tele- } \\
\text { phonic/ } \\
\text { Mail } \\
(\mathrm{N}=9)\end{array}$ & $\begin{array}{l}\text { Com- } \\
\text { munity } \\
\text { Based } \\
(\mathrm{N}=9)\end{array}$ & $\begin{array}{l}\text { ED } \\
\text { Based } \\
(\mathrm{N}=7)\end{array}$ & $\begin{array}{l}\text { Ambulatory } \\
\text { Intensive } \\
\text { Caring Unit } \\
(\mathrm{N}=4)\end{array}$ & $\begin{array}{l}\text { Primary } \\
\text { Care } \\
(\mathrm{N}=9)\end{array}$ & $\begin{array}{l}\text { Home } \\
\text { Based } \\
(\mathrm{N}=4)\end{array}$ \\
\hline \multirow{34}{*}{$\begin{array}{l}\text { Utilization } \\
\text { outcomes }\end{array}$} & ED visits, all cause ${ }^{a}$ & HNHC patients & $\mathrm{I}$ & L-ND & $\mathrm{I}$ & M-F & I & $\mathrm{I}$ & $\mathrm{I}$ \\
\hline & ED visits at 270 days, all cause & HNHC patients & - & - & 11 & - & - & - & - \\
\hline & ED visits at 180 days, all cause & HNHC patients & - & - & 11 & - & - & - & - \\
\hline & ED visits, ACSC & HNHC patients & 11 & L-ND & - & - & - & I & 1 \\
\hline & ED visits, outpatient & HNHC patients & 11 & - & - & - & - & - & - \\
\hline & ED visit resulted in inpatient admission & HNHC patients & 11 & - & - & - & - & - & - \\
\hline & ED, any $(\%)$ & HNHC patients & - & - & $\mathrm{I1}$ & - & - & 11 & - \\
\hline & Psychiatric emergency visits & HNHC patients & - & - & $\mathrm{I1}$ & 11 & - & - & - \\
\hline & Inpatient admissions, all cause ${ }^{a}$ & HNHC patients & 1 & L-ND & 1 & $\mathrm{~L}-\mathrm{F}$ & I & I & 1 \\
\hline & Inpatient admissions, any (\%) & HNHC patients & - & 1 & 11 & - & - & L-F & 1 \\
\hline & Inpatient admissions at 270 days, all cause & HNHC patients & - & - & 11 & - & - & - & - \\
\hline & Inpatient admissions at 180 days, all cause & HNHC patients & - & - & 11 & - & - & - & - \\
\hline & Inpatient admissions, ACSC & HNHC patients & 11 & L-ND & 11 & - & - & I & L-F \\
\hline & Inpatient admissions, any ACSC (\%) & HNHC patients & - & 1 & - & - & - & I & L-F \\
\hline & Acute medical/surgery stays & HNHC patients & - & - & - & - & 11 & - & - \\
\hline & Other inpatient stays & HNHC patients & - & - & - & - & 11 & - & - \\
\hline & Inpatient days & HNHC patients & - & - & I & 11 & 11 & 11 & - \\
\hline & Medical inpatient admissions & HNHC patients & - & - & - & 11 & - & - & - \\
\hline & Medical inpatient days & HNHC patients & - & - & - & 11 & - & - & - \\
\hline & Psychiatric inpatient admissions & HNHC patients & - & - & 11 & 11 & - & - & - \\
\hline & Psychiatric inpatient days & HNHC patients & - & - & - & 11 & - & - & - \\
\hline & Total hospital encounters & HNHC patients & - & - & 11 & - & - & - & - \\
\hline & $\begin{array}{l}\text { Hospital encounter resulted in discharge to } \\
\text { hospital or observation stay }\end{array}$ & HNHC patients & - & - & 11 & - & - & - & - \\
\hline & $\begin{array}{l}\text { Hospital encounter resulted in discharge from } \\
\text { ED }\end{array}$ & HNHC patients & - & - & 11 & - & - & - & - \\
\hline & Outpatient visits & HNHC patients & - & - & $\mathrm{I} 1$ & I & - & I & - \\
\hline & Outpatient visits at 6 months & HNHC patients & - & 11 & - & - & - & - & - \\
\hline & Outpatient visits at 12 months & HNHC patients & - & 11 & - & - & - & - & - \\
\hline & Outpatient visits at 30 months & HNHC patients & - & 11 & - & - & - & - & - \\
\hline & Outpatient substance use treatment visits & HNHC patients & - & - & 11 & - & - & - & - \\
\hline & Outpatient mental health visits & HNHC patients & - & - & 11 & - & - & - & - \\
\hline & Outpatient mental health visit, any & HNHC patients & - & - & 11 & - & - & - & - \\
\hline & Primary care visits & HNHC patients & $11^{b}$ & - & - & $\mathrm{L}-\mathrm{F}^{\mathrm{c}}$ & I & I & - \\
\hline & Primary care visits at 360 days, all cause & HNHC patients & - & - & 11 & - & - & - & - \\
\hline & Primary care visits at 270 days, all cause & HNHC patients & - & - & 11 & - & - & - & - \\
\hline
\end{tabular}




\begin{tabular}{|c|c|c|c|c|c|c|c|c|c|}
\hline $\begin{array}{l}\text { Outcome } \\
\text { Group }\end{array}$ & Outcome Measure & Population & $\begin{array}{l}\text { System } \\
\text { Level }(\mathrm{N}=5)\end{array}$ & $\begin{array}{l}\text { Tele- } \\
\text { phonic/ } \\
\text { Mail } \\
(\mathrm{N}=9)\end{array}$ & $\begin{array}{l}\text { Com- } \\
\text { munity } \\
\text { Based } \\
(\mathrm{N}=9)\end{array}$ & $\begin{array}{l}\text { ED } \\
\text { Based } \\
(\mathrm{N}=7)\end{array}$ & $\begin{array}{l}\text { Ambulatory } \\
\text { Intensive } \\
\text { Caring Unit } \\
(\mathrm{N}=3)\end{array}$ & $\begin{array}{l}\text { Primary } \\
\text { Care } \\
(\mathrm{N}=10)\end{array}$ & $\begin{array}{l}\text { Home } \\
\text { Based } \\
(\mathrm{N}=4)\end{array}$ \\
\hline \multirow{29}{*}{$\begin{array}{l}\text { Utilization } \\
\text { outcomes } \\
\text { (continued) }\end{array}$} & Primary care visits at 180 days, all cause & HNHC patients & - & - & 11 & - & - & - & - \\
\hline & Total utilization & HNHC patients & - & 11 & - & - & - & 11 & - \\
\hline & 180-day readmission, count & HNHC patients & - & - & I & - & - & - & - \\
\hline & 180 -day readmission, any $(\%)$ & HNHC patients & - & - & 11 & - & - & - & - \\
\hline & 180 -day readmission, $\geq 2(\%)$ & HNHC patients & - & - & 11 & - & - & - & - \\
\hline & Specialist visits & HNHC patients & 11 & - & - & - & 11 & 11 & - \\
\hline & Prescription drugs, any & HNHC patients & - & - & 11 & - & - & - & - \\
\hline & Long-term care, any & HNHC patients & - & - & 11 & - & - & - & - \\
\hline & FQHC visits & HNHC patients & 11 & - & - & - & - & - & - \\
\hline & $\begin{array}{l}\text { Filled } \geq 3 \text { antidepressant prescriptions in first } 6 \\
\text { months }\end{array}$ & HNHC patients & - & - & - & - & - & 11 & - \\
\hline & Specialty mental health visit in first 6 months & HNHC patients & - & - & - & - & - & 11 & - \\
\hline & Cancelled visits and/or no shows & HNHC patients & - & - & - & - & - & 11 & - \\
\hline & Intensive care unit visits & HNHC patients & - & - & - & - & 11 & - & - \\
\hline & Dental visits & HNHC patients & - & - & - & - & 11 & - & - \\
\hline & Care center visits & HNHC patients & - & - & - & - & - & 11 & - \\
\hline & $\begin{array}{l}\text { Probability of entering institutional long-term care } \\
\text { within the demonstration year }\end{array}$ & HNHC patients & 11 & - & - & - & - & - & - \\
\hline & Long-term institutionalization rate & HNHC patients & - & - & - & - & - & - & 11 \\
\hline & Probability of hospice use & HNHC patients & 11 & - & - & - & - & - & - \\
\hline & Probability of SNF use & HNHC patients & 11 & - & - & - & - & - & - \\
\hline & Probability of home health use & HNHC patients & 11 & - & - & - & - & - & - \\
\hline & Home health days & HNHC patients & 11 & - & - & - & - & - & - \\
\hline & Home health visits & HNHC patients & 11 & - & - & - & - & - & - \\
\hline & $\begin{array}{l}\text { Visits in nonacute settings by primary care } \\
\text { clinicians }\end{array}$ & HNHC patients & 11 & - & - & - & - & - & - \\
\hline & Visits in nonacute settings by specialists & HNHC patients & 11 & - & - & - & - & - & - \\
\hline & Care management visits & HNHC patients & - & - & - & - & 11 & - & - \\
\hline & Mental healthcare visits & HNHC patients & - & - & - & - & 11 & - & - \\
\hline & Homeless care visits & HNHC patients & - & - & - & - & 11 & - & - \\
\hline & ED visits at 180 days, all cause & $\begin{array}{l}\text { HNHC patients } \\
\text { with a mental } \\
\text { health diagnosis }\end{array}$ & - & - & 11 & - & - & - & - \\
\hline & Inpatient admissions at 180 days, all cause & $\begin{array}{l}\text { HNHC patients } \\
\text { with a mental } \\
\text { health diagnosis }\end{array}$ & - & - & 11 & - & - & - & - \\
\hline
\end{tabular}




\begin{tabular}{|c|c|c|c|c|c|c|c|c|c|}
\hline $\begin{array}{l}\text { Outcome } \\
\text { Group }\end{array}$ & Outcome Measure & Population & $\begin{array}{l}\text { System } \\
\text { Level }(\mathrm{N}=5)\end{array}$ & $\begin{array}{l}\text { Tele- } \\
\text { phonic/ } \\
\text { Mail } \\
(\mathrm{N}=9)\end{array}$ & $\begin{array}{l}\text { Com- } \\
\text { / munity } \\
\text { Based } \\
(\mathrm{N}=9)\end{array}$ & $\begin{array}{l}\text { ED } \\
\text { Based } \\
(N=7)\end{array}$ & $\begin{array}{l}\text { Ambulatory } \\
\text { Intensive } \\
\text { Caring Unit } \\
(\mathrm{N}=3)\end{array}$ & $\begin{array}{l}\text { Primary } \\
\text { Care } \\
(\mathrm{N}=10)\end{array}$ & $\begin{array}{l}\text { Home } \\
\text { Based } \\
(\mathrm{N}=4)\end{array}$ \\
\hline \multirow[t]{13}{*}{$\begin{array}{l}\text { Utilization } \\
\text { outcomes } \\
\text { (continued) }\end{array}$} & Primary care visits at 180 days, all cause & $\begin{array}{l}\text { HNHC patients } \\
\text { with a mental } \\
\text { health diagnosis }\end{array}$ & - & - & 11 & - & - & - & - \\
\hline & Outpatient visits at 6 months & $\begin{array}{l}\text { HNHC patients } \\
\text { with arthritis }\end{array}$ & - & 11 & - & - & - & - & - \\
\hline & Outpatient visits at 6 months & $\begin{array}{l}\text { HNHC patients } \\
\text { with high blood } \\
\text { pressure }\end{array}$ & - & 11 & - & - & - & - & - \\
\hline & Outpatient visits at 6 months & $\begin{array}{l}\text { HNHC diabetes } \\
\text { patients }\end{array}$ & - & $\mathrm{I1}$ & - & - & - & - & - \\
\hline & Outpatient visits at 12 months & $\begin{array}{l}\text { HNHC patients } \\
\text { with arthritis }\end{array}$ & - & $\mathrm{I1}$ & - & - & - & - & - \\
\hline & Outpatient visits at 12 months & $\begin{array}{l}\text { HNHC patients } \\
\text { with high blood } \\
\text { pressure }\end{array}$ & - & 11 & - & - & - & - & - \\
\hline & Outpatient visits at 12 months & $\begin{array}{l}\text { HNHC diabetes } \\
\text { patients }\end{array}$ & - & 11 & - & - & - & - & - \\
\hline & Outpatient visits at 30 months & $\begin{array}{l}\text { HNHC patients } \\
\text { with arthritis }\end{array}$ & - & 11 & - & - & - & - & - \\
\hline & Outpatient visits at 30 months & $\begin{array}{l}\text { HNHC patients } \\
\text { with high blood } \\
\text { pressure }\end{array}$ & - & 11 & - & - & - & - & - \\
\hline & Outpatient visits at 30 months & $\begin{array}{l}\text { HNHC diabetes } \\
\text { patients }\end{array}$ & - & $\mathrm{I1}$ & - & - & - & - & - \\
\hline & Total utilization (\%) & $\begin{array}{l}\text { HNHC patients } \\
\text { living in a low } \\
\text { income area }\end{array}$ & - & 11 & - & - & - & - & - \\
\hline & Total utilization (\%) & $\begin{array}{l}\text { HNHC patients } \\
\text { living in a low } \\
\text { education area }\end{array}$ & - & 11 & - & - & - & - & - \\
\hline & Total utilization (\%) & $\begin{array}{l}\text { HNHC patients } \\
\text { with Medicaid }\end{array}$ & - & 11 & - & - & - & - & - \\
\hline \multirow[t]{6}{*}{$\begin{array}{l}\text { Cost } \\
\text { outcomes }\end{array}$} & Total costs & HNHC patients & L-ND & L-ND & I & I1 & $\mathrm{L}-\mathrm{F}$ & L-F & 1 \\
\hline & Inpatient costs & HNHC patients & - & - & 1 & ${\mathrm{~L}-N D^{\mathrm{C}}}$ & 11 & 11 & - \\
\hline & ED costs & HNHC patients & - & - & I & $\mathrm{L}-\mathrm{F}$ & 11 & 11 & - \\
\hline & Hospital costs of care & HNHC patients & - & - & - & I & - & - & - \\
\hline & Hospital charges & HNHC patients & - & - & 11 & - & - & - & - \\
\hline & Hospital payments received & HNHC patients & - & - & 11 & - & - & - & - \\
\hline
\end{tabular}




\begin{tabular}{|c|c|c|c|c|c|c|c|c|c|}
\hline $\begin{array}{l}\text { Outcome } \\
\text { Group }\end{array}$ & Outcome Measure & Population & $\begin{array}{l}\text { System } \\
\text { Level }(N=5)\end{array}$ & $\begin{array}{l}\text { Tele- } \\
\text { phonic/ } \\
\text { Mail } \\
(\mathrm{N}=9)\end{array}$ & $\begin{array}{l}\text { Com- } \\
\text { munity } \\
\text { Based } \\
(\mathrm{N}=9)\end{array}$ & $\begin{array}{l}\text { ED } \\
\text { Based } \\
(\mathrm{N}=7)\end{array}$ & $\begin{array}{l}\text { Ambulatory } \\
\text { Intensive } \\
\text { Caring Unit } \\
(\mathrm{N}=3)\end{array}$ & $\begin{array}{l}\text { Primary } \\
\text { Care } \\
(\mathrm{N}=10)\end{array}$ & $\begin{array}{l}\text { Home } \\
\text { Based } \\
(\mathrm{N}=4)\end{array}$ \\
\hline \multirow{17}{*}{$\begin{array}{l}\text { Cost } \\
\text { outcomes } \\
\text { (continued) }\end{array}$} & Indirect ED costs & HNHC patients & - & - & 11 & - & - & - & - \\
\hline & Medicaid cost & HNHC patients & - & - & - & 11 & - & - & - \\
\hline & Psychiatric emergency costs & HNHC patients & - & - & - & 11 & - & - & - \\
\hline & Psychiatric hospital costs & HNHC patients & - & - & - & 11 & - & - & - \\
\hline & All non-ED case management costs & HNHC patients & - & - & - & 11 & - & - & - \\
\hline & Acute costs & HNHC patients & 11 & - & - & - & - & - & - \\
\hline & Post-acute costs & HNHC patients & - & - & - & - & - & 11 & - \\
\hline & Outpatient department cost & HNHC patients & 11 & - & - & - & - & - & - \\
\hline & Outpatient costs & HNHC patients & 11 & - & 11 & $I^{\mathrm{C}}$ & 11 & 11 & - \\
\hline & Prescription or pharmacy costs & HNHC patients & - & - & $\mathrm{I1}$ & 11 & - & 11 & - \\
\hline & Primary care physician cost & HNHC patients & 11 & - & - & - & - & - & - \\
\hline & Long-term care costs & HNHC patients & - & - & 11 & - & - & - & - \\
\hline & Other costs & HNHC patients & - & - & - & - & - & 11 & - \\
\hline & Total costs & $\begin{array}{l}\text { High-cost, high-risk } \\
\text { HNHC patients }\end{array}$ & - & - & - & - & - & - & 1 \\
\hline & Total costs & $\begin{array}{l}\text { High-cost HNHC } \\
\text { patients }\end{array}$ & - & - & - & - & - & - & 1 \\
\hline & Total costs & $\begin{array}{l}\text { HNHC patients } \\
\text { with dementia }\end{array}$ & 11 & - & - & - & - & - & - \\
\hline & Total costs & $\begin{array}{l}\text { HNHC patients } \\
\text { without dementia }\end{array}$ & 11 & - & - & - & - & - & - \\
\hline \multirow{15}{*}{$\begin{array}{l}\text { Clinical and } \\
\text { functional } \\
\text { outcomes }\end{array}$} & Mortality rate & HNHC patients & 11 & L-ND & L-ND & 11 & I & I & L-ND \\
\hline & Influenza vaccine & HNHC patients & - & I & - & - & - & $\mathrm{L}-\mathrm{U}$ & L-F \\
\hline & Progression to ESRD & HNHC patients & - & I & - & - & - & - & - \\
\hline & PHC score (physical health) & HNHC patients & - & 11 & - & - & - & 11 & 11 \\
\hline & MHC score (mental health) & HNHC patients & - & 11 & - & - & - & 11 & 11 \\
\hline & PQH-2 score (depression) & HNHC patients & - & 11 & - & - & - & 11 & 11 \\
\hline & Number of ADLs difficult to do & HNHC patients & - & 11 & - & - & - & 11 & 11 \\
\hline & Number ADLs receiving help & HNHC patients & - & 11 & - & - & - & 11 & $\mathrm{I1}$ \\
\hline & Helping to cope with a chronic condition & HNHC patients & - & 11 & - & - & - & 11 & $\mathrm{I1}$ \\
\hline & Number of helpful discussion topics & HNHC patients & - & 11 & - & - & - & 11 & 11 \\
\hline & Discussing treatment choices & HNHC patients & - & 11 & - & - & - & 11 & $\mathrm{I} 1$ \\
\hline & Communicating with providers & HNHC patients & - & 11 & - & - & - & 11 & 11 \\
\hline & Getting answers to questions quickly & HNHC patients & - & 11 & - & - & - & 11 & $\mathrm{I1}$ \\
\hline & Multimorbidity Hassles score & HNHC patients & - & 11 & - & - & - & 11 & $\mathrm{I1}$ \\
\hline & Percent receiving help setting goals & HNHC patients & - & 11 & - & - & - & 11 & 11 \\
\hline
\end{tabular}




\begin{tabular}{|c|c|c|c|c|c|c|c|c|c|}
\hline $\begin{array}{l}\text { Outcome } \\
\text { Group }\end{array}$ & Outcome Measure & Population & $\begin{array}{l}\text { System } \\
\text { Level }(N=5)\end{array}$ & $\begin{array}{l}\text { Tele- } \\
\text { phonic/ } \\
\text { Mail } \\
(\mathrm{N}=9)\end{array}$ & $\begin{array}{l}\text { Com- } \\
\text { munity } \\
\text { Based } \\
(\mathrm{N}=9)\end{array}$ & $\begin{array}{l}\text { ED } \\
\text { Based } \\
(\mathbf{N}=7)\end{array}$ & $\begin{array}{l}\text { Ambulatory } \\
\text { Intensive } \\
\text { Caring Unit } \\
(\mathrm{N}=3)\end{array}$ & $\begin{array}{l}\text { Primary } \\
\text { Care } \\
(\mathrm{N}=10)\end{array}$ & $\begin{array}{l}\text { Home } \\
\text { Based } \\
(\mathrm{N}=4)\end{array}$ \\
\hline \multirow{9}{*}{$\begin{array}{l}\text { Clinical and } \\
\text { functional } \\
\text { outcomes } \\
\text { (continued) }\end{array}$} & Percent receiving help making a care plan & HNHC patients & - & 11 & - & - & - & 11 & 11 \\
\hline & Self-efficacy: Take all medications & HNHC patients & - & 11 & - & - & - & 11 & 11 \\
\hline & Self-efficacy: Plan meals and snacks & HNHC patients & - & 11 & - & - & - & 11 & 11 \\
\hline & Self-efficacy: Exercise 2 or 3 times weekly & HNHC patients & - & 11 & - & - & - & 11 & 11 \\
\hline & $\begin{array}{l}\text { Self-care activities: Prescribed medications taken } \\
\text { (mean \# of days) }\end{array}$ & HNHC patients & - & 11 & - & - & - & 11 & 11 \\
\hline & $\begin{array}{l}\text { Self-care activities: Followed healthy eating plan } \\
\text { (mean \# of days) }\end{array}$ & HNHC patients & - & 11 & - & - & - & 11 & 11 \\
\hline & $\begin{array}{l}\text { Self-care activities: } 30 \text { minutes of continuous } \\
\text { physical activity (mean \# of days) }\end{array}$ & HNHC patients & - & 11 & - & - & - & 11 & 11 \\
\hline & Patient satisfaction & HNHC patients & - & - & - & 11 & 11 & 11 & - \\
\hline & Psychiatric symptoms (total BSI) & HNHC patients & - & - & - & 11 & - & - & - \\
\hline & Access to care & HNHC patients & - & - & - & - & 11 & - & - \\
\hline & SF-36 Summary Score & HNHC patients & - & - & - & - & - & 11 & - \\
\hline & SF-36 Mental Health Function Score & HNHC patients & - & - & - & - & - & 11 & - \\
\hline & SF-20 subscale: Social Functioning & HNHC patients & & - & - & - & - & 11 & - \\
\hline & SF-20 subscale: Mental Health & HNHC patients & - & - & - & - & - & 11 & - \\
\hline & SF-20 subscale: General Health & HNHC patients & - & - & - & - & - & 11 & - \\
\hline & SF-20 subscale: Physical Functioning & HNHC patients & - & - & - & - & - & 11 & - \\
\hline & SF-20 subscale: Role Functioning & HNHC patients & - & - & - & - & - & 11 & - \\
\hline & SF-20 subscale: Pain Perception & HNHC patients & - & - & - & - & - & 11 & - \\
\hline & Change in HAM-D score & HNHC patients & - & - & - & - & - & 11 & - \\
\hline & In remission (HAM-D < 7) & HNHC patients & - & - & - & - & - & 11 & - \\
\hline & Patient-centered care coordination & HNHC patients & - & - & - & - & 11 & - & - \\
\hline & Relationship with providers: trusted provider & HNHC patients & - & - & - & - & 11 & - & - \\
\hline & $\begin{array}{l}\text { Relationship with providers: feel respected by } \\
\text { provider }\end{array}$ & HNHC patients & - & - & - & - & 11 & - & - \\
\hline & $\begin{array}{l}\text { Healthcare hassles summary score (challenges in } \\
\text { getting care) }\end{array}$ & HNHC patients & - & - & - & - & 11 & - & - \\
\hline & $\begin{array}{l}\text { Patient assessment of chronic illness care } \\
\text { (PACIC) Summary Score (receipt of care for } \\
\text { chronic illness) }\end{array}$ & HNHC patients & - & - & - & - & 11 & - & - \\
\hline & Progression to ESRD & $\begin{array}{l}\text { HNHC CKD } \\
\text { patients }\end{array}$ & - & I & - & - & - & - & - \\
\hline
\end{tabular}




\begin{tabular}{|c|c|c|c|c|c|c|c|c|c|}
\hline $\begin{array}{l}\text { Outcome } \\
\text { Group }\end{array}$ & Outcome Measure & Population & $\begin{array}{l}\text { System } \\
\text { Level }(\mathrm{N}=5)\end{array}$ & $\begin{array}{l}\text { Tele- } \\
\text { phonic/ } \\
\text { Mail } \\
(\mathrm{N}=9)\end{array}$ & $\begin{array}{l}\text { Com- } \\
\text { munity } \\
\text { Based } \\
(N=9)\end{array}$ & $\begin{array}{l}\text { ED } \\
\text { Based } \\
(\mathrm{N}=7)\end{array}$ & $\begin{array}{l}\text { Ambulatory } \\
\text { Intensive } \\
\text { Caring Unit } \\
(\mathrm{N}=3)\end{array}$ & $\begin{array}{l}\text { Primary } \\
\text { Care } \\
(\mathrm{N}=10)\end{array}$ & $\begin{array}{l}\text { Home } \\
\text { Based } \\
(\mathrm{N}=4)\end{array}$ \\
\hline \multirow{9}{*}{$\begin{array}{l}\text { Clinical and } \\
\text { functional } \\
\text { outcomes } \\
\text { (continued) }\end{array}$} & Graft or fistula prior to hemodialysis & $\begin{array}{l}\text { HNHC CKD } \\
\text { patients }\end{array}$ & - & I & - & - & - & - & - \\
\hline & Graft or fistula prior to hemodialysis & $\begin{array}{l}\text { HNHC ESRD } \\
\text { patients }\end{array}$ & - & I & - & - & - & - & - \\
\hline & $\mathrm{HbA1c}$ test & $\begin{array}{l}\text { HNHC patients, } \\
\text { diabetes subgroup }\end{array}$ & 11 & 1 & - & - & - & 1 & 1 \\
\hline & LDL-C test & $\begin{array}{l}\text { HNHC patients, } \\
\text { diabetes subgroup }\end{array}$ & 11 & I & - & - & - & 1 & 1 \\
\hline & LDL-C test & HNHC IVD patients & - & 1 & - & - & - & 1 & 1 \\
\hline & Eye exam & $\begin{array}{l}\text { HNHC patients, } \\
\text { diabetes subgroup }\end{array}$ & 11 & i & - & - & - & - & - \\
\hline & Nephrology/nephropathy test & $\begin{array}{l}\text { HNHC patients, } \\
\text { diabetes subgroup }\end{array}$ & 11 & 1 & - & - & - & - & - \\
\hline & Lipid test & $\begin{array}{l}\text { HNHC patients, } \\
\text { IVD subgroup }\end{array}$ & 11 & 1 & - & - & - & - & - \\
\hline & Oxygen saturation test & $\begin{array}{l}\text { HNHC COPD } \\
\text { patients }\end{array}$ & - & - & - & - & - & - & 1 \\
\hline \multirow[t]{16}{*}{$\begin{array}{l}\text { Social risk } \\
\text { outcomes }\end{array}$} & $\begin{array}{l}\text { Participation in Supplemental Nutrition Assistance } \\
\text { Program, any }\end{array}$ & HNHC patients & - & - & 11 & - & - & - & - \\
\hline & $\begin{array}{l}\text { Receipt of temporary assistance for needy } \\
\text { families, any }\end{array}$ & HNHC patients & - & - & 11 & - & - & - & - \\
\hline & Receipt of general assistance, any & HNHC patients & - & - & 11 & - & - & - & - \\
\hline & Ever housed & HNHC patients & - & - & 11 & $\mathrm{I1}$ & - & - & - \\
\hline & Jail stays & HNHC patients & - & - & 11 & - & - & - & - \\
\hline & Criminal convictions, any & HNHC patients & - & - & 11 & - & - & - & - \\
\hline & Criminal convictions & HNHC patients & - & - & 11 & - & - & - & - \\
\hline & Shelter days & HNHC patients & - & - & 11 & - & - & - & - \\
\hline & Drug/alcohol treatment, any & HNHC patients & - & - & 11 & - & - & - & - \\
\hline & Overall wellbeing & HNHC patients & - & - & - & - & - & 11 & - \\
\hline & Problem alcohol use, any & HNHC patients & - & - & - & 11 & - & - & - \\
\hline & Homelessness, any & HNHC patients & - & - & $\mathrm{I1}$ & 11 & - & - & - \\
\hline & Homeless months & HNHC patients & - & - & 11 & - & - & - & - \\
\hline & No health insurance, any & HNHC patients & - & - & - & 11 & - & - & - \\
\hline & No social security income, any & HNHC patients & - & - & - & 11 & - & - & - \\
\hline & Basic financial needs unmet & HNHC patients & - & - & - & 11 & - & - & - \\
\hline
\end{tabular}

I1: Insufficient, only one sample reporting on the outcome; I: Insufficient, 2+ samples reporting on the outcome within the model type; L-F: Low strength of evidence for favorable findings for the outcome; L-ND: Low strength of evidence for no difference for the outcome; L-U: Low strength of evidence for unfavorable findings for the outcome; -: No eligible evidence; M-F: Moderate strength of evidence for favorable findings for the outcome. 
a Includes visits at 12 months.

${ }^{\mathrm{b}}$ Defined as evaluation and management primary care visits by Kahn et al. ${ }^{122}$

c Shumway et al. specified the outpatient and inpatient costs as medical outpatient costs and medical hospital costs. ${ }^{116}$

$\mathrm{ACSC}=$ ambulatory care sensitive conditions; $\mathrm{ADL}=$ activities of daily living; $\mathrm{BSI}=$ brief symptom inventory; $\mathrm{CKD}=$ chronic kidney disease; $\mathrm{COPD}=$ chronic obstructive pulmonary disease; ED = emergency department; ESRD = end-stage renal disease; FQHC = Federally Qualified Health Center; HAM-D = Hamilton Depression Rating Scale.; $\mathrm{HbA1}=$ hemoglobin A1c; HNHC = high-need, high-cost; IVD = ischemic vascular disease; LDL-C = low-density lipoprotein cholesterol; MHC = mental health composite; $\mathrm{PACIC}=$ patient assessment of chronic illness care; $\mathrm{PHC}=$ physical health composite; $\mathrm{PQH}-2=$ patient health questionnaire- 2 ; $\mathrm{SF}=$ short form; $\mathrm{SNF}=$ skilled nursing facility; $\mathrm{SOE}=$ strength of evidence. 
Table B-15. Study characteristics for system-level transformation models

\begin{tabular}{|c|c|c|c|c|c|c|}
\hline $\begin{array}{l}\text { First Author, } \\
\text { Year, Site(s) }\end{array}$ & $\begin{array}{l}\text { Brief Description } \\
\text { (Sample Size) }\end{array}$ & $\begin{array}{l}\text { Study Design } \\
\text { (Risk of Bias } \\
\text { Assessment) }\end{array}$ & $\begin{array}{l}\text { Patient Selection: } \\
\text { High Healthcare } \\
\text { Use or Cost; Time } \\
\text { Period }\end{array}$ & $\begin{array}{l}\text { Patient } \\
\text { Selection: } \\
\text { Chronic } \\
\text { Conditions }\end{array}$ & $\begin{array}{l}\text { Patient } \\
\text { Selection: } \\
\text { Other }\end{array}$ & $\begin{array}{l}\text { Additional } \\
\text { Selected } \\
\text { Patient } \\
\text { Characteristics }\end{array}$ \\
\hline $\begin{array}{l}\text { Kahn et al., } \\
2016^{122} \\
503 \text { FQHCs }\end{array}$ & $\begin{array}{l}\text { Support for FQHCs } \\
\text { obtaining PCMH } \\
\text { status } \\
\text { (HNHC high ED use } \\
\text { patient sample } \\
\mathrm{N}=\mathrm{NR} \text { out of } \\
730,353 \\
\text { beneficiaries total) } \\
\text { Intervention (N=NR } \\
\text { out of } 269,364 \\
\text { beneficiaries total) } \\
\text { Comparison ( } \mathrm{N}=\mathrm{NR} \\
\text { out of } 360,989 \\
\text { beneficiaries total) }\end{array}$ & $\begin{array}{l}\text { Observational } \\
\text { study } \\
\text { (RoB: some } \\
\text { concerns) }\end{array}$ & $\begin{array}{l}\text { Utilization of ED } \\
\text { visits at baseline: } \\
\text { 90th percentile vs. } \\
<90 \text { th percentile }\end{array}$ & NA & $\begin{array}{l}\text { Medicare FFS } \\
\text { beneficiaries; } \\
\text { attribution to } \\
\text { the practice or } \\
\text { clinic } \\
\text { responsible for } \\
\text { the greatest } \\
\text { number of } \\
\text { primary care } \\
\text { services over } \\
\text { the 12-month } \\
\text { period } \\
\text { preceded the } \\
\text { demonstration }\end{array}$ & $\mathrm{NA}$ \\
\hline $\begin{array}{l}\text { Kimmy et al., } \\
2019^{103,132} \\
\text { National: } 14 \\
\text { practices }\end{array}$ & $\begin{array}{l}\text { Incentive payment } \\
(\mathrm{N}=42,132) \\
\text { Intervention } \\
(\mathrm{N}=8,216) \\
\text { Comparison } \\
(\mathrm{N}=33,916)\end{array}$ & $\begin{array}{l}\text { Observational } \\
\text { study } \\
\text { (RoB: some } \\
\text { concerns) }\end{array}$ & $\begin{array}{l}\text { Hospitalization and } \\
\text { use of acute or } \\
\text { subacute } \\
\text { rehabilitation } \\
\text { services }\end{array}$ & $\begin{array}{l}2+\text { chronic } \\
\text { conditions } \\
2+\text { ADLs that } \\
\text { require human } \\
\text { assistance }\end{array}$ & $\begin{array}{l}\text { Medicare FFS } \\
\text { beneficiaries; } \\
\text { all IAH-eligible } \\
\text { patients of the } \\
\text { IAH practices, } \\
\text { including those } \\
\text { who received } \\
\text { home-based } \\
\text { care before } \\
\text { the } \\
\text { demonstration } \\
\text { began; not in } \\
\text { hospice or } \\
\text { long-term care } \\
\text { for the entire } \\
\text { time they were } \\
\text { eligible for the } \\
\text { intervention in } \\
\text { a given year }\end{array}$ & $\begin{array}{l}\text { Number of } \\
\text { chronic } \\
\text { conditions in } \\
\text { Year } 4 \text { Total } \\
<6: 9.8 \% \\
6-9: 43.7 \% \\
>9: 46.6 \% \\
\text { HCC: } 3.90 \\
\text { Depression: } \\
54.3 \%\end{array}$ \\
\hline $\begin{array}{l}\text { Peikes et al., } \\
2018^{101} \\
\text { AR, CO, NJ, } \\
\text { OR, NY, OH, } \\
\text { KY, OK: } 502 \\
\text { practices and } \\
40 \text { payers }\end{array}$ & $\begin{array}{l}\text { Primary care model } \\
\text { Shared savings: } \\
\text { APM } \\
(\mathrm{N}=1,730,958) \\
\text { Intervention } \\
(\mathrm{N}=565,674) \\
\text { Comparison } \\
(\mathrm{N}=1,165,284) \\
\text { Subgroups }(\mathrm{N}=\mathrm{NR})\end{array}$ & $\begin{array}{l}\text { Observational } \\
\text { study } \\
\text { (RoB: some } \\
\text { concerns) }\end{array}$ & $\begin{array}{l}2+\text { hospitalizations } \\
\text { in previous } 2 \text { years }\end{array}$ & $\begin{array}{l}2+\text { of } 13 \text { eligible } \\
\text { chronic conditions } \\
\text { including } \\
\text { congestive heart } \\
\text { failure, COPD, } \\
\text { acute myocardial } \\
\text { infarction, } \\
\text { ischemic heart } \\
\text { disease, diabetes, } \\
\text { any cancer other } \\
\text { than skin cancer, } \\
\text { stroke, } \\
\text { depression, } \\
\text { dementia, atrial } \\
\text { fibrillation, } \\
\text { osteoporosis, } \\
\text { rheumatoid } \\
\text { arthritis or } \\
\text { osteoarthritis, } \\
\text { chronic kidney } \\
\text { disease }\end{array}$ & $\begin{array}{l}\text { Received care } \\
\text { in a CPC } \\
\text { practice }\end{array}$ & NR \\
\hline
\end{tabular}




\begin{tabular}{|c|c|c|c|c|c|c|}
\hline $\begin{array}{l}\text { First Author, } \\
\text { Year, Site(s) }\end{array}$ & $\begin{array}{l}\text { Brief Description } \\
\text { (Sample Size) }\end{array}$ & $\begin{array}{l}\text { Study Design } \\
\text { (Risk of Bias } \\
\text { Assessment) }\end{array}$ & $\begin{array}{l}\text { Patient Selection: } \\
\text { High Healthcare } \\
\text { Use or Cost; Time } \\
\text { Period }\end{array}$ & $\begin{array}{l}\text { Patient } \\
\text { Selection: } \\
\text { Chronic } \\
\text { Conditions }\end{array}$ & $\begin{array}{l}\text { Patient } \\
\text { Selection: } \\
\text { Other }\end{array}$ & $\begin{array}{l}\text { Additional } \\
\text { Selected } \\
\text { Patient } \\
\text { Characteristics }\end{array}$ \\
\hline $\begin{array}{l}\text { Peikes et al., } \\
2019^{123,133} \\
\text { AR, CO, HI, } \\
\text { KC, KY, MI, } \\
\text { MT, NJ, NY } \\
\text { (Greater } \\
\text { Buffalo); NY } \\
\text { (North } \\
\text { Hudson- } \\
\text { Capital), ND, } \\
\text { NE, OH, OK, } \\
\text { OR, PA, RI, } \\
\text { TN: } \\
\text { 1,373 } \\
\text { practices }\end{array}$ & $\begin{array}{l}\text { Primary care model } \\
\text { Shared savings: } \\
\text { APM } \\
\text { Track } 1 \text { multiple } \\
\text { chronic condition } \\
\text { subgroup ( } \mathrm{N}=\mathrm{NR} \text { of } \\
5,163,969) \\
\text { Intervention ( } \mathrm{N}=\mathrm{NR} \\
\text { of } 1,189,438) \\
\text { Comparison ( } \mathrm{N}=\mathrm{NR} \\
\text { of } 3,974,531)\end{array}$ & $\begin{array}{l}\text { Observational } \\
\text { study } \\
\text { (RoB: some } \\
\text { concerns) }\end{array}$ & $\begin{array}{l}1+\text { hospitalizations } \\
\text { in past } 1 \text { year }\end{array}$ & $\begin{array}{l}2+\text { of } 12 \text { eligible } \\
\text { chronic conditions } \\
\text { including } \\
\text { congestive heart } \\
\text { failure, COPD, } \\
\text { history of acute } \\
\text { myocardial } \\
\text { infarction, } \\
\text { ischemic heart } \\
\text { disease, diabetes, } \\
\text { severe cancer, } \\
\text { history of stroke, } \\
\text { depression, } \\
\text { dementia, atrial } \\
\text { fibrillation, } \\
\text { rheumatoid } \\
\text { arthritis or } \\
\text { osteoarthritis, } \\
\text { chronic kidney } \\
\text { disease }\end{array}$ & $\begin{array}{l}\text { Enrolled in } \\
\text { Medicare } \\
\text { Parts A and B, } \\
\text { Medicare FFS } \\
\text { as primary } \\
\text { payer, do not } \\
\text { have ESRD } \\
\text { and not } \\
\text { enrolled in } \\
\text { hospice, are } \\
\text { not institution- } \\
\text { alized or } \\
\text { incarcerated, } \\
\text { and are not } \\
\text { attributed to a } \\
\text { PCP for a } \\
\text { nonoverlap } \\
\text { CMS service }\end{array}$ & NR \\
\hline $\begin{array}{l}\text { Peikes et al., } \\
2019^{123,133} \\
\text { AR, CO, HI, } \\
\text { KC, KY, MI, } \\
\text { MT, NJ, NY } \\
\text { (Greater } \\
\text { Buffalo); NY } \\
\text { (North } \\
\text { Hudson- } \\
\text { Capital), ND, } \\
\text { NE, OH, OK, } \\
\text { OR, PA, RI, } \\
\text { TN: 1,515 } \\
\text { practices }\end{array}$ & $\begin{array}{l}\text { Primary care model } \\
\text { Shared savings: } \\
\text { APM } \\
\text { Track } 2 \text { multiple } \\
\text { chronic condition } \\
\text { subgroup ( }=\mathrm{NR} \text { of } \\
4,804,265) \\
\text { Intervention ( } \mathrm{N}=\mathrm{NR} \\
\text { of } 1,443,553) \\
\text { Comparison }(\mathrm{N}=\mathrm{NR} \\
\text { of } 3,360,712)\end{array}$ & $\begin{array}{l}\text { Observational } \\
\text { study } \\
\text { (RoB: some } \\
\text { concerns) }\end{array}$ & $\begin{array}{l}1+\text { hospitalizations } \\
\text { in past } 1 \text { year }\end{array}$ & $\begin{array}{l}2+\text { of } 12 \text { eligible } \\
\text { chronic conditions } \\
\text { including } \\
\text { congestive heart } \\
\text { failure, COPD, } \\
\text { history of acute } \\
\text { myocardial } \\
\text { infarction, } \\
\text { ischemic heart } \\
\text { disease, diabetes, } \\
\text { severe cancer, } \\
\text { history of stroke, } \\
\text { depression, } \\
\text { dementia, atrial } \\
\text { fibrillation, } \\
\text { rheumatoid } \\
\text { arthritis or } \\
\text { osteoarthritis, and } \\
\text { chronic kidney } \\
\text { disease }\end{array}$ & $\begin{array}{l}\text { Enrolled in } \\
\text { Medicare } \\
\text { Parts A and B, } \\
\text { Medicare FFS } \\
\text { as primary } \\
\text { payer, not } \\
\text { ESRD and not } \\
\text { in hospice, not } \\
\text { institution- } \\
\text { alized or } \\
\text { incarcerated, } \\
\text { and are not } \\
\text { attributed to a } \\
\text { PCP for a } \\
\text { nonoverlap } \\
\text { CMS service }\end{array}$ & NR \\
\hline
\end{tabular}

$\overline{\mathrm{ADL}}=$ activities of daily living; $\mathrm{APM}=$ advanced alternative payment model; $\mathrm{AR}=$ Arkansas; $\mathrm{CMS}=\mathrm{Centers}$ for Medicare \& Medicaid Services; $\mathrm{CO}=$ Colorado; $\mathrm{COPD}=$ chronic obstructive pulmonary disease; $\mathrm{CPC}=$ comprehensive primary care; $\mathrm{ED}=$ emergency department; ESRD = end-stage renal disease; FFS $=$ fee-for-service; FQHC $=$ Federally Qualified Health Center; HI = Hawaii; HNHC = high-need, high-cost; IAH = Independence at Home; KC = Kansas City; KY = Kentucky; MI = Michigan; MT $=$ Montana; $\mathrm{N}=$ number; NA = not applicable; $\mathrm{ND}=$ North Dakota; $\mathrm{NE}=$ Nebraska; $\mathrm{NJ}=$ New Jersey; NR $=$ not reported; $\mathrm{NY}=$ New York; $\mathrm{OH}=$ Ohio; $\mathrm{OK}=$ Oklahoma; $\mathrm{OR}=$ Oregon; $\mathrm{PA}=$ Pennsylvania; $\mathrm{PCMH}=$ patient-centered medical home; $\mathrm{PCP}=$ primary care provider; $\mathrm{RI}=$ Rhode Island; $\mathrm{RoB}=$ risk of bias; $\mathrm{TN}=$ Tennessee; $v$ s. = versus. 
Table B-16. Intervention characteristics for system-level transformation models

\begin{tabular}{|c|c|c|c|c|c|c|c|c|c|c|}
\hline $\begin{array}{l}\text { First } \\
\text { Author, } \\
\text { Year, } \\
\text { Site(s) }\end{array}$ & $\begin{array}{l}\text { Intervention: } \\
\text { Brief } \\
\text { Description }\end{array}$ & $\begin{array}{l}\text { Intervention } \\
\text { Duration }\end{array}$ & $\begin{array}{l}\text { Assessment, } \\
\text { Education, } \\
\text { Skills, } \\
\text { Monitoring }\end{array}$ & $\begin{array}{l}\text { Coordination } \\
\text { and Continuity } \\
\text { of Care }\end{array}$ & $\begin{array}{l}\text { Referral } \\
\text { to/Linkages to } \\
\text { Community- } \\
\text { Based Support } \\
\text { Services }\end{array}$ & Providers & $\begin{array}{l}\text { Mode of } \\
\text { Delivery } \\
\text { Setting(s) }\end{array}$ & Intensity & $\begin{array}{l}\text { Impact on } \\
\text { Clinician } \\
\text { Workload/ } \\
\text { Clinical } \\
\text { Practice }\end{array}$ & Comparison \\
\hline $\begin{array}{l}\text { Kahn et } \\
\text { al., } \\
2016^{122} \\
\\
503 \\
\text { FQHCs }\end{array}$ & $\begin{array}{l}\text { Three } \\
\text { intervention } \\
\text { components to } \\
\text { support FQHC } \\
\text { transformation } \\
\text { into PCMHs: } \\
\text { quarterly care } \\
\text { management } \\
\text { fee payments, } \\
\text { technical } \\
\text { assistance } \\
\text { (TA), and data } \\
\text { and } \\
\text { performance } \\
\text { feedback } \\
\text { reports }\end{array}$ & 3 years & $\begin{array}{l}\text { Periodically } \\
\text { received three } \\
\text { types of } \\
\text { feedback } \\
\text { reports: the } \\
\text { biannual NCQA } \\
\text { RAS report, the } \\
\text { quarterly cost } \\
\text { and utilization } \\
\text { data reports, } \\
\text { and the quarterly } \\
\text { claims-based } \\
\text { beneficiary-level } \\
\text { report } \\
\text { summarizing } \\
\text { cost, utilization, } \\
\text { and health. } \\
\text { FQHCs were } \\
\text { offered TA to } \\
\text { prepare } \\
\text { documentation } \\
\text { for NCQA } \\
\text { PCMH } \\
\text { recognition } \\
\text { through } \\
\text { extensive } \\
\text { learning systems } \\
\text { involving varying } \\
\text { partners }\end{array}$ & $\begin{array}{l}\text { Intervention goals } \\
\text { based on PCMH } \\
\text { principles, which } \\
\text { are designed to } \\
\text { encourage } \\
\text { doctors, } \\
\text { hospitals, and } \\
\text { other healthcare } \\
\text { providers to work } \\
\text { together to better } \\
\text { coordinate care } \\
\text { for patients }\end{array}$ & NR & $\begin{array}{l}\text { PCMHs are } \\
\text { physician- or } \\
\text { nurse } \\
\text { practitioner- } \\
\text { directed } \\
\text { medical } \\
\text { practices }\end{array}$ & NR & $\overline{N R}$ & NR & $\begin{array}{l}\text { Usual care at } \\
\text { comparison } \\
\text { FQHCs }\end{array}$ \\
\hline
\end{tabular}




\begin{tabular}{|c|c|c|c|c|c|c|c|c|c|c|}
\hline $\begin{array}{l}\text { First } \\
\text { Author, } \\
\text { Year, } \\
\text { Site(s) }\end{array}$ & $\begin{array}{l}\text { Intervention: } \\
\text { Brief } \\
\text { Description }\end{array}$ & $\begin{array}{l}\text { Intervention } \\
\text { Duration }\end{array}$ & $\begin{array}{l}\text { Assessment, } \\
\text { Education, } \\
\text { Skills, } \\
\text { Monitoring }\end{array}$ & $\begin{array}{l}\text { Coordination } \\
\text { and Continuity } \\
\text { of Care }\end{array}$ & $\begin{array}{l}\text { Referral } \\
\text { to/Linkages to } \\
\text { Community- } \\
\text { Based Support } \\
\text { Services }\end{array}$ & Providers & $\begin{array}{l}\text { Mode of } \\
\text { Delivery } \\
\text { Setting(S) }\end{array}$ & Intensity & $\begin{array}{l}\text { Impact on } \\
\text { Clinician } \\
\text { Workload/ } \\
\text { Clinical } \\
\text { Practice } \\
\end{array}$ & Comparison \\
\hline $\begin{array}{l}\text { Kimmy et } \\
\text { al., } \\
2019^{103} \\
\text { Effect of } \\
\text { incentive } \\
\text { payment } \\
\text { National: } \\
14 \\
\text { practices }\end{array}$ & $\begin{array}{l}\text { Practices may } \\
\text { earn an } \\
\text { additional } \\
\text { payment if their } \\
\text { chronically ill, } \\
\text { functionally } \\
\text { limited patients' } \\
\text { Medicare } \\
\text { expenditures } \\
\text { are below an } \\
\text { estimated } \\
\text { spending target } \\
\text { and if the } \\
\text { practice meets } \\
\text { required } \\
\text { standards for a } \\
\text { set of quality } \\
\text { measures }\end{array}$ & Up to 4 years & $\begin{array}{l}\text { Clinicians are } \\
\text { available at all } \\
\text { hours of the day; } \\
\text { carry out } \\
\text { individualized } \\
\text { care plans; and } \\
\text { use electronic } \\
\text { health } \\
\text { information } \\
\text { systems, remote } \\
\text { monitoring, and } \\
\text { mobile } \\
\text { diagnostic } \\
\text { technology }\end{array}$ & $\begin{array}{l}\text { Report on other } \\
\text { measures, } \\
\text { including fall risk } \\
\text { assessments and } \\
\text { depression } \\
\text { screenings, to } \\
\text { promote the } \\
\text { provision of such } \\
\text { care }\end{array}$ & $\begin{array}{l}\text { Some practices } \\
\text { added social } \\
\text { workers or other } \\
\text { staff to } \\
\text { coordinate care } \\
\text { for their patients } \\
\text { with other } \\
\text { organizations }\end{array}$ & $\begin{array}{l}\text { Physicians or } \\
\text { nurse } \\
\text { practitioners. } \\
\text { Team may } \\
\text { have also } \\
\text { included } \\
\text { physician } \\
\text { assistants, } \\
\text { clinical staff, } \\
\text { and other } \\
\text { health and } \\
\text { social services } \\
\text { staff }\end{array}$ & Face-to-face & $\begin{array}{l}\text { Clinicians } \\
\text { made 3-15 } \\
\text { home visits } \\
\text { per day, } \\
\text { varied by } \\
\text { site }\end{array}$ & $\begin{array}{l}\leq 1 \text { home } \\
\text { visit and no } \\
\text { visit from a } \\
\text { participating } \\
\text { practice in } \\
\text { study year }\end{array}$ & $\begin{array}{l}\text { Usual care of } \\
\text { Medicare- } \\
\text { eligible } \\
\text { beneficiaries } \\
\text { living in IAH } \\
\text { regions }\end{array}$ \\
\hline
\end{tabular}




\begin{tabular}{|c|c|c|c|c|c|c|c|c|c|c|}
\hline $\begin{array}{l}\text { First } \\
\text { Author, } \\
\text { Year, } \\
\text { Site(s) }\end{array}$ & $\begin{array}{l}\text { Intervention: } \\
\text { Brief } \\
\text { Description }\end{array}$ & $\begin{array}{l}\text { Intervention } \\
\text { Duration }\end{array}$ & $\begin{array}{l}\text { Assessment, } \\
\text { Education, } \\
\text { Skills, } \\
\text { Monitoring }\end{array}$ & $\begin{array}{l}\text { Coordination } \\
\text { and Continuity } \\
\text { of Care }\end{array}$ & $\begin{array}{l}\text { Referral } \\
\text { to/Linkages to } \\
\text { Community- } \\
\text { Based } \\
\text { Support } \\
\text { Services }\end{array}$ & Providers & $\begin{array}{l}\text { Mode of } \\
\text { Delivery } \\
\text { Setting(S) }\end{array}$ & Intensity & $\begin{array}{l}\text { Impact on } \\
\text { Clinician } \\
\text { Workload/ } \\
\text { Clinical } \\
\text { Practice }\end{array}$ & Comparison \\
\hline $\begin{array}{l}\text { Peikes et } \\
\text { al., } \\
2018^{101} \\
\text { AR, CO, } \\
\text { NJ, OR, } \\
\text { NY, OH, } \\
\text { KY, OK: } \\
502 \\
\text { practices } \\
\text { and } 40 \\
\text { payers }\end{array}$ & $\begin{array}{l}\text { Comprehensiv } \\
\text { e Primary Care } \\
\text { (CPC) Initiative }\end{array}$ & 51 months & $\begin{array}{l}\text { CPC practices } \\
\text { received } \\
\text { financial } \\
\text { support, data } \\
\text { feedback, and } \\
\text { learning support }\end{array}$ & $\begin{array}{l}\text { Practices } \\
\text { required to } \\
\text { address access } \\
\text { and continuity, } \\
\text { planned care for } \\
\text { chronic conditions } \\
\text { and preventive } \\
\text { care, risk- } \\
\text { stratified care } \\
\text { management, } \\
\text { patient and } \\
\text { caregiver } \\
\text { engagement }\end{array}$ & $\begin{array}{l}\text { Practices } \\
\text { required to } \\
\text { address } \\
\text { coordination of } \\
\text { care across the } \\
\text { medical } \\
\text { neighborhood }\end{array}$ & $\begin{array}{l}\text { CPC practices, } \\
\text { multiple } \\
\text { contractors and } \\
\text { organizations } \\
\text { provided } \\
\text { different } \\
\text { intervention } \\
\text { elements to } \\
\text { CPC practices } \\
\text { Patients } \\
\text { received } \\
\text { intervention } \\
\text { services from } \\
\text { regular practice } \\
\text { staff and from } \\
\text { specialized } \\
\text { staff (e.g., care } \\
\text { coordinators, } \\
\text { care managers, } \\
\text { social workers) }\end{array}$ & $\begin{array}{l}\text { CMS sent } \\
\text { reports on } \\
\text { practice and } \\
\text { patient-level } \\
\text { data; learning } \\
\text { support was } \\
\text { peer-to-peer, } \\
\text { didactic, and } \\
\text { one-on-one }\end{array}$ & $\begin{array}{l}\text { Reports and } \\
\text { financial } \\
\text { support } \\
\text { were sent } \\
\text { quarterly, } \\
\text { frequency of } \\
\text { learning } \\
\text { support } \\
\text { varied }\end{array}$ & $\begin{array}{l}\text { Practices } \\
\text { perceived } \\
\text { that a big } \\
\text { benefit of } \\
\text { CPC } \\
\text { participation } \\
\text { was } \\
\text { increased } \\
\text { capacity to } \\
\text { provide care } \\
\text { management } \\
\text { services to } \\
\text { high-risk } \\
\text { patients; } \\
\text { practices } \\
\text { shared with } \\
\text { CMS any net } \\
\text { savings in } \\
\text { healthcare } \\
\text { costs beyond } \\
\text { amount } \\
\text { required to } \\
\text { cover their } \\
\text { care } \\
\text { management } \\
\text { fee } \\
\text { payments; } \\
\text { within } \\
\text { practices, } \\
\text { care } \\
\text { managers } \\
\text { were } \\
\text { increasingly } \\
\text { integrated } \\
\text { into } \\
\text { clinicians' } \\
\text { work } \\
\end{array}$ & $\begin{array}{l}\text { Usual care at } \\
\text { non-CPC } \\
\text { practices }\end{array}$ \\
\hline
\end{tabular}




\begin{tabular}{|c|c|c|c|c|c|c|c|c|c|c|}
\hline $\begin{array}{l}\text { First } \\
\text { Author, } \\
\text { Year, } \\
\text { Site(s) }\end{array}$ & $\begin{array}{l}\text { Intervention: } \\
\text { Brief } \\
\text { Description }\end{array}$ & $\begin{array}{l}\text { Intervention } \\
\text { Duration }\end{array}$ & $\begin{array}{l}\text { Assessment, } \\
\text { Education, } \\
\text { Skills, } \\
\text { Monitoring }\end{array}$ & $\begin{array}{l}\text { Coordination } \\
\text { and Continuity } \\
\text { of Care }\end{array}$ & $\begin{array}{l}\text { Referral } \\
\text { to/Linkages to } \\
\text { Community- } \\
\text { Based Support } \\
\text { Services }\end{array}$ & Providers & $\begin{array}{l}\text { Mode of } \\
\text { Delivery } \\
\text { Setting(S) }\end{array}$ & Intensity & $\begin{array}{l}\text { Impact on } \\
\text { Clinician } \\
\text { Workload/ } \\
\text { Clinical } \\
\text { Practice } \\
\end{array}$ & Comparison \\
\hline $\begin{array}{l}\text { Peikes et } \\
\text { al., } \\
2019^{123} \\
\\
\text { AR, CO, } \\
\text { HI, KC, } \\
\text { KY, MI, } \\
\text { MT, NJ, } \\
\text { NY } \\
\text { (Greater } \\
\text { Buffalo); } \\
\text { NY (North } \\
\text { Hudson- } \\
\text { Capital), } \\
\text { ND, NE, } \\
\text { OH, OK, } \\
\text { OR, PA, } \\
\text { RI, TN: } \\
\text { 2,888 } \\
\text { practices }\end{array}$ & $\begin{array}{l}\text { Comprehensive } \\
\text { Primary Care } \\
\text { Plus (CPC+) }\end{array}$ & 2 years & $\begin{array}{l}\text { Practice-focused } \\
\text { intervention; } \\
\text { CPC+ practices } \\
\text { received } \\
\text { financial } \\
\text { support, data } \\
\text { feedback, health } \\
\text { IT support, and } \\
\text { learning support; } \\
\text { track } 2 \text { CPC+ } \\
\text { practices } \\
\text { received } \\
\text { enhanced } \\
\text { payments and } \\
\text { replacement of } \\
\text { some fee-for- } \\
\text { service } \\
\text { payments with } \\
\text { prospective } \\
\text { payments }\end{array}$ & $\begin{array}{l}\text { Required to } \\
\text { address access } \\
\text { and continuity, } \\
\text { care } \\
\text { management, } \\
\text { comprehensive- } \\
\text { ness and } \\
\text { coordination, } \\
\text { patient and } \\
\text { caregiver } \\
\text { engagement, and } \\
\text { planned care and } \\
\text { population health } \\
\text { CMS-specified } \\
\text { care delivery } \\
\text { requirements } \\
\text { within each of } \\
\text { these functions; } \\
\text { they were } \\
\text { considered a } \\
\text { starting point and } \\
\text { practices could } \\
\text { choose which } \\
\text { care delivery } \\
\text { requirements or } \\
\text { other changes to } \\
\text { adopt first, which } \\
\text { personnel would } \\
\text { be involved and } \\
\text { which tactics they } \\
\text { would pursue }\end{array}$ & $\begin{array}{l}\text { Care } \\
\text { management, } \\
\text { comprehensive- } \\
\text { ness and } \\
\text { coordination are } \\
2 \text { of the } 5 \text { key } \\
\text { functions of a } \\
\text { CPC+ practice }\end{array}$ & $\begin{array}{l}\text { CPC+ } \\
\text { practices; CMS } \\
\text { partnered with } \\
79 \text { public and } \\
\text { private payers } \\
\text { across } 18 \\
\text { CPC+ regions; } \\
\text { various } \\
\text { contractors and } \\
\text { organizations } \\
\text { provided } \\
\text { intervention } \\
\text { elements to } \\
\text { CPC+ } \\
\text { practices } \\
\text { Practices hired } \\
\text { new staff to } \\
\text { support CPC+ } \\
\text { activities: care } \\
\text { managers, } \\
\text { behavioral } \\
\text { health } \\
\text { specialists, } \\
\text { clinical } \\
\text { pharmacists, } \\
\text { social workers, } \\
\text { data analysts, } \\
\text { dietitians, } \\
\text { diabetes } \\
\text { educators, and } \\
\text { Ql staff }\end{array}$ & $\begin{array}{l}\text { Practices } \\
\text { received data } \\
\text { reports; } \\
\text { learning was } \\
\text { delivered in } \\
\text { groups and in- } \\
\text { person } \\
\text { practice } \\
\text { coaching }\end{array}$ & $\begin{array}{l}\text { Reports and } \\
\text { financial } \\
\text { support } \\
\text { were sent } \\
\text { quarterly, } \\
\text { frequency of } \\
\text { learning } \\
\text { support NR }\end{array}$ & $\mathrm{NR}$ & $\begin{array}{l}\text { Usual care at } \\
\text { non-CPC+ } \\
\text { practices }\end{array}$ \\
\hline
\end{tabular}

$\overline{\mathrm{AR}}=$ Arkansas; $\mathrm{CMS}=$ Centers for Medicare \& Medicaid Services; $\mathrm{CO}=$ Colorado; $\mathrm{CPC}=$ Comprehensive Primary Care; $\mathrm{CPC}+=\mathrm{Comprehensive} \mathrm{Primary} \mathrm{Care} \mathrm{Plus;} \mathrm{FQHC}=$

Federally Qualified Health Center; HI = Hawaii; IT = information technology; KC = Kansas City; KY = Kentucky; MI = Michigan; MT = Montana; NCQA = National Committee for Quality Assurance; ND = North Dakota; NE = Nebraska; NJ = New Jersey; NR = not reported; NY = New York; OH = Ohio; OK = Oklahoma; OR = Oregon; PA =

Pennsylvania; $\mathrm{PCMH}=$ patient-centered medical home; $\mathrm{QI}=$ quality improvement; $\mathrm{RAS}=$ Readiness Assessment $\mathrm{Survey} ; \mathrm{RI}=\mathrm{Rhode} \mathrm{Island}$; $\mathrm{TA}=$ technical assistance; $\mathrm{TN}=$

Tennessee. 
Table B-17. Healthcare utilization outcomes for system-level transformation model studies

\begin{tabular}{|c|c|c|c|c|}
\hline Utilization Measures & Study Design & $\begin{array}{l}\text { Direction of } \\
\text { Change in } \\
\text { Intervention } \\
\text { Group (G1) }\end{array}$ & $\begin{array}{l}\text { Direction of } \\
\text { Change in } \\
\text { Comparison } \\
\text { Group (G2) }\end{array}$ & Difference \\
\hline \multirow[t]{2}{*}{ Inpatient admissions } & Observational & NR & NR & $\begin{array}{l}\text { FQHC: adjusted year } 3 \text { difference in visits: }-5.32 \\
(\mathrm{SE}: 28.60)(p>0.10)^{122}\end{array}$ \\
\hline & Observational & NR & NR & $\begin{array}{l}\text { IAH incentive payment 5-year average annual } \\
\text { effect } \mathrm{DiD}=-0.08(\mathrm{SE}: 0.05)(p>0.10)^{103,132}\end{array}$ \\
\hline $\begin{array}{l}\text { Inpatient admissions, } \\
\text { ACSC }\end{array}$ & Observational & NR & NR & $\begin{array}{l}\text { Greater reduction in } \mathrm{G} 1 \text { than } \mathrm{G} 2 \text { : IAH incentive } \\
\text { payment } 5 \text {-year average annual effect } \mathrm{DiD}=- \\
0.04 \text { (SE: } 0.02)(p<0.05)^{103,132}\end{array}$ \\
\hline \multirow[t]{2}{*}{ ED visits } & Observational & NR & NR & $\begin{array}{l}\text { FQHC: adjusted year } 3 \text { difference in } \\
\text { visits: }-80.75 \text { (SE: } 87.65)(p>0.10)^{122}\end{array}$ \\
\hline & Observational & NR & NR & $\begin{array}{l}\text { Greater reduction in } \mathrm{G} 1 \text { than } \mathrm{G} 2 \text { : IAH incentive } \\
\text { payment } 5 \text {-year average annual effect } \mathrm{DiD}=- \\
0.14(\mathrm{SE}: 0.06)(p<0.01)^{103,132}\end{array}$ \\
\hline ED visits, outpatient & Observational & NR & NR & $\begin{array}{l}\text { IAH incentive payment 5-year average annual } \\
\text { effect DiD=-0.02 (SE: } 0.06)(p>0.10)^{103,132}\end{array}$ \\
\hline $\begin{array}{l}\text { ED visits resulted in } \\
\text { inpatient admission }\end{array}$ & Observational & $\mathrm{NR}$ & $\mathrm{NR}$ & $\begin{array}{l}\text { Greater reduction in } \mathrm{G} 1 \text { than } \mathrm{G} 2 \text { : IAH incentive } \\
\text { payment } 5 \text {-year average annual effect } \mathrm{DiD}=- \\
0.11(\mathrm{SE}: 0.05)(p<0.05)^{103,132}\end{array}$ \\
\hline ED visits, ACSC & Observational & NR & NR & $\begin{array}{l}\text { IAH incentive payment 5-year average annual } \\
\text { effect } \mathrm{DiD}=-0.00(\mathrm{SE}: 0.01)(p>0.10)^{103,132}\end{array}$ \\
\hline Primary care visits ${ }^{b}$ & Observational & NR & NR & $\begin{array}{l}\text { FQHC: adjusted year } 3 \text { difference in } \\
\text { visits: }-132.58 \text { (SE: } 84.18)(p>0.10)^{122}\end{array}$ \\
\hline Specialist visits & Observational & NR & NR & $\begin{array}{l}\text { FQHC: adjusted year } 3 \text { difference in } \\
\text { visits: }-29.67 \text { (SE: } 78.82)(p>0.10)^{122}\end{array}$ \\
\hline FQHC visits & Observational & NR & NR & $\begin{array}{l}\text { FQHC: adjusted year } 3 \text { difference in } \\
\text { visits: }-15.90(\mathrm{SE}: 54.65)(p>0.10)^{122}\end{array}$ \\
\hline $\begin{array}{l}\text { Probability of entering } \\
\text { institutional long-term } \\
\text { care within the } \\
\text { demonstration year } \\
\end{array}$ & Observational & NR & NR & $\begin{array}{l}\text { IAH incentive payment 4-year average annual } \\
\text { effect DiD=-0.38 (SE: } 0.37)(p>0.10)^{132}\end{array}$ \\
\hline $\begin{array}{l}\text { Probability of hospice } \\
\text { use }\end{array}$ & Observational & NR & NR & $\begin{array}{l}\text { IAH incentive payment 4-year average annual } \\
\text { effect DiD }=-0.83(\mathrm{SE}: 0.68)(p>0.10)^{103}\end{array}$ \\
\hline $\begin{array}{l}\text { Probability of SNF } \\
\text { use }\end{array}$ & Observational & NR & NR & $\begin{array}{l}\text { IAH incentive payment 4-year average annual } \\
\text { effect } \mathrm{DiD}=0.19 \text { (SE: } 0.82)(p>0.10)^{103}\end{array}$ \\
\hline $\begin{array}{l}\text { Probability of home } \\
\text { health use }\end{array}$ & Observational & NR & $\mathrm{NR}$ & $\begin{array}{l}\text { IAH incentive payment 4-year average annual } \\
\text { effect } \mathrm{DiD}=-0.45(\mathrm{SE}: 0.70)(p>0.10)^{103}\end{array}$ \\
\hline Home health days & Observational & NR & NR & $\begin{array}{l}\text { IAH incentive payment 4-year average annual } \\
\text { effect } \mathrm{DiD}=-0.58(\mathrm{SE}: 5.67)(p>0.10)^{103}\end{array}$ \\
\hline Home health visits & Observational & NR & NR & $\begin{array}{l}\text { IAH incentive payment 4-year average annual } \\
\text { effect } \mathrm{DiD}=0.14(\mathrm{SE}: 2.43)(p>0.10)^{103}\end{array}$ \\
\hline $\begin{array}{l}\text { Visits in nonacute } \\
\text { settings by primary } \\
\text { care clinicians }\end{array}$ & Observational & NR & NR & $\begin{array}{l}\text { IAH incentive payment 4-year average annual } \\
\text { effect } \mathrm{DiD}=0.59(\mathrm{SE}: 0.57)(p>0.10)^{103}\end{array}$ \\
\hline $\begin{array}{l}\text { Visits in nonacute } \\
\text { settings by specialists }\end{array}$ & Observational & NR & NR & $\begin{array}{l}\text { IAH incentive payment 4-year average annual } \\
\text { effect DiD=-0.39 (SE: } 0.32)(p>0.10)^{103}\end{array}$ \\
\hline
\end{tabular}

a The reported p-value reflect the authors' adjustment for multiple comparisons.

${ }^{\mathrm{b}}$ Defined as Evaluation and Management primary care visits by Kahn et al. ${ }^{122}$

ACSC = ambulatory care sensitive conditions; $\mathrm{DiD}=$ difference-in-difference; $\mathrm{ED}=$ emergency department; FQHC $=$ Federally Qualified Health Center; G = group; IAH = Independence at Home; NR = not reported; SE = standard error; SNF = skilled nursing facility. 
Table B-18. Strength of evidence for system-level transformation model versus usual-care outcomes

\begin{tabular}{|c|c|c|c|c|c|}
\hline Population & Outcome & Results & $\begin{array}{l}\text { Study Design } \\
\text { and Sample Size }\end{array}$ & $\begin{array}{l}\text { Strength of } \\
\text { Evidence } \\
\text { Domains }\end{array}$ & $\begin{array}{l}\text { Overall } \\
\text { Evidence } \\
\text { Strength } \\
\text { (Direction of } \\
\text { Effect) }\end{array}$ \\
\hline $\begin{array}{l}\mathrm{HNHC} \\
\text { patients }\end{array}$ & ED visits & $\begin{array}{l}\text { FQHC: adj diff=-80.75 } \\
(p>0.10):{ }^{122} \\
\text { IAH incentive payment: } \\
\text { lower use in } G 1 \text { than } G 2 \text { : } \\
\text { DiD=-0.14 }(p<0.01)^{103}\end{array}$ & $2 \mathrm{OBSs}, \mathrm{N}=\mathrm{NR}^{\mathrm{a}}$ & $\begin{array}{l}\text { Moderate study } \\
\text { limitations, } \\
\text { inconsistent, direct, } \\
\text { imprecise }\end{array}$ & Insufficient \\
\hline $\begin{array}{l}\mathrm{HNHC} \\
\text { patients }\end{array}$ & $\begin{array}{l}\text { Inpatient } \\
\text { admissions }\end{array}$ & $\begin{array}{l}\text { FQHC: adj diff=-5.32 } \\
(p>0.10))^{122} \\
\text { IAH incentive payment } \\
\text { DiD=-0.08 (SE: } 0.05) \\
(p>0.10)^{103}\end{array}$ & 2 OBSs, $\mathrm{N}=\mathrm{NR}^{\mathrm{a}}$ & $\begin{array}{l}\text { Moderate study } \\
\text { limitations, } \\
\text { consistent, direct, } \\
\text { imprecise }\end{array}$ & Insufficient \\
\hline $\begin{array}{l}\mathrm{HNHC} \\
\text { patients }\end{array}$ & Total cost & $\begin{array}{l}\text { FQHC: adj diff=\$387.23 } \\
(p>0.10) ;{ }^{122} \\
\text { CPC: } \text { DiD=-\$45 }(p=0.23) ; 101 \\
\text { CPC+ sample 1: DiD=6.2 } \\
(p>0.10) ;{ }^{133} \\
\text { CPC+ sample 2: DiD=43.0 } \\
(p=04) ; 133 \\
\text { IAH incentive payment } \\
\text { DiD=-200 (SE: } 151) \\
(p>0.10)^{103} \\
\text { Pooled mean } \\
\text { difference: }-\$ 5.41(95 \% \\
\text { Cl, -38.28 to } 49.10) ; 5 \\
\text { observational samples; } \\
\left.\right|^{2}=44.6 \%\end{array}$ & $5 \mathrm{OBSs}, \mathrm{N}=\mathrm{NR}^{\mathrm{a}}$ & $\begin{array}{l}\text { Moderate study } \\
\text { limitations, } \\
\text { inconsistent, direct, } \\
\text { imprecise }\end{array}$ & $\begin{array}{l}\text { Low (No } \\
\text { difference) }\end{array}$ \\
\hline
\end{tabular}

${ }^{\mathrm{a}} \mathrm{The} \mathrm{FQHC},{ }^{122} \mathrm{CPC},{ }^{101}$ and $\mathrm{CPC}+{ }^{123}$ studies did not report sample sizes for their HNHC patient populations; the total sample size for the FQHC was 730,353, 1,730,958 for CPC, 5,163,969 for CPC+ Sample 1, and 4,804,265 for CPC+ Sample 2. The sample size was 42,132 for the Independence at Home study. ${ }^{103}$

Note: $\mathrm{CPC}+$ sample 1: HNHC patients in $\mathrm{CPC}+$ practices making less advanced care delivery changes; $\mathrm{CPC}+$ sample $2: \mathrm{HNHC}$ patients in $\mathrm{CPC}+$ practices making more advanced care delivery changes.

adj diff = adjusted difference; $\mathrm{CI}=$ confidence interval; $\mathrm{DiD}=$ difference-in-difference; $\mathrm{ED}=$ emergency department; $\mathrm{FQHC}=$ Federally Qualified Health Center; $\mathrm{HNHC}=$ high need, high cost; $\mathrm{IAH}=$ Independence at Home; $\mathrm{N}=$ number; $\mathrm{NR}=$ not reported; OBS = observational study; vs. = versus. 
Table B-19. Cost outcomes for system-level transformation model studies

\begin{tabular}{|c|c|c|c|c|}
\hline $\begin{array}{l}\text { Cost } \\
\text { Measures }\end{array}$ & Study Design & $\begin{array}{l}\text { Direction of } \\
\text { Change in } \\
\text { Intervention } \\
\text { Group (G1) }\end{array}$ & $\begin{array}{l}\text { Direction of } \\
\text { Change in } \\
\text { Comparison } \\
\text { Group (G2) }\end{array}$ & Difference \\
\hline \multirow[t]{5}{*}{ Total cost (\$) } & Observational & NR & NR & $\begin{array}{l}\text { FQHC: adjusted difference=387.23 (SE: 494.62) } \\
(p>0.10)^{122}\end{array}$ \\
\hline & Observational & NR & NR & $\begin{array}{l}\text { IAH incentive payment 5-year average annual effect } \\
\text { DiD=-200 (SE: 151) }(p>0.10)^{103,132}\end{array}$ \\
\hline & Observational & NR & NR & CPC DiD=-45 $(p=0.23)^{101}$ \\
\hline & Observational & NR & NR & $\begin{array}{l}\text { CPC+ Sample } 1 \text { 2-year impact DiD=6.2 (SE: 19.2) } \\
(p>0.10))^{123,133}\end{array}$ \\
\hline & Observational & NR & NR & $\begin{array}{l}\text { Greater increase in G1 than G2: CPC+ Sample 2 2- } \\
\text { year impact DiD=43.0 (SE: } 20.5)(p=0.04)^{123,133}\end{array}$ \\
\hline Outpatient cost & Observational & NR & NR & $\begin{array}{l}\text { FQHC: adjusted differences in visits: } 290.07 \text { (SE: } \\
\text { 178.26) }(p>0.10)^{122}\end{array}$ \\
\hline Acute cost & Observational & NR & NR & $\begin{array}{l}\text { FQHC: adjusted for differences in visits: } 292.47 \text { (SE: } \\
315.40)(p>0.10)^{122}\end{array}$ \\
\hline$\overline{\text { OPD cost }}$ & Observational & NR & NR & $\begin{array}{l}\text { FQHC: adjusted for differences in visits: } 218.92 \text { (SE: } \\
150.97)(p>0.10)^{122}\end{array}$ \\
\hline $\begin{array}{l}\text { Primary care } \\
\text { physician cost }\end{array}$ & Observational & NR & NR & $\begin{array}{l}\text { FQHC: adjusted differences in visits: } 18.99 \text { (SE: 26.65) } \\
(p>0.10)^{122}\end{array}$ \\
\hline
\end{tabular}

Note: CPC+ sample 1: HNHC patients in CPC+ practices making less advanced care delivery changes; CPC+ sample 2: $\mathrm{HNHC}$ patients in $\mathrm{CPC}+$ practices making more advanced care delivery changes.

$\mathrm{CPC}+=$ Comprehensive Primary Care Plus; DiD = difference-in-difference; FQHC = Federally Qualified Health Center; G = group; $\mathrm{HNHC}=$ high-need, high-cost; IAH = Independence at Home; NR = not reported; OPD = outpatient department; $\mathrm{SE}=$ standard error. 
Table B-20. Cost outcomes for system-level transformation model studies: Subgroup outcomes

\begin{tabular}{|c|c|c|c|c|}
\hline $\begin{array}{l}\text { Cost } \\
\text { Measures }\end{array}$ & Study Design & $\begin{array}{l}\text { Direction of } \\
\text { Change in } \\
\text { Intervention } \\
\text { Group (G1) }\end{array}$ & $\begin{array}{l}\text { Direction of } \\
\text { Change in } \\
\text { Comparison } \\
\text { Group (G2) }\end{array}$ & Difference \\
\hline \multirow[t]{2}{*}{$\begin{array}{l}\text { Total cost } \\
\text { (PBPM) }\end{array}$} & Observational & NR & NR & $\begin{array}{l}\text { Beneficiaries with dementia subgroup: IAH incentive } \\
\text { payment } \mathrm{DiD}=-222(\mathrm{SE}: 143)(p=N S)^{103}\end{array}$ \\
\hline & Observational & NR & NR & $\begin{array}{l}\text { Beneficiaries without dementia subgroup: IAH } \\
\text { incentive payment } \mathrm{DiD}=-347(\mathrm{SE}: 279)(\mathrm{p}=\mathrm{NS})^{103}\end{array}$ \\
\hline
\end{tabular}

Table B-21. Clinical and functional outcomes for system-level transformation model studies Clinical and

Functional Outcomes Study Design Difference Between Intervention Group (G1) and Comparison Group (G2) Mortality rate Observational IAH incentive payment 5-year average annual effect DiD: -0.32 (SE: 0.55) $(p>0.10)^{103,132}$

DiD = difference-in-difference; $\mathrm{G}$ = group; IAH = Independence at Home; NR = not reported; SE = standard error.

Table B-22. Clinical and functional outcomes for system-level transformation model studies: Subgroup outcomes

\begin{tabular}{lll}
\hline $\begin{array}{l}\text { Clinical and } \\
\text { Functional } \\
\text { Outcomes }\end{array}$ & Study Design & Difference Between Intervention Group (G1) and Comparison Group (G2) \\
\hline HbA1c test & Observational & $\begin{array}{l}\text { FQHC diabetes subgroup: adjusted year 3 difference in visits: 0.35 (SE: 1.16) } \\
(p>0.10)^{122}\end{array}$ \\
\hline LDL test & Observational & $\begin{array}{l}\text { FQHC diabetes subgroup: adjusted year 3 difference in visits: -1.17 (SE: 1.37) } \\
(p>0.10)^{122}\end{array}$ \\
\hline Eye exam & Observational & $\begin{array}{l}\text { FQHC diabetes subgroup: adjusted year 3 difference in visits: 1.09 (SE: 1.53) } \\
(p>0.10)^{122}\end{array}$ \\
\hline Nephropathy test & Observational & $\begin{array}{l}\text { FQHC diabetes subgroup: adjusted year 3 difference in visits: 2.88 (SE: 1.60) } \\
(p>0.10)^{122}\end{array}$ \\
\hline $\begin{array}{l}\text { All 4 recommended } \\
\text { diabetes tests }\end{array}$ & Observational & $\begin{array}{l}\text { FQHC diabetes subgroup: adjusted year 3 difference in visits: }-0.51 \text { (SE: 0.45) } \\
(p>0.10)^{122}\end{array}$ \\
\hline Lipid test & Observational & $\begin{array}{l}\text { FQHC IVD subgroup: adjusted year 3 difference in visits: }-0.81 \text { (SE: 1.80) } \\
(p>0.10)^{122}\end{array}$ \\
\hline
\end{tabular}

FQHC = Federally Qualified Health Center; $\mathrm{G}=$ group; HbA1c $=$ hemoglobin A1c; IVD = ischemic vascular disease; LDL = low-density lipoprotein; $\mathrm{NR}=$ not reported; $\mathrm{SE}=$ standard error. 
Table B-23. Study characteristics for telephonic/mail models

\begin{tabular}{|c|c|c|c|c|c|c|}
\hline $\begin{array}{l}\text { First Author, } \\
\text { Year, Site(s) }\end{array}$ & Sample Size & $\begin{array}{l}\text { Study Design } \\
\text { (Risk of Bias } \\
\text { Assessment) }\end{array}$ & $\begin{array}{l}\text { Patient } \\
\text { Selection: } \\
\text { High } \\
\text { Healthcare } \\
\text { Use or Cost; } \\
\text { Time Period }\end{array}$ & $\begin{array}{l}\text { Patient } \\
\text { Selection: } \\
\text { Chronic } \\
\text { Conditions }\end{array}$ & $\begin{array}{l}\text { Patient } \\
\text { Selection: } \\
\text { Other }\end{array}$ & $\begin{array}{l}\text { Additional } \\
\text { Selected } \\
\text { Patient } \\
\text { Characteristics }\end{array}$ \\
\hline $\begin{array}{l}\text { McCall et al., } \\
2010^{79} \\
48 \text { counties in } \\
\text { western TX }\end{array}$ & $\begin{array}{l}\text { HNHC patients } \\
\text { only }(\mathrm{N}=2,815) \\
\text { Intervention } \\
(\mathrm{N}=1,986) \\
\text { Comparison } \\
(\mathrm{N}=1,969)\end{array}$ & $\begin{array}{l}\text { RCT } \\
\text { (RoB: some } \\
\text { concerns) }\end{array}$ & $\begin{array}{l}\text { Medicare } \\
\text { costs of } \\
\$ 6,000 \text { or } \\
\text { more in past } 1 \\
\text { year }\end{array}$ & NA & $\begin{array}{l}\text { Medicare FFS } \\
\text { beneficiaries, } \\
\text { majority of } \\
\text { visits to TX } \\
\text { Tech U Health } \\
\text { Sciences } \\
\text { Center or } \\
\text { Physician } \\
\text { Network } \\
\text { Services (a } \\
\text { PCP) }\end{array}$ & NR \\
\hline $\begin{array}{l}\text { McCall et al., } \\
2010^{81} \\
\text { Suffolk, } \\
\text { Nassau, and } \\
\text { Queens, NY: } \\
6 \text { nephrology } \\
\text { practices }\end{array}$ & $\begin{array}{l}\text { Original sample } \\
(\mathrm{N}=6,996) \\
\text { Intervention } \\
(\mathrm{N}=4,996) \\
\text { Comparison } \\
(\mathrm{N}=2,000) \\
\text { Diabetes subgroup } \\
(\mathrm{N}=2,165) \\
\text { ESRD subgroup } \\
(\mathrm{N}=331) \\
\text { IVD subgroup } \\
(\mathrm{N}=2,434)\end{array}$ & $\begin{array}{l}\text { RCT } \\
\text { (RoB: some } \\
\text { concerns) }\end{array}$ & $\begin{array}{l}\text { Medicare } \\
\text { costs of } \\
\$ 5,000 \text { or } \\
\text { more in past } 1 \\
\text { year }\end{array}$ & $\begin{array}{l}\text { Chronic kidney } \\
\text { disease } \\
\text { diagnosis on at } \\
\text { least one claim, } \\
\text { HCC > } 1.7 \text { (high } \\
\text { risk for future } \\
\text { healthcare } \\
\text { utilization), } \\
\text { excluded ESRD } \\
\text { patients }\end{array}$ & $\begin{array}{l}\text { Medicare FFS } \\
\text { beneficiaries } \\
\text { with primary } \\
\text { residence in } \\
\text { the intervention } \\
\text { county/region }\end{array}$ & NR \\
\hline $\begin{array}{l}\text { McCall et al., } \\
2010^{81} \\
\text { Suffolk, } \\
\text { Nassau, and } \\
\text { Queens, NY: } \\
6 \text { nephrology } \\
\text { practices }\end{array}$ & $\begin{array}{l}\text { Refresh sample } \\
(\mathrm{N}=3,341) \\
\text { Intervention } \\
(\mathrm{N}=2,385) \\
\text { Comparison } \\
(\mathrm{N}=956) \\
\text { Diabetes subgroup } \\
(\mathrm{N}=1,280) \\
\text { ESRD subgroup } \\
(\mathrm{N}=97) \\
\text { IVD subgroup } \\
(\mathrm{N}=1,508)\end{array}$ & $\begin{array}{l}\text { RCT } \\
\text { (RoB: some } \\
\text { concerns) }\end{array}$ & $\begin{array}{l}\text { Medicare } \\
\text { costs of } \\
\$ 5,000 \text { or } \\
\text { more in past } 1 \\
\text { year }\end{array}$ & $\begin{array}{l}\text { CKD diagnosis } \\
\text { as evidence by } \\
\text { at least one } \\
\text { claim, HCC > } 1.7 \\
\text { (high risk for } \\
\text { future healthcare } \\
\text { utilization), } \\
\text { excluded ESRD } \\
\text { patients }\end{array}$ & $\begin{array}{l}\text { Medicare FFS } \\
\text { beneficiary with } \\
\text { primary } \\
\text { residence in } \\
\text { the intervention } \\
\text { county/region, } \\
\text { excluded } \\
\text { patients } \\
\text { institutionalized } \\
\text { from March to } \\
\text { May } 2006 \text { (part } \\
\text { of the baseline } \\
\text { period) }\end{array}$ & NR \\
\hline
\end{tabular}




\begin{tabular}{|c|c|c|c|c|c|c|}
\hline $\begin{array}{l}\text { First Author, } \\
\text { Year, Site(s) }\end{array}$ & Sample Size & $\begin{array}{l}\text { Study Design } \\
\text { (Risk of Bias } \\
\text { Assessment) }\end{array}$ & $\begin{array}{l}\text { Patient } \\
\text { Selection: } \\
\text { High } \\
\text { Healthcare } \\
\text { Use or Cost; } \\
\text { Time Period }\end{array}$ & $\begin{array}{l}\text { Patient } \\
\text { Selection: } \\
\text { Chronic } \\
\text { Conditions }\end{array}$ & $\begin{array}{l}\text { Patient } \\
\text { Selection: } \\
\text { Other }\end{array}$ & $\begin{array}{l}\text { Additional } \\
\text { Selected } \\
\text { Patient } \\
\text { Characteristics }\end{array}$ \\
\hline $\begin{array}{l}\text { Urato et al., } \\
2013^{82} \\
\text { Sites in NY } \\
\text { counties: } \\
\text { Nassau, } \\
\text { Suffolk, } \\
\text { Queens, } \\
\text { Kings, } \\
\text { Westchester, } \\
\text { Richmond, } \\
\text { Rockland, } \\
\text { and Bronx }\end{array}$ & $\begin{array}{l}\text { Original sample } \\
(\mathrm{N}=5,889) \\
\text { Intervention } \\
(\mathrm{N}=2,945) \\
\text { Comparison } \\
(\mathrm{N}=2,944) \\
\text { Diabetes subgroup } \\
(\mathrm{N}=2,284) \\
\text { CKD subgroup } \\
(\mathrm{N}=3,159) \\
\text { Intervention } \\
\text { IVD subgroup } \\
\text { ( } \mathrm{N}=2,030)\end{array}$ & $\begin{array}{l}\text { RCT } \\
\text { (RoB: some } \\
\text { concerns) }\end{array}$ & $\begin{array}{l}\text { Medicare } \\
\text { costs of } \\
\$ 5,000 \text { or } \\
\text { more for CKD } \\
\text { beneficiaries } \\
\text { and } \$ 12,000 \\
\text { or more for } \\
\text { ESRD } \\
\text { beneficiaries in } \\
\text { past } 1 \text { year }\end{array}$ & $\begin{array}{l}\text { Stage } 3 \text { CKD } \\
\text { diagnosis, as } \\
\text { evidence by at } \\
\text { least one claim }\end{array}$ & $\begin{array}{l}\text { Medicare FFS } \\
\text { beneficiaries } \\
\text { with primary } \\
\text { residence in } \\
\text { the intervention } \\
\text { county/region }\end{array}$ & $\begin{array}{l}\text { Mean HCC } \\
\text { score: } 2.65\end{array}$ \\
\hline $\begin{array}{l}\text { Urato et al., } \\
2013^{82} \\
\text { Sites in NY } \\
\text { counties: } \\
\text { Nassau, } \\
\text { Suffolk, } \\
\text { Queens, } \\
\text { Kings, } \\
\text { Westchester, } \\
\text { Richmond, } \\
\text { Rockland, } \\
\text { and Bronx }\end{array}$ & $\begin{array}{l}\text { Refresh sample } \\
(\mathrm{N}=4,467) \\
\text { Intervention } \\
(\mathrm{N}=2,234) \\
\text { Comparison } \\
(\mathrm{N}=2,233) \\
\text { Diabetes subgroup } \\
(\mathrm{N}=2,202) \\
\mathrm{CKD} \text { subgroup } \\
(\mathrm{N}=1,663) \\
\mathrm{IVD} \text { subgroup } \\
(\mathrm{N}=2,061)\end{array}$ & $\begin{array}{l}\text { RCT } \\
\text { (RoB: some } \\
\text { concerns) }\end{array}$ & $\begin{array}{l}\text { Medicare } \\
\text { costs of } \\
\$ 5,000 \text { or } \\
\text { more for CKD } \\
\text { beneficiaries } \\
\text { and } \$ 12,000 \\
\text { or more for } \\
\text { ESRD } \\
\text { beneficiaries in } \\
\text { past } 1 \text { year }\end{array}$ & $\begin{array}{l}\text { Stage } 3 \text { CKD } \\
\text { diagnosis, as } \\
\text { evidence by at } \\
\text { least one claim }\end{array}$ & $\begin{array}{l}\text { Medicare FFS } \\
\text { beneficiaries } \\
\text { with primary } \\
\text { residence in } \\
\text { the intervention } \\
\text { county/region }\end{array}$ & NR \\
\hline $\begin{array}{l}\text { Dally et al., } \\
2002^{90} \\
\mathrm{OH}\end{array}$ & $\begin{array}{l}(\mathrm{N}=593) \\
\text { Intervention } \\
(\mathrm{N}=297) \\
\text { Comparison } \\
(\mathrm{N}=296)\end{array}$ & $\begin{array}{l}\text { RCT } \\
\text { (RoB: some } \\
\text { concerns) }\end{array}$ & $\begin{array}{l}11+\text { outpatient } \\
\text { visits in } 2 \\
\text { years }\end{array}$ & $\begin{array}{l}\text { 1+ visit with a } \\
\text { diagnosis of at } \\
\text { least } 1 \text { of } 3 \\
\text { targeted } \\
\text { conditions } \\
\text { (arthritis, } \\
\text { hypertension, } \\
\text { diabetes) }\end{array}$ & $\begin{array}{l}\text { Age: } 18-64 ; \\
\text { Kaiser } \\
\text { Permanente } \\
\text { Ohio patient }\end{array}$ & \\
\hline $\begin{array}{l}\text { McCall et al., } \\
2011^{80} \\
\text { Central OR } \\
\text { and central } \\
\text { WA: } 2 \text { large } \\
\text { multispecialty } \\
\text { group } \\
\text { practices }\end{array}$ & $\begin{array}{l}\text { Original } \mathrm{HNHC} \\
\text { patient sample } \\
(\mathrm{N}=125) \\
\text { Intervention } \\
(\mathrm{N}=66) \\
\text { Comparison } \\
(\mathrm{N}=59)\end{array}$ & $\begin{array}{l}\text { RCT } \\
\text { (RoB: some } \\
\text { concerns) }\end{array}$ & $\begin{array}{l}\text { Medicare } \\
\text { costs of } \\
\$ 6,000 \text { or } \\
\text { more in } 1 \text { year }\end{array}$ & $\begin{array}{l}\text { HF, diabetes, or } \\
\text { COPD diagnosis } \\
\text { on at least } 1 \\
\text { claim }\end{array}$ & $\begin{array}{l}\text { Medicare FFS } \\
\text { beneficiaries; } \\
2+\text { visits to the } \\
\text { HBC medical } \\
\text { practices }\end{array}$ & NR \\
\hline
\end{tabular}




\begin{tabular}{|c|c|c|c|c|c|c|}
\hline $\begin{array}{l}\text { First Author, } \\
\text { Year, Site(s) }\end{array}$ & Sample Size & $\begin{array}{l}\text { Study Design } \\
\text { (Risk of Bias } \\
\text { Assessment) }\end{array}$ & $\begin{array}{l}\text { Patient } \\
\text { Selection: } \\
\text { High } \\
\text { Healthcare } \\
\text { Use or Cost; } \\
\text { Time Period }\end{array}$ & $\begin{array}{l}\text { Patient } \\
\text { Selection: } \\
\text { Chronic } \\
\text { Conditions }\end{array}$ & $\begin{array}{l}\text { Patient } \\
\text { Selection: } \\
\text { Other }\end{array}$ & $\begin{array}{l}\text { Additional } \\
\text { Selected } \\
\text { Patient } \\
\text { Characteristics }\end{array}$ \\
\hline $\begin{array}{l}\text { McCall et al., } \\
2011^{80} \\
\text { Central OR } \\
\text { and central } \\
\text { WA: } 2 \text { large } \\
\text { multispecialty } \\
\text { group } \\
\text { practices }\end{array}$ & $\begin{array}{l}\text { Refresh HNHC } \\
\text { patient sample } \\
(\mathrm{N}=227) \\
\text { Intervention } \\
(\mathrm{N}=120) \\
\text { Comparison } \\
(\mathrm{N}=107)\end{array}$ & $\begin{array}{l}\text { RCT } \\
\text { (RoB: some } \\
\text { concerns) }\end{array}$ & $\begin{array}{l}\text { Medicare } \\
\text { costs of } \\
\$ 6,000 \text { or } \\
\text { more in } 1 \text { year }\end{array}$ & $\begin{array}{l}\text { HF, diabetes, or } \\
\text { COPD diagnosis } \\
\text { on inpatient, } \\
\text { outpatient } \\
\text { hospital, or } \\
\text { physician claims } \\
\text { only }\end{array}$ & $\begin{array}{l}\text { Medicare FFS } \\
\text { beneficiaries; } \\
2+\text { visits to the } \\
\text { HBC medical } \\
\text { practices }\end{array}$ & NR \\
\hline $\begin{array}{l}\text { Schickedanz } \\
\text { et al., 2019121 } \\
\text { Southern CA: } \\
1 \text { health } \\
\text { system } \\
\text { including } 13 \\
\text { medical } \\
\text { centers }\end{array}$ & $\begin{array}{l}\mathrm{N}=34,225) \\
\text { Intervention } \\
(\mathrm{N}=7,107) \\
\text { Comparison } \\
(\mathrm{N}=27,118)\end{array}$ & $\begin{array}{l}\text { Observational } \\
\text { (RoB: some } \\
\text { concerns) }\end{array}$ & $\begin{array}{l}\text { Predicted to } \\
\text { be in top } 1 \% \text { of } \\
\text { healthcare } \\
\text { utilization in } \\
\text { health system } \\
\text { in the next } 1 \\
\text { year }\end{array}$ & NA & $\begin{array}{l}\text { Age: 18+; } \\
\text { Kaiser } \\
\text { Permanente } \\
\text { Southern } \\
\text { California } \\
\text { patient }\end{array}$ & $\begin{array}{l}\text { Nonwhite: } 50 \% \\
\text { Cancer: } 46 \% \\
\text { Diabetes: } 13 \% \\
\text { CAD/CHF: } 33 \% \\
\text { Asthma: } 6 \% \\
\text { Charlson } \\
\text { Comorbidity } \\
\text { score: } 7 \text { (3) } \\
\text { Depression: } 6 \% \\
\text { Lives in low- } \\
\text { income census } \\
\text { tract: } 14 \% ; \\
\text { Medicare: } 60 \% \text {; } \\
\text { Commercial } \\
\text { insurance: } 25 \%\end{array}$ \\
\hline
\end{tabular}

$\mathrm{CA}=$ California $; \mathrm{CAD}=$ coronary artery disease $\mathrm{CHF}=$ congestive heart failure; $\mathrm{CKD}=$ chronic kidney disease $; \mathrm{COPD}=$ chronic obstructive pulmonary disease; $\mathrm{ESRD}=$ end-stage renal disease; $\mathrm{FFS}=$ fee-for-service; $\mathrm{HF}=$ heart failure; $\mathrm{HBC}=\mathrm{Health}$ Buddy Consortium; HCC $=$ hierarchical condition category; HNHC = high-need, high-cost; IVD = ischemic vascular disease; $\mathrm{N}$ $=$ number; $\mathrm{NA}=$ not applicable; $\mathrm{NR}=$ not reported; $\mathrm{NY}=\mathrm{New}$ York; $\mathrm{OH}=$ Ohio; $\mathrm{OR}=$ Oregon; $\mathrm{PCP}=$ primary care practice; $\mathrm{RCT}=$ randomized controlled trial; $\mathrm{RoB}=$ risk of bias; $\mathrm{TX}=$ Texas; $\mathrm{U}=$ University; $\mathrm{WA}=$ Washington. 
Table B-24. Intervention characteristics for telephonic/mail models

\begin{tabular}{|c|c|c|c|c|c|c|c|c|c|}
\hline $\begin{array}{l}\text { First Author, } \\
\text { Year, Site(s) }\end{array}$ & $\begin{array}{l}\text { Intervention: } \\
\text { Brief } \\
\text { Description }\end{array}$ & $\begin{array}{l}\text { Intervention } \\
\text { Duration }\end{array}$ & $\begin{array}{l}\text { Assessment, } \\
\text { Education, Skills, } \\
\text { Monitoring }\end{array}$ & $\begin{array}{l}\text { Coordination } \\
\text { and } \\
\text { Continuity of } \\
\text { Care }\end{array}$ & $\begin{array}{l}\text { Referral } \\
\text { to/Linkages to } \\
\text { Community- } \\
\text { Based Support } \\
\text { Services }\end{array}$ & Providers & $\begin{array}{l}\text { Mode of } \\
\text { Delivery } \\
\text { Setting(s) }\end{array}$ & Intensity & Comparison \\
\hline $\begin{array}{l}\text { McCall et al., } \\
2010^{79} \\
48 \text { counties } \\
\text { in western } \\
\text { TX }\end{array}$ & $\begin{array}{l}\text { TX Senior Trails } \\
\text { Program: Care } \\
\text { Management for } \\
\text { High-Cost } \\
\text { Beneficiaries } \\
\text { Demonstration: } \\
\text { TX Tech } \\
\text { University Health } \\
\text { Sciences Center } \\
\text { Shared savings } \\
\text { and care } \\
\text { management }\end{array}$ & $\begin{array}{l}\text { NR; up to } 16 \\
\text { months }\end{array}$ & $\begin{array}{l}\text { Patient education } \\
\text { and coaching of } \\
\text { chronic conditions } \\
\text { and self- } \\
\text { management skills }\end{array}$ & $\begin{array}{l}\text { Facilitate } \\
\text { communication } \\
\text { with providers, } \\
\text { care plan } \\
\text { compliance, } \\
\text { hospital } \\
\text { discharge } \\
\text { planning, } \\
\text { medication } \\
\text { adherence, } \\
\text { access to } \\
\text { clinics; sharing } \\
\text { information } \\
\text { with physicians }\end{array}$ & $\begin{array}{l}\text { Care team drew } \\
\text { on community } \\
\text { resources to assist } \\
\text { with social issues }\end{array}$ & $\begin{array}{l}\text { Nurse care } \\
\text { managers, nurses } \\
\text { for telephone } \\
\text { support, social } \\
\text { workers }\end{array}$ & $\begin{array}{l}\text { Telephone, } \\
\text { face-to-face, } \\
\text { written: in } \\
\text { patient } \\
\text { homes, } \\
\text { physician } \\
\text { offices, or in } \\
\text { the hospital, } \\
\text { as needed }\end{array}$ & $\begin{array}{l}\text { Mean contacts per } \\
\text { beneficiary: } 6 \\
\text { (median: } 4 \text { ) } \\
97 \% \text { of } \\
\text { participants had } \\
1+\text { contacts with a } \\
\text { care manager or } \\
\text { physician, } 50 \% \\
\text { had } 2-4 \text { contacts, } \\
\text { and } 25 \% \text { had } 5-9 \\
\text { contacts. } \\
\text { Written contact } \\
\text { was most frequent, } \\
\text { face-to-face was } \\
\text { least frequent } \\
\text { (20\% had face-to- } \\
\text { face contact with } \\
\text { the care manager) }\end{array}$ & $\begin{array}{l}\text { Usual care: } \\
\text { comparison } \\
\text { group was } \\
\text { not contacted }\end{array}$ \\
\hline
\end{tabular}




\begin{tabular}{|c|c|c|c|c|c|c|c|c|c|}
\hline $\begin{array}{l}\text { First Author, } \\
\text { Year, Site(s) }\end{array}$ & $\begin{array}{l}\text { Intervention: } \\
\text { Brief } \\
\text { Description }\end{array}$ & $\begin{array}{l}\text { Intervention } \\
\text { Duration }\end{array}$ & $\begin{array}{l}\text { Assessment, } \\
\text { Education, Skills, } \\
\text { Monitoring }\end{array}$ & $\begin{array}{l}\text { Coordination } \\
\text { and } \\
\text { Continuity of } \\
\text { Care }\end{array}$ & $\begin{array}{l}\text { Referral } \\
\text { to/Linkages to } \\
\text { Community- } \\
\text { Based Support } \\
\text { Services }\end{array}$ & Providers & $\begin{array}{l}\text { Mode of } \\
\text { Delivery } \\
\text { Setting(s) }\end{array}$ & Intensity & Comparison \\
\hline $\begin{array}{l}\text { McCall et al., } \\
2010^{81} \\
\text { Suffolk, } \\
\text { Nassau, and } \\
\text { Queens, NY: } \\
6 \text { nephrology } \\
\text { practices }\end{array}$ & $\begin{array}{l}\text { Care } \\
\text { Management for } \\
\text { High-Cost } \\
\text { Beneficiaries } \\
\text { Demonstration: } \\
\text { VillageHealth I } \\
\\
\text { Shared savings } \\
\text { and one-on-one } \\
\text { nurse care } \\
\text { manager support }\end{array}$ & $\begin{array}{l}\text { Up to } 36 \\
\text { months for } \\
\text { original } \\
\text { sample, up to } \\
24 \text { months } \\
\text { for refresh } \\
\text { sample }\end{array}$ & $\begin{array}{l}\text { Initial and } \\
\text { continuous risk } \\
\text { evaluation, } \\
\text { telemonitor health } \\
\text { failure patients, } \\
\text { 24-hour hotline for } \\
\text { assistance } \\
\text { requests, develop } \\
\text { care plan, renal } \\
\text { disease education }\end{array}$ & $\begin{array}{l}\text { Coordinated } \\
\text { care, referral to } \\
\text { nephrologist } \\
\text { when reach } \\
\text { stage IV CKD, } \\
\text { support from } \\
\text { pharmacist, } \\
\text { medication } \\
\text { therapy } \\
\text { management }\end{array}$ & NR & $\begin{array}{l}\text { Care managers } \\
\text { (phone and field } \\
\text { RNs), } \\
\text { pharmacists, } \\
\text { dietitians: } \\
\text { telephone support } \\
\text { and education } \\
\text { materials; social } \\
\text { workers: } \\
\text { telephone } \\
\text { psychosocial } \\
\text { support (e.g., } \\
\text { insurance, } \\
\text { transportation); } \\
\text { health service } \\
\text { assistants } \\
\text { provided admin } \\
\text { support for } \\
\text { patients and } \\
\text { providers }\end{array}$ & $\begin{array}{l}\text { Telephone, } \\
\text { face-to-face: } \\
\text { NR }\end{array}$ & $\begin{array}{l}\text { On average, } \\
\text { participants were } \\
\text { contacted about } \\
\text { every } 1.4 \text { months } \\
\text { or had } 13 \text { contacts } \\
\text { over } 18 \text { months. } \\
\text { Nearly all had a } \\
\text { telephone or in- } \\
\text { person contact } \\
\text { during the last } 18 \\
\text { months, mostly by } \\
\text { telephone }\end{array}$ & $\begin{array}{l}\text { Usual care: } \\
\text { comparison } \\
\text { group was } \\
\text { not contacted }\end{array}$ \\
\hline
\end{tabular}




\begin{tabular}{|c|c|c|c|c|c|c|c|c|c|}
\hline $\begin{array}{l}\text { First Author, } \\
\text { Year, Site(s) }\end{array}$ & $\begin{array}{l}\text { Intervention: } \\
\text { Brief } \\
\text { Description }\end{array}$ & $\begin{array}{l}\text { Intervention } \\
\text { Duration }\end{array}$ & $\begin{array}{l}\text { Assessment, } \\
\text { Education, Skills, } \\
\text { Monitoring }\end{array}$ & $\begin{array}{l}\text { Coordination } \\
\text { and } \\
\text { Continuity of } \\
\text { Care }\end{array}$ & $\begin{array}{l}\text { Referral } \\
\text { to/Linkages to } \\
\text { Community- } \\
\text { Based Support } \\
\text { Services }\end{array}$ & Providers & $\begin{array}{l}\text { Mode of } \\
\text { Delivery } \\
\text { Setting(s) }\end{array}$ & Intensity & Comparison \\
\hline $\begin{array}{l}\text { Urato et al., } \\
2013^{82} \\
\text { Sites in NY } \\
\text { counties: } \\
\text { Nassau, } \\
\text { Suffolk, } \\
\text { Queens, } \\
\text { Kings, } \\
\text { Westchester, } \\
\text { Richmond, } \\
\text { Rockland, } \\
\text { and Bronx }\end{array}$ & $\begin{array}{l}\text { Extended } \\
\text { Medicare Care } \\
\text { Management for } \\
\text { High Cost } \\
\text { Beneficiaries } \\
\text { (CMHCB) } \\
\text { Demonstration: } \\
\text { VillageHealth II } \\
\text { Shared savings } \\
\text { and disease } \\
\text { management/ } \\
\text { case } \\
\text { management } \\
\text { through a care } \\
\text { management } \\
\text { organization }\end{array}$ & $\begin{array}{l}\text { Up to } 21 \\
\text { months for } \\
\text { original } \\
\text { sample, up to } \\
11 \text { months } \\
\text { for refresh } \\
\text { sample }\end{array}$ & $\begin{array}{l}\text { Provided } \\
\text { individualized } \\
\text { assessment, } \\
\text { including risk } \\
\text { stratification, and } \\
\text { tailored care plans; } \\
\text { education related } \\
\text { to self- } \\
\text { management } \\
\text { activities to } \\
\text { decrease risk for } \\
\text { acute } \\
\text { exacerbations of } \\
\text { chronic diseases }\end{array}$ & $\begin{array}{l}\text { Facilitated } \\
\text { patient } \\
\text { relationships } \\
\text { with } \\
\text { physicians, } \\
\text { helped patients } \\
\text { comply with } \\
\text { physician care } \\
\text { plans, hospital } \\
\text { discharge } \\
\text { planning } \\
\text { support, } \\
\text { medication } \\
\text { management }\end{array}$ & $\begin{array}{l}\text { Referrals or } \\
\text { provision for } \\
\text { ancillary services } \\
\text { (drugs, community } \\
\text { services) }\end{array}$ & $\begin{array}{l}\text { Nurse care } \\
\text { managers, nurses } \\
\text { for telephone } \\
\text { support, registered } \\
\text { dietitian, } \\
\text { pharmacist, social } \\
\text { worker }\end{array}$ & $\begin{array}{l}\text { Face-to-face } \\
\text { or telephone } \\
\text { contact with } \\
\text { nurse care } \\
\text { manager, in- } \\
\text { person } \\
\text { educational } \\
\text { classes: in- } \\
\text { patient home } \\
\text { or over } \\
\text { telephone } \\
\text { - CKD } \\
\text { patients } \\
\text { provided } \\
\text { telephone } \\
\text { support } \\
\text { only } \\
\text { - ESRD } \\
\text { patients } \\
\text { provided } \\
\text { phone or } \\
\text { in- person } \\
\text { support }\end{array}$ & $\begin{array}{l}\text { At least monthly } \\
\text { contact with care } \\
\text { manager; }>50 \% \text { of } \\
\text { beneficiaries did } \\
\text { not get a call or in- } \\
\text { person meeting } \\
\text { with a care } \\
\text { manager in the } \\
\text { last } 15 \text { months } \\
\\
\text { Telephonic contact } \\
\text { was the dominant } \\
\text { form of contact } \\
\text { (about } 70 \% \text { ) }\end{array}$ & $\begin{array}{l}\text { Usual care: } \\
\text { comparison } \\
\text { group was } \\
\text { not contacted } \\
\end{array}$ \\
\hline
\end{tabular}




\begin{tabular}{|c|c|c|c|c|c|c|c|c|c|}
\hline $\begin{array}{l}\text { First Author, } \\
\text { Year, Site(s) }\end{array}$ & $\begin{array}{l}\text { Intervention: } \\
\text { Brief } \\
\text { Description }\end{array}$ & $\begin{array}{l}\text { Intervention } \\
\text { Duration }\end{array}$ & $\begin{array}{l}\text { Assessment, } \\
\text { Education, Skills, } \\
\text { Monitoring }\end{array}$ & $\begin{array}{l}\text { Coordination } \\
\text { and } \\
\text { Continuity of } \\
\text { Care }\end{array}$ & $\begin{array}{l}\text { Referral } \\
\text { to/Linkages to } \\
\text { Community- } \\
\text { Based Support } \\
\text { Services }\end{array}$ & Providers & $\begin{array}{l}\text { Mode of } \\
\text { Delivery } \\
\text { Setting(s) }\end{array}$ & Intensity & Comparison \\
\hline $\begin{array}{l}\text { Dally et al., } \\
2002^{90} \\
\mathrm{OH}\end{array}$ & $\begin{array}{l}\text { Mailed health } \\
\text { promotion } \\
\text { program }\end{array}$ & $\begin{array}{l}90 \% \\
\text { remained } \\
\text { enrolled for } \\
30 \text { months }\end{array}$ & $\begin{array}{l}\text { Health risk } \\
\text { appraisal (HRA) } \\
\text { questionnaire, } \\
\text { personalized letter } \\
\text { and report with } \\
\text { feedback after } \\
\text { each questionnaire } \\
\text { with } \\
\text { recommendations } \\
\text { to reduce the } \\
\text { health risks } \\
\text { identified by the } \\
\text { questionnaire, and } \\
\text { condition-specific } \\
\text { health education } \\
\text { pamphlets and } \\
\text { books }\end{array}$ & $\overline{N R}$ & NR & $\begin{array}{l}\text { A vendor provided } \\
\text { all intervention- } \\
\text { related materials }\end{array}$ & $\begin{array}{l}\text { All materials } \\
\text { were mailed } \\
\text { to } \\
\text { participants' } \\
\text { homes }\end{array}$ & $\begin{array}{l}\text { After initial HRA } \\
\text { questionnaire, } 3 \\
\text { additional HRA } \\
\text { questionnaires and } \\
\text { individualized } \\
\text { feedback } \\
\text { letters/reports } \\
\text { were delivered } \\
\text { approximately } \\
\text { every } 3 \text { months }\end{array}$ & $\begin{array}{l}\text { Controls also } \\
\text { received and } \\
\text { completed } \\
\text { the baseline } \\
\text { HRAs, } \\
\text { education } \\
\text { materials, } \\
\text { and an } \\
\text { incentive to } \\
\text { complete the } \\
\text { final } \\
\text { questionnaire }\end{array}$ \\
\hline $\begin{array}{l}\text { McCall et al., } \\
2011^{80} \\
\text { Central OR } \\
\text { and central } \\
\text { WA: } 2 \text { large } \\
\text { multispecialty } \\
\text { group } \\
\text { practices }\end{array}$ & $\begin{array}{l}\text { Care } \\
\text { Management for } \\
\text { High-Cost } \\
\text { Beneficiaries } \\
\text { Demonstration: } \\
\text { Health Buddy } \\
\text { Consortium } \\
\text { Shared savings } \\
\text { and Health } \\
\text { Buddy® disease } \\
\text { management } \\
\text { (Health Buddy® } \\
\text { device allowed } \\
\text { for daily, routine } \\
\text { communication } \\
\text { with program } \\
\text { staff) }\end{array}$ & $\begin{array}{l}\text { Up to } 38 \\
\text { months for } \\
\text { original } \\
\text { population, } \\
\text { up to } 26 \\
\text { months for } \\
\text { refresh } \\
\text { population }\end{array}$ & $\begin{array}{l}\text { Daily Health } \\
\text { Buddy } \\
\text { questionnaire to } \\
\text { assess health } \\
\text { condition, followup } \\
\text { from nurse CM as } \\
\text { appropriate }\end{array}$ & $\begin{array}{l}13 \text { disease- } \\
\text { specific care } \\
\text { management } \\
\text { programs; } \\
\text { triaged and } \\
\text { coordinated } \\
\text { medical, } \\
\text { psychological, } \\
\text { or social } \\
\text { services }\end{array}$ & $\begin{array}{l}\text { Coordinated social } \\
\text { services, as } \\
\text { needed }\end{array}$ & $\begin{array}{l}\text { Nurse care } \\
\text { managers, } \\
\text { physicians }\end{array}$ & $\begin{array}{l}\text { Telephone, } \\
\text { over Health } \\
\text { Buddy device }\end{array}$ & $\begin{array}{l}\text { Nearly all } \\
\text { intervention group } \\
\text { members who } \\
\text { used the device } \\
\text { received at least } \\
\text { one call from a } \\
\text { care manager } \\
\text { during the demo } \\
\text { and nearly } 60 \% \\
\text { received }>20 \\
\text { contacts during } \\
\text { this same period. } \\
\text { Over } 60 \% \text { of } \\
\text { participants never } \\
\text { had a device and } \\
\text { scheduled regular } \\
\text { telephone calls } \\
\text { with a nurse care } \\
\text { manager }\end{array}$ & $\begin{array}{l}\text { Usual care: } \\
\text { comparison } \\
\text { group was } \\
\text { not contacted }\end{array}$ \\
\hline
\end{tabular}




\begin{tabular}{|c|c|c|c|c|c|c|c|c|c|}
\hline $\begin{array}{l}\text { First Author, } \\
\text { Year, Site(s) }\end{array}$ & $\begin{array}{l}\text { Intervention: } \\
\text { Brief } \\
\text { Description }\end{array}$ & $\begin{array}{l}\text { Intervention } \\
\text { Duration }\end{array}$ & $\begin{array}{l}\text { Assessment, } \\
\text { Education, Skills, } \\
\text { Monitoring }\end{array}$ & $\begin{array}{l}\text { Coordination } \\
\text { and } \\
\text { Continuity of } \\
\text { Care }\end{array}$ & $\begin{array}{l}\text { Referral } \\
\text { to/Linkages to } \\
\text { Community- } \\
\text { Based Support } \\
\text { Services }\end{array}$ & Providers & $\begin{array}{l}\text { Mode of } \\
\text { Delivery } \\
\text { Setting(s) }\end{array}$ & Intensity & Comparison \\
\hline $\begin{array}{l}\text { Schickedanz } \\
\text { et al., } 2019^{121} \\
\text { Southern CA: } \\
1 \text { health } \\
\text { system } \\
\text { including } 13 \\
\text { medical } \\
\text { centers }\end{array}$ & $\begin{array}{l}\text { Health Leads } \\
\text { Program: social } \\
\text { needs screening } \\
\text { and navigation } \\
\text { intervention }\end{array}$ & $\begin{array}{l}\text { NR; up to } 14 \\
\text { months } \\
\text { (followup } \\
\text { time) }\end{array}$ & $\begin{array}{l}\text { Social needs } \\
\text { screener, intake } \\
\text { assessment }\end{array}$ & NR & $\begin{array}{l}\text { Tailored referral to } \\
\text { community-based } \\
\text { services (i.e., food } \\
\text { banks, housing } \\
\text { programs, or other } \\
\text { resources to } \\
\text { address the } \\
\text { identified social } \\
\text { need) immediately } \\
\text { or during followup } \\
\text { calls }\end{array}$ & $\begin{array}{l}\text { Program } \\
\text { associates } \\
\text { provided screening } \\
\text { and navigation }\end{array}$ & Telephone & $\begin{array}{l}\text { Followup calls at } \\
\text { minimum every } 2 \\
\text { weeks until call } \\
\text { were no longer } \\
\text { needed or loss to } \\
\text { followup }\end{array}$ & Usual care \\
\hline
\end{tabular}

$\mathrm{CA}=$ California; $\mathrm{CKD}=$ chronic kidney disease; $\mathrm{CM}=$ case manager; $\mathrm{CMHCB}=$ Care Management for High Cost Beneficiaries; $\mathrm{ESRD}=$ end-stage renal disease; $\mathrm{HRA}=$ health risk appraisal; $\mathrm{NR}=$ not reported; $\mathrm{NY}=\mathrm{New}$ York; $\mathrm{OH}=\mathrm{Ohio} ; \mathrm{OR}=$ Oregon; $\mathrm{RN}=$ registered nurse; $\mathrm{TX}=$ Texas; $\mathrm{WA}=$ Washington. 
Table B-25. Healthcare utilization outcomes for telephonic/mail model studies

\begin{tabular}{|c|c|c|c|c|}
\hline Utilization Measures & Study Design & $\begin{array}{l}\text { Direction of } \\
\text { Change in } \\
\text { Intervention } \\
\text { Group (G1) }\end{array}$ & $\begin{array}{l}\text { Direction of } \\
\text { Change in } \\
\text { Comparison } \\
\text { Group (G2) }\end{array}$ & Difference \\
\hline \multirow[t]{4}{*}{$\begin{array}{l}\text { Inpatient admissions, all } \\
\text { cause }\end{array}$} & RCT & $\widehat{\vartheta}$ & 仓 & $\begin{array}{l}\text { Original sample DiD: IRR=0.94 (95\% } \\
\mathrm{Cl}, 0.82 \text { to } 1.07)^{81}\end{array}$ \\
\hline & $\overline{\mathrm{RCT}}$ & 仓 & 仓 & $\begin{array}{l}\text { Refresh sample DiD: IRR=0.96 }(95 \% \\
\mathrm{Cl}, 0.80 \text { to } 1.15)^{81}\end{array}$ \\
\hline & $\overline{\mathrm{RCT}}$ & 仓 & 仓 & $\begin{array}{l}\text { Original sample DiD: IRR=1.06 (95\% } \\
\mathrm{Cl}, 0.95 \text { to } 1.19)^{82}\end{array}$ \\
\hline & $\overline{\mathrm{RCT}}$ & 及 & 马 & $\begin{array}{l}\text { Refresh sample DiD: IRR=0.98 (95\% } \\
\mathrm{Cl}, 0.86 \text { to } 1.11)^{82}\end{array}$ \\
\hline \multirow[t]{4}{*}{ Inpatient admissions, ACSC } & RCT & $\widehat{\bigcup}$ & 仓 & $\begin{array}{l}\text { Original sample DiD: IRR=1.05 (95\% } \\
\mathrm{Cl}, 0.87 \text { to } 1.28)^{82}\end{array}$ \\
\hline & $\overline{\mathrm{RCT}}$ & $\widehat{\bigcup}$ & Љ & $\begin{array}{l}\text { Refresh sample DiD: IRR=0.98 }(95 \% \\
\mathrm{Cl}, 0.80 \text { to } 1.20)^{82}\end{array}$ \\
\hline & $\overline{\mathrm{RCT}}$ & $\widehat{1}$ & 仓 & $\begin{array}{l}\text { Original sample DiD: IRR=0.83 (95\% } \\
\mathrm{Cl}, 0.67 \text { to } 1.04)^{81}\end{array}$ \\
\hline & $\overline{\mathrm{RCT}}$ & 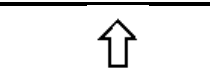 & $\widehat{\vartheta}$ & $\begin{array}{l}\text { Refresh sample DiD: IRR=1.02 (95\% } \\
\mathrm{Cl}, 0.77 \text { to } 1.36)^{81}\end{array}$ \\
\hline \multirow[t]{2}{*}{$\begin{array}{l}\text { Inpatient admissions, any } \\
(\%)\end{array}$} & RCT & $\widehat{S}$ & $\widehat{\vartheta}$ & $\begin{array}{l}\text { Original sample DiD: OR=0.98 (95\% } \\
\mathrm{Cl}, 0.82 \text { to } 1.18)^{81}\end{array}$ \\
\hline & $\overline{\mathrm{RCT}}$ & П & -- & $\begin{array}{l}\text { Refresh sample DiD: OR=0.94 (95\% } \\
\mathrm{Cl}, 0.74 \text { to } 1.18)^{81}\end{array}$ \\
\hline \multirow[t]{2}{*}{$\begin{array}{l}\text { Inpatient Admissions, ACSC } \\
(\%)\end{array}$} & RCT & 4 & 仓 & $\begin{array}{l}\text { Original sample DiD: OR=0.86 (95\% } \\
\mathrm{Cl}, 0.69 \text { to } 1.08)^{81}\end{array}$ \\
\hline & $\overline{\mathrm{RCT}}$ & 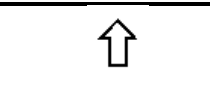 & $\widehat{\vartheta}$ & $\begin{array}{l}\text { Refresh sample DiD: OR=0.93 (95\% } \\
\mathrm{Cl}, 0.70 \text { to } 1.25)^{81}\end{array}$ \\
\hline \multirow[t]{4}{*}{ ED visits, all cause } & $\mathrm{RCT}$ & $\widehat{S}$ & $\widehat{ن}$ & $\begin{array}{l}\text { Original sample DiD: IRR=1.04 (95\% } \\
\mathrm{Cl}, 0.91 \text { to } 1.19)^{81}\end{array}$ \\
\hline & $\overline{\mathrm{RCT}}$ & 仓 & $\widehat{\vartheta}$ & $\begin{array}{l}\text { Refresh sample DiD: IRR=1.01 (95\% } \\
\mathrm{Cl}, 0.82 \text { to } 1.24)^{81}\end{array}$ \\
\hline & $\overline{\mathrm{RCT}}$ & $\widehat{\bigcup}$ & $\widehat{\vartheta}$ & $\begin{array}{l}\text { Original sample DiD: IRR=1.03 (95\% } \\
\mathrm{Cl}, 0.90 \text { to } 1.17)^{82}\end{array}$ \\
\hline & $\overline{\mathrm{RCT}}$ & $\widehat{\vartheta}$ & $\widehat{仓}$ & $\begin{array}{l}\text { Refresh sample DiD: IRR=0.97 (95\% } \\
\mathrm{Cl}, 0.85 \text { to } 1.10)^{82}\end{array}$ \\
\hline \multirow[t]{4}{*}{ ED visits, ACSC } & RCT & 个 & 仓 & $\begin{array}{l}\text { Original sample DiD: IRR=1.09 (95\% } \\
\mathrm{Cl}, 0.90 \text { to } 1.33)^{82}\end{array}$ \\
\hline & $\overline{\mathrm{RCT}}$ & $\Omega$ & Љ & $\begin{array}{l}\text { Refresh sample DiD: IRR=1.00 (95\% } \\
\mathrm{Cl}, 0.81 \text { to } 1.23)^{82}\end{array}$ \\
\hline & $\overline{\mathrm{RCT}}$ & 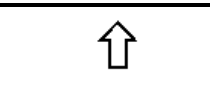 & 仓 & $\begin{array}{l}\text { Original sample DiD: IRR=0.87 (95\% } \\
\mathrm{Cl}, 0.71 \text { to } 1.08)^{81}\end{array}$ \\
\hline & $\overline{\mathrm{RCT}}$ & 仓 & $\widehat{\bigcup}$ & $\begin{array}{l}\text { Refresh sample DiD: IRR=1.07 (95\% } \\
\mathrm{Cl}, 0.79 \text { to } 1.45)^{81}\end{array}$ \\
\hline Outpatient visits at 6 months & RCT & NR & NR & $\begin{array}{l}\text { Total sample: Poisson coefficient } \\
=-0.0328(p=0.27)^{90}\end{array}$ \\
\hline $\begin{array}{l}\text { Outpatient visits at } 12 \\
\text { months }\end{array}$ & RCT & 仓 & 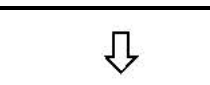 & $\begin{array}{l}\text { Total sample: Poisson coefficient } \\
=-0.0341(p=0.11)^{90}\end{array}$ \\
\hline
\end{tabular}




\begin{tabular}{lcccc}
\hline Utilization Measures & Study Design & $\begin{array}{l}\text { Direction of } \\
\text { Change in } \\
\text { Intervention } \\
\text { Group (G1) }\end{array}$ & $\begin{array}{l}\text { Direction of } \\
\text { Change in } \\
\text { Comparison } \\
\text { Group (G2) }\end{array}$ & Difference \\
\hline $\begin{array}{l}\text { Outpatient visits at 30 } \\
\text { months }\end{array}$ & RCT & NR & NR & $\begin{array}{l}\text { Total sample: Lower use in G1 than } \\
\text { G2: Poisson coefficient } \\
=-0.0260(p=0.04)^{90}\end{array}$ \\
\hline Total Utilization (\%) & Observational & NR & NR & $\begin{array}{l}\text { Total sample DiD: }:^{a}-2.2\left(95 \% \mathrm{Cl}^{-1}-4.5\right. \\
\text { to } 0.1)^{121}\end{array}$ \\
\hline
\end{tabular}

a Total utilization includes a count of all visits in emergency department, outpatient, and/or inpatient settings. The subgroups were based on the census tract estimates of patients' home address. The low-income subgroup included patients who lived in census tracts where a plurality of residents had income below $\$ 34,575$. The low-education subgroup included patients who lived in census tracts where a plurality of residents had less than a high school education.

$\hat{\mathrm{V}}=$ Increase in the outcome between the intervention period and the baseline period; the difference between the intervention and comparison groups was not statistically significant.

$\S=$ Reduction in the outcome between the intervention period and the baseline period; the difference between the intervention and comparison groups was not statistically significant.

$\mathrm{ACSC}=$ ambulatory care sensitive conditions; $\mathrm{CI}=$ confidence interval; $\mathrm{DiD}=$ difference-in-difference $\mathrm{ED}=$ emergency department; $\mathrm{G}$ = group; IRR = incidence rate ratio; $\mathrm{NR}=$ not reported; $\mathrm{OR}=$ odds ratio; $\mathrm{RCT}=$ randomized controlled trial. 
Table B-26. Healthcare utilization outcomes for telephonic/mail model studies: Subgroup outcomes

\begin{tabular}{|c|c|c|c|c|}
\hline Utilization Measures & Study Design & $\begin{array}{l}\text { Direction of } \\
\text { Change in } \\
\text { Intervention } \\
\text { Group (G1) }\end{array}$ & $\begin{array}{l}\text { Direction of } \\
\text { Change in } \\
\text { Comparison } \\
\text { Group (G2) }\end{array}$ & Difference \\
\hline \multirow[t]{3}{*}{$\begin{array}{l}\text { Outpatient visits at } 6 \\
\text { months }\end{array}$} & $\mathrm{RCT}$ & NR & NR & $\begin{array}{l}\text { Arthritis subgroup: Poisson coefficient= } \\
-0.0710(p=0.16)^{90}\end{array}$ \\
\hline & $\overline{\mathrm{RCT}}$ & NR & NR & $\begin{array}{l}\text { Blood pressure subgroup: Poisson } \\
\text { coefficient }=0.0838(p=0.15)^{90}\end{array}$ \\
\hline & $\overline{\mathrm{RCT}}$ & NR & NR & $\begin{array}{l}\text { Diabetes subgroup: Poisson coefficient= } \\
-0.0879(p=0.07)^{90}\end{array}$ \\
\hline \multirow[t]{3}{*}{$\begin{array}{l}\text { Outpatient visits at } 12 \\
\text { months }\end{array}$} & $\mathrm{RCT}$ & & & $\begin{array}{l}\text { Arthritis subgroup: Lower use in } \mathrm{G} 1 \text { than } \mathrm{G} 2 \text { : } \\
\text { Poisson coefficient } \\
=-0.1130(\mathrm{p}<0.01)^{90}\end{array}$ \\
\hline & $\overline{\mathrm{RCT}}$ & & & $\begin{array}{l}\text { Blood pressure subgroup: Higher use in } G 1 \\
\text { than } G 2 \text { : Poisson coefficient }=0.0938 \\
(p=0.02)^{90}\end{array}$ \\
\hline & $\overline{\mathrm{RCT}}$ & $几$ & & $\begin{array}{l}\text { Diabetes subgroup: Poisson coefficient= } \\
-0.0651(p=0.06)^{90}\end{array}$ \\
\hline \multirow[t]{3}{*}{$\begin{array}{l}\text { Outpatient visits at } 30 \\
\text { months }\end{array}$} & $\mathrm{RCT}$ & NR & NR & $\begin{array}{l}\text { Arthritis subgroup: Lower use in G1 than G2: } \\
\text { Poisson coefficient } \\
=-0.1004(p<0.01)^{90}\end{array}$ \\
\hline & $\mathrm{RCT}$ & NR & NR & $\begin{array}{l}\text { Blood pressure subgroup: Poisson } \\
\text { coefficient }=0.0317(p=0.21)^{90}\end{array}$ \\
\hline & $\overline{\mathrm{RCT}}$ & NR & NR & $\begin{array}{l}\text { Diabetes subgroup: Poisson coefficient= } \\
-0.0146(p=0.50)^{90}\end{array}$ \\
\hline \multirow[t]{3}{*}{ Total utilization (\%) } & Observational & NR & NR & $\begin{array}{l}\text { Low-income area subgroup } \mathrm{DiD}:^{\text {a }} \text { Greater } \\
\text { reduction in } \mathrm{G} 1:-7.0(95 \% \mathrm{Cl}-11.9 \text { to }-1.9)^{121}\end{array}$ \\
\hline & Observational & NR & NR & $\begin{array}{l}\text { Low-education area subgroup DiD: }{ }^{a} \text { Greater } \\
\text { reduction in } \mathrm{G} 1 \text { : } \\
-11.5(95 \% \mathrm{Cl},-17.6 \text { to }-5.0)^{121}\end{array}$ \\
\hline & Observational & NR & NR & $\begin{array}{l}\text { Medicaid insurance subgroup DiD: }{ }^{\mathrm{a}} \text { Greater } \\
\text { reduction in } \mathrm{G} 1 \text { : } \\
-12.1(95 \% \mathrm{Cl},-18.1 \text { to }-5.6)^{121}\end{array}$ \\
\hline
\end{tabular}

$=$ Increase in the outcome between the intervention period and the baseline period; the difference between the intervention and comparison groups was statistically significant.

- Reduction in the outcome between the intervention period and the baseline period; the difference between the intervention and comparison groups was statistically significant.

$仓=$ Increase in the outcome between the intervention period and the baseline period; the difference between the intervention and comparison groups was not statistically significant.

$\Omega=$ Reduction in the outcome between the intervention period and the baseline period; the difference between the intervention and comparison groups was not statistically significant.

$\mathrm{CI}=$ confidence interval; $\mathrm{DiD}=$ difference-in differences; $\mathrm{G}=$ group; $\mathrm{NR}=$ not reported; $\mathrm{RCT}=$ randomized controlled trial . 
Table B-27. Strength of evidence for telephonic/mail models versus usual-care outcomes ${ }^{a}$

\begin{tabular}{|c|c|c|c|c|c|}
\hline Population & Outcome & Results & $\begin{array}{l}\text { Study Design } \\
\text { and Sample } \\
\text { Size }\end{array}$ & $\begin{array}{l}\text { Strength of } \\
\text { Evidence } \\
\text { Domains }\end{array}$ & $\begin{array}{l}\text { Overall } \\
\text { Evidence } \\
\text { Strength } \\
\text { (Direction of } \\
\text { Effect) }\end{array}$ \\
\hline $\begin{array}{l}\mathrm{HNHC} \\
\text { patients }\end{array}$ & $\begin{array}{l}\text { ED visits, all } \\
\text { cause }\end{array}$ & $\begin{array}{l}\text { VH I: Original sample DiD: IRR=1.04 } \\
(95 \% \mathrm{Cl}, 0.91 \text { to } 1.19)^{81} \\
\text { VH I: Refresh sample DiD: IRR=1.01 } \\
(95 \% \mathrm{Cl}, 0.82 \text { to } 1.24)^{81} \\
\text { VH II: Original sample DiD: IRR=1.03 } \\
\text { (95\% Cl, } 0.90 \text { to } 1.17)^{82} \\
\text { VH II: Refresh sample DiD: IRR=0.97 } \\
(95 \% \mathrm{Cl}, 0.85 \text { to } 1.10)^{82} \\
\text { Pooled rate ratio: } 1.01(95 \% \mathrm{Cl}, 0.94 \text { to } \\
\text { 1.08); } 4 \text { RCT samples; }\left.\right|^{2}=0 \%\end{array}$ & $\begin{array}{l}4 \text { RCTs, } \\
\mathrm{N}=20,693\end{array}$ & $\begin{array}{l}\text { Moderate study } \\
\text { limitations, } \\
\text { inconsistent, } \\
\text { imprecise, direct }\end{array}$ & $\begin{array}{l}\text { Low (No } \\
\text { difference) }\end{array}$ \\
\hline $\begin{array}{l}\mathrm{HNHC} \\
\text { patients }\end{array}$ & $\begin{array}{l}\text { ED visits, } \\
\text { ACSC }\end{array}$ & $\begin{array}{l}\text { VH II: Original sample DiD: IRR=1.09 } \\
(95 \% \mathrm{Cl}, 0.90 \text { to } 1.33)^{82} \\
\text { VH II: Refresh sample DiD: IRR=1.00 } \\
(95 \% \mathrm{Cl}, 0.81 \text { to } 1.23)^{82} \\
\text { VH I: Original sample DiD: IRR=0.87 } \\
(95 \% \mathrm{Cl}, 0.71 \text { to } 1.08)^{81} \\
\text { VH II: Refresh sample DiD: IRR=1.07 } \\
(95 \% \mathrm{Cl}, 0.79 \text { to } 1.45)^{81} \\
\text { Pooled rate ratio: } 0.99(95 \% \mathrm{Cl}, 0.88 \text { to } \\
\text { 1.10); } 4 \text { RCT samples; }\left.\right|^{2}=0 \%\end{array}$ & $\begin{array}{l}4 \text { RCTs, } \\
\mathrm{N}=20,693\end{array}$ & $\begin{array}{l}\text { Moderate study } \\
\text { limitations, } \\
\text { inconsistent, } \\
\text { imprecise, direct }\end{array}$ & $\begin{array}{l}\text { Low (No } \\
\text { difference) }\end{array}$ \\
\hline $\begin{array}{l}\mathrm{HNHC} \\
\text { patients }\end{array}$ & $\begin{array}{l}\text { Inpatient } \\
\text { admissions, } \\
\text { all cause }\end{array}$ & $\begin{array}{l}\text { VH I: Original sample DiD: IRR=0.94 } \\
(95 \% \mathrm{Cl}, 0.82 \text { to } 1.07)^{81} \\
\text { VH I: Refresh sample DiD: IRR=0.96 } \\
(95 \% \mathrm{Cl}, 0.80 \text { to } 1.15)^{81} \\
\text { VH II: Original sample DiD: IRR=1.06 } \\
(95 \% \mathrm{CI}, 0.95 \text { to } 1.19)^{82} \\
\text { VH II: Refresh sample DiD: IRR=0.98 } \\
(95 \% \mathrm{Cl}, 0.86 \text { to } 1.11)^{82} \\
\text { Pooled rate ratio: } 0.99(95 \% \mathrm{Cl}, 0.92 \text { to } \\
\text { 1.06); } 4 \text { RCT samples; }\left.\right|^{2}=0 \%\end{array}$ & $\begin{array}{l}4 \text { RCTs, } \\
\mathrm{N}=20,693\end{array}$ & $\begin{array}{l}\text { Moderate study } \\
\text { limitations, } \\
\text { inconsistent, } \\
\text { imprecise, direct }\end{array}$ & $\begin{array}{l}\text { Low (No } \\
\text { difference) }\end{array}$ \\
\hline $\begin{array}{l}\mathrm{HNHC} \\
\text { patients }\end{array}$ & $\begin{array}{l}\text { Inpatient } \\
\text { admissions, } \\
\text { ACSC }\end{array}$ & $\begin{array}{l}\text { VH II: Original sample DiD: IRR=1.05 } \\
(95 \% \mathrm{Cl}, 0.87 \text { to } 1.28)^{82} \\
\text { VH II: Refresh sample DiD: IRR=0.98 } \\
(95 \% \mathrm{Cl}, 0.80 \text { to } 1.20)^{82} \\
\text { VH I: Original sample DiD: IRR=0.83 } \\
(95 \% \mathrm{Cl}, 0.67 \text { to } 1.04)^{81} \\
\text { VH I: Refresh sample DiD: IRR=1.02 } \\
(95 \% \mathrm{Cl}, 0.77 \text { to } 1.36)^{81} \\
\text { Pooled rate ratio: } 0.95(95 \% \mathrm{Cl}, 0.85 \text { to } \\
\text { 1.06); } 4 \text { RCT samples; }\left.\right|^{2}=0 \%\end{array}$ & $\begin{array}{l}4 \text { RCTs, } \\
N=20,693\end{array}$ & $\begin{array}{l}\text { Moderate study } \\
\text { limitations, } \\
\text { inconsistent, } \\
\text { imprecise, direct }\end{array}$ & $\begin{array}{l}\text { Low (No } \\
\text { difference) }\end{array}$ \\
\hline $\begin{array}{l}\mathrm{HNHC} \\
\text { patients }\end{array}$ & $\begin{array}{l}\text { Inpatient } \\
\text { admissions, } \\
\text { any }(\%)\end{array}$ & $\begin{array}{l}\text { VH I: Original sample DiD: OR=0.98 } \\
(95 \% \mathrm{Cl}, 0.82 \text { to } 1.18)^{81} \\
\text { VH I: Refresh sample DiD: OR=0.94 } \\
(95 \% \mathrm{Cl}, 0.74 \text { to } 1.18)^{81}\end{array}$ & $\begin{array}{l}2 \text { RCTs, } \\
\mathrm{N}=10,337\end{array}$ & $\begin{array}{l}\text { Moderate study } \\
\text { limitations, } \\
\text { consistent, } \\
\text { imprecise, direct }\end{array}$ & Insufficient \\
\hline $\begin{array}{l}\mathrm{HNHC} \\
\text { patients }\end{array}$ & $\begin{array}{l}\text { Inpatient } \\
\text { admissions, } \\
\text { ACSC }(\%)\end{array}$ & $\begin{array}{l}\text { VH I: Original sample DiD: OR=0.86 } \\
(95 \% \mathrm{Cl}, 0.69 \text { to } 1.08)^{81} \\
\text { VH I: Refresh sample DiD: OR=0.93 } \\
(95 \% \mathrm{Cl}, 0.70 \text { to } 1.25)^{81}\end{array}$ & $\begin{array}{l}\text { RCTs, } \\
\mathrm{N}=10,337\end{array}$ & $\begin{array}{l}\text { Moderate study } \\
\text { limitations, } \\
\text { consistent, } \\
\text { imprecise, direct }\end{array}$ & Insufficient \\
\hline
\end{tabular}




\begin{tabular}{|c|c|c|c|c|c|}
\hline Population & Outcome & Results & $\begin{array}{l}\text { Study Design } \\
\text { and Sample } \\
\text { Size }\end{array}$ & $\begin{array}{l}\text { Strength of } \\
\text { Evidence } \\
\text { Domains }\end{array}$ & $\begin{array}{l}\text { Overall } \\
\text { Evidence } \\
\text { Strength } \\
\text { (Direction of } \\
\text { Effect) }\end{array}$ \\
\hline $\begin{array}{l}\mathrm{HNHC} \\
\text { patients }\end{array}$ & Total cost & $\begin{array}{l}\text { TST: DiD=120 }(p>0.05)^{79} \\
\text { HB: Original sample DiD }=-308 \\
(p>0.05)^{80} \\
\text { HB: Refresh sample DiD=178 } \\
(p>0.05)^{80} \\
\text { VH I: Original sample DiD }=-111 \\
(p>0.05)^{81} \\
\text { VH I: Refresh sample DiD }=-142 \\
(p>0.05)^{81} \\
\text { VH II: Original sample DiD }=206 \\
(p>0.05)^{82} \\
\text { VH II: Refresh sample DiD }=-99 \\
(p>0.05)^{82} \\
\text { Pooled mean difference: }-\$ 8.52(95 \% \\
C I,-130.02 \text { to } 112.98) ; 7 \text { RCT samples; } \\
I^{2}=22.4 \%\end{array}$ & $\begin{array}{l}7 \text { RCTs, } \\
\mathrm{N}=25,000\end{array}$ & $\begin{array}{l}\text { Moderate study } \\
\text { limitations, } \\
\text { inconsistent, } \\
\text { imprecise, direct }\end{array}$ & $\begin{array}{l}\text { Low (No } \\
\text { difference) }\end{array}$ \\
\hline $\begin{array}{l}\mathrm{HNHC} \\
\text { patients }\end{array}$ & Mortality rate & $\begin{array}{l}\text { VH I: Original sample diff }=0.8(p=0.51)^{81} \\
\text { VH I: Refresh sample diff }=-1.1 \\
(p=0.49)^{81} \\
\text { VH II: Original sample diff }=0.6 \\
(p=0.61)^{82} \\
\text { VH II: Refresh sample diff }=0.3 \\
(p=0.76)^{82} \\
\text { Pooled mean difference: } 0.34(95 \% \mathrm{CI} \text {, } \\
-1.06 \text { to } 1.74) ; 4 \text { RCT samples; }\left.\right|^{2}=0 \%\end{array}$ & $\begin{array}{l}14 \text { RCTs, } \\
\mathrm{N}=20,693\end{array}$ & $\begin{array}{l}\text { Moderate study } \\
\text { limitations, } \\
\text { inconsistent, } \\
\text { imprecise, direct }\end{array}$ & $\begin{array}{l}\text { Low (No } \\
\text { difference) }\end{array}$ \\
\hline $\begin{array}{l}\mathrm{HNHC} \\
\text { patients }\end{array}$ & $\begin{array}{l}\text { Influenza } \\
\text { vaccine }\end{array}$ & $\begin{array}{l}\text { VH I: Original sample DiD: OR=1.12 } \\
(95 \% \mathrm{Cl}, 0.93 \text { to } 1.34)^{;}{ }^{81} \\
\text { VH I: Refresh sample DiD: OR=0.91 } \\
(95 \% \mathrm{Cl}, 0.72 \text { to } 1.15)^{81}\end{array}$ & $\begin{array}{l}2 \text { RCTs, } \\
\mathrm{N}=10,337\end{array}$ & $\begin{array}{l}\text { Moderate study } \\
\text { limitations, } \\
\text { inconsistent, } \\
\text { imprecise, direct }\end{array}$ & Insufficient \\
\hline $\begin{array}{l}\mathrm{HNHC} \\
\text { patients }\end{array}$ & $\begin{array}{l}\text { Progression } \\
\text { to ESRD }\end{array}$ & $\begin{array}{l}\text { VH I: Original sample diff: }-0.75(95 \% \\
\mathrm{Cl},-1.90 \text { to } 0.41)^{81} \\
\text { VH I: Refresh sample diff: } 0.91(95 \% \\
\mathrm{Cl},-2.23 \text { to } 0.41)^{81}\end{array}$ & $\begin{array}{l}2 \text { RCTs, } \\
\mathrm{N}=10,337\end{array}$ & $\begin{array}{l}\text { Moderate study } \\
\text { limitations, } \\
\text { inconsistent, } \\
\text { imprecise, direct }\end{array}$ & Insufficient \\
\hline $\begin{array}{l}\mathrm{HNHC} \\
\text { patients } \\
\text { CKD } \\
\text { subgroup }\end{array}$ & $\begin{array}{l}\text { Progression } \\
\text { to ESRD }\end{array}$ & $\begin{array}{l}\text { VH II: Original sample diff: Greater in } \\
\text { G1: } 2.92(95 \% \mathrm{Cl}, 0.30 \text { to } 5.54)^{82} \\
\text { VH II: Refresh sample diff: } 0.37(95 \% \\
\mathrm{Cl},-2.53 \text { to } 3.28)^{82}\end{array}$ & $\begin{array}{l}2 \text { RCTs, } \\
\mathrm{N}=4,822\end{array}$ & $\begin{array}{l}\text { Moderate study } \\
\text { limitations, } \\
\text { imprecise, } \\
\text { inconsistent, } \\
\text { direct }\end{array}$ & Insufficient \\
\hline $\begin{array}{l}\mathrm{HNHC} \\
\text { patients } \\
\text { CKD } \\
\text { subgroup }\end{array}$ & $\begin{array}{l}\text { Graft or } \\
\text { fistula prior } \\
\text { to } \\
\text { hemodialysis }\end{array}$ & $\begin{array}{l}\text { VH II: Original sample diff: Lower in G1: } \\
-3.09(95 \% \mathrm{Cl},-5.93 \text { to }-0.24)^{82} \\
\text { VH II: Refresh sample diff: }-2.05(95 \% \\
\mathrm{Cl},-6.39 \text { to } 2.30)^{82}\end{array}$ & $\begin{array}{l}2 \text { RCTs, } \\
\mathrm{N}=4,822\end{array}$ & $\begin{array}{l}\text { Moderate study } \\
\text { limitations, } \\
\text { consistent, } \\
\text { imprecise, direct }\end{array}$ & Insufficient \\
\hline $\begin{array}{l}\text { HNHC } \\
\text { patients } \\
\text { ESRD } \\
\text { subgroup }\end{array}$ & $\begin{array}{l}\text { Graft or } \\
\text { fistula prior } \\
\text { to } \\
\text { hemodialysis }\end{array}$ & $\begin{array}{l}\text { VH I: Original sample diff: }-6.08(95 \% \\
\mathrm{Cl},-15.75 \text { to } 3.59)^{81} \\
\mathrm{VH} \mathrm{I}: \text { Refresh sample diff: } 2.87(95 \% \\
\mathrm{Cl},-16.72 \text { to } 22.46)^{81}\end{array}$ & $\begin{array}{l}2 \text { RCTs, } \\
N=428\end{array}$ & $\begin{array}{l}\text { Moderate study } \\
\text { limitations, } \\
\text { inconsistent, } \\
\text { imprecise, direct }\end{array}$ & Insufficient \\
\hline $\begin{array}{l}\mathrm{HNHC} \\
\text { patients } \\
\text { Diabetes } \\
\text { subgroup }\end{array}$ & $\mathrm{HbA1c}$ test & $\begin{array}{l}\text { VH II: Original sample DiD: OR=1.22 } \\
\text { (95\% Cl, } 0.73 \text { to } 2.03)^{82} \\
\text { VH II: Refresh sample DiD: OR=0.76 } \\
(95 \% \mathrm{Cl}, 0.47 \text { to } 1.23)^{82} \\
\text { VH I: Original sample DiD: OR=1.02 } \\
(95 \% \mathrm{Cl}, 0.68 \text { to } 1.54)^{81} \\
\text { VH I: Refresh sample DiD: OR=0.95 } \\
(95 \% \mathrm{Cl}, 0.56 \text { to } 1.61)^{81}\end{array}$ & $\begin{array}{l}4 \text { RCTs, } \\
\mathrm{N}=7,931\end{array}$ & $\begin{array}{l}\text { Moderate study } \\
\text { limitations, } \\
\text { inconsistent, } \\
\text { imprecise, direct }\end{array}$ & Insufficient \\
\hline
\end{tabular}




\begin{tabular}{|c|c|c|c|c|c|}
\hline Population & Outcome & Results & $\begin{array}{l}\text { Study Design } \\
\text { and Sample } \\
\text { Size }\end{array}$ & $\begin{array}{l}\text { Strength of } \\
\text { Evidence } \\
\text { Domains }\end{array}$ & $\begin{array}{l}\text { Overall } \\
\text { Evidence } \\
\text { Strength } \\
\text { (Direction of } \\
\text { Effect) } \\
\end{array}$ \\
\hline $\begin{array}{l}\text { HNHC } \\
\text { patients } \\
\text { Diabetes } \\
\text { subgroup }\end{array}$ & LDL test & $\begin{array}{l}\text { VH II: Original sample DiD: OR=1.05 } \\
(95 \% \mathrm{Cl}, 0.70 \text { to } 1.58)^{82} \\
\text { VH II: Refresh sample DiD: OR=1.15 } \\
(95 \% \mathrm{Cl}, 0.80 \text { to } 1.67)^{82} \\
\text { VH I: Original sample DiD: OR=1.19 } \\
(95 \% \mathrm{Cl}, 0.84 \text { to } 1.68)^{81} \\
\text { VH I: Refresh sample DiD: OR=0.72 } \\
(95 \% \mathrm{Cl}, 0.42 \text { to } 1.24)^{81}\end{array}$ & $\begin{array}{l}4 \text { RCTs, } \\
\mathrm{N}=7,931\end{array}$ & $\begin{array}{l}\text { Moderate study } \\
\text { limitations, } \\
\text { inconsistent, } \\
\text { imprecise, direct }\end{array}$ & Insufficient \\
\hline $\begin{array}{l}\text { HNHC } \\
\text { patients } \\
\text { IVD } \\
\text { subgroup }\end{array}$ & LDL test & $\begin{array}{l}\text { VH I: Original sample DiD: OR=0.98 } \\
(95 \% \mathrm{Cl}, 0.72 \text { to } 1.35)^{81} \\
\text { VH II: Refresh sample DiD: OR=0.88 } \\
(95 \% \mathrm{Cl}, 0.54 \text { to } 1.43)^{81}\end{array}$ & $\begin{array}{l}2 \text { RCTs, } \\
\mathrm{N}=3,942\end{array}$ & $\begin{array}{l}\text { Moderate study } \\
\text { limitations, } \\
\text { consistent, } \\
\text { imprecise, direct }\end{array}$ & Insufficient \\
\hline $\begin{array}{l}\mathrm{HNHC} \\
\text { patients } \\
\text { Diabetes } \\
\text { subgroup }\end{array}$ & Eye exam & $\begin{array}{l}\text { VH II: Original sample DiD: OR=1.05 } \\
(95 \% \mathrm{Cl}, 0.81 \text { to } 1.137)^{82} \\
\text { VH II: Refresh sample DiD: OR=1.25 } \\
(95 \% \mathrm{Cl}, 0.94 \text { to } 1.66)^{82}\end{array}$ & $\begin{array}{l}2 \text { RCTs, } \\
\mathrm{N}=4,486\end{array}$ & $\begin{array}{l}\text { Moderate study } \\
\text { limitations, } \\
\text { imprecise, } \\
\text { consistent, direct }\end{array}$ & Insufficient \\
\hline $\begin{array}{l}\mathrm{HNHC} \\
\text { patients } \\
\text { Diabetes } \\
\text { subgroup } \\
\end{array}$ & Nephrology & $\begin{array}{l}\text { VH II: Original sample DiD: OR=0.92 } \\
(95 \% \mathrm{Cl}, 0.71 \text { to } 1.18)^{82} \\
\text { VH II: Refresh sample DiD: OR=1.30 } \\
(95 \% \mathrm{Cl}, 1.01 \text { to } 1.67)^{82}\end{array}$ & $\begin{array}{l}2 \text { RCTs, } \\
\mathrm{N}=4,486\end{array}$ & $\begin{array}{l}\text { Moderate study } \\
\text { limitations, } \\
\text { inconsistent, } \\
\text { imprecise, direct }\end{array}$ & Insufficient \\
\hline $\begin{array}{l}\text { HNHC } \\
\text { patients } \\
\text { IVD } \\
\text { subgroup } \\
\end{array}$ & Lipid panel & $\begin{array}{l}\text { VH II: Original sample DiD: OR=1.10 } \\
(95 \% \mathrm{Cl}, 0.85 \text { to } 1.44)^{82} \\
\text { VH II: Refresh sample DiD: OR=1.22 } \\
(95 \% \mathrm{Cl}, 0.17 \text { to } 0.92)^{82}\end{array}$ & $\begin{array}{l}2 \text { RCTs, } \\
\mathrm{N}=4,091\end{array}$ & $\begin{array}{l}\text { Moderate study } \\
\text { limitations, } \\
\text { consistent, } \\
\text { imprecise, direct }\end{array}$ & Insufficient \\
\hline $\begin{array}{l}\text { a Compariso } \\
\text { ACSC = am } \\
\text { difference; } \\
\text { HbAlc = he } \\
\text { low-density } \\
\text { Village Hea }\end{array}$ & $\begin{array}{l}\text { up partici } \\
\text { ory care s } \\
\text { difference } \\
\text { obin Alc; } \\
\text { rotein; N } \\
\text { s. = versu }\end{array}$ & $\begin{array}{l}\text { for Dally et al. received baseline educ } \\
\text { ive conditions; CI = confidence interva } \\
=\text { emergency department; ESRD = en } \\
\text { HC = high-need, high-cost; IRR = inci } \\
\text { mber; OR = odds ratio; RCT = random }\end{array}$ & $\begin{array}{l}\text { naterials and } \\
=\text { chronic } \mathrm{k} \\
\text { e renal diseas } \\
\text { ate ratio; IVI } \\
\text { ontrolled trial }\end{array}$ & $\begin{array}{l}\text { tives. }^{90} \\
\text { disease; } \mathrm{DiD}=\mathrm{di} \\
=\text { group; } \mathrm{HB}=\mathrm{Her} \\
\text { chemic vascular di } \\
=\text { Texas Senior T }\end{array}$ & $\begin{array}{l}\text { erence-in- } \\
\text { h Buddy; } \\
\text { ease; LDL = } \\
\text { ils; VH = }\end{array}$ \\
\hline
\end{tabular}


Table B-28. Cost outcomes for telephonic/mail model studies

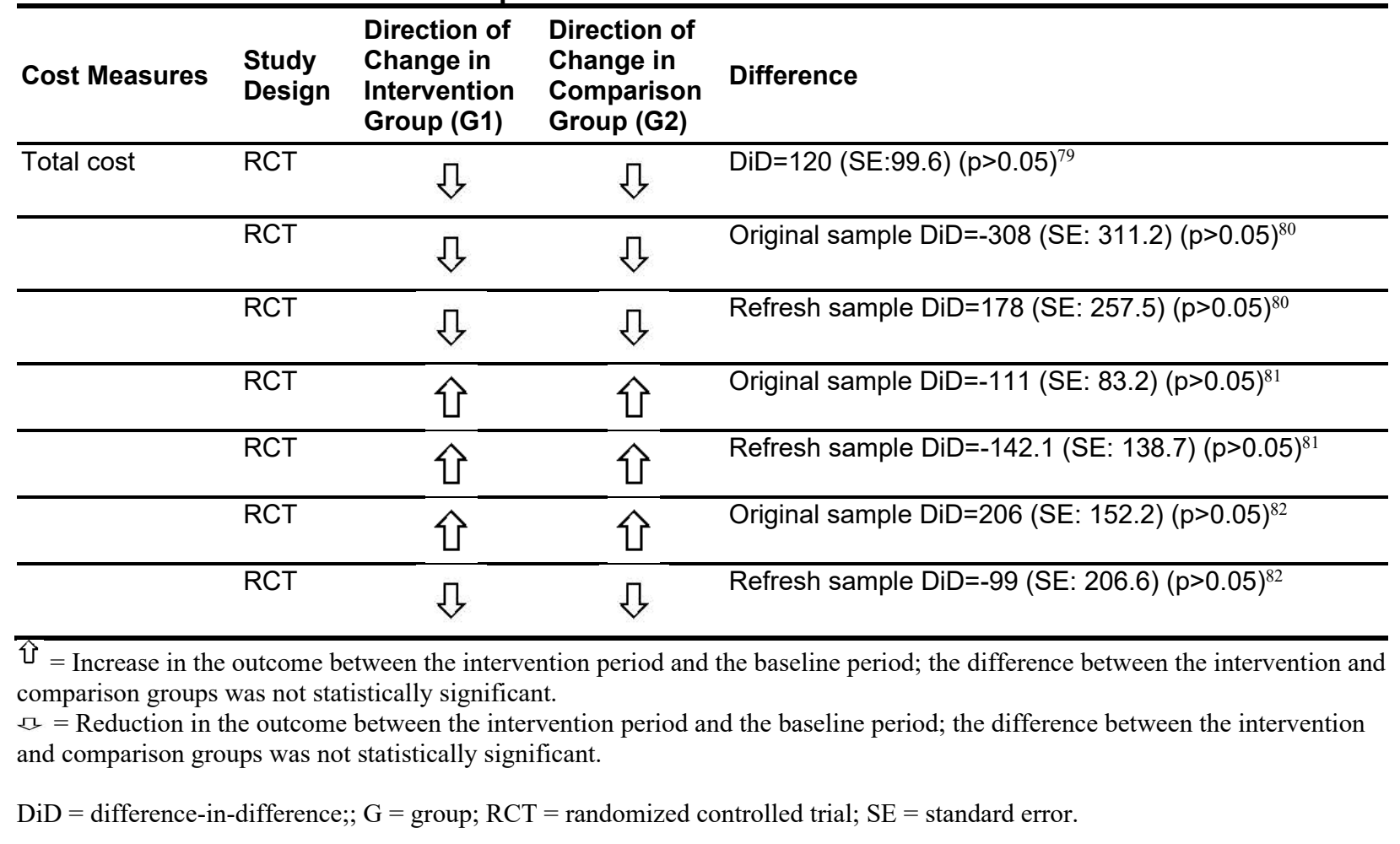


Table B-29. Clinical and functional outcomes for telephonic/mail model studies

\begin{tabular}{|c|c|c|}
\hline Clinical and Functional Outcomes & $\begin{array}{l}\text { Study } \\
\text { Design }\end{array}$ & $\begin{array}{l}\text { Difference Between Intervention Group (G1) and } \\
\text { Comparison Group (G2) }\end{array}$ \\
\hline \multirow[t]{4}{*}{ Mortality rate } & RCT & Original sample difference $=0.8(p=0.51)^{81}$ \\
\hline & RCT & Refresh sample difference $=-1.1(p=0.49)^{81}$ \\
\hline & RCT & Original sample difference $=0.6(p=0.61)^{82}$ \\
\hline & $\overline{\mathrm{RCT}}$ & Refresh sample difference $=0.3(p=0.76)^{82}$ \\
\hline \multirow[t]{2}{*}{ Influenza vaccine } & RCT & Original sample DiD: OR=1.12 $(95 \% \mathrm{Cl}, 0.93 \text { to } 1.34)^{81}$ \\
\hline & $\overline{\mathrm{RCT}}$ & Refresh sample DiD: OR=0.91 (95\% Cl, 0.72 to 1.15$)^{81}$ \\
\hline \multirow[t]{2}{*}{ Progression to ESRD } & RCT & Original sample difference $=-0.75(95 \% \mathrm{Cl},-1.90 \text { to } 0.41)^{81}$ \\
\hline & $\overline{\mathrm{RCT}}$ & Refresh sample difference $=-0.91(95 \% \mathrm{Cl},-2.23 \text { to } 0.41)^{81}$ \\
\hline PHC score (physical health) & RCT & ANCOVA-adjusted IE=-0.1 (p>0.05) ${ }^{81}$ \\
\hline MHC score (mental health) & RCT & ANCOVA-adjusted IE $=0.0(p>0.05)^{81}$ \\
\hline PHQ-2 (depression, 0 to 6) & RCT & $\begin{array}{l}\text { Lower score in G1 than G2: }{ }^{a} \text { ANCOVA-adjusted IE=-0.45 } \\
(p<0.05)^{81}\end{array}$ \\
\hline Number of ADLs difficult to do (0 to 6$)$ & RCT & ANCOVA-adjusted intervention effect $=-0.02(p>0.05)^{81}$ \\
\hline Number of ADLs receiving help (0 to 6 ) & RCT & ANCOVA-adjusted IE $=0.21(p>0.05)^{81}$ \\
\hline Helping to cope with a chronic condition (1 to 5) & RCT & ANCOVA-adjusted IE=0.10, $(p>0.05)^{81}$ \\
\hline Number of helpful discussion topics (0 to 5 ) & $\mathrm{RCT}$ & ANCOVA-adjusted IE $=0.08(p>0.05)^{81}$ \\
\hline Discussing treatment choices (1 to 4 ) & RCT & $\begin{array}{l}\text { Lower score in G1 than G2:b ANCOVA-adjusted IE }=-0.19 \\
(p<0.05)^{81}\end{array}$ \\
\hline Communicating with providers (0 to 100 ) & RCT & ANCOVA-adjusted IE $=2.7(p>0.05)^{81}$ \\
\hline Getting answers to questions quickly (0 to 100$)$ & RCT & ANCOVA-adjusted IE $=-0.8(p>0.05)^{81}$ \\
\hline Multimorbidity Hassles score (0 to 24) & RCT & ANCOVA-adjusted IE $=0.15(p>0.05)^{81}$ \\
\hline Percent receiving help setting goals & RCT & ANCOVA-adjusted IE=9.5 (p>0.05) ${ }^{81}$ \\
\hline Percent receiving help making a care plan & $\mathrm{RCT}$ & ANCOVA-adjusted IE $=4.0(p>0.05)^{81}$ \\
\hline Self-efficacy: Take all medications (1 to 5) & RCT & ANCOVA-adjusted IE $=0.03(p>0.05)^{81}$ \\
\hline Self-efficacy: Plan meals and snacks (1 to 5) & RCT & ANCOVA-adjusted IE $=-0.08(p>0.05)^{81}$ \\
\hline $\begin{array}{l}\text { Self-efficacy: Exercise } 2 \text { or } 3 \text { times weekly (1 to } \\
5 \text { ) }\end{array}$ & RCT & ANCOVA-adjusted IE $=0.14(p>0.05)^{81}$ \\
\hline $\begin{array}{l}\text { Self-care activities: Prescribed medications } \\
\text { taken (mean \# of days) }\end{array}$ & RCT & ANCOVA-adjusted IE $=-0.15(p>0.05)^{81}$ \\
\hline $\begin{array}{l}\text { Self-care activities: Followed healthy eating } \\
\text { plan (mean \# of days) }\end{array}$ & RCT & ANCOVA-adjusted IE $=-0.03(p>0.05)^{81}$ \\
\hline $\begin{array}{l}\text { Self-care activities: } 30 \text { minutes of continuous } \\
\text { physical activity (mean \# of days) }\end{array}$ & RCT & ANCOVA-adjusted IE $=-0.30(p>0.05)^{81}$ \\
\hline
\end{tabular}

${ }^{a}$ Lower scores in the PHQ-2 indicate fewer depressive symptoms.

${ }^{b}$ Lower scores indicate worse experience, satisfaction, or self-management.

$\mathrm{ADL}=$ activities of daily living; $\mathrm{ANCOVA}=$ analysis of covariance; $\mathrm{CI}=$ confidence interval; $\mathrm{DiD}=$ difference-in-difference; $\mathrm{ESRD}=$ end-stage renal disease; $\mathrm{G}=$ group $; \mathrm{IE}=$ intervention effect; $\mathrm{MHC}=$ mental health composite; $\mathrm{OR}=\mathrm{odds}$ ratio; $\mathrm{PHC}=$ physical health composite; $\mathrm{PHQ}-2$ = patient health questionnaire-2; RCT = randomized controlled trial. 
Table B-30. Clinical and functional outcomes for telephonic/mail model studies: Subgroup outcomes

\begin{tabular}{|c|c|c|}
\hline $\begin{array}{l}\text { Clinical and Functional } \\
\text { Outcomes }\end{array}$ & $\begin{array}{l}\text { Study } \\
\text { Design }\end{array}$ & ifference Bet \\
\hline \multirow[t]{2}{*}{ Progression to ESRD } & RCT & $\begin{array}{l}\text { Chronic kidney disease patients subgroup: Original sample difference: Greater in G1: } \\
2.92(95 \% \mathrm{Cl}, 0.30 \text { to } 5.54)^{82}\end{array}$ \\
\hline & $\overline{\mathrm{RCT}}$ & $\begin{array}{l}\text { Chronic kidney disease patients subgroup: Refresh sample difference: } 0.37(95 \% \\
\mathrm{Cl},-2.53 \text { to } 3.28)^{82}\end{array}$ \\
\hline \multirow[t]{4}{*}{$\begin{array}{l}\text { Graft or fistula prior to } \\
\text { hemodialysis }\end{array}$} & RCT & $\begin{array}{l}\text { Chronic kidney disease patients subgroup: Original sample difference: Lower in G1: - } \\
3.09(95 \% \mathrm{Cl},-5.93 \text { to }-0.24)^{82}\end{array}$ \\
\hline & $\overline{\mathrm{RCT}}$ & $\begin{array}{l}\text { Chronic kidney disease patients subgroup: Refresh sample difference: }-2.05(95 \% \mathrm{Cl} \text {, } \\
-6.39 \text { to } 2.30)^{82}\end{array}$ \\
\hline & $\overline{\mathrm{RCT}}$ & $\begin{array}{l}\text { End-stage renal disease patients subgroup: Original sample difference: }-6.08(95 \% \\
\mathrm{Cl},-15.75 \text { to } 3.59)^{81}\end{array}$ \\
\hline & $\mathrm{T}$ & $\begin{array}{l}\text { End-stage renal disease patients subgroup: Refresh sample difference: } 2.87 \text { (95\% Cl, } \\
-16.72 \text { to } 22.46)^{81}\end{array}$ \\
\hline \multirow[t]{4}{*}{ HbA1c test } & RCT & Diabetes patients subgroup: Original sample DiD: OR=1.22 $(95 \% \mathrm{Cl}, 0.73 \text { to } 2.03)^{82}$ \\
\hline & $\overline{\mathrm{RCT}}$ & Diabetes patients subgroup: Refresh sample DiD: OR=0.76 $(95 \% \mathrm{Cl}, 0.47 \text { to } 1.23)^{82}$ \\
\hline & $\overline{R C T}$ & subgroup: Orig \\
\hline & RCT & group: Re \\
\hline \multirow[t]{6}{*}{ LDL-C test } & RCT & Diabetes patients subgroup: Original sample DiD: $\mathrm{OR}=1.05(95 \% \mathrm{Cl}, 0.70 \mathrm{t}$ \\
\hline & $\overline{\mathrm{RCT}}$ & Diabetes patients subgroup: Refresh sample DiD: $O R=1$. \\
\hline & RCT & Diabetes patients subgroup: Original sample DiD: OR=1.19 $(95 \% \mathrm{Cl}, 0.84 \text { to } 1.68)^{81}$ \\
\hline & RCT & Diabetes patients subgroup: Refresh sample DiD: OR=0.72 $(95 \% \mathrm{Cl}, 0.42 \text { to } 1.24)^{81}$ \\
\hline & $\overline{R C T}$ & group: Original s \\
\hline & RCT & IVD $\mathrm{p}$ \\
\hline \multirow[t]{2}{*}{ Eye exam } & RCT & Diabetes patients subgroup: Original sample DiD: $O R=1$. \\
\hline & $\overline{R C T}$ & Diabetes patients subgroup: Refresh sample DiD: OR=1.25 $(95 \% \mathrm{Cl}, 0.94 \text { to } 1.66)^{82}$ \\
\hline \multirow[t]{2}{*}{ Nephrology } & RCT & Diabetes patients subgroup: Original sample DiD: OR=0.92 $(95 \% \mathrm{Cl}, 0.71 \text { to } 1.18)^{82}$ \\
\hline & $\overline{\mathrm{RCT}}$ & $\begin{array}{l}\text { Diabetes patients subgroup: Refresh sample DiD: Greater increase in G1 than G2: } \\
\mathrm{OR}=1.30(95 \% \mathrm{Cl}, 1.01 \text { to } 1.67)^{82}\end{array}$ \\
\hline \multirow[t]{2}{*}{ All 4 measures $^{\text {a }}$} & RCT & Diabetes patients subgroup: Original sample DiD: OR=1.01 $(95 \% \mathrm{Cl}, 0.80 \text { to } 1.29)^{82}$ \\
\hline & $\overline{R C T}$ & Diabetes patients subgroup: Refresh sample DiD: OR=1.18 $(95 \% \mathrm{Cl}, 0.93 \text { to } 1.52)^{82}$ \\
\hline \multirow[t]{2}{*}{ None of the measures ${ }^{b}$} & RCT & Diabetes patients subgroup: Original sample DiD: OR=1.74 $(95 \% \mathrm{Cl}, 0.35 \text { to } 8.70)^{82}$ \\
\hline & $\overline{\mathrm{RCT}}$ & Diabetes patients subgroup: Refresh sample DiD: OR=0.60 $(95 \% \mathrm{Cl}, 0.16 \text { to } 2.33)^{82}$ \\
\hline \multirow[t]{2}{*}{ Lipid panel } & RCT & IVD patient subgroup: Original sample DiD: OR=1.10 $(95 \% \mathrm{Cl}, 0.85 \text { to } 1.44)^{82}$ \\
\hline & $\overline{\mathrm{RCT}}$ & $\begin{array}{l}\text { IVD patient subgroup: Refresh sample DiD: greater increase in } \mathrm{G} 1 \text { than } \mathrm{G} 2: \mathrm{OR}=1.22 \\
(95 \% \mathrm{Cl}, 0.17 \text { to } 0.92)^{82}\end{array}$ \\
\hline \multicolumn{3}{|c|}{$\begin{array}{l}\text { a The "All } 4 \text { measures" is the rate at which beneficiaries receive all of the following four diabetes measures: rate of annual } \\
\text { HbAlc testing, low-density lipoprotein cholesterol (LDL-C) screening, receipt of a retinal eye exam, and medical attention for } \\
\text { nephropathy. } \\
\text { b The "None of the measures" is the rate at which beneficiaries did not receive any of the four diabetes measures. } \\
\mathrm{CI}=\text { confidence interval; DiD = difference-in-difference; ESRD = end-stage renal disease; } \mathrm{G}=\text { group; HbA1c = hemoglobin } \\
\text { Alc; IVD = ischemic vascular disease; LDL-C = low-density lipoprotein cholesterol; OR = odds ratio; RCT = randomized } \\
\text { controlled trial. }\end{array}$} \\
\hline
\end{tabular}


Table B-31. Study characteristics for community-based models

\begin{tabular}{|c|c|c|c|c|c|c|}
\hline $\begin{array}{l}\text { First Author, } \\
\text { Year, Site(s) }\end{array}$ & Sample Size & $\begin{array}{l}\text { Study Design } \\
\text { (Risk of Bias } \\
\text { Assessment) }\end{array}$ & $\begin{array}{l}\text { Patient } \\
\text { Selection: High } \\
\text { Healthcare Use } \\
\text { or Cost; Time } \\
\text { Period }\end{array}$ & $\begin{array}{l}\text { Patient } \\
\text { Selection: } \\
\text { Chronic } \\
\text { Conditions }\end{array}$ & $\begin{array}{l}\text { Patient Selection: } \\
\text { Other }\end{array}$ & $\begin{array}{l}\text { Additional } \\
\text { Selected Patient } \\
\text { Characteristics }\end{array}$ \\
\hline $\begin{array}{l}\text { Finkelstein et } \\
\text { al., } 2020^{96} \\
\text { Camden, NJ; } 4 \\
\text { local-area } \\
\text { hospital } \\
\text { systems }\end{array}$ & $\begin{array}{l}\mathrm{N}=800) \\
\text { Intervention } \\
(\mathrm{N}=399) \\
\text { Comparison } \\
(\mathrm{N}=401)\end{array}$ & $\begin{array}{l}\text { RCT } \\
\text { (RoB: Low) }\end{array}$ & $\begin{array}{l}1 \text { or more IP } \\
\text { admissions in } \\
\text { past } 6 \text { months }\end{array}$ & $\begin{array}{l}2 \text { or more } \\
\text { chronic } \\
\text { conditions }\end{array}$ & $\begin{array}{l}\text { At least } 2 \text { of the } \\
\text { following traits or } \\
\text { conditions } \\
\text { constituting medically } \\
\text { and socially complex } \\
\text { needs: use of } 5 \text { or } \\
\text { more active } \\
\text { outpatient } \\
\text { medications, difficulty } \\
\text { accessing services, } \\
\text { lack of social } \\
\text { support, a coexisting } \\
\text { MH condition, an } \\
\text { active drug habit, } \\
\text { and/or } \\
\text { homelessness; } 18-80 \\
\text { years of age } \\
\text { Exclusion criteria: } \\
\text { uninsured, } \\
\text { cognitively impaired, } \\
\text { oncology patient, } \\
\text { admitted for a } \\
\text { surgical procedure } \\
\text { for an acute health } \\
\text { problem, for mental } \\
\text { healthcare (with no } \\
\text { comorbid physical } \\
\text { health conditions), or } \\
\text { for complications of a } \\
\text { progressive chronic } \\
\text { disease that has } \\
\text { limited treatments }\end{array}$ & $\begin{array}{l}\geq 65 \text { years: } 28 \% \\
\text { Nonwhite: } 85 \% \\
\text { Medicare: } 48 \% \\
\text { Medicaid: } 45 \% \\
\text { Hypertension: } \\
\text { 80.6\%; CHF: } \\
33.9 \% \text {; diabetes: } \\
53.1 \% \\
\text { Needs help with } \\
\text { mobility: } 62 \% \\
\text { Self-reported } \\
\text { health: poor: } 54 \% \\
\text { Depression: } 30 \% \\
\text { Substance abuse: } \\
44 \%\end{array}$ \\
\hline
\end{tabular}




\begin{tabular}{|c|c|c|c|c|c|c|}
\hline $\begin{array}{l}\text { First Author, } \\
\text { Year, Site(s) }\end{array}$ & Sample Size & $\begin{array}{l}\text { Study Design } \\
\text { (Risk of Bias } \\
\text { Assessment) }\end{array}$ & $\begin{array}{l}\text { Patient } \\
\text { Selection: High } \\
\text { Healthcare Use } \\
\text { or Cost; Time } \\
\text { Period }\end{array}$ & $\begin{array}{l}\text { Patient } \\
\text { Selection: } \\
\text { Chronic } \\
\text { Conditions }\end{array}$ & $\begin{array}{l}\text { Patient Selection: } \\
\text { Other }\end{array}$ & $\begin{array}{l}\text { Additional } \\
\text { Selected Patient } \\
\text { Characteristics }\end{array}$ \\
\hline $\begin{array}{l}\text { Raven et al., } \\
2020^{109} \\
\text { Santa Clara, } \\
\text { CA: } 1 \text { site }\end{array}$ & $\begin{array}{l}\mathrm{N}=423) \\
\text { Intervention } \\
(\mathrm{N}=199) \\
\text { Comparison } \\
(\mathrm{N}=224)\end{array}$ & $\begin{array}{l}\text { RCT (ROB: } \\
\text { some } \\
\text { concerns) }\end{array}$ & $\begin{array}{l}\text { Various } \\
\text { combinations of } \\
\text { the ED and } \\
\text { psychiatric ED, } \\
\text { medical and } \\
\text { psychiatric } \\
\text { inpatient stays in } \\
\text { the county-funded } \\
\text { public hospital, } \\
\text { and/or jail in past } \\
\text { 1-2 years at high } \\
\text { enough levels to } \\
\text { meet a threshold } \\
\text { score (threshold } \\
\text { score NR) }\end{array}$ & NR & $\begin{array}{l}\text { Met the Federal } \\
\text { definition of chronic } \\
\text { homelessness } \\
\text { (homeless for 1+ } \\
\text { years or } 4+\text { episodes } \\
\text { in the prior } 3 \text { years } \\
\text { that last for more } \\
\text { than a year total, with } \\
\text { a disabling } \\
\text { condition), lived in } \\
\text { Santa Clara County, } \\
\text { not incarcerated, not } \\
\text { engaged in another } \\
\text { intensive case } \\
\text { management } \\
\text { program or other } \\
\text { permanent } \\
\text { supportive housing } \\
\text { program, did not } \\
\text { require nursing home } \\
\text { level care, and did } \\
\text { not have metastatic } \\
\text { cancer or qualify for } \\
\text { hospice care }\end{array}$ & $\begin{array}{l}\text { Mean age: } 51.5 \\
\text { Nonwhite: } 35 \% \\
\text { Medicaid: } 35 \% \\
\text { Medicare: } 27 \%\end{array}$ \\
\hline $\begin{array}{l}\text { Bell et al., } \\
2015^{112} \\
\text { King County, } \\
\text { Washington: } 1 \\
\text { site }\end{array}$ & $\begin{array}{l}(\mathrm{N}=1,120) \\
\text { Intervention } \\
(\mathrm{N}=557) \\
\text { Comparison } \\
(\mathrm{N}=563)\end{array}$ & $\begin{array}{l}\text { RCT (ROB: } \\
\text { low) }\end{array}$ & $\begin{array}{l}\text { Determined to be } \\
\text { at risk for high } \\
\text { future healthcare } \\
\text { costs }\end{array}$ & $\begin{array}{l}\text { Disabled } \\
\text { with mental } \\
\text { health } \\
\text { and/or } \\
\text { substance } \\
\text { abuse } \\
\text { problems } \\
\end{array}$ & $\begin{array}{l}\text { Medicaid } \\
\text { beneficiaries }\end{array}$ & $\begin{array}{l}\text { Mean age: } 51 \\
\text { Nonwhite: } 43 \% \\
\text { Medicaid: } 100 \% \\
\text { Medicare: NR } \\
\text { Serious mental } \\
\text { illness: } 50 \%\end{array}$ \\
\hline $\begin{array}{l}\text { Sevak et al., } \\
2018^{85,124} \\
\text { Aurora, CO; } \\
\text { San Diego, } \\
\text { CA; Allentown, } \\
\text { PA; Kansas } \\
\text { City, MO: } 1 \text { site } \\
\text { per location }\end{array}$ & $\begin{array}{l}(\mathrm{N}=1,279) \\
\text { Intervention } \\
(\mathrm{N}=149) \\
\text { Comparison } \\
(\mathrm{N}=1,130)\end{array}$ & $\begin{array}{l}\text { Observational } \\
\text { study } \\
\text { (RoB: some } \\
\text { concerns) }\end{array}$ & $\begin{array}{l}\text { Initial inclusion } \\
\text { criteria: } 2+ \\
\text { inpatient } \\
\text { admissions in } 6 \\
\text { months } \\
2 \text { of } 4 \text { sites } \\
\text { amended criteria: } \\
1 \text { site expanded } \\
\text { criteria to also } \\
\text { include } 3+ \\
\text { inpatient } \\
\text { admissions in } \\
\text { past } 12 \text { months, } \\
1 \text { site expanded } \\
\text { criteria to } 3+ \\
\text { hospital events } \\
\text { (admissions or } \\
\text { ED visits) in past } \\
6 \text { months }\end{array}$ & NA & $\begin{array}{l}\text { Medicare FFS } \\
\text { beneficiaries } \\
\text { Exclusion: patients } \\
\text { whose conditions } \\
\text { could not be } \\
\text { managed with } \\
\text { existing program } \\
\text { resources }\end{array}$ & $\begin{array}{l}\text { Mean age: } 59 \\
\text { years } \\
\text { Black: } 48.4 \% \\
\text { Hispanic: } 8.5 \% \\
\text { Zip code poverty } \\
\text { rate: } 25.6 \% \\
\text { Dual coverage at } \\
\text { enrollment: } 69 \% \\
\text { Alzheimer's: } 8.5 \% \\
\text { Cancer: } 5.3 \% \\
\text { CHF: } 56.0 \% \\
\text { CKD: } 63.0 \% \\
\text { COPD: } 56.3 \% \\
\text { Diabetes: } 71.1 \%\end{array}$ \\
\hline
\end{tabular}




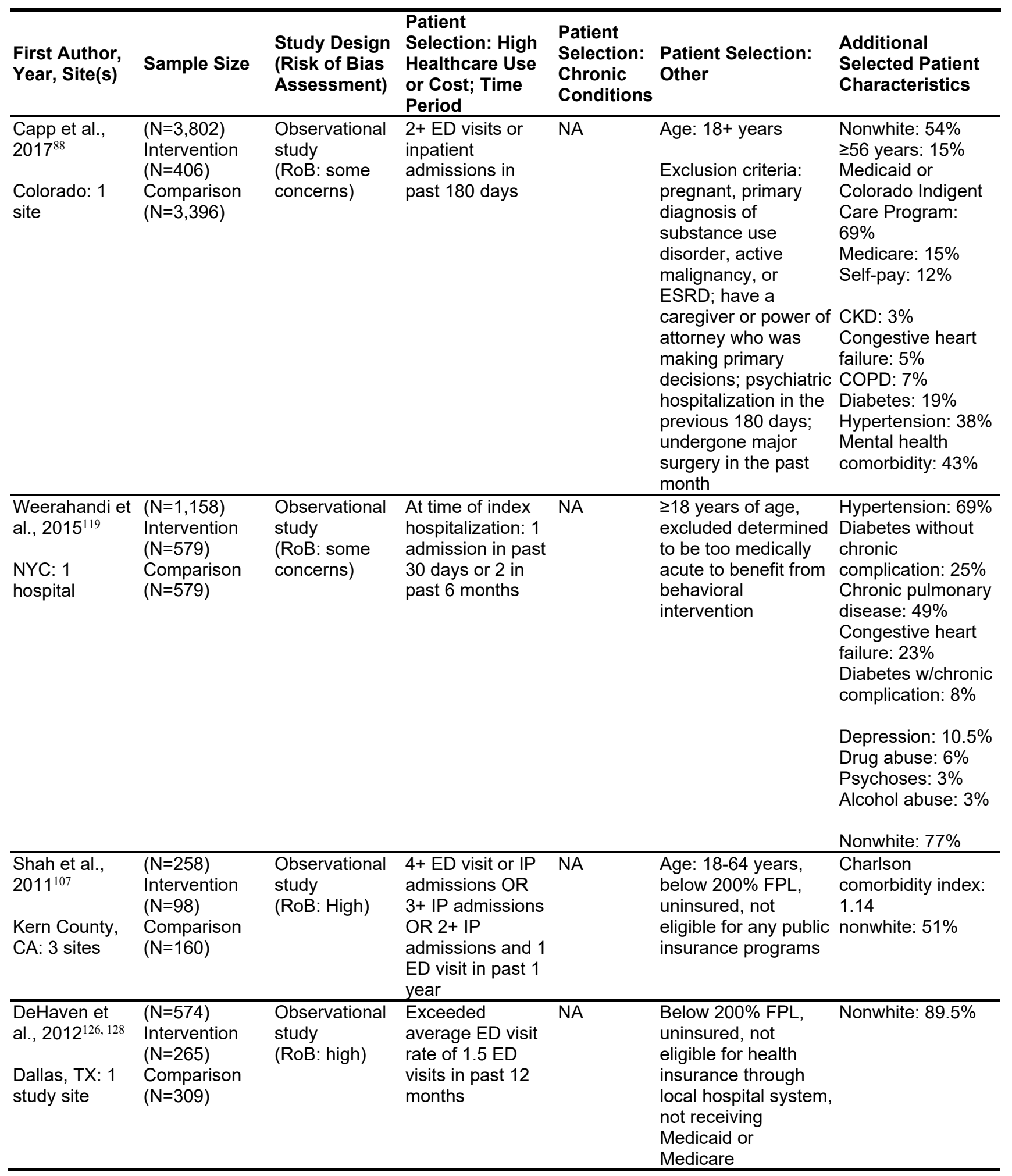




\begin{tabular}{|c|c|c|c|c|c|c|}
\hline $\begin{array}{l}\text { First Author, } \\
\text { Year, Site(s) }\end{array}$ & Sample Size & $\begin{array}{l}\text { Study Design } \\
\text { (Risk of Bias } \\
\text { Assessment) }\end{array}$ & $\begin{array}{l}\text { Patient } \\
\text { Selection: High } \\
\text { Healthcare Use } \\
\text { or Cost; Time } \\
\text { Period }\end{array}$ & $\begin{array}{l}\text { Patient } \\
\text { Selection: } \\
\text { Chronic } \\
\text { Conditions }\end{array}$ & $\begin{array}{l}\text { Patient Selection: } \\
\text { Other }\end{array}$ & $\begin{array}{l}\text { Additional } \\
\text { Selected Patient } \\
\text { Characteristics }\end{array}$ \\
\hline $\begin{array}{l}\text { Thompson et } \\
\text { al., } 2018^{95} \\
\text { Memphis, TN: } \\
1 \text { site }\end{array}$ & $\begin{array}{l}(\mathrm{N}=439) \\
\text { Intervention } \\
(\mathrm{N}=159) \\
\text { Comparison } \\
(\mathrm{N}=280)\end{array}$ & $\begin{array}{l}\text { Observational } \\
\text { study } \\
\text { (RoB: high) }\end{array}$ & $\begin{array}{l}\text { 11+ hospital } \\
\text { encounters } \\
\text { originating in the } \\
\text { ED in past } 1 \text { year }\end{array}$ & NA & $\begin{array}{l}\text { Resident of } \\
\text { Memphis, TN, in } \\
38109 \text { zip code }\end{array}$ & $\begin{array}{l}\text { Moderate or severe } \\
\text { Charlson } \\
\text { comorbidity index } \\
(>3): 13 \% \\
\text { Nonwhite: } 97 \% \\
\text { None/missing PCP: } \\
21 \%\end{array}$ \\
\hline
\end{tabular}

$\mathrm{CA}=$ California $; \mathrm{CHF}=$ congestive heart failure $\mathrm{CKD}=$ chronic kidney disease $\mathrm{CO}=\mathrm{Colorado}$; $\mathrm{COPD}=$ chronic obstructive pulmonary disease; $\mathrm{ED}=$ emergency department; $\mathrm{ESRD}=$ end-stage renal disease; $\mathrm{FFS}=$ fee-for-service; $\mathrm{FPL}=$ federal poverty line; $\mathrm{IP}=$ inpatient; $\mathrm{MH}=$ mental health; $\mathrm{MO}=$ Missouri; $\mathrm{N}=$ number; $\mathrm{NA}=$ not applicable; $\mathrm{NJ}=\mathrm{New}$ Jersey; $\mathrm{NR}=$ not reported; $\mathrm{NYC}=$ New York City; $\mathrm{PA}=$ Pennsylvania; $\mathrm{PCP}=$ primary care provider; $\mathrm{RCT}=$ randomized controlled trial; $\mathrm{RoB}=$ risk of bias; $\mathrm{TN}=$ Tennessee; $\mathrm{TX}=$ Texas. 
Table B-32. Intervention characteristics for community-based models

\begin{tabular}{|c|c|c|c|c|c|c|c|c|c|}
\hline $\begin{array}{l}\text { First } \\
\text { Author, } \\
\text { Year, } \\
\text { Site(s) }\end{array}$ & $\begin{array}{l}\text { Intervention: } \\
\text { Brief Description }\end{array}$ & $\begin{array}{l}\text { Intervention } \\
\text { Duration }\end{array}$ & $\begin{array}{l}\text { Assessment, } \\
\text { Education, } \\
\text { Skills, } \\
\text { Monitoring }\end{array}$ & $\begin{array}{l}\text { Coordination } \\
\text { and Continuity } \\
\text { of Care }\end{array}$ & $\begin{array}{l}\text { Referral } \\
\text { to/Linkages } \\
\text { to } \\
\text { Community- } \\
\text { Based } \\
\text { Support } \\
\text { Services } \\
\end{array}$ & Providers & $\begin{array}{l}\text { Mode of } \\
\text { Delivery } \\
\text { Setting(s) }\end{array}$ & Intensity & Comparison \\
\hline $\begin{array}{l}\text { Finkelstein } \\
\text { et al., 202096 } \\
\text { Camden, } \\
\text { NJ; } 4 \text { local- } \\
\text { area } \\
\text { hospital } \\
\text { systems }\end{array}$ & $\begin{array}{l}\text { Camden Core } \\
\text { Model: } \\
\text { hotspotting }\end{array}$ & $\begin{array}{l}\text { Median: } 92 \\
\text { days; tailored to } \\
\text { patient needs } \\
\text { and } \\
\text { responsiveness }\end{array}$ & $\begin{array}{l}\text { Disease-specific } \\
\text { self-care } \\
\text { coaching, patient } \\
\text { education }\end{array}$ & $\begin{array}{l}\text { Scheduled and } \\
\text { accompanied } \\
\text { patients to initial } \\
\text { post-IP primary } \\
\text { and specialty } \\
\text { care visits and } \\
\text { followup care, } \\
\text { medication } \\
\text { reconciliation, } \\
\text { medication } \\
\text { management }\end{array}$ & $\begin{array}{l}\text { Assistance } \\
\text { applying for } \\
\text { social } \\
\text { services and } \\
\text { BH programs }\end{array}$ & $\begin{array}{l}\text { Multidisciplinary: } \\
\text { RNs, social } \\
\text { workers, LPNs, } \\
\text { CHWs, and } \\
\text { health coaches }\end{array}$ & $\begin{array}{l}\text { Face-to-face } \\
\text { Enrollment in } \\
\text { the hospital; } \\
\text { subsequent } \\
\text { service } \\
\text { delivery } \\
\text { through home } \\
\text { visits, PCP, } \\
\text { and specialty } \\
\text { care }\end{array}$ & $\begin{array}{l}\text { Received both } \\
\text { a home visit } \\
\text { within } 14 \text { days } \\
\text { and provider } \\
\text { visit within } 60 \\
\text { days: } 75 \% \text { of } \\
\text { participants; } \\
\text { further contact } \\
\text { tailored to } \\
\text { individual }\end{array}$ & $\begin{array}{l}\text { Usual post- } \\
\text { discharge care } \\
\text { that could } \\
\text { include home } \\
\text { visits or other } \\
\text { outreach }\end{array}$ \\
\hline $\begin{array}{l}\text { Raven et al., } \\
2020^{109} \\
\text { Santa Clara, } \\
\text { CA: } 1 \text { site }\end{array}$ & $\begin{array}{l}\text { Project Welcome } \\
\text { Home (PWH), a } \\
\text { permanent } \\
\text { supportive } \\
\text { housing } \\
\text { intervention with } \\
\text { intensive case } \\
\text { management } \\
\text { services }\end{array}$ & Up to 4 years & $\begin{array}{l}\text { Voluntary } \\
\text { support services } \\
\text { included mental } \\
\text { health and } \\
\text { substance use } \\
\text { services; } \\
\text { medication } \\
\text { support, } \\
\text { community living } \\
\text { skills, } \\
\text { educational and } \\
\text { vocational } \\
\text { support, and } \\
\text { money } \\
\text { management }\end{array}$ & $\begin{array}{l}\text { Community- } \\
\text { based case } \\
\text { management } \\
\text { services }\end{array}$ & $\begin{array}{l}\text { Connected } \\
\text { participants } \\
\text { to temporary } \\
\text { housing, } \\
\text { permanent } \\
\text { supportive } \\
\text { housing, and } \\
\text { rehousing }\end{array}$ & $\begin{array}{l}\text { Master's level } \\
\text { social behavioral } \\
\text { health providers, } \\
\text { bachelor's level } \\
\text { case managers, } \\
\text { and staff with } \\
\text { lived experience } \\
\text { (peers) }\end{array}$ & $\overline{N R}$ & $\overline{N R}$ & Usual care \\
\hline
\end{tabular}




\begin{tabular}{|c|c|c|c|c|c|c|c|c|c|}
\hline $\begin{array}{l}\text { First } \\
\text { Author, } \\
\text { Year, } \\
\text { Site(s) }\end{array}$ & $\begin{array}{l}\text { Intervention: } \\
\text { Brief Description }\end{array}$ & $\begin{array}{l}\text { Intervention } \\
\text { Duration }\end{array}$ & $\begin{array}{l}\text { Assessment, } \\
\text { Education, } \\
\text { Skills, } \\
\text { Monitoring }\end{array}$ & $\begin{array}{l}\text { Coordination } \\
\text { and Continuity } \\
\text { of Care }\end{array}$ & $\begin{array}{l}\text { Referral } \\
\text { to/Linkages } \\
\text { to } \\
\text { Community- } \\
\text { Based } \\
\text { Support } \\
\text { Services } \\
\end{array}$ & Providers & $\begin{array}{l}\text { Mode of } \\
\text { Delivery } \\
\text { Setting(s) }\end{array}$ & Intensity & Comparison \\
\hline $\begin{array}{l}\text { Bell et al., } \\
2015^{112} \\
\text { King } \\
\text { County, } \\
\text { Washington: } \\
1 \text { site }\end{array}$ & $\begin{array}{l}\text { Kings County } \\
\text { Care Partners } \\
\text { (KCCP) Program, } \\
\text { a registered } \\
\text { nurse-led care } \\
\text { management } \\
\text { intervention }\end{array}$ & $\begin{array}{l}\text { Up to } 24 \\
\text { months }\end{array}$ & $\begin{array}{l}\text { Completed a } \\
\text { comprehensive } \\
\text { in-person } \\
\text { assessment of } \\
\text { their medical and } \\
\text { social needs with } \\
\text { their RN care } \\
\text { manager and } \\
\text { frequent in- } \\
\text { person and } \\
\text { phone monitoring }\end{array}$ & $\begin{array}{l}\text { Care manager } \\
\text { arranged to join } \\
\text { the participant } \\
\text { at } 1+\text { clinic } \\
\text { appointments, } \\
\text { provided } \\
\text { participants with } \\
\text { chronic disease } \\
\text { self- } \\
\text { management } \\
\text { coaching, and } \\
\text { coordinated } \\
\text { care across the } \\
\text { medical and } \\
\text { mental health } \\
\text { systems }\end{array}$ & $\begin{array}{l}\text { Care } \\
\text { manager } \\
\text { connected } \\
\text { participants } \\
\text { to community } \\
\text { resources }\end{array}$ & $\begin{array}{l}\text { Three full-time } \\
\text { RNs, two social } \\
\text { workers (MSWs) } \\
\text { with drug/alcohol } \\
\text { treatment } \\
\text { training, and a } \\
\text { bachelor's-level } \\
\text { chemical } \\
\text { dependency } \\
\text { counselor }\end{array}$ & $\begin{array}{l}\text { Mixture of } \\
\text { face-to-face, } \\
\text { telephone, } \\
\text { and letter }\end{array}$ & NR & Usual care \\
\hline $\begin{array}{l}\text { Sevak et al., } \\
2018^{85,124} \\
\text { Aurora, CO; } \\
\text { San Diego, } \\
\text { CA; } \\
\text { Allentown, } \\
\text { PA; Kansas } \\
\text { City, MO: } 1 \\
\text { site per } \\
\text { location }\end{array}$ & $\begin{array}{l}\text { Health Care } \\
\text { Innovation Award: } \\
\text { Rutgers Center } \\
\text { for State Health } \\
\text { Policy (CSHP) } \\
\text { community-based } \\
\text { care } \\
\text { management/care } \\
\text { coordination for } \\
\text { high-risk patients, } \\
\text { replication of } \\
\text { Camden Coalition } \\
\text { model }\end{array}$ & $\begin{array}{l}\text { Mean: } 4.2 \\
\text { months (site } \\
\text { means ranged } \\
\text { from } 2.4 \\
\text { months to } 6.3 \\
\text { months) } \\
\end{array}$ & $\begin{array}{l}\text { Sites received } \\
\text { technical } \\
\text { assistance to } \\
\text { implement the } \\
\text { intervention } \\
\text { Pt education } \\
\text { about the } \\
\text { importance of } \\
\text { using primary } \\
\text { and specialty } \\
\text { care instead of, } \\
\text { or as a followup } \\
\text { to, emergency } \\
\text { and hospital care } \\
\text { and about } \\
\text { managing } \\
\text { medical and } \\
\text { social needs } \\
\end{array}$ & $\begin{array}{l}\text { Developed } \\
\text { individualized } \\
\text { care plans, } \\
\text { integrated care } \\
\text { management } \\
\text { services } \\
\text { through mobile } \\
\text { care teams }\end{array}$ & $\begin{array}{l}\text { Assisted in } \\
\text { enrollment in } \\
\text { social service } \\
\text { and BH } \\
\text { service } \\
\text { programs }\end{array}$ & $\begin{array}{l}\text { Differing } \\
\text { combination of } \\
\text { RNs, NPs, social } \\
\text { workers, CHWs, } \\
\text { peer health } \\
\text { coaches, } \\
\text { medical } \\
\text { assistants, and } \\
\text { BH providers }\end{array}$ & $\begin{array}{l}\text { Face-to-face, } \\
\text { telephone } \\
\text { calls to } \\
\text { physicians or } \\
\text { other service } \\
\text { providers } \\
\text { care teams } \\
\text { met with } \\
\text { participants in } \\
\text { their homes } \\
\text { or in other } \\
\text { community } \\
\text { locations } \\
\text { (e.g., library) }\end{array}$ & $\begin{array}{l}\text { Mean staff } \\
\text { contacts }=10.3 \\
\text { per participant } \\
\text { per month, } \\
\text { almost } 6 \text { hours } \\
\text { per participant } \\
\text { per month }\end{array}$ & Usual care \\
\hline
\end{tabular}




\begin{tabular}{|c|c|c|c|c|c|c|c|c|c|}
\hline $\begin{array}{l}\text { First } \\
\text { Author, } \\
\text { Year, } \\
\text { Site(s) }\end{array}$ & $\begin{array}{l}\text { Intervention: } \\
\text { Brief Description }\end{array}$ & $\begin{array}{l}\text { Intervention } \\
\text { Duration }\end{array}$ & $\begin{array}{l}\text { Assessment, } \\
\text { Education, } \\
\text { Skills, } \\
\text { Monitoring }\end{array}$ & $\begin{array}{l}\text { Coordination } \\
\text { and Continuity } \\
\text { of Care }\end{array}$ & $\begin{array}{l}\text { Referral } \\
\text { to/Linkages } \\
\text { to } \\
\text { Community- } \\
\text { Based } \\
\text { Support } \\
\text { Services } \\
\end{array}$ & Providers & $\begin{array}{l}\text { Mode of } \\
\text { Delivery } \\
\text { Setting(s) }\end{array}$ & Intensity & Comparison \\
\hline $\begin{array}{l}\text { Capp et al., } \\
2017^{88} \\
\text { Colorado: } 1 \\
\text { site }\end{array}$ & $\begin{array}{l}\text { Bridges to Care } \\
\text { (B2C), an ED- } \\
\text { initiated, } \\
\text { multidisciplinary, } \\
\text { community-based } \\
\text { program that } \\
\text { provides intensive } \\
\text { medical, } \\
\text { behavioral health, } \\
\text { and social care } \\
\text { coordination } \\
\text { services following } \\
\text { an ED visit or } \\
\text { hospital discharge }\end{array}$ & 60 days & $\begin{array}{l}\text { Depression } \\
\text { screening, } \\
\text { behavioral health } \\
\text { screening, } \\
\text { helping patient } \\
\text { learn } \\
\text { empowerment } \\
\text { skills and using } \\
\text { "teach back" } \\
\text { opportunities to } \\
\text { ensure the } \\
\text { patient } \\
\text { understands } \\
\text { results and next } \\
\text { steps }\end{array}$ & $\begin{array}{l}\text { Patient services } \\
\text { include } \\
\text { coordinating } \\
\text { primary and } \\
\text { specialty care }\end{array}$ & $\begin{array}{l}\text { Care plan } \\
\text { and } \\
\text { associated } \\
\text { patient } \\
\text { services can } \\
\text { include } \\
\text { assistance } \\
\text { with obtaining } \\
\text { housing } \\
\text { resources, } \\
\text { insurance or } \\
\text { disability } \\
\text { benefits, } \\
\text { refugee } \\
\text { services, and } \\
\text { access to } \\
\text { transportation } \\
\text {, and filling } \\
\text { prescriptions }\end{array}$ & $\begin{array}{l}\text { Primary care } \\
\text { provider, care } \\
\text { coordinator, } \\
\text { health coach, } \\
\text { behavioral health } \\
\text { evaluator, and } \\
\text { community } \\
\text { health worker }\end{array}$ & Face-to-face & $\begin{array}{l}\text { First home } \\
\text { visit occurs } 24- \\
72 \text { hours post- } \\
\text { enrollment } \\
\text { date; second } \\
\text { visit is } \\
\text { conducted by } \\
\text { PCP within } 1 \\
\text { week of ED } \\
\text { visit/discharge; } \\
\text { third and } \\
\text { fourth visits } \\
\text { are conducted } \\
\text { within } 30 \text { days } \\
\text { of enrollment. } \\
\text { Fifth and sixth } \\
\text { visits depend } \\
\text { on patient } \\
\text { specific needs. } \\
\text { Final two visits } \\
\text { help patient } \\
\text { transition out } \\
\text { of program. }\end{array}$ & Usual care \\
\hline $\begin{array}{l}\text { Weerahandi } \\
\text { et al., } \\
2015^{119} \\
\text { NYC: } 1 \\
\text { hospital }\end{array}$ & $\begin{array}{l}\text { Preventable } \\
\text { Admissions Care } \\
\text { Team (PACT) } \\
\text { program: social } \\
\text { work transition of } \\
\text { care. }\end{array}$ & 35 days & $\begin{array}{l}\text { Comprehensive } \\
\text { psychosocial } \\
\text { assessment } \\
\text { during } \\
\text { hospitalization }\end{array}$ & $\begin{array}{l}\text { Facilitated } \\
\text { communication } \\
\text { with PCP and } \\
\text { specialists; } \\
\text { collaborated } \\
\text { with caregivers; } \\
\text { scheduled PCP } \\
\text { appointment } \\
\text { within } 10 \text { days } \\
\text { of discharge }\end{array}$ & NR & $\begin{array}{l}\text { MSWs with } \\
\text { experience and } \\
\text { training working } \\
\text { with at-risk, } \\
\text { vulnerable } \\
\text { populations }\end{array}$ & $\begin{array}{l}\text { Phone; face- } \\
\text { to-face: home } \\
\text { visits and } \\
\text { while } \\
\text { attending } \\
\text { appointments }\end{array}$ & NR & $\begin{array}{l}\text { Usual care: } \\
\text { social worker } \\
\text { assistance only } \\
\text { during IP }\end{array}$ \\
\hline
\end{tabular}




\begin{tabular}{|c|c|c|c|c|c|c|c|c|c|}
\hline $\begin{array}{l}\text { First } \\
\text { Author, } \\
\text { Year, } \\
\text { Site(s) }\end{array}$ & $\begin{array}{l}\text { Intervention: } \\
\text { Brief Description }\end{array}$ & $\begin{array}{l}\text { Intervention } \\
\text { Duration }\end{array}$ & $\begin{array}{l}\text { Assessment, } \\
\text { Education, } \\
\text { Skills, } \\
\text { Monitoring }\end{array}$ & $\begin{array}{l}\text { Coordination } \\
\text { and Continuity } \\
\text { of Care }\end{array}$ & $\begin{array}{l}\text { Referral } \\
\text { to/Linkages } \\
\text { to } \\
\text { Community- } \\
\text { Based } \\
\text { Support } \\
\text { Services } \\
\end{array}$ & Providers & $\begin{array}{l}\text { Mode of } \\
\text { Delivery } \\
\text { Setting(s) }\end{array}$ & Intensity & Comparison \\
\hline $\begin{array}{l}\text { Shah et al., } \\
2011^{107} \\
\text { Kern } \\
\text { County, CA: } \\
3 \text { sites }\end{array}$ & $\begin{array}{l}\text { Care } \\
\text { Management } \\
\text { Program (CMP) } \\
\text { for low-income } \\
\text { high utilizers of } \\
\text { hospital services }\end{array}$ & NR & $\begin{array}{l}\text { Assisted in goal } \\
\text { creation/reaching } \\
\text { goals }\end{array}$ & $\begin{array}{l}\text { Care navigation } \\
\text { (schedule } \\
\text { appts, referral } \\
\text { follow up, refill } \\
\text { meds), care } \\
\text { transitions } \\
\text { (assistance in } \\
\text { IP and } \\
\text { discharge), and } \\
\text { communication } \\
\text { with providers } \\
\text { (accompany to } \\
\text { appointments } \\
\text { and followup). }\end{array}$ & $\begin{array}{l}\text { Arranged for } \\
\text { social } \\
\text { services } \\
\text { (connect with } \\
\text { agency staff, } \\
\text { referrals) }\end{array}$ & $\begin{array}{l}\text { Care managers } \\
\text { with experience } \\
\text { as case workers } \\
\text { or medical office } \\
\text { assistants }\end{array}$ & $\begin{array}{l}\text { Face-to-face: } \\
\text { at appoint- } \\
\text { ments, } \\
\text { patients' } \\
\text { homes, or } \\
\text { resource } \\
\text { centers }\end{array}$ & $\begin{array}{l}\text { Met at least } \\
\text { monthly }\end{array}$ & Usual care \\
\hline
\end{tabular}




\begin{tabular}{|c|c|c|c|c|c|c|c|c|c|}
\hline $\begin{array}{l}\text { First } \\
\text { Author, } \\
\text { Year, } \\
\text { Site(s) }\end{array}$ & $\begin{array}{l}\text { Intervention: } \\
\text { Brief Description }\end{array}$ & $\begin{array}{l}\text { Intervention } \\
\text { Duration }\end{array}$ & $\begin{array}{l}\text { Assessment, } \\
\text { Education, } \\
\text { Skills, } \\
\text { Monitoring }\end{array}$ & $\begin{array}{l}\text { Coordination } \\
\text { and Continuity } \\
\text { of Care }\end{array}$ & $\begin{array}{l}\text { Referral } \\
\text { to/Linkages } \\
\text { to } \\
\text { Community- } \\
\text { Based } \\
\text { Support } \\
\text { Services }\end{array}$ & Providers & $\begin{array}{l}\text { Mode of } \\
\text { Delivery } \\
\text { Setting(s) }\end{array}$ & Intensity & Comparison \\
\hline $\begin{array}{l}\text { DeHaven et } \\
\text { al., } 2012^{128} \\
\text { Dallas, TX: } \\
\text { 1 study site }\end{array}$ & $\begin{array}{l}\text { Project Access } \\
\text { Dallas (PAD): } \\
\text { community faith- } \\
\text { health partnership } \\
\text { to improve access } \\
\text { to care and } \\
\text { preventive } \\
\text { services to the } \\
\text { uninsured, care } \\
\text { coordination } \\
\\
\text { Participants } \\
\text { received } \$ 750 \text { a } \\
\text { year in pharmacy } \\
\text { benefits and were } \\
\text { eligible for } \\
\text { laboratory tests, } \\
\text { ancillary } \\
\text { procedures, and } \\
\text { IP hospital care. } \\
\text { CCC pts: more } \\
\text { complex and } \\
\text { chronic problems, } \\
\text { assigned a CHW } \\
\text { Self-care pts: less } \\
\text { serious illnesses, } \\
\text { access to a } \\
\text { telephone help } \\
\text { line for medical } \\
\text { care questions } \\
\text { and CHW } \\
\text { services on } \\
\text { request }\end{array}$ & Up to 1 year & $\begin{array}{l}\text { Intake interview } \\
\text { and HRA to } \\
\text { assign to CCC or } \\
\text { self-care } \\
\text { CCC pts: CHWs } \\
\text { developed care } \\
\text { coordination } \\
\text { plan, taught } \\
\text { health education } \\
\text { and self- } \\
\text { sufficiency }\end{array}$ & $\begin{array}{l}\text { CCC pts: } \\
\text { identified and } \\
\text { addressed } \\
\text { social concerns, } \\
\text { identified } \\
\text { patients with or } \\
\text { at risk of } \\
\text { developing type } \\
2 \text { diabetes, } \\
\text { identified } \\
\text { patients with } \\
\text { depression, } \\
\text { provided ED } \\
\text { and referrals for } \\
\text { cancer } \\
\text { screening, } \\
\text { provided care } \\
\text { coordination } \\
\text { and other } \\
\text { support } \\
\text { services (e.g., } \\
\text { transportation, } \\
\text { translation) }\end{array}$ & $\begin{array}{l}\text { CCW link } \\
\text { patients to } \\
\text { other service } \\
\text { organizations }\end{array}$ & $\begin{array}{l}\text { HRA: } \\
\text { community-clinic } \\
\text { or hospital-based } \\
\text { coordinator } \\
\text { Services: CHWs, } \\
\text { volunteer PCPs, } \\
\text { and specialists }\end{array}$ & $\begin{array}{l}\text { Face-to-face } \\
\text { for CCC pts; } \\
\text { phone for } \\
\text { self-care pts: } \\
\text { in primary } \\
\text { care and } \\
\text { specialty care } \\
\text { offices } \\
\text { Volunteer } \\
\text { PCPs and } \\
\text { specialists } \\
\text { met with } \\
\text { CHWs } \\
\text { monthly to } \\
\text { discuss } \\
\text { patients }\end{array}$ & $\begin{array}{l}\text { CCC pts: at } \\
\text { least monthly } \\
\text { self-care: as } \\
\text { needed }\end{array}$ & Usual care \\
\hline
\end{tabular}




\begin{tabular}{|c|c|c|c|c|c|c|c|c|c|}
\hline $\begin{array}{l}\text { First } \\
\text { Author, } \\
\text { Year, } \\
\text { Site(s) }\end{array}$ & $\begin{array}{l}\text { Intervention: } \\
\text { Brief Description }\end{array}$ & $\begin{array}{l}\text { Intervention } \\
\text { Duration }\end{array}$ & $\begin{array}{l}\text { Assessment, } \\
\text { Education, } \\
\text { Skills, } \\
\text { Monitoring }\end{array}$ & $\begin{array}{l}\text { Coordination } \\
\text { and Continuity } \\
\text { of Care }\end{array}$ & $\begin{array}{l}\text { Referral } \\
\text { to/Linkages } \\
\text { to } \\
\text { Community- } \\
\text { Based } \\
\text { Support } \\
\text { Services }\end{array}$ & Providers & $\begin{array}{l}\text { Mode of } \\
\text { Delivery } \\
\text { Setting(s) }\end{array}$ & Intensity & Comparison \\
\hline $\begin{array}{l}\text { Thompson } \\
\text { et al., } 2018^{95} \\
\text { Memphis, } \\
\text { TN: } 1 \text { site }\end{array}$ & $\begin{array}{l}\text { Familiar Faces } \\
\text { Program } \\
\text { Community } \\
\text { navigators (blend } \\
\text { of CHWs and } \\
\text { patient } \\
\text { navigators) to } \\
\text { bridge gap } \\
\text { between patients } \\
\text { and the } \\
\text { healthcare and } \\
\text { social systems }\end{array}$ & Up to 1 year & $\begin{array}{l}\text { Created a plan } \\
\text { for patients' } \\
\text { health behaviors, } \\
\text { tailored health } \\
\text { information to } \\
\text { client needs, and } \\
\text { motivated them } \\
\text { to make healthy } \\
\text { choices }\end{array}$ & $\begin{array}{l}\text { Helped to } \\
\text { identify and } \\
\text { eliminate } \\
\text { barriers to } \\
\text { health, } \\
\text { coordinated } \\
\text { care }\end{array}$ & $\begin{array}{l}\text { Connecting } \\
\text { patients to } \\
\text { health and } \\
\text { social } \\
\text { resources in } \\
\text { their } \\
\text { community }\end{array}$ & $\begin{array}{l}\text { Community } \\
\text { navigators } \\
\text { employed in the } \\
\text { hospital system } \\
\text { and received the } \\
\text { training }\end{array}$ & $\begin{array}{l}\text { Initial } \\
\text { engagement } \\
\text { was face-to- } \\
\text { face at the } \\
\text { ED/hospital. } \\
\text { The mode of } \\
\text { delivery of } \\
\text { other } \\
\text { services was } \\
\text { not reported }\end{array}$ & NR & Usual care \\
\hline \multicolumn{10}{|c|}{ 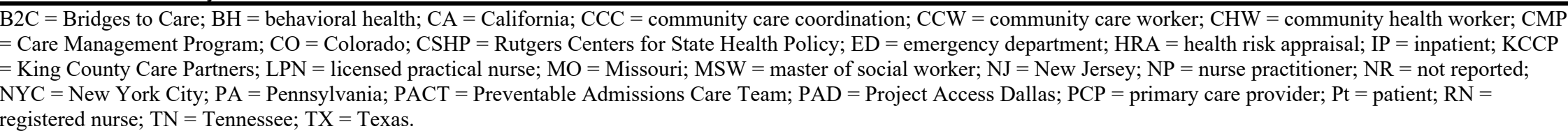 } \\
\hline
\end{tabular}


Table B-33. Healthcare utilization outcomes for community-based model studies

\begin{tabular}{|c|c|c|c|c|}
\hline Utilization Measures & Study Design & $\begin{array}{l}\text { Direction of } \\
\text { Change in } \\
\text { Intervention } \\
\text { Group (G1) }\end{array}$ & $\begin{array}{l}\text { Direction of } \\
\text { Change in } \\
\text { Comparison } \\
\text { Group (G2) }\end{array}$ & Difference \\
\hline \multirow[t]{2}{*}{$\begin{array}{l}\text { 180-day readmissions, } \\
\text { count }\end{array}$} & RCT & NR & NR & aBGD $=0.01(95 \% \mathrm{Cl},-0.25 \text { to } 0.27)^{96}$ \\
\hline & Observational & NR & NR & G1 vs. G2: $p=0.32^{119}$ \\
\hline $\begin{array}{l}\text { 180-day readmissions, any } \\
(\%)\end{array}$ & RCT & NR & NR & $\mathrm{aBGD}=0.82(95 \% \mathrm{Cl},-5.97 \text { to } 7.61)^{96}$ \\
\hline $\begin{array}{l}\text { 180-day readmissions, } \geq 2 \\
(\%)\end{array}$ & RCT & NR & NR & $\mathrm{aBGD}=0.27(95 \% \mathrm{Cl},-6.22 \text { to } 6.77)^{96}$ \\
\hline \multirow[t]{6}{*}{ ED visits, all cause ${ }^{a}$} & RCT & NR & NR & $\mathrm{IRR}=0.85(95 \% \mathrm{Cl}, 0.67$ to 1.08$)(\mathrm{p}>0.05)^{109}$ \\
\hline & RCT & NR & NR & $\mathrm{DiD}=-0.3(95 \% \mathrm{Cl},-5.0$ to 4.5$)(\mathrm{p}=0.91)^{112}$ \\
\hline & Observational & NR & NR & $\begin{array}{l}\mathrm{DiD}=0.057(90 \% \mathrm{Cl},-0.194 \text { to } 0.309) \\
(p=0.704)^{85,124}\end{array}$ \\
\hline & Observational & & $\overline{N R}$ & $\begin{array}{l}\text { Greater reduction in } G 1: R R=0.6748 \\
(p<0.0001)^{107}\end{array}$ \\
\hline & Observational & NR & NR & Greater reduction in G1: NR $(p<0.01)^{126,128}$ \\
\hline & Observational & NR & NR & $\begin{array}{l}\text { Greater reduction in } G 1 \text { than } G 2 \text { : DiD=- } \\
1.623(p<0.01)^{88}\end{array}$ \\
\hline $\begin{array}{l}\text { ED visits at } 270 \text { days, all } \\
\text { cause }\end{array}$ & Observational & NR & NR & $\begin{array}{l}\text { Greater reduction in } G 1 \text { than } G 2 \text { : DiD=- } \\
1.091(p<0.01)^{88}\end{array}$ \\
\hline $\begin{array}{l}\text { ED visits at } 180 \text { days, all } \\
\text { cause }\end{array}$ & Observational & & & $\begin{array}{l}\text { Greater reduction in G1 than G2: DiD=- } \\
1.005(p<0.01)^{88}\end{array}$ \\
\hline ED visit, any & RCT & NR & NR & $\mathrm{DiD}=0.96(95 \% \mathrm{Cl}, 0.67$ to 1.38$)(\mathrm{p}=0.82)^{112}$ \\
\hline Emergency psychiatric visits & RCT & NR & NR & $\begin{array}{l}\text { Greater reduction in G1 than G2: IRR=0.62 } \\
(95 \% \mathrm{Cl}, 0.43 \text { to } 0.91)(p<0.05)^{109}\end{array}$ \\
\hline \multirow{5}{*}{$\begin{array}{l}\text { Inpatient admissions, all } \\
\text { cause }^{a}\end{array}$} & RCT & NR & NR & IRR=0.97 $(95 \% \mathrm{Cl}, 0.70$ to 1.35$)(\mathrm{p}>0.05)^{109}$ \\
\hline & RCT & NR & NR & $\mathrm{DiD}=0.3(95 \% \mathrm{Cl},-1.2$ to 1.9$)(\mathrm{p}=0.68)^{112}$ \\
\hline & Observational & NR & NR & DiD: $-0.116(90 \% \mathrm{Cl},-0.252 \text { to } 0.020)^{85,124}$ \\
\hline & Observational & 乃 & NR & RR: $0.8070(p=0.3771)^{107}$ \\
\hline & Observational & NR & NR & $\begin{array}{l}\text { Greater reduction in G1 than G2: DiD=- } \\
0.906(p<0.01)^{88}\end{array}$ \\
\hline $\begin{array}{l}\text { Inpatient admissions at } 270 \\
\text { days, all cause }\end{array}$ & Observational & NR & NR & $\begin{array}{l}\text { Greater reduction in } \mathrm{G} 1 \text { than } \mathrm{G} 2 \text { : DiD=- } \\
0.438(p<0.01)^{88}\end{array}$ \\
\hline $\begin{array}{l}\text { Inpatient admissions at } 180 \\
\text { days, all cause }\end{array}$ & Observational & $\Omega$ & $\Omega$ & $\mathrm{DiD}=-0.159(p<0.1)^{88}$ \\
\hline Inpatient admissions, any & RCT & NR & NR & $\mathrm{DiD}=0.92(95 \% \mathrm{Cl}, 0.66$ to 1.27$)(\mathrm{p}=0.60)^{112}$ \\
\hline Inpatient admissions, ACSC & Observational & NR & NR & $\mathrm{DiD}=-0.027(90 \% \mathrm{Cl},-0.081 \text { to } 0.028)^{85,124}$ \\
\hline Inpatient psychiatric stays & RCT & NR & NR & $\mathrm{IRR}=0.73(95 \% \mathrm{Cl}, 0.36$ to 1.45$)(\mathrm{p}>0.05)^{109}$ \\
\hline \multirow[t]{5}{*}{ Inpatient days } & RCT & NR & NR & aBGD $=-0.32(95 \% \mathrm{Cl},-2.17 \text { to } 1.53)^{96}$ \\
\hline & $\mathrm{RCT}$ & NR & NR & IRR=1.12 (95\% Cl, 0.79 to 1.59) $(p>0.05)^{109}$ \\
\hline & Observational & $\Omega$ & NR & RR: NR $(p=N S)^{107}$ \\
\hline & Observational & NR & NR & Greater reduction in G1: NR $(p<0.05)^{126,128}$ \\
\hline & Observational & & & $\begin{array}{l}\text { Greater reduction in G1 than G2: DiD: }-8 \\
(95 \% \mathrm{Cl},-14 \text { to }-2)^{95}\end{array}$ \\
\hline Total hospital encounters & Observational & & & $\begin{array}{l}\text { Greater reduction in G1 than G2: DiD: }-13 \\
(95 \% \mathrm{Cl},-19 \text { to }-6)^{95}\end{array}$ \\
\hline
\end{tabular}




\begin{tabular}{|c|c|c|c|c|}
\hline Utilization Measures & Study Design & $\begin{array}{l}\text { Direction of } \\
\text { Change in } \\
\text { Intervention } \\
\text { Group (G1) }\end{array}$ & $\begin{array}{l}\text { Direction of } \\
\text { Change in } \\
\text { Comparison } \\
\text { Group (G2) }\end{array}$ & Difference \\
\hline $\begin{array}{l}\text { Hospital encounter resulted } \\
\text { in discharge to hospital or } \\
\text { observation stay }\end{array}$ & Observational & & & $\begin{array}{l}\text { Greater reduction in G1 than G2: DiD: }-12 \\
(95 \% \mathrm{Cl},-19 \text { to }-5)^{95}\end{array}$ \\
\hline $\begin{array}{l}\text { Hospital encounter resulted } \\
\text { in discharge from ED }\end{array}$ & Observational & & & $\begin{array}{l}\text { Greater reduction in G1 than G2: DiD: }-12 \\
(95 \% \mathrm{Cl},-19 \text { to }-4)^{95}\end{array}$ \\
\hline Outpatient visit & RCT & $\overline{N R}$ & $\overline{N R}$ & $\begin{array}{l}\mathrm{DiD}=-0.11(95 \% \mathrm{Cl},-0.51 \text { to } 0.28) \\
(p=0.58)^{112}\end{array}$ \\
\hline $\begin{array}{l}\text { Outpatient substance use } \\
\text { treatment visits }\end{array}$ & RCT & NR & NR & $\mathrm{IRR}=0.76(95 \% \mathrm{Cl}, 0.46$ to 1.24$)(\mathrm{p}>0.05)^{109}$ \\
\hline $\begin{array}{l}\text { Outpatient mental health } \\
\text { visits }\end{array}$ & $\mathrm{RCT}$ & NR & NR & $\begin{array}{l}\text { Greater increase in G1 than G2: IRR=1.84 } \\
(95 \% \mathrm{Cl}, 1.43 \text { to } 2.37)(p<0.01)^{109}\end{array}$ \\
\hline $\begin{array}{l}\text { Outpatient mental health } \\
\text { visit, any }\end{array}$ & RCT & NR & NR & $\begin{array}{l}\text { Greater increase in G1 than G2: DiD=1.30 } \\
(95 \% \mathrm{Cl}, 1.07 \text { to } 1.58)(p<0.01)^{112}\end{array}$ \\
\hline $\begin{array}{l}\text { Primary care visits at } 360 \\
\text { days, all cause }\end{array}$ & Observational & NR & NR & $\begin{array}{l}\text { Greater increase in G1 than G2: DiD=1.932 } \\
(p<0.01)^{88}\end{array}$ \\
\hline $\begin{array}{l}\text { Primary care visits at } 270 \\
\text { days, all cause }\end{array}$ & Observational & NR & NR & $\begin{array}{l}\text { Greater increase in G1 than G2: DiD }=1.517 \\
(p<0.01)^{88}\end{array}$ \\
\hline $\begin{array}{l}\text { Primary care visits at } 180 \\
\text { days }\end{array}$ & Observational & & & $\begin{array}{l}\text { Greater increase in } G 1 \text { than } G 2: \text { DiD }=1.218 \\
(p<0.01)^{88}\end{array}$ \\
\hline Prescription drugs, any & RCT & NR & NR & $\begin{array}{l}\mathrm{DiD}=1.99(95 \% \mathrm{Cl}, 0.29 \text { to } 13.70) \\
(p=0.49)^{112}\end{array}$ \\
\hline Long-term care, any & RCT & $\overline{N R}$ & NR & $\mathrm{DiD}=1.09(95 \% \mathrm{Cl}, 0.88$ to 1.35$)(\mathrm{p}=0.42)^{112}$ \\
\hline
\end{tabular}

${ }^{a}$ Followup time for the outcomes was 12 months for CHSP, ${ }^{85,124} \mathrm{CMP},{ }^{107}$ and PAD ${ }^{126,128}$ and 360 days for B2C. ${ }^{88}$

- Increase in the outcome between the intervention period and the baseline period; the difference between the intervention and comparison groups was statistically significant.

- Reduction in the outcome between the intervention period and the baseline period; the difference between the intervention and comparison groups was statistically significant.

$\sqrt{S}=$ Reduction in the outcome between the intervention period and the baseline period; the difference between the intervention and comparison groups was not statistically significant.

aBGD = adjusted between-group difference; $\mathrm{ACSC}=$ ambulatory care sensitive conditions; $\mathrm{CI}=$ confidence interval; $\mathrm{DiD}=$ difference-in-difference; $\mathrm{ED}=$ emergency department; $\mathrm{G}=$ group; IRR = incidence rate ratio; $\mathrm{NR}=$ not reported; $\mathrm{NS}=$ not statistically significant; $\mathrm{RCT}=$ randomized controlled trial; $\mathrm{RR}=$ relative risk. 
Table B-34. Healthcare utilization outcomes for community-based model studies: Subgroup outcomes

\begin{tabular}{|c|c|c|c|c|}
\hline Utilization Measures & Study Design & $\begin{array}{l}\text { Direction of } \\
\text { Change in } \\
\text { Intervention } \\
\text { Group (G1) } \\
\end{array}$ & $\begin{array}{l}\text { Direction of } \\
\text { Change in } \\
\text { Comparison } \\
\text { Group (G2) }\end{array}$ & Difference \\
\hline $\begin{array}{l}\text { ED visits at } 180 \text { days, all } \\
\text { cause }\end{array}$ & Observational & & & $\begin{array}{l}\text { Patients with a mental health diagnosis } \\
\text { subgroup: Greater reduction in } \mathrm{G} 1 \text { than } \mathrm{G} 2 \text { : } \\
\text { DiD=-1.377 }(p<0.01)^{88}\end{array}$ \\
\hline $\begin{array}{l}\text { Inpatient admissions at } \\
180 \text { days, all cause }\end{array}$ & Observational & & & $\begin{array}{l}\text { Patients with a mental health diagnosis } \\
\text { subgroup: Greater reduction in } \mathrm{G} 1 \text { than } \mathrm{G} 2 \text { : } \\
\mathrm{DiD}=-0.417(p<0.01)^{88}\end{array}$ \\
\hline $\begin{array}{l}\text { Primary care visits at } \\
180 \text { days }\end{array}$ & Observational & & & $\begin{array}{l}\text { Patients with a mental health diagnosis } \\
\text { subgroup: Greater increase in } G 1 \text { than } G 2 \text { : } \\
\text { DiD=1.404 }(p<0.01)^{88}\end{array}$ \\
\hline
\end{tabular}

- Increase in the outcome between the intervention period and the baseline period; the difference between the intervention and comparison groups was statistically significant.

- Reduction in the outcome between the intervention period and the baseline period; the difference between the intervention and comparison groups was statistically significant.

$\mathrm{DiD}=$ difference-in-difference; $\mathrm{ED}=$ emergency department; $\mathrm{G}=$ group. 
Table B-35. Strength of evidence for community-based models versus usual-care outcomes

\begin{tabular}{|c|c|c|c|c|c|}
\hline Population & Outcome & Results & $\begin{array}{l}\text { Study } \\
\text { Design and } \\
\text { Sample Size }\end{array}$ & $\begin{array}{l}\text { Strength of } \\
\text { Evidence Domains }\end{array}$ & $\begin{array}{l}\text { Overall Evidence } \\
\text { Strength (Direction of } \\
\text { Effect) }\end{array}$ \\
\hline $\begin{array}{l}\mathrm{HNHC} \\
\text { patients }\end{array}$ & $\begin{array}{l}\text { 180-day } \\
\text { readmissi } \\
\text { ons }\end{array}$ & $\begin{array}{l}\text { Camden RCT: } \\
\text { aBGD=0.01 }(95 \% \mathrm{Cl},- \\
0.25 \text { to } 0.27) ; 96 \\
\text { PACT: RR: NR } \\
(p=0.32)^{119}\end{array}$ & $\begin{array}{l}1 \mathrm{RCT} \\
\mathrm{N}=800 \\
1 \mathrm{OBS} \\
\mathrm{N}=1,158\end{array}$ & $\begin{array}{l}\text { Moderate study } \\
\text { limitations, } \\
\text { consistency unknown, } \\
\text { imprecise, direct }\end{array}$ & Insufficient \\
\hline $\begin{array}{l}\mathrm{HNHC} \\
\text { patients }\end{array}$ & $\begin{array}{l}\text { ED visits, } \\
\text { all cause }\end{array}$ & $\begin{array}{l}\text { PWH: IRR=0.85 }(95 \% \\
\mathrm{Cl}, 0.67 \text { to } 1.08)^{109} \\
\mathrm{KCCP}: \mathrm{DiD}=-0.3(95 \% \\
\mathrm{Cl},-5.0 \text { to } 4.5)^{112} \\
\mathrm{CSHP} \text { DiD: } 0.057(90 \% \\
\mathrm{Cl},-0.194 \text { to } 0.309) \\
(p=0.704)^{85,}, 124 \\
\mathrm{~B} 2 \mathrm{C}: \mathrm{Greater} \text { reduction } \\
\text { in } \mathrm{G} 1: \mathrm{DiD}=-1.623 \\
(p<0.01)^{88} \\
\mathrm{CMP}: \mathrm{Greater} \text { reduction } \\
\text { in G1: RR=0.6748 } \\
(p<0.0001)^{107} \\
\mathrm{PAD}: \mathrm{Greater} \text { reduction } \\
\text { in G1: NR }(p<0.01)^{126,} \\
\text { 128 }\end{array}$ & $\begin{array}{l}2 \text { RCTs, } \\
\mathrm{N}=1,543 \\
4 \mathrm{OBSs} \\
\mathrm{N}=5,913\end{array}$ & $\begin{array}{l}\text { High study limitations } \\
\text { (two high RoB OBS } \\
\text { studies), }{ }^{07,126,128} \\
\text { inconsistent, } \\
\text { imprecise, direct }\end{array}$ & Insufficient (Mixed findings) \\
\hline $\begin{array}{l}\mathrm{HNHC} \\
\text { patients }\end{array}$ & $\begin{array}{l}\text { Inpatient } \\
\text { admission } \\
\mathrm{s}, \text { all } \\
\text { cause }\end{array}$ & $\begin{array}{l}\text { CSHP DiD: }-0.116 \\
(90 \% \mathrm{Cl},-0.252 \text { to } \\
0.020)^{85,124} \\
\text { CMP: RR: } 0.8070 \\
(p=0.38)^{107} \\
\text { B2C: Greater reduction } \\
\text { in G1: DiD=-0.906 } \\
(p<0.01)^{88}\end{array}$ & $\begin{array}{l}3 \text { OBSs, } \\
N=5,339\end{array}$ & $\begin{array}{l}\text { Moderate study } \\
\text { limitations (one high } \\
\text { RoB OBS studies), }{ }^{107} \\
\text { consistent, imprecise, } \\
\text { direct }\end{array}$ & Insufficient \\
\hline $\begin{array}{l}\mathrm{HNHC} \\
\text { patients }\end{array}$ & $\begin{array}{l}\text { Inpatient } \\
\text { days }\end{array}$ & $\begin{array}{l}\text { Camden RCT: aBGD=- } \\
0.32(95 \% \mathrm{Cl},-2.17 \text { to } \\
1.53)^{96} \\
\text { PWH: IRR=1.12 }(95 \% \\
\mathrm{Cl}, 0.79 \text { to } 1.59)^{109} \\
\mathrm{CMP}: \mathrm{RR} \text { : NR } \\
(\mathrm{p}=\mathrm{NS})^{107} \\
\text { PAD: Greater reduction } \\
\text { in G1: NR (p<0.05) })^{126,} \\
\text { 128 } \\
\text { Familiar Faces: Greater } \\
\text { reduction in G1 than } \\
\text { G2: DiD: }-8 \%(95 \% \mathrm{Cl},- \\
14 \% \text { to }-2 \%)^{95}\end{array}$ & $\begin{array}{l}2 \text { RCTs, } \\
N=1,223 \\
3 \text { OBSs, } \\
N=1,271\end{array}$ & $\begin{array}{l}\text { High study limitations } \\
\text { (three high RoB } \\
\text { studies), }{ }^{95,107,126,128} \\
\text { inconsistent, } \\
\text { imprecise, direct }\end{array}$ & Insufficient (Mixed findings) \\
\hline $\begin{array}{l}\mathrm{HNHC} \\
\text { patients }\end{array}$ & $\begin{array}{l}\text { Total } \\
\text { costs }\end{array}$ & $\begin{array}{l}\text { KCCP: DiD=51 }(95 \% \\
\text { Cl, }-242 \text { to } 344)^{112} \\
\text { CSHP DiD: }-1405(90 \% \\
\text { Cl, }-3509 \text { to } 700) \\
(p=0.268) ; 85,124 \\
\text { Familiar Faces: DiD: - } \\
4903(95 \% \mathrm{Cl},-\$ 13,579 \\
\text { to } \$ 3774)^{95}\end{array}$ & $\begin{array}{l}1 \mathrm{RCT} \\
\mathrm{N}=1,120 \\
2 \text { OBSs, } \\
\mathrm{N}=1,718\end{array}$ & $\begin{array}{l}\text { High study limitations } \\
\text { (one high RoB OBS } \\
\text { studies), }{ }^{95} \\
\text { inconsistent, } \\
\text { imprecise, direct }\end{array}$ & Insufficient \\
\hline $\begin{array}{l}\mathrm{HNHC} \\
\text { patients }\end{array}$ & $\begin{array}{l}\text { Inpatient } \\
\text { costs }\end{array}$ & $\begin{array}{l}\text { KCCP: DiD=-12 }(95 \% \\
\text { Cl, }-260 \text { to } 236)^{112} \\
\text { CSHP DiD }=-120(90 \% \\
\text { Cl, }-1891 \text { to } 1652)^{85,124}\end{array}$ & $\begin{array}{l}1 \mathrm{RCT} \\
\mathrm{N}=1,120 \\
1 \mathrm{OBS} \\
\mathrm{N}=1,279\end{array}$ & $\begin{array}{l}\text { Moderate study } \\
\text { limitations, consistent, } \\
\text { imprecise, direct }\end{array}$ & Insufficient \\
\hline
\end{tabular}




\begin{tabular}{|c|c|c|c|c|c|}
\hline Population & Outcome & Results & $\begin{array}{l}\text { Study } \\
\text { Design and } \\
\text { Sample Size }\end{array}$ & $\begin{array}{l}\text { Strength of } \\
\text { Evidence Domains }\end{array}$ & $\begin{array}{l}\text { Overall Evidence } \\
\text { Strength (Direction of } \\
\text { Effect) }\end{array}$ \\
\hline $\begin{array}{l}\mathrm{HNHC} \\
\text { patients }\end{array}$ & ED costs & $\begin{array}{l}\text { KCCP: } \mathrm{DiD}=-8(95 \% \mathrm{Cl} \text {, } \\
\text {-26 to } 10)^{112} \\
\text { PAD: Lower costs in } \\
\text { G1: NR }(p=0.01)^{126,128}\end{array}$ & $\begin{array}{l}1 \mathrm{RCT} \\
\mathrm{N}=1,120 \\
1 \mathrm{OBS} \\
\mathrm{N}=574\end{array}$ & $\begin{array}{l}\text { High study limitations } \\
\text { (one high RoB OBS } \\
\text { studies), }{ }^{126,128} \\
\text { consistent, imprecise, } \\
\text { direct }\end{array}$ & Insufficient \\
\hline $\begin{array}{l}\mathrm{HNHC} \\
\text { patients }\end{array}$ & Mortality & $\begin{array}{l}\text { Camden RCT: adjusted } \\
\text { difference }=-1.17(95 \% \\
\text { Cl, }-5.25 \text { to } 2.91)^{96} \\
\text { PWH: Difference }=3.9 \% \\
\text { (P NR) } \\
\text { KCCP: aOR=0.65 }(95 \% \\
\text { Cl, } 0.39 \text { to } 1.09)^{112}\end{array}$ & $\begin{array}{l}3 \text { RCTs, } \\
\mathrm{N}=2,343\end{array}$ & $\begin{array}{l}\text { Moderate study } \\
\text { limitations, consistent, } \\
\text { imprecise, direct }\end{array}$ & Low (No difference) \\
\hline
\end{tabular}


Table B-36. Cost outcomes for community-based model studies

\begin{tabular}{|c|c|c|c|c|}
\hline Cost Measures & Study Design & $\begin{array}{l}\text { Direction of } \\
\text { Change in } \\
\text { Intervention } \\
\text { Group (G1) }\end{array}$ & $\begin{array}{l}\text { Direction of } \\
\text { Change in } \\
\text { Comparison } \\
\text { Group (G2) }\end{array}$ & Difference \\
\hline Hospital charges & RCT & NR & NR & $\begin{array}{l}\text { aBGD }=3,722(95 \% \mathrm{Cl},-23,438 \text { to } \\
30,882)^{66}\end{array}$ \\
\hline $\begin{array}{l}\text { Hospital payments } \\
\text { received }\end{array}$ & RCT & NR & NR & $\begin{array}{l}\text { aBGD }=680(95 \% \mathrm{Cl},-3,415 \text { to } \\
4,775)^{96}\end{array}$ \\
\hline \multirow[t]{3}{*}{ Total costs } & RCT & NR & NR & $\begin{array}{l}\mathrm{DiD}=51(95 \% \mathrm{Cl},-242 \text { to } 344) \\
(p=0.73)^{112}\end{array}$ \\
\hline & Observational & NR & NR & $\begin{array}{l}\text { DiD: }-1,405(90 \% \mathrm{Cl},-3,509 \text { to } 700) \\
(p=0.268)^{85,124}\end{array}$ \\
\hline & Observational & 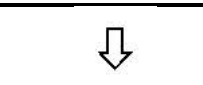 & Љ & $\begin{array}{l}\text { DiD: }-4,903(95 \% \mathrm{Cl},-\$ 13,579 \text { to } \\
\$ 3774)^{95}\end{array}$ \\
\hline \multirow[t]{2}{*}{ Inpatient costs } & RCT & NR & NR & $\begin{array}{l}\text { DiD=-12 (95\% Cl, }-260 \text { to } 236) \\
(p=0.92)^{112}\end{array}$ \\
\hline & Observational & NR & NR & $\begin{array}{l}\text { DiD: }-120(90 \% \mathrm{Cl},-1,891 \text { to } 1,652) \\
(p=0.911)^{85,124}\end{array}$ \\
\hline \multirow[t]{2}{*}{ ED costs } & RCT & NR & NR & $\begin{array}{l}\mathrm{DiD}=-8(95 \% \mathrm{Cl},-26 \text { to } 10) \\
(p=0.38)^{112}\end{array}$ \\
\hline & Observational & NR & NR & $\begin{array}{l}\text { Lower costs in G1: }{ }^{a} \mathrm{NR}(p=0.01)^{126} \text {, } \\
\text {, }\end{array}$ \\
\hline Indirect ED costs & Observational & NR & NR & $\begin{array}{l}\text { Lower costs in } \mathrm{G} 1:^{\mathrm{b}} \mathrm{NR}(\mathrm{p}=0.03)^{126} \text {, } \\
\text { 128 }\end{array}$ \\
\hline Outpatient costs & RCT & NR & NR & $\begin{array}{l}\mathrm{DiD}=31(95 \% \mathrm{Cl},-47 \text { to } 109) \\
(p=0.43)^{112}\end{array}$ \\
\hline Prescription drug costs & RCT & NR & NR & $\begin{array}{l}\text { Greater increase in G1 than G2: } \\
D i D=74(95 \% \mathrm{Cl}, 3 \text { to } 145) \\
(p=0.048)^{112}\end{array}$ \\
\hline Long-term care costs & RCT & NR & NR & $\begin{array}{l}\mathrm{DiD}=36(95 \% \mathrm{Cl},-35 \text { to } 107) \\
(p=0.33)^{112}\end{array}$ \\
\hline
\end{tabular}

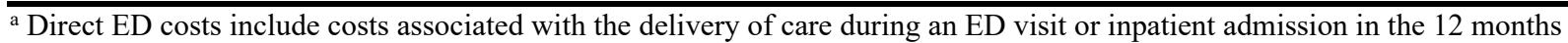
following enrollment.

${ }^{\mathrm{b}}$ Indirect ED costs are the fixed costs related to building, maintenance, staffing, and utilities in the 12 months following enrollment.

$\Omega=$ Reduction in the outcome between the intervention period and the baseline period; the difference between the intervention and comparison groups was not statistically significant.

aBGD = adjusted between-group difference; $\mathrm{CI}=$ confidence interval; $\mathrm{DiD}=$ difference-in-difference $\mathrm{ED}=\mathrm{emergency}$ department; $\mathrm{G}=$ group; $\mathrm{NR}=$ not reported; $\mathrm{RCT}$ = randomized controlled trial.

Table B-37. Clinical and functional outcomes for community-based model studies

\begin{tabular}{lll}
\hline $\begin{array}{l}\text { Clinical and Functional } \\
\text { Outcomes }\end{array}$ & Study Design & $\begin{array}{l}\text { Difference Between Intervention Group (G1) and } \\
\text { Comparison Group (G2) }\end{array}$ \\
\hline Mortality & RCT & Difference=-1.17 (95\% Cl, -5.25 to 2.91$)^{96}$ \\
\cline { 2 - 3 } & RCT & \\
\cline { 2 - 3 } & RCT & aOR=0.65 (95\% Cl, 0.39 to 1.09$)(p=0.10)^{112}$
\end{tabular}

$\mathrm{aOR}=$ adjusted odds ratio; $\mathrm{CI}=$ confidence interval; $\mathrm{G}=$ group $\mathrm{NR}=$ not reported; $\mathrm{RCT}=$ randomized controlled trial. 
Table B-38. Social risk outcomes for community-based model studies

\begin{tabular}{|c|c|c|}
\hline Social Risk Outcomes & Study Design & Difference \\
\hline $\begin{array}{l}\text { Participation in supplemental nutrition } \\
\text { assistance program (\%) }\end{array}$ & RCT & $\mathrm{AD}=4.59(95 \% \mathrm{Cl}, 0.52 \text { to } 8.65)^{96}$ \\
\hline $\begin{array}{l}\text { Receipt of temporary assistance for needy } \\
\text { families }(\%)\end{array}$ & $\mathrm{RCT}$ & $\mathrm{AD}=0.69(95 \% \mathrm{Cl},-0.34 \text { to } 1.71)^{96}$ \\
\hline Receipt of general assistance (\%) & RCT & $\mathrm{AD}=0.68(95 \% \mathrm{Cl},-1.82 \text { to } 3.18)^{96}$ \\
\hline Ever housed & RCT & $\begin{array}{l}\text { Greater increase in } \mathrm{G} 1 \text { than } \mathrm{G} 2 \text { : IRR=1.84 }(95 \% \mathrm{Cl} \text {, } \\
1.43 \text { to } 2.37)(p<0.01)^{109}\end{array}$ \\
\hline Any homeless months & RCT & $\mathrm{DiD}=0.83(95 \% \mathrm{Cl}, 0.60$ to 1.17$)(\mathrm{p}=0.29)^{112}$ \\
\hline Homeless months (mean per 1,000 months) & $\mathrm{RCT}$ & $\mathrm{DiD}=-1.5(95 \% \mathrm{Cl},-4.3$ to 1.3$)(\mathrm{p}=0.29)^{112}$ \\
\hline Jail stays & RCT & IRR=1.01 (95\% Cl, 0.73 to 1.40$)(p>0.05)^{109}$ \\
\hline Any criminal convictions & RCT & $\mathrm{DiD}=1.95(95 \% \mathrm{Cl}, 1.10$ to 3.44$)(\mathrm{p}=0.02)^{112}$ \\
\hline Criminal convictions (mean per 1,000 months) & RCT & $\mathrm{DiD}=8.9(95 \% \mathrm{Cl},-1.5$ to 19.3$)(\mathrm{p}=0.09)^{112}$ \\
\hline Shelter days & RCT & $\begin{array}{l}\text { Greater reduction in } \mathrm{G} 1 \text { than } \mathrm{G} 2: \mathrm{IRR}=0.30(95 \% \\
\mathrm{Cl}, 0.17 \text { to } 0.53)(\mathrm{p}<0.01)^{109}\end{array}$ \\
\hline Any drug/alcohol treatment & RCT & $\mathrm{DiD}=0.92(95 \% \mathrm{Cl}, 0.65$ to 1.30$)(\mathrm{p}=0.62)^{112}$ \\
\hline
\end{tabular}

$\mathrm{AD}=$ adjusted difference; $\mathrm{CI}=$ confidence interval; $\mathrm{DiD}=$ difference-in-difference; $\mathrm{G}=$ group; $\mathrm{IRR}=$ incidence rate ratio; $\mathrm{RCT}$ $=$ randomized controlled trial. 
Table B-39. Study characteristics of ED-based care model interventions

\begin{tabular}{|c|c|c|c|c|c|c|}
\hline $\begin{array}{l}\text { First Author, } \\
\text { Year, Site(s) }\end{array}$ & Sample Size & $\begin{array}{l}\text { Study Design } \\
\text { (Risk of Bias } \\
\text { Assessment) }\end{array}$ & $\begin{array}{l}\text { Patient } \\
\text { Selection: High } \\
\text { Healthcare Use } \\
\text { or Cost; Time } \\
\text { Period }\end{array}$ & $\begin{array}{l}\text { Patient } \\
\text { Selection: } \\
\text { Chronic } \\
\text { Conditions }\end{array}$ & $\begin{array}{l}\text { Patient } \\
\text { Selection: Other }\end{array}$ & $\begin{array}{l}\text { Additional } \\
\text { Selected Patient } \\
\text { Characteristics }\end{array}$ \\
\hline $\begin{array}{l}\text { Kelley et al., } \\
2020^{110} \\
\text { New Haven, } \\
\text { CT: } 1 \text { site }\end{array}$ & $\begin{array}{l}(\mathrm{N}=100) \\
\text { Intervention } \\
(\mathrm{N}=49) \\
\text { Comparison } \\
(\mathrm{N}=51)\end{array}$ & $\begin{array}{l}\text { RCT (ROB: } \\
\text { low) }\end{array}$ & $\begin{array}{l}\text { 4-18 ED visits in } \\
\text { past year }\end{array}$ & NA & $\begin{array}{l}18-62 \text { years, } \\
\text { active Medicaid } \\
\text { insurance, } \\
\text { resident of one of } \\
12 \text { surrounding } \\
\text { towns, and } \\
\text { English or } \\
\text { Spanish } \\
\text { speaking }\end{array}$ & $\begin{array}{l}\text { Mean age: } 40 \\
\text { Nonwhite: } 82 \% \\
\text { Medicaid: } 100 \% \\
\text { Medicare: NR }\end{array}$ \\
\hline $\begin{array}{l}\text { Lin et al., } \\
2017^{111} \\
\text { Boston, MA: } 1 \\
\text { site }\end{array}$ & $\begin{array}{l}(\mathrm{N}=72) \\
\text { Intervention } \\
(\mathrm{N}=36) \\
\text { Comparison } \\
(\mathrm{N}=36)\end{array}$ & $\begin{array}{l}\text { RCT (ROB: } \\
\text { some } \\
\text { concerns) }\end{array}$ & $\begin{array}{l}\text { Most ED visits } \\
\text { during the } 30- \\
\text { day period and } \\
12-\text { month period } \\
\text { preceding the } \\
\text { introduction of } \\
\text { the program }\end{array}$ & NA & NA & $\begin{array}{l}\text { Mean age: } 48 \\
\text { Nonwhite: } 57 \% \\
\text { Medicaid: } 44 \% \\
\text { Medicare: } 43 \%\end{array}$ \\
\hline $\begin{array}{l}\text { Shumway et } \\
\text { al., } 2008^{116} \\
\text { San Francisco, } \\
\text { CA: } 1 \text { hospital }\end{array}$ & $\begin{array}{l}\mathrm{N}=252) \\
\text { Intervention } \\
(\mathrm{N}=167) \\
\text { Comparison } \\
(\mathrm{N}=85)\end{array}$ & $\begin{array}{l}\text { RCT } \\
\text { (RoB: some } \\
\text { concerns) }\end{array}$ & $\begin{array}{l}5+\text { ED visits in } \\
\text { past } 1 \text { year }\end{array}$ & $\mathrm{NA}$ & $\begin{array}{l}\text { Age: } 18+; \\
\text { psychosocial } \\
\text { problems that } \\
\text { could be } \\
\text { addressed with } \\
\text { case } \\
\text { management }\end{array}$ & $\begin{array}{l}\text { Nonwhite: } 87 \% \text {; } \\
\text { Homeless: } 81 \% \\
\text { Alcohol problems, } \\
\text { alcohol use: } 57 \% \\
\text { Lack health } \\
\text { insurance: } 67 \% \\
\text { Charlson } \\
\text { Comorbidity Index } \\
\text { (Mean [SD]): } 1.4 \\
\text { (2.2) } \\
\text { Most common } \\
\text { diagnosis in prior } 1 \\
\text { year: mental } \\
\text { disorders, } 22 \%\end{array}$ \\
\hline $\begin{array}{l}\text { Seaberg et al., } \\
2017^{118} \\
\text { Chattanooga, } \\
\text { TN metro area: } \\
5 \text { sites }\end{array}$ & $\begin{array}{l}\mathrm{N}=304) \\
\text { Intervention } \\
(\mathrm{N}=163) \\
\text { Comparison } \\
(\mathrm{N}=141)\end{array}$ & $\begin{array}{l}\text { RCT } \\
\text { (RoB: some } \\
\text { concerns) }\end{array}$ & $\begin{array}{l}5+\text { ED visits in } \\
\text { past } 1 \text { year }\end{array}$ & $\mathrm{NA}$ & NA & NA \\
\hline
\end{tabular}




\begin{tabular}{|c|c|c|c|c|c|c|}
\hline $\begin{array}{l}\text { First Author, } \\
\text { Year, Site(s) }\end{array}$ & Sample Size & $\begin{array}{l}\text { Study Design } \\
\text { (Risk of Bias } \\
\text { Assessment) }\end{array}$ & $\begin{array}{l}\text { Patient } \\
\text { Selection: high } \\
\text { Healthcare Use } \\
\text { or Cost; Time } \\
\text { Period }\end{array}$ & $\begin{array}{l}\text { Patient } \\
\text { Selection: } \\
\text { Chronic } \\
\text { Conditions }\end{array}$ & $\begin{array}{l}\text { Patient } \\
\text { Selection: Other }\end{array}$ & $\begin{array}{l}\text { Additional } \\
\text { Selected Patient } \\
\text { Characteristics }\end{array}$ \\
\hline $\begin{array}{l}\text { Enard and } \\
\text { Ganelin, } \\
2013^{127} \\
\text { Houston, TX: } 1 \\
\text { site }\end{array}$ & $\begin{array}{l}\mathrm{N}=13,642) \\
\text { Intervention } \\
(\mathrm{N}=1,905) \\
\text { Comparison } \\
(\mathrm{N}=11,737)\end{array}$ & $\begin{array}{l}\text { Observational } \\
\text { study } \\
\text { (RoB: high) }\end{array}$ & $\begin{array}{l}\text { Frequent use of } \\
\text { the ED for } \\
\text { primary care, } \\
\text { data included } \\
\text { visits to any of } \\
\text { the } 9 \text { EDs in the } \\
\text { healthcare } \\
\text { system, } \\
\text { receiving urgent } \\
\text { or primary care } \\
\text { in the ED (levels } \\
3,4 \text {, and } 5 \\
\text { medical } \\
\text { decisions of } \\
\text { minimal to } \\
\text { moderate } \\
\text { complexity but } \\
\text { may be } \\
\text { considered PCP } \\
\text { patients) in past } \\
1 \text { year }\end{array}$ & NA & $\begin{array}{l}\text { Age: 18-64; on } \\
\text { Medicaid, } \\
\text { uninsured/self- } \\
\text { pay, or covered } \\
\text { by TX public } \\
\text { health benefit }\end{array}$ & $\begin{array}{l}\text { Nonwhite: } 82 \% \\
\text { Age 18-34: } 58.6 \% \\
\text { Uninsured: } 62.7 \%\end{array}$ \\
\hline $\begin{array}{l}\text { McCormack et } \\
\text { al., } 2013^{129} \\
\text { New York, NY: } \\
1 \text { site }\end{array}$ & $\begin{array}{l}(\mathrm{N}=60) \\
\text { Intervention } \\
(\mathrm{N}=20) \\
\text { Prospective } \\
\text { controls } \\
(\mathrm{N}=20) \\
\text { Retrospective } \\
\text { controls } \\
(\mathrm{N}=20)\end{array}$ & $\begin{array}{l}\text { Observational } \\
\text { study (RoB: } \\
\text { high) }\end{array}$ & $\begin{array}{l}5+\text { ED visits } \\
\text { annually for } 2 \\
\text { consecutive } \\
\text { years and } 1 \\
\text { within } 6 \text { months }\end{array}$ & $\begin{array}{l}\text { Alcohol } \\
\text { dependence }\end{array}$ & $\begin{array}{l}\text { Undomiciled } \\
\text { without shelter } \\
\text { use for } 9 \text { of } 24 \\
\text { months }\end{array}$ & $\begin{array}{l}\text { Mean age: } 50.0+/- \\
10.0 \text { years } \\
\text { Nonwhite: NR } \\
\text { Medicaid: NR } \\
\text { Medicare: NR }\end{array}$ \\
\hline $\begin{array}{l}\text { Navratil-Strawn } \\
\text { et al., } 2014^{120} \\
\text { National }\end{array}$ & $\begin{array}{l}(\mathrm{N}=14,140) \\
\text { Intervention } \\
(\mathrm{N}=7,070) \\
\text { Comparison } \\
(\mathrm{N}=7,070)\end{array}$ & $\begin{array}{l}\text { Observational } \\
\text { study } \\
\text { (RoB: some } \\
\text { concerns) }\end{array}$ & $\begin{array}{l}3+E D \text { visits in } \\
\text { past } 1 \text { year }\end{array}$ & NA & $\begin{array}{l}\text { Age: } 65+; \\
\text { UnitedHealth- } \\
\text { Care's AARP } \\
\text { Medigap } \\
\text { insurance }\end{array}$ & $\begin{array}{l}\text { Live in area with } \\
\text { medium/high } \\
\text { Minority status: } \\
38 \%\end{array}$ \\
\hline
\end{tabular}


Table B-40. Intervention characteristics of ED-based care model interventions

\begin{tabular}{|c|c|c|c|c|c|c|c|c|c|}
\hline $\begin{array}{l}\text { First Author, } \\
\text { Year, Site(s) }\end{array}$ & $\begin{array}{l}\text { Intervention: } \\
\text { Brief } \\
\text { Description }\end{array}$ & $\begin{array}{l}\text { Intervention } \\
\text { Duration }\end{array}$ & $\begin{array}{l}\text { Assessment, } \\
\text { Education, Skills, } \\
\text { Monitoring }\end{array}$ & $\begin{array}{l}\text { Coordination and } \\
\text { Continuity of Care }\end{array}$ & $\begin{array}{l}\text { Referral } \\
\text { to/Linkages to } \\
\text { Community-Based } \\
\text { Support Services }\end{array}$ & Providers & $\begin{array}{l}\text { Mode of } \\
\text { Delivery } \\
\text { Setting(s) }\end{array}$ & Intensity & Comparison \\
\hline $\begin{array}{l}\text { Kelley et al., } \\
2020^{110} \\
\text { New Haven, } \\
\text { CT: } 1 \text { site }\end{array}$ & $\begin{array}{l}\text { Project } \\
\text { Access-New } \\
\text { Haven: ED- } \\
\text { initiated } \\
\text { patient } \\
\text { navigation } \\
\text { program (ED- } \\
\text { PN) }\end{array}$ & 12 months & $\begin{array}{l}\text { Completed a } \\
\text { detailed } \\
\text { questionnaire with } \\
\text { the patient (via } \\
\text { interview) about } \\
\text { demographics, } \\
\text { socioeconomic } \\
\text { status, health } \\
\text { literacy, medical } \\
\text { conditions, clinical } \\
\text { and social needs, } \\
\text { health-related } \\
\text { quality of life, } \\
\text { utilization of } \\
\text { healthcare services, } \\
\text { access/barriers to } \\
\text { care, and reasons } \\
\text { for ED use. Open- } \\
\text { ended questions } \\
\text { were also asked to } \\
\text { elucidate ways in } \\
\text { which the patient } \\
\text { could most benefit } \\
\text { from patient } \\
\text { navigator services }\end{array}$ & $\begin{array}{l}\text { Patient navigators } \\
\text { connected patients to } \\
\text { primary care by } \\
\text { meeting face-to-face } \\
\text { with patients, offering } \\
\text { accompaniment to } \\
\text { PCP visit(s), phoning } \\
\text { each patient regularly } \\
\text { to remind them of } \\
\text { medical appointments, } \\
\text { and problem-solving to } \\
\text { overcome personal } \\
\text { barriers such as } \\
\text { transportation. Patient } \\
\text { navigator and patient } \\
\text { created a task list } \\
\text { based on the } \\
\text { provider's } \\
\text { recommendations } \\
\text { including assisting in } \\
\text { scheduling any } \\
\text { additional } \\
\text { appointments } \\
\text { recommended by PCP }\end{array}$ & $\begin{array}{l}\text { Connected patients } \\
\text { to local resources to } \\
\text { address social } \\
\text { needs such as } \\
\text { precarious housing, } \\
\text { food insecurity, or } \\
\text { insurance questions }\end{array}$ & $\begin{array}{l}\text { Nurse } \\
\text { navigator and a } \\
\text { trained patient } \\
\text { navigator }\end{array}$ & $\begin{array}{l}\text { Face-to- } \\
\text { face or } \\
\text { over the } \\
\text { phone }\end{array}$ & $\begin{array}{l}\text { Patient navigators } \\
\text { scheduled regular } \\
\text { phone calls to } \\
\text { each patient every } \\
2 \text { weeks during } \\
\text { weeks } 0-4 \text { and } \\
\text { every } 4 \text { weeks } \\
\text { during weeks } 13- \\
52\end{array}$ & Usual care \\
\hline
\end{tabular}




\begin{tabular}{|c|c|c|c|c|c|c|c|c|c|}
\hline $\begin{array}{l}\text { First Author, } \\
\text { Year, Site(s) }\end{array}$ & $\begin{array}{l}\text { Intervention: } \\
\text { Brief } \\
\text { Description }\end{array}$ & $\begin{array}{l}\text { Intervention } \\
\text { Duration }\end{array}$ & $\begin{array}{l}\text { Assessment, } \\
\text { Education, Skills, } \\
\text { Monitoring }\end{array}$ & $\begin{array}{l}\text { Coordination and } \\
\text { Continuity of Care }\end{array}$ & $\begin{array}{l}\text { Referral } \\
\text { to/Linkages to } \\
\text { Community-Based } \\
\text { Support Services }\end{array}$ & Providers & $\begin{array}{l}\text { Mode of } \\
\text { Delivery } \\
\text { Setting(s) }\end{array}$ & Intensity & Comparison \\
\hline $\begin{array}{l}\text { Lin et al., } \\
2017^{111} \\
\text { Boston, MA: } \\
1 \text { site }\end{array}$ & $\begin{array}{l}\text { Pilot ED- } \\
\text { based care } \\
\text { coordination } \\
\text { and } \\
\text { community } \\
\text { health worker } \\
\text { program }\end{array}$ & 7 months & $\begin{array}{l}\text { ED physicians } \\
\text { performed a } \\
\text { detailed chart } \\
\text { review for all } \\
\text { patients to identify } \\
\text { unmet medical and } \\
\text { social issues driving } \\
\text { frequent ED visits } \\
\text { and CHWs reviewed } \\
\text { each patient's chart } \\
\text { and called patients } \\
\text { to conduct a } \\
\text { standardized intake } \\
\text { assessment to } \\
\text { determine unmet } \\
\text { needs }\end{array}$ & $\begin{array}{l}\text { Acute care plans } \\
\text { developed in } \\
\text { conjunction with the } \\
\text { patient's longitudinal } \\
\text { providers including } \\
\text { PCPs and uploaded to } \\
\text { EHR to be visible to all } \\
\text { clinicians and } \\
\text { assignment of an ED- } \\
\text { based CHW who } \\
\text { assisted with care } \\
\text { coordination and other } \\
\text { tailored needs (e.g., } \\
\text { connect with primary } \\
\text { care, provide } \\
\text { transportation) }\end{array}$ & $\begin{array}{l}\text { CHW addressed } \\
\text { unmet social and } \\
\text { behavioral needs } \\
\text { that contributed to } \\
\text { ED utilization (e.g., } \\
\text { food banks) }\end{array}$ & $\begin{array}{l}\text { ED physician } \\
\text { and physician } \\
\text { assistant, ED } \\
\text { community } \\
\text { health worker, } \\
\text { and nurse care } \\
\text { coordinator }\end{array}$ & $\begin{array}{l}\text { Face-to- } \\
\text { face or } \\
\text { phone } \\
\text { including } \\
\text { home visits }\end{array}$ & NR & Usual care \\
\hline $\begin{array}{l}\text { Shumway et } \\
\text { al., } 2008^{116} \\
\text { San } \\
\text { Francisco, } \\
\text { CA: } 1 \text { hospital }\end{array}$ & $\begin{array}{l}\text { Case } \\
\text { management }\end{array}$ & 24 months & $\begin{array}{l}\text { Psychosocial } \\
\text { problems and } \\
\text { functioning were } \\
\text { assessed at study } \\
\text { entry and at } 6,12, \\
18 \text {, and } 24 \text { months. } \\
\text { Psychosocial } \\
\text { assessment } \\
\text { included } \\
\text { homelessness, } \\
\text { problem alcohol } \\
\text { use, lack of health } \\
\text { insurance, lack of } \\
\text { Social Security } \\
\text { income, unmet } \\
\text { basic financial } \\
\text { needs, and } \\
\text { psychiatric } \\
\text { symptoms. }\end{array}$ & $\begin{array}{l}\text { Provided linkage to } \\
\text { medical care providers } \\
\text { and ongoing assertive } \\
\text { community outreach to } \\
\text { maintain continuity of } \\
\text { care }\end{array}$ & $\begin{array}{l}\text { Assistance in } \\
\text { obtaining stable } \\
\text { housing, income } \\
\text { entitlements, and } \\
\text { referral to } \\
\text { substance abuse } \\
\text { services when } \\
\text { needed }\end{array}$ & $\begin{array}{l}\text { Master's-level } \\
\text { psychiatric } \\
\text { social workers } \\
\text { provided most } \\
\text { case } \\
\text { management } \\
\text { services in } \\
\text { collaboration } \\
\text { with a nurse } \\
\text { practitioner, a } \\
\text { primary care } \\
\text { physician, and } \\
\text { a psychiatrist }\end{array}$ & $\begin{array}{l}\text { Face-to- } \\
\text { face } \\
\text { individual } \\
\text { and group } \\
\text { sessions }\end{array}$ & $\mathrm{NR}$ & Usual care \\
\hline
\end{tabular}




\begin{tabular}{|c|c|c|c|c|c|c|c|c|c|}
\hline $\begin{array}{l}\text { First Author, } \\
\text { Year, Site(s) }\end{array}$ & $\begin{array}{l}\text { Intervention: } \\
\text { Brief } \\
\text { Description }\end{array}$ & $\begin{array}{l}\text { Intervention } \\
\text { Duration }\end{array}$ & $\begin{array}{l}\text { Assessment, } \\
\text { Education, Skills, } \\
\text { Monitoring }\end{array}$ & $\begin{array}{l}\text { Coordination and } \\
\text { Continuity of Care }\end{array}$ & $\begin{array}{l}\text { Referral } \\
\text { to/Linkages to } \\
\text { Community-Based } \\
\text { Support Services } \\
\end{array}$ & Providers & $\begin{array}{l}\text { Mode of } \\
\text { Delivery } \\
\text { Setting(s) }\end{array}$ & Intensity & Comparison \\
\hline $\begin{array}{l}\text { Seaberg et } \\
\text { al., } 2017^{118} \\
\text { Chattanooga, } \\
\text { TN metro } \\
\text { area: } 5 \text { sites }\end{array}$ & $\begin{array}{l}\text { Patient } \\
\text { navigation for } \\
\text { ED patients }\end{array}$ & 12 months & $\begin{array}{l}\text { Reviewed } \\
\text { diagnoses and } \\
\text { prescriptions }\end{array}$ & NR & $\begin{array}{l}\text { Arranged followup } \\
\text { appointments and } \\
\text { identified relevant } \\
\text { community } \\
\text { resources }\end{array}$ & $\begin{array}{l}\text { Patient } \\
\text { navigator with } \\
\text { hospital case } \\
\text { management } \\
\text { training }\end{array}$ & $\begin{array}{l}\text { In person } \\
\text { and via } \\
\text { telephone }\end{array}$ & $\begin{array}{l}\text { Initial ED visit, } \\
\text { subsequent ED } \\
\text { visits, followup } \\
\text { calls within } 2 \\
\text { weeks and } 12 \\
\text { months of initial } \\
\text { ED visit } \\
\end{array}$ & Usual care \\
\hline $\begin{array}{l}\text { Enard and } \\
\text { Ganelin, } \\
2013^{127} \\
\text { Houston, TX: } \\
1 \text { site }\end{array}$ & $\begin{array}{l}\text { ED-based } \\
\text { patient } \\
\text { navigation } \\
\text { program }\end{array}$ & $\leq 10$ days & $\begin{array}{l}\text { Initial assessment to } \\
\text { determine barriers } \\
\text { to appropriate } \\
\text { primary care use. } \\
\text { Educate patients on } \\
\text { importance of } \\
\text { making and keeping } \\
\text { appointments and } \\
\text { receiving preventive } \\
\text { health care. Help } \\
\text { patients identify } \\
\text { barriers to primary } \\
\text { care and identify } \\
\text { local, state, and } \\
\text { federal resources } \\
\text { appropriate for their } \\
\text { needs }\end{array}$ & $\begin{array}{l}\text { Patient navigators } \\
\text { maintain relationships } \\
\text { with community-based } \\
\text { providers to bolster } \\
\text { referral relationships } \\
\text { ensure that contact } \\
\text { information is current }\end{array}$ & $\begin{array}{l}\text { Connect patients } \\
\text { with neighborhood } \\
\text { providers or clinics } \\
\text { and assess their } \\
\text { needs for specific } \\
\text { types of referrals } \\
\text { based on access } \\
\text { issues and health } \\
\text { conditions. }\end{array}$ & $\begin{array}{l}\text { CHWs as } \\
\text { patient } \\
\text { navigators }\end{array}$ & $\begin{array}{l}\text { In person } \\
\text { and via } \\
\text { telephone }\end{array}$ & $\begin{array}{l}\text { Initial ED visit and } \\
\text { a followup call } 3 \text { to } \\
10 \text { days later }\end{array}$ & Usual care \\
\hline $\begin{array}{l}\text { McCormack } \\
\text { et al., 2013 } \\
\text { New York, } \\
\text { NY: } 1 \text { site }\end{array}$ & $\begin{array}{l}\text { Coordinated } \\
\text { case } \\
\text { management } \\
\text { and facilitated } \\
\text { access to } \\
\text { homeless } \\
\text { outreach } \\
\text { services }\end{array}$ & 6 months & $\begin{array}{l}\text { Social workers } \\
\text { approached patients } \\
\text { and, if authorized, } \\
\text { faxed intake and } \\
\text { medical release } \\
\text { forms to the } \\
\text { outreach team. On a } \\
\text { subsequent visit, the } \\
\text { outreach team came } \\
\text { to the ED to confirm } \\
\text { eligibility and } \\
\text { complete enrollment }\end{array}$ & $\begin{array}{l}\text { Social worker and } \\
\text { outreach team met } \\
\text { with participants to } \\
\text { relocate patients into } \\
\text { supportive settings, } \\
\text { coordinate } \\
\text { aultidisciplinary care, } \\
\text { and update plans } \\
\text { based on participants' } \\
\text { medical, psychosocial, } \\
\text { and housing needs }\end{array}$ & $\begin{array}{l}\text { Care plans to offer } \\
\text { shelter on } \\
\text { discharge }\end{array}$ & $\begin{array}{l}\text { Social worker } \\
\text { and outreach } \\
\text { team }\end{array}$ & $\begin{array}{l}\text { Face-to- } \\
\text { face }\end{array}$ & $\begin{array}{l}\text { Frequency based } \\
\text { on number of } \\
\text { visits to the ED }\end{array}$ & Usual care \\
\hline
\end{tabular}




\begin{tabular}{|c|c|c|c|c|c|c|c|c|c|}
\hline $\begin{array}{l}\text { First Author, } \\
\text { Year, Site(s) }\end{array}$ & $\begin{array}{l}\text { Intervention: } \\
\text { Brief } \\
\text { Description }\end{array}$ & $\begin{array}{l}\text { Intervention } \\
\text { Duration }\end{array}$ & $\begin{array}{l}\text { Assessment, } \\
\text { Education, Skills, } \\
\text { Monitoring }\end{array}$ & $\begin{array}{l}\text { Coordination and } \\
\text { Continuity of Care }\end{array}$ & $\begin{array}{l}\text { Referral } \\
\text { to/Linkages to } \\
\text { Community-Based } \\
\text { Support Services }\end{array}$ & Providers & $\begin{array}{l}\text { Mode of } \\
\text { Delivery } \\
\text { Setting(s) }\end{array}$ & Intensity & Comparison \\
\hline $\begin{array}{l}\text { Navratil- } \\
\text { Strawn et al., } \\
2014^{120} \\
\text { National }\end{array}$ & $\begin{array}{l}\text { Emergency } \\
\text { Room } \\
\text { Decision- } \\
\text { Support } \\
\text { (ERDS) } \\
\text { program }\end{array}$ & $\begin{array}{l}\text { NR; up to } 12 \\
\text { months } \\
\text { (followup } \\
\text { time) }\end{array}$ & $\begin{array}{l}\text { Assessment of } \\
\text { health needs and } \\
\text { treatment options }\end{array}$ & $\begin{array}{l}\text { Make appointments } \\
\text { with providers, refer to } \\
\text { care coordination } \\
\text { programs }\end{array}$ & $\begin{array}{l}\text { Provide } \\
\text { connections with } \\
\text { health resources }\end{array}$ & Nurse & Telephone & NR & Usual care \\
\hline
\end{tabular}

$\mathrm{CA}=$ California; CHW = community health worker; ED = emergency department; ED-PN = ED-initiated Patient Navigation; EHR = electronic health record; ERDS = Emergency

Room Decision-Support; MA = Massachusetts; NR = not reported; NY = New York; $\mathrm{PCP}=$ primary care provider; $\mathrm{TN}=\mathrm{Tennessee}$;X $=$ Texas 
Table B-41. Healthcare utilization outcomes for ED-based care model studies

\begin{tabular}{|c|c|c|c|c|}
\hline Utilization Measures & Study Design & $\begin{array}{l}\text { Direction of } \\
\text { Change in } \\
\text { Intervention } \\
\text { Group (G1) } \\
\end{array}$ & $\begin{array}{l}\text { Direction of } \\
\text { Change in } \\
\text { Comparison } \\
\text { Group (G2) } \\
\end{array}$ & Difference \\
\hline \multirow[t]{6}{*}{ ED visits } & $\mathrm{RCT}$ & & & $\begin{array}{l}\text { Greater reduction in G1 than G2: DiD=-1.37 } \\
(95 \% \mathrm{Cl},-2.40 \text { to }-0.34)(p=0.01)^{110}\end{array}$ \\
\hline & $\overline{R C T}$ & NR & NR & $\begin{array}{l}\text { Between group difference (G1-G2): }-35 \% \\
(p=0.10)^{111}\end{array}$ \\
\hline & $\overline{\mathrm{RCT}}$ & & & Lower use in $\mathrm{G} 1$ than $\mathrm{G} 2^{\mathrm{a}}(\mathrm{p}<0.01)^{116}$ \\
\hline & $\overline{\mathrm{RCT}}$ & & & $\begin{array}{l}\text { Greater reduction in } G 1 \text { than } G 2 \\
(p<0.0001)^{118}\end{array}$ \\
\hline & Observational & & & $\begin{array}{l}\text { Greater reduction in } \mathrm{G} 1 \text { than } \mathrm{G} 2: \mathrm{DiD}=-178 \\
(p=0.033)^{120}\end{array}$ \\
\hline & Observational & $\overline{N R}$ & NR & $\begin{array}{l}\text { Greater reduction in G1 than G2: DiD } \\
\text { (prospective controls): }-12.1(95 \% \mathrm{Cl},-22.1 \\
\text { to }-2.0)(p=0.02) \\
\text { DiD (retrospective controls): }-12.8(95 \% \mathrm{Cl} \text {, } \\
-26.1 \text { to } 0.6)(p=0.06)^{129}\end{array}$ \\
\hline \multirow[t]{2}{*}{ ED visits, any } & Observational & & & $\begin{array}{l}\text { Lower use in G1 than G2 among patients } \\
\text { with PCR-ED visits in prior } 24 \text { months } \\
\geq 1: \text { OR=0.55 (95\% Cl, } 0.47 \text { to } 0.63) ; \\
\geq 2: \text { OR=0.46 (95\% Cl, } 0.37 \text { to } 0.57) ; \\
\geq 3: \text { OR=0.32 }(95 \% \mathrm{Cl}, 0.24 \text { to } 0.44) ; \\
\geq 4: \text { OR=0.29 }(95 \% \mathrm{Cl}, 0.19 \text { to } 0.44) ; \text { or } \\
\geq 5: \text { OR }=0.31(95 \% \mathrm{Cl}, 0.17 \text { to } 0.54)^{127}\end{array}$ \\
\hline & Observational & & & $\begin{array}{l}\text { G1 vs. G2 among patients with PCR-ED } \\
\text { visits in prior } 12 \text { months } \\
\geq 1: \text { OR=0.83 (95\% Cl, } 0.71 \text { to } 0.98) ; \\
\geq 2: \text { OR=0.72 (95\% Cl, } 0.57 \text { to } 0.93) ; \\
\geq 3: \text { OR=0.90 (95\% Cl, } 0.60 \text { to } 1.3) ; \\
\geq 4: \text { OR=0.98 }(95 \% \mathrm{Cl}, 0.52 \text { to } 1.8) ; \text { or } \\
\geq 5: O R=0.96(95 \% \mathrm{Cl}, 0.39 \text { to } 2.3)^{127}\end{array}$ \\
\hline \multirow[t]{2}{*}{$\begin{array}{l}\text { Inpatient admissions, } \\
\text { all cause }\end{array}$} & $\mathrm{RCT}$ & & & $\begin{array}{l}\text { Greater reduction in G1 than G2: DiD=-0.97 } \\
(95 \% \mathrm{Cl},-1.56 \text { to }-0.38)(p=0.001)^{110}\end{array}$ \\
\hline & Observational & & & $\begin{array}{l}\text { Greater reduction in } \mathrm{G} 1 \text { than } \mathrm{G} 2: \mathrm{DiD}=-53 \\
(p=0.002)^{120}\end{array}$ \\
\hline Inpatient days & Observational & $\overline{N R}$ & $\overline{N R}$ & $\begin{array}{l}\text { DiD (prospective controls): }-8.5(95 \% \\
\mathrm{Cl},-22.8 \text { to } 5.8)(p=0.24) \\
\text { DiD (retrospective controls): }-19.0(95 \% \mathrm{Cl} \text {, } \\
-34.3 \text { to }-3.6)(p=0.06)^{129}\end{array}$ \\
\hline $\begin{array}{l}\text { Medical inpatient } \\
\text { admissions }\end{array}$ & $\mathrm{RCT}$ & & & G1 vs. $G 2^{a}(p=N S)^{116}$ \\
\hline Medical inpatient days & $\mathrm{RCT}$ & & 5 & G1 vs. $G 2^{a}(p=N S)^{116}$ \\
\hline $\begin{array}{l}\text { Psychiatric } \\
\text { emergency visits }\end{array}$ & $\mathrm{RCT}$ & & -- & $\mathrm{G} 1$ vs. $\mathrm{G} 2^{\mathrm{a}}(\mathrm{p}=\mathrm{NS})^{116}$ \\
\hline $\begin{array}{l}\text { Psychiatric inpatient } \\
\text { admissions }\end{array}$ & $\mathrm{RCT}$ & & 凡 & G1 vs. $G 2^{a}(p=N S)^{116}$ \\
\hline $\begin{array}{l}\text { Psychiatric inpatient } \\
\text { days }\end{array}$ & RCT & & 约 & G1 vs. $G 2^{a}(p=N S)^{116}$ \\
\hline
\end{tabular}




\begin{tabular}{|c|c|c|c|c|}
\hline Utilization Measures & Study Design & $\begin{array}{l}\text { Direction of } \\
\text { Change in } \\
\text { Intervention } \\
\text { Group (G1) }\end{array}$ & $\begin{array}{l}\text { Direction of } \\
\text { Change in } \\
\text { Comparison } \\
\text { Group (G2) }\end{array}$ & Difference \\
\hline \multirow[t]{2}{*}{$\overline{\text { Outpatient visits }}$} & RCT & 仓 & $\hat{ن}$ & $\begin{array}{l}\text { DiD: } 0.60(95 \% \mathrm{Cl},-0.43 \text { to } 1.63) \\
(p=0.25)^{110}\end{array}$ \\
\hline & $\overline{\mathrm{RCT}}$ & Љ & Љ & G1 vs. $G 2^{a}(p=N S)^{116}$ \\
\hline \multirow[t]{2}{*}{ 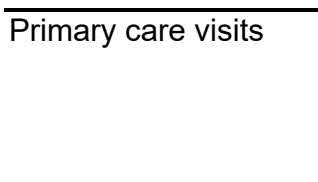 } & RCT & & & Greater use in $\mathrm{G} 1$ than $\mathrm{G} 2(\mathrm{p}=0.001)^{118}$ \\
\hline & $\overline{\text { Observational }}$ & & & $\begin{array}{l}\text { Smaller reduction in } \mathrm{G} 1 \text { than } \mathrm{G} 2 \mathrm{D} \text { : } \mathrm{D}=897 \\
(\mathrm{p}<0.001)^{120}\end{array}$ \\
\hline
\end{tabular}

Interaction between level of prior ED use ( 5 to 11 or $\geq 12$ visits in prior 12 months) and group: $\mathrm{p}=\mathrm{NS}$.

- Increase in the outcome between the intervention period and the baseline period; the difference between the intervention and comparison groups was statistically significant.

- Reduction in the outcome between the intervention period and the baseline period; the difference between the intervention and comparison groups was statistically significant.

$仓=$ Increase in the outcome between the intervention period and the baseline period; the difference between the intervention and comparison groups was not statistically significant.

$\Omega=$ Reduction in the outcome between the intervention period and the baseline period; the difference between the intervention and comparison groups was not statistically significant.

$\mathrm{CI}=$ confidence interval; $\mathrm{DiD}=$ difference-in differences; $\mathrm{ED}=$ emergency department $\mathrm{G}=$ group; $\mathrm{NR}=$ not reported; $\mathrm{NS}=$ not statistically significant; $\mathrm{OR}=$ odds ratio; $\mathrm{PCR}-\mathrm{ED}=$ primary care-related emergency department; $\mathrm{RCT}=$ randomized controlled trial; vs. = versus. 
Table B-42. Strength of evidence for ED-based care models versus usual-care outcomes

\begin{tabular}{|c|c|c|c|c|c|}
\hline Populatio & Outcome & Results & $\begin{array}{l}\text { Study Design } \\
\text { and Sample } \\
\text { Size }\end{array}$ & $\begin{array}{l}\text { Strength of } \\
\text { Evidence Domains }\end{array}$ & $\begin{array}{l}\text { Overall Evidence } \\
\text { Strength } \\
\text { (Direction of } \\
\text { Effect) }\end{array}$ \\
\hline $\begin{array}{l}\mathrm{HNHC} \\
\text { patients }\end{array}$ & ED visits & 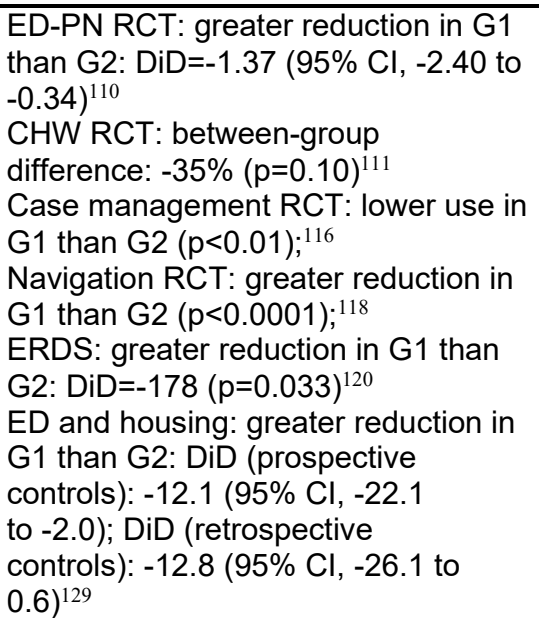 & $\begin{array}{l}4 \text { RCTs, } \mathrm{N}=728 \\
2 \text { OBSs, } \\
\mathrm{N}=14,200\end{array}$ & $\begin{array}{l}\text { Moderate study } \\
\text { limitations ( } 2 \text { high } \\
\text { RoB OBS studies), }{ }^{129} \\
\text { consistent, precise, } \\
\text { direct }\end{array}$ & $\begin{array}{l}\text { Moderate } \\
\text { (Favorable) }\end{array}$ \\
\hline $\begin{array}{l}\mathrm{HNHC} \\
\text { patients }\end{array}$ & $\begin{array}{l}\text { Inpatient } \\
\text { admissions, } \\
\text { all cause }\end{array}$ & $\begin{array}{l}\text { ED-PN RCT: greater reduction in G1 } \\
\text { than G2: DiD }=-0.97(95 \% \mathrm{Cl},-1.56 \text { to } \\
-0.38)(p=0.001)^{110} \\
\text { ERDS: greater reduction in } \mathrm{G} 1 \text { than } \\
\text { G2: DiD }=-53(p=0.002)^{120}\end{array}$ & $\begin{array}{l}1 \mathrm{RCT}, \mathrm{N}=100 \\
1 \mathrm{OBS} \\
\mathrm{N}=14,140\end{array}$ & $\begin{array}{l}\text { Moderate study } \\
\text { limitations, } \\
\text { consistent, precise, } \\
\text { direct }\end{array}$ & Low (Favorable) \\
\hline $\begin{array}{l}\mathrm{HNHC} \\
\text { patients }\end{array}$ & $\begin{array}{l}\text { Primary } \\
\text { care visits }\end{array}$ & $\begin{array}{l}\text { Navigation RCT: greater use in } G 1 \\
\text { than } G 2(p=0.001)^{118} \\
\text { ERDS: smaller reduction in } \mathrm{G} 1 \text { than } \\
\text { G2: } D i D=897(p<0.001)^{120}\end{array}$ & $\begin{array}{l}1 \mathrm{RCT}, \mathrm{N}=304 \\
1 \mathrm{OBS} \\
\mathrm{N}=14,140\end{array}$ & $\begin{array}{l}\text { Moderate study } \\
\text { limitations, } \\
\text { consistent, precise, } \\
\text { direct }\end{array}$ & Low (Favorable) \\
\hline $\begin{array}{l}\mathrm{HNHC} \\
\text { patients }\end{array}$ & $\begin{array}{l}\text { Outpatient } \\
\text { visits }\end{array}$ & $\begin{array}{l}\text { ED-PN RCT: DiD: } 0.60(95 \% \\
\text { Cl, }-0.43 \text { to } 1.63)(p=0.25)^{110} \\
\text { Case management RCT: G1 vs. G2 } \\
(p=N S)^{116}\end{array}$ & 2 RCTs, $N=352$ & $\begin{array}{l}\text { Moderate study } \\
\text { limitations, } \\
\text { inconsistent, } \\
\text { imprecise, direct }\end{array}$ & $\begin{array}{l}\text { Insufficient (Mixed } \\
\text { findings) }\end{array}$ \\
\hline $\begin{array}{l}\mathrm{HNHC} \\
\text { patients }\end{array}$ & ED costs & $\begin{array}{l}\text { CHW RCT: between-group } \\
\text { difference }=-15 \%(p=0.20)^{111} \\
\text { Case management RCT: lower in } G 1 \\
\text { than } G 2^{a}(p<0.01)^{116} \\
\text { Navigation RCT: greater reduction in } \\
\text { G1 than } G 2(p<0.0001)^{118} \\
\text { ERDS: } D i D=-21(p=0.140)^{120}\end{array}$ & $\begin{array}{l}3 \text { RCTs, } \mathrm{N}=628 \\
1 \text { OBS, } \\
\mathrm{N}=14,140\end{array}$ & $\begin{array}{l}\text { Moderate study } \\
\text { limitations; } \\
\text { consistent, precise, } \\
\text { direct }\end{array}$ & Low (Favorable) \\
\hline $\begin{array}{l}\mathrm{HNHC} \\
\text { patients }\end{array}$ & $\begin{array}{l}\text { Inpatient } \\
\text { costs }\end{array}$ & $\begin{array}{l}\text { CHW RCT: between-group } \\
\text { difference=-8\% }(p=0.10)^{111} \\
\text { Case management RCT: G1 vs. G2 } \\
(p=N S)^{116} \\
\text { ERDS: DiD=-59 }(p=0.080)^{120}\end{array}$ & $\begin{array}{l}2 \text { RCTs, } \mathrm{N}=324 \\
1 \text { OBS, } \\
\mathrm{N}=14,140\end{array}$ & $\begin{array}{l}\text { Moderate study } \\
\text { limitations, } \\
\text { inconsistent, } \\
\text { imprecise, direct }\end{array}$ & $\begin{array}{l}\text { Low (No } \\
\text { difference) }\end{array}$ \\
\hline $\begin{array}{l}\mathrm{HNHC} \\
\text { patients }\end{array}$ & $\begin{array}{l}\text { Hospital } \\
\text { costs of } \\
\text { care }\end{array}$ & $\begin{array}{l}\text { ED-PN RCT: DiD=-10,202 (95\% } \\
\text { Cl, }-22,464 \text { to } 2,062)^{110} \\
\text { Case management RCT: G1 vs. G2 } \\
(p=N S)^{116}\end{array}$ & 2 RCTs, N=352 & $\begin{array}{l}\text { Moderate study } \\
\text { limitations, } \\
\text { inconsistent, } \\
\text { imprecise, direct }\end{array}$ & Insufficient \\
\hline $\begin{array}{l}\mathrm{HNHC} \\
\text { patients }\end{array}$ & $\begin{array}{l}\text { Outpatient } \\
\text { costs }\end{array}$ & $\begin{array}{l}\text { Case management RCT: G1 vs. G2 } \\
(p=N S)^{116} \\
\text { ERDS: } D i D=10(p=0.828)^{120}\end{array}$ & $\begin{array}{l}1 \mathrm{RCT}, \mathrm{N}=252 \\
1 \mathrm{OBS} \\
\mathrm{N}=14,140\end{array}$ & $\begin{array}{l}\text { Moderate study } \\
\text { limitations, } \\
\text { inconsistent, } \\
\text { imprecise, direct }\end{array}$ & Insufficient \\
\hline
\end{tabular}

CHW = community health worker; $\mathrm{CI}=$ confidence interval: DiD = difference-in differences; ED = emergency department; EDPN = ED-initiated Patient Navigation; ERDS = Emergency Room Decision-Support; G = group; HNHC = high-need, high-cost; $\mathrm{N}=$ number; $\mathrm{NS}=$ not significant; OBS = observational study; $\mathrm{RCT}=$ randomized controlled trial; $\mathrm{RoB}=$ risk of bias; $\mathrm{vs}$. $=$ versus. 
Table B-43. Cost outcomes for ED-based care model studies

\begin{tabular}{|c|c|c|c|c|}
\hline Cost Measures & $\begin{array}{l}\text { Study } \\
\text { Design }\end{array}$ & $\begin{array}{l}\text { Direction of } \\
\text { Change in } \\
\text { Intervention } \\
\text { Group (G1) }\end{array}$ & $\begin{array}{l}\text { Direction of } \\
\text { Change in } \\
\text { Comparison } \\
\text { Group (G2) }\end{array}$ & Difference \\
\hline \multirow[t]{4}{*}{ ED costs } & $\mathrm{RCT}$ & NR & NR & $\begin{array}{l}\text { Between-group difference (G1-G2) } \\
=-15 \%(p=0.20)^{111}\end{array}$ \\
\hline & $\overline{\mathrm{RCT}}$ & & & Lower in $\mathrm{G} 1$ than $\mathrm{G} 2^{\mathrm{a}}(\mathrm{p}<0.01)^{116}$ \\
\hline & $\overline{\mathrm{RCT}}$ & & & $\begin{array}{l}\text { Greater reduction in } \mathrm{G} 1 \text { than } \mathrm{G} 2 \\
(\mathrm{p}<0.0001)^{118}\end{array}$ \\
\hline & Observational & & & $\mathrm{DiD}=-21(p=0.140)^{120}$ \\
\hline \multirow[t]{3}{*}{ Inpatient costs } & $\mathrm{RCT}$ & & & G1 vs. $\mathrm{G}^{\mathrm{a}, \mathrm{b}}(\mathrm{p}=\mathrm{NS})^{116}$ \\
\hline & $\overline{\mathrm{RCT}}$ & $\overline{N R}$ & NR & $\begin{array}{l}\text { Between group difference (G1-G2) } \\
=-8 \%(p=0.10)^{111}\end{array}$ \\
\hline & Observational & & & $\mathrm{DiD}=-59(p=0.080)^{120}$ \\
\hline$\overline{\text { Medicaid cost (payment) }}$ & $\mathrm{RCT}$ & & & $\begin{array}{l}\mathrm{DiD}=-5,765(95 \% \mathrm{Cl},-15,883 \text { to } \\
4,353)(p=0.26)^{110}\end{array}$ \\
\hline $\begin{array}{l}\text { Psychiatric emergency } \\
\text { costs }\end{array}$ & $\mathrm{RCT}$ & & & G1 vs. $G 2^{a}(p=N S)^{116}$ \\
\hline Psychiatric hospital costs & RCT & & & G1 vs. $G 2^{a}(p=N S)^{116}$ \\
\hline \multirow[t]{2}{*}{ Hospital costs of care } & RCT & & & $\begin{array}{l}\mathrm{DiD}=-10,202(95 \% \mathrm{Cl},-22,464 \text { to } \\
2,062)(p=0.10)^{110}\end{array}$ \\
\hline & $\overline{R C T}$ & & 凡 & G1 vs. $G 2^{a, c}(p=N S)^{116}$ \\
\hline $\begin{array}{l}\text { All non-ED case } \\
\text { management costs }\end{array}$ & RCT & & $\sqrt{2}$ & G1 vs. $G 2^{a}(p=N S)^{116}$ \\
\hline Total costs $(\$)$ & Observational & & & $\mathrm{DiD}=-40(p=0.502)^{120}$ \\
\hline \multirow[t]{2}{*}{ Outpatient costs } & $\mathrm{RCT}$ & & - & G1 vs. $G 2^{a, b}(p=N S)^{116}$ \\
\hline & Observational & 乃 & $ת$ & $\mathrm{DiD}=10(p=0.828)^{120}$ \\
\hline Prescription costs (\$) & Observational & $\Delta$ & & $\mathrm{DiD}=9(\mathrm{p}=0.201)^{120}$ \\
\hline
\end{tabular}

Interaction between level of prior ED use ( 5 to 11 or $\geq 12$ visits in prior 12 months) and group: $\mathrm{p}=\mathrm{NS}$.

${ }^{b}$ Shumway et al. specified the outpatient and inpatient costs as medical outpatient costs and medical hospital costs. ${ }^{116}$

'Shumway et al. included the costs for the ED case management intervention in all hospital costs. ${ }^{116}$

- Reduction in the outcome between the intervention period and the baseline period; the difference between the intervention and comparison groups was statistically significant.

$\hat{\mathrm{V}}=$ Increase in the outcome between the intervention period and the baseline period; the difference between the intervention and comparison groups was not statistically significant.

$\checkmark=$ Reduction in the outcome between the intervention period and the baseline period; the difference between the intervention and comparison groups was not statistically significant.

$\mathrm{CI}=$ confidence interval; $\mathrm{DiD}=$ difference-in differences; $\mathrm{ED}=$ emergency department $\mathrm{G}=$ group; $\mathrm{NR}=$ not reported; $\mathrm{NS}=$ not statistically significant; RCT $=$ randomized controlled trial; vs. = versus. 
Table B-44. Clinical and functional outcomes for ED-based care model studies

\begin{tabular}{lll}
\hline Clinical and Functional Outcomes & Study Design & $\begin{array}{l}\text { Difference Between Intervention Group (G1) } \\
\text { and Comparison Group (G2) }\end{array}$ \\
\hline Mortality & RCT & $\begin{array}{l}\text { G1: 0/20 vs. prospective G2: } 2 / 20 \text { and } \\
\text { retrospective } G 2: 7 / 20(p=N R)^{129}\end{array}$ \\
\hline Satisfaction (4-point Likert scale) & RCT & G1 vs. G2 $(p=N S)^{118}$ \\
\hline Psychiatric symptoms (total BSI) & RCT & G1 vs. G2 ${ }^{a}(p=N S)^{116}$ \\
\hline
\end{tabular}

${ }^{a}$ Interaction between level of prior ED use (5 to 11 or $\geq 12$ visits in prior 12 months) and group: $\mathrm{p}=\mathrm{NS}$.

$\mathrm{BSI}=$ brief symptom inventory; $\mathrm{ED}=$ emergency department; $\mathrm{G}=$ group; $\mathrm{NR}=$ not reported; $\mathrm{NS}=$ not statistically significant; $\mathrm{RCT}=$ randomized controlled trial; vs. $=$ versus.

Table B-45. Social risk outcomes for ED-based care model studies

\begin{tabular}{|c|c|c|}
\hline Social Risk Outcomes & Study Design & $\begin{array}{l}\text { Difference Between Intervention Group (G1) } \\
\text { and Comparison Group (G2) }\end{array}$ \\
\hline Housed & $\mathrm{RCT}$ & $\begin{array}{l}\mathrm{G} 1: 18 / 20 \text { vs. prospective } \mathrm{G} 2: 0 / 20 \text { and } \\
\text { retrospective } \mathrm{G} 2: 0 / 20(p=N R)^{129}\end{array}$ \\
\hline Problem alcohol use (\%) & RCT & Lower in $\mathrm{G} 1$ than $\mathrm{G} 2^{\mathrm{a}}(\mathrm{p}=0.04)^{116}$ \\
\hline Homelessness (\%) & RCT & Lower in $\mathrm{G} 1$ than $\mathrm{G} 2^{\mathrm{a}}(\mathrm{p}<0.01)^{116}$ \\
\hline No health insurance (\%) & $\mathrm{RCT}$ & Lower in $\mathrm{G} 1$ than $\mathrm{G} 2^{\mathrm{a}}(\mathrm{p}=0.02)^{116}$ \\
\hline No social security income (\%) & $\mathrm{RCT}$ & Lower in $\mathrm{G} 1$ than $\mathrm{G} 2^{\mathrm{a}}(\mathrm{p}<0.01)^{116}$ \\
\hline Basic financial needs unmet & $\mathrm{RCT}$ & Lower in $\mathrm{G} 1$ than $\mathrm{G}^{\mathrm{a}}(\mathrm{p}=0.04)^{116}$ \\
\hline
\end{tabular}

$\mathrm{ED}=$ emergency department; $\mathrm{G}=$ group; $\mathrm{NR}=$ not reported; $\mathrm{RCT}=$ randomized controlled trial; vs. = versus. 
Table B-46. Study characteristics of alCU (ambulatory intensive caring unit) interventions

\begin{tabular}{|c|c|c|c|c|c|}
\hline $\begin{array}{l}\text { First Author, } \\
\text { Year, Site(s) }\end{array}$ & Sample Size & $\begin{array}{l}\text { Study } \\
\text { Design (Risk } \\
\text { of Bias } \\
\text { Assessment) }\end{array}$ & $\begin{array}{l}\text { Patient Selection: } \\
\text { High Healthcare Use } \\
\text { or Cost; Time Period }\end{array}$ & $\begin{array}{l}\text { Patient Selection: } \\
\text { Chronic } \\
\text { Conditions }\end{array}$ & $\begin{array}{l}\text { Patient Selection: } \\
\text { Other }\end{array}$ \\
\hline $\begin{array}{l}\text { Yoon et al., } \\
\text { 201987; } \\
\text { Zalman, } 2019^{97} \\
\\
\text { GA, OH, WI, } \\
\text { NC, CA: } 5 \text { sites }\end{array}$ & $\begin{array}{l}(\mathrm{N}=2,210) \\
\text { Intervention }(\mathrm{N}=1,105) \\
\text { Comparison }(\mathrm{N}=1,105) \\
(\mathrm{N}=1,527) \\
\text { Intervention }(\mathrm{N}=759) \\
\text { Comparison }(\mathrm{N}=768)\end{array}$ & $\begin{array}{l}\text { RCT } \\
\text { (RoB: some } \\
\text { concerns) }\end{array}$ & $\begin{array}{l}\text { Veterans whose risk } \\
\text { of } 90 \text {-day } \\
\text { hospitalization was } \geq \\
90 \text { th percentile based } \\
\text { on the VA's Care } \\
\text { Assessment Need } \\
\text { (CAN) score and who } \\
\text { had experienced a } \\
\text { hospitalization or ED } \\
\text { visit in past } 6 \text { months }\end{array}$ & NA & $\begin{array}{l}\text { Intensive } \\
\text { management teams at } \\
\text { each site reviewed } \\
\text { patient charts to } \\
\text { determine whether } \\
\text { participants would } \\
\text { benefit from intensive } \\
\text { services }\end{array}$ \\
\hline $\begin{array}{l}\text { Durfee et al., } \\
2018^{83} \\
\text { CO: } 1 \text { site }\end{array}$ & $\begin{array}{l}(\mathrm{N}=3,636) \\
\text { Intervention }(\mathrm{N}=1,749) \\
\text { Comparison }(\mathrm{N}=1,887)\end{array}$ & $\begin{array}{l}\text { Observational } \\
\text { study } \\
\text { (RoB: some } \\
\text { concerns) }\end{array}$ & $\begin{array}{l}\text { IP admission (analysis } \\
\text { index admission) and } \\
\text { at least } 2 \text { other } \\
\text { admissions OR at } \\
\text { least one other } \\
\text { admission with a } \\
\text { serious mental health } \\
\text { diagnosis in past } 1 \\
\text { year }\end{array}$ & NA & Age: 19+ \\
\hline $\begin{array}{l}\text { Vickery et al., } \\
2018^{100,125} \\
\text { MN: } 1 \text { site }\end{array}$ & $\begin{array}{l}\text { Primary care model } \\
\text { (HNHC N=NR of total } \\
\mathrm{N}=92,891) \\
\text { Intervention ( } \mathrm{N}=\mathrm{NR} \text { of } \\
19,433) \\
\text { Comparison ( } \mathrm{N}=\mathrm{NR} \text { of } \\
73,458)\end{array}$ & $\begin{array}{l}\text { Observational } \\
\text { study } \\
\text { (RoB: some } \\
\text { concerns) }\end{array}$ & $\begin{array}{l}\text { HNHC patient } \\
\text { subgroup: More than } \\
4 \text { ED visits or } 2 \\
\text { inpatient hospital visits } \\
\text { in past } 1 \text { year }\end{array}$ & NA & $\begin{array}{l}\text { Whole study } \\
\text { population: Adults with } \\
1+\text { months of } \\
\text { enrollment under early } \\
\text { Medicaid expansion }\end{array}$ \\
\hline $\begin{array}{l}\text { Horn et al., } \\
2016^{92} \\
\text { Albuquerque, } \\
\text { NM: } 1 \\
\text { academic } \\
\text { medical center }\end{array}$ & $\begin{array}{l}(\mathrm{N}=1547) \\
\text { Intervention }(\mathrm{N}=753) \\
\text { Comparison }(\mathrm{N}=794)\end{array}$ & $\begin{array}{l}\text { Observational } \\
\text { study } \\
\text { (RoB: high) }\end{array}$ & $\begin{array}{l}\text { High cost (top 1\%) in } \\
\text { past } 1 \text { year }\end{array}$ & $\begin{array}{l}\text { Medically complex } \\
\text { patients with a } \\
\text { chronic medical } \\
\text { condition and at } \\
\text { high risk for future } \\
\text { hospitalization }\end{array}$ & $\begin{array}{l}\text { Participant selection } \\
\text { guided by the } \\
\text { likelihood of recurrent } \\
\text { illness and response } \\
\text { to care management, } \\
\text { and patient willingness } \\
\text { to participate in the } \\
\text { program and be } \\
\text { monitored and } \\
\text { contacted }\end{array}$ \\
\hline
\end{tabular}

aICU = ambulatory intensive caring unit; $\mathrm{CA}=$ California; $\mathrm{CAN}=$ care assessment need; $\mathrm{CO}=\mathrm{Colorado}$; $\mathrm{ED}=$ emergency department; $\mathrm{GA}=$ Georgia; $\mathrm{IP}=$ inpatient; $\mathrm{MN}=$ Minnesota; $\mathrm{N}=$ number; $\mathrm{NA}=$ not applicable; $\mathrm{NC}=$ North Carolina; $\mathrm{NM}=$ New Mexico; $\mathrm{NR}=$ not reported; $\mathrm{OH}=$ Ohio; $\mathrm{RCT}=$ randomized controlled trial; $\mathrm{RoB}=$ risk of bias; $\mathrm{VA}=$ Department of Veterans Affairs; WI = Wisconsin. 
Table B-47. Intervention characteristics of alCU (ambulatory intensive caring unit) interventions

\begin{tabular}{|c|c|c|c|c|c|c|c|c|c|}
\hline $\begin{array}{l}\text { First Author, } \\
\text { Year, Site(s) }\end{array}$ & $\begin{array}{l}\text { Intervention: } \\
\text { Brief } \\
\text { Description }\end{array}$ & $\begin{array}{l}\text { Intervention } \\
\text { Duration }\end{array}$ & $\begin{array}{l}\text { Assessment, } \\
\text { Education, Skills, } \\
\text { Monitoring }\end{array}$ & $\begin{array}{l}\text { Coordination } \\
\text { and } \\
\text { Continuity of } \\
\text { Care }\end{array}$ & $\begin{array}{l}\text { Referral } \\
\text { to/Linkages } \\
\text { to } \\
\text { Community- } \\
\text { Based } \\
\text { Support } \\
\text { Services }\end{array}$ & Providers & $\begin{array}{l}\text { Mode of } \\
\text { Delivery } \\
\text { Setting(s) }\end{array}$ & Intensity & Comparison \\
\hline $\begin{array}{l}\text { Yoon et al., } \\
2019^{87,97} \\
\text { GA, OH, WI, } \\
\text { NC, CA: } 5 \\
\text { sites }\end{array}$ & $\begin{array}{l}\text { Augmenting } \\
\text { the VA's } \\
\text { PCMH PACT } \\
\text { with a PACT- } \\
\text { PIM } \\
\text { intervention } \\
\text { for highest } \\
\text { cost patients; } \\
\text { locally } \\
\text { tailored by } \\
\text { site }\end{array}$ & $\begin{array}{l}\text { Up to } 15 \\
\text { months }\end{array}$ & $\begin{array}{l}\text { Initial assessment: } \\
\text { record review, } \\
\text { followed by } \\
\text { comprehensive in- } \\
\text { person } \\
\text { assessment for } \\
\text { medical, MH, and } \\
\text { social needs; } \\
\text { goals assessment; } \\
\text { health coaching } \\
\text { for patient and } \\
\text { caregivers, } \\
\text { pharmacist } \\
\text { medication } \\
\text { reconciliation and } \\
\text { adherence } \\
\text { monitoring }\end{array}$ & $\begin{array}{l}\text { Care } \\
\text { coordination; } \\
\text { transitional } \\
\text { care } \\
\text { management } \\
\text { post IP } \\
\text { discharge; } \\
\text { feedback to } \\
\text { PCP, } \\
\text { assistance with } \\
\text { navigating } \\
\text { healthcare } \\
\text { services }\end{array}$ & $\begin{array}{l}\text { NR: VA } \\
\text { provides } \\
\text { many support } \\
\text { services in- } \\
\text { house }\end{array}$ & $\begin{array}{l}\text { Interdisciplinary } \\
\text { team: physician } \\
\text { or nurse } \\
\text { practitioner, a } \\
\text { nurse, } \\
\text { pharmacist, } \\
\text { rehabilitation } \\
\text { therapists, MH } \\
\text { and addiction } \\
\text { support }\end{array}$ & $\begin{array}{l}\text { Outpatient, } \\
\text { home, and } \\
\text { phone }\end{array}$ & $\begin{array}{l}\text { Limited: } 1-2 \\
\text { encounters or } \\
\text { referral to PCP; } \\
\text { Full: goal was } 3+ \\
\text { encounters in } \\
\text { person or by } \\
\text { phone from PIM } \\
\text { team; received } \\
\text { by } 44 \% \text { of } \\
\text { participants. } \\
\text { Tailored to } \\
\text { individual needs. } \\
\text { Full-intervention } \\
\text { participants } \\
\text { received mean of } \\
14 \text { encounters } \\
\text { (range: } 3-116 \text { ) } \\
\end{array}$ & $\begin{array}{l}\text { Patient } \\
\text { Aligned Care } \\
\text { Team } \\
\text { (PACT) only }\end{array}$ \\
\hline $\begin{array}{l}\text { Durfee et al., } \\
2018^{83} \\
\text { CO: } 1 \text { sites }\end{array}$ & $\begin{array}{l}\text { IOC in } \\
\text { integrated } \\
\text { delivery } \\
\text { system }\end{array}$ & NR & $\begin{array}{l}\text { In-depth intake } \\
\text { assessment } \\
\text { included } \\
\text { determining } \\
\text { medical barriers to } \\
\text { improving health, } \\
\text { taking into } \\
\text { account BH } \\
\text { needs, social } \\
\text { determinants of } \\
\text { health, and } \\
\text { patient-identified } \\
\text { priorities }\end{array}$ & $\begin{array}{l}\text { Sought to } \\
\text { develop } \\
\text { comprehensive } \\
\text { care plans. } \\
\text { More nursing } \\
\text { support } \\
\text { allowed for } \\
\text { medical } \\
\text { interventions to } \\
\text { be done within } \\
\text { the clinic } \\
\text { instead of the } \\
\text { ED or hospital }\end{array}$ & NR & $\begin{array}{l}\text { Eight existing } \\
\text { family practice } \\
\text { and internal } \\
\text { medicine } \\
\text { teams } \\
\text { composed of a } \\
\text { PCP, medical } \\
\text { assistant, and } \\
\text { shared nursing } \\
\text { and social work } \\
\text { resources. } \\
\text { Supported by } \\
\text { clinical } \\
\text { pharmacists, } \\
\text { patient } \\
\text { navigators, BH } \\
\text { clinicians }\end{array}$ & $\begin{array}{l}\text { Additional } \\
\text { staffing to } \\
\text { existing } \\
\text { PCPs and } \\
\text { developed } \\
\text { IOCs (new, } \\
\text { specialized } \\
\text { primary } \\
\text { care } \\
\text { clinics). } \\
\text { Face-to- } \\
\text { face with } \\
\text { care team; } \\
\text { navigators } \\
\text { and } \\
\text { pharmacists } \\
\text { primarily by } \\
\text { phone }\end{array}$ & $\begin{array}{l}\text { IOC had higher } \\
\text { staff-patient ratio } \\
\text { than regular PCP } \\
\text { clinic, longer } \\
\text { visits, walk-in } \\
\text { availability. Mean } \\
\text { number of } \\
\text { encounters per } \\
\text { patient: NR }\end{array}$ & $\begin{array}{l}\text { Usual care: } \\
\text { historic } \\
\text { comparison } \\
\text { group who } \\
\text { received } \\
\text { care prior to } \\
\text { implementing } \\
\text { the IOC }\end{array}$ \\
\hline
\end{tabular}




\begin{tabular}{|c|c|c|c|c|c|c|c|c|c|}
\hline $\begin{array}{l}\text { First Author, } \\
\text { Year, Site(s) }\end{array}$ & $\begin{array}{l}\text { Intervention: } \\
\text { Brief } \\
\text { Description }\end{array}$ & $\begin{array}{l}\text { Intervention } \\
\text { Duration }\end{array}$ & $\begin{array}{l}\text { Assessment, } \\
\text { Education, Skills, } \\
\text { Monitoring }\end{array}$ & $\begin{array}{l}\text { Coordination } \\
\text { and } \\
\text { Continuity of } \\
\text { Care }\end{array}$ & $\begin{array}{l}\text { Referral } \\
\text { to/Linkages } \\
\text { to } \\
\text { Community- } \\
\text { Based } \\
\text { Support } \\
\text { Services }\end{array}$ & Providers & $\begin{array}{l}\text { Mode of } \\
\text { Delivery } \\
\text { Setting(s) }\end{array}$ & Intensity & Comparison \\
\hline $\begin{array}{l}\text { Vickery et al., } \\
2018^{100} \\
\text { MN: } 1 \text { site }\end{array}$ & $\begin{array}{l}\text { Hennepin } \\
\text { Health } \\
\text { Accountable } \\
\text { Care } \\
\text { Organization } \\
\text { (HH ACO) }\end{array}$ & 24 months & $\begin{array}{l}\text { Developing } \\
\text { patient-specific } \\
\text { plans based on } \\
\text { need, patient } \\
\text { education, and } \\
\text { goal setting }\end{array}$ & $\begin{array}{l}\text { Connected } \\
\text { patients to } \\
\text { primary care } \\
\text { and other } \\
\text { necessary } \\
\text { services, } \\
\text { increased } \\
\text { access to care } \\
\text { for mental } \\
\text { illness and } \\
\text { substance use } \\
\text { (behavioral } \\
\text { health), } \\
\text { including } \\
\text { integration } \\
\text { within primary } \\
\text { care, care } \\
\text { coordination } \\
\text { and disease } \\
\text { management } \\
\text { service } \\
\text { intensity based } \\
\text { on risk }\end{array}$ & $\begin{array}{l}\text { Integrated } \\
\text { county } \\
\text { services for } \\
\text { social and } \\
\text { behavioral } \\
\text { needs } \\
\text { (housing, } \\
\text { vocational, } \\
\text { social } \\
\text { services) with } \\
\text { health care, } \\
\text { increased } \\
\text { access to } \\
\text { services to } \\
\text { meet social } \\
\text { needs, } \\
\text { improved } \\
\text { access to } \\
\text { dental } \\
\text { services; } \\
\text { high-risk } \\
\text { patients } \\
\text { referred to a } \\
\text { Coordinated } \\
\text { Care Center }\end{array}$ & $\begin{array}{l}\text { Care } \\
\text { coordination } \\
\text { team: RN care } \\
\text { coordinators } \\
\text { embedded in } \\
\text { primary care } \\
\text { clinics, } \\
\text { clinical social } \\
\text { workers, CHWs } \\
\text { Coordinated } \\
\text { care center } \\
\text { team: } \\
\text { physicians, } \\
\text { NPs or PAs, } \\
\text { care } \\
\text { coordinators, } \\
\text { social workers, } \\
\text { psychologists, } \\
\text { pharmacists, } \\
\text { licensed } \\
\text { chemical } \\
\text { dependency } \\
\text { counselors, } \\
\text { and part-time } \\
\text { addiction } \\
\text { psychiatrist } \\
\text { support }\end{array}$ & $\begin{array}{l}\text { Patients } \\
\text { received } \\
\text { care at } \\
\text { various } \\
\text { care } \\
\text { settings, } \\
\text { program } \\
\text { managed } \\
\text { by county }\end{array}$ & $\begin{array}{l}\text { NR; based on } \\
\text { patient risk }\end{array}$ & $\begin{array}{l}\text { Usual care: } \\
\text { enrolled in } \\
\text { non- } \\
\text { Hennepin } \\
\text { Health } \\
\text { managed } \\
\text { care in } \\
\text { Hennepin or } \\
\text { Ramsey } \\
\text { County }\end{array}$ \\
\hline
\end{tabular}




\begin{tabular}{|c|c|c|c|c|c|c|c|c|c|}
\hline $\begin{array}{l}\text { First Author, } \\
\text { Year, Site(s) }\end{array}$ & $\begin{array}{l}\text { Intervention: } \\
\text { Brief } \\
\text { Description }\end{array}$ & $\begin{array}{l}\text { Intervention } \\
\text { Duration }\end{array}$ & $\begin{array}{l}\text { Assessment, } \\
\text { Education, Skills, } \\
\text { Monitoring }\end{array}$ & $\begin{array}{l}\text { Coordination } \\
\text { and } \\
\text { Continuity of } \\
\text { Care }\end{array}$ & $\begin{array}{l}\text { Referral } \\
\text { to/Linkages } \\
\text { to } \\
\text { Community- } \\
\text { Based } \\
\text { Support } \\
\text { Services } \\
\end{array}$ & Providers & $\begin{array}{l}\text { Mode of } \\
\text { Delivery } \\
\text { Setting(s) }\end{array}$ & Intensity & Comparison \\
\hline $\begin{array}{l}\text { Horn et al., } \\
2016^{92} \\
\text { Albuquerque, } \\
\text { NM: } 1 \\
\text { academic } \\
\text { medical center }\end{array}$ & $\begin{array}{l}\text { Care One, an } \\
\text { intensive } \\
\text { chronic care, } \\
\text { primary care- } \\
\text { oriented } \\
\text { program } \\
\text { designed to } \\
\text { target HNHC } \\
\text { patients }\end{array}$ & NR & $\begin{array}{l}\text { Assessment of } \\
\text { whether amenable } \\
\text { to care } \\
\text { management } \\
\text { based on } \\
\text { interview and } \\
\text { medical record } \\
\text { review }\end{array}$ & $\begin{array}{l}\text { Provided } \\
\text { access to } \\
\text { specialty care } \\
\text { consultations, } \\
\text { assistance } \\
\text { from nurse } \\
\text { coordinators } \\
\text { and social } \\
\text { workers, and } \\
\text { assistance with } \\
\text { unanticipated } \\
\text { problems } \\
\text { related to } \\
\text { access or } \\
\text { quality }\end{array}$ & $\begin{array}{l}\text { Assistance } \\
\text { with social } \\
\text { services, } \\
\text { such as } \\
\text { transportation } \\
\text { to clinical } \\
\text { appointments, } \\
\text { food stamp } \\
\text { applications, } \\
\text { etc. }\end{array}$ & $\begin{array}{l}\text { A physician, } \\
\text { social } \\
\text { worker/case } \\
\text { manager, } \\
\text { patient care } \\
\text { coordinator, } \\
\text { and MH } \\
\text { therapist. A } \\
\text { pharmacist } \\
\text { assists with } \\
\text { medication } \\
\text { management } \\
\text { for patients } \\
\text { with complex } \\
\text { comorbidities }\end{array}$ & $\begin{array}{l}\text { Primary } \\
\text { care }\end{array}$ & NR & Usual care \\
\hline
\end{tabular}

Georgia; HH ACO = Hennepin Health Accountable Care Organization; HNHC = high-need, high-cost; IOC = intensive outpatient clinic; IP = inpatient; $\mathrm{MH}=$ mental health; MN

$=$ Minnesota; $\mathrm{NC}=$ North Carolina; $\mathrm{NM}=$ New Mexico; $\mathrm{NP}=$ nurse practitioner; $\mathrm{NR}=$ not reported; $\mathrm{OH}=\mathrm{Ohio}$; $\mathrm{PA}=$ physician assistant; $\mathrm{PACT}=$ patient aligned care team;

PCMH = Patient-Centered Medical Homes; PCP = primary care provider; PIM = PACT-intensive management; RN = registered nurse; VA = Department of Veterans Affairs; WI

$=$ Wisconsin. 
Table B-48. Healthcare utilization outcomes for alCU (ambulatory intensive caring unit) model studies

\begin{tabular}{|c|c|c|c|c|}
\hline $\begin{array}{l}\text { Utilization } \\
\text { Measures }\end{array}$ & Study Design & $\begin{array}{l}\text { Direction of } \\
\text { Change in } \\
\text { Intervention } \\
\text { Group (G1) }\end{array}$ & $\begin{array}{l}\text { Direction of Change } \\
\text { in Comparison } \\
\text { Group (G2) }\end{array}$ & Difference \\
\hline $\begin{array}{l}\text { Acute medical/ } \\
\text { surgery inpatient } \\
\text { stays }\end{array}$ & $\mathrm{RCT}$ & NR & NR & DiD: $1.13(95 \% \mathrm{Cl}, 0.92 \text { to } 1.38)^{87}$ \\
\hline $\begin{array}{l}\text { Other inpatient } \\
\text { stays }^{a}\end{array}$ & $\mathrm{RCT}$ & NR & NR & DiD: $1.04(95 \% \mathrm{Cl}, 0.66 \text { to } 1.65)^{87}$ \\
\hline \multirow[t]{2}{*}{ Inpatient admissions } & Observational & & & $\begin{array}{l}\text { DiD: lower reduction in G1 than G2 } \\
\text { (negative finding) }(p<0.01)^{83}\end{array}$ \\
\hline & Observational & NR & NR & $\begin{array}{l}\text { Lower use in G1 vs. G2: aMD=-26.11 } \\
(95 \% \mathrm{Cl},-35.9 \text { to }-16.3)^{100,125}\end{array}$ \\
\hline Inpatient days & Observational & NR & NR & $\begin{array}{l}\text { G1 vs. G2: aMD=-219.7 }(95 \% \mathrm{Cl},-826 \text { to } \\
386.6)^{100,125}\end{array}$ \\
\hline ED visits & $\mathrm{RCT}$ & NR & NR & DiD: $1.02(95 \% \mathrm{Cl}, 0.93 \text { to } 1.13)^{87}$ \\
\hline Observational & & NR & NR & $\begin{array}{l}\text { G1 vs. G2: } a M D=34.22(95 \% \mathrm{Cl},-10.9 \text { to } \\
79.3)^{100,125}\end{array}$ \\
\hline Primary care visits & $\mathrm{RCT}$ & NR & NR & $\begin{array}{l}\text { Greater use in G1: DiD: } 1.40(95 \% \mathrm{Cl} \text {, } \\
1.30 \text { to } 1.50)^{87}\end{array}$ \\
\hline Observational & & & NR NR & $\begin{array}{l}\text { G1 vs. G2: } a M D=6.0(95 \% \mathrm{Cl}:-39.3 \text { to } \\
51.4)^{100,125}\end{array}$ \\
\hline $\begin{array}{l}\text { Care management } \\
\text { visits }\end{array}$ & $\mathrm{RCT}$ & NR & NR & $\begin{array}{l}\text { Greater use in G1: DiD: } 2.70(95 \% \mathrm{Cl} \text {, } \\
1.77 \text { to } 4.12)^{87}\end{array}$ \\
\hline Specialty care visits & $\mathrm{RCT}$ & NR & NR & DiD: $1.03(95 \% \mathrm{Cl}, 0.96 \text { to } 1.10)^{87}$ \\
\hline $\begin{array}{l}\text { Mental healthcare } \\
\text { visits }\end{array}$ & $\mathrm{RCT}$ & NR & NR & $\begin{array}{l}\text { Greater use in G1: DiD: } 1.33(95 \% \mathrm{Cl} \text {, } \\
1.17 \text { to } 1.52)^{87}\end{array}$ \\
\hline Homeless care visits & $\mathrm{RCT}$ & NR & NR & DiD: $1.11(95 \% \mathrm{Cl}, 0.86 \text { to } 1.44)^{87}$ \\
\hline $\begin{array}{l}\text { Intensive care unit } \\
\text { visits }\end{array}$ & Observational & NR & NR & $\begin{array}{l}\text { G1 vs. G2: aMD=0.1 (95\% Cl: }-0.7 \text { to } \\
0.9)^{100,125}\end{array}$ \\
\hline Dental visits & Observational & NR & NR & $\begin{array}{l}\text { Greater reduction in G1 vs. G2: aMD=- } \\
30.7(95 \% \mathrm{Cl},-41.0 \text { to }-20.3)^{100,125}\end{array}$ \\
\hline
\end{tabular}


Table B-49. Cost outcomes for alCU (ambulatory intensive caring unit) model studies

\begin{tabular}{|c|c|c|c|c|}
\hline Cost Measures & Study Design & $\begin{array}{l}\text { Direction of } \\
\text { Change in } \\
\text { Intervention } \\
\text { Group (G1) }\end{array}$ & $\begin{array}{l}\text { Direction of } \\
\text { Change in } \\
\text { Comparison } \\
\text { Group (G2) }\end{array}$ & Difference \\
\hline Outpatient costs & RCT & & & $\begin{array}{l}\text { DiD: greater increase in G1 than G2: } 2636 \\
(95 \% \mathrm{Cl}, 524 \text { to } 4748)^{87}\end{array}$ \\
\hline Inpatient costs & RCT & & & DiD: $-2,164(95 \% \mathrm{Cl},-7,916 \text { to } 3,587)^{87}$ \\
\hline ED costs & $\mathrm{RCT}$ & & & DiD:-20 $(95 \% \mathrm{Cl},-277 \text { to } 237)^{87}$ \\
\hline \multirow{3}{*}{$\begin{array}{l}\text { Total costs/ } \\
\text { charges }\end{array}$} & RCT & & & DiD: $471(95 \% \mathrm{Cl},-6,347 \text { to } 7,290)^{87}$ \\
\hline & $\overline{\text { Observational }}$ & & & $\begin{array}{l}\text { DiD: greater reduction in } \mathrm{G} 1 \text { than } \mathrm{G} 2 \\
(\mathrm{p}<0.04)^{83}\end{array}$ \\
\hline & Observational & & & $\begin{array}{l}\text { DiD: greater reduction in G1 than G2: } \\
\$ 44,504(p<0.01)^{92}\end{array}$ \\
\hline
\end{tabular}

= Increase in the outcome between the intervention period and the baseline period; the difference between the intervention and comparison groups was statistically significant.

= Reduction in the outcome between the intervention period and the baseline period; the difference between the intervention and comparison groups was statistically significant.

$\widehat{\mathrm{v}}=$ Increase in the outcome between the intervention period and the baseline period; the difference between the intervention and comparison groups was not statistically significant.

$\sqrt{\Omega}=$ Reduction in the outcome between the intervention period and the baseline period; the difference between the intervention and comparison groups was not statistically significant.

$\mathrm{CI}=$ confidence interval; $\mathrm{DiD}=$ difference-in-difference; $\mathrm{ED}=$ emergency department; $\mathrm{G}=$ group; $\mathrm{RCT}=$ randomized controlled trial. 
Table B-50. Strength of evidence for alCU models versus usual-care outcomes

\begin{tabular}{|c|c|c|c|c|c|}
\hline Population & Outcome & Results & $\begin{array}{l}\text { Study } \\
\text { Design and } \\
\text { Sample } \\
\text { Size }\end{array}$ & $\begin{array}{l}\text { Strength of } \\
\text { Evidence Domains }\end{array}$ & $\begin{array}{l}\text { Overall } \\
\text { Evidence } \\
\text { Strength } \\
\text { (Direction of } \\
\text { Effect) } \\
\end{array}$ \\
\hline $\begin{array}{l}\mathrm{HNHC} \\
\text { patients }\end{array}$ & $\begin{array}{l}\text { ED visits, all } \\
\text { cause }\end{array}$ & $\begin{array}{l}\text { PIM: DiD: } 1.02 \text { (95\% Cl, } 0.93 \text { to } \\
\text { 1.13) }{ }^{87} \\
\text { HH ACO: G1 vs. G2: } \\
\text { aMD=34.22 ( } 95 \% \mathrm{Cl},-10.9 \text { to } \\
79.3)^{100,125}\end{array}$ & $\begin{array}{l}1 \mathrm{RCT}^{87} \\
(\mathrm{~N}=2,210) \\
1 \mathrm{OBS}^{100,125} \\
\left(\mathrm{~N}=\mathrm{NR}^{\mathrm{a}}\right)\end{array}$ & $\begin{array}{l}\text { Moderate study } \\
\text { limitations, } \\
\text { consistent, } \\
\text { imprecise, direct }\end{array}$ & Insufficient \\
\hline $\begin{array}{l}\mathrm{HNHC} \\
\text { patients }\end{array}$ & $\begin{array}{l}\text { Inpatient } \\
\text { admissions }\end{array}$ & $\begin{array}{l}\text { IOC: DiD: Lower reduction in G1 } \\
\text { than } G 2 \text { (negative finding) } \\
(p<0.01)^{83} \\
\text { HH ACO: Lower use in } \mathrm{G} 1 \text { vs. } \\
\text { G2: aMD }=-26.11(95 \% \mathrm{Cl},-35.9 \\
\text { to }-16.3)^{100,125}\end{array}$ & $\begin{array}{l}2 \mathrm{OBSs}^{83,100} \\
125 \\
\left(\mathrm{~N}=\mathrm{NR}^{\mathrm{a}}\right)\end{array}$ & $\begin{array}{l}\text { Moderate study } \\
\text { limitations, } \\
\text { inconsistent, precise, } \\
\text { direct }\end{array}$ & Insufficient \\
\hline $\begin{array}{l}\text { Primary } \\
\text { care visits }\end{array}$ & $\begin{array}{l}\text { Primary care } \\
\text { visits }\end{array}$ & $\begin{array}{l}\text { PIM: Greater use in G1: DiD: } \\
1.40(95 \% \mathrm{Cl}, 1.30 \text { to } 1.50)^{87} \\
\mathrm{HH} \text { ACO: } \mathrm{G} 1 \text { vs. G2: aMD }=6.0 \\
(95 \% \mathrm{Cl}:-39.3 \text { to } 51.4)^{100,125}\end{array}$ & $\begin{array}{l}1 \mathrm{RCT}^{87} \\
(\mathrm{~N}=2,210) \\
1 \mathrm{OBS}^{100,125} \\
\left(\mathrm{~N}=\mathrm{NR}^{\mathrm{a}}\right) \\
\end{array}$ & $\begin{array}{l}\text { Moderate study } \\
\text { limitations, } \\
\text { inconsistent, precise, } \\
\text { direct }\end{array}$ & Insufficient \\
\hline $\begin{array}{l}\mathrm{HNHC} \\
\text { patients }\end{array}$ & Total costs & $\begin{array}{l}\text { PIM: DiD: } 471(95 \% \mathrm{Cl},-6,347 \text { to } \\
7,290)^{87} \\
\text { IOC: DiD: greater reduction in } \\
\text { G1 than G2 }(p<0.04) ; 83 \\
\text { Care One DiD: }-\$ 44,504 \\
(p<0.01)^{92}\end{array}$ & $\begin{array}{l}1 \mathrm{RCT} \\
\mathrm{N}=2,210 \\
2 \text { OBSs, } \\
\mathrm{N}=5,183\end{array}$ & $\begin{array}{l}\text { Moderate study } \\
\text { limitations, } \\
\text { consistent, precise, } \\
\text { direct }\end{array}$ & Low (Favorable) \\
\hline $\begin{array}{l}\mathrm{HNHC} \\
\text { patients }\end{array}$ & $\begin{array}{l}\text { Mortality 1-year } \\
\text { post- } \\
\text { randomization }\end{array}$ & $\begin{array}{l}\text { PIM: }(p=0.93)^{87} \\
\text { IOC: Lower in } G 1 \text { than } G 2 \text { : } \\
(p<0.01)^{83}\end{array}$ & $\begin{array}{l}1 \mathrm{RCT} \\
\mathrm{N}=2,210 \\
1 \mathrm{OBS} \\
\mathrm{N}=3,636\end{array}$ & $\begin{array}{l}\text { Moderate study } \\
\text { limitations, } \\
\text { inconsistent, } \\
\text { imprecise, direct }\end{array}$ & Insufficient \\
\hline
\end{tabular}

${ }^{\mathrm{a}}$ The $\mathrm{HH} \mathrm{ACO}^{100,125}$ study did not report sample sizes for their HNHC populations; the total sample size for the study was 92,891 . The sample size for the IOC study was $3,636 .^{83}$

aICU = ambulatory intensive caring unit; $\mathrm{CI}=$ confidence interval; $\mathrm{DiD}=$ difference-in- difference; $\mathrm{G}=$ group; $\mathrm{HH} \mathrm{ACO}=$

Hennepin Health Accountable Care Organization; HNHC = high need, high cost; IOC: Intensive Outpatient Clinic; $\mathrm{N}=$ number; OBS = observational study; PIM: Patient Aligned Care Team (PACT)-Intensive Management; RCT = randomized controlled trial; vs. = versus. 
Appendix Table B-51. Clinical and functional outcomes for alCU (ambulatory intensive caring unit) model studies

\begin{tabular}{|c|c|c|}
\hline Clinical and Functional Outcomes & Study Design & $\begin{array}{l}\text { Difference Between Intervention Group (G1) and } \\
\text { Comparison Group (G2) }\end{array}$ \\
\hline \multirow[t]{2}{*}{ Mortality, 1-year post-randomization } & RCT & $(p=0.93)^{87}$ \\
\hline & Observational & Lower in $G 1$ than $G 2:(p<0.01)^{83}$ \\
\hline Patient-centered care coordination & RCT & $\begin{array}{l}\text { AOR for all } 6 \text { measured dimensions past } 6 \text { months }^{a} \\
(p=N S)^{97}\end{array}$ \\
\hline Access to care & RCT & AOR for all 3 measured dimensions ${ }^{b}(p=N S)^{97}$ \\
\hline Patient satisfaction with care & RCT & AOR for all 4 measured dimensions ${ }^{c}(p=N S)^{97}$ \\
\hline Relationships with Providers: trusted provider & $\mathrm{RCT}$ & $\begin{array}{l}\text { Greater in } \mathrm{G} 1 \text { than } \mathrm{G} 2: \mathrm{AOR}=1.30(95 \% \mathrm{Cl}, 1.04 \text { to } \\
1.62)^{97}\end{array}$ \\
\hline $\begin{array}{l}\text { Relationships with Providers: feel respected by } \\
\text { provider }\end{array}$ & $\mathrm{RCT}$ & $(p=N S)^{97}$ \\
\hline $\begin{array}{l}\text { Healthcare hassles summary score (challenges } \\
\text { in getting care) }\end{array}$ & $\mathrm{RCT}$ & $(p=0.61)^{97}$ \\
\hline $\begin{array}{l}\text { Patient assessment of chronic illness care } \\
\text { (PACIC) summary score (receipt of care for } \\
\text { chronic illness) }\end{array}$ & RCT & Greater in G1 than G2: $(p=0.022)^{97}$ \\
\hline \multicolumn{3}{|c|}{$\begin{array}{l}\text { a Goals assessed: barriers, medications reviewed, between-visit reminders, primary care informed about specialty care, VA } \\
\text { healthcare provider helps coordinate care from different doctors and services, someone talked to them about their health goals, } \\
\text { report } 10 \text { out of } 10 \text { satisfaction with primary care, patient assessment of chronic illness care based on PACIC scale, not } \\
\text { significant for medications reviewed in past } 6 \text { months, between-visit reminders in past } 6 \text { months, primary care informed about } \\
\text { specialty care in past } 6 \text { months. } \\
\text { b Dimensions included access to needed services, access to provider when questions about care arise, and received needed } \\
\text { services. } \\
{ }^{c} \text { Dimensions included satisfaction with overall care at VA facility, social services, mental healthcare services, and primary care } \\
\text { services. }\end{array}$} \\
\hline
\end{tabular}

$\mathrm{AOR}=$ adjusted odds ratio; $\mathrm{CI}=$ confidence interval; $\mathrm{G}=$ group NS = not statistically significant; PACIC $=$ patient assessment of chronic illness care; $\mathrm{RCT}=$ randomized controlled trial; VA = Department of Veterans Affairs. 
Table B-52. Study characteristics of primary care-based interventions

\begin{tabular}{|c|c|c|c|c|c|c|}
\hline $\begin{array}{l}\text { First Author, Year, } \\
\text { Site(s) }\end{array}$ & $\begin{array}{l}\text { Type of } \\
\text { Intervention; } \\
\text { Sample Size }\end{array}$ & $\begin{array}{l}\text { Study Design } \\
\text { (Risk of Bias } \\
\text { Assessment) }\end{array}$ & $\begin{array}{l}\text { Patient Selection: } \\
\text { High Healthcare Use } \\
\text { or Cost; Time Period }\end{array}$ & $\begin{array}{l}\text { Patient Selection: Chronic } \\
\text { Conditions }\end{array}$ & $\begin{array}{l}\text { Patient Selection: } \\
\text { Other }\end{array}$ & $\begin{array}{l}\text { Additional Selected } \\
\text { Patient } \\
\text { Characteristics }\end{array}$ \\
\hline $\begin{array}{l}\text { McCall et al., } 2010^{86} \\
5 \text { MA counties } \\
\text { (Norfolk, Suffolk, } \\
\text { Middlesex, Essex, and } \\
\text { Plymouth) }\end{array}$ & $\begin{array}{l}\text { Primary care } \\
\text { model includes } \\
\text { home visits } \\
\text { pay-for- } \\
\text { performance APM } \\
\text { (Original } \mathrm{N}=5,374) \\
\text { Intervention } \\
(\mathrm{N}=2,619) \\
\text { Comparison } \\
(\mathrm{N}=2,755)\end{array}$ & $\begin{array}{l}\mathrm{RCT} \\
\text { (RoB: some } \\
\text { concerns) }\end{array}$ & $\begin{array}{l}\text { Beneficiaries with } \\
\mathrm{HCC} \text { risk scores } \geq 2.0 \\
\text { and annual costs of } \\
\geq \$ 2,000 \text { or } \mathrm{HCC} \text { risk } \\
\text { scores } \geq 3.0 \text { and } \\
\geq \$ 1,000 \text { annual } \\
\text { medical costs in past } \\
1 \text { year }\end{array}$ & HCC risk scores $\geq 2.0$ & $\begin{array}{l}\text { Medicare FFS } \\
\text { beneficiaries; at } \\
\text { least } 2 \text { visits to MA } \\
\text { General Hospital } \\
\text { physicians for a } \\
\text { selected group of } \\
\text { outpatient and ED } \\
\text { procedures }\end{array}$ & $\begin{array}{l}\text { Nonwhite: } 13.4 \% \\
\text { Medicaid: } 5.3 \%\end{array}$ \\
\hline $\begin{array}{l}\text { McCall et al., } 2010^{86} \\
5 \text { MA counties } \\
\text { (Norfolk, Suffolk, } \\
\text { Middlesex, Essex, and } \\
\text { Plymouth) }\end{array}$ & $\begin{array}{l}\text { Primary care } \\
\text { model includes } \\
\text { home visits } \\
\text { pay-for- } \\
\text { performance APM } \\
\text { (Refresh } \mathrm{N}=1,569) \\
\text { Intervention } \\
(\mathrm{N}=785) \\
\mathrm{Comparison} \\
(\mathrm{N}=784)\end{array}$ & $\begin{array}{l}\text { RCT } \\
\text { (RoB: some } \\
\text { concerns) }\end{array}$ & $\begin{array}{l}\text { Beneficiaries with } \\
\mathrm{HCC} \text { risk scores } \geq 2.0 \\
\text { and annual costs of } \\
\geq \$ 2,000 \text { or } \mathrm{HCC} \text { risk } \\
\text { scores } \geq 3.0 \text { and } \\
\geq \$ 1,000 \text { annual } \\
\text { medical costs in past } \\
1 \text { year }\end{array}$ & HCC risk scores $\geq 2.0$ & $\begin{array}{l}\text { Medicare FFS } \\
\text { beneficiaries; at } \\
\text { least } 2 \text { visits to MA } \\
\text { General Hospital } \\
\text { physicians for a } \\
\text { selected group of } \\
\text { outpatient and ED } \\
\text { procedures }\end{array}$ & $\begin{array}{l}\text { Nonwhite: } 12.8 \% \\
\text { Medicaid: } 5.4 \%\end{array}$ \\
\hline $\begin{array}{l}\text { Sledge et al., } 2006^{115} \\
\text { Northeastern U.S.: } 1 \\
\text { site }\end{array}$ & $\begin{array}{l}\text { Primary care } \\
\text { model } \\
(\mathrm{N}=96) \\
\text { Intervention }(\mathrm{N}=47) \\
\text { Comparison } \\
(\mathrm{N}=49)\end{array}$ & $\begin{array}{l}\text { RCT } \\
\text { (RoB: low) }\end{array}$ & $\begin{array}{l}2+\text { medical or surgical } \\
\text { hospital admissions } \\
\text { per year, excluded } \\
\text { highest cost outliers in } \\
12-18 \text { month period }\end{array}$ & NA & Age: $18+$ & $\begin{array}{l}\text { Nonwhite: } 62.5 \% \\
\text { Medicare/Medicaid: } \\
93 \% \\
\text { Major depression: } \\
34 \% \\
6 \text { th grade or lower } \\
\text { reading level: } 32 \% \text { of } \\
\text { those who spoke } \\
\text { English ( } \mathrm{n}=91) \\
\end{array}$ \\
\hline $\begin{array}{l}\text { Coleman et al., } \\
2001^{117}\end{array}$ & $\begin{array}{l}\text { Primary care } \\
\text { model: (Group } \\
\text { visits) }\end{array}$ & $\begin{array}{l}\mathrm{RCT} \\
\text { (RoB: some } \\
\text { concerns) }\end{array}$ & $\begin{array}{l}11+\text { outpatient visits in } \\
\text { past } 18 \text { months }\end{array}$ & $\begin{array}{l}1+\text { self-reported chronic } \\
\text { condition }\end{array}$ & Age: $60+$ & NA \\
\hline $\begin{array}{l}\text { Denver, CO: } 19 \\
\text { physician-nurse teams } \\
\text { in } 8 \text { PCP practices }\end{array}$ & $\begin{array}{l}(\mathrm{N}=295) \\
\text { Intervention } \\
(\mathrm{N}=146) \\
\text { Comparison } \\
(\mathrm{N}=149)\end{array}$ & & & & & \\
\hline
\end{tabular}




\begin{tabular}{|c|c|c|c|c|c|c|}
\hline $\begin{array}{l}\text { First Author, Year, } \\
\text { Site(s) }\end{array}$ & $\begin{array}{l}\text { Type of } \\
\text { Intervention; } \\
\text { Sample size } \\
\end{array}$ & $\begin{array}{l}\text { Study Design } \\
\text { (Risk of Bias } \\
\text { Assessment) } \\
\end{array}$ & $\begin{array}{l}\text { Patient Selection: } \\
\text { High Healthcare Use } \\
\text { or Cost; Time Period }\end{array}$ & $\begin{array}{l}\text { Patient Selection: Chronic } \\
\text { Conditions }\end{array}$ & $\begin{array}{l}\text { Patient Selection: } \\
\text { Other }\end{array}$ & $\begin{array}{l}\text { Additional Selected } \\
\text { Patient } \\
\text { Characteristics } \\
\end{array}$ \\
\hline $\begin{array}{l}\text { Katzelnick et al., } \\
2000^{99} \\
\text { WI, WA, MA: } 163 \\
\text { physician practices } \\
\text { affiliated with } 1 \text { of } 3 \\
\text { included HMOs }\end{array}$ & $\begin{array}{l}\text { Primary care } \\
\text { model } \\
(\mathrm{N}=407) \\
\text { Intervention } \\
(\mathrm{N}=218) \\
\text { Comparison } \\
(\mathrm{N}=189)\end{array}$ & $\begin{array}{l}\text { RCT } \\
\text { (RoB: some } \\
\text { concerns) }\end{array}$ & $\begin{array}{l}\text { Ambulatory visit } \\
\text { counts above the 85th } \\
\text { percentile (including } \\
\text { PCP, medical } \\
\text { specialty, and walk-in } \\
\text { clinic visits-not } \mathrm{MH} \\
\text { provider visits) in } \\
\text { previous } 2 \text { years }\end{array}$ & $\begin{array}{l}\text { Screened positive for current } \\
\text { major depression or major } \\
\text { depression in partial } \\
\text { remission (HAM-D score of } \\
15 \text { or more) }\end{array}$ & Age: $25-63$ & Female: $77 \%$ \\
\hline $\begin{array}{l}\text { Powers et al., } 2020^{108} \\
\text { Memphis, TN: } 1 \text { site }\end{array}$ & $\begin{array}{l}\text { Primary care } \\
\text { model } \\
(\mathrm{N}=253) \\
\text { Intervention } \\
(\mathrm{N}=93) \\
\text { Comparison } \\
(\mathrm{N}=160) \\
\end{array}$ & $\begin{array}{l}\text { RCT } \\
\text { (RoB: some } \\
\text { concerns) }\end{array}$ & $\begin{array}{l}\text { Top } 5 \% \text { of total } \\
\text { medical expenditures } \\
\text { in past year and } 2+ \\
\text { inpatient admissions } \\
\text { or } 3+\text { ED visits in past } \\
\text { year }\end{array}$ & $\begin{array}{l}\text { Top 5\% chronic Illness } \\
\text { Intensity Index }(\mathrm{Cl} 3) \text { score } \\
\text { and } 2+\text { chronic conditions }\end{array}$ & NA & $\begin{array}{l}\text { Mean age: } 45 \\
\text { Nonwhite: NR } \\
\text { Medicaid: } 100 \% \\
\text { Medicare: NR }\end{array}$ \\
\hline $\begin{array}{l}\text { Crane et al., } 2012^{98} \\
\text { Hendersonville, NC: } 1 \\
\text { site }\end{array}$ & $\begin{array}{l}\text { Primary care } \\
\text { model: Group } \\
\text { Visits } \\
(\mathrm{N}=72) \\
\text { Intervention }(\mathrm{N}=36) \\
\text { Comparison } \\
(\mathrm{N}=36)\end{array}$ & $\begin{array}{l}\text { Observational } \\
\text { study } \\
\text { (RoB: high) }\end{array}$ & $\begin{array}{l}6+\text { ED visits in past } 1 \\
\text { year }\end{array}$ & NA & $\begin{array}{l}\text { Below } 200 \% \text { FPL; } \\
\text { uninsured }\end{array}$ & $\begin{array}{l}\text { Median age: } 32 \\
\text { The following were } \\
\text { only reported in } \\
\text { intervention group } \\
\text { Chronic pain: } 75 \% \\
\text { Uninsured: } 100 \% \\
\text { Substance abuse: } \\
47 \% \\
\text { Depression: } 36 \% \\
\end{array}$ \\
\hline $\begin{array}{l}\text { Adam et al., } 2010^{102} \\
\text { MN: } 1 \text { residency clinic }\end{array}$ & $\begin{array}{l}\text { Primary care } \\
\text { model } \\
(\mathrm{N}=21) \\
\text { Intervention }(\mathrm{N}=13) \\
\text { Comparison }(\mathrm{N}=8)\end{array}$ & $\begin{array}{l}\text { Observational } \\
\text { study } \\
\text { (RoB: high) }\end{array}$ & $\begin{array}{l}8+\text { clinic visits in past } \\
1 \text { year }\end{array}$ & NA & Age: $18+$ & $\begin{array}{l}\text { Psychiatric diagnosis: } \\
85 \% \\
\text { Nonwhite: } 28 \% \\
\text { Female: } 65 \% \\
\text { Median age: } 49.5 \\
\end{array}$ \\
\hline $\begin{array}{l}\text { Harrison et al., } 2020^{130} \\
\text { Philadelphia, PA: } 12 \\
\text { sites }\end{array}$ & $\begin{array}{l}\text { Primary care } \\
\text { model } \\
(\mathrm{N}=3,048) \\
\mathrm{CBCM} \text { enrollee } \\
(\mathrm{N}=896) \\
\text { Comparison } \\
(\mathrm{N}=2,152)\end{array}$ & $\begin{array}{l}\text { Observational } \\
\text { (ROB: some } \\
\text { concerns) }\end{array}$ & $\begin{array}{l}\text { Top } 10 \% \text { of total costs } \\
\text { for the Medicaid MCO } \\
\text { in past year }\end{array}$ & NA & $\begin{array}{l}\text { Received primary } \\
\text { care at } 1 \text { of } 12 \\
\text { participating clinical } \\
\text { practices, } 18+ \\
\text { years, enrolled in } \\
\text { Medicaid }\end{array}$ & $\begin{array}{l}\text { Percentage in age } \\
\text { range (years): } \\
\text { 18-39: } 27 \% \\
40-59: 60 \% \\
\geq 60: 12 \% \\
\text { Nonwhite: } 88 \% \\
\text { Medicaid } 2+\text { years: } \\
82 \% \\
\text { Medicare: NR }\end{array}$ \\
\hline
\end{tabular}

poverty line; HAM-D = Hamilton Depression Rating Scale; HCC = hierarchical condition category; HNHC = high-need, high-cost; MA = Massachusetts; MCO = managed care 
organization; $\mathrm{MH}=$ mental health $; \mathrm{MN}=$ Minnesota $\mathrm{N}=$ number; $\mathrm{NA}=$ not applicable; $\mathrm{NC}=$ North Carolina; $\mathrm{NR}=$ not reported; $\mathrm{PA}=\mathrm{Pennsylvania}$; $\mathrm{PCP}=$ primary care provider; $\mathrm{RCT}=$ randomized controlled trial; $\mathrm{RoB}=$ risk of bias; $\mathrm{TN}=$ Tennessee; U.S. = United States; WA = Washington; WI = Wisconsin. 
Table B-53. Intervention characteristics of primary care-based interventions

\begin{tabular}{|c|c|c|c|c|c|c|c|c|c|}
\hline $\begin{array}{l}\text { First Author, } \\
\text { Year, Site(s) }\end{array}$ & $\begin{array}{l}\text { Intervention: } \\
\text { Brief } \\
\text { Description }\end{array}$ & $\begin{array}{l}\text { Intervention } \\
\text { Duration }\end{array}$ & $\begin{array}{l}\text { Assessment, } \\
\text { Education, Skills, } \\
\text { Monitoring }\end{array}$ & $\begin{array}{l}\text { Coordination } \\
\text { and Continuity } \\
\text { of Care }\end{array}$ & $\begin{array}{l}\text { Referral } \\
\text { to/Linkages to } \\
\text { Community- } \\
\text { Based } \\
\text { Support } \\
\text { Services }\end{array}$ & Providers & $\begin{array}{l}\text { Mode of } \\
\text { Delivery } \\
\text { Setting(s) }\end{array}$ & Intensity & Comparison \\
\hline $\begin{array}{l}\text { McCall et al., } \\
2010^{86} \\
5 \text { MA counties } \\
\text { (Norfolk, } \\
\text { Suffolk, } \\
\text { Middlesex, } \\
\text { Essex, and } \\
\text { Plymouth) }\end{array}$ & $\begin{array}{l}\text { Provider- } \\
\text { based care } \\
\text { management } \\
\text { program }\end{array}$ & $\begin{array}{l}\text { Up to } 36 \\
\text { months for } \\
\text { original } \\
\text { population, } \\
\text { up to } 24 \\
\text { months for } \\
\text { refresh } \\
\text { population }\end{array}$ & $\begin{array}{l}\text { Conducted } \\
\text { comprehensive } \\
\text { assessment to } \\
\text { evaluate the unique } \\
\text { needs of each } \\
\text { patient; educated } \\
\text { patients about } \\
\text { resources available } \\
\text { and lifestyle changes } \\
\text { that could help to } \\
\text { prevent } \\
\text { exacerbations of } \\
\text { disease, to prevent } \\
\text { or delay } \\
\text { hospitalization and } \\
\text { about the purpose of } \\
\text { their medications and } \\
\text { other treatment } \\
\text { interventions; } \\
\text { reviewed self- } \\
\text { management } \\
\text { activities }\end{array}$ & $\begin{array}{l}\text { The role of the } \\
\text { case manager is } \\
\text { to provide } \\
\text { support across } \\
\text { patients' } \\
\text { continuum of care }\end{array}$ & $\begin{array}{l}\text { Connect } \\
\text { patients to } \\
\text { resources to } \\
\text { meet medical } \\
\text { and } \\
\text { psychosocial } \\
\text { needs }\end{array}$ & $\begin{array}{l}\text { Nurse case } \\
\text { managers } \\
\text { supported by case } \\
\text { management } \\
\text { program project } \\
\text { manager, an } \\
\text { administrative } \\
\text { assistant, a } \\
\text { community } \\
\text { resource } \\
\text { specialist, and a } \\
\text { patient financial } \\
\text { counselor as well } \\
\text { as social workers } \\
\text { to help with mental } \\
\text { health program } \\
\text { and pharmacists }\end{array}$ & $\begin{array}{l}\text { In person at } \\
\text { primary care } \\
\text { offices, } \\
\text { hospitals, } \\
\text { and home } \\
\text { visits as } \\
\text { needed and } \\
\text { via telephone }\end{array}$ & $\begin{array}{l}\text { Among the original } \\
\text { population, } 97 \% \text { of } \\
\text { the intervention } \\
\text { group received at } \\
\text { least } 1 \text { contact. } \\
\text { The mean number } \\
\text { of contacts per } \\
\text { patient was } 8 \text {. A } \\
\text { higher proportion } \\
\text { of patients in the } \\
\text { HCC risk score } \\
\text { group received } 10 \\
\text { or more calls } \\
\text { during the } 36- \\
\text { month period } \\
\text { compared with the } \\
\text { low HCC risk } \\
\text { score group (27\% } \\
\text { compared to } 17 \%) \text {, } \\
\text { with } 10 \% \text { of } \\
\text { patients in the high } \\
\text { HCC risk score } \\
\text { group receiving } \\
20+\text { phone calls } \\
\text { compared with } 4 \% \\
\text { in the low HHC } \\
\text { risk score group. } \\
\text { In the refresh } \\
\text { group, } 87 \% \\
\text { received at least } 1 \\
\text { contact, and the } \\
\text { mean number of } \\
\text { contacts was } 4\end{array}$ & 列 \\
\hline
\end{tabular}




\begin{tabular}{|c|c|c|c|c|c|c|c|c|c|}
\hline $\begin{array}{l}\text { First Author, } \\
\text { Year, Site(s) }\end{array}$ & $\begin{array}{l}\text { Intervention: } \\
\text { Brief } \\
\text { Description }\end{array}$ & $\begin{array}{l}\text { Intervention } \\
\text { Duration }\end{array}$ & $\begin{array}{l}\text { Assessment, } \\
\text { Education, Skills, } \\
\text { Monitoring }\end{array}$ & $\begin{array}{l}\text { Coordination } \\
\text { and Continuity } \\
\text { of Care }\end{array}$ & $\begin{array}{l}\text { Referral } \\
\text { to/Linkages to } \\
\text { Community- } \\
\text { Based } \\
\text { Support } \\
\text { Services }\end{array}$ & Providers & $\begin{array}{l}\text { Mode of } \\
\text { Delivery } \\
\text { Setting(s) }\end{array}$ & Intensity & Comparison \\
\hline $\begin{array}{l}\text { Sledge et al., } \\
2006^{115} \\
\text { Northeastern } \\
\text { U.S.: } 1 \text { site }\end{array}$ & $\begin{array}{l}\text { Primary } \\
\text { Intensive } \\
\text { Care (PIC) }\end{array}$ & 1 year & $\begin{array}{l}\text { Comprehensive } \\
\text { interdisciplinary } \\
\text { medical and } \\
\text { psychosocial } \\
\text { assessment, used a } \\
\text { patient-centered } \\
\text { approach to improve } \\
\text { self-care patterns } \\
\text { and coping skills, } \\
\text { aimed to track and } \\
\text { facilitate completion } \\
\text { of recommendations } \\
\text { made to the PCP } \\
\text { based on the } \\
\text { assessment }\end{array}$ & $\begin{array}{l}\text { A report and } \\
\text { recommendations } \\
\text { for care were } \\
\text { presented to PCP } \\
\text { and subspecialty } \\
\text { providers; the } \\
\text { recommendations } \\
\text { were intended to } \\
\text { optimize chronic } \\
\text { illness } \\
\text { management; } \\
\text { case manager } \\
\text { used patient- } \\
\text { centered } \\
\text { approach to } \\
\text { improve } \\
\text { coordination of } \\
\text { care }\end{array}$ & $\begin{array}{l}\text { Offered } \\
\text { assistance with } \\
\text { referrals and } \\
\text { appointments } \\
\end{array}$ & $\begin{array}{l}\text { Psychiatric nurse } \\
\text { and team including } \\
\text { social worker, } \\
\text { psychiatrist, and } \\
\text { general internist }\end{array}$ & $\begin{array}{l}\text { In person } \\
\text { and via } \\
\text { telephone; } \\
\text { home visits } \\
\text { when } \\
\text { necessary }\end{array}$ & $\begin{array}{l}\text { Varied based on } \\
\text { patient needs; at } \\
\text { minimum included } \\
\text { a monthly } \\
\text { telephone call; } \\
\text { patients were } \\
\text { defined by } 3 \text { levels } \\
\text { of contact: } \\
\text { minimum contact, } \\
\text { biweekly contact, } \\
\text { and weekly or } \\
\text { greater contact }\end{array}$ & $\begin{array}{l}\text { Usual care } \\
\text { (psychiatric } \\
\text { consultation } \\
\text { provided } \\
\text { only if } \\
\text { requested by } \\
\text { PCP) }\end{array}$ \\
\hline
\end{tabular}




\begin{tabular}{|c|c|c|c|c|c|c|c|c|c|}
\hline $\begin{array}{l}\text { First Author, } \\
\text { Year, Site(s) }\end{array}$ & $\begin{array}{l}\text { Intervention: } \\
\text { Brief } \\
\text { Description }\end{array}$ & $\begin{array}{l}\text { Intervention } \\
\text { Duration }\end{array}$ & $\begin{array}{l}\text { Assessment, } \\
\text { Education, Skills, } \\
\text { Monitoring }\end{array}$ & $\begin{array}{l}\text { Coordination } \\
\text { and Continuity } \\
\text { of Care }\end{array}$ & $\begin{array}{l}\text { Referral } \\
\text { to/Linkages to } \\
\text { Community- } \\
\text { Based } \\
\text { Support } \\
\text { Services }\end{array}$ & Providers & $\begin{array}{l}\text { Mode of } \\
\text { Delivery } \\
\text { Setting(s) }\end{array}$ & Intensity & Comparison \\
\hline $\begin{array}{l}\text { Coleman et al., } \\
2001^{117} \\
\text { Denver, CO: } \\
19 \text { physician- } \\
\text { nurse teams in } \\
8 \text { PCP } \\
\text { practices }\end{array}$ & $\begin{array}{l}\text { Patient group } \\
\text { visits model } \\
\text { of care }\end{array}$ & & $\begin{array}{l}\text { Education on general } \\
\text { and specific health } \\
\text { topics, medication } \\
\text { management, } \\
\text { exercise, and } \\
\text { nutrition; } \\
\text { assessments } \\
\text { included health } \\
\text { promotion activities } \\
\text { such as blood } \\
\text { pressure } \\
\text { measurement and } \\
\text { need for and delivery } \\
\text { of immunizations and } \\
\text { medication refills and } \\
\text { ongoing chronic } \\
\text { disease } \\
\text { management and } \\
\text { evaluation of acute } \\
\text { conditions in } 1: 1 \\
\text { sessions }\end{array}$ & $\begin{array}{l}\text { Provided active } \\
\text { care coordination } \\
\text { within the primary } \\
\text { care team and } \\
\text { between other } \\
\text { providers and } \\
\text { care settings; } \\
\text { promoted } \\
\text { continuity of care } \\
\text { with the health } \\
\text { team }\end{array}$ & NR & $\begin{array}{l}\text { Primary care } \\
\text { physician, nurse, } \\
\text { pharmacist. } \\
\text { Periodic ancillary } \\
\text { providers: dietitian, } \\
\text { social worker, } \\
\text { physical therapist }\end{array}$ & In person & $\begin{array}{l}\text { Group visits were } \\
\text { held monthly for } \\
24 \text { months, } 120 \\
\text { minutes per } \\
\text { session, with an } \\
\text { average } \\
\text { attendance of } 8 \text { to } \\
12 \text { participants per } \\
\text { group }\end{array}$ & Usual care \\
\hline
\end{tabular}




\begin{tabular}{|c|c|c|c|c|c|c|c|c|c|}
\hline $\begin{array}{l}\text { First Author, } \\
\text { Year, Site(s) }\end{array}$ & $\begin{array}{l}\text { Intervention: } \\
\text { Brief } \\
\text { Description }\end{array}$ & $\begin{array}{l}\text { Intervention } \\
\text { Duration }\end{array}$ & $\begin{array}{l}\text { Assessment, } \\
\text { Education, Skills, } \\
\text { Monitoring }\end{array}$ & $\begin{array}{l}\text { Coordination } \\
\text { and Continuity } \\
\text { of Care }\end{array}$ & $\begin{array}{l}\text { Referral } \\
\text { to/Linkages to } \\
\text { Community- } \\
\text { Based } \\
\text { Support } \\
\text { Services }\end{array}$ & Providers & $\begin{array}{l}\text { Mode of } \\
\text { Delivery } \\
\text { Setting(s) }\end{array}$ & Intensity & Comparison \\
\hline $\begin{array}{l}\text { Katzelnick et } \\
\text { al., } 2000^{99} \\
\text { WI, WA, MA: } \\
163 \text { physician } \\
\text { practices } \\
\text { affiliated with } 1 \\
\text { of } 3 \text { included } \\
\text { HMOs }\end{array}$ & $\begin{array}{l}\text { Depression } \\
\text { management } \\
\text { program } \\
(\mathrm{DMP})\end{array}$ & 1 year & $\begin{array}{l}\text { Assessed patients to } \\
\text { confirm diagnosis } \\
\text { and appropriateness } \\
\text { for medication; } \\
\text { patients and PCPs } \\
\text { received education } \\
\text { about depression; } \\
\text { periodic followup with } \\
\text { PCP to monitor } \\
\text { patient status and } \\
\text { telephone monitoring } \\
\text { by coordinators }\end{array}$ & $\begin{array}{l}\text { PC was } \\
\text { supported by } \\
\text { coordinators who } \\
\text { reviewed patient } \\
\text { prescription refills } \\
\text { and office visits } \\
\text { and monitored } \\
\text { treatment } \\
\text { adherence, } \\
\text { response, and } \\
\text { adverse effects }\end{array}$ & $\begin{array}{l}\text { Study } \\
\text { psychiatrists } \\
\text { had ongoing } \\
\text { contact with } \\
\text { PCPs via } \\
\text { periodic case } \\
\text { reviews and } \\
\text { as-needed } \\
\text { telephone } \\
\text { consultation; } \\
\text { psychiatric } \\
\text { consultations } \\
\text { were } \\
\text { encouraged for } \\
\text { patients not } \\
\text { responding to } \\
\text { treatment by } \\
10 \text { weeks and } \\
\text { those with } \\
\text { more } \\
\text { complicated } \\
\text { depression }\end{array}$ & $\begin{array}{l}\text { PCPs, } \\
\text { psychiatrists, and } \\
\text { treatment } \\
\text { coordinators with } \\
\text { some clinical } \\
\text { mental health } \\
\text { experience }\end{array}$ & $\begin{array}{l}\text { In person } \\
\text { and via } \\
\text { telephone }\end{array}$ & $\begin{array}{l}\text { Coordinators } \\
\text { made telephone } \\
\text { contact at } 2 \\
\text { weeks, } 10 \text { weeks, } \\
18 \text { weeks, and } 30 \\
\text { weeks and have } \\
\text { an average of } 2.7 \\
\text { contacts per } \\
\text { patient; followup } \\
\text { visits with the PCP } \\
\text { were prescheduled } \\
\text { at } 1,3,6 \text {, and } 10 \\
\text { weeks, } \\
\text { subsequent visits } \\
\text { occurred } \\
\text { approximately } \\
\text { every } 10 \text { weeks }\end{array}$ & Usual care \\
\hline
\end{tabular}




\begin{tabular}{|c|c|c|c|c|c|c|c|c|c|}
\hline $\begin{array}{l}\text { First Author, } \\
\text { Year, Site(s) }\end{array}$ & $\begin{array}{l}\text { Intervention: } \\
\text { Brief } \\
\text { Description }\end{array}$ & $\begin{array}{l}\text { Intervention } \\
\text { Duration }\end{array}$ & $\begin{array}{l}\text { Assessment, } \\
\text { Education, Skills, } \\
\text { Monitoring }\end{array}$ & $\begin{array}{l}\text { Coordination } \\
\text { and Continuity } \\
\text { of Care }\end{array}$ & $\begin{array}{l}\text { Referral } \\
\text { to/Linkages to } \\
\text { Community- } \\
\text { Based } \\
\text { Support } \\
\text { Services }\end{array}$ & Providers & $\begin{array}{l}\text { Mode of } \\
\text { Delivery } \\
\text { Setting(s) }\end{array}$ & Intensity & Comparison \\
\hline $\begin{array}{l}\text { Powers et al., } \\
2020^{108} \\
\text { Memphis, TN: } \\
1 \text { site }\end{array}$ & $\begin{array}{l}\text { Complex } \\
\text { care } \\
\text { management } \\
\text { program }\end{array}$ & 12 months & $\begin{array}{l}\text { In-person intake visit } \\
\text { to assess patient's } \\
\text { medical, behavioral, } \\
\text { and social risk } \\
\text { factors. The patient } \\
\text { and care team co- } \\
\text { developed a tailored } \\
\text { care plan that } \\
\text { outlined } \\
\text { interventions, roles, } \\
\text { and responsibilities. } \\
\text { CHW called patients } \\
\text { at least weekly to } \\
\text { assess progress and } \\
\text { troubleshoot barriers }\end{array}$ & $\begin{array}{l}\text { CHW responsible } \\
\text { for patient } \\
\text { outreach, } \\
\text { engagement, } \\
\text { activation, and } \\
\text { accompaniment } \\
\text { while the social } \\
\text { worker was } \\
\text { responsible for } \\
\text { coordinating } \\
\text { referrals to social } \\
\text { service agencies } \\
\text { and other medical } \\
\text { providers and the } \\
\text { PCP was } \\
\text { responsible for } \\
\text { proving } \\
\text { comprehensive } \\
\text { care for acute } \\
\text { and chronic } \\
\text { conditions and for } \\
\text { coordinating with } \\
\text { specialist and } \\
\text { inpatient } \\
\text { providers }\end{array}$ & $\begin{array}{l}\text { CHW } \\
\text { accompanied } \\
\text { patients to } \\
\text { specialist, } \\
\text { social service, } \\
\text { and other } \\
\text { appointments } \\
\text { as needed. } \\
\text { Social worker } \\
\text { responsible for } \\
\text { counseling and } \\
\text { brief } \\
\text { interventions } \\
\text { for patients } \\
\text { with behavioral } \\
\text { health needs } \\
\text { and for } \\
\text { coordinating } \\
\text { referrals to } \\
\text { social service } \\
\text { agencies. }\end{array}$ & $\begin{array}{l}\text { Community health } \\
\text { worker, a social } \\
\text { worker, and a } \\
\text { primary care } \\
\text { provider }\end{array}$ & $\begin{array}{l}\text { Telephone or } \\
\text { face-to-face } \\
\text { at the PCP } \\
\text { office }\end{array}$ & $\begin{array}{l}\text { Weekly phone call } \\
\text { from CHW and } \\
\text { monthly in person } \\
\text { followup visit to } \\
\text { review and revise } \\
\text { the care plan }\end{array}$ & Usual care \\
\hline
\end{tabular}




\begin{tabular}{|c|c|c|c|c|c|c|c|c|c|}
\hline $\begin{array}{l}\text { First Author, } \\
\text { Year, Site(s) }\end{array}$ & $\begin{array}{l}\text { Intervention: } \\
\text { Brief } \\
\text { Description }\end{array}$ & $\begin{array}{l}\text { Intervention } \\
\text { Duration }\end{array}$ & $\begin{array}{l}\text { Assessment, } \\
\text { Education, Skills, } \\
\text { Monitoring }\end{array}$ & $\begin{array}{l}\text { Coordination } \\
\text { and Continuity } \\
\text { of Care }\end{array}$ & $\begin{array}{l}\text { Referral } \\
\text { to/Linkages to } \\
\text { Community- } \\
\text { Based } \\
\text { Support } \\
\text { Services }\end{array}$ & Providers & $\begin{array}{l}\text { Mode of } \\
\text { Delivery } \\
\text { Setting(s) }\end{array}$ & Intensity & Comparison \\
\hline $\begin{array}{l}\text { Crane et al., } \\
2012^{98} \\
\text { Hendersonville, } \\
\text { NC: } 1 \text { site }\end{array}$ & $\begin{array}{l}\text { Care } \\
\text { management } \\
\text { and drop-in } \\
\text { group } \\
\text { medical } \\
\text { appointments } \\
\text { (DIGMAs) }\end{array}$ & 1 year & $\begin{array}{l}\text { Small-group } \\
\text { sessions } \\
\text { emphasized life } \\
\text { skills; group and } \\
\text { individual sessions } \\
\text { addressed health } \\
\text { and behavioral } \\
\text { issues identified by } \\
\text { the patient }\end{array}$ & $\begin{array}{l}\text { For patients with } \\
\text { a PCP, care other } \\
\text { than emotional or } \\
\text { group support } \\
\text { provided in the } \\
\text { program was } \\
\text { reported to or } \\
\text { coordinated with } \\
\text { the PCP. All care } \\
\text { was documented } \\
\text { in an electronic } \\
\text { medical record, } \\
\text { including all } \\
\text { phone calls. } \\
\text { These records } \\
\text { could be } \\
\text { accessed by } \\
\text { physicians in the } \\
\text { ED as needed. }\end{array}$ & $\begin{array}{l}\text { Program was } \\
\text { based at a } \\
\text { county free } \\
\text { clinic that } \\
\text { provided office } \\
\text { space for case } \\
\text { manager, room } \\
\text { for DIGMA, } \\
\text { and variety of } \\
\text { wrap-around } \\
\text { services to } \\
\text { intervention } \\
\text { group including } \\
\text { free } \\
\text { prescriptions at } \\
\text { onsite } \\
\text { pharmacy }\end{array}$ & $\begin{array}{l}\text { The care team } \\
\text { consisted of a } \\
\text { family physician, } 2 \\
\text { behavioral health } \\
\text { providers, and a } \\
\text { nurse care } \\
\text { manager }\end{array}$ & $\begin{array}{l}\text { In person in } \\
\text { clinic or via } \\
\text { telephone }\end{array}$ & $\begin{array}{l}\text { DIGMA visits were } \\
\text { scheduled twice a } \\
\text { week for } 1 \text { hour; } \\
\text { small group } \\
\text { sessions with care } \\
\text { manager, } \\
\text { scheduled twice a } \\
\text { week for } 1 \text { hour; } \\
\text { direct telephone } \\
\text { access to RN care } \\
\text { manager available } \\
\text { Monday-Friday, } 8 \\
\text { AM to } 5 \text { PM; } \\
\text { median number of } \\
\text { visits per month } \\
\text { per patient was } 2 \\
\text { and median } \\
\text { number of patient } \\
\text { contacts per } \\
\text { month was } 3.5 \\
\end{array}$ & 更 \\
\hline $\begin{array}{l}\text { Adam et al., } \\
2010^{102} \\
\text { MN: } 1 \\
\text { residency clinic }\end{array}$ & $\begin{array}{l}\text { Family } \\
\text { medicine } \\
\text { care team }\end{array}$ & 6 months & $\begin{array}{l}\text { Care team met to } \\
\text { review the healthcare } \\
\text { status of a case } \\
\text { patient and develop } \\
\text { a care plan based on } \\
\text { discussions with the } \\
\text { patient's primary } \\
\text { physician. A member } \\
\text { of the team called } \\
\text { the patient to } \\
\text { schedule a free visit } \\
\text { to review the care } \\
\text { plan }\end{array}$ & $\begin{array}{l}\text { The team was } \\
\text { interdisciplinary; } \\
\text { providing joint } \\
\text { care with } \\
\text { consultants was } \\
\text { encouraged } \\
\text { when indicated, } \\
\text { as was engaging } \\
\text { family members } \\
\text { or other } \\
\text { stakeholders in } \\
\text { the patient's care }\end{array}$ & $\begin{array}{l}\text { Care plans } \\
\text { included } \\
\text { referrals as } \\
\text { needed to care } \\
\text { such as mental } \\
\text { health } \\
\text { treatment or } \\
\text { medications }\end{array}$ & $\begin{array}{l}\text { Faculty physician, } \\
4 \text { resident } \\
\text { physicians, the } \\
\text { clinic psychologist, } \\
\text { pharmacist, triage } \\
\text { nurse, certified } \\
\text { medical assistant, } \\
\text { and front desk } \\
\text { manager }\end{array}$ & $\begin{array}{l}\text { In person at } \\
\text { family } \\
\text { medicine } \\
\text { residency } \\
\text { clinic }\end{array}$ & $\begin{array}{l}\text { Care team met } 1 \\
\text { time per week to } \\
\text { discuss the care } \\
\text { and status of a } \\
\text { patient }\end{array}$ & \\
\hline
\end{tabular}




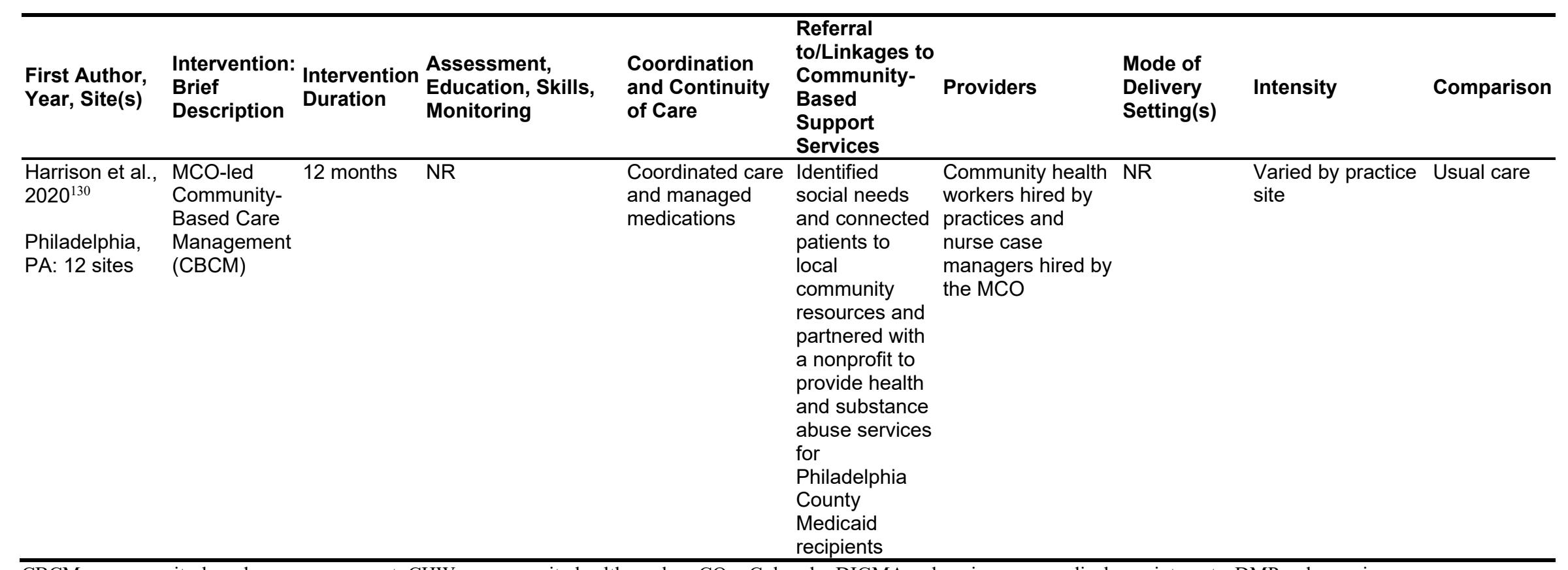

$\mathrm{CBCM}=$ community-based care management; $\mathrm{CHW}=$ community health worker; $\mathrm{CO}=$ Colorado; DIGMA = drop-in group medical appointments; DMP = depression

management program; $\mathrm{ED}=$ emergency department; $\mathrm{HCC}=$ hierarchical condition category; $\mathrm{MA}=$ Massachusetts; $\mathrm{MCO}=$ managed care organization; $\mathrm{MN}=\mathrm{Minnesota} ; \mathrm{NC}=$

North Carolina; NR = not reported; $\mathrm{PC}=$ primary care; $\mathrm{PCP}=$ primary care provider; $\mathrm{PIC}=$ primary intensive care; $\mathrm{RN}=$ registered nurse; TN = Tennessee; U.S. = United States;

$\mathrm{WA}=$ Washington $; \mathrm{WI}=$ Wisconsin. 
Table B-54. Healthcare utilization outcomes for primary care-based model studies

\begin{tabular}{|c|c|c|c|c|}
\hline Utilization Measures & Study Design & $\begin{array}{l}\text { Direction of } \\
\text { Change in } \\
\text { Intervention } \\
\text { Group (G1) }\end{array}$ & $\begin{array}{l}\text { Direction of } \\
\text { Change in } \\
\text { Comparison } \\
\text { Group (G2) }\end{array}$ & Difference \\
\hline \multirow[t]{8}{*}{ ED visits, all cause } & RCT & & & $\begin{array}{l}\text { Difference in change over time, G1 vs. G2: } \\
(p=0.9)^{115}\end{array}$ \\
\hline & $\overline{\mathrm{RCT}}$ & & & $\begin{array}{l}\text { Original sample: IRR=0.94 }(95 \% \mathrm{Cl}, 0.81 \text { to } \\
1.09)^{86}\end{array}$ \\
\hline & $\overline{\mathrm{RCT}}$ & & & $\begin{array}{l}\text { Refresh sample: Lower increase in G1 than } \\
\text { G2: IRR }=0.75(95 \% \mathrm{Cl}, 0.57 \text { to } 0.99)^{86}\end{array}$ \\
\hline & $\overline{\mathrm{RCT}}$ & NR & NR & $\begin{array}{l}\text { Lower use in } \mathrm{G} 1 \text { than } \mathrm{G} 2 \text { : aMD }=-0.42(95 \% \\
\mathrm{Cl},-0.13 \text { to }-0.72)^{117}\end{array}$ \\
\hline & $\overline{\mathrm{RCT}}$ & NR & NR & aMD $=-0.02(95 \% \mathrm{Cl},-0.51$ to 0.47$)(p=1.00)^{108}$ \\
\hline & $\overline{\text { Observational }}$ & NR & NR & $\begin{array}{l}\text { Greater use in } \mathrm{G} 1 \text { than } \mathrm{G} 2: \mathrm{aMD}=0.18(95 \% \\
\mathrm{Cl}, 0.01 \text { to } 0.37)^{130}\end{array}$ \\
\hline & $\overline{\text { Observational }}$ & & & Greater reduction in $\mathrm{G} 1$ than $\mathrm{G} 2:(p=0.005)^{98}$ \\
\hline & Observational & & & Difference $=0.5(p=N R)^{102}$ \\
\hline$\overline{E D}$, any (\%) & $\mathrm{RCT}$ & $\overline{N R}$ & NR & $\begin{array}{l}\text { Lower use in G1 than G2: aRR=0.64 }(95 \% \mathrm{Cl} \text {, } \\
0.44 \text { to } 0.86)^{117}\end{array}$ \\
\hline \multirow[t]{2}{*}{ ED visits, ACSC } & RCT & & & $\begin{array}{l}\text { Original sample: IRR=0.90 }(95 \% \mathrm{Cl}, 0.70 \text { to } \\
1.16)^{86}\end{array}$ \\
\hline & RCT & & & $\begin{array}{l}\text { Refresh sample: IRR=0.80 }(95 \% \mathrm{Cl}, 0.51 \text { to } \\
1.25)^{86}\end{array}$ \\
\hline \multirow[t]{8}{*}{$\begin{array}{l}\text { Inpatient admissions, all } \\
\text { cause }\end{array}$} & RCT & & & $\begin{array}{l}\text { Difference in change over time, G1 vs. G2: } \\
(p=0.55)^{115}\end{array}$ \\
\hline & $\overline{\mathrm{RCT}}$ & & & $\begin{array}{l}\text { Original sample: lower increase in G1 than } \\
\mathrm{G} 2 \text { : IRR }=0.81(95 \% \mathrm{Cl}, 0.70 \text { to } 0.94)^{86}\end{array}$ \\
\hline & $\overline{\mathrm{RCT}}$ & & & $\begin{array}{l}\text { Refresh sample: lower increase in G1 than } \\
\text { G2: IRR: } 0.76(95 \% \mathrm{Cl}, 0.58 \text { to } 0.99)^{86}\end{array}$ \\
\hline & $\overline{\mathrm{RCT}}$ & NR & NR & $\begin{array}{l}\text { Lower use in G1 than G2 (mean \# of } \\
\text { admissions): } 0.44 \text { vs. } 0.81(p=0.04)^{117}\end{array}$ \\
\hline & $\overline{\mathrm{RCT}}$ & & & G1 vs. G2: $(p=0.09)^{99}$ \\
\hline & $\overline{\mathrm{RCT}}$ & NR & NR & $\begin{array}{l}\text { Greater reduction in G1 than G2: aMD }=-0.32 \\
(95 \% \mathrm{Cl},-0.54 \text { to }-0.11)(p=0.014)^{108}\end{array}$ \\
\hline & $\overline{\text { Observational }}$ & NR & NR & $\begin{array}{l}\text { Greater use in } \mathrm{G} 1 \text { than } \mathrm{G} 2: \text { aMD }=0.10(95 \% \\
\mathrm{Cl}, 0.03 \text { to } 0.16)^{130}\end{array}$ \\
\hline & Observational & -- & -- & Difference $=0(p=N R)^{102}$ \\
\hline \multirow[t]{2}{*}{$\begin{array}{l}\text { Inpatient admissions, } \\
\text { any }(\%)\end{array}$} & RCT & & & $\begin{array}{l}\text { Original sample: lower increase in G1 than } \\
\mathrm{G} 2, \mathrm{OR}=0.65(95 \% \mathrm{Cl}, 0.55 \text { to } 0.78\}^{86}\end{array}$ \\
\hline & $\overline{\mathrm{RCT}}$ & & & $\begin{array}{l}\text { Refresh sample: greater reduction in G1 than } \\
\mathrm{G} 2, \mathrm{OR}=0.66(95 \% \mathrm{Cl}, 0.48 \text { to } 0.90)^{86}\end{array}$ \\
\hline
\end{tabular}




\begin{tabular}{|c|c|c|c|c|}
\hline Utilization Measures & Study Design & $\begin{array}{l}\text { Direction of } \\
\text { Change in } \\
\text { Intervention } \\
\text { Group (G1) }\end{array}$ & $\begin{array}{l}\text { Direction of } \\
\text { Change in } \\
\text { Comparison } \\
\text { Group (G2) }\end{array}$ & Difference \\
\hline \multirow[t]{2}{*}{$\begin{array}{l}\text { Inpatient admissions, } \\
\text { ACSC }\end{array}$} & $\mathrm{RCT}$ & & & $\begin{array}{l}\text { Original sample: IRR=0.87 }(95 \% \mathrm{Cl}, 0.66 \text { to } \\
1.14)^{86}\end{array}$ \\
\hline & $\mathrm{RCT}$ & & & $\begin{array}{l}\text { Refresh sample: IRR=0.78 }(95 \% \mathrm{Cl}, 0.49 \text { to } \\
1.24)^{86}\end{array}$ \\
\hline \multirow[t]{2}{*}{$\begin{array}{l}\text { Inpatient admissions, } \\
\text { any ACSC (\%) }\end{array}$} & $\mathrm{RCT}$ & & & $\begin{array}{l}\text { Original sample: lower increase in G1 than } \\
\mathrm{G} 2, \mathrm{OR}=0.73(95 \% \mathrm{Cl}, 0.57 \text { to } 0.95)^{86}\end{array}$ \\
\hline & $\overline{\mathrm{RCT}}$ & & & $\begin{array}{l}\text { Refresh sample: OR=0.79 }(95 \% \mathrm{Cl}, 0.51 \text { to } \\
1.21)^{86}\end{array}$ \\
\hline Inpatient days & RCT & NR & NR & $\begin{array}{l}\text { Greater reduction in } \mathrm{G} 1 \text { vs. G2: aMD }=-3.46 \\
(95 \% \mathrm{Cl},-4.04 \text { to }-2.89)(\mathrm{p}<0.001)^{108}\end{array}$ \\
\hline \multirow[t]{3}{*}{ Primary care visits } & $\mathrm{RCT}$ & & & $\begin{array}{l}\text { Difference in change over time, G1 vs. G2: } \\
(p=0.055)^{115}\end{array}$ \\
\hline & RCT & NR & NR & G1 vs. G2: $(p=0.20)^{117}$ \\
\hline & Observational & NR & NR & $\begin{array}{l}\text { Less use in } \mathrm{G} 1 \text { than } \mathrm{G} 2 \text { : aMD=-1.83 }(95 \% \mathrm{Cl} \text {, } \\
-2.10 \text { to }-1.55)^{130}\end{array}$ \\
\hline \multirow[t]{2}{*}{ Outpatient visits } & $\mathrm{RCT}$ & & & Greater increase in $\mathrm{G} 1$ than $\mathrm{G} 2:(\mathrm{p}=0.02)^{99}$ \\
\hline & $\overline{\text { Observational }}$ & & & Difference $=4.5(p=N R)^{102}$ \\
\hline Care center visits & RCT & NR & NR & aMD: $0.47\left(95 \% \mathrm{Cl},-0.16\right.$ to 1.11) $(p=0.576)^{108}$ \\
\hline Specialist visits & $\mathrm{RCT}$ & NR & NR & $\begin{array}{l}\text { Greater reduction in G1 vs. G2: aMD: }-1.35 \\
(95 \% \mathrm{Cl},-1.98 \text { to }-0.73)(p<0.001)^{108}\end{array}$ \\
\hline Total visits & Observational & NR & NR & $\begin{array}{l}\text { Less use in } \mathrm{G} 1 \text { than } \mathrm{G} 2 \text { : aMD: }-1.55(95 \% \mathrm{Cl} \text {, } \\
-1.93 \text { to }-1.21)^{130}\end{array}$ \\
\hline $\begin{array}{l}\text { Filled } \geq 3 \\
\text { antidepressant } \\
\text { prescriptions in first } 6 \\
\text { months } \\
\end{array}$ & $\mathrm{RCT}$ & NR & NR & Greater use in G1 than G2: $(p<0.001)^{99}$ \\
\hline $\begin{array}{l}\text { Specialty mental health } \\
\text { visit in first } 6 \text { months }\end{array}$ & $\mathrm{RCT}$ & NR & NR & Greater use in $\mathrm{G} 1$ than $\mathrm{G} 2:(\mathrm{p}=0.03)^{99}$ \\
\hline $\begin{array}{l}\text { Cancelled visits and/or } \\
\text { no shows }\end{array}$ & Observational & & & Difference $=3.5(p=N R)^{102}$ \\
\hline
\end{tabular}

${ }^{a}$ Outpatient visits were defined as primary care visits and group intervention visits for the intervention group and as primary care visits only for the comparison group.

= Increase in the outcome between the intervention period and the baseline period; the difference between the intervention and comparison groups was statistically significant.

- Reduction in the outcome between the intervention period and the baseline period; the difference between the intervention and comparison groups was statistically significant.

$\widehat{\mathrm{V}}=$ Increase in the outcome between the intervention period and the baseline period; the difference between the intervention and comparison groups was not statistically significant.

$\Omega=$ Reduction in the outcome between the intervention period and the baseline period; the difference between the intervention and comparison groups was not statistically significant.

$\mathrm{ACSC}=$ ambulatory care sensitive conditions; $\mathrm{aMD}=$ adjusted mean difference; $\mathrm{aRR}=$ adjusted risk ratio; $\mathrm{CI}=$ confidence interval; $\mathrm{ED}=$ emergency department; $\mathrm{G}=$ group; $\mathrm{IRR}=$ incidence rate ratio; $\mathrm{NR}=$ not reported; $\mathrm{OR}=$ odds ratio; $\mathrm{RCT}=$ randomized controlled trial; vs. $=$ versus . 
Table B-55. Strength of evidence for primary care-based models versus usual-care outcomes

\begin{tabular}{|c|c|c|c|c|c|}
\hline Population & Outcome & Results & $\begin{array}{l}\text { Study } \\
\text { Design and } \\
\text { Sample Size }\end{array}$ & $\begin{array}{l}\text { Strength of } \\
\text { Evidence } \\
\text { Domains }\end{array}$ & $\begin{array}{l}\text { Overall Evidence Strength } \\
\text { (Direction of Effect) }\end{array}$ \\
\hline HNHC patients & $\begin{array}{l}\text { ED visits, all } \\
\text { cause }\end{array}$ & 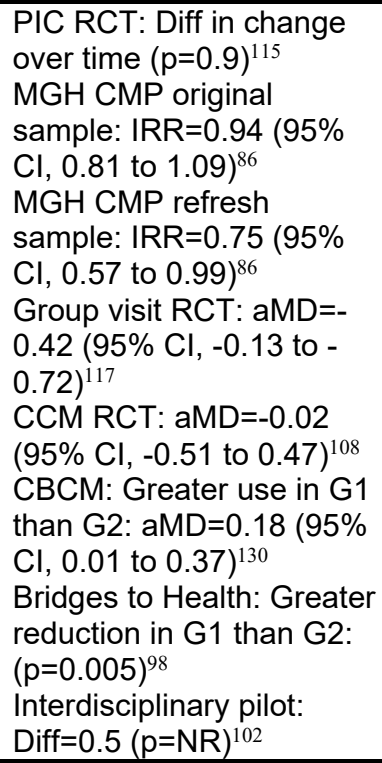 & $\begin{array}{l}5 \text { RCTs, } \\
N=7,587 \\
3 \text { OBSs, } \\
N=3,141\end{array}$ & $\begin{array}{l}\text { Moderate study } \\
\text { limitations ( } 2 \\
\text { high RoB OBS } \\
\text { studies), }{ }^{98,102} \\
\text { inconsistent, } \\
\text { imprecise, } \\
\text { direct }\end{array}$ & Insufficient (Mixed findings) \\
\hline HNHC patients & $\begin{array}{l}\text { ED visits, } \\
\text { ACSC }\end{array}$ & $\begin{array}{l}\text { MGH CMP original } \\
\text { sample: IRR=0.90 }(95 \% \\
\mathrm{CI}, 0.70 \text { to } 1.16)^{86} \\
\text { MGH CMP refresh } \\
\text { sample: IRR }=0.80(95 \% \\
\mathrm{Cl}, 0.51 \text { to } 1.25)^{86}\end{array}$ & $\begin{array}{l}2 \text { RCTs, } \\
\mathrm{N}=6,943\end{array}$ & $\begin{array}{l}\text { Moderate study } \\
\text { limitations, } \\
\text { consistent } \\
\text { imprecise, } \\
\text { direct }\end{array}$ & 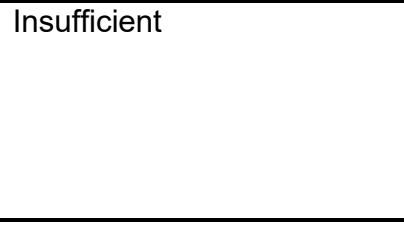 \\
\hline HNHC patients & $\begin{array}{l}\text { Inpatient } \\
\text { admissions, } \\
\text { all cause }\end{array}$ & $\begin{array}{l}\text { PIC RCT: diff in change } \\
\text { over time: }(p=0.55)^{115} \\
\text { MGH CMP original } \\
\text { sample: IRR=0.81 (95\% } \\
\mathrm{Cl}, 0.70 \text { to } 0.94)^{86} \\
\text { MGH CMP refresh } \\
\text { sample: IRR: } 0.76 \text { (95\% } \\
\text { Cl, 0.58 to 0.99) } \\
\text { Group visit RCT: less use } \\
\text { in G1 than G2: } 0.44 \text { vs. } \\
0.81,(p=0.04)^{117} \\
\text { DMP RCT: G1 vs. G2: } \\
\text { (p=0.09) } \\
\text { CCM RCT: Greater } \\
\text { reduction in G1 than G2: } \\
\text { aMD=-0.32 (95\% Cl, - } \\
0.54 \text { to }-0.11)^{108} \\
\text { CBCM: Greater use in G1 } \\
\text { than G2=aMD: } 0.10(95 \% \\
\text { CI, } 0.03 \text { to } 0.16)^{130} \\
\text { Interdisciplinary Pilot: } \\
\text { diff=0 (p=NR) }{ }^{102}\end{array}$ & $\begin{array}{l}6 \text { RCTs, } \\
\mathrm{N}=7,994 \\
2 \text { OBS, } \\
\mathrm{N}=3,069\end{array}$ & $\begin{array}{l}\text { Moderate study } \\
\text { limitations (one } \\
\text { high RoB OBS } \\
\text { studies), }{ }^{102} \\
\text { consistent, } \\
\text { precise, direct }\end{array}$ & $x^{2}$ \\
\hline HNHC patients & $\begin{array}{l}\text { Inpatient } \\
\text { admissions, } \\
\text { any }(\%)\end{array}$ & $\begin{array}{l}\text { MGH CMP: original } \\
\text { sample: OR=0.65 }(95 \% \\
\mathrm{CI}, 0.55 \text { to } 0.78)^{86} \\
\text { MGH CMP refresh } \\
\text { sample: OR=0.66 }(95 \% \\
\mathrm{Cl}, 0.48 \text { to } 0.90)^{86}\end{array}$ & $\begin{array}{l}2 \text { RCTs, } \\
\mathrm{N}=6,943\end{array}$ & $\begin{array}{l}\text { Moderate study } \\
\text { limitations, } \\
\text { consistent, } \\
\text { precise, direct }\end{array}$ & 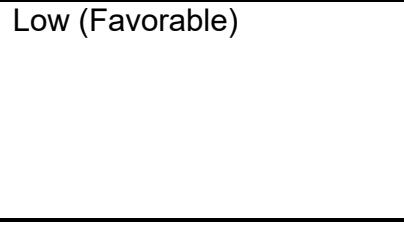 \\
\hline
\end{tabular}




\begin{tabular}{|c|c|c|c|c|c|}
\hline Population & Outcome & Results & $\begin{array}{l}\text { Study } \\
\text { Design and } \\
\text { Sample Size }\end{array}$ & $\begin{array}{l}\text { Strength of } \\
\text { Evidence } \\
\text { Domains }\end{array}$ & $\begin{array}{l}\text { Overall Evidence Strength } \\
\text { (Direction of Effect) }\end{array}$ \\
\hline HNHC patients & $\begin{array}{l}\text { Inpatient } \\
\text { admissions, } \\
\text { ACSC }\end{array}$ & $\begin{array}{l}\text { MGH CMP original } \\
\text { sample: IRR=0.87 }(95 \% \\
\mathrm{Cl}, 0.66 \text { to } 1.14)^{86} \\
\text { MGH CMP refresh } \\
\text { sample: IRR }=0.78(95 \% \\
\mathrm{Cl}, 0.49 \text { to } 1.24)^{86}\end{array}$ & $\begin{array}{l}2 \text { RCTs, } \\
\mathrm{N}=6,943\end{array}$ & $\begin{array}{l}\text { Moderate study } \\
\text { limitations, } \\
\text { consistent, } \\
\text { imprecise, } \\
\text { direct }\end{array}$ & Insufficient \\
\hline HNHC patients & $\begin{array}{l}\text { Inpatient } \\
\text { admissions, } \\
\text { any ACSC } \\
(\%)\end{array}$ & $\begin{array}{l}\text { MGH CMP original } \\
\text { sample: OR=0.73 }(95 \% \\
\mathrm{Cl}, 0.57 \text { to } 0.95)^{86} \\
\text { MGH CMP refresh } \\
\text { sample: OR=0.79 }(95 \% \\
\mathrm{Cl}, 0.51 \text { to } 1.21)^{86}\end{array}$ & $\begin{array}{l}2 \text { RCTs, } \\
\mathrm{N}=6,943\end{array}$ & $\begin{array}{l}\text { Moderate study } \\
\text { limitations, } \\
\text { consistent, } \\
\text { imprecise, } \\
\text { direct }\end{array}$ & Insufficient \\
\hline HNHC patients & $\begin{array}{l}\text { Primary care } \\
\text { visits }\end{array}$ & $\begin{array}{l}\text { PIC RCT: diff in change } \\
\text { over time: }(p=0.055) ;{ }^{115} \\
\text { RCT group visits: } \mathrm{G} 1 \text { vs. } \\
\text { G2: }(p=0.20) ;{ }^{117} \\
\text { CBCM: Less use in G1 } \\
\text { than G2: aMD=-1.83 } \\
(95 \% \mathrm{Cl},-2.10 \text { to - } \\
1.55) ; 130\end{array}$ & $\begin{array}{l}2 \text { RCTs, } \\
N=391 \\
1 \text { OBS } \\
N=3,048\end{array}$ & $\begin{array}{l}\text { Moderate study } \\
\text { limitations, } \\
\text { inconsistent } \\
\text { imprecise, } \\
\text { direct }\end{array}$ & Insufficient (Mixed findings) \\
\hline HNHC patients & $\begin{array}{l}\text { Outpatient } \\
\text { visits }\end{array}$ & $\begin{array}{l}\text { DMP: greater use in G1 } \\
\text { than G2: }(p=0.02)^{99} \\
\text { Interdisciplinary pilot: } \\
\text { diff=4.5 }(p=N R)^{102}\end{array}$ & $\begin{array}{l}1 \mathrm{RCT} \\
\mathrm{N}=407 \\
1 \text { OBS, } \mathrm{N}=21\end{array}$ & $\begin{array}{l}\text { High study } \\
\text { limitations (one } \\
\text { high RoB OBS } \\
\text { studies) }^{102} \\
\text { imprecise, } \\
\text { inconsistent, } \\
\text { direct }\end{array}$ & Insufficient \\
\hline HNHC patients & Total cost & $\begin{array}{l}\text { PIC RCT: diff in change } \\
\text { over time, G1 vs. G2: } \\
\text { ( } p=0.82)^{115} \\
\text { MGH CMP: original } \\
\text { sample DiD: }-288 \\
\text { ( } p<0.01)^{86} \\
\text { MGH CMP: refresh } \\
\text { sample DiD: }-355 \\
\text { ( } p<0.05)^{86} \\
\text { CCM RCT: Greater } \\
\text { reduction in G1 vs. G2: } \\
\text { aMD=-7,732 (95\% } \\
\text { Cl, }-14,914 \text { to }-550)^{108} \\
\text { CBCM: aMD=829 (95\% } \\
\text { Cl, }-1,279 \text { to } 3,098)^{130} \\
\text { Pooled mean } \\
\text { difference: }-\$ 3,848.43 \\
(95 \% \mathrm{Cl},-5,514.24 \\
\text { to }-2,182.61) ; 3 \mathrm{RCT} \\
\text { samples, } N=7,196, \\
\mathrm{l}^{2}=0.0 \%\end{array}$ & $\begin{array}{l}4 \text { RCTs, } \\
N=7,292 \\
1 \text { OBS, } \\
N=3,048\end{array}$ & $\begin{array}{l}\text { Moderate study } \\
\text { limitations, } \\
\text { consistent, } \\
\text { imprecise, } \\
\text { direct }\end{array}$ & Low (Favorable) \\
\hline HNHC patients & $\begin{array}{l}\text { Mortality } \\
\text { rate }\end{array}$ & $\begin{array}{l}\text { MGH CMP: original } \\
\text { sample diff: G1 vs. } \\
\text { G2, -1.63 ( } p=0.19)^{86} \\
\text { MGH CMP: refresh } \\
\text { sample diff: G1 vs. } \\
\text { G2: }-3.97(p=0.04)^{86}\end{array}$ & $\begin{array}{l}2 \text { RCTs, } \\
\mathrm{N}=6,943\end{array}$ & $\begin{array}{l}\text { Moderate study } \\
\text { limitations, } \\
\text { imprecise, } \\
\text { inconsistent, } \\
\text { direct }\end{array}$ & Insufficient \\
\hline
\end{tabular}




\begin{tabular}{|c|c|c|c|c|c|}
\hline Population & Outcome & Results & $\begin{array}{l}\text { Study } \\
\text { Design and } \\
\text { Sample Size }\end{array}$ & $\begin{array}{l}\text { Strength of } \\
\text { Evidence } \\
\text { Domains }\end{array}$ & $\begin{array}{l}\text { Overall Evidence Strength } \\
\text { (Direction of Effect) }\end{array}$ \\
\hline HNHC patients & $\begin{array}{l}\text { Influenza } \\
\text { vaccine }\end{array}$ & $\begin{array}{l}\text { MGH CMP: original } \\
\text { sample DiD OR=0.79 } \\
(95 \% \mathrm{Cl}, 0.66 \text { to } 0.95)^{86} \\
\text { MGH CMP refresh } \\
\text { sample DiD: OR=0.64 } \\
(95 \% \mathrm{Cl}, 0.46 \text { to } 0.87)^{86}\end{array}$ & $\begin{array}{l}2 \text { RCTs, } \\
\mathrm{N}=6,943\end{array}$ & $\begin{array}{l}\text { Moderate study } \\
\text { limitations, } \\
\text { consistent, } \\
\text { precise, direct }\end{array}$ & Low (Unfavorable) \\
\hline $\begin{array}{l}\text { HNHC patients } \\
\text { Diabetes } \\
\text { subgroup }\end{array}$ & HbA1c test & $\begin{array}{l}\text { MGH CMP, original } \\
\text { sample: DiD OR=0.99 } \\
(95 \% \mathrm{Cl}, 0.56 \text { to } 1.76)^{86} \\
\text { MGH CMP refresh } \\
\text { sample: DiD OR=0.70 } \\
(95 \% \mathrm{Cl}, 0.27 \text { to } 1.84)^{86}\end{array}$ & $\begin{array}{l}2 \text { RCTs, } \\
\mathrm{N}=1,959\end{array}$ & $\begin{array}{l}\text { Moderate study } \\
\text { limitations, } \\
\text { consistent, } \\
\text { imprecise, } \\
\text { direct }\end{array}$ & Insufficient \\
\hline $\begin{array}{l}\text { HNHC patients } \\
\text { Diabetes } \\
\text { subgroup }\end{array}$ & LDL-C test & $\begin{array}{l}\text { MGH CMP original } \\
\text { sample: DiD OR=0.85 } \\
(95 \% \mathrm{Cl}, 0.58 \text { to } 1.24)^{86} \\
\text { MGH CMP refresh } \\
\text { sample: DiD OR=1.72 } \\
(95 \% \mathrm{Cl}, 0.86 \text { to } 3.42)^{86}\end{array}$ & $\begin{array}{l}2 \text { RCTs, } \\
\mathrm{N}=1,959\end{array}$ & $\begin{array}{l}\text { Moderate study } \\
\text { limitations, } \\
\text { inconsistent, } \\
\text { imprecise, } \\
\text { direct }\end{array}$ & Insufficient \\
\hline $\begin{array}{l}\text { HNHC patients } \\
\text { IVD subgroup }\end{array}$ & LDL-C test & $\begin{array}{l}\text { MGH CMP original } \\
\text { sample: DiD OR=0.92 } \\
(95 \% \mathrm{Cl}, 0.63 \text { to } 1.33)^{86} \\
\text { MGH refresh sample: DiD } \\
\text { OR=1.40 }(95 \% \mathrm{Cl}, 0.76 \text { to } \\
2.58)^{86}\end{array}$ & $\begin{array}{l}2 \text { RCTs, } \\
\mathrm{N}=1,923\end{array}$ & $\begin{array}{l}\text { Moderate study } \\
\text { limitations, } \\
\text { inconsistent, } \\
\text { imprecise, } \\
\text { direct }\end{array}$ & Insufficient \\
\hline
\end{tabular}

ACSC = ambulatory care sensitive conditions; aMD = adjusted mean difference; $\mathrm{CBCM}=$ community-based care management; $\mathrm{CCM}=$ complex care management $\mathrm{CI}=$ confidence interval; $\mathrm{DiD}=$ difference-in-difference; $\mathrm{DMP}=$ depression management program; $\mathrm{ED}=$ emergency department; $\mathrm{G}=$ group; HbA1c = hemoglobin A1c; HNHC = high-need, high-cost; IRR = incidence rate ratio; IVD = ischemic vascular disease; LDL-C = low-density lipoprotein cholesterol; MGH CMP = Massachusetts General Hospital, Care Management Program, N = number; NR = not reported; OBS = observational study; OR = odds ratio; PIC = Primary Intensive Care; RCT = randomized controlled trial; RoB = risk of bias; vs. = versus. 
Table B-56. Cost outcomes for primary care-based model studies

\begin{tabular}{|c|c|c|c|c|}
\hline Cost Measures & Study Design & $\begin{array}{l}\text { Direction of } \\
\text { Change in } \\
\text { Intervention } \\
\text { Group (G1) }\end{array}$ & $\begin{array}{l}\text { Direction of } \\
\text { Change in } \\
\text { Comparison } \\
\text { Group (G2) }\end{array}$ & Difference \\
\hline \multirow[t]{5}{*}{ Total cost } & $\mathrm{RCT}$ & & & $\begin{array}{l}\text { Difference in change over time, G1 vs. } \\
\text { G2: }(p=0.82)^{115}\end{array}$ \\
\hline & $\overline{\mathrm{RCT}}$ & & & $\begin{array}{l}\text { Original sample DiD: Lower increase in } \\
\text { G1 than G2: }-288(82.1),(p<0.01)^{86}\end{array}$ \\
\hline & $\mathrm{RCT}$ & & & $\begin{array}{l}\text { Refresh sample DiD: Lower increase in } \\
\text { G1 than G2: }-355(157.6), p<0.05^{86}\end{array}$ \\
\hline & $\overline{\mathrm{RCT}}$ & NR & $\mathrm{NR}$ & $\begin{array}{l}\text { Greater reduction in G1 vs. G2: aMD=- } \\
7,732(95 \% \mathrm{Cl},-14,914 \text { to }-550) \\
(p=0.036)^{108}\end{array}$ \\
\hline & Observational & NR & NR & aMD $=829(95 \% \mathrm{Cl},-1,279 \text { to } 3,098)^{130}$ \\
\hline Inpatient costs & Observational & NR & NR & aMD=297 $(95 \% \mathrm{Cl},-1,150 \text { to } 1,729)^{130}$ \\
\hline Pharmacy costs & Observational & NR & NR & aMD=110 (95\% Cl, -875 to 1,109$)^{130}$ \\
\hline Outpatient costs & Observational & NR & NR & aMD $=10(95 \% \mathrm{Cl},-439 \text { to } 492)^{130}$ \\
\hline Postacute costs & Observational & NR & NR & aMD $=362(95 \% \mathrm{Cl}, 150 \text { to } 569)^{130}$ \\
\hline ED costs & Observational & NR & NR & aMD=5 $(95 \% \mathrm{Cl},-155 \text { to } 171)^{130}$ \\
\hline Other costs & Observational & NR & NR & aMD $=45(95 \% \mathrm{Cl},-159 \text { to } 262)^{130}$ \\
\hline
\end{tabular}

$\mathrm{aMD}=$ adjusted mean difference; $\mathrm{CI}=$ confidence interval; $\mathrm{DiD}=$ difference-in-difference $; \mathrm{Ed}=$ emergency department; $\mathrm{G}=$ group; $\mathrm{NR}=$ not reported; $\mathrm{RCT}=$ randomized controlled trial; vs. $=$ versus. 
Table B-57. Clinical and functional outcomes for primary care-based model studies

\begin{tabular}{|c|c|c|}
\hline $\begin{array}{l}\text { Clinical and Functional } \\
\text { Outcomes }\end{array}$ & Study Design & $\begin{array}{l}\text { Difference Between Intervention Group (G1) and Comparison } \\
\text { Group (G2) }\end{array}$ \\
\hline \multirow[t]{2}{*}{ Mortality rate } & RCT & Original sample difference: G1 vs. G2, $-1.63(\mathrm{p}=0.19)^{86}$ \\
\hline & RCT & Refresh sample difference: lower in G1 than G2: $-3.97(p=0.04)^{86}$ \\
\hline \multirow[t]{2}{*}{ Influenza vaccine } & RCT & $\begin{array}{l}\text { Original sample DiD: increased less in G1 than G2: OR=0.79 } \\
(95 \% \mathrm{Cl}, 0.66 \text { to } 0.95)^{86}\end{array}$ \\
\hline & $\overline{\mathrm{RCT}}$ & $\begin{array}{l}\text { Refresh sample DiD: increased less in G1 than G2: OR=0.64 } \\
(95 \% \mathrm{Cl}, 0.46 \text { to } 0.87)^{86}\end{array}$ \\
\hline PHC score & RCT & $\begin{array}{l}\text { Better in G1 than G2: ANCOVA-adjusted intervention effect=2.3, } \\
p<0.01^{86}\end{array}$ \\
\hline MHC score & RCT & ANCOVA-adjusted intervention effect $=1.1, p>0.05^{86}$ \\
\hline $\begin{array}{l}\text { PQH-2 score (depression } 0 \text { to } \\
\text { 6) }\end{array}$ & RCT & ANCOVA-adjusted intervention effect $=-0.03, p>0.05^{86}$ \\
\hline $\begin{array}{l}\text { Number of ADLs difficult to do } \\
(0 \text { to } 6)\end{array}$ & RCT & ANCOVA-adjusted intervention effect $=-0.28, p>0.05^{86}$ \\
\hline $\begin{array}{l}\text { Number ADLs receiving help } \\
\text { (0 to } 6)\end{array}$ & RCT & ANCOVA-adjusted intervention effect $=-0.21, p>0.05^{86}$ \\
\hline Patient satisfaction & RCT & Difference in change over time, $G 1$ vs. $G 2: p=0.30^{115}$ \\
\hline SF-36 Summary Score & RCT & Difference in change over time, $G 1$ vs. $G 2: p=0.32^{115}$ \\
\hline SF-36 Mental Health Function & RCT & Difference in change over time, $G 1$ vs. $G 2: p=0.6^{115}$ \\
\hline
\end{tabular}

Score

\begin{tabular}{|c|c|c|}
\hline Change in HAM-D score & RCT & Greater decrease in G1 than G2: $p<0.001^{99}$ \\
\hline In remission (HAM-D <7) & RCT & Higher proportion in $\mathrm{G} 1$ than $\mathrm{G} 2: \mathrm{p}<0.001^{99}$ \\
\hline $\begin{array}{l}\text { SF-20 subscale: Social } \\
\text { Functioning }\end{array}$ & RCT & Better in $\mathrm{G} 1$ than $\mathrm{G} 2: \mathrm{p}<0.05$ (data NR) (19 $^{99}$ \\
\hline SF-20 subscale: Mental Health & RCT & Better in $\mathrm{G} 1$ than $\mathrm{G} 2: \mathrm{p}<0.05$ (data NR) ${ }^{99}$ \\
\hline $\begin{array}{l}\text { SF-20 subscale: General } \\
\text { Health }\end{array}$ & RCT & 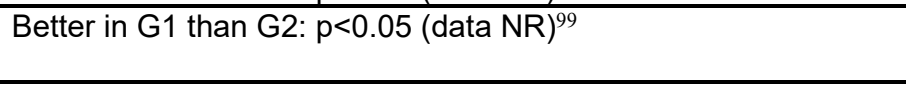 \\
\hline $\begin{array}{l}\text { SF-20 subscale: Physical } \\
\text { Functioning }\end{array}$ & RCT & G1 vs. $G 2: p=N S(\text { data NR) })^{99}$ \\
\hline $\begin{array}{l}\text { SF-20 subscale: Role } \\
\text { Functioning }\end{array}$ & RCT & G1 vs. G2: $p=N S$ (data NR) $)^{99}$ \\
\hline $\begin{array}{l}\text { SF-20 subscale: Pain } \\
\text { Perception }\end{array}$ & RCT & G1 vs. G2: $p=N S$ (data NR) ${ }^{99}$ \\
\hline $\begin{array}{l}\text { Helping to cope with a chronic } \\
\text { condition (1 to } 5 \text { ) }\end{array}$ & RCT & $\begin{array}{l}\text { G1 vs. G2 (N=590): ANCOVA-adjusted intervention effect=0.16, } \\
p>0.05^{86}\end{array}$ \\
\hline $\begin{array}{l}\text { Number of helpful discussion } \\
\text { topics ( } 0 \text { to } 5)\end{array}$ & RCT & $\begin{array}{l}\text { G1 vs. G2 (N=590): ANCOVA-adjusted intervention effect=-0.02, } \\
p>0.05^{86}\end{array}$ \\
\hline $\begin{array}{l}\text { Discussing treatment choices } \\
\text { (1 to } 4)\end{array}$ & RCT & $\begin{array}{l}\text { Better score in G1 than G2: ANCOVA-adjusted intervention } \\
\text { effect }=0.26, p<0.01^{86}\end{array}$ \\
\hline $\begin{array}{l}\text { Communicating with providers } \\
(0 \text { to } 100)\end{array}$ & RCT & $\begin{array}{l}\text { Better score in G1 than G2: ANCOVA-adjusted intervention } \\
\text { effect }=4.5, p<0.05^{86}\end{array}$ \\
\hline $\begin{array}{l}\text { Getting answers to questions } \\
\text { quickly (0 to } 100)\end{array}$ & RCT & $\begin{array}{l}\text { G1 vs. G2 (N=590): ANCOVA-adjusted intervention effect=5.0, } \\
p>0.05^{86}\end{array}$ \\
\hline $\begin{array}{l}\text { Multimorbidity Hassles score } \\
\text { (0 to } 24)\end{array}$ & RCT & $\begin{array}{l}\text { G1 vs. G2 (N=590): ANCOVA-adjusted intervention effect=-0.27, } \\
p>0.05^{86}\end{array}$ \\
\hline $\begin{array}{l}\text { Percentage receiving help } \\
\text { setting goals }\end{array}$ & RCT & $\begin{array}{l}\text { G1 vs. G2 (N=590): ANCOVA-adjusted intervention effect=-5.6, } \\
p>0.05^{86}\end{array}$ \\
\hline $\begin{array}{l}\text { Percentage receiving help } \\
\text { making a care plan }\end{array}$ & RCT & $\begin{array}{l}\text { G1 vs. G2 (N=590): ANCOVA-adjusted intervention effect=2.3, } \\
p>0.05^{86}\end{array}$ \\
\hline $\begin{array}{l}\text { Self-efficacy: Take all } \\
\text { medications ( } 1 \text { to } 5)\end{array}$ & RCT & $\begin{array}{l}\text { G1 vs. G2 (N=590): ANCOVA-adjusted intervention effect=0.05, } \\
p>0.05^{86}\end{array}$ \\
\hline $\begin{array}{l}\text { Self-efficacy: Plan meals and } \\
\text { snacks (1 to } 5)\end{array}$ & RCT & $\begin{array}{l}\text { G1 vs. G2 (N=590): ANCOVA-adjusted intervention effect }=0.01 \text {, } \\
p>0.05^{86}\end{array}$ \\
\hline $\begin{array}{l}\text { Self-efficacy: Exercise } 2 \text { or } 3 \\
\text { times weekly ( } 1 \text { to } 5)\end{array}$ & RCT & $\begin{array}{l}\text { G1 vs. G2 (N=590): ANCOVA-adjusted intervention effect }=0.11 \text {, } \\
p>0.05^{86}\end{array}$ \\
\hline
\end{tabular}




\begin{tabular}{|c|c|c|}
\hline $\begin{array}{l}\text { Clinical and Functional } \\
\text { Outcomes }\end{array}$ & Study Design & $\begin{array}{l}\text { Difference Between Intervention Group (G1) and Comparison } \\
\text { Group (G2) }\end{array}$ \\
\hline $\begin{array}{l}\text { Self-care activities: Prescribed } \\
\text { medications taken (mean \# of } \\
\text { days) }\end{array}$ & RCT & $\begin{array}{l}\text { G1 vs. G2 (N=590): ANCOVA-adjusted intervention effect=-0.10, } \\
p>0.05^{86}\end{array}$ \\
\hline $\begin{array}{l}\text { Self-care activities: Followed } \\
\text { healthy eating plan (mean \# of } \\
\text { days) }\end{array}$ & RCT & $\begin{array}{l}\text { G1 vs. G2 (N=590), ANCOVA-adjusted intervention effect=-0.16, } \\
p>0.05\end{array}$ \\
\hline $\begin{array}{l}\text { Self-care activities: } 30 \text { minutes } \\
\text { of continuous physical activity } \\
\text { (mean \# of days) }\end{array}$ & RCT & $\begin{array}{l}\text { G1 vs. G2 (N=590): ANCOVA-adjusted intervention effect=-0.05, } \\
p>0.05^{86}\end{array}$ \\
\hline
\end{tabular}


Table B-58. Clinical and functional outcomes for primary care-based model studies: Subgroup outcomes

\begin{tabular}{|c|c|c|}
\hline $\begin{array}{l}\text { Clinical and Functional } \\
\text { Outcomes }\end{array}$ & Study Design & $\begin{array}{l}\text { Difference Between Intervention Group (G1) and Comparison } \\
\text { Group (G2) }\end{array}$ \\
\hline \multirow[t]{2}{*}{ HbA1c test } & RCT & $\begin{array}{l}\text { Original sample diabetes subgroup: DiD OR=0.99 }(95 \% \mathrm{Cl}, 0.56 \text { to } \\
1.76)^{86}\end{array}$ \\
\hline & $\overline{\mathrm{RCT}}$ & $\begin{array}{l}\text { Refresh sample diabetes subgroup: DiD OR=0.70 }(95 \% \mathrm{Cl}, 0.27 \text { to } \\
1.84)^{86}\end{array}$ \\
\hline \multirow[t]{4}{*}{ LDL-C test } & RCT & $\begin{array}{l}\text { Original sample diabetes subgroup: DiD OR=0.85 }(95 \% \mathrm{Cl}, 0.58 \text { to } \\
1.24)^{86}\end{array}$ \\
\hline & $\overline{\mathrm{RCT}}$ & $\begin{array}{l}\text { Refresh sample diabetes subgroup: DiD OR=1.72 }(95 \% \mathrm{Cl}, 0.86 \text { to } \\
3.42)^{86}\end{array}$ \\
\hline & RCT & Original sample IVD subgroup: $\mathrm{DiD} \mathrm{OR}=0.92(95 \% \mathrm{Cl}, 0.63 \text { to } 1.33)^{86}$ \\
\hline & RCT & Refresh sample IVD subgroup: DiD OR=1.40 (95\% Cl, 0.76 to 2.58$)^{86}$ \\
\hline
\end{tabular}

Table B-59. Social risk outcomes for primary care-based model studies

\begin{tabular}{lll}
\hline Social Risk Outcomes & Study Design & $\begin{array}{l}\text { Difference Between Intervention Group (G1) } \\
\text { and Comparison Group (G2) }\end{array}$ \\
\hline Overall well-being & Observational & G1 vs. G2: $p=N^{102}$ \\
\hline$G=$ group; NR = not reported; vs. = versus. &
\end{tabular}


Table B-60. Study characteristics for home-based care interventions

\begin{tabular}{|c|c|c|c|c|c|c|}
\hline $\begin{array}{l}\text { First Author, } \\
\text { Year, Site(s) }\end{array}$ & Sample Size & $\begin{array}{l}\text { Study Design } \\
\text { (Risk of Bias } \\
\text { Assessment) }\end{array}$ & $\begin{array}{l}\text { Patient Selection: } \\
\text { High Healthcare Use } \\
\text { or Cost; Time Period }\end{array}$ & $\begin{array}{l}\text { Patient Selection: } \\
\text { Chronic Conditions }\end{array}$ & Patient Selection: Other & $\begin{array}{l}\text { Additional Selected } \\
\text { Patient Characteristics }\end{array}$ \\
\hline $\begin{array}{l}\text { McCall et al., } \\
2010^{84} \\
\text { CA, FL, TX }\end{array}$ & $\begin{array}{l}\text { (Original } \mathrm{N}=16,077) \\
\text { Intervention }(\mathrm{N}=11,516) \\
\text { Comparison }(\mathrm{N}=4,561) \\
\text { (COPD subgroup } \\
\mathrm{N}=3,344) \\
\text { Intervention }(\mathrm{N}=2,384) \\
\text { Comparison }(\mathrm{N}=960) \\
\text { (Diabetes subgroup } \\
\mathrm{N}=4,502) \\
\text { Intervention ( } \mathrm{N}=3,223) \\
\text { Comparison }(\mathrm{N}=1,279) \\
\text { (IVD subgroup } \\
\mathrm{N}=7,356) \\
\text { Intervention ( } \mathrm{N}=5,223) \\
\text { Comparison }(\mathrm{N}=2,133) \\
\text { (High-cost-only } \mathrm{PBPM} \\
\text { subgroup } \\
\mathrm{N}=4,344) \\
\text { Intervention ( } \mathrm{N}=3,105) \\
\text { Comparison }(\mathrm{N}=1,239) \\
\text { (High-cost and high-risk } \\
\mathrm{PBPM} \text { subgroup } \\
\mathrm{N}=6,802) \\
\text { Intervention ( } \mathrm{N}=4,845) \\
\text { Comparison }(\mathrm{N}=1,957)\end{array}$ & $\begin{array}{l}\text { RCT } \\
\text { (RoB: some } \\
\text { concerns) }\end{array}$ & $\begin{array}{l}\text { High costs with top } 5 \% \\
\text { of costs and } 2+ \\
\text { hospitalizations in past } \\
1 \text { year }\end{array}$ & $\begin{array}{l}\text { 1+ diagnosis from a list, } \\
\text { such as heart failure; } \\
\text { HCC score was } \geq 2.75 \\
\text { OR if had an HCC score } \\
<2.75 \text {, had a diagnosis of } \\
\text { selected clinical } \\
\text { conditions including } \\
\text { peripheral vascular } \\
\text { disease, ischemic heart } \\
\text { disease, hypertensive } \\
\text { heart and/or kidney } \\
\text { disease, heart failure, } \\
\text { chronic obstructive } \\
\text { pulmonary disease } \\
\text { (COPD), and asthma }\end{array}$ & $\begin{array}{l}\text { Medicare FFS } \\
\text { beneficiaries }\end{array}$ & $\begin{array}{l}\text { Nonwhite: } 27 \% \\
\text { Mean HCC: } 2.8\end{array}$ \\
\hline
\end{tabular}




\begin{tabular}{|c|c|c|c|c|c|c|}
\hline $\begin{array}{l}\text { First Author, } \\
\text { Year, Site(s) }\end{array}$ & Sample Size & $\begin{array}{l}\text { Study Design } \\
\text { (Risk of Bias } \\
\text { Assessment) } \\
\end{array}$ & $\begin{array}{l}\text { Patient Selection: } \\
\text { High Healthcare Use } \\
\text { or Cost; Time Period }\end{array}$ & $\begin{array}{l}\text { Patient Selection: } \\
\text { Chronic Conditions }\end{array}$ & Patient Selection: Other & $\begin{array}{l}\text { Additional Selected } \\
\text { Patient Characteristics }\end{array}$ \\
\hline $\begin{array}{l}\text { McCall et al., } \\
2010^{84} \\
\text { CA, FL, TX }\end{array}$ & $\begin{array}{l}\text { (Refresh } \mathrm{N}=18,344) \\
\text { Intervention }(\mathrm{N}=13,104) \\
\text { Comparison }(\mathrm{N}=5,240) \\
\text { (COPD subgroup } \\
\mathrm{N}=4,735) \\
\text { Intervention }(\mathrm{N}=3,393) \\
\text { Comparison }(\mathrm{N}=1,342) \\
\text { (Diabetes subgroup } \\
\mathrm{N}=5,950) \\
\text { Intervention }(\mathrm{N}=4,199) \\
\text { Comparison }(\mathrm{N}=1,751) \\
\text { (IVD subgroup } \mathrm{N}=7,554) \\
\text { Intervention }(\mathrm{N}=5,384) \\
\text { Comparison }(\mathrm{N}=2,170) \\
\text { (High-cost-only } \mathrm{PBPM} \\
\text { subgroup } \mathrm{N}=1,414) \\
\text { Intervention }(\mathrm{N}=1,027) \\
\text { Comparison ( } \mathrm{N}=387) \\
\\
\text { (High-cost and high-risk } \\
\text { PBPM subgroup } \\
\mathrm{N}=8,598) \\
\text { Intervention ( } \mathrm{N}=6,142) \\
\text { Comparison ( } \mathrm{N}=2,456) \\
\end{array}$ & $\begin{array}{l}\mathrm{RCT} \\
\text { (RoB: some } \\
\text { concerns) }\end{array}$ & $\begin{array}{l}2+\text { hospitalizations in } \\
\text { past } 1 \text { year }\end{array}$ & HCC score was $>2.749$ & $\begin{array}{l}\text { Medicare FFS } \\
\text { beneficiaries; excluded } \\
\text { beneficiaries with } \\
\text { drug/alcohol psychosis or } \\
\text { dependence, major } \\
\text { depressive, bipolar, and } \\
\text { paranoid disorders; } \\
\text { institutionalized in last } 3 \\
\text { months of previous year; } \\
\text { had a hospital claims } \\
\text { where discharge date was } \\
\text { equal to admission date }\end{array}$ & $\begin{array}{l}\text { Nonwhite: } 40 \% \\
\text { Mean HCC: } 3.8\end{array}$ \\
\hline
\end{tabular}




\begin{tabular}{|c|c|c|c|c|c|c|}
\hline $\begin{array}{l}\text { First Author, } \\
\text { Year, Site(s) }\end{array}$ & Sample Size & $\begin{array}{l}\text { Study Design } \\
\text { (Risk of Bias } \\
\text { Assessment) }\end{array}$ & $\begin{array}{l}\text { Patient Selection: } \\
\text { High Healthcare Use } \\
\text { or Cost; Time Period }\end{array}$ & $\begin{array}{l}\text { Patient Selection: } \\
\text { Chronic Conditions }\end{array}$ & Patient Selection: Other & $\begin{array}{l}\text { Additional Selected } \\
\text { Patient Characteristics }\end{array}$ \\
\hline $\begin{array}{l}\text { Kimmy et al., } \\
2019^{103} \\
\text { National: } 14 \\
\text { practices }\end{array}$ & $\begin{array}{l}\text { (Home-based care } \\
\mathrm{N}=181,001) \\
\text { Intervention }(\mathrm{N}=30,324) \\
\text { Comparison }(\mathrm{N}=150,677)\end{array}$ & $\begin{array}{l}\text { Observational } \\
\text { study } \\
\text { (RoB: some } \\
\text { concerns) }\end{array}$ & $\begin{array}{l}\text { Hospitalization and use } \\
\text { of acute or subacute } \\
\text { rehabilitation services; } \\
\text { and } 1+\text { home visit from } \\
\text { the IAH practice in past } \\
1 \text { year }\end{array}$ & $\begin{array}{l}\text { 2+ chronic conditions } \\
2+\text { ADLs that require } \\
\text { human assistance, } \\
\text { new to home-based } \\
\text { primary care ( } 2+\text { E\&M } \\
\text { visits from a primary care } \\
\text { clinician in the home or } \\
\text { an assisted living facility } \\
\text { during the } 6 \text {-month } \\
\text { period starting with the } \\
\text { first home visit), } \\
\text { majority of E\&M visits } \\
\text { from a primary care } \\
\text { clinician during the same } \\
\text { period must have taken } \\
\text { place in the home or } \\
\text { assisted living facility }\end{array}$ & $\begin{array}{l}\text { Medicare FFS } \\
\text { beneficiaries, new patients } \\
\text { receiving home-based } \\
\text { primary care who were } \\
\text { IAH eligible and lived in an } \\
\text { area served by an IAH } \\
\text { practice }\end{array}$ & $\begin{array}{l}\text { Mean HCC : } 3.686 \\
\text { Chronically critically } \\
\text { ill/medically complex: } \\
29.1 \% \\
\text { Depression: } 31.9 \%\end{array}$ \\
\hline $\begin{array}{l}\text { Valluru et al., } \\
2019^{131} \\
\text { Philadelphia, } \\
\text { PA; Richmond, } \\
\text { VA; } \\
\text { Washington, } \\
\text { D.C.: } 3 \text { sites }\end{array}$ & $\begin{array}{l}(\mathrm{N}=1,376) \\
\mathrm{IAH} \text { patients at } 3 \text { sites } \\
(\mathrm{N}=721) \\
\text { Comparison with home- } \\
\text { based care } \\
(\mathrm{N}=82) \\
\text { Comparison without } \\
\text { home-based care } \\
(\mathrm{N}=573)\end{array}$ & $\begin{array}{l}\text { Observational } \\
\text { study (ROB: } \\
\text { high) }\end{array}$ & $\begin{array}{l}\text { Nonelective } \\
\text { hospitalization and } \\
\text { post-acute care use, } \\
\text { either skilled home care } \\
\text { or skilled nursing } \\
\text { facility, in past year }\end{array}$ & $2+$ chronic conditions & $\begin{array}{l}\text { Enrollment in } 1 \text { of } 3 \text { sites, } \\
\text { FFS Medicare, score of } 6+ \\
\text { in JEN Frailty Index }\end{array}$ & $\begin{array}{l}\text { Percentage in age } \\
\text { range: } \\
<75: 31 \% \\
75-84: 30 \% \\
\geq 85: 39 \% \\
\text { African American: } 62 \% \\
\text { Medicaid: NR } \\
\text { Medicare: } 100 \% \\
\text { Mean HCC: } 3.58\end{array}$ \\
\hline
\end{tabular}

$\mathrm{ADL}$ = activities of daily living; $\mathrm{CA}=$ California; $\mathrm{COPD}=$ chronic obstructive pulmonary disease; $\mathrm{E} \& \mathrm{M}=$ evaluation and management; $\mathrm{FFS}=$ fee-for-service; $\mathrm{FL}=\mathrm{Florida}$; HCC

$=$ hierarchical condition category; IAH = Independence at Home; IVD = ischemic vascular disease; $\mathrm{N}=$ number; $\mathrm{NR}=$ not reported; $\mathrm{OR}=$ odds ratio; $\mathrm{PA}=\mathrm{Pennsylvania}$; $\mathrm{PBPM}=$

per beneficiary per month; RCT $=$ randomized controlled trial; RoB $=$ risk of bias; $\mathrm{TX}=$ Texas, $\mathrm{VA}=$ Virginia. 
Table B-61. Intervention characteristics for home-based models

\begin{tabular}{|c|c|c|c|c|c|c|c|c|c|}
\hline $\begin{array}{l}\text { First } \\
\text { Author, } \\
\text { Year, } \\
\text { Site(s) }\end{array}$ & $\begin{array}{l}\text { Intervention: } \\
\text { Brief } \\
\text { Description }\end{array}$ & $\begin{array}{l}\text { Intervention } \\
\text { Duration }\end{array}$ & $\begin{array}{l}\text { Assessment, } \\
\text { Education, } \\
\text { Skills, } \\
\text { Monitoring }\end{array}$ & $\begin{array}{l}\text { Coordination } \\
\text { and Continuity } \\
\text { of Care }\end{array}$ & $\begin{array}{l}\text { Referral } \\
\text { to/Linkages to } \\
\text { Community- } \\
\text { Based } \\
\text { Support } \\
\text { Services } \\
\end{array}$ & Providers & $\begin{array}{l}\text { Mode of } \\
\text { Delivery } \\
\text { Setting(S) }\end{array}$ & Intensity & Comparison \\
\hline $\begin{array}{l}\text { McCall et } \\
\text { al., 2010 } \\
\text { CA, FL, TX }\end{array}$ & $\begin{array}{l}\text { Evaluation of } \\
\text { Medicare Care } \\
\text { Management } \\
\text { for High Cost } \\
\text { Beneficiaries } \\
\text { (CMHCB) } \\
\text { Demonstration: } \\
\text { Care Level } \\
\text { Management } \\
\text { (CLM) } \\
\text { home-based } \\
\text { primary care for } \\
\text { patients with } \\
\text { multiple chronic } \\
\text { conditions }\end{array}$ & $\begin{array}{l}\text { Up to } 29 \\
\text { months for } \\
\text { original } \\
\text { population, } \\
\text { up to } 18 \\
\text { months for } \\
\text { refresh } \\
\text { population }\end{array}$ & $\begin{array}{l}\text { Assessment tool } \\
\text { on patient acuity: } \\
\text { number of } \\
\text { admissions and } \\
\text { emergency room } \\
\text { visits within the } \\
\text { last } 6 \text { months, } \\
\text { presence of } \\
\text { unmet social and } \\
\text { emotional needs, } \\
\text { expected } \\
\text { number of PVP } \\
\text { visits needed in } \\
\text { the next } 30 \text { days, } \\
\text { and presence of } \\
\text { compliance, } \\
\text { psychiatric, or } \\
\text { ongoing home } \\
\text { health issues }\end{array}$ & $\begin{array}{l}\text { Provided home- } \\
\text { based care and } \\
\text { 24/7 access to a } \\
\text { PVP to patients; } \\
\text { care } \\
\text { management } \\
\text { addressed } \\
\text { adherence to } \\
\text { treatment } \\
\text { regimens, } \\
\text { coordination of } \\
\text { care services, } \\
\text { end-of-life } \\
\text { planning, home } \\
\text { safety, } \\
\text { socioeconomic } \\
\text { issues, } \\
\text { psychosocial } \\
\text { issues, and } \\
\text { medication } \\
\text { management }\end{array}$ & $\begin{array}{l}\text { Helped } \\
\text { selected } \\
\text { beneficiaries } \\
\text { receive } \\
\text { services from } \\
\text { community- } \\
\text { based ancillary } \\
\text { services as } \\
\text { needed }\end{array}$ & $\begin{array}{l}\text { PVPs, NPs to } \\
\text { support PVPs, } \\
\text { nurse care } \\
\text { managers as } \\
\text { patient advocates } \\
\text { and care } \\
\text { coordinators } \\
\text { (PVPs were } \\
\text { adjuncts to } \\
\text { patients' PCP) }\end{array}$ & $\begin{array}{l}\text { Face-to-face } \\
\text { and by phone }\end{array}$ & $\begin{array}{l}12 \% \text { had no } \\
\text { contact, } \\
75 \% \text { of } \\
\text { beneficiaries had } \\
\text { one or more } \\
\text { physician visits, } \\
22 \% \text { had } 10 \text { or } \\
\text { more visits, and } \\
14 \% \text { had } 20 \text { or } \\
\text { more visits. } 88 \% \\
\text { of beneficiaries } \\
\text { received a } \\
\text { telephone call } \\
\text { from a nurse or } \\
\text { physician, while } \\
24 \% \text { received } 10 \\
\text { or more calls, } \\
\text { and } 39 \% \text { of } \\
\text { beneficiaries } \\
\text { received } 20 \text { or } \\
\text { more calls }\end{array}$ & Usual care \\
\hline
\end{tabular}




\begin{tabular}{|c|c|c|c|c|c|c|c|c|c|}
\hline $\begin{array}{l}\text { First } \\
\text { Author, } \\
\text { Year, } \\
\text { Site(s) }\end{array}$ & $\begin{array}{l}\text { Intervention: } \\
\text { Brief } \\
\text { Description }\end{array}$ & $\begin{array}{l}\text { Intervention } \\
\text { Duration }\end{array}$ & $\begin{array}{l}\text { Assessment, } \\
\text { Education, } \\
\text { Skills, } \\
\text { Monitoring }\end{array}$ & $\begin{array}{l}\text { Coordination } \\
\text { and Continuity } \\
\text { of Care }\end{array}$ & $\begin{array}{l}\text { Referral } \\
\text { to/Linkages to } \\
\text { Community- } \\
\text { Based } \\
\text { Support } \\
\text { Services }\end{array}$ & Providers & $\begin{array}{l}\text { Mode of } \\
\text { Delivery } \\
\text { Setting(S) }\end{array}$ & Intensity & Comparison \\
\hline $\begin{array}{l}\text { Kimmy et } \\
\text { al., } 2019^{103} \\
\text { Effect of } \\
\text { home-based } \\
\text { primary care } \\
\text { National: } 14 \\
\text { practices }\end{array}$ & $\begin{array}{l}\text { Practices may } \\
\text { earn an } \\
\text { additional } \\
\text { payment if their } \\
\text { chronically ill, } \\
\text { functionally } \\
\text { limited patients' } \\
\text { Medicare } \\
\text { expenditures } \\
\text { are below an } \\
\text { estimated } \\
\text { spending target } \\
\text { and if the } \\
\text { practice meets } \\
\text { required } \\
\text { standards for a } \\
\text { set of quality } \\
\text { measures }\end{array}$ & $\begin{array}{l}\text { Up to } 4 \\
\text { years }\end{array}$ & $\begin{array}{l}\text { Clinicians are } \\
\text { available at all } \\
\text { hours of the day; } \\
\text { carry out } \\
\text { individualized } \\
\text { care plans; and } \\
\text { use electronic } \\
\text { health } \\
\text { information } \\
\text { systems, remote } \\
\text { monitoring, and } \\
\text { mobile } \\
\text { diagnostic } \\
\text { technology }\end{array}$ & $\begin{array}{l}\text { Report on other } \\
\text { measures, } \\
\text { including fall risk } \\
\text { assessments } \\
\text { and depression } \\
\text { screenings, to } \\
\text { promote the } \\
\text { provision of such } \\
\text { care }\end{array}$ & $\begin{array}{l}\text { Some practices } \\
\text { added social } \\
\text { workers or } \\
\text { other staff to } \\
\text { coordinate care } \\
\text { for their } \\
\text { patients with } \\
\text { other } \\
\text { organizations }\end{array}$ & $\begin{array}{l}\text { Physicians or } \\
\text { nurse } \\
\text { practitioners; team } \\
\text { may have also } \\
\text { included physician } \\
\text { assistants, clinical } \\
\text { staff, and other } \\
\text { health and social } \\
\text { services staff }\end{array}$ & Face-to-face & $\begin{array}{l}\text { Clinicians made } \\
3-15 \text { home visits } \\
\text { per day, varied } \\
\text { by site }\end{array}$ & $\begin{array}{l}\text { Usual care: } \\
\text { Patients who } \\
\text { did not } \\
\text { receive } \\
\text { primary care } \\
\text { in the home } \\
\text { during the } 6 \\
\text { months after } \\
\text { their index } \\
\text { date }\end{array}$ \\
\hline $\begin{array}{l}\text { Valluru et } \\
\text { al., } 2019^{131} \\
\text { Philadelphia } \\
\text {, PA; } \\
\text { Richmond, } \\
\text { VA; } \\
\text { Washington, } \\
\text { DC: } 3 \text { sites }\end{array}$ & $\begin{array}{l}\text { Home-based } \\
\text { primary care } \\
\text { integrated with } \\
\text { long-term } \\
\text { service } \\
\text { supports } \\
\text { (LTSS) }\end{array}$ & 36 months & NR & $\begin{array}{l}\text { Integrated care } \\
\text { coordination with } \\
\text { community } \\
\text { supports } \\
\text { including adult } \\
\text { day healthcare } \\
\text { and home health } \\
\text { aide-provided } \\
\text { personal care } \\
\text { services }\end{array}$ & $\begin{array}{l}\text { Assistance with } \\
\text { meals and } \\
\text { transportation } \\
\text { and social } \\
\text { workers who } \\
\text { collaborate with } \\
\text { various } \\
\text { community } \\
\text { LTSS } \\
\text { resources }\end{array}$ & $\begin{array}{l}\text { Care managers, } \\
\text { case managers, or } \\
\text { social workers } \\
\text { depending on the } \\
\text { site }\end{array}$ & $\begin{array}{l}\text { Face-to-face in } \\
\text { patient home }\end{array}$ & NR & $\begin{array}{l}\text { Usual care: } \\
\text { Home-based } \\
\text { care without } \\
\text { long-term } \\
\text { services and } \\
\text { supports or } \\
\text { no home- } \\
\text { based care }\end{array}$ \\
\hline
\end{tabular}

$\mathrm{CA}=$ California; $\mathrm{CLM}=$ care level management; $\mathrm{CMHCB}=$ Care Management for High Cost Beneficiaries; DC = District of Columbia; FL = Florida; LTSS = long-term services and supports $\mathrm{NP}=$ nurse practitioner; $\mathrm{NR}=$ not reported; $\mathrm{PA}=$ Pennsylvania; $\mathrm{PCP}=$ primary care provider; $\mathrm{PVP}=$ personal visiting physician; $\mathrm{TX}=\mathrm{Texas}$; $\mathrm{VA}=\mathrm{Virginia}$. 
Table B-62. Healthcare utilization outcomes for home-based care model studies

\begin{tabular}{|c|c|c|c|}
\hline Utilization Measures & Study Design & $\begin{array}{l}\text { Direction of Direction of } \\
\text { Change in Change in } \\
\text { Intervention Comparison } \\
\text { Group (G1) Group (G2) }\end{array}$ & Difference \\
\hline \multirow[t]{3}{*}{$\begin{array}{l}\text { Inpatient admissions, all } \\
\text { cause }\end{array}$} & RCT & & $\begin{array}{l}\text { Original sample DiD: IRR=0.94 }(95 \% \mathrm{Cl}, 0.87 \text { to } \\
1.01)^{84}\end{array}$ \\
\hline & $\mathrm{RCT}$ & & $\begin{array}{l}\text { Refresh sample DiD: IRR=0.94 }(95 \% \mathrm{Cl}, 0.88 \text { to } \\
1.00)^{84}\end{array}$ \\
\hline & Observational & NR & $\begin{array}{l}\text { Lower reduction in } \mathrm{G} 1 \text { than } \mathrm{G} 2: \text { home-based } \\
\text { care } \mathrm{DiD}=0.05(90 \% \mathrm{Cl}, 0.01 \text { to } 0.09)^{103}\end{array}$ \\
\hline \multirow[t]{2}{*}{$\begin{array}{l}\text { Inpatient admissions, } \\
\text { any all cause }(\%)\end{array}$} & $\mathrm{RCT}$ & & $\begin{array}{l}\text { Original sample DiD: OR=1.05 }(95 \% \mathrm{Cl}, 0.93 \text { to } \\
1.18)^{84}\end{array}$ \\
\hline & RCT & & $\begin{array}{l}\text { Refresh sample DiD: OR=.93 }(95 \% \mathrm{Cl}, 0.85 \text { to } \\
1.03)^{84}\end{array}$ \\
\hline \multirow[t]{3}{*}{$\begin{array}{l}\text { Inpatient admissions, } \\
\text { ACSC }\end{array}$} & $\mathrm{RCT}$ & & $\begin{array}{l}\text { Greater reduction in G1 than G2: original } \\
\text { sample DiD: IRR=0.86 }(95 \% \mathrm{Cl}, 0.76 \text { to } 0.97)^{84}\end{array}$ \\
\hline & $\mathrm{RCT}$ & & $\begin{array}{l}\text { Greater reduction in G1 than G2: refresh } \\
\text { sample DiD: IRR=0.89 }(95 \% \mathrm{Cl}, 0.81 \text { to } 0.99)^{84}\end{array}$ \\
\hline & Observational & NR & $\begin{array}{l}\text { Home-based care sample DiD=0.00 }(90 \% \mathrm{Cl},- \\
0.02 \text { to } 0.02)^{103}\end{array}$ \\
\hline \multirow[t]{2}{*}{$\begin{array}{l}\text { Inpatient admissions, } \\
\text { any ACSC (\%) }\end{array}$} & $\mathrm{RCT}$ & & $\begin{array}{l}\text { Greater reduction in G1 than G2: original } \\
\text { sample DiD: OR=0.87 }(95 \% \mathrm{Cl}, 0.77 \text { to } 0.99)^{84}\end{array}$ \\
\hline & $\mathrm{RCT}$ & & $\begin{array}{l}\text { Greater reduction in G1 than G2: refresh } \\
\text { sample DiD: OR=.90 }(95 \% \mathrm{Cl}, 0.81 \text { to } 1.00)^{84}\end{array}$ \\
\hline \multirow[t]{3}{*}{ ED visits, all cause } & RCT & & $\begin{array}{l}\text { Original sample DiD: IRR=0.88 }(95 \% \mathrm{Cl}, 0.69 \text { to } \\
1.12)^{84}\end{array}$ \\
\hline & $\mathrm{RCT}$ & & $\begin{array}{l}\text { Refresh sample DiD: IRR=0.95 }(95 \% \mathrm{Cl}, 0.85 \text { to } \\
1.07)^{84}\end{array}$ \\
\hline & Observational & NR & $\begin{array}{l}\text { Home-based care } \mathrm{DiD}=0.00(90 \% \mathrm{Cl},-0.04 \text { to } \\
0.05)(p>0.10)^{103}\end{array}$ \\
\hline \multirow[t]{3}{*}{ ED visits, ACSC } & $\mathrm{RCT}$ & & $\begin{array}{l}\text { Original sample DiD: IRR=0.89 }(95 \% \mathrm{Cl}, 0.66 \text { to } \\
1.18)^{84}\end{array}$ \\
\hline & $\mathrm{RCT}$ & & $\begin{array}{l}\text { Refresh sample DiD: IRR=1.06 }(95 \% \mathrm{Cl}, 0.87 \text { to } \\
1.30)^{84}\end{array}$ \\
\hline & Observational & NR & $\begin{array}{l}\text { Home-based care } \mathrm{DiD}=0.00(90 \% \mathrm{Cl},-0.02 \text { to } \\
0.01)(p>0.10)^{103}\end{array}$ \\
\hline $\begin{array}{l}\text { Long-term } \\
\text { institutionalization rate }\end{array}$ & Observational & NR & $\begin{array}{l}\text { G1: } 8.1 \%, G 2 \text { with home-based care: } 17.7 \% \text {, } \\
\text { G2 without home-based care: } 16.4 \%: p<0.05^{131}\end{array}$ \\
\hline
\end{tabular}

- Increase in the outcome between the intervention period and the baseline period; the difference between the intervention and comparison groups was statistically significant.

- Reduction in the outcome between the intervention period and the baseline period; the difference between the intervention and comparison groups was statistically significant.

$\hat{\mathrm{S}}=$ Increase in the outcome between the intervention period and the baseline period; the difference between the intervention and comparison groups was not statistically significant.

$\sqrt{S}=$ Reduction in the outcome between the intervention period and the baseline period; the difference between the intervention and comparison groups was not statistically significant.

$\mathrm{ACSC}=$ ambulatory care sensitive conditions; $\mathrm{CI}=$ confidence interval; $\mathrm{DiD}=$ difference-in-difference $\mathrm{ED}=$ emergency department; $\mathrm{G}$ = group; IRR = incidence rate ratio; $\mathrm{NR}=$ not reported; $\mathrm{OR}=$ odds ratio; $\mathrm{RCT}$ = randomized controlled trial. 
Table B-63. Strength of evidence for home-based care models versus usual-care outcomes

\begin{tabular}{|c|c|c|c|c|c|}
\hline Population & Outcome & Results & $\begin{array}{l}\text { Study Design } \\
\text { and Sample } \\
\text { Size }\end{array}$ & $\begin{array}{l}\text { Strength of Evidence } \\
\text { Domains }\end{array}$ & $\begin{array}{l}\text { Overall Evidence } \\
\text { Strength (Direction } \\
\text { of Effect) }\end{array}$ \\
\hline $\begin{array}{l}\mathrm{HNHC} \\
\text { patients }\end{array}$ & $\begin{array}{l}\text { ED visits, all } \\
\text { cause }\end{array}$ & $\begin{array}{l}\text { CLM original sample } \\
\text { DiD: IRR }=0.88(95 \% \mathrm{CI} \text {, } \\
0.69 \text { to } 1.12)^{84} \\
\text { CLM refresh sample } \\
\text { DiD: IRR }=0.95(95 \% \mathrm{CI} \text {, } \\
0.85 \text { to } 1.07)^{84} \\
\text { IAH home-based care: } \\
\text { higher use in } \mathrm{G} 1 \text { than } \\
\mathrm{G} 2: \mathrm{DiD}=0.00(90 \% \\
\mathrm{Cl},-0.04 \text { to } 0.05) \\
(p>0.10)^{103}\end{array}$ & $\begin{array}{l}2 \text { RCTs, } \\
\mathrm{N}=34,421 \\
1 \mathrm{OBS} \\
\mathrm{N}=181,246\end{array}$ & $\begin{array}{l}\text { Moderate study } \\
\text { limitations, imprecise, } \\
\text { inconsistent, direct }\end{array}$ & Insufficient \\
\hline $\begin{array}{l}\mathrm{HNHC} \\
\text { patients }\end{array}$ & $\begin{array}{l}\text { ED visits, } \\
\text { ACSC }\end{array}$ & $\begin{array}{l}\text { CLM original sample } \\
\text { DiD: IRR }=0.89(95 \% \mathrm{Cl} \text {, } \\
0.66 \text { to } 1.18)^{84} \\
\text { CLM refresh sample } \\
\text { DiD: IRR }=1.06(95 \% \mathrm{Cl} \text {, } \\
0.87 \text { to } 1.30)^{84} \\
\text { IAH home-based care } \\
\text { sample DiD=0.00 }(90 \% \\
\mathrm{Cl},-0.02 \text { to } 0.01 \\
\mathrm{p}>0.10)^{103}\end{array}$ & $\begin{array}{l}2 \text { RCTs, } \\
N=34,421 \\
1 \text { OBS, } \\
N=181,246\end{array}$ & $\begin{array}{l}\text { Moderate study } \\
\text { limitations, } \\
\text { inconsistent, } \\
\text { imprecise, direct }\end{array}$ & Insufficient \\
\hline $\begin{array}{l}\mathrm{HNHC} \\
\text { patients }\end{array}$ & $\begin{array}{l}\text { Inpatient } \\
\text { admissions, all } \\
\text { cause }\end{array}$ & $\begin{array}{l}\text { CLM original sample: } \\
\text { IRR=0.94 }(95 \% \mathrm{Cl}, 0.87 \\
\text { to } 1.01)^{84} \\
\text { CLM refresh sample: } \\
\text { IRR }=0.94(95 \% \mathrm{Cl}, 0.88 \\
\text { to } 1.00) ; 84 \\
\text { IAH home-based care: } \\
\text { lower reduction in G1 } \\
\text { than } \mathrm{G} 2: \mathrm{DiD}=0.05(90 \% \\
\mathrm{Cl}, 0.01 \text { to } 0.09)^{103}\end{array}$ & $\begin{array}{l}2 \text { RCTs, } \\
\mathrm{N}=34,421 \\
1 \mathrm{OBS} \\
\mathrm{N}=181,246\end{array}$ & $\begin{array}{l}\text { Moderate study } \\
\text { limitations, imprecise, } \\
\text { inconsistent, direct }\end{array}$ & Insufficient \\
\hline $\begin{array}{l}\mathrm{HNHC} \\
\text { patients }\end{array}$ & $\begin{array}{l}\text { Inpatient } \\
\text { admissions, } \\
\text { ACSC }\end{array}$ & $\begin{array}{l}\text { CLM original sample: } \\
\text { DiD: IRR }=0.86(95 \% \mathrm{Cl} \text {, } \\
0.76 \text { to } 0.97)^{84} \\
\text { CLM refresh sample: } \\
\text { DiD: IRR }=0.89(95 \% \mathrm{Cl} \text {, } \\
0.81 \text { to } 0.99)^{84} \\
\text { IAH home-based care } \\
\text { sample: } \mathrm{DiD}=0.00(90 \% \\
\mathrm{Cl},-0.02 \text { to } 0.02)^{103}\end{array}$ & $\begin{array}{l}2 \text { RCTs, } \\
\mathrm{N}=34,421 \\
1 \mathrm{OBS} \\
\mathrm{N}=181,246\end{array}$ & $\begin{array}{l}\text { Moderate study } \\
\text { limitations, imprecise, } \\
\text { consistent, direct }\end{array}$ & Low (Favorable) \\
\hline $\begin{array}{l}\mathrm{HNHC} \\
\text { patients }\end{array}$ & $\begin{array}{l}\text { Inpatient } \\
\text { admissions, } \\
\text { any all cause } \\
(\%)\end{array}$ & $\begin{array}{l}\text { CLM original sample: } \\
\text { DiD: OR }=1.05(95 \% \mathrm{Cl} \text {, } \\
0.93 \text { to } 1.18)^{84} \\
\text { CLM refresh sample: } \\
\text { DiD: OR }=0.93(95 \% \mathrm{Cl} \text {, } \\
0.85 \text { to } 1.03)^{84}\end{array}$ & $\begin{array}{l}\text { RCTs, } \\
\mathrm{N}=34,421\end{array}$ & $\begin{array}{l}\text { Moderate study } \\
\text { limitations, imprecise, } \\
\text { inconsistent, direct }\end{array}$ & Insufficient \\
\hline
\end{tabular}




\begin{tabular}{|c|c|c|c|c|c|}
\hline Population & Outcome & Results & $\begin{array}{l}\text { Study Design } \\
\text { and Sample } \\
\text { Size }\end{array}$ & $\begin{array}{l}\text { Strength of Evidence } \\
\text { Domains }\end{array}$ & $\begin{array}{l}\text { Overall Evidence } \\
\text { Strength (Direction } \\
\text { of Effect) }\end{array}$ \\
\hline $\begin{array}{l}\mathrm{HNHC} \\
\text { patients }\end{array}$ & $\begin{array}{l}\text { Inpatient } \\
\text { admissions, any } \\
\text { ACSC (\%) }\end{array}$ & $\begin{array}{l}\text { CLM original sample: } \\
\text { DiD: OR=0.87 }(95 \% \mathrm{Cl} \\
0.77 \text { to } 0.99)^{84} \\
\text { CLM refresh sample: } \\
\text { DiD: OR=0.90 }(95 \% \mathrm{Cl} \\
0.81 \text { to } 1.00)^{84}\end{array}$ & $\begin{array}{l}2 \text { RCTs, } \\
\mathrm{N}=34,421\end{array}$ & $\begin{array}{l}\text { Moderate study } \\
\text { limitations; precise, } \\
\text { consistent, direct }\end{array}$ & Low (Favorable) \\
\hline $\begin{array}{l}\text { HNHC } \\
\text { patients }\end{array}$ & Total cost & $\begin{array}{l}\text { CLM original sample } \\
\text { DiD=41 }(p>0.05) ; 84 \text { CLM } \\
\text { refresh sample DiD=-29 } \\
(p>0.05)^{84} \\
\text { IAH home-based care } \\
\text { sample } \mathrm{DiD}=451(90 \% \\
\mathrm{Cl}, 342.4 \text { to } 559.6, \\
p<0.10)^{103}\end{array}$ & $\begin{array}{l}2 \text { RCTs, } \\
N=34,421 \\
1 \text { OBS, } \\
N=181,246\end{array}$ & $\begin{array}{l}\text { Moderate study } \\
\text { limitations, } \\
\text { inconsistent, } \\
\text { imprecise, direct }\end{array}$ & Insufficient \\
\hline $\begin{array}{l}\text { High-cost, } \\
\text { high risk } \\
\text { patient } \\
\text { subgroup }\end{array}$ & Total cost & $\begin{array}{l}\text { CLM original sample: } \\
\text { DiD=107 }(p>0.05)^{84} \text { CLM } \\
\text { refresh sample DiD=-21 } \\
(p>0.05)^{84}\end{array}$ & $\begin{array}{l}2 \text { RCTs, } \\
\mathrm{N}=15,400\end{array}$ & $\begin{array}{l}\text { Moderate study } \\
\text { limitations, } \\
\text { inconsistent, } \\
\text { imprecise, direct }\end{array}$ & Insufficient \\
\hline $\begin{array}{l}\text { High-cost } \\
\text { only patient } \\
\text { subgroup }\end{array}$ & Total cost & $\begin{array}{l}\text { CLM original sample } \\
\text { DiD }=-170(p>0.05)^{84} \\
\text { CLM refresh sample: } \\
\text { DiD=-236 }(p>0.05)^{84}\end{array}$ & $\begin{array}{l}2 \text { RCTs, } \\
\mathrm{N}=5,758\end{array}$ & $\begin{array}{l}\text { Moderate study } \\
\text { limitations, consistent, } \\
\text { imprecise, direct }\end{array}$ & Insufficient \\
\hline $\begin{array}{l}\mathrm{HNHC} \\
\text { patients }\end{array}$ & Mortality rate & $\begin{array}{l}\text { CLM original sample: diff } \\
\text { in mean rate }=0.4 \text {, } \\
(p=0.63)^{84} \\
\text { CLM refresh sample: Diff } \\
\text { in mean rate }=0.1 \\
(p=0.88)^{84} \\
\text { IAH LTSS: G1 vs. G2 } \\
\text { with HBC and G2 } \\
\text { without HBC=NR } \\
(p>0.05)^{131}\end{array}$ & $\begin{array}{l}2 \text { RCTs, } \\
\mathrm{N}=34,421 \\
1 \mathrm{OBS} \\
\mathrm{N}=1,376\end{array}$ & $\begin{array}{l}\text { Moderate study } \\
\text { limitations, consistent, } \\
\text { imprecise, direct }\end{array}$ & Low (No difference) \\
\hline $\begin{array}{l}\mathrm{HNHC} \\
\text { patients }\end{array}$ & $\begin{array}{l}\text { Influenza } \\
\text { vaccine }\end{array}$ & $\begin{array}{l}\text { CLM original sample: } \\
\text { DiD OR }=1.15(95 \% \mathrm{Cl} \text {, } \\
1.02 \text { to } 1.30)^{84} \\
\text { CLM refresh sample: } \\
\text { DiD OR }=1.15(95 \% \mathrm{Cl} \text {, } \\
1.03 \text { to } 1.27)^{84}\end{array}$ & $\begin{array}{l}\text { 2 RCTs, } \\
\mathrm{N}=34,421\end{array}$ & $\begin{array}{l}\text { Moderate study } \\
\text { limitations, consistent, } \\
\text { precise, direct }\end{array}$ & Low (Favorable) \\
\hline $\begin{array}{l}\mathrm{HNHC} \\
\text { patients } \\
\text { COPD } \\
\text { subgroup }\end{array}$ & $\begin{array}{l}\text { Oxygen } \\
\text { saturation test }\end{array}$ & $\begin{array}{l}\text { CLM original sample: } \\
\text { DiD OR }=1.02(95 \% \mathrm{Cl} \text {, } \\
0.77 \text { to } 1.34)^{84} \\
\text { CLM refresh sample: } \\
\text { DiD OR }=0.97(95 \% \mathrm{Cl} \text {, } \\
0.77 \text { to } 1.22)^{84}\end{array}$ & $\begin{array}{l}2 \text { RCTs, } \\
\mathrm{N}=8,079\end{array}$ & $\begin{array}{l}\text { Moderate study } \\
\text { limitations, } \\
\text { inconsistent, } \\
\text { imprecise, direct }\end{array}$ & Insufficient \\
\hline $\begin{array}{l}\mathrm{HNHC} \\
\text { patients } \\
\text { Diabetes } \\
\text { subgroup }\end{array}$ & $\mathrm{HbA1c}$ test & $\begin{array}{l}\text { CLM original sample: } \\
\text { DiD OR=0.91 }(95 \% \mathrm{Cl} \text {, } \\
0.74 \text { to } 1.13)^{84} \\
\text { CLM refresh: DiD } \\
\text { OR=0.98 }(95 \% \mathrm{Cl}, 0.82 \\
\text { to } 1.18)^{84}\end{array}$ & $\begin{array}{l}2 \text { RCTs, } \\
\mathrm{N}=10,452\end{array}$ & $\begin{array}{l}\text { Moderate study } \\
\text { limitations, consistent, } \\
\text { imprecise, direct }\end{array}$ & Insufficient \\
\hline $\begin{array}{l}\mathrm{HNHC} \\
\text { patients } \\
\text { Diabetes } \\
\text { subgroup }\end{array}$ & LDL-C test & $\begin{array}{l}\text { CLM original sample: } \\
\text { DiD OR=0.92 }(95 \% \mathrm{Cl} \text {, } \\
0.75 \text { to } 1.12)^{84} \\
\text { CLM refresh sample: } \\
\text { DiD OR }=0.97(95 \% \mathrm{Cl} \text {, } \\
0.77 \text { to } 1.22)^{84}\end{array}$ & $\begin{array}{l}2 \text { RCTs, } \\
\mathrm{N}=10,452\end{array}$ & $\begin{array}{l}\text { Moderate study } \\
\text { limitations, consistent, } \\
\text { imprecise, direct }\end{array}$ & Insufficient \\
\hline
\end{tabular}




\begin{tabular}{|c|c|c|c|c|c|}
\hline Population & Outcome & Results & $\begin{array}{l}\text { Study Design } \\
\text { and Sample } \\
\text { Size }\end{array}$ & $\begin{array}{l}\text { Strength of Evidence } \\
\text { Domains }\end{array}$ & $\begin{array}{l}\text { Overall Evidence } \\
\text { Strength (Direction } \\
\text { of Effect) }\end{array}$ \\
\hline $\begin{array}{l}\text { IVD patient } \\
\text { Subgroup }\end{array}$ & LDL-C test & $\begin{array}{l}\text { CLM original sample: } \\
\text { DiD OR }=0.89(95 \% \mathrm{Cl} \text {, } \\
0.76 \text { to } 1.05)^{84} \\
\text { CLM refresh sample: } \\
\text { DiD OR }=0.95(95 \% \mathrm{Cl} \text {, } \\
0.81 \text { to } 1.11)^{84}\end{array}$ & $\begin{array}{l}2 \text { RCTs, } \\
\mathrm{N}=14,910\end{array}$ & $\begin{array}{l}\text { Moderate study } \\
\text { limitations, consistent, } \\
\text { imprecise, direct }\end{array}$ & Insufficient \\
\hline
\end{tabular}

$\overline{\mathrm{ACSC}}=$ ambulatory care sensitive conditions; $\mathrm{CI}=$ confidence interval; $\mathrm{CLM}=$ care level management; $\mathrm{COPD}=$ chronic obstructive pulmonary disease; $\mathrm{DiD}=$ difference-in-difference; $\mathrm{ED}=$ emergency department; $\mathrm{G}=$ group; HbA1c = hemoglobin A1c; $\mathrm{HBC}=$ home-based care; HNHC = high-need, high-cost; IAH = Independence at Home; IRR = incidence rate ratio; IVD = ischemic vascular disease; LDL-C = low-density lipoprotein cholesterol; LTSS = long-term services and supports; $\mathrm{N}=$ number; $\mathrm{NR}=$ not reported; OBS = observational study; $\mathrm{OR}=$ odds ratio; $\mathrm{RCT}=$ randomized controlled trial; vs. $=$ versus. 
Table B-64. Cost outcomes for home-based care model studies

\begin{tabular}{|c|c|c|c|c|}
\hline Cost Measures & Study Design & $\begin{array}{l}\text { Direction of } \\
\text { Change in } \\
\text { Intervention } \\
\text { Group (G1) }\end{array}$ & $\begin{array}{l}\text { Direction of } \\
\text { Change in } \\
\text { Comparison } \\
\text { Group (G2) }\end{array}$ & Difference \\
\hline \multirow[t]{3}{*}{ Total cost } & $\mathrm{RCT}$ & 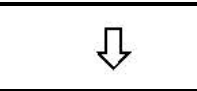 & $\Omega$ & $\begin{array}{l}\text { Original sample DiD=41 (SE: 67.9) } \\
(p>0.05)^{84}\end{array}$ \\
\hline & $\mathrm{RCT}$ & & & $\begin{array}{l}\text { Refresh sample DiD=-29 (SE: 73.1) } \\
(p>0.05)^{84}\end{array}$ \\
\hline & Observational & NR & NR & $\begin{array}{l}\text { Greater increase in G1 than G2: home- } \\
\text { based care DiD }=\$ 451 \text { (SE: } 66)(90 \% \mathrm{Cl} \text {, } \\
342.4 \text { to } 559.6)^{103}\end{array}$ \\
\hline
\end{tabular}

$\widehat{\mathrm{V}}=$ Increase in the outcome between the intervention period and the baseline period; the difference between the intervention and comparison groups was not statistically significant.

$\checkmark=$ Reduction in the outcome between the intervention period and the baseline period; the difference between the intervention and comparison groups was not statistically significant.

$\mathrm{CI}=$ confidence interval $; \mathrm{DiD}=$ difference in difference $\mathrm{G}=$ group $; \mathrm{NR}=$ not reported; $\mathrm{NS}=$ not statistically significant; $\mathrm{RCT}=$ randomized controlled trial; $\mathrm{SE}=$ standard error.

Table B-65. Cost outcomes for home-based care model studies: Subgroup outcomes

\begin{tabular}{|c|c|c|c|c|}
\hline Cost Measures & Study Design & $\begin{array}{l}\text { Direction of } \\
\text { Change in } \\
\text { Intervention } \\
\text { Group (G1) }\end{array}$ & $\begin{array}{l}\text { Direction of } \\
\text { Change in } \\
\text { Comparison } \\
\text { Group (G2) }\end{array}$ & Difference \\
\hline \multirow[t]{4}{*}{ Total cost } & RCT & $\Re$ & $\sqrt{ }$ & $\begin{array}{l}\text { Original sample high-cost, high-risk } \\
\text { subgroup } D i D=107 \text { (SE: } 127.6)(p>0.05)^{84}\end{array}$ \\
\hline & $\overline{\mathrm{RCT}}$ & $\sqrt{2}$ & & $\begin{array}{l}\text { Refresh sample high-cost, high-risk } \\
\text { subgroup DiD=-21 (SE: } 121.3)(p>0.05)^{84}\end{array}$ \\
\hline & $\mathrm{RCT}$ & $\Omega$ & 7 & $\begin{array}{l}\text { Original sample high-cost-only subgroup } \\
\text { DiD=-170 (SE: 104.0) }(p>0.05)^{84}\end{array}$ \\
\hline & $\overline{\mathrm{RCT}}$ & 几 & $\square$ & $\begin{array}{l}\text { Refresh sample high-cost-only subgroup } \\
\text { DiD=-236 (SE: 197.5) }(p>0.05)^{84}\end{array}$ \\
\hline
\end{tabular}

$\sqrt{\Omega}=$ Reduction in the outcome between the intervention period and the baseline period; the difference between the intervention and comparison groups was not statistically significant.

$\mathrm{DiD}=$ difference-in-difference $\mathrm{G}=$ group $\mathrm{RCT}=$ randomized controlled trial; $\mathrm{SE}=$ standard error. 
Table B-66. Clinical and functional outcomes for home-based care model studies

\begin{tabular}{|c|c|c|}
\hline $\begin{array}{l}\text { Clinical and Functional } \\
\text { Outcomes }\end{array}$ & Study Design & $\begin{array}{l}\text { Difference Between Intervention Group (G1) and Comparison Group } \\
\text { (G2) }\end{array}$ \\
\hline \multirow[t]{3}{*}{ Mortality rate } & RCT & Original sample: difference in mean rates $=0.4,(p=0.63)^{84}$ \\
\hline & $\overline{\mathrm{RCT}}$ & Refresh sample: difference in mean rates $=0.1(p=0.88)^{84}$ \\
\hline & $\overline{\text { OBS }}$ & $\begin{array}{l}\text { G1: } 35.8 \% \text {, G2 with home-based care: } 24.9 \%, G 2 \text { without home-based } \\
\text { care: } 26.9 \%: p>0.05^{131}\end{array}$ \\
\hline \multirow[t]{2}{*}{ Influenza vaccine } & RCT & $\begin{array}{l}\text { DiD greater in G1 than G2: original sample: DiD OR=1.15 }(95 \% \mathrm{Cl}, 1.02 \text { to } \\
1.30)^{84}\end{array}$ \\
\hline & $\overline{\mathrm{RCT}}$ & $\begin{array}{l}\text { DiD greater in G1 than G2: refresh sample: } \mathrm{DiD} \text { OR=1.15 }(95 \% \mathrm{Cl}, 1.03 \text { to } \\
1.27)^{84}\end{array}$ \\
\hline $\begin{array}{l}\text { PHC score (physical } \\
\text { health) }\end{array}$ & RCT & Greater in G1 than G2: ANCOVA-adjusted IE $=2.1\left(p<0.05^{84}\right)$ \\
\hline $\begin{array}{l}\text { MHC score (mental } \\
\text { health) }\end{array}$ & RCT & ANCOVA-adjusted IE $=1.7\left(p>0.05^{84}\right)$ \\
\hline $\begin{array}{l}\text { PHQ-2 score } \\
\text { (depression) }\end{array}$ & RCT & ANCOVA-adjusted IE $=0.26\left(p>0.05^{84}\right)$ \\
\hline $\begin{array}{l}\text { Number of activities of } \\
\text { daily living (ADLs) } \\
\text { difficult to do }\end{array}$ & RCT & ANCOVA-adjusted IE $=0.03\left(p>0.05^{84}\right)$ \\
\hline $\begin{array}{l}\text { Number ADLs receiving } \\
\text { help }\end{array}$ & $\mathrm{RCT}$ & ANCOVA-adjusted IE $=0.00\left(p>0.05^{84}\right)$ \\
\hline $\begin{array}{l}\text { Helping to cope with a } \\
\text { chronic condition }\end{array}$ & RCT & ANCOVA-adjusted IE $=0.19\left(p>0.05^{84}\right)$ \\
\hline $\begin{array}{l}\text { Number of helpful } \\
\text { discussion topics }\end{array}$ & $\mathrm{RCT}$ & ANCOVA-adjusted IE $=0.20\left(p>0.05^{84}\right)$ \\
\hline $\begin{array}{l}\text { Discussing treatment } \\
\text { choices }\end{array}$ & RCT & Greater in G1 than G2: ANCOVA-adjusted IE $=0.23\left(p<0.05^{84}\right)$ \\
\hline $\begin{array}{l}\text { Communicating with } \\
\text { providers }\end{array}$ & RCT & Greater in G1 than G2: ANCOVA-adjusted IE $=6.55\left(p<0.01^{84}\right)$ \\
\hline $\begin{array}{l}\text { Getting answers to } \\
\text { questions quickly }\end{array}$ & $\mathrm{RCT}$ & ANCOVA-adjusted IE $=4.90\left(p>0.05^{84}\right)$ \\
\hline $\begin{array}{l}\text { Multimorbidity Hassles } \\
\text { score }\end{array}$ & RCT & ANCOVA-adjusted IE $=-0.44\left(p>0.05^{84}\right)$ \\
\hline $\begin{array}{l}\text { Percentage receiving } \\
\text { help setting goals }\end{array}$ & $\mathrm{RCT}$ & ANCOVA-adjusted IE $=6.1\left(p>0.05^{84}\right)$ \\
\hline $\begin{array}{l}\text { Percentage receiving } \\
\text { help making a care plan }\end{array}$ & RCT & ANCOVA-adjusted IE $=3.9\left(p>0.05^{84}\right)$ \\
\hline $\begin{array}{l}\text { Self-efficacy: Take all } \\
\text { medications }\end{array}$ & RCT & ANCOVA-adjusted IE $=0.20\left(p>0.05^{84}\right)$ \\
\hline $\begin{array}{l}\text { Self-efficacy: Plan meals } \\
\text { and snacks }\end{array}$ & RCT & ANCOVA-adjusted IE $=0.15\left(p>0.05^{84}\right)$ \\
\hline $\begin{array}{l}\text { Self-efficacy: Exercise } 2 \\
\text { or } 3 \text { times weekly }\end{array}$ & RCT & ANCOVA-adjusted IE $=0.20\left(p>0.05^{84}\right)$ \\
\hline $\begin{array}{l}\text { Self-care activities: } \\
\text { Prescribed medications } \\
\text { taken }\end{array}$ & RCT & ANCOVA-adjusted IE $=0.06\left(p>0.05^{84}\right)$ \\
\hline $\begin{array}{l}\text { Self-care activities: } \\
\text { Followed healthy eating } \\
\text { plan }\end{array}$ & $\mathrm{RCT}$ & ANCOVA-adjusted IE $=-0.03\left(p>0.05^{84}\right)$ \\
\hline
\end{tabular}

plan

Self-care activities: $30 \quad$ RCT $\quad$ Greater in G1 than G2: ANCOVA-adjusted IE $=0.63\left(p<0.05^{84}\right)$

minutes of continuous

physical activity

$\mathrm{ADL}=$ activities of daily living; ANCOVA = analysis of covariance; $\mathrm{CI}=$ confidence interval; $\mathrm{DiD}=$ difference-in-difference; $\mathrm{G}$ = group; $\mathrm{IE}=$ intervention effect; $\mathrm{MHC}=$ mental health composite; $\mathrm{OR}=$ odds ratio; $\mathrm{PHC}=$ physical health composite; $\mathrm{PHQ}-2=$ patient health questionnaire-2; RCT = randomized controlled trial. 
Table B-67. Clinical and functional outcomes for home-based care model studies: Subgroup outcomes

\begin{tabular}{|c|c|c|}
\hline $\begin{array}{l}\text { Clinical and Functional } \\
\text { Outcomes }\end{array}$ & Study Design & $\begin{array}{l}\text { Difference Between Intervention Group (G1) and Comparison Group } \\
\text { (G2) }\end{array}$ \\
\hline \multirow[t]{2}{*}{ Oxygen saturation test } & RCT & Original sample COPD subgroup: DiD OR=1.02 $(95 \% \mathrm{Cl}, 0.77 \text { to } 1.34)^{84}$ \\
\hline & $\overline{\mathrm{RCT}}$ & Refresh sample COPD subgroup: DiD OR=0.97 (95\% Cl, 0.77 to 1.22$)^{84}$ \\
\hline \multirow[t]{2}{*}{ HbA1c test } & RCT & Original sample diabetes subgroup: DiD OR=0.91 $(95 \% \mathrm{Cl}, 0.74 \text { to } 1.13)^{84}$ \\
\hline & $\overline{\mathrm{RCT}}$ & Refresh sample diabetes subgroup: $\mathrm{DiD} \mathrm{OR}=0.98(95 \% \mathrm{Cl}, 0.82 \text { to } 1.18)^{84}$ \\
\hline \multirow[t]{4}{*}{ LDL-C test } & RCT & Original sample diabetes subgroup: DiD OR=0.92 $(95 \% \mathrm{Cl}, 0.75 \text { to } 1.12)^{84}$ \\
\hline & $\overline{\mathrm{RCT}}$ & Refresh sample diabetes subgroup: DiD OR=0.97 (95\% Cl, 0.77 to 1.22$)^{84}$ \\
\hline & $\overline{\mathrm{RCT}}$ & Original sample IVD subgroup: DiD OR=0.89 $(95 \% \mathrm{Cl}, 0.76 \text { to } 1.05)^{84}$ \\
\hline & $\overline{\mathrm{RCT}}$ & Refresh sample IVD subgroup: DiD OR=0.95 $(95 \% \mathrm{Cl}, 0.81 \text { to } 1.11)^{84}$ \\
\hline
\end{tabular}

$\mathrm{CI}=$ confidence interval; $\mathrm{COPD}=$ chronic obstructive pulmonary disease; $\mathrm{DiD}=$ difference-in-difference; $\mathrm{HbA} 1 \mathrm{c}=$ hemoglobin A1c; IVD = ischemic vascular disease; LDL-C = low-density lipoprotein-cholesterol; OR = odds ratio; $\mathrm{RCT}=$ randomized controlled trial. 


\section{Appendix B Figures}

Figure B-2. System-level transformation models versus usual care, total cost

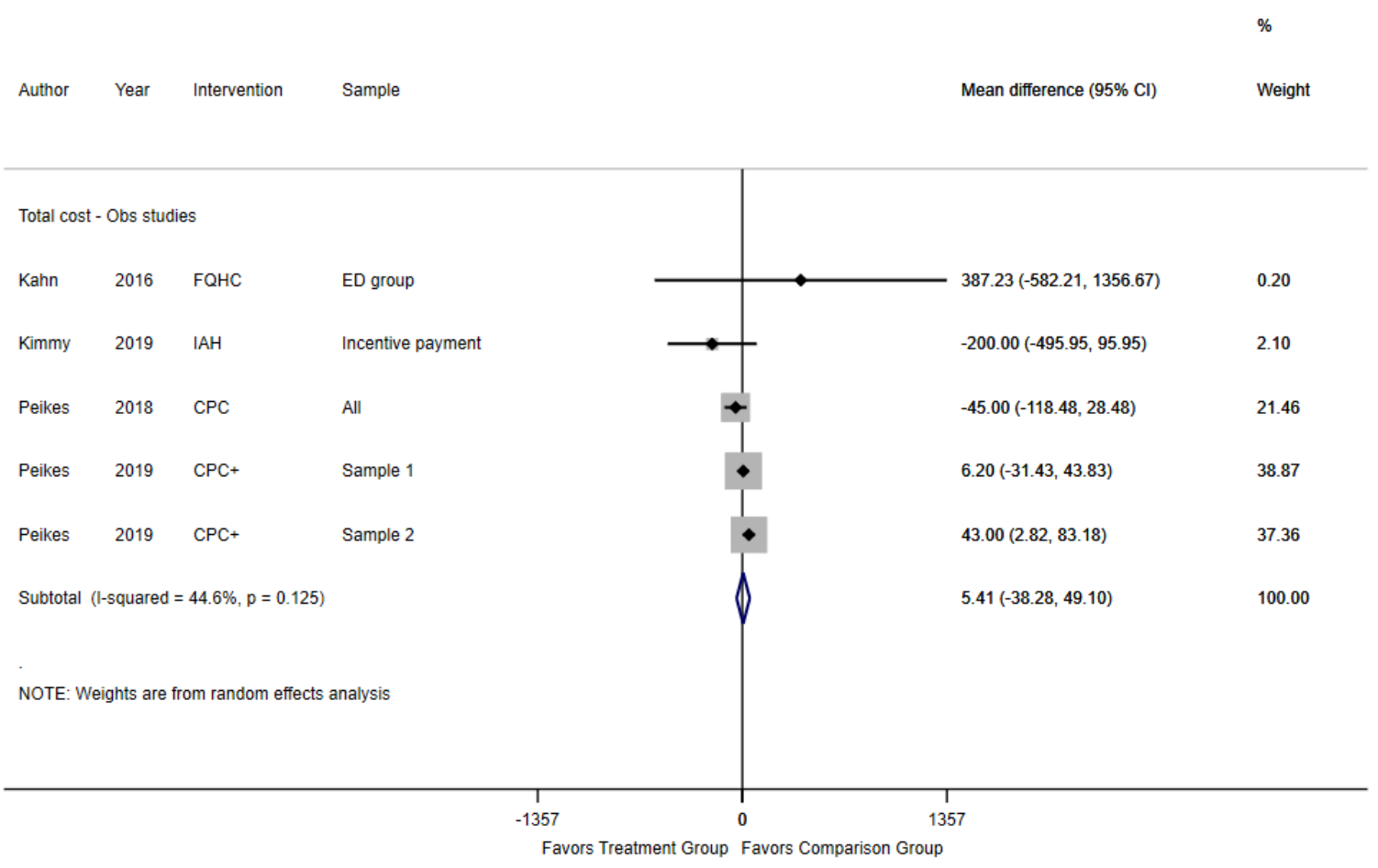

Figure B-3. Telephonic/mail models versus usual care, all-cause ED visits

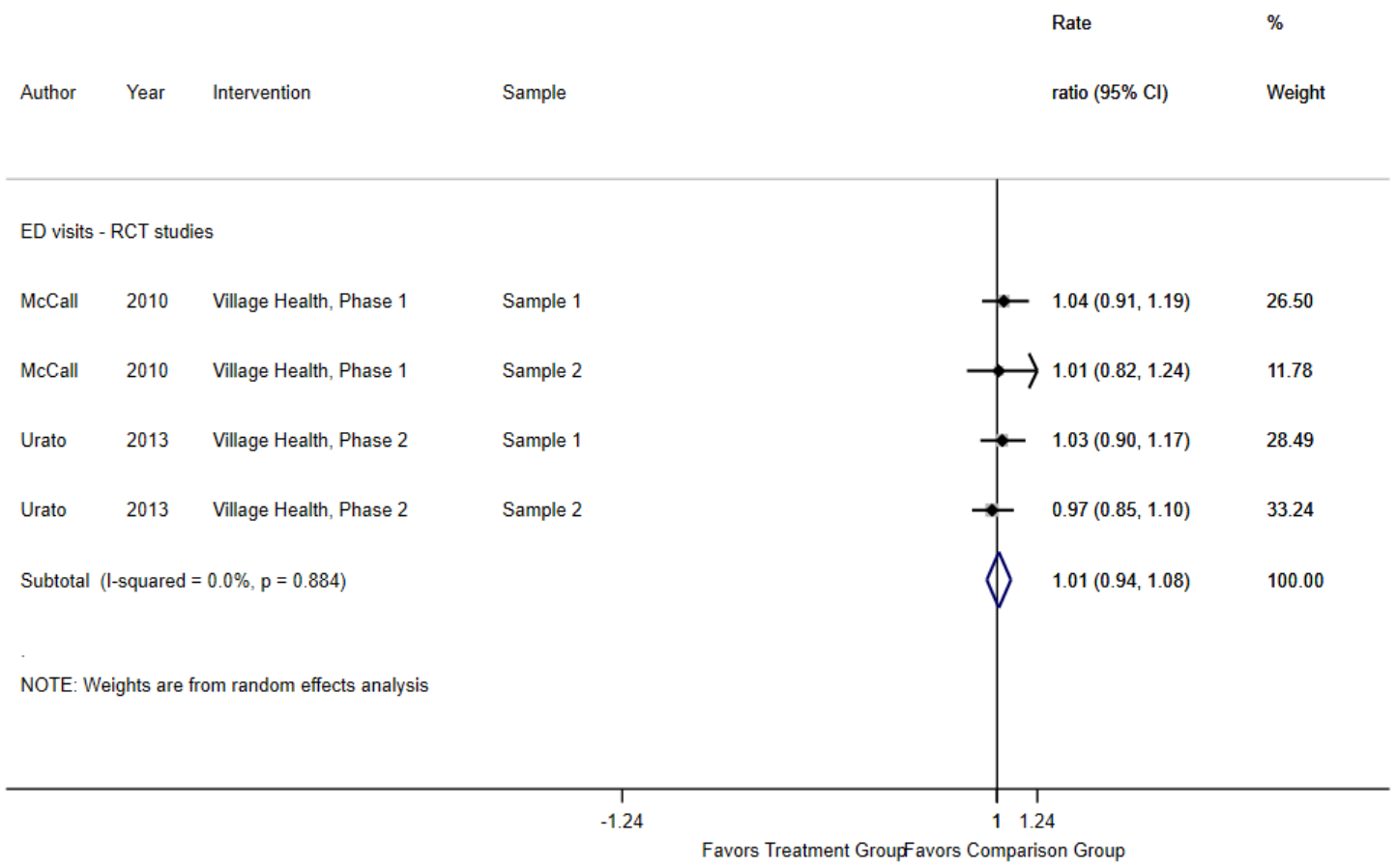


Figure B-4. Telephonic/mail models versus usual care, ACSC ED visits

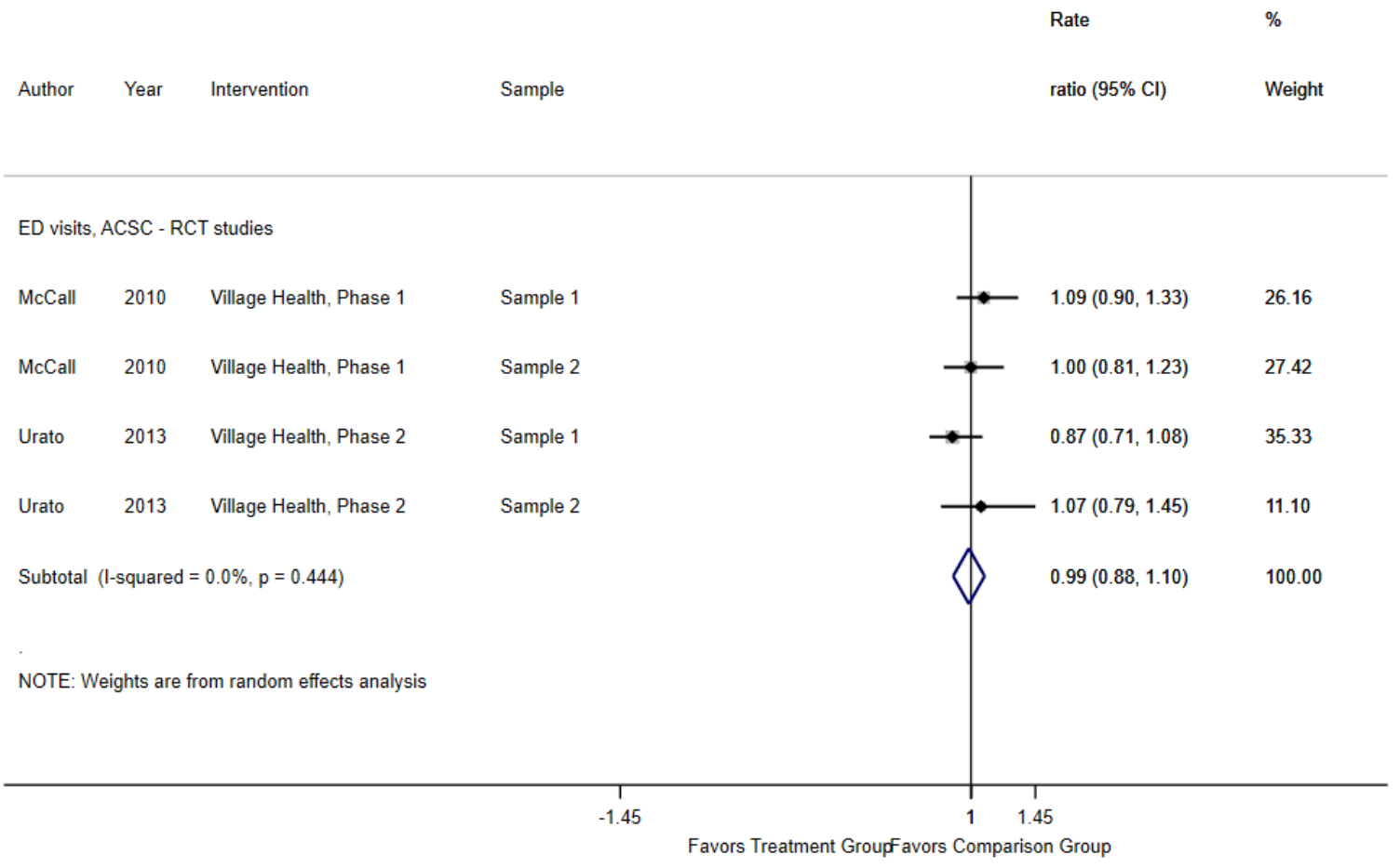

Figure B-5. Telephonic/mail models versus usual care, all-cause inpatient admissions

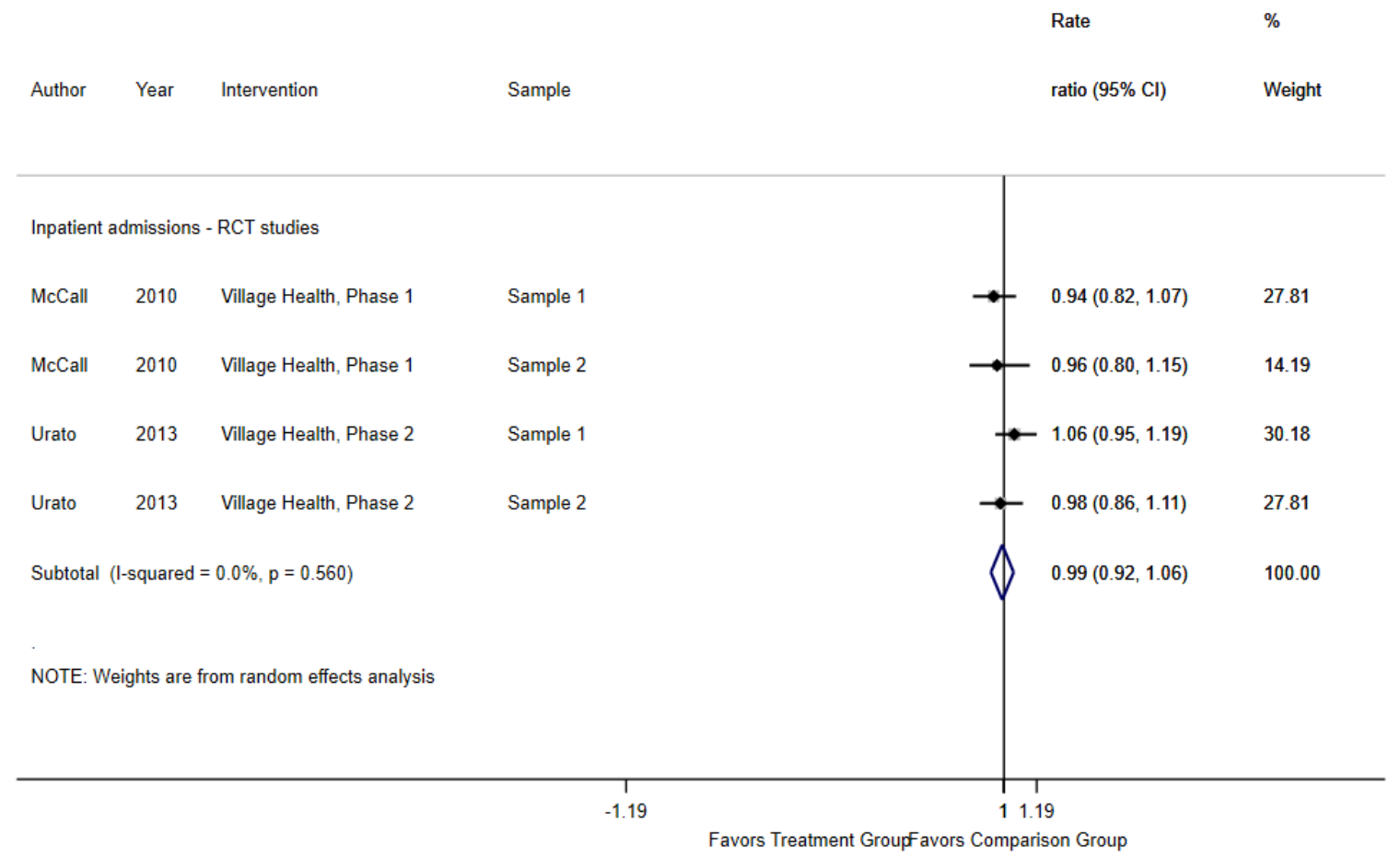


Figure B-6. Telephonic/mail models versus usual care, ACSC inpatient admissions

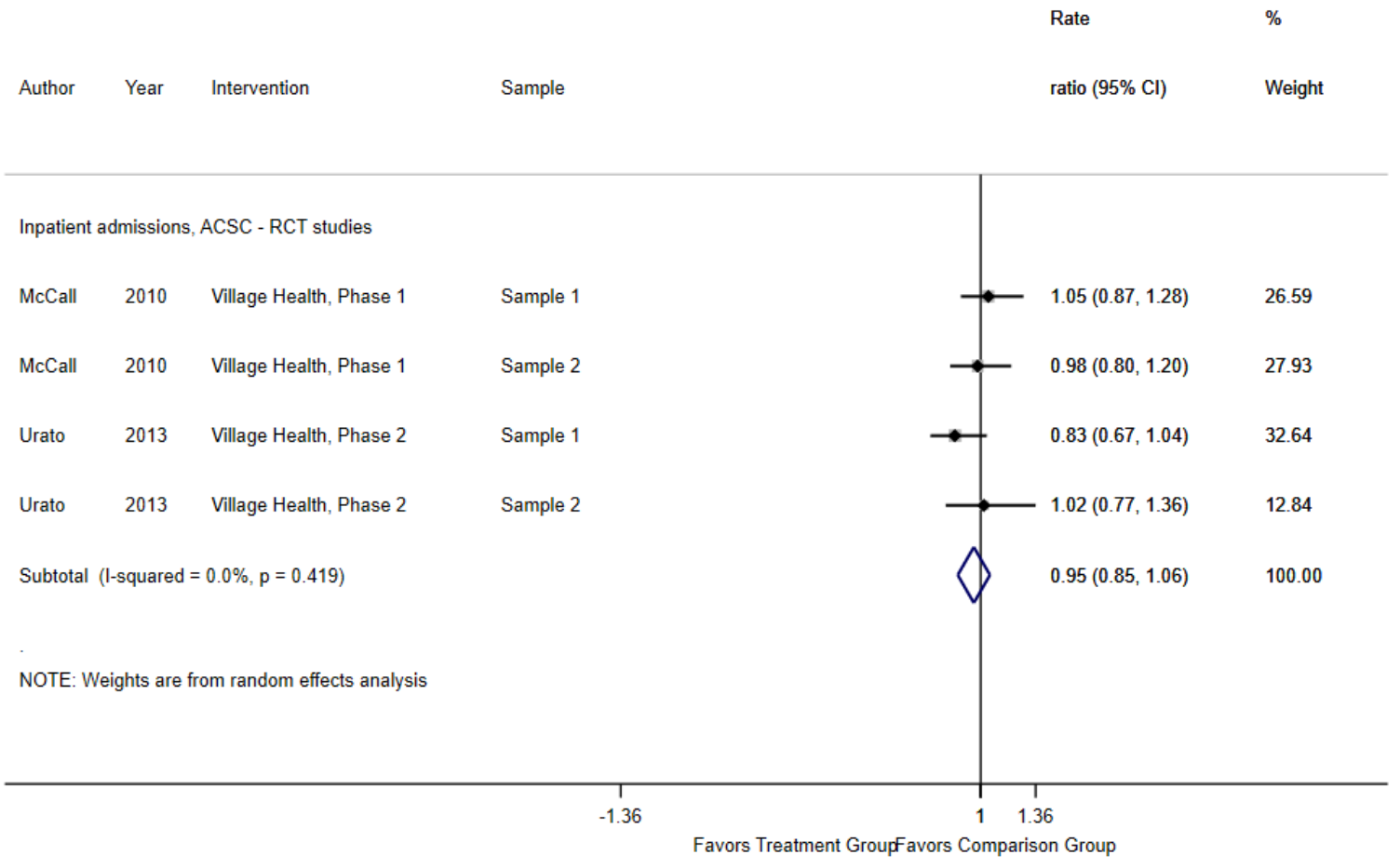

Figure B-7. Telephonic/mail models versus usual care, total cost

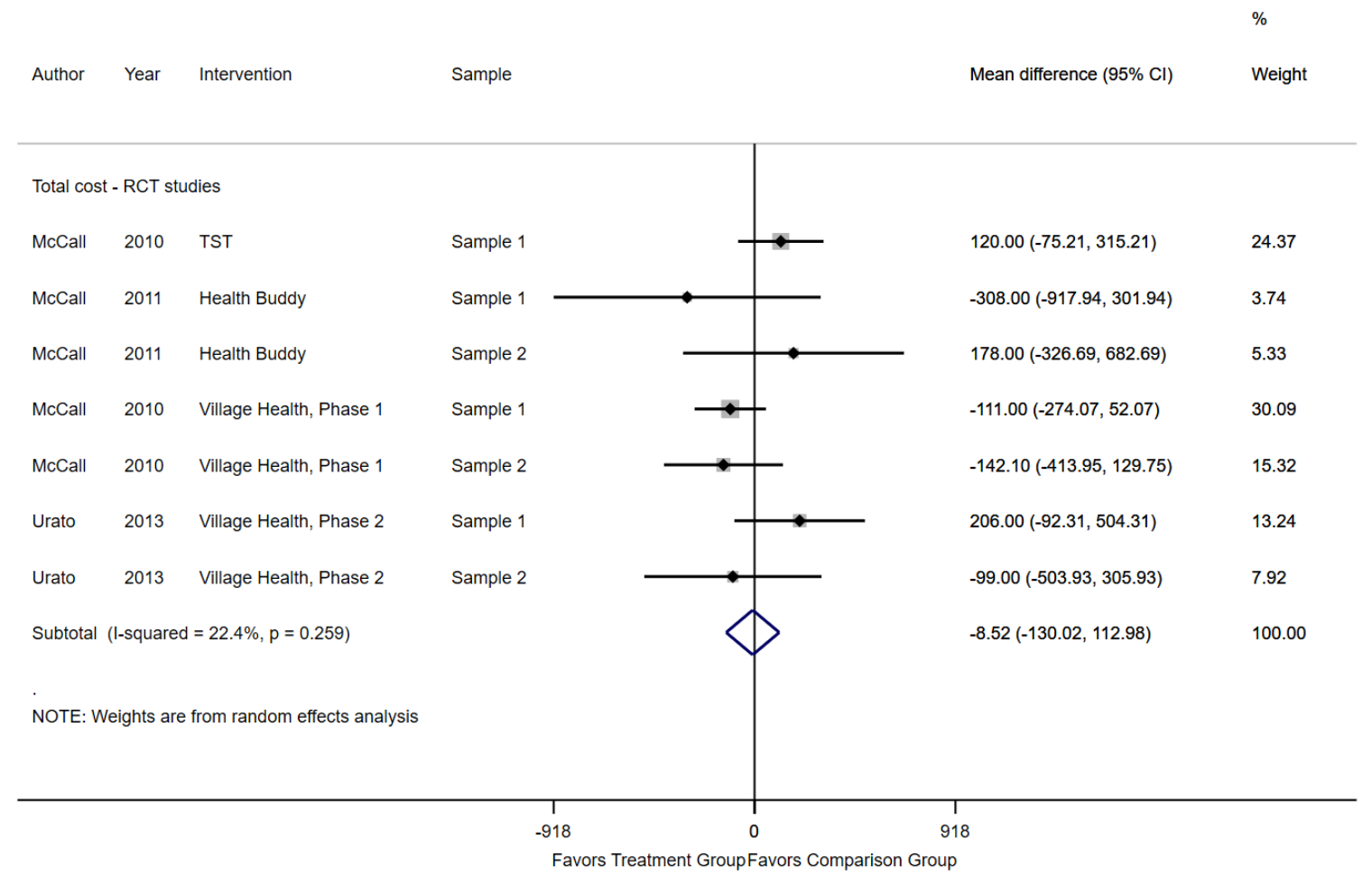


Figure B-8. Telephonic/mail models versus usual care, mortality rate

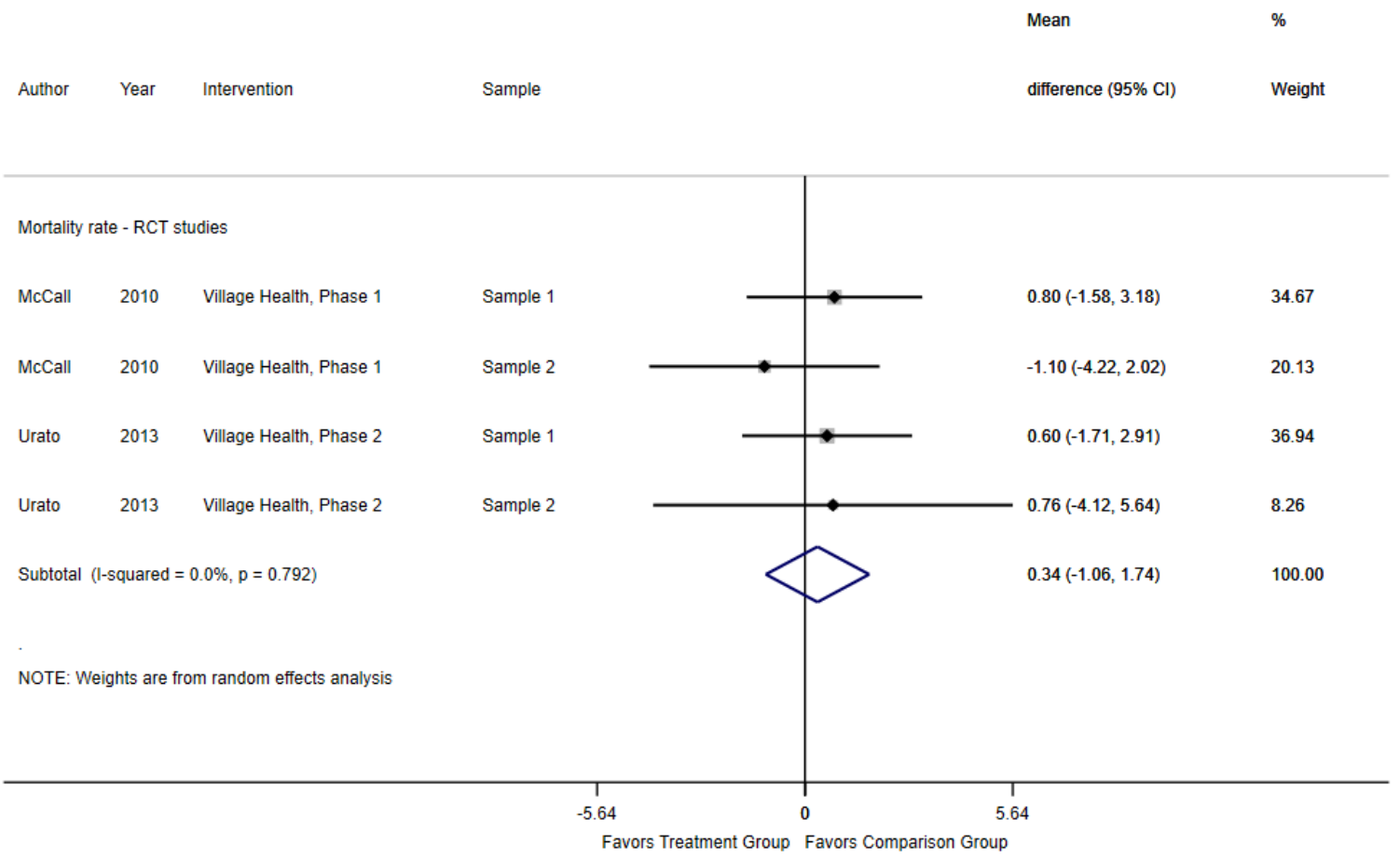

Figure B-9. Primary care models versus usual care, total cost

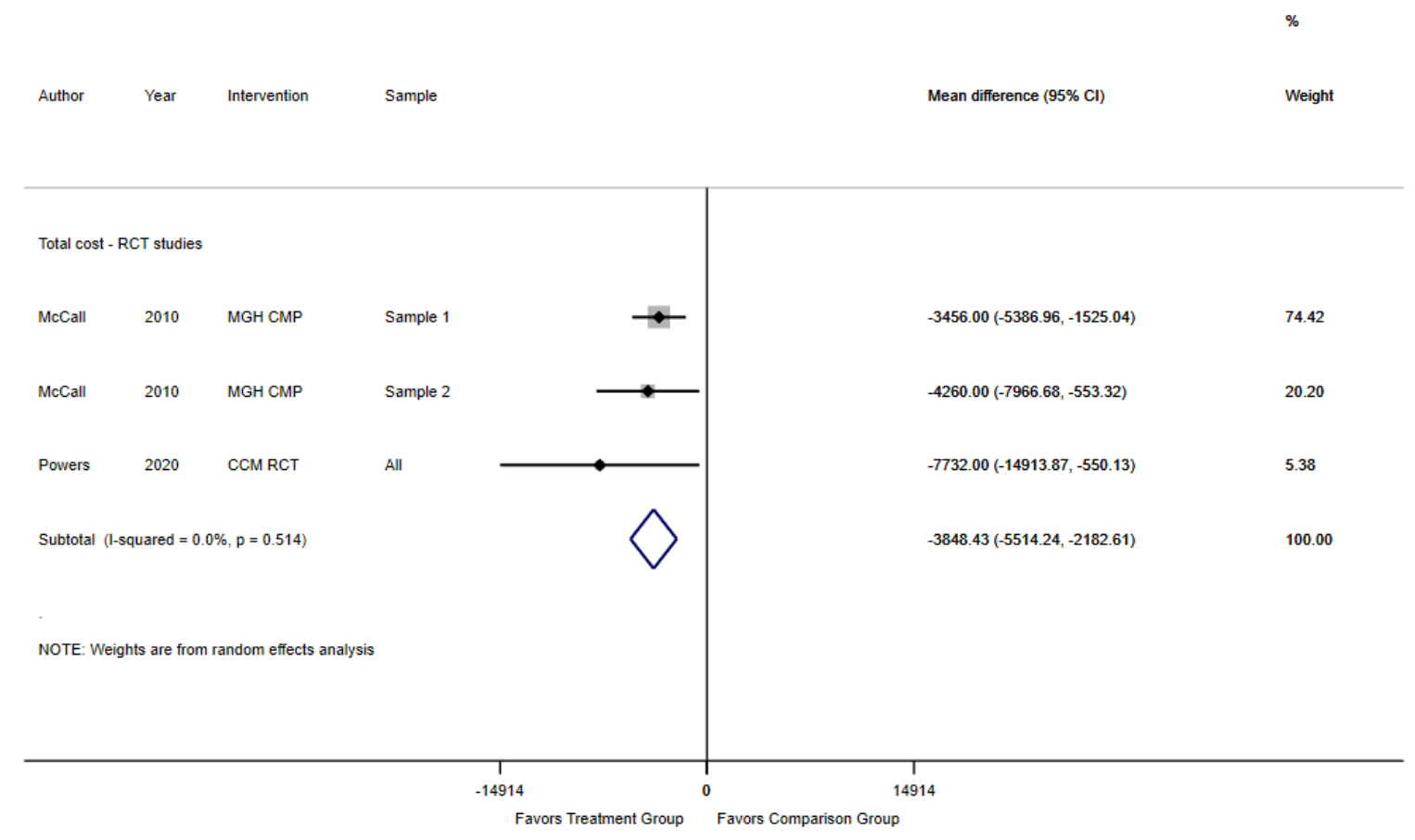




\section{Appendix C. Appendix References}

1. RAMESES Project. Quality standards for realist synthesis (for researchers and peer-reviewers). Oxford: Nuffield Department of Primary Care Health Sciences, University of Oxford; 2014. www.ramesesproject.org). Accessed on August 122019.

2. Sterne J. Personal communication. 2020.

3. Noyes J, Booth A, Cargo M, et al. Chapter 21: Qualitative evidence. In: Higgins JPT, Thomas J, Chandler J, Cumpston M, Li T, Page MJ, et al., eds. Cochrane handbook for systematic reviews of interventions version 6.2. Cochrane; 2021.

4. Critical Appraisal Skills Programme. CASP qualitative checklist. [online]. Oxford: Critical Appraisal Skills Programme; 2018. https://caspuk.net/wp-content/uploads/2018/01/CASPQualitative-Checklist-2018.pdf. Accessed on November 72019.

5. Wong G. Data gathering for realist reviews: looking for needles in haystacks. In: Emmel N, Greenhalgh J, Manzano A, Monaghan M, Dalkin $\mathrm{S}$, eds. Doing realist research. London: Sage; 2018.

6. Wong G, Greenhalgh T, Westhorp G, et al. RAMESES publication standards: realist syntheses. BMC Med. 2013 2013/01/29;11(1):21. doi: 10.1186/1741-7015-11-21.

7. Berg RC, Nanavati J. Realist review: current practice and future prospects. J Res Pract. 2016;12(1).

8. Sterne JA, Hernan MA, Reeves BC, et al. ROBINS-I: a tool for assessing risk of bias in non-randomised studies of interventions. BMJ. 2016 Oct 12;355:i4919. doi: 10.1136/bmj.i4919. PMID: 27733354.

9. Higgins JPT, Green S. Cochrane handbook for systematic reviews of interventions. The Cochrane Collaboration; 2011.

www.handbook.cochrane.org. Accessed on January 102017.

10. Agency for Healthcare Research and Quality. Methods guide for effectiveness and comparative effectiveness reviews. AHRQ Publication No. 10(14)-EHC063-EF. Rockville, MD: Agency for Healthcare Research and Quality; January 2014. www.effectivehealthcare.ahrq.gov

11. Carroll C, Booth A, Leaviss J, et al. "Best fit" framework synthesis: refining the method. BMC Med Res Methodol. 2013 Mar 13;13:37. doi: 10.1186/1471-2288-13-37. PMID: 23497061.
12. National Academy of Medicine. Effective care for high-need patients. Opportunities for improving outcomes, value, and health. Washington, DC: National Academy of Sciences; 2017.

13. Pawson R, Greenhalgh T, Harvey G, et al. Realist review--a new method of systematic review designed for complex policy interventions. $\mathrm{J}$ Health Serv Res Policy. 2005 Jul;10(Suppl 1):2134. doi: 10.1258/1355819054308530. PMID: 16053581 .

14. Berkman ND, Lohr KN, Ansari MT, et al. Grading the strength of a body of evidence when assessing health care interventions: an EPC update. J Clin Epidemiol. 2015 Nov;68(11):131224. doi: 10.1016/j.jclinepi.2014.11.023. PMID: 25721570 .

15. Atkins D, Chang SM, Gartlehner G, et al. Assessing applicability when comparing medical interventions: AHRQ and the Effective Health Care Program. J Clin Epidemiol. 2011 Nov;64(11):1198-207. doi: 10.1016/j.jclinepi.2010.11.021. PMID: 21463926.

16. Szymkowiak D, Montgomery AE, Johnson EE, et al. Persistent super-utilization of acute care services among subgroups of veterans experiencing homelessness. Med Care. 2017 Oct;55(10):893-900. doi: 10.1097/mlr.0000000000000796. PMID 28863030 .

17. Hardy M, Cho A, Stavig A, et al. Understanding frequent emergency department use among primary care patients. Popul Health Manag. 2018 Feb;21(1):24-31. doi: 10.1089/pop.2017.0030. PMID: 28609191.

18. Bell J, Turbow S, George M, et al. Factors associated with high-utilization in a safety net setting. BMC Health Serv Res. 2017 Apr 14;17(1):273. doi: 10.1186/s12913-017-2209-0. PMID: 28410614.

19. Robinson RL, Grabner M, Palli SR, et al. Covariates of depression and high utilizers of healthcare: impact on resource use and costs. J Psychosom Res. 2016;85:35-43. doi: 10.1016/j.jpsychores.2016.04.002.

20. Rohrer JE, Rasmussen N, Adamson SA. Illness severity and total visits in family medicine. $\mathrm{J}$ Eval Clin Pract. 2008;14(1):65-9. 
21. Sterling S, Chi F, Weisner C, et al. Association of behavioral health factors and social determinants of health with high and persistently high healthcare costs. Prev Med Rep. 2018;11:154-9. doi: 10.1016/j.pmedr.2018.06.017.

22. Yang C, Delcher C, Shenkman E, et al. Identifying high health care utilizers using postregression residual analysis of health expenditures from a state Medicaid program. AMIA Annual Symposium; 2017. 586: AMIA Symposium proceedings; 2017. pp. 1848-57.

23. Reichard A, Gulley SP, Rasch EK, et al. Diagnosis isn't enough: understanding the connections between high health care utilization, chronic conditions and disabilities among U.S. working age adults. Disabil Health J. 2015;8(4):535-46. doi: 10.1016/j.dhjo.2015.04.006.

24. Meek JA, Lyon BL, May FE, et al. Targeting high utilisers: predictive validity of a screening questionnaire. Disease Management and Health Outcomes. 2000;8(4):223-32. doi: 10.2165/00115677-200008040-00005.

25. Yang C, Delcher C, Shenkman E, et al. Machine learning approaches for predicting high cost high need patient expenditures in health care. Biomed Eng Online. 2018 Nov 20;17(Suppl 1):131. doi: 10.1186/s12938-018-0568-3. PMID: 30458798.

26. Prenovost KM, Fihn SD, Maciejewski ML, et al. Using item response theory with health system data to identify latent groups of patients with multiple health conditions. PLoS One.

2018;13(11):e0206915. doi:

10.1371/journal.pone.0206915. PMID: 30475823 .

27. Birmingham LE, Cochran T, Frey JA, et al. Emergency department use and barriers to wellness: a survey of emergency department frequent users. BMC Emerg Med. 2017 May 10;17(1):16. doi: 10.1186/s12873-017-0126-5 PMID: 28486935.

28. Kanzaria HK, Niedzwiecki MJ, Montoy JC, et al. Persistent frequent emergency department use: core group exhibits extreme levels of use for more than a decade. Health Aff (Millwood). 2017 Oct 1;36(10):1720-8. doi: 10.1377/hlthaff.2017.0658. PMID: 28971916.

29. Ganguli I, Thompson RW, Ferris TG. What can five high cost patients teach us about healthcare spending? Healthc (Amst). 2017 Dec;5(4):20413. doi: 10.1016/j.hjdsi.2016.12.004. PMID: 28039014.
30. Behr JG, Diaz R. Emergency department frequent utilization for non-emergent presentments: results from a regional urban trauma center study. PLoS One. 2016;11(1):e0147116. doi: 10.1371/journal.pone.0147116. PMID: 26784515 .

31. Colligan EM, Pines JM, Colantuoni E, et al. Risk factors for persistent frequent emergency department use in Medicare beneficiaries. Ann Emerg Med. 2016 Jun;67(6):721-9. doi: 10.1016/j.annemergmed.2016.01.033. PMID: 26947801

32. Buhumaid R, Riley J, Sattarian M, et al. Characteristics of frequent users of the emergency department with psychiatric conditions. J Health Care Poor Underserved. 2015 Aug;26(3):941-50. doi: 10.1353/hpu.2015.0079. PMID: 26320924.

33. Thakarar K, Morgan JR, Gaeta JM, et al. Predictors of frequent emergency room visits among a homeless population. PLoS One. 2015;10(4):e0124552. doi: 10.1371/journal.pone.0124552. PMID: 25906394.

34. Vinton DT, Capp R, Rooks SP, et al. Frequent users of US emergency departments: characteristics and opportunities for intervention. Emerg Med J. 2014 Jul;31(7):526-32. doi: 10.1136/emermed-2013-202407. PMID: 24473411 .

35. Hasegawa K, Tsugawa Y, Camargo CA, Jr., et al. Frequent utilization of the emergency department for acute heart failure syndrome: a populationbased study. Circ Cardiovasc Qual Outcomes. 2014 Sep;7(5):735-42. doi: 10.1161/circoutcomes.114.000949. PMID 25139183.

36. Hasegawa K, Tsugawa Y, Tsai CL, et al. Frequent utilization of the emergency department for acute exacerbation of chronic obstructive pulmonary disease. Respir Res. 2014 Apr 10;15:40. doi: 10.1186/1465-9921-15-40. PMID: 24717062 .

37. Hasegawa K, Sullivan AF, Tovar Hirashima E, et al. A multicenter observational study of US adults with acute asthma: who are the frequent users of the emergency department? J Allergy Clin Immunol Pract. 2014 Nov-Dec;2(6):733-40. doi: 10.1016/j.jaip.2014.06.012. PMID: 25439365 .

38. Doran KM, Colucci AC, Wall SP, et al. Reasons for emergency department use: do frequent users differ? Am J Manag Care. 2014 Nov 1;20(11):e506-14. PMID: 25730349. 
39. Liu SW, Nagurney JT, Chang Y, et al. Frequent ED users: are most visits for mental health, alcohol, and drug-related complaints? Am J Emerg Med. 2013 Oct;31(10):1512-5. doi: 10.1016/j.ajem.2013.08.006. PMID: 24035051.

40. Chang G, Weiss AP, Orav EJ, et al. Predictors of frequent emergency department use among patients with psychiatric illness. Gen Hosp Psychiatry. 2014 Nov-Dec;36(6):716-20. doi: 10.1016/j.genhosppsych.2014.09.010. PMID: 25312277.

41. Billings J, Raven MC. Dispelling an urban legend: frequent emergency department users have substantial burden of disease. Health Aff (Millwood). 2013 Dec;32(12):2099-108. doi: 10.1377/hlthaff.2012.1276. PMID: 24301392.

42. Milbrett P, Halm M. Characteristics and predictors of frequent utilization of emergency services. J Emerg Nurs. 2009 Jun;35(3):191-8; quiz 273. doi: 10.1016/j.jen.2008.04.032. PMID: 19446122.

43. Hunt KA, Weber EJ, Showstack JA, et al. Characteristics of frequent users of emergency departments. Ann Emerg Med. 2006 Jul;48(1):18. doi: 10.1016/j.annemergmed.2005.12.030. PMID: 16781914.

44. Friedman BW, Serrano D, Reed M, et al. Use of the emergency department for severe headache. A population-based study. Headache. 2009 Jan;49(1):21-30. doi: 10.1111/j.15264610.2008.01282.x. PMID: 19040677.

45. Ruger JP, Richter CJ, Spitznagel EL, et al. Analysis of costs, length of stay, and utilization of emergency department services by frequent users: implications for health policy. Acad Emerg Med. 2004 Dec;11(12):1311-7. doi: 10.1197/j.aem.2004.07.008. PMID: 15576522.

46. Mandelberg JH, Kuhn RE, Kohn MA. Epidemiologic analysis of an urban, public emergency department's frequent users. Acad Emerg Med. 2000 Jun;7(6):637-46. doi: 10.1111/j.1553-2712.2000.tb02037.x. PMID: 10905642 .

47. Zuckerman S, Shen YC. Characteristics of occasional and frequent emergency department users: do insurance coverage and access to care matter? Med Care. 2004 Feb;42(2):176-82. doi: 10.1097/01.mlr.0000108747.51198.41. PMID: 14734955 .

48. Blumenthal KJ, Chang Y, Ferris TG, et al. Using a self-reported global health measure to identify patients at high risk for future healthcare utilization. J Gen Intern Med. 2017;32(8):877-82. doi: 10.1007/s1 1606-017-4041-y.
49. Hasselman D. Super utilizer summit: common themes from innovative complex care management programs. Center for Health Care Strategies 2013.

50. Porter M, Quillen D, Agana DF, et al. Are patients frequently readmitted to the hospital different from the other admitted patients? J Am Board Fam Med. 2019 Jan-Feb;32(1):58-64. doi: 10.3122/jabfm.2019.01.180052.

51. Walker EA, Katon W, Russo J, et al. Health care costs associated with posttraumatic stress disorder symptoms in women. Arch Gen Psychiatry. 2003 Apr;60(4):369-74. doi: 10.1001/archpsyc.60.4.369.

52. Yang C, Delcher C, Shenkman E, et al. Clustering inter-arrival time of health care encounters for high utilizers. 2018 IEEE 20th International Conference on e-Health Networking, Applications and Services, Healthcom 2018; 2018 September 17-20; Ostrava, Czech Republic. Curran Associates.

53. Yang C, Delcher C, Shenkman E, et al. Expenditure variations analysis using residuals for identifying high health care utilizers in a state Medicaid program. BMC Med Inform Decis Mak. 2019;19(1):N.PAG-N.PAG. doi: 10.1186/s12911-019-0870-4.

54. Chang ET, Piegari R, Wong ES, et al. Which patients are persistently high-risk for hospitalization? Am J Manag Care. 2019 Sep 1;25(9):e274-e81. PMID: 31518099.

55. Wong ES, Yoon J, Piegari RI, et al. Identifying latent subgroups of high-risk patients using risk score trajectories. J Gen Intern Med. 2018 Dec;33(12):2120-6. doi: 10.1007/s11606-0184653-x. PMID: 30225769.

56. Bayliss EA, Powers JD, Ellis JL, et al. Applying sequential analytic methods to self-reported information to anticipate care needs. EGEMS (Wash DC). 2016;4(1):1258. doi: 10.13063/23279214.1258. PMID: 27563684.

57. Newcomer SR, Steiner JF, Bayliss EA. Identifying subgroups of complex patients with cluster analysis. Am J Manag Care. 2011 Aug 1;17(8):e324-32. PMID: 21851140.

58. Chan B, Hulen E, Edwards S, et al. "It's like riding out the chaos": caring for socially complex patients in an ambulatory intensive care unit (AICU). Ann Fam Med. 2019 Nov;17(6):495-501. doi: 10.1370/afm.2464. PMID: 31712287. 
59. Doran KM, Raven MC, Rosenheck RA. What drives frequent emergency department use in an integrated health system? National data from the Veterans Health Administration. Ann Emerg Med. 2013 Aug;62(2):151-9. doi: 10.1016/j.annemergmed.2013.02.016. PMID: 23582617.

60. Raven MC, Billings JC, Goldfrank LR, et al. Medicaid patients at high risk for frequent hospital admission: real-time identification and remediable risks. J Urban Health. 2009 Mar;86(2):230-41. doi: 10.1007/s11524-0089336-1. PMID: 19082899.

61. Das LT, Kaushal R, Garrison K, et al. Drivers of preventable high health care utilization: a qualitative study of patient, physician and health system leader perspectives. J Health Serv Res Policy. 2019 Sep 10;25(4):1355819619873685. doi: $10.1177 / 1355819619873685$. PMID: 31505976 .

62. Billings J, Mijanovich T. Improving the management of care for high-cost Medicaid patients. Health Aff (Millwood). 2007 NovDec;26(6):1643-54. doi: 10.1377/hlthaff.26.6.1643. PMID: 17978384.

63. Emechebe N, Lyons Taylor P, Amoda O, et al. Passive social health surveillance and inpatient readmissions. Am J Manag Care. 2019 Aug;25(8):388-95. PMID: 31419096.

64. Birmingham LE, Cheruvu VK, Frey JA, et al. Distinct subgroups of emergency department frequent users: a latent class analysis. Am J Emerg Med. 2020 Jan;38(1):83-8. doi: 10.1016/j.ajem.2019.04.029. PMID: 31023586.

65. Castillo EM, Brennan JJ, Howard J, et al. Factors associated with geriatric frequent users of emergency departments. Ann Emerg Med. 2019 Aug;74(2):270-5. doi: 10.1016/j.annemergmed.2018.12.013. PMID: 30704786.

66. Hyer JM, Paredes AZ, White S, et al. Assessment of utilization efficiency using machine learning techniques: a study of heterogeneity in preoperative healthcare utilization among superutilizers. Am J Surg. 2020 Sep;220(3):714-20. doi: 10.1016/j.amjsurg.2020.01.043. PMID: 32008721 .

67. Kanzaria HK, Niedzwiecki M, Cawley CL, et al. Frequent emergency department users: focusing solely on medical utilization misses the whole person. Health Aff (Millwood). 2019

Nov;38(11):1866-75. doi: 10.1377/hlthaff.2019.00082. PMID: 31682499.

68. Keeney T, Joyce NR, Meyers DJ, et al. Persistence of high-need status over time among fee-for-service Medicare beneficiaries. Med Care Res Rev.7. doi: 10.1177/1077558719901219.
69. Surbhi S, Graetz I, Wan JY, et al. Medication nonadherence, mental health, opioid use, and inpatient and emergency department use in superutilizers. Am J Manag Care. 2020;26(3):E98E103. doi: 10.37765/ajmc.2020.42642.

70. Berkowitz SA, Seligman HK, Meigs JB, et al. Food insecurity, healthcare utilization, and high cost: a longitudinal cohort study. Am J Manag Care. 2018 Sep;24(9):399-404. PMID: 30222918.

71. Figueroa JF, Zhou X, Jha AK. Characteristics and spending patterns of persistently high-cost Medicare patients. Health Aff (Millwood). 2019 Jan;38(1):107-14. doi: 10.1377/hlthaff.2018.05160. PMID: 30615516.

72. Lee NS, Whitman N, Vakharia N, et al. High-cost patients: hot-spotters don't explain the half of it. J Gen Intern Med. 2017 Jan;32(1):28-34. doi: 10.1007/s11606-016-3790-3. PMID: 27480529.

73. Powers BW, Yan J, Zhu J, et al. Subgroups of high-cost Medicare advantage patients: an observational study. J Gen Intern Med. 2019 Feb;34(2):218-25. doi: 10.1007/s11606-0184759-1. PMID: 30511290.

74. Mohammed Moazam Ali M. The role of social and clinical determinants in the frequent utilization of emergency departments. The George Washington University, ProQuest Dissertations Publishing; 2018.

75. Gopalan K. Service delivery and quality of care for individuals with mental illness: University of Pittsburgh; 2017.

76. Grant RW, McCloskey J, Hatfield M, et al. Use of latent class analysis and k-means clustering to identify complex patient profiles. JAMA Netw Open. 2020 Dec 1;3(12):e2029068. doi: 10.1001/jamanetworkopen.2020.29068. PMID: 33306116 .

77. Brannon E, Wang T, Lapedis J, et al. Towards a learning health system to reduce emergency department visits at a population level. AMIA Symposium; 2018. Annual Symposium proceedings; 2018. pp. 295-304.

78. Gross K, Brenner JC, Truchil A, et al. Building a citywide, all-payer, hospital claims database to improve health care delivery in a low-income, urban community. Popul Health Manag. 2013;16:S-20. doi: 10.1089/pop.2013.0037.

79. McCall N, Cromwell J, Urato C, et al. Evaluation of Medicare Care Management for High Cost Beneficiaries (CMHCB) Demonstration: Texas Senior Trails (TST): final report RTI International Research Triangle Park, NC: 2010. https://www.cms.gov/reports/downloads/CMHC B TST_McCall 2010.pdf 
80. McCall N, Cromwell J, Smith K, et al. Evaluation of Medicare Care Management for High Cost Beneficiaries (CMHCB) Demonstration: the Health Buddy ${ }^{\circledR}$ Consortium (HBC): revised final report RTI International Research Triangle Park, NC: April 20112011.

https://www.cms.gov/Research-Statistics-Dataand-Systems/Statistics-Trends-and-

Reports/Reports/downloads/mccall_eval_of_cmh cb_emo april 2011.pdf

81. McCall N, Cromwell J, Urato C, et al. Evaluation of Medicare Care Management for High Cost Beneficiaries (CMHCB) Demonstration: VillageHealth's Key to Better Health (KTBH): final report RTI International Research Triangle Park, NC: 2010. https://www.cms.gov/ResearchStatistics-Data-and-Systems/Statistics-Trendsand-

Reports/Reports/downloads/McCall KTBH Fina 12010.pdf

82. Urato C, McCall N, Cromwell J, et al. Evaluation of the Extended Medicare Care Management for High Cost Beneficiaries (CMHCB)

Demonstration: VillageHealth's Key to Better Health (KTBH): final report RTI International Research Triangle Park, NC: 2013. https://innovation.cms.gov/files/reports/cmhcbvillagehealth.pdf

83. Durfee J, Johnson T, Batal H, et al. The impact of tailored intervention services on charges and mortality for adult super-utilizers. Healthc (Amst). 2018 Dec;6(4):253-8. doi: 10.1016/j.hjdsi.2017.08.004. PMID: 28847571.

84. McCall N, Cromwell J, Urato C, et al. Evaluation of Medicare Care Management for High Cost Beneficiaries (CMHCB) Demonstration: Care Level Management (CLM) RTI International. Research Triangle Park, NC: 2010. https://www.cms.gov/Research-Statistics-Dataand-Systems/Statistics-Trends-andReports/Reports/downloads/CMHCB CLM Mc Call 2010.pdf

85. Peterson G, Blue L, Moreno L, et al. Evaluation of Health Care Innovation Awards (HCIA): Primary Care Redesign Programs: third annual report Mathematica Policy Research. Princeton, NJ: 2017.

https://downloads.cms.gov/files/cmmi/hciaprimarycareredesign-thirdannualrpt.pdf

86. McCall N, Cromwell J, Urato C. Evaluation of Medicare Care Management for High Cost Beneficiaries (CMHCB) Demonstration: Massachusetts General Hospital and Massachusetts General Physician Organization (MGH): final report RTI International. Research Triangle Park, NC: 2010.
87. Yoon J, Chang E, Rubenstein LV, et al. Impact of primary care intensive management on high-risk veterans' costs and utilization. Ann Intern Med. 2018 Oct 2;169(7):515-6. doi: 10.7326/118-0461. PMID: 30285201 .

88. Capp R, Misky GJ, Lindrooth RC, et al. Coordination program reduced acute care use and increased primary care visits among frequent emergency care users. Health Aff (Millwood). 2017;36(10):1705-11. doi: 10.1377/hlthaff.2017.0612.

89. Bayliss EA, Ellis JL, Powers JD, et al. Using self-reported data to segment older adult populations with complex care needs. EGEMS (Wash DC). 2019 Apr 12;7(1):12. doi: 10.5334/egems.275. PMID: 31065556.

90. Dally DL, Dahar W, Scott A, et al. The impact of a health education program targeting patients with high visit rates in a managed care organization. Am J Health Promot. 2002;17(2):101-11. doi: 10.4278/0890-117117.2.101.

91. Roberts SR, Crigler J, Ramirez C, et al. Working with socially and medically complex patients: when care transitions are circular, overlapping, and continual rather than linear and finite. $\mathrm{J}$ Healthc Qual. 2015 Jul-Aug;37(4):245-65. doi: 10.1097/jhq.0000000000000006. PMID: 26147126.

92. Horn BP, Crandall C, Moffett M, et al. The economic impact of intensive care management for high-cost medically complex patients: an evaluation of New Mexico's care one program. Popul Health Manag. 2016 Dec;19(6):398-404. doi: 10.1089/pop.2015.0142. PMID: 27031738.

93. Wilber KH, Allen D, Shannon GR, et al. Partnering managed care and community-based services for frail elders: the care advocate program. J Am Geriatr Soc. 2003 Jun;51(6):80712. doi: 10.1046/j.1365-2389.2003.51257.x. PMID: 12757567.

94. Fleming MD, Shim JK, Yen IH, et al. Patient engagement at the margins: health care providers' assessments of engagement and the structural determinants of health in the safety-net. Soc Sci Med. 2017 Jun;183:11-8. doi: 10.1016/j.socscimed.2017.04.028. PMID: 28445806 .

95. Thompson MP, Podila PSB, Clay C, et al. Community navigators reduce hospital utilization in super-utilizers. Am J Manag Care. 2018 Feb;24(2):70-6. PMID: 29461853.

96. Finkelstein A, Zhou A, Taubman S, et al. Health care hotspotting - a randomized, controlled trial. N Engl J Med. 2020 Jan 9;382(2):152-62. doi: 10.1056/NEJMsa1906848. PMID: 31914242. 
97. Zulman DM, Chang ET, Wong A, et al. Effects of intensive primary care on high-need patient experiences: survey findings from a Veterans Affairs randomized quality improvement trial. J Gen Intern Med. 2019 May;34(Suppl 1):75-81. doi: 10.1007/s11606-019-04965-0. PMID: 31098977.

98. Crane S, Collins L, Hall J, et al. Reducing utilization by uninsured frequent users of the emergency department: combining case management and drop-in group medical appointments. J Am Board Fam Med. 2012 MarApr;25(2):184-91. doi:

10.3122/jabfm.2012.02.110156. PMID: 22403199 .

99. Katzelnick DJ, Simon GE, Pearson SD, et al. Randomized trial of a depression management program in high utilizers of medical care. Arch Fam Med. 2000 Apr;9(4):345-51. doi: 10.1001/archfami.9.4.345.

100. Vickery KD, Shippee ND, Menk J, et al. Integrated, accountable care for Medicaid expansion enrollees: a comparative evaluation of Hennepin Health. Med Care Res Rev. 2020. doi: $10.1177 / 1077558718769481$.

101. Peikes D, Anglin G, Dale S, et al. Evaluation of the Comprehensive Primary Care initiative: fourth annual report Mathematica Policy Research.Princeton, NJ: 2018. https://www.mathematica.org/publications/evalua tion-of-the-comprehensive-primary-careinitiative-fourth-annual-report

102. Adam P, Brandenburg DL, Bremer KL, et al. Effects of team care of frequent attenders on patients and physicians. Fam Syst Health. 2010 Sep;28(3):247-57. doi: 10.1037/a0020944. PMID: 20939629.

103. Kimmey L, Anderson M, Cheh V, et al. Evaluation of the Independence at Home Demonstration: an examination of the first four years Mathematica Policy Research. Princeton, NJ: 2019.

https://www.mathematica.org/publications/evalua tion-of-the-independence-at-homedemonstration-an-examination-of-the-first-fouryears

104. Hibbard JH, Greene J, Sacks R, et al. Adding a measure of patient self-management capability to risk assessment can improve prediction of high costs. Health Aff (Millwood). 2016

Mar;35(3):489-94. doi:

10.1377/hlthaff.2015.1031. PMID: 26953304.

105. Mautner DB, Pang HC, Brenner JC, et al. Generating hypotheses about care needs of high utilizers: lessons from patient interviews. Popul Health Manag. 2013 Oct;16:S26-S33. doi: 10.1089/pop.2013.0033.
106. Zulman DM, Ezeji-Okoye SC, Shaw JG, et al. Partnered research in healthcare delivery redesign for high-need, high-cost patients: development and feasibility of an Intensive Management Patient-Aligned Care Team (ImPACT). J Gen Intern Med. 2014 Dec;29 Suppl 4:861-9. doi: 10.1007/s11606-014-3022-7. PMID: 25355084.

107. Shah R, Chen C, O'Rourke S, et al. Evaluation of care management for the uninsured. Med Care. $2011 \mathrm{Feb}$;9(2):166-71. doi: 10.1097/MLR.0b013e3182028e81. PMID: 21206292.

108. Powers BW, Modarai F, Palakodeti S, et al. Impact of complex care management on spending and utilization for high-need, high-cost Medicaid patients. Am J Manag Care. 2020 Feb 1;26(2):e57-e63. doi: 10.37765/ajmc.2020.42402. PMID: 32059101.

109. Raven MC, Niedzwiecki MJ, Kushel M. A randomized trial of permanent supportive housing for chronically homeless persons with high use of publicly funded services. Health Serv Res. 2020 Oct;55 Suppl 2(Suppl 2):797-806. doi: 10.1111/1475-6773.13553. PMID: 32976633.

110. Kelley L, Capp R, Carmona JF, et al. Patient navigation to reduce emergency department (ED) utilization among Medicaid insured, frequent ED users: a randomized controlled trial. J Emerg Med. 2020;58(6):967-77. doi: 10.1016/j.jemermed.2019.12.001.

111. Lin MP, Blanchfield BB, Kakoza RM, et al. EDbased care coordination reduces costs for frequent ED users. Am J Manag Care. 2017 Dec;23(12):762-6. PMID: 29261242.

112. Bell JF, Krupski A, Joesch JM, et al. A randomized controlled trial of intensive care management for disabled Medicaid beneficiaries with high health care costs. Health Serv Res. 2015 Jun;50(3):663-89. doi: 10.1111/14756773.12258. PMID: 25427656.

113. Sherry M, Wolff JL, Ballreich J, et al. Bridging the Silos of Service Delivery for High-Need, High-Cost Individuals. Popul Health Manag. 2016 Dec;19(6):421-8. doi: 10.1089/pop.2015.0147. PMID: 27006987.

114. Tanio C, Chen C. Innovations at Miami practice show promise for treating high-risk Medicare patients. Health Aff (Millwood). 2013 Jun;32(6):1078-82. doi: 10.1377/hlthaff.2012.0201. PMID: 23733982.

115. Sledge WH, Brown KE, Levine JM, et al. A randomized trial of primary intensive care to reduce hospital admissions in patients with high utilization of inpatient services. Dis Manag. 2006;9(6):328-38. doi: 10.1089/dis.2006.9.328. 
116. Shumway M, Boccellari A, O'Brien K, et al. Cost-effectiveness of clinical case management for $\mathrm{ED}$ frequent users: results of a randomized trial. Am J Emerg Med. 2008 Feb;26(2):155-64. doi: 10.1016/j.ajem.2007.04.021. PMID: 18272094.

117. Coleman EA, Eilertsen TB, Kramer AM, et al. Reducing emergency visits in older adults with chronic illness. A randomized, controlled trial of group visits. Eff Clin Pract. 2001 MarApr;4(2):49-57. PMID: 11329985.

118. Seaberg D, Elseroad S, Dumas M, et al. Patient navigation for patients frequently visiting the emergency department: a randomized, controlled trial. Acad Emerg Med. 2017 Nov;24(11):132733. doi: 10.1111/acem.13280. PMID: 28834070.

119. Weerahandi H, Basso Lipani M, Kalman J, et al. Effects of a psychosocial transitional care model on hospitalizations and cost of care for high utilizers. Soc Work Health Care. 2015;54(6):48598. doi: 10.1080/00981389.2015.1040141.

120. Navratil-Strawn JL, Hawkins K, Wells TS, et al. An emergency room decision-support program that increased physician office visits, decreased emergency room visits, and saved money. Popul Health Manag. 2014 Oct;17(5):257-64. doi: 10.1089/pop.2013.0117. PMID: 24865849.

121. Schickedanz A, Sharp A, Hu YR, et al. Impact of social needs navigation on utilization among high utilizers in a large integrated health system: a quasi-experimental study. J Gen Intern Med. 2019 Nov;34(11):2382-9. doi: 10.1007/s11606019-05123-2. PMID: 31228054.

122. Kahn KL, Timbie JW, Friedberg MW, et al. Evaluation of CMS's Federally Qualified Health Center (FQHC) Advanced Primary Care Practice (APCP) Demonstration: final report RAND Corporation. Santa Monica, CA: 2017. https://www.rand.org/pubs/research reports/RR8 $\underline{86 \mathrm{z} 2 . \mathrm{html}}$

123. Peikes D, Anglin G, Harrington M, et al. Independent evaluation of comprehensive primary care plus $(\mathrm{CPC}+)$ first annual report Mathematica Policy Research. Princeton, NJ: 2019.

https://www.mathematica.org/publications/indepe ndent-evaluation-of-comprehensive-primarycare-plus-cpc-first-annual-report

124. Sevak P, Stepanczuk CN, Bradley KWV, et al. Effects of a community-based care management model for super-utilizers. Am J Manag Care. 2018 Nov 1;24(11):e365-e70.
125. Sandberg SF, Erikson C, Owen R, et al. Hennepin Health: a safety-net accountable care organization for the expanded Medicaid population. Health Aff (Millwood). 2014 Nov;33(11):1975-84. doi: 10.1377/hlthaff.2014.0648. PMID: 25367993.

126. DeHaven M, Kitzman-Ulrich H, Gimpel N, et al. The effects of a community-based partnership, Project Access Dallas (PAD), on emergency department utilization and costs among the uninsured. J Public Health (Oxf). 2012 Dec;34(4):577-83. doi: 10.1093/pubmed/fds027. PMID: 22653885.

127. Enard KR, Ganelin DM. Reducing preventable emergency department utilization and costs by using community health workers as patient navigators. J Healthc Manag. 2013 NovDec;58(6):412-27; discussion 28. PMID: 24400457.

128. Gimpel N, Marcee A, Kennedy K, et al. Patient perceptions of a community-based care coordination system. Health Promot Pract. 2010 Mar;11(2):173-81. doi: 10.1177/1524839908320360. PMID: 19131540.

129. McCormack RP, Hoffman LF, Wall SP, et al. Resource-limited, collaborative pilot intervention for chronically homeless, alcohol-dependent frequent emergency department users. Am J Public Health. 2013 Dec;103 Suppl 2(Suppl 2):S221-4. doi: 10.2105/ajph.2013.301373. PMID: 24148034.

130. Harrison JM, Oganisian A, Grande DT, et al. Economic outcomes of insurer-led care management for high-cost medicaid patients. Am J Manag Care. 2020 Jul;26(7):310-6. doi: 10.37765/ajmc.2020.43769.

131. Valluru G, Yudin J, Patterson CL, et al. Integrated home- and community-based services improve community survival among independence at home Medicare beneficiaries without increasing Medicaid costs. J Am Geriatr Soc. 2019 Jul;67(7):1495-501. doi: 10.1111/jgs.15968. PMID: 31074846.

132. Li E, Kimmey L, Cheh V. Evaluation of the independence at home demonstration: an examination of the first five years Mathematica Policy Research. Princeton, NJ: 2020. https://innovation.cms.gov/files/reports/iahyr5evalrpt.pdf

133. Anglin G, Peikes D, Petersen D, et al. Independent evaluation of comprehensive primary care plus $(\mathrm{CPC}+)$ : second annual report Mathematica Policy Research. Princeton, NJ: 2020.

https://www.mathematica.org/publications/indepe ndent-evaluation-of-comprehensive-primarycare-plus-cpc-second-annual-report 
134. Chukmaitov AS, Tang A, Carretta HJ, et al. Characteristics of all, occasional, and frequent emergency department visits due to ambulatory care-sensitive conditions in Florida. J Ambul Care Manage. 2012 Apr-Jun;35(2):149-58. doi: 10.1097/JAC.0b013e318244d222. PMID: 22415289.

135. Hempstead K, Delia D, Cantor JC, et al. The fragmentation of hospital use among a cohort of high utilizers: implications for emerging care coordination strategies for patients with multiple chronic conditions. Med Care. 2014 Mar;52 Suppl 3:S67-74. doi:

10.1097/mlr.0000000000000049. PMID: 24561761.

136. Leininger LJ, Friedsam D, Voskuil K, et al. Predicting high-need cases among new Medicaid enrollees. Am J Manag Care. 2014 Sep 1;20(9):e399-407. PMID: 25364876.

137. Leininger L, Avery K. The capacity of selfreported health measures to predict high-need Medicaid enrollees. Princeton, NJ: Robert Wood Johnson Foundation; 2015.

138. Wherry LR, Burns ME, Leininger LJ. Using selfreported health measures to predict high-need cases among Medicaid-eligible adults. Health Serv Res. 2014 Dec;49 Suppl 2:2147-72. doi: 10.1111/1475-6773.12222. PMID: 25130916.

139. Levinson CM, Druss BG. Health beliefs and depression in a group of elderly high utilizers of medical services. Gen Hosp Psychiatry. 2005;27(2):97-9. doi:

10.1016/j.genhosppsych.2004.09.010.

140. Hwang AS, Liu SW, Yelibi C, et al. Characteristics of persistent emergency department high utilizers in a large primary care practice-based research network. J Gen Intern Med. 2014 Apr;29:S47-S. 